\title{
GEORG FISCHER
}

\section{SAMPLING IN DER MUSIKPRODUKTION}

Das Spannungsfeld zwischen Urheberrecht und Kreativität

\section{MIT EINEM VORWORT VON LEONHARD DOBUSCH}


SAMPLING IN DER MUSIKPRODUKTION 


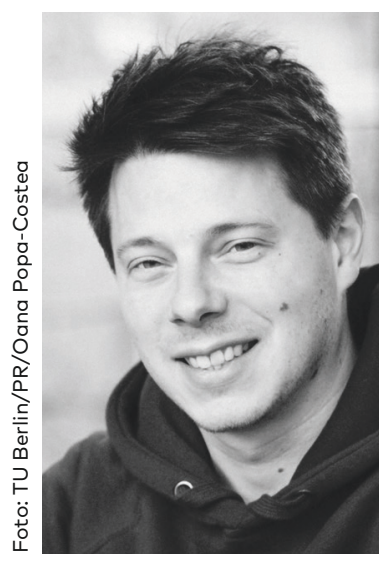

Dr. Georg Fischer ist Technik- und Innovationssoziologe und aktuell als Wissenschaftlicher Mitarbeiter am Lehrstuhl Geschichte und Theorie der populären Musik an der Humboldt-Universität zu Berlin beschäftigt. Er ist Gründungsmitglied des Fachausschusses »Urheberrecht« der Gesellschaft für Musikwirtschafts- und Musikkulturforschung (GMM). Daneben arbeitet er in der Musikindustrie im Bereich Lizenzierung und Verwertungsgesellschaften. 
Georg Fischer

SAMPLING IN DER

MUSIKPRODUKTION

Das Spannungsfeld zwischen

Urheberrecht und Kreativität 
Diese Publikation wurde aus dem Open-Access-Publikationsfonds der Technischen Universität Berlin unterstützt.

Georg Fischer

Sampling in der Musikproduktion

Das Spannungsfeld zwischen Urheberrecht und Kreativität

Mit einem Vorwort von Leonhard Dobusch

ISBN (Print) 978-3-96317-190-I

ISBN (ePDF) 978-3-963I7-72I-7

DOI I0.I463I/978-3-963I7-72I-7

Zugl.: Berlin, Technische Universität, Diss., 2019 u. d.T. $<$ Urheberrecht und Kreativität in der samplingbasierten Musikproduktion>

Erschienen 2020 bei: Büchner-Verlag eG, Marburg

Satz und Umschlaggestaltung: DeinSatz Marburg | If

Bildnachweis Umschlag: beornbjorn / photocase.de

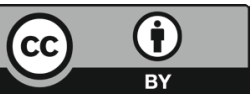

Dieses Werk erscheint unter der Creative-Commons-Lizenz CC BY 4.0: https://creativecommons.org/licenses/by/4.0/. Die Bedingungen der Creative-Commons-Lizenz gelten nur für Originalmaterial. Die Wiederverwendung von Material aus anderen Quellen (gekennzeichnet mit Quellenangabe) wie z. B. Schaubilder, Abbildungen, Fotos und Textauszüge erfordert ggf. weitere Nutzungsgenehmigungen durch den jeweiligen Rechteinhaber.

Bibliografische Informationen der Deutschen Nationalbibliothek Die Deutsche Nationalbibliothek verzeichnet diese Publikation in der Deutschen Nationalbibliografie, detaillierte bibliografische Angaben sind im Internet über http://dnb.de abrufbar.

www.buechner-verlag.de 


\section{Inhalt}

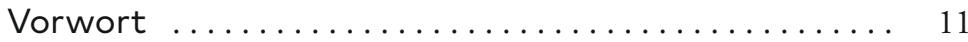

"Nur mir" oder die Frage:

Wem gehört eigentlich ein Klang? ............. 13

\section{TEIL 1 - THEORIE}

1 Der Kampf um die Hoheit zur technischen Reproduzierbarkeit.................. 23

I.I Steigerungs- und Suspensionstendenzen technischer Reproduzierbarkeit .................... 23

I.I.I Die Steigerung technischer Reproduzierbarkeit als akademisches und künstlerisches Thema . . . . . . 23

I.I.2 Gefangen in der Zwischenablage: Suspension technischer Reproduzierbarkeit . . . . . . . . . . . 27

I.I.3 Urheberrechtliche Konfigurationen technischer Reproduzierbarkeit und ihre Delegation an Technologie . . 31

I.2 Der Status der Neuheit in Urheberrecht

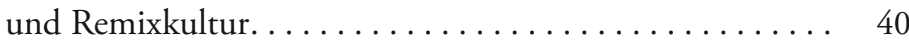

I.2.I Vorsicht: Kann Spuren alter Werke enthalten!

Der Neuheitsimperativ des deutschen Urheberrechts . . . 41

I.2.2 Fifty Shades of Referentiality. Sampling und der Neuheitsimperativ der Remixkultur . . . . . . . . . 51

I.3 Résumé und forschungsanleitende Fragen . . . . . . . . . . 58 
2 Neuheit und Kreativität in der Innovationsgesellschaft ............... 61

2.I Das Neue als Zentralkategorie der Innovationsgesellschaft: Innovationen als nachhaltige Neuerungen ........... 62

2.2 Zwischen gewohnten Überraschungen und

Propertisierung: Das Kreativsubjekt an der Schnittstelle von Kunst, Wirtschaft und Recht . . . . . . . . . . . 67

2.3 Kunstsoziologische Perspektiven auf Neuheit und Kreativität . . . . . . . . . . . . . . . . . . . 74

2.3.I Die Kunst als autonomes gesellschaftliches Funktionssystem . . . . . . . . . . . . . . 77

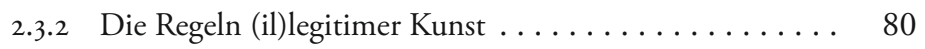

2.3.3 Kunst als kollektives Handeln .............. 85

2.4 Kreativität als kollektives Handeln $\ldots \ldots \ldots \ldots \ldots \ldots .94$

2.4.I Kreativität als Kontribution ................ 96

2.4.2 Kreativität als Exploration und Rekonstruktion....... 98

2.4.3 Kreativität als Symbolisation ............... 102

\section{TEIL 2 - HISTORIE}

3 Historische Entwicklung von Sampling im 20. Jahrhundert ... . . . . . . . . . . . . . . . . . 109

3.I Steigerung technischer Reproduzierbarkeit und vereinzelte künstlerische Experimente (I878-1945) . . . . . 110

3.2 Ausbreitung und Institutionalisierung von Cut and PasteVerfahren in verschiedenen Kunstwelten (1945-1970) . . . . 117

3.3 Konsolidierung und Ausdifferenzierung analoger Remixkulturen (1969-1979) . . . . . . . . . . . . 125

3.4 Von analogen Praktiken hin zu digitalem Sampling

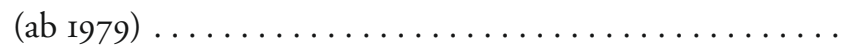


4 Sampling zwischen Kreativität und Kriminalität. . 145

4.I Urheberrechtliche Konfigurationen technischer

Reproduzierbarkeit. Sampling als illegale Kunst .... . . . 146

4.I.I Neue Technik, neue Fragen: „Digital sampling:

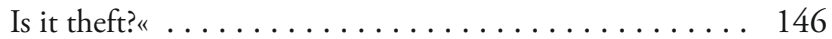

4.I.2 Neue, kriminelle Kunst: "Thievery in the form

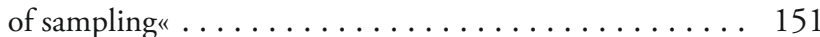

4.I.3 Neue Probleme: »All Samples Cleared?« . . . . . . . . . . . 156

4.I.4 Neue Normalität: "Get a License or do not sample!« . . . 162

4.2 Urheberrecht als Anreiz und Hemmnis für Kreativität . . . 167

4.2.I Dominante Perspektiven: Stimulations- vs.

Marginalisierungsthese .................. 167

4.2.2 Ansätze einer empirisch orientierten

Urheberrechtsforschung . . . . . . . . . . . . 170

4.2.2.I Umgehungsstrategien als afrodiasporische Praktiken des Widerstands ............ 170

4.2.2.2 Sampling im Spannungsfeld von Postmoderne und Urheberrecht . . . . . . . . . . . . . 176

4.2.2.3 Ethik und Ästhetik samplebasierter Musikproduktion ..................... 179

4.2.2.4 Die Kosten der Lizenzierung . . . . . . . . . . . . 185

4.2.2.5 Sampling und empirische Urheberrechtsforschung im deutschsprachigen Raum ...... 193

\section{TEIL 3 - EMPIRIE}

5 Methodik ............................ 199

5.I Forschungslücke und Formulierung der Forschungsfrage . . 199

5.2 Methodische Ausgangspunkte . . . . . . . . . . . 201

5.2.I Sensible soziale Bereiche im Lichte des Interpretativen Paradigmas . . . . . . . . . . . . . . . . . 201

5.2.2 Fokussierte Ethnografie ..................... 203

5.2 .3 Schauplätze...................... 207 
5.3 Methodisches Vorgehen . . . . . . . . . . . . . . 208

5.3.I Feldzugang und theoretisches Sampling .......... 208

5.3.2 Datenerhebung und -analyse .............. 212

5.3.3 Strategische Sensibilisierung für Eigen und Fremd..... 218

6 Kopieren, Komponieren, Koordinieren -

Die Kunstwelt samplingbasierter Popmusik und ihre urheberrechtlichen Verwicklungen ..... 221

6.I Kopieren ....................... 223

6.I.I Konsum und Beschaffung: Wie Serendipität gemanagt wird ................. 224

6.I.I.I Die Ausstellung des eigenen Konsums . . . . . . . 224

6.I.I.2 Legalität und Legitimität der Beschaffung . . . . 232

6.I.2 Distribution und Publikation: Wie Zugang ermöglicht und Aufmerksamkeit geschaffen werden . . . . . . . . 240

6.I.2.I Öffentliche, teilöffentliche und private Musik... 240

6.I.2.2 Steigerung der Detektabilität ............ 245

6.2 Komponieren ..................... 250

6.2.I Ästhetische Reparaturen und klangliche Originalität . . . . 251

6.2.I.I Klänge und Limitationen . . . . . . . . . . . 251

6.2.I.2 Ästhetisierung von Kopiervorgängen . . . . . . . 256

6.2.2 Lost in the Loop . . . . . . . . . . . . . . . 260

6.2.2.I Praktiken der Versionierung ............. 260

6.2.2.2 "Wo dieses Nachdenken einfach aufhört" . . . . . 268

6.3 Koordinieren . . . . . . . . . . . . . . . . . . 270

6.3.I Unmögliche Kooperationen . . . . . . . . . . . . . 271

6.3.I.I "Wenn man Glück hat" . . . . . . . . . . . . . 271

6.3.I.2 Lizenzierungsstrategien unter Risiko . . . . . . . 275

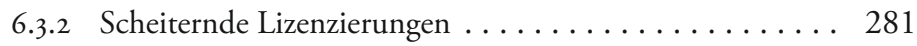

6.3.2.I Künstlerische Reaktionen ............. 281

6.3.2.2 Umgehungsstrategien (»Wenn die Klänge nicht frei sind, dann wird's kompliziert») . . . . . 284 


\section{TEIL 4 - DISKUSSION}

\section{Von der Umgehung der Kreativität} zur Kreativität der Umgehung . . . . . . . . . . . . . 297

7.I Sampling als kreatives kollektives Handeln . . . . . . . . . 299

7.2 Kreative Umgehungsstrategien ............... 307

7.3 Umgehungskreativität als Schatteninnovation ........ 319

7.4 Ausblick ...................... 326

\section{ANHANG}

A Methodischer Anhang .................. 335

A.r Reflexion der eigenen Feldposition ............. 335

A.r.I Ästhetische Affizierung . . . . . . . . . . . . . . 335

A.r.2 Musik und Wissenschaft ................. 341

A.r.3 Verschiebungen $\ldots \ldots \ldots \ldots \ldots \ldots \ldots \ldots \ldots \ldots$

B Quellenverzeichnis ................... 351

B.I Literaturverzeichnis .................. 351

B.2 Zitierte Internetseiten $\ldots \ldots \ldots \ldots \ldots \ldots \ldots \ldots \ldots \ldots$

B.3 Abbildungs- und Tabellenverzeichnis .......... 376

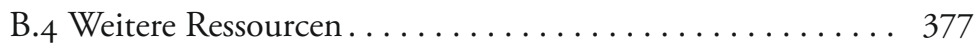

B.4.I Zitierte Gesetze . . . . . . . . . . . . . . . . . 377

B.4.2 Verfahrensgang "Metall auf Metall«. . . . . . . . . . 377

B.4.3 Zitierte Gerichtsurteile und -verfahren . . . . . . . . . 378

B.4.4 Allgemeine juristische und musikindustrielle

Ressourcen . . . . . . . . . . . . . . . . . . . . . . 379

B.4.5 Discografie ....................... 380

B.4.6 Zitierte Filme .................... 382

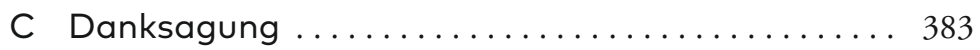





\section{Vorwort}

Georg Fischer ist ein Musiker. Das merkt man diesem Buch auch an. Denn jenseits aller soziologischer Konzepte und empirischer Analysen zeichnet es sich durch ein tiefer liegendes Verständnis des Gegenstands aus, das zu erwerben auch im Rahmen einer mehrjährigen wissenschaftlichen Bearbeitung allein nicht in diesem Ausmaß möglich wäre. Gleichzeitig ist mit so einer großen Nähe zum Gegenstand immer auch die Gefahr verbunden, die für eine kritische Analyse notwendige Distanz zu verlieren. Ethnographen sprechen von der Gefahr des Going Native, zu starken Identifikation mit jener Kultur, die es zu ergründen gilt.

Der Wissenschaftler Georg Fischer begegnet dieser Gefahr in seiner Arbeit offensiv. Die Offenlegung und Diskussion der eigenen Position im Rahmen seines Forschungsvorhabens geschieht nicht nur in Form einer lästigen Pflichtübung, sondern ist hinsichtlich ihrer Offenheit und Reflektiertheit beispielgebend. Auf diese Weise gelingt es ihm, das Vorverständnis und die Vorerfahrung des Musikers mit dem distanzierten und systematisierenden Blick des Wissenschaftlers auf eine Weise zu kombinieren, die dieses Buch zu einer erkenntnisreichen Lektüre macht.

Der Fokus der Arbeit könnte dabei zeitgemäßer gar nicht sein. Galten die untersuchten samplingbasierten Praktiken der Musikproduktion zu Beginn vielleicht als interessantes Nischenphänomen, stehen sie heute exemplarisch für die digitale Kulturtechnik schlechthin: Remix. Während im vermeintlich ursprungslosen Original das Alte bis zur Unkenntlichkeit in den Hintergrund tritt, zeichnet sich Remix dadurch aus, dass Altes im Neuen kenntlich bleibt. Nicht ohne 
Pathos aber deshalb nicht weniger zutreffend wird dessen Bedeutung im Manifest der Initiative "Recht auf Remix" wie folgt beschrieben:

Wir leben in einem Zeitalter des Remix. Kreativität und Kultur bauten schon immer auf bereits Bestehendem auf. Internet und digitale Technologien ermöglichen aber die kreative Nutzung existierender Werke in völlig neuen Dimensionen: Nie zuvor war es so vielen möglich, Werke auf so unterschiedliche Arten zu verändern und so einfach anderen zugänglich zu machen. Mehr denn je gilt heute: „Everything is a Remix.»

Die dafür zentrale Bedeutung von »Referentialität« wiederum ist es, die Georg Fischer in seiner Arbeit in Form eines Kontinuums für den Bereich samplingbasierter Musikproduktion auffächert und auf diese Weise die Bandbreite an sowohl Potentialitäten wie auch Komplikationen im Nexus von Ästhetik, Ökonomie und Recht erfahrbar macht. Kreativität zeigt sich dabei als kollektives Handeln, das durch rechtliche Regulierung incentiviert, gehemmt, umgelenkt, nie aber vollends determiniert werden kann. Mit William James gesprochen: "Something always escapes."

Im Bereich der samplingbasierten Musikproduktion sind es "Schatteninnovationen" in Form diverser Umgehungsstrategien, die einer übermäßig restriktiven urheberrechtlichen Ordnung quasi »entfliehen«. Der Begriff der Schatteninnovation impliziert dabei nicht nur deren geringere Sichtbarkeit, er illustriert auch dass diese hinsichtlich Verwertbarkeit im Schatten etablierter kultureller Praktiken stehen. Auch hier sind die Einsichten im Bereich samplingbasierter Musikproduktion instruktiv für Umgehungskreativität und Schatteninnovationen in anderen Feldern.

Diese Referenzen zu anderen Bereichen digitaler Remixkultur und darüber hinaus herstellen zu können ist nicht nur ein Ergebnis der Lektüre, es entspricht letztlich dem weitreichenden Referenzrahmen, den Georg Fischer in seinem Buch aufspannt. 


\section{"Nur mir" oder die Frage: Wem gehört eigentlich ein Klang?}

"Dieses Leben ist mir. Nur mir! Mir nur ganz alleine.

Nur mir. Nur mir, nur mir, nur mir ganz allein.«

- Refrain aus Nur mir von Sabrina Setlur (1997)

Sampling bezeichnet eine musikalische Kopierpraxis, bei der eine digitale Kopie eines Klangs in einen neuen musikalischen Zusammenhang gestellt wird. Seit etwa 40 Jahren prägt dieses Verfahren die Popmusik und fast genauso lange wird darum auch vor Gericht gestritten. In Deutschland sorgt der Urheberrechtsstreit zwischen Kraftwerk und Moses Pelham seit etwa 20 Jahren für Aufregung und mediale Aufmerksamkeit, insbesondere nachdem sich im Mai 2016 das Bundesverfassungsgericht in Karlsruhe und im Juli 2019 der Europäische Gerichtshof dazu geäußert hatten. Der ursprüngliche Streit reicht aber deutlich weiter zurück: Bereits 1997 hatte der Musikproduzent Moses Pelham für das Stück »Nur mir« von Sabrina Setlur ein etwa I,5 Sekunden langes Sample aus dem Stück »Metall auf Metall« (1977) von Kraftwerk verwendet. Der Ausschnitt stellt eine Kopie einer Rhythmussequenz aus »Metall auf Metall« dar und wurde von Moses Pelham als »Loop«, als fortlaufende Schleife, eingesetzt allerdings ohne Kraftwerk vorher um Erlaubnis zu fragen. ${ }^{\text {I Wenige }}$ Jahre später klagte Kraftwerk gegen die Verwendung des Samples. Zwischenzeitlich war das Stück »Nur mir« mit Setlurs Gesang auf ei-

I Moses Pelham als liberalen Vertreter in urheberrechtlichen Fragen zu sehen oder gar mit einer Abschaffung des Urheberrechts in Verbindung zu bringen, ist trotz seiner Rolle im Fall »Nur mir« abwegig. Zwischen 2006 und 2013 betrieb er mit "Digiprotect« eine der deutschen Musikindustrie nahestehende Firma, die sich auf Abmahnungen von Urheberrechtsverletzungen in digitalen Tauschbörsen spezialisiert hatte. 
nem Album und als Singleauskopplung veröffentlicht worden, hatte es kurzzeitig sogar auf Platz 27 der deutschen Charts geschafft.

So schnell der musikindustrielle Erfolg von "Nur mir« auch vorüber war - der Rechtsstreit um das darin enthaltene Sample ist erstaunlich stabil. Er zieht sich über knapp zwei Jahrzehnte und durch sämtliche gerichtlichen Instanzen vom Landgericht Hamburg bis zum Europäischen Gerichtshof, ohne dass es bisher zu einer endgültigen Entscheidung kommen konnte. Im Dezember 2012 urteilte der Bundesgerichtshof, dass Sampling ohne Genehmigung der Originalurheber_in illegal sei, "wenn es einem durchschnittlich ausgestatteten und befähigten Musikproduzenten zum Zeitpunkt der Benutzung der fremden Tonaufnahme möglich ist, eine eigene Tonaufnahme herzustellen, die dem Original bei einer Verwendung im selben musikalischen Zusammenhang aus Sicht des angesprochenen Verkehrs gleichwertig ist" (Bundesgerichtshof 20I2: Rn. 40). Diese Auslegung des urheberrechtlichen Werkschutzes, die der Jurist und Musikwissenschaftler Frédéric Döhl (20I6: 32I) als "Replay-Gebot" bezeichnet, wird im internationalen rechtswissenschaftlichen Kontext allerdings als »rather exotic solution« (Jütte/Maier 20I7: 784) gesehen. Im Sommer 2016 schließlich wurde das Replay-Gebot vom Bundesverfassungsgericht wieder kassiert. Die Begründung berief sich dabei auf die spezifischen Aspekte samplingbasierter Musikgenres: „Im Ergebnis muss die Nutzung von Samples bei einer kunstspezifischen Betrachtungsweise auch unabhängig von der Nachspielbarkeit grundsätzlich möglich sein." (Bundesverfassungsgericht 2016: Rn. 92) Im Juli 2019 äußerte sich dann noch der Europäische Gerichtshof zu dem Fall, nachdem das Bundesverfassungsgericht mit seiner Entscheidung 2017 an den Bundesgerichtshof zurückgegeben hatte. Der Bundesgerichtshof sah in seiner nunmehr dritten Beschäftigung mit dem strittigen Sample die Harmonisierung des paneuropäischen Urheberrechts tangiert und verwies das Verfahren an den Europäischen Gerichtshof zur weiteren Klärung.

Zwischenzeitlich hatte das Thema Urheberrecht auf europäischer Ebene aufgrund der EU-weiten Reform zu einem extensiven und 
erbittert geführten politischen Streit geführt, an dessen Höhepunkt im Frühjahr 2019 mehrere zehntausend Menschen alleine in Berlin auf der Straße protestierten: vor allem gegen Uploadfilter und befürchtete Zensurmechanismen - und für eine freiheitliche und offene Kultur im Netz. Freilich ging es bei der EU-Reform nur indirekt um Themen wie Sampling, Remixing und Internet-Memes, sondern mehr darum, die großen Weichen der rechtlich-technischen Regulation des Internets zu stellen, um auf diese Weise das Verhältnis zwischen Verlagen, Urheber_innen, Konsument_innen und Plattformen neu auszutarieren. Doch im Kern kreisen sowohl der Streit um das ungenehmigte Kraftwerk-Sample in "Nur mir" wie auch die durch die EU-Reform entstandenen Diskussionen um das gleiche Problem: nämlich um die Reproduktionshoheit bezüglich eines Guts, oder anders gesagt um die Frage, wer unter welchen Umständen wieviel von einer Sache kopieren darf?

Diese Frage nach der Hoheit zur technischen Reproduzierbarkeit lässt sich verstehen als eine genuin urheberrechtliche, die - das lehrt die historische Perspektive - je nach Verfügbarkeit von Kopiertechnologien immer wieder auf's Neue gestellt und beantwortet werden muss. Der Europäische Gerichtshof indes gab auf die Frage nach den Reproduktionsmodalitäten des strittigen Samples eine ambivalente Antwort: Einerseits erkannte er die Reproduktionshoheit der Tonträgerhersteller_innen prinzipiell an und urteilte, dass auch die Vervielfältigung eines sehr kurzen Audiofragments bereits eine teilweise Vervielfältigung des enthaltenden Tonträgers bedeute. Mit diesem Punkt stärkte er also die Sichtweise des Bundesgerichtshofs und von Kraftwerk, die das ausschließliche Verbreitungsrecht durch Pelhams Übernahme verletzt sahen. Auf der anderen Seite jedoch schloss der Europäische Gerichtshof eine unerlaubte Vervielfältigung aus, wenn ein übernommenes Audiofragment »in geänderter und beim Hören nicht wiedererkennbarer Form in einem neuen Werk" verwendet werde (Europäischer Gerichtshof 2019: Rn. 29). Daneben stärkte der Europäische Gerichtshof die prinzipielle Möglichkeit, sich beim Sampling auf das Zitatrecht zu berufen, sofern das Sample mit dem 
Ziel genutzt werde, mit dem gesampelten Werk zu interagieren. Dies wiederum stellt eine Voraussetzung dar, die nur dann erfüllt werden kann, wenn das gesampelte Werk im neuen Werk erkennbar bleibe. Diese Frage nach der Erkennbarkeit muss allerdings wieder der Bundesgerichtshof in seiner nunmehr vierten Entscheidung im Fall beantworten.

Auch wenn diese Aspekte widersprüchlich erscheinen mögen, aus soziologischer Sicht weisen sie auf einen interessanten Fall jenseits der Grenzen des Urheberrechts hin, der die Frage nach der Kunstfreiheit impliziert. Genau diese Kunstfreiheit sah Pelham verletzt, weswegen er zusammen mit anderen Kläger_innen 2016 eine Verfassungsklage angestrengt hatte. Die Prozessierenden vertraten die Meinung, dass die 2012 vom Bundesgerichtshof vorgenommene, besonders restriktive Auslegung des Urheberrechts jene mit dem Sampling verbundene Kreativität unmöglich mache und dadurch die Kunstfreiheit verletze. Insofern lässt sich die grundsätzliche Frage, die auch das Bundesverfassungsgericht in seiner Entscheidung zu klären suchte, noch weiter fassen. Sie betrifft das Verhältnis von künstlerischer Freiheit und urheberrechtlichem Schutz: Welcher urheberrechtliche Schutz ist angemessen, um kreative Prozesse in der Kunst zu ermöglichen? Wieviel ist notwendig, wieviel schädlich?

Wie diametral sich die Vorstellungen von Kreativität und künstlerischen Schaffensprozessen gegenüber stehen können, zeigen die von Kraftwerk und Pelham öffentlich vertretenen Positionen. Kraftwerks Gründungsmitglied Ralf Hütter erklärte 2017 in einem Interview mit Spiegel Online:

"Es ist absurd. Klänge, die wir erarbeitet haben, das ist wie ein Garten. In unserem Garten kann man nicht einfach die Blumen rausreißen und woanders weiterzüchten, in irgendwelchen Schlagern oder Kommerzprodukten. Deshalb setze ich mich für das Urheberrecht ein. Dafür, dass nicht nur komplette Melodien, sondern auch klangliche Strukturen als Werk gelten. Nicht ein einzelner Fitzel, sondern die Geräuschkomposition." (Ralf Hütter zitiert in Frank 20I7) 
Hütters Position vergleicht den Werkschutz seines Geistigen Eigentums mit dem Schutz materiellen Eigentums (»wie ein Garten«) und fordert eine entsprechend starke Kontrolle über sämtliche Teile seines Werks. Um im Bild zu bleiben, verbietet Hütter die Entnahme und Weiterzucht seiner ästhetischen Produkte (»Blumen«), erwartet also, um Erlaubnis gebeten zu werden. ${ }^{2}$ Die rhetorische Abwertung von »irgendwelchen Schlagern und Kommerzprodukten" hindert ihn nicht daran, im gleichen Interview ein vierteiliges Blue-ray Box Set von Kraftwerks Live-Auftritten bewerben zu lassen, das von einem Major im gleichen Jahr veröffentlicht wurde und knapp I70 Euro kostet.

Dagegen vertrat Pelham im Rahmen der Verhandlung vor dem Bundesverfassungsgericht öffentlich die folgende Position, in der die Aneignungsstrategien fremden geistigen Materials als künstlerischer Moment erscheinen: "Ich kann mich mit anderen Tonträgern, mit anderer Kunst nicht auseinandersetzen, wenn ich [...] grundsätzlich nicht sampeln darf. Und so kann es meine Kunstform nicht geben. « $^{3}$ In einer anderen Stellungnahme wird er noch deutlicher: "Hip Hop ist ohne Sampling nicht möglich, darum stehe ich heute hier. Ich halte das für mein gutes Recht. Es gibt keine Kunst im luftleeren Raum, es geht immer um die Auseinandersetzung mit anderer Kunst» (Pelham zitiert nach Ismaiel-Wendt 20I6: 175).

Beide Parteien pochen also auf ihr Recht, auf eine gesellschaftlich ausgehandelte Konvention, die sich im formalen Urheberrecht beziehungsweise im Grundrecht auf künstlerische Freiheit abbilde. Die Aussagen eignen sich für ein erstes, wenn auch noch sehr grobes Bild

22005 genehmigte Ralf Hütter der Band Coldplay eine Interpolation, also eine nachgespielte Passage aus dem Stück »Computer Love« von I98I. Im Original ist die Melodie auf einem Synthesizer eingespielt, in der Version von Coldplay auf Gitarre. Die Passage ist relativ kurz, aber bei Coldplay prominent als melodisches Hauptthema eingesetzt, was die britische Rockband vermutlich mit dazu bewog, Hütter in einem persönlichen Brief um eine Lizenzvereinbarung zu bitten.

3 Moses Pelham zitiert in der Tagesschau vom 25.II.20I5. Siehe http://www.tages schau.de/multimedia/video/video-I35863.html (20.12.2015). 
des Verhältnisses von Urheberrecht und Kreativität in der samplingbasierten Musikproduktion. Es sind strategische Stellungnahmen, die so prägnant und differenziert wie möglich eine Außendarstellung über ein journalistisches Interview diskursiv verankern sollen. Man könnte auch sagen: Die Aussagen bilden die Spitzen des Diskurses. Sie dienen damit grundsätzlich als empirisches Material für die vorliegende Arbeit, sind jedoch ohne Triangulation mit anderen Daten nur bedingt aussagekräftig.

"Nur mir« und der langjährige Rechtsstreit um die darin enthaltene unautorisierte Rhythmuskopie dienen für diese Arbeit als Stichwortgeber. Denn "Nur mir« ist typisch für die Verwendung von Samples innerhalb der Popmusik, was Länge, Verarbeitung und Einsatz betrifft. An dem Fall lässt sich auch gut erkennen, wie enorm digitale Kopierpraktiken mit den Prinzipien Geistigen Eigentums konfligieren können. Diese Konfliktlinie, die entlang der Hoheit zur technischen Reproduzierbarkeit verläuft, wird im Laufe der Arbeit aufgebrochen und für die Praxis des Samplings theoretisch, historisch und empirisch untersucht. Die grundsätzliche Frage, die in der Arbeit bearbeitet wird, betrifft also das Verhältnis von Urheberrecht und Kreativität in der samplingbasierten Musikproduktion: Mit welchen Mitteln wird Geistiges Eigentum in der Musikindustrie gegen unerwünschte Nutzungen mittels Sampling geschützt? Wie gehen die sampelnden Akteure ihrerseits mit der widrigen urheberrechtlichen Umgebung um? Und schließlich: Was bedeuten die rechtlichen Restriktionen für ihre alltägliche, kreative Arbeit?

Die vorliegende Studie gliedert sich in vier Teile: Zuerst wird im theoretischen Teil die Konfliktlinie zur Hoheit technischer Reproduzierbarkeit aufgebrochen und innerhalb eines größeren Zusammenhangs mit Fragen der Neuheit in Urheberrecht und Remixkultur sichtbar gemacht. In diesem Zuge schlage ich außerdem ein heuristisches Modell vor, das für die Frage nach der Wiedererkennbarkeit und Referentialität von Samples hilfreich ist (Kapitel I). Anschließend erläutere ich meine theoretische Perspektive in Bezug auf inno- 
vations- und kunstsoziologische Ansätze und präzisiere mein Verständnis von Kreativität (Kapitel 2).

Darauf folgt der historische Teil dieser Arbeit, in dem ich die Praxis des Samplings als Innovation des 20. Jahrhunderts darstelle (Kapitel 3), um im direkten Anschluss den Forschungsstand zu Sampling, Kreativität und Urheberrecht beziehungsweise Copyright aufzuarbeiten (Kapitel 4).

Auf dieser theoretisch und historisch informierten Grundlage wird die Forschungsfrage für den dritten, empirischen Teil dieser Arbeit festgelegt und für eine Entscheidung zu den methodischen Modalitäten der Datenerhebung und -analyse genutzt (Kapitel 5). Im Rahmen einer fokussierten Ethnografie beschreibe, verdichte und analysiere ich schließlich die Praktiken der Kunstwelt samplingbasierter $\mathrm{Mu}$ sikproduktion unter besonderer Berücksichtigung urheberrechtlicher Restriktionen (Kapitel 6).

Im abschließenden vierten Teil der Arbeit beantworte ich mithilfe einer Zusammenführung der theoretischen, historischen und empirischen Teile dieser Arbeit die Forschungsfrage, interpretiere meine Ergebnisse und erläutere meine These von der Umgehungskreativität als Innovation im Schatten des Urheberrechts (Kapitel 7). 

TEIL 1 - THEORIE 



\section{Der Kampf um die Hoheit zur technischen Reproduzierbarkeit}

\subsection{Steigerungs- und Suspensionstendenzen technischer Reproduzierbarkeit}

\subsubsection{Die Steigerung technischer Reproduzierbarkeit als akademisches und künstlerisches Thema}

Als digitale Kopierpraxis kann die musikalische Praxis des Samplings im Kontext anderer künstlerischer Kopierpraktiken oder noch allgemeiner als Verfahren technischer Reproduzierbarkeit betrachtet werden. Zahlreiche sozial-, medien- und kulturwissenschaftliche Untersuchungen der letzten Jahrzehnte beschäftigen sich mit diesem Thema, beispielsweise mit der Praxis des Kopierens oder dem Verhältnis von Kopie und Original. Einer der einflussreichsten und frühesten Beiträge zu diesem Diskurs ist Walter Benjamins »Das Kunstwerk im Zeitalter seiner technischen Reproduzierbarkeit« (Benjamin 1963). Unter dem Eindruck neuer technischer Reproduktionsmedien wie Fotografie und Film und der massenhaften Distribution von Kulturgütern stellte Benjamin in diesem, bereits in den I930er Jahren verfassten Text die Frage, was mit einem Kunstwerk passiere, wenn es in massenhafter Weise vervielfältigt werde. Benjamins Ansicht nach verliere das originale Kunstwerk durch den Akt der Vervielfältigung genau diejenige Qualität, die es eigentlich zum Kunstwerk qualifiziere, nämlich seine Authentizität, oder wie Benjamin es nennt, seine "Aura«.

Benjamins Arbeit wird grundlegend für die Untersuchung weiterer Verfahren technischer Reproduzierbarkeit, mit denen es ermöglicht 
wird, Objekte und Informationen zu vervielfältigen. Diese Verfahren differenzieren sich im 19. und 20. Jahrhundert stark aus: eine Erweiterung und Steigerung technischer Reproduzierbarkeit ist die Folge. Benjamin nennt eingangs antike Guss- und Prägetechniken zur Reproduktion von Münzen und ähnlichem. Ab der Neuzeit tragen auch Buchdruck und Kupferstich dazu bei, auf Trägermedien gebannte Informationen vervielfältigen und dadurch leichter zugänglich machen zu können. Die Fotografie und die bewegten Bilder des Films, die Benjamin so beeindruckten, und etwas später auch Schallplatten und Tonbänder legten schließlich die Grundlage für die massenhafte Reproduktion von ästhetischen Gütern innerhalb industrieller Zusammenhänge. Die digitale Reproduktion von Informationen zusammen mit der weltumspannenden Vernetzung des Internets bedeutet eine weitere Steigerung technischer Reproduzierbarkeit. Darüber hinaus ist es zu Beginn des 2I. Jahrhunderts möglich, mittels der Klontechnologie Lebewesen genetisch identisch zu replizieren oder mithilfe der 3D-Drucktechnologie physische Objekte präzise zu kopieren.

Die Potentiale technischer Reproduzierbarkeit faszinieren und inspirieren. Oftmals unter Rückgriff auf Benjamin entstanden etwa seit den I980er Jahren diverse Ansätze zur Untersuchung technischer Reproduzierbarkeit, ${ }^{4}$ die es sich zum Ziel machten, das Verhältnis von Original und Kopie differenzierter zu bestimmen, die Kopie aus ihrer nachteiligen Position zu befreien oder zumindest die als übertrieben wahrgenommene Position des Originals zu schwächen. Einige zentrale Arbeiten seien hier genannt: In den 1980er Jahren entwarf Jean Baudrillard in seiner poststrukturalistischen Theorie der Simulation die These der Ununterscheidbarkeit von Original und Kopie, die sich in einer immer stärker verbildlichten Gesellschaft manifestiert und zu prinzipieller Referenzlosigkeit in der sogenannten »Hyperrealität« führt (Baudrillard 1994). Die in den Cultural Studies

4 Siehe dazu auch die Sammlung von mehr als 40 Aufsätzen und Formulierungen, die sich bereits im Titel an Benjamins "Das Kunstwerk im Zeitalter seiner technischen Reproduzierbarkeit« anlehnen: http://reproduzierbarkeit.tumblr.com (25.06.2016). 
beheimatete Celia Lury beschrieb in Anschluss an Benjamin sehr differenziert die kulturellen Entwicklungen, die aus der mechanischen (Re)Produktion von kulturindustrieller Massenware erwachsen und sich auf das gesellschaftliche Verständnis von Originalität, Authentizität und Legalität auswirken (Lury 1993). Hillel Schwartz untersuchte in einer kulturwissenschaftlichen Perspektive die gesellschaftliche Funktion der Kopie, zum Beispiel bei Zwillingen, Doppelgängern oder Imitationen (Schwartz 1996). Und der Kunsthistoriker Wolfgang Ullrich (2009) zeigte in einer Reihe von Beispielen, die sich von der frühen Neuzeit bis zur Gegenwart hin erstrecken, dass durch die Fixierung auf die Prinzipien des Originals und der Originalität die stille Relevanz von Reproduktionen verdeckt wird - obgleich sich die besondere Aura eines Originals auch stark durch Reproduktionen konstituiert.

Weitere Publikationen folgten, die den interdisziplinären Kopiediskurs bis heute prägen und dafür teilweise feldspezifische Konzepte von (digitalen) Kopien und Originalen entwickeln. So unterschiedlich die Beiträge im Einzelnen sind, sie teilen eine gemeinsame Faszination für Kopiervorgänge, die historische Steigerung technischer Reproduzierbarkeit oder die daraus entstehenden Effekte in gesellschaftlichen Bereichen wie Kunst, Recht, Politik und anderen. So problematisieren Gisela Fehrmann und Kolleginnen (2004) in dem Band »Originalkopie« das starre dichotome Verhältnis von Original und Kopie und plädieren für eine differenzierte Betrachtung sogenannter "Praktiken des Sekundären«. Mit Dirk von Gehlens »Mashup. Lob der Kopie« (von Gehlen 20Io) und Marcus Boons »In Praise of Copying " (Boon 20IO) erschienen im gleichen Jahr zwei Bücher, die beide in stark affirmativer Absicht, wenn auch in spezifischer Weise, die kulturelle, künstlerische und kreative Kraft des Kopierens als Kulturtechnik erkunden. In dieselbe Kerbe schlugen auch Autoren wie Lawrence Lessig oder Aram Sinnreich, denen sich durch die breite gesellschaftliche Verfügbarkeit digitaler Technologien mit exakten Kopiermöglichkeiten und dem Aufstieg des Internets samt illegaler File-Sharing-Plattformen ein ganz neues akademisches Betätigungs- 
feld im Bereich des Kopierens erschloss (Lessig 2004, 2008; Sinnreich 20IO, 20I6). Unter dem scheinbar paradoxen Begriff des "Massenoriginals« diskutiert Jörg Metelmann (2016) schließlich die gesellschaftlichen Entwicklungen von Individualisierung und Massenkultur. Er macht damit auf verschiedene Phänomene aufmerksam, in denen trotz oder wegen serieller Produktionsweise individualistische Bedürfnisse verarbeitet werden. Neben dem Phänomen "Selfie« nennt er Turnschuhe, die Konsument_innen innerhalb eines bestimmten Rahmens selbst designen können und die dann industriell als »mass customization" produziert werden.

Auch in der literarischen und filmischen Auseinandersetzung lässt sich eine starke Faszination für das Phänomen der (exakten) Kopie, für das Verwischen der Grenzen von Original und Kopie, Realität und Fiktion oder Authentizität und Fake erkennen: Die Steigerung technischer Reproduzierbarkeit wurde - in der Regel gewendet als Sciene-Fiction-Dystopie - in (erfolgreichen) Hollywood-Produktionen wie »Blade Runner« (1982), "Matrix« (1999), "Inception" (2010) oder auch "Jurassic Park" (1993) als Sujet publikumswirksam verfilmt. All diese Auseinandersetzungen, egal ob sie eher neutral, euphorisch, latent affirmativ oder offen dystopisch ausfallen, zeigen das große Interesse an dem Prinzip, das Benjamin treffend »technische Reproduzierbarkeit« nannte und das sich unter dem Stichwort von Macht diskutieren lässt. Denn technische Reproduzierbarkeit ermächtigt gesellschaftliche Akteure dazu, für unterschiedliche Zwecke Kopien von Objekten anzufertigen - auch wenn ihnen die Kopien mitunter über den Kopf wachsen wie in den genannten Dystopien.

Der kursorische Überblick zu den genannten Arbeiten lässt zwei Schlüsse zu, die ich im Folgenden aufnehmen und weiterführen möchte. Einerseits ist es ratsam, verschiedene Formen und Verwendungsarten von Kopien zu unterscheiden. Konkret möchte ich in dieser Arbeit physische, digitale und referentielle Kopierverfahren auseinanderhalten (siehe Abschnitt I.I.3). Andererseits geraten durch den starken Fokus auf die Potentiale und Steigerungstendenzen technischer Reproduzierbarkeit die sich gleichermaßen entwickelnden 
Suspensionsmechanismen aus dem Blick, die Reproduzierbarkeit wieder einhegen, einschränken oder verhindern sollen. Dabei ließen sich an dem gegenläufigen Prinzip von Steigerung und Suspension von Kopiervorgängen mit Gewinn gesellschaftliche Machtverhältnisse ablesen und gesellschaftstheoretisch untersuchen. Im folgenden Abschnitt I.I.2 widme ich mich daher der Frage, mit welchen Methoden und Interessen technische Reproduzierbarkeit suspendiert wird.

\subsubsection{Gefangen in der Zwischenablage: Suspension technischer Reproduzierbarkeit}

In Anschluss an den Medienwissenschaftler Jens Schröter, der darauf drängt, die Sphäre der »Nicht-Reproduzierbarkeit« ernst zu nehmen, und damit eine Gegenposition zu Benjamin einnimmt, möchte ich auf die verdeckten oder übersehenen Mechanismen zur Suspension technischer Reproduzierbarkeit aufmerksam machen und sie auf den Fall der samplingbasierten Popmusik anwenden. Mit der Formulierung seiner Gegenposition zu Benjamin geht es Schröter weniger darum, die Rolle der technischen Reproduzierbarkeit in der gegenwärtigen Gesellschaft kleinzureden oder gar zu bestreiten. ${ }^{5}$ Er plädiert aber für eine differenzierte Perspektive, die gegenläufige Entwicklungen einzufangen weiß:

"Das Ausgreifen der Reproduzierbarkeit - gleich ob das Prinzip schon immer existiert hat oder nicht - auf immer weitere Gegenstandsbereiche hat zwingend die Entstehung einer technischen Nicht-Reproduzierbarkeit zur Folge. Die Beschreibung der Moderne als eines Zeitalters stets gesteigerter Reproduzierbarkeit ist nicht falsch, aber

5 Auf dem Umschlag des von Jens Schröter herausgegebenen Doppelbands mit dem Titel »Kulturen des Kopierschutzes« befindet sich eine Abbildung mit ungeöffneten Kondompackungen: ein humorvoll gemeinter Hinweis auf die diversen Techniken zur Einschränkung oder Verhinderung sexueller Reproduzierbarkeit. 
einseitig. Vor allem, wenn daraus wie bei Anders oder Baudrillard die Implosion der Differenz von Original und Kopie geschlussfolgert wird: Geld, geheime Dokumente, Personalpapiere sollen nicht oder genauer: nur von bestimmten Institutionen reproduziert werden dürfen.« (Schröter 20IO: I4; Hervorhebungen weggelassen)

Schröters Kritik richtet sich damit gegen Ansätze, die er innerhalb eines "Narrativs zunehmend gesteigerter Reproduzierbarkeit» (Schröter 20IO: I4) verortet sieht und die seiner Ansicht nach die Potentiale der technischen Reproduzierbarkeit zu Ungunsten gegenläufiger Entwicklungen überrepräsentieren. Um eine Wende hin zur Erforschung der Sphäre der Nicht-Reproduzierbarkeit, ihrer Mechanismen und Prinzipien hin zu fundieren, führt er zwei alltagsnahe Beispiele weiter aus: Geld und Personalpapiere. Denn auch wenn es für alle Menschen mit Zugang zu einem Farbkopierer relativ einfach erscheint, einen Geldschein zu kopieren, so stabilisieren diverse soziotechnische Schutzmechanismen die Unterscheidbarkeit von originalem und kopiertem Geld oder sorgen dafür, dass Falschgeld gar nicht erst in Umlauf gerät. Auf der einen Seite stellen Sicherheitsmerkmale wie die in die Geldscheine eingewobenen Hologramme sicher, dass echtes Geld von Fälschungen zügig unterscheidbar gemacht werden kann. Die Reproduktion von Hologrammen selbst ist aufgrund eines komplizierten geometrisch-optischen Verfahrens nicht für »Otto Normalbürger an einem Kopierer möglich" (Schröter 2013: 255), sondern nur unter bestimmten Bedingungen und für bestimmte gesellschaftliche Institutionen. Auf der anderen Seite gibt es in diversen Druckern und Kopierern sowie in Adobe Photoshop ab einer bestimmten Version einen automatischen Kopierschutz. Dieser wird von einer europäischen Behörde definiert und zur Verfügung gestellt. Banknoten können anhand bestimmter Merkmale der sogenannten "EURion-Konstellation" identifiziert werden, wenn sie für einen Kopiervorgang eingescannt werden. Der Kopiervorgang wird daraufhin abgebrochen (Schröter 20IO: 26). 
Die Hoheit ${ }^{6}$ zur technischen Reproduzierbarkeit (kurz: Reproduktionshoheit), wie ich sie in Anschluss an Schröter nenne, ist also umkämpft. Im Beispiel des Gelds liegt sie ausschließlich bei dazu befugten Organisationen, in Deutschland ist nur die Bundesdruckerei von der Europäischen Zentralbank (EZB) dazu autorisiert, Euroscheine herzustellen. Bei Personalpapieren wie Pässen, Ausweisen oder Führerscheinen, die materielle Unikate darstellen, ist die Situation ähnlich. Da diese Dokumente eine bestimmte Identität auf einen bestimmten Menschen zuordnen, gibt es auch nur ein Exemplar, das als echt gilt. Schröter (20I0: 22) unterscheidet folglich zwischen echten und falschen Originalen, wodurch die klassische Dichotomie zwischen echtem Original und falscher Kopie angegriffen wird.

Bei Geld und Ausweispapieren handelt es sich bekanntlich um offizielle, an Staatsautoritäten gebundene Dokumente, deren technische Reproduzierbarkeit eingeschränkt wird, um die gewünschte Knappheit des Guts monopolistisch zu bewahren und zu regulieren. Dieses Privileg ist gesetzlich festgeschrieben und wird an die genannten Technologien, in diesem Falle zur Zertifizierung von Echtheit, delegiert. Kopierer sind zwar Mittel zur Aufrechterhaltung und Steigerung technischer Reproduzierbarkeit, ihre Reichweite wird aber begrenzt, um die Differenz zwischen erwünschten und unerwünschten Kopien zu stabilisieren. Diese Differenz stellt damit eine gesellschaftlich umkämpfte Ressource (vgl. Bourdieu 1987) dar, um deren Deutungshoheit und Kontrolle fortlaufend gerungen wird. Besagte Differenz wird daher selbst fortlaufend reproduziert, indem unerlaubte Reproduktionen unter Strafe gestellt und technisch verunmöglicht werden.

6 Der Begriff der Hoheit ist hier dem Staatsrecht und der Geopolitik entlehnt, wo er in erster Linie die territoriale Souveränität für ein geografisch eingegrenztes Gebiet bezeichnet. Abstrahiert davon lässt sich auch für nicht-geografische Bereiche von Hoheit sprechen, insofern sie unter der Kontrolle und der Verfügung eines bestimmten Akteurs stehen. In diesem Sinne taucht in der deutschsprachigen Soziologie des Öfteren der Begriff der Deutungshoheit auf, der die diskursive Kontrolle eines (mächtigen) Akteurs über ein bestimmtes Thema meint und gesellschaftliches Ringen darum impliziert (siehe zum Beispiel Maeße 20I7). 
Mit der Behauptung einer gesellschaftlichen Sphäre der Nicht-Reproduzierbarkeit geht es Schröter (2010: 23) weniger darum, "Reproduzierbarkeit und Nicht-Reproduzierbarkeit gegeneinander auszuspielen, sondern ihre historisch, kulturell, ja situativ konkreten Konfigurationen zu beobachten«. Dementsprechend sei Reproduzierbarkeit auch nicht etwas,

"das es gibt oder nicht, sondern [...] etwas, das gestuft und verteilt vorliegt. Eine bestimmte Reproduzierbarkeit steht großen und finanzstarken Unternehmen und/oder staatlichen Institutionen zur Verfügung. [...] Den meisten Menschen steht sie nicht zur Verfügung. Daher sind eben auch nicht ,wir in ein Zeitalter der technischen Reproduzierbarkeit, eine Kultur der Kopie oder eine Epoche der Simulation übergegangen. Die Homogenität eines solchen Übergangs im ,Wir zu behaupten, verdeckt die unterschiedlichen Stufungen und Verteilungen von Reproduzierbarkeit und Nicht-Reproduzierbarkeit und mithin ihre Funktionen für die stets umkämpfte Reproduktion gesellschaftlicher Macht.« (Schröter 20IO: 29 f., Hervorhebungen im Original)

Die von Schröter vorgeschlagene Betrachtung der Stufungen und Verteilungen technischer Reproduzierbarkeit halte ich für einen hilfreichen Ausgangspunkt, um eine differenzierte Analyse der Kopierpraktiken des Samplings und ihren urheberrechtlichen Restriktionen in Angriff zu nehmen. Dabei interpretiere ich das von Schröter beschriebene Phänomen als einen Antagonismus, an dessen Bewegungen sich gesellschaftliche Machtverhältnisse ablesen und deuten lassen. Denn so offensichtlich die Steigerung der technischen Reproduzierbarkeit im 20. Jahrhundert auch ist, sie ist begleitet von diversen Gegenmaßnahmen und wiederum subversiven "Gegenpraktiken und Gegentechnologien, die diese Zurichtungen zu unterlaufen suchen" (Schröter 20I4: 20). Gleichfalls werde ich in Abgrenzung zu Schröter nicht die These von der "Sphäre der Nicht-Reproduzierbarkeit" fortschreiben. Die vorangestellte Negation ist vor allem dabei 
hilfreich, auf das dahinter liegende Spannungsverhältnis aufmerksam zu machen, nämlich auf den Kampf um die Hoheit zur technischen Reproduzierbarkeit. Um das antagonistische Verhältnis zwischen Potentialität und Restriktivität adäquat zu beschreiben, werde ich hingegen auf die Konfigurationen der Reproduzierbarkeit, also auf die Stufungen und Verteilungen, fokussieren.

\subsubsection{Urheberrechtliche Konfigurationen technischer Reproduzierbarkeit und ihre Delegation an Technologie}

Sozialwissenschaftlich gewendet impliziert der Kampf um die Reproduktionshoheit die vielschichtige Frage, wie technische Reproduzierbarkeit konfiguriert wird: Wer darf unter welchen Bedingungen und zu welchen Anteilen was kopieren? Diese Frage lässt sich erweitern und aufschlüsseln: Wer, das heißt welcher gesellschaftliche Akteur, ist aufgrund welcher Ressourcen in der Lage, Kopien von Objekten herzustellen oder in Umlauf zu bringen, aber auch den Unterschied zwischen echt und falsch beziehungsweise zwischen Original, Kopie und Plagiat zu definieren? Auf welche Weise wird etwas als Eigentum markiert und Autorschaft dafür behauptet? Und unter welchen Bedingungen und mit welchen Mitteln wird die Reproduktion erlaubt und kontrolliert, aber auch eingeschränkt und verhindert? Das deutsche Urheberrecht ist ein Regelsystem, das für ein sozialwissenschaftliches Studium solcher Konfigurationen technischer Reproduzierbarkeit besonders geeignet erscheint. Sein enger Verwandter, das angloamerikanische Copyright, trägt die Frage nach der Reproduktionshoheit, also nach dem right to copy, bereits in sich.

Bevor diese Aspekte vertieft werden, ist es allerdings angebracht, das Phänomen der Kopie näher zu beleuchten und spezifische Formen zu unterscheiden. Drei Typen scheinen mir im Diskurs dominant zu sein (wenn auch nicht immer sauber getrennt): die physische, die digitale und die referentielle Kopie. Von ihnen lässt sich sprechen, 
je nachdem, ob es sich um physisch-materielle Objekte, vom Trägermedium unabhängige Informationen oder soziale Bedeutungen handelt, die kopiert werden. Die physische Kopie beinhaltet einen hohen Ähnlichkeitsgrad der kopierten Objekte, aber nicht ihre physische Identität. Es handelt sich um materielle, rivale Güter, die in ihrer physischen Präsenz als Exemplar unter mehreren vorkommen (beispielsweise seriell hergestellte Güter wie Autos des gleichen Herstellers und der gleichen Baureihe oder die bereits genannten Geldscheine). Die digitale Kopie hingegen zeichnet sich durch ihren nicht-physischen, daher auch non-rivalen und vom Trägermedium lösbaren Inhalt aus, der eine Übersetzung von analogen Informationen in digital codierte Entsprechungen darstellt und daher verlustfrei und unbegrenzt oft kopiert werden kann - im Gegensatz zu der nicht-verlustfreien Kopie bei analogen Trägermedien wie Magnettonband oder VHS-Kassette. Ich orientiere mich dabei an dem erweiterten Begriff der Digitalität von Felix Stalder:

"Informationen sind digital codiert, wenn sie mittels eines begrenzten Systems diskreter (das heißt durch endliche Intervalle oder Abstände voneinander getrennter), in sich bedeutungsloser Zeichen gespeichert werden. Das erlaubt es, Informationen von einem Träger auf einen anderen verlustfrei zu kopieren und die jeweiligen Zeichen, einzeln oder in Gruppen, frei zu arrangieren. So gesehen ist die digitale Codierung nicht notwendigerweise an Computer gebunden, sondern kann mit allen Materialien realisiert werden: Ein Mosaik ist ein digitales Verfahren, bei dem visuelle Informationen mithilfe von verschiedenfarbigen Steinen codiert werden, ähnlich wie bei einem digitalen Bild, das aus Bildpunkten besteht. Die Auflösung ist beim Mosaik natürlich sehr viel niedriger.» (Stalder 20I6: IOO-I).

Schließlich unterscheide ich als dritten Typ die referentielle Kopie. Referentiell sind Kopien, wenn sie in symbolischer Form einen Bezug auf etwas Anderes herstellen, beispielsweise als Zitat, Nachahmung oder Assoziation. Die referentielle Kopie basiert auf der physischen 
oder digitalen Kopie, operiert aber auf der symbolischen Ebene arrangierbarer Bedeutungen. Sie nimmt eine andere Bedeutung auf, kopiert sie damit in gewisser Weise und stellt sie so in einen Zusammenhang. Der Bereich der Musik, insbesondere der Popmusik, besteht zu großen Teilen aus intentional organisierten Bedeutungen in Form von Klängen, die je nach Genre mit unterschiedlichen Graden der Referentialität ausgestattet werden, wie in Abschnitt I.2.2 ausführlich diskutiert wird.

Als formales Regelsystem stellt das deutsche Urheberrecht ein auf Gesetzen, Gesetzesauslegungen und Auslegungen von Gesetzesauslegungen basierendes grammatisches Instrument zur gesellschaftlichen Regulierung der Reproduktionshoheit dar. Zur Herstellung einer Balance von Schutz und Anreiz zur Produktion neuer Werke (Kocatepe 20I7) enthält es eine Fülle von Konfigurationen technischer Reproduzierbarkeit, beispielsweise die Privatkopie, die Rechtsfigur der zufälligen Doppelschöpfung, die Zitatschranke oder die grundsätzliche Regel, dass 70 Jahre nach dem Tod einer Autor_in der urheberrechtliche Werkschutz erlischt und ihr Werk automatisch in den Bereich der Gemeinfreiheit übergeht. Bei diesen Konfigurationen handelt es sich um gesellschaftlich ausgehandelte Konventionen, die zu unterschiedlichen historischen Zeitpunkten vereinbart und formal kodifiziert wurden. Wie ich anhand eines kurzen historischen Rückblicks zeigen möchte, ist die Ausdifferenzierung urheberrechtlicher Regeln dabei an Innovationen zur Steigerung der technischen Reproduzierbarkeit gekoppelt.

Aufschlussreich in diesem Zusammenhang ist, dass das Aufkommen des Buchdrucks und des Urheberrechts historisch miteinander in Verbindung steht. Stalder (20I6: IOI) versteht mithilfe seines weiten Verständnisses von Digitalität den Buchdruck als digitales Verfahren, da dieser - freilich als mechanischer Prozess - die analogen Zeichen von Handschriften in standardisierte, nahezu verlustfrei reproduzierbare und austauschbare Lettern transferieren konnte. Eine massenweise Vervielfältigung von Texten, die zuvor nur handschriftlich erfolgte und entsprechend viel Mühe kostete, wurde so durch 
die Druckpresse möglich. Niklas Luhmann vermutet dabei, dass der Buchdruck aufgrund der technischen Erleichterung des Vervielfältigens seinen Anteil bei der Aufwertung des Neuen hatte, während sich die bisherige gesellschaftliche Präferenz für das Alte und Bewährte verringerte:

"Viel diffus verstreutes, mündlich tradiertes Wissen konnte nun für den Druck verschriftlicht und publiziert werden. Die Bücher selbst forderten ihre Leser zur Verbesserung des gebotenen Wissens auf. Auch hatte in den früheren Schreibwerkstätten das ständige Abschreiben die Texte durch hinzukommende Fehler verschlechtert. Bei der Vorbereitung für den Druck konnte dagegen editorische Arbeit geleistet, der Text also verbessert werden, so dass jetzt die neuen Bücher die Vermutung für sich haben, besser zu sein als die alten." (Luhmann 1995: 64).

Die Steigerung technischer Reproduzierbarkeit, so eine Beobachtung, die im Laufe der Arbeit immer wieder als These aufgegriffen wird, geht einher mit einer Steigerung der Detektabilität. Im Fall des Buchdrucks bedeutet dies, dass sich Fehler aufgrund einer besseren Vergleichbarkeit leichter detektieren lassen. ${ }^{7}$ Luhmann zufolge beginne mit dieser Entwicklung ein erhöhtes gesellschaftliches Interesse für Neues und Neuheit, das sich auch in der gleichzeitigen Abwertung des Begriffs copia zeige. Dieser indizierte ursprünglich in der Rhetorik die Reichhaltigkeit der Redensarten und die Gesamtmenge allen verfügbaren Wissens (lateinisch copia: Menge, Vorrat, Luxus), also das "Schöpfen aus dem Reichtum der Kenntnis perfekter Formen" (Luhmann 2008a: 155), erhielt später aber die negative Konnotation

7 Ein Beispiel für die Verstetigung fehlerhafter Kopien ist die Redewendung "mumpsimus", die auch als Metapher für ein Beharren auf überlieferte Traditionen steht. Im lateinischen Originaltext steht eigentlich »sumpsimus«; dies wurde aber durch einen, vermutlich von Mönchen gemachten Übertragungsfehler zum sinnlosen "mumpsimus« kopiert. Siehe https:/en.wiktionary.org/wiki/mumpsi mus (10.03.2018). 
des bereits Vorhandenen und Verbrauchten. Durch die Konstitution der Kopie erfuhr auch der Begriff des Originals eine Aufwertung, indem es nicht mehr die eher neutrale "Gegenwart des Ursprungs" (lateinisch origo: Abstammung, Ursprung, Herkunft) bezeichnete, sondern nun »ein Produkt ohne Präzedenz« anzeigte (Luhmann I995: 64, 70-7).

Die Geschichte des Geistigen Eigentums, egal ob in seiner Autor-zentrierten Variante des deutschen Urheberrechts oder in der stärker auf Bildung und Ökonomie fokussierenden angloamerikanischen Version, lässt sich als Entwicklung verstehen, die entscheidend von den Technologien der Reproduzierbarkeit getrieben ist. Bereits an Begriffen wie "Buchprivileg" und "Nachdruckverbot", die etwa im I6. Jahrhundert aufkommen, lassen sich deutlich die Fehden erkennen, die um die gesellschaftliche Kompetenz der Büchervervielfältigung und Distribution ausgetragen wurden und nicht selten auch mit Zensurfragen in Verbindung standen (Seifert 20I4: 98-IOO). Ähnlich wie heute waren diese ersten Druckbefugnisse an hegemoniale Grenzen gebunden und grundsätzlich zeitlich befristet. Durch die Entwicklung eines eigenen Buchmarktes etwa im I8. Jahrhundert entstanden mit dem deutschen Urheberrecht, dem französischen Droit d'auteur und dem angloamerikanischen Copyright Law dann umfassende territorial-juristische Regelwerke zur Einschränkung der technischen Reproduzierbarkeit, um unautorisierte Nachdrucke zu verhindern. Anders als es der Begriff »Urheberrecht " nahe legt, ging es dabei zunächst aber weniger um die Rechte der Autor_innen als vielmehr um die der Verleger_innen (Baldwin 20I4: 54-6).

Die Ausdifferenzierung der urheberrechtlichen Grammatik gewinnt im 19. und 20. Jahrhundert durch aufkommende Reproduktionstechnologien weiter an Fahrt, wie Monika Dommann (20I4) anhand der Rechtsgeschichte der Fotokopie und den Technologien zur Speicherung und Verbreitung von Musik- und Tonaufnahmen von etwa I850 bis I980 nachweist. In der gegenwärtigen Gesellschaft ist der Zugriff auf digitale Kopien alltäglich und global geworden. Die Ausbreitung von Kopiermechanismen in digitalen Technologien 
wie Smartphones, Computern oder Software hat durch verlustfrei herstellbare Kopien immaterieller Objekte einen enormen Grad der Ausbreitung erreicht und dadurch infrastrukturellen Charakter erhalten. In der Regel erkennen wir heute nicht, wie sehr unser Leben auf Kopierprozessen fußt, auch weil diese in zahlreichen Situationen invisibilisiert werden. ${ }^{8}$

Es sind jedoch nicht nur die formalen Regeln, die Reproduktionshoheit urheberrechtlich konfigurieren, sondern auch in Technologien eingelassene Delegationen dieser Regeln. Vergleichbar mit einem Hotelschlüssel, der qua seines schweren Anhängers zur Rückgabe an der Rezeption auffordert oder jenen speed bumps auf Straßen, die zum langsamen Fahren zwingen (Latour 1990), werden die Kopierschutzmechanismen vorwiegend in denjenigen Situationen eingesetzt, in denen für die rechteinhabenden Akteure die Rechtsdurchsetzung der urheberrechtlichen Grammatik nicht effektiv greift oder weit genug reicht. Die zwar ausgehandelten oder zumindest formalisierten, aber missachteten urheberrechtlichen Konfigurationen technischer Reproduzierbarkeit werden auf diese Weise mit Technologien verschränkt und durch die materialisierten Hilfsmechanismen sozial gehärtet. Folgende Beispiele lassen sich für eine solche Verschränkung anführen:

8 Der infrastrukturelle Charakter von Kopien wird immer dann besonders deutlich, wenn eine Störung des typischen Ablaufs oder eine anderweitige Irritation vorliegt. Bei einer Filmvorführung in einem Kinosaal beispielsweise ist die Infrastruktur von digitalen Filmkopien unwesentlich, insofern Kinobesucher_innen nichts von der Organisation und Verwaltung der Filmkopien mitbekommen. Die Vorgänge laufen invisibilisert hinter den Kulissen ab, selbst das Projektionsgerät ist in einem nicht zugänglichen Raum untergebracht. Es wirft den Film an die Kinoleinwand, den die Kinobesucher_innen alle im gleichzeitigen Vollzug konsumieren. Befindet man sich jedoch auf einem Langstreckenflug in einem Flugzeug, ist die Situation eine andere: Zwar können die Passagier_innen um einen herum den gleichen Film ansehen wie man selbst auf dem eigenen Bildschirm, aber sie tun dies in der Regel nicht synchron, sondern zeitversetzt, mit persönlichen Pausen, Vorspulen etc. Auch hier wird der Film wie im Kino als Kopie abgespielt, aber die Ungleichzeitigkeit des Gleichzeitigen macht den infrastrukturellen Charakter der Kopiervorgänge sichtbar. 
(I) Im Mai 2016 wurde von IBM ein Patent für ein Kopiergerät angemeldet, das Text- oder Bildmaterial wie Songtexte oder Fotografien vor dem Druck auf ihren urheberrechtlichen Schutz hin überprüft und gegebenenfalls den Kopiervorgang nicht ausführt. In der technischen Beschreibung des Patents steht:

»In an approach for determining printability of an electronic file, a computer electronically receives a file for printing. The computer parses the file for one or more of text, images, and formatting indicative of potential copyrighted material. The computer, in response to identifying any text, images or formatting indicative of potential copyrighted material, identifies potential copyrighted material within the file.« (IBM 2016)

Ähnlich wie der von Schröter beschriebene Kopierer, der das Auflegen von Geldscheinen erkennt und automatisch den Kopiervorgang abbricht, detektiert auch die von IBM patentierte Maschine urheberrechtlich geschütztes Material. Sie nutzt dafür selbst Verfahren technischer Reproduzierbarkeit zum Abgleich. Seit einigen Jahren ist außerdem bekannt, dass bekannte Druckerhersteller wie Xerox oder Hewlett Packard Markierungstechniken beim Druck des Papiers einsetzen, um die Originalität des Dokuments präzise nachverfolgen zu können. Durch diese Technologie, die als "Machine Identification Code» (MIC) bekannt ist, lassen sich Informationen über die Herkunft des Dokuments mittels eines Punktrasters nahezu unsichtbar in das Papier einschreiben, wie beispielsweise die Seriennummer des Geräts, Ort und Uhrzeit oder angemeldete Benutzer_in.

(2) Daneben stellt das »Digital Rights Management (DRM) eine softwarebasierte Verschränkung von urheberrechtlicher Grammatik und technischem Kopierschutz dar, bei der die Abstufungen technischer Reproduzierbarkeit besonders deutlich werden. Unter DRM versteht man grundsätzlich ein Bündel von verschiedenen Technologien der Kontrolle, Distribution und Verwertung, die die Reichweite der Re- 
produzierbarkeit digitaler Kopien regulieren: „Die digitale Rechteverwaltung identifiziert digitale Werke, regelt den Zugang und die Nutzung dieser und überwacht gleichzeitig die Einhaltung ebendieser Kontrollinstanzen" (Köhne 20I0: 65). Viele der DRM-Mechanismen wurden als Reaktion auf digitale Tauschbörsen und die darin "vagabundierenden Kopien" (von Gehlen 20IO: IOI) von Software, Filmen und Musikstücken konzipiert. Für Volker Grassmuck ist DRM sogar "das in Technologie gegossene Misstrauen gegenüber den Nutzern" (Grassmuck 2006: 179). In einem PDF-Dokument beispielsweise können die "Sicherheitseinstellungen« je nach Schärfe folgende Aktionen verhindern: »das Dokument drucken, verändern, per Cut-andPaste Stellen extrahieren, mit anderen Dokumenten verbinden und Kommentare anlegen (Grassmuck 2006: I66). Microsofts »Windows Media Digital Rights Management" vergibt Rechte, um Dateien auf bestimmten Geräten wiederzugeben, auf CDs zu brennen oder mit einem tragbaren Gerät zu synchronisieren. Und ein besonders rigider DRM-Kopierschutz für Audio- und Videodateien, der allerdings von der Unterhaltungsindustrie unter anderem wegen Unmuts und Umgehungsstrategien der Nutzer_innen relativ zügig wieder abgeschafft wurde (Dolata 2008: 355), definierte sogar die Anzahl der Kopien, die Nutzer_innen von einer Datei anfertigen können. ${ }^{9}$ Gegenwärtig zeichnet sich ab, dass das auf Geistigem Eigentum basierende Kontrollprinzip von DRM zunehmend bei physischen Konsumgütern angewendet wird und Lizenzierungszwänge für materielles Eigentum erzwingt, wie sich bei vernetzten Haushaltsgeräten des internet of things oder der Reparatur von Fahrzeugen zeigt (Bigelow 2015).

9 Die Kontrolle über die Dateiverwaltung via DRM kann auch für den umgekehrten Fall, also für das fremdbestimmte Hinzufügen von Musik in die Mediatheken der Nutzer verwendet werden, wie die Kooperation zwischen Apple und der Band U2 zeigt: 2014 wurde ein komplettes Album der Band kostenlos auf alle Computer mit iTunes-Installation distribuiert. Da dies ungefragt geschah und sich das Album auch nicht ohne Weiteres löschen ließ, führte die PR-Aktion jedoch nicht zum gewünschten Erfolg. U2 sahen sich später sogar dazu genötigt, eine Entschuldigung zu formulieren. Das Album trägt im Übrigen den Titel "Songs of Innocence». 
(3) Da sich digitale Kopien auch hervorragend zum Abgleich einsetzen lassen, werden diese gleichermaßen dazu genutzt, technische Reproduzierbarkeit einzuhegen und zu kontrollieren. Führende Videound Audioplattformen wie Youtube oder Soundcloud arbeiten seit einigen Jahren mit einem algorithmischen Identifikationssystem zur automatischen Kontrolle über das Hochladen und Veröffentlichen urheberrechtlich geschützten Materials. Indem die Majors der Filmund Musikindustrie ihre Kataloge zur Identifizierung zunehmend bei den Plattformen hinterlegen und dadurch urheberrechtliche upload filter schaffen, wird die Zone der technischen Reproduzierbarkeit fortlaufend eingeschränkt. Das Hochladen von DJ-Sets, mit kurzen Musikausschnitten unterlegten Amateurvideos oder samplebasierter Musik steht dadurch in einem ständigen Wettbewerb mit seiner urheberrechtlich induzierten, technisch gestützten Verhinderung.

Die medienwissenschaftlich informierte Darstellung zeigt, dass eine Perspektive, die vornehmlich die Potentialität und Errungenschaften der technischen Reproduzierbarkeit fokussiert, dazu neigt, gegenläufige Entwicklungen zu übersehen. Aus diesem Grund scheint es ratsam, für eine Untersuchung der Praktiken samplingbasierter Popmusik und ihrer urheberrechtlichen Verwicklungen stärker auf die gegenläufigen Mechanismen zur Suspension technischer Reproduzierbarkeit zu fokussieren. Die vielfältige Kultur, die sich um die Kopierpraxis des Samplings seit den I980er Jahren entwickelt hat und den intentionalen Umgang mit Referentialität zentral stellt, bietet in diesem Sinne ein reichhaltiges Untersuchungsfeld und zahlreiche Anknüpfungspunkte. Die Hoheit zur Reproduzierbarkeit, ihre grammatisch-technischen Einschränkungen und die als Reaktion dazu wiederum erfolgenden Umgehungsstrategien können damit am Fall des Samplings beispielhaft für andere gesellschaftliche Bereiche studiert werden. 


\subsection{Der Status der Neuheit in Urheberrecht und Remixkultur}

Mit einem für Kopierprozesse geschärften Blick werden im folgenden Abschnitt die urheberrechtlichen Konfigurationen für das Sampling ${ }^{\text {IO }}$ näher spezifiziert und anschließend mit den genrehaften Neuheitsanforderungen samplingbasierter Popmusik kontrastiert. Für den ersten Teil konzentriere ich mich auf die grammatischen Mechanismen des Urheberrechts, die innerhalb der juristischen Diskussion bis zum Urteil des Bundesverfassungsgerichts (2016) maßgeblich waren und damit die Entwicklung samplingbasierter Popmusik in Deutschland begleitet und geprägt haben. Im Juni 2017 hat der Bundesgerichtshof sein Urteil dem Europäischen Gerichtshof zur Harmonisierung vorgelegt (Jütte/Maier 2017), dessen Urteil im Sommer 2019 veröffentlicht wurde und ein weiteres Urteil des Bundesgerichtshofs nach sich ziehen wird (vermutlich 2020). Da meine empirische Untersuchung vor allem im Zeitraum zwischen 2014 und 2016 stattfand, bespreche ich hier die generelle urheberrechtliche Konfiguration des Samplings vorwiegend auf Stand des besonders restriktiven Urteils des Bundesgerichtshofs (2012).

Die in der Einleitung erfolgte Gegenüberstellung der Positionen Hütters und Pelhams ließ die Verhärtung der Fronten, die die Verwendung von Kopien entweder als Diebstahl Geistigen Eigentums oder als legitime Kunstform interpretieren, schon gut erkennen. Um die konkrete Ausformung beider Positionen besser zu verstehen, bietet sich das jeweilige Verständnis von Neuheit als Vergleichspunkt an. Denn in Innovationsgesellschaften, so wie sie von den

IO Dass der Einsatz von Samples auch religiös konfiguriert sein kann, zeigt das Beispiel eines britischen DJs, der 2017 in einem tunesischen Club Techno auflegte und dabei ein Stück mit einem etwa 20 Sekunden langen Sample eines Gebetsrufs spielte. Die Veranstaltung wurde daraufhin abgebrochen, der Club geschlossen und der DJ in Untersuchungshaft genommen. Er hatte die alleinige Hoheit der Muezzine zur öffentlichen Reproduktion des Gebetsrufs verletzt, siehe Fischer (2017). 
Antragsteller_innen des Graduiertenkollegs verstanden werden, hat sich Neuheit zum ubiquitär geforderten Merkmal von Produkten und Verfahren sowie zum dominanten Kriterium der Bewertung in nahezu allen Bereichen des gesellschaftlichen Lebens entwickelt. Innovationen werden dadurch in zunehmendem Maße reflexiv, das heißt "mit Absicht, mit Bezug auf viele Andere und im Kontext allgemeiner Forderungen nach strategischer Herstellung von Neuem vorangetrieben" (Hutter et al. 20I6: I8). Die Fixierung auf das Neue wird durch den Blick auf die Innovationsgrammatiken und die darin formulierten Neuheitsimperative in Urheberrecht und Popmusik dabei besonders deutlich. Es zeigt sich, dass Neuheit das zentrale Kriterium für die Reproduktionshoheit darstellt. Allerdings treten mit der Frage nach der sozialen Bewertung von Neuheit unterschiedliche semantische Festlegungen zu Tage. Oder anders formuliert: Zwar wird Neuheit überall gefordert, doch nicht überall wird das Gleiche darunter verstanden. Dies berührt insbesondere das Problem, ab welchem Selbständigkeitsgrad von einem neuen Kunstwerk gesprochen werden kann oder in welcher Menge Spuren des Alten im Neuen enthalten sein dürfen. Das semantische Problem der Neuheitsbewertung verschleppt sich in der Folge zu praktischen und institutionellen Problemen, die sich - wie das kurze Sample aus »Nur mir« eindrucksvoll zeigt - zu einem bald 20 Jahre währenden Rechtsstreit bis hinauf auf die Ebene des Bundesverfassungsgerichts und des Europäischen Gerichtshofs aufschaukeln.

\subsubsection{Vorsicht: Kann Spuren alter Werke enthalten! Der Neuheitsimperativ des deutschen Urheberrechts}

Das Urheberrechtsgesetz (UrhG) stellt die abstrakteste Formulierung urheberrechtlicher Konventionen dar. Es regelt, dass ausschließlich sogenannte »Werke«, also »nur persönliche geistige Schöpfungen « (UrhG $\$ 2$ Abs. 2) unter urheberrechtlichen Schutz fallen. Die Autorschaft muss dabei eine menschliche sein: Vollautomatisch erzeugte Produkte 
wie Übersetzungen oder Hervorbringungen von nicht-menschlichen Akteuren wie Robotern oder Tieren (vgl. Guadamuz 2016) genießen keinen urheberrechtlichen Schutz. Eine weitere Anforderung an ein Werk ist die konkrete Fixierung in einer Form: Bloße Ideen gelten nicht als schutzfähig; erst die Überführung einer Idee in beispielsweise einen Text, Klang, eine Melodie oder Partitur macht aus einem geistigen Erzeugnis ein prinzipiell schutzfähiges Gut. Nach Erfüllung dieser quasi-formalen Erfordernisse muss sich eine menschliche Schöpfung durch einen gewissen Grad an Individualität auszeichnen. Das Urheberrecht kennt für diese Minimalforderung nach Neuheit den Begriff der "Schöpfungshöhe«. Nach dem urheberrechtlichen Prinzip der "Kleinen Münze« ist die Schöpfungshöhe jedoch relativ niedrig gehängt: Schon vergleichsweise einfache Erfindungen wie Handyklingeltöne oder simple Melodien wie die Tonfolge der Tagesschau genießen urheberrechtlichen Schutz (Bisges 20I4: 43). Dagegen liegen " $[\mathrm{r}]$ ein handwerksmäßige, banale, routinemäßige Erzeugnisse $[. .$.$] au-$ ßerhalb jeglicher Schutzfähigkeit» (Salagean 2008: 76).

Aus der Erfüllung der urheberrechtlichen Anforderungen im Sinne eines Werkes ergeben sich weitreichende Privilegien für die Urheber_in. Die Schutzdauer eines Werks beträgt 70 Jahre bis nach dem Tod der Urheber_in. Das Urheberrecht ist zudem vererblich (UrhG $\$ 28$ Abs. I). Wird ein Werk beispielsweise 1975 veröffentlicht und die Urheber_in stirbt 30 Jahre später, so wird dieses Werk erst im Jahre 2076 gemeinfrei. Bis zu ihrem Tod wird der Urheber_in und ihren Erb_innen »das ausschließliche Recht« zugestanden, das Werk in körperlicher und unkörperlicher Form zu verwerten, sei es durch Vervielfältigung, Verbreitung und Ausstellung sowie durch Aufführungen und Sendungen (UrhG $\$$ I5 Abs. I und 2).

Ausnahmen vom urheberrechtlichen Schutz sind in den sogenannten "Schranken« definiert: Diese schränken die Schutzprivilegien der Urheber_innen ein und sollen für einen prinzipiellen Ausgleich mit gegenläufigen, allgemein-öffentlichen oder individuellen Interessen sorgen. Typische Beispiele für urheberrechtliche Schranken sind das Zitatrecht für wissenschaftliche und literarische Arbei- 
ten (UrhG $\$$ 5I), die als »Panoramafreiheit« bekannte Schranke, die Bildaufnahmen von öffentlichen Plätzen gestattet (UrhG $\$$ 59), oder eine vereinfachte Zugänglichmachung von Werken oder Werkkopien für körperlich oder geistig behinderte Menschen (UrhG $\$ 45$ ).

In der Auslegung der im Urheberrechtsgesetz formulierten Grammatik erwachsen drei zentrale urheberrechtliche Anforderungen für das Sampling. Es soll nicht der Eindruck erweckt werden, dass diese vollkommen statisch sind. Selbstverständlich wird die Grammatik des Urheberrechts fortlaufend dynamisch ausgelegt und so - gerade die Urteile des deutschen Bundesverfassungsgerichts und des Europäischen Gerichtshofs stellen das unter Beweis - besteht regelmäßig Anlass zu Diskussion, Aktualisierung und Anwendung urheberrechtlicher Konventionen. Unter dem Gesichtspunkt eines rechtlichen Imperativs zur Neuheit haben sich im Zusammenhang mit dem Sampling seit den I990er Jahren jedoch verschiedene Restriktionen ergeben, die sich folgendermaßen zusammenfassen lassen: (I) Die generelle Zustimmungspflicht seitens der Originalurheber_in bei der Veröffentlichung und Verwertung samplebasierter Musik; (2) die Zustimmungspflicht kann nur umgangen werden, wenn ein hinreichend großer Abstand zwischen originalem und derivativem Werk gewahrt wird; (3) die Berücksichtigung leistungsschutzrechtlicher Implikationen.

(I) Generelle Zustimmungspflicht bei einer Bearbeitung: Der urheberrechtliche Werkbegriff stellt die Verbindung zwischen Urheber_in und Werk zentral. Aus diesem Verhältnis ergibt sich ein exklusiver Schutz für die Urheber_in zur privilegierten Veröffentlichung und Verwertung des Werks. Dies schließt auch die Veränderung des Werks mit ein. Werden durch das Sampling Töne aus einem bestehenden Werk kopiert und für die Erstellung eines derivativen Produkts benutzt, handelt es sich urheberrechtlich gesehen um eine "Bearbeitung " des Originalwerks, solange die kopierten Töne im derivativen Produkt erkennbar bleiben. Ob das derivative Produkt bereits Werkcharakter im Sinne des Urheberrechts erhält, ist erst einmal nachrangig. Entscheidend ist, dass laut Urheberrechtsgesetz "Bearbeitungen 
oder andere Umgestaltungen des Werkes nur mit Einwilligung des Urhebers des bearbeiteten oder umgestalteten Werkes veröffentlicht oder verwertet werden [dürfen] « $(U \mathrm{rhG} \$ 23)$. Soll ein samplebasiertes Musikstück also legal verwertet oder auch nur veröffentlicht werden, müssen die derivativen Nutzungen aller Samples bei den Originalurheber_innen genehmigt werden, wobei jene ohne Angabe von Gründen verweigern oder eine beliebige Lizenzierungssumme nennen können. Es gibt also kein Recht auf Sampling, wohl aber eine Pflicht zur Einholung der Erlaubnis der Gesampelten.

(2) Abstand zwischen originalem und derivativem Werk: Die "Freie Benutzung« (UrhG $\$ 24$ Abs. I) fungiert laut Döhl als »die Schlüsselnorm für fremdreferenzielles Komponieren im deutschen Urheberrecht" (Döhl 2016: 4I; Hervorhebung im Original) und bietet grundsätzlich genügend interpretative Ambiguität, um rechtliche Freiräume für derivatives Werkschaffen abzustecken. Insofern lassen sich an diesem Paragraphen und seiner restriktiven Interpretation auch der verdichtete urheberrechtliche Neuheitsimperativ und das daraus resultierende Konfliktpotential mit der im Sampling verhandelten Referentialität gut ablesen. Für eine zustimmungsfreie Bearbeitung wird ein deutlicher Abstand zwischen originalem und derivativem Werk eingefordert: „Ein selbständiges Werk, das in freier Benutzung des Werkes eines anderen geschaffen worden ist, darf ohne Zustimmung des Urhebers des benutzten Werkes veröffentlicht und verwertet werden.«(UrhG $\$ 24$ Abs. I) Nach bisheriger Fachmeinung liegt eine Freie Benutzung aber nur dann vor, »wenn die Wesenszüge des Originals gegenüber dem neuen Werk verblassen « (Jani 2008: 300). ${ }^{\text {II }}$ Die Merkmale des originalen Werks müssen also zu Gunsten

II Auch die sogenannte "Parodieschranke« und die "Zitatschranke« stellen wichtige Ausnahmen vom Werkschutz dar. Beide spielen für die rechtliche Behandlung des Samplings in Deutschland derzeit allerdings nur eine untergeordnete Rolle, auch wenn der Europäische Gerichtshof (2019) die Zitatschranke als prinzipiell legitimes Mittel beim Sampling betont hat - unter der Bedingung, dass eine Interaktion mit dem gesampelten Werk stattfindet. Unklar in dem Urteil des 
Europäischen Gerichtshofs bleibt allerdings die Definition von Interaktion, denn meinem Verständnis nach stellt das Sampling eines Fragments ja bereits eine Interaktion mit dem Ausgangswerk dar, so wie auch Parodien als Interaktionen mit dem Ausgangswerk verstanden werden können. Die Parodie wird im Urheberrecht vor allem als antithematische Auseinandersetzung verstanden, der ein deutlicher innerer Abstand zwischen originalem und derivativem Werk zugrunde liegen muss. Dies kann in den meisten Fällen beim Sampling nicht begründet werden. Auch bei der Parodie wird die visuelle Metapher "Verblassen« zur Veranschaulichung gebraucht und argumentativ eingesetzt. Die Orientierung an visuellen Praktiken wirkt sich allerdings nachteilig aus für musikalische Schaffensformen, denn Töne können - im Gegensatz zu Farben, Zeichnungen oder anderen visuellen Formausdrücken - nur verklingen, nicht aber verblassen. Die Zitatschranke orientiert sich meiner Wahrnehmung nach ebenfalls vorwiegend an visuellen Schaffensweisen, wobei hier das Schöpferische im schriftlichen Ausdruck der Literatur dominiert. Als Zitat wird im Urheberrecht die Verwendung eines Werkteils (Kleinzitat) oder sogar eines gesamten Werks (Großzitat) in einem neuen selbständigen Werk betrachtet. Der Umfang des zitierten Werks rechtfertigt sich durch den besonderen Zweck des Zitats, beispielsweise um im wissenschaftlichen Sinne einen Beleg für die zitierte Stelle anzuführen. Die Fundstelle des Zitats muss dabei nachvollziehbar angegeben werden. Auch muss das Zitat im neuen Werk deutlich als Zitat markiert werden, in einem Text beispielsweise durch schriftliche Anführungszeichen, die den Anfang und das Ende des Zitierten erkennen lassen. Für das Musikzitat, das in UrhG $\$$ II ausdrücklich als Unterform des Kleinzitats angeführt wird, gilt allerdings wie in einem literarischen oder wissenschaftlichen Text die Anforderung, dass es nicht als Grundlage des neuen Werks fungieren darf. Eine loopbasierte Musikproduktion, die ein Sample in fortlaufender Wiederholung verwendet und möglicherweise auch bearbeitet, wird meiner Meinung nach dadurch vom Zitatprivileg ausgeschlossen. Vermutlich wäre ein musikalisches Sample im Sinne des urheberrechtlichen Zitatbegriffs nur dann legal, wenn es im neuen Stück ein einziges Mal (ohne Wiederholung) erklingt und gleichzeitig keine anderen Töne zu hören sind, um eine mögliche Rekontextualisierung des ästhetischen Gehalts des Samples und damit unter Berücksichtigung des starren Melodienschutzes eine Bearbeitung zu vermeiden. Erschwerend kommt das Fehlen einer Entsprechung von schriftlichen Anführungszeichen im Medium der Musik hinzu: Das Knistern der gesampelten Schallplatte kann möglicherweise als hinreichender akustischer Hinweis auf die Fremdreferenz gewertet werden, jedoch wird damit im musikalischen Werk selbst noch nicht vereindeutigt, was in zitierender Absicht gesampelt wurde. Der Gebrauch von Samples ist meiner Meinung nach vielfältiger und von verschiedenen Graden von Referentialität geprägt, die nicht deckungsgleich sind mit dem vergleichsweise engen Verständnis des urheberrechtlichen Zitatbegriffs (siehe dazu ausführlicher auch Kapitel I.2.2). 
der Merkmale des derivativen Werks zurücktreten. Ein selbständiges Werk im Sinne des Urheberrechts entsteht also nur dann, wenn es eine so starke Neuheit aufweist, dass die Verbindungen zu verwendeten originalen Werken nicht mehr als Spuren ersichtlich sind. Die spannende Frage, die sich hier aufdrängt und die auch vom Europäischen Gerichtshof (2019) ins Spiel gebracht wurde, lautet nun aber: Welche rezipierende Instanz wird bezüglich der Erkennbarkeit eigentlich angelegt? Je nach Wissenstand, Alter, Herkunft oder anderen sozialstrukturellen Faktoren kann die Erkennbarkeit eines Samples oder eines Stücks natürlich beträchtlich variieren und Künstler_innen machen es sich je nach Genre zur Aufgabe, mit den Erwartungen des adressierten Publikums zu spielen (siehe auch Kapitel I.2.2). Erschwerend kommt hinzu, dass der musikalische Bereich der Melodien komplett von Regelung der Freien Benutzung ausgenommen wird. Es greift der "starre Melodieschutz" (Döhl 20I6: 25I), denn "Absatz I gilt nicht für die Benutzung eines Werkes der Musik, durch welche eine Melodie erkennbar dem Werk entnommen und einem neuen Werk zugrunde gelegt wird." (UrhG \$24 Abs. 2) Da jedoch gerade die Erkennbarkeit originaler Quellen im referentiellen Sinne ein grundsätzliches ästhetisches Merkmal des Samplings darstellt, sind Konflikte mit dem Sampling auf Basis der unfreien Auslegung der Freien Benutzung und des Melodienprivilegs unvermeidlich. Zudem stellte der Europäische Gerichtshof (2019) die generelle Vereinbarkeit der deutschen Regelung der Freien Benutzung mit dem Unionsrecht infrage, so dass es aller Voraussicht nach auch hier zu neuen Auslegungen und Anpassungen kommen wird.

(3) Leistungsschutzrecht: Die leistungsschutzrechtlichen Implikationen stellen ein weiteres urheberrechtliches Problem für die Praxis des Samplings dar. Während die bisher dargestellten Restriktionen vorwiegend die kreativen, also künstlerisch-schöpferischen Handlungen bei der Produktion eines Werks abdecken, werden im Leistungsschutzrecht die unternehmerischen und organisatorischen Leistungen berücksichtigt. Diese, die künstlerische Kreativität unterstützenden 
und ihr zuarbeitenden Anteile, werden im Gesetz als "verwandte Schutzrechte« bezeichnet. In der Arbeitsteilung der Musikindustrie beispielsweise werden Leistungsschutzrechte für Akteure wirksam, die als ausübende Künstler_innen Werke einsingen oder einspielen, eine Aufführung aufzeichnen, auf einem Tonträger speichern oder in anderer Form aus einem kreativen Akt ein warenförmiges Gut machen, also für Interpret_innen, Toningenieur_innen oder Labelbetreiber_innen (Häuser 2002: I4I). Der Tonträger als Ganzes ist durch das Leistungsschutzrecht vor unerlaubten Kopien und Piraterie geschützt - und damit auch sämtliche Teile und Ausschnitte daraus. Im exakten Wortlaut heißt es im Gesetz: „Der Hersteller eines Tonträgers hat das ausschließliche Recht, den Tonträger zu vervielfältigen, zu verbreiten und öffentlich zugänglich zu machen." (UrhG $\$ 85$ Abs. I) Im Falle des Samplings bedeutet diese Regelung, dass die Verwendung eines kopierten Ausschnitts von einem Tonträger (wie einer CD oder einer Schallplatte), unabhängig von den Zustimmungserfordernissen der schöpferischen Urheber_in, die Zustimmung des Tonträgerherstellers verlangt. Durch die Rechtsprechung des Bundesgerichtshofs im Jahr 2012 wurde dieser leistungsschutzrechtliche Anteil enorm gestärkt (Wagner 20ı6: 517).

Kraftwerk hatten sich für ihr Album "Trans Europa Express» (1977) thematisch an einer imaginierten Europareise per Zug orientiert, was die Abbildung eines Zugs auf dem Plattencover und die allgemeine Gestaltung des Werks indizieren. Auch das Stück »Metall auf Metall« ist ebenso wenig inspirations- oder referenzfrei: Es enthält eine markante rhythmische Monotonie, die an Zuggeräusche erinnert, und ist auch vom Aufbau an den Verlauf einer Bahnreise angelehnt. Die von Moses Pelham kopierte Rhythmussequenz hat im Original eine Länge von etwas mehr als eineinhalb Sekunden und besteht aus einer Ansammlung von 6 metallisch klingenden Schlägen. Vermutlich erreicht diese Komposition noch nicht die urheberrechtlichen Erfordernisse der Schöpfungshöhe. Da "Metall auf Metall» von Kraftwerk aber im Eigenverlag beziehungsweise im Eigenlabel veröffentlicht wurde, fielen der Band die Leistungsschutzrechte zu. 
Der Bundesgerichtshof argumentierte, dass das Leistungsschutzrecht an der Aufnahme über das Urheberrecht hinausgehen kann: "Eine entsprechende Anwendung des $\$ 24$ Abs. I UrhG scheidet nach der Rechtsprechung des Senats allerdings unter anderem dann aus, wenn es möglich ist, die auf dem Tonträger aufgezeichnete Tonfolge selbst einzuspielen" (Bundesgerichtshof 20I2: Rn. I3) Aus dieser Feststellung ergibt sich die dritte Neuheitsforderung: Samples dürfen nicht direkt als Klangkopien verwendet werden, wenn es möglich ist, das betreffende Sample in Eigenproduktion nachzubauen (sogenannte Interpolation). ${ }^{12}$ Pikanterweise dehnt dieses "Replay-Gebot « oder "Tonaufnahmeprivileg" (Döhl 20I6: 244) den Schutz auf musikalische Phrasen jeder Art aus, selbst wenn sie unterhalb der juristischen Schöpfungshöhe liegen. Die Schöpfungshöhe erreichenden Samples sind allerdings durch das Urheberrecht bereits geschützt. Ein zustimmungsfreies Sampling wäre durch die Rechtsprechung des Bundesgerichtshofs also vollständig verunmöglicht worden. Nach der Aufhebung des Urteils durch das Bundesverfassungsgericht hatte der Bundesgerichtshof diese Fragen 2017 dem Europäischen Gerichtshof vorgelegt (Bundesgerichtshof 20I7; Jütte/Maier 20I7).

Der Blick in das Urheberrecht offenbart ein Neuheitsverständnis, das auf Abgeschlossenheit und Selbständigkeit eines Werkes drängt. Daraus resultieren zwei generelle Punkte: Der urheberrechtliche Imperativ zu einer als absolut verstandenen Neuheit incentiviert einerseits eine entsprechende Kreativität und baut damit ein Anreizsystem zur Produktion spurloser Werke, die eine Autonomieästhetik bedie-

I2 Bemerkenswerterweise erfahren äquivalente Nachbildungen auch in anderen musikrechtlichen Zusammen-hängen Bevorzugung. So ist die identische Nachstellung ganzer Stücke innerhalb des deutschen Urheberrechts im Kontrast zum Sampling deutlich freier geregelt. Coverversionen, also musikalische Wiederaufführungen eines existierenden Stücks unter Beibehaltung der textlichen und kompositorischen Merkmale, sind urheberrechtlich unbedenklich, solange die gecoverten Originalurheber_innen GEMA-Mitglieder sind und die Coverversion bei der GEMA als "Aufführung" registriert wird. Eine Autorisierung ist nicht erforderlich. 
nen. Aus dem Schutz des Verhältnisses von Werk und Urheber_in erwächst andererseits ein System zur geistigen, materiellen und monetären Kontrolle der in die Form selbständiger Werke geronnenen Kreativität. Die Neuheit des derivativen Werks avanciert zum entscheidenden Kriterium für eine zustimmungsfreie Benutzung von Samples: Die leistungsschutzrechtliche Dimension des Samplings verbot bis zur Aufhebung durch das Bundesverfassungsgericht die Benutzung selbst kürzester Klangfetzen und verlangte die Herstellung eines klanglichen Äquivalents. Nach dem Prinzip der Kleinen Münze unterliegen musikalische Schöpfungen am unteren Rand der Schöpfungshöhe bereits dem urheberrechtlichen Schutz, der im Sinne der Freien Benutzung erst durch einen hinreichend großen Abstand zwischen Original und Derivat überwunden werden kann. Melodien bleiben davon unberührt.

Überspitzt und konsequent weiter gedacht ergibt sich für das Sampling aus den drei angeführten Hürden eine urheberrechtliche Umgebung in Deutschland, die Lawrence Lessig für das US-amerikanische Copyright Law als "permission culture« bezeichnet hat: "A permission culture means a lawyer's culture-a culture in which the ability to create requires a call to your lawyer« (Lessig 2004: 192). Samples müssen vor Veröffentlichung und Verwertung "geklärt«, das heißt lizenziert werden. Das als "Sample Clearing« bekannte Verfahren bedeutet die vertragliche Klärung von Leistungsschutz- und Urheberrechten für jedes einzelne Sample und damit die Mobilisierung von zeitlichen, monetären und organisatorischen Ressourcen. Auf diese Weise wird gleichzeitig ein sich selbst verstärkender Mechanismus in Gang gehalten, der einerseits ein bürgerliches Originalitätsideal bedient, andererseits Sampling als musikalische Praxis in der öffentlichen Wahrnehmung marginalisiert: Indem spurlose künstlerische Werke bevorzugt und in den Kanon des künstlerisch Wertvollen gehoben werden, werden sie retrospektiv als kreativ validiert. An dieser impliziten Festlegung von Kreativität müssen sich derivative Werke nun messen lassen, die aufgrund der komplizierten und Kräfte raubenden Lizenzierungssituation gleichermaßen von Beginn an 
Schwierigkeiten haben, eine ähnliche gesellschaftliche Sichtbarkeit zu erreichen wie bereits etablierte Werke.

Die Behauptungen einer völlig voraussetzungslosen Schöpfung, einer als absolut verstandenen Neuheit und einer urheberrechtlichen Autonomieästhetik sind allerdings nicht problemlos aufrechtzuerhalten. Selbst die Überwindung von Referentialität, also die Verwischung fremdwerklicher Spuren, stellt zwar ein hehres künstlerisches Ziel dar, bleibt aber schon logisch innerhalb der Grenzen von Referentialität verhaftet. Die Annahme, ein künstlerisches Produkt sei ohne Bezug auf Fremdes, sozusagen in vollkommener Freiheit, hergestellt worden, entgeht diesem Dilemma nicht. ${ }^{13}$ Denn der Verweis auf den nicht erfolgten Fremdbezug bleibt trotzdem ein intellektueller Verweis. Auch die Produktion eines referenzlosen Werks geschieht damit in Auseinandersetzung mit dem bereits Bestehenden, quasi ex negativo. Wie nun gezeigt wird, problematisiert das Verfahren des Samplings diesen Umstand der Referentialität und betont ihn in besonderer Weise als künstlerischen Aspekt.

I3 Mit dem gleichen Ziel, allerdings in Umkehrung der Argumente untersucht der Literaturwissenschaftler Harold Bloom (1997 [1973]) die Autonomieästhetik in der Literatur. Er spezifiziert dafür die Angst von Schriftsteller_innen, zu stark dem Einfluss ihrer Idole ausgesetzt zu sein und sich daher über die Maßen an dem als übermächtig erlebten Werk zu orientieren. Bloom begründet diese »Einflussangst ("anxiety of influence») mit psychoanalytisch-poststrukturalistischem Vokabular und steht in Verbindung mit der literaturwissenschaftlichen Intertextualitätstheorie (siehe Fußnote I4). Bloom beschreibt verschiedene Techniken, wie Autor_innen ihre Idole in den neuen Werken gleichermaßen unterdrücken und kreativ als Quellen oder rhetorische Figuren integrieren. Seine Theorie hat eine gewisse Nähe zu der psychologischen These der Kryptonmnesie, die davon ausgeht, dass Erinnerungen verdrängt und vergessen werden, unbewusst aber als eigene Ideen wieder zum Vorschein kommen, beispielsweise bei der Produktion eines künstlerischen Werks. Die kryptomnetischen Implikationen werden in der Rechtswissenschaft zumindest beachtet (beispielsweise Dreyer et al. 2009: 137), es ist allerdings fraglich, wie relevant das Konzept dort wirklich ist. In der Popmusik scheint die Einflussangst heute urheberrechtlich durchaus begründet zu sein, wie die Plagiatsstreitigkeiten um »Whole Lotta Love« von Led Zeppelin oder um "Blurred Lines" von Robin Thicke und Pharell Williams zeigen (Bennett 20I4, Ortland 20I6). 


\subsubsection{Fifty Shades of Referentiality. Sampling und der Neuheitsimperativ der Remixkultur}

Gegenüber der urheberrechtlichen Neuheitsforderung nach tendenziell spurlosen, eigenständigen und abgeschlossenen Werken möchte ich in diesem Abschnitt den ästhetischen Neuheitsimperativ skizzieren, der in der Remixkultur vorherrscht. Remixkultur wird dabei als Sammelbegriff verstanden, der verschiedene popkulturelle Praktiken des Bearbeitens, Verfremdens und Kombinierens von bereits existierenden und mit Bedeutung versehenen Medienmaterialien bündelt. Die Praktik des Remixens, deren Geschichte in Kapitel 3 dieser Arbeit ausführlich behandelt wird, ist vor etwa 20 Jahren »zum Inbegriff der Netzkultur, der Verschmelzung von Produzenten- und Konsumenten-/Rezipienten-Rollen und der Veralltäglichung derivativen Werkschaffens geworden" (Reißmann et al. 2017: 156). Damit bezeichnet Remixing heute eine relativ genau umrissene Studiopraxis populärer Musik genauso wie einen oft metaphorisch gebrauchten Sammelbegriff für andere künstlerische Praktiken des Kopierens und Verweisens im Sinne einer "generic description of a creative approach" (Borschke 20I7: 36; vgl. für einen Überblick Djordjevic/Dobusch 2014 und Navas et al. 2015). Semantisch verweist Remixkultur damit einerseits auf die Ausdifferenzierung von Sampling-Praktiken im musikalischen Bereich, andererseits auf verwandte Praktiken gesteigerter technischer Reproduzierbarkeit wie beispielsweise Internet-Memes (Fischer/Grünewald-Schukalla 20I8). Gemeinsam ist den Praktiken der Remixkultur ein aneignender und relativ unbekümmerter Umgang mit Medienmaterialien, die fortlaufend weiterbearbeitet und in neue Kontexte eingebettet werden.

In der Remixkultur herrscht ein besonderes Verhältnis zwischen Altem und Neuem. Im Gegensatz zu spurlosen, hochgradig autonomen Werken bleibt beim Remix das Alte im Neuen erkennbar. Das Alte muss nicht vollständig überwunden oder negiert werden. Vielmehr lassen sich Altes und Neues auf eine Verbindung ein, die es ihnen erlaubt, neben-, mit- oder ineinander zu existieren. Die Span- 
nung, die durch ihre Vereinigung entsteht, ist gewünscht und wird als ästhetischer Aspekt explizit gemacht. Stalder zufolge bildet dieses Phänomen der »Referentialität « ${ }^{14}$ eine zentrale Säule einer »Kultur der Digitalität«, wie er am Beispiel der Travestiefigur und Gewinnerin des Eurovision Song Contests 20I4 Conchita Wurst anmerkt:

"Nicht die Brüche zwischen den Elementen der alten Ordnung stehen im Vordergrund, sondern deren Synthese in der Gegenwart. Conchita Wurst, die bärtige Diva, ist nicht zwischen widerstreitenden Polen zerrissen. Sie präsentiert vielmehr eine gelungene Synthese, etwas Neues, in sich Stimmiges, das sich gerade dadurch auszeichnet, dass die Elemente der alten Ordnung (Mann/Frau) sichtbar sind und gleichzeitig transzendiert werden.« (Stalder 2016: 99)

Bezogen auf das Sampling meint das den derivativen Zugriff via copy and paste auf abgeschlossene Werke im Sinne des Urheberrechts sowie auf andere, als unfertig begriffene Materialien wie found sounds, Geräusche oder andere profane Töne. Im Bereich des Samplings haben sich verschiedene Formen entwickelt, die ich im Anschluss an Stalder anhand dreier idealtypischer referentieller Stile beschreiben werde. Diese lassen sich dahingehend unterscheiden, welche Art von Referentialität sie zulassen beziehungsweise fordern und welche Form ästhetischer Originalität damit verknüpft ist. Die Idealtypen werden als Punkte auf einem Kontinuum als eineindeutige, eindeutige und uneindeutige

I4 Für diese Arbeit folge ich Stalders heuristischem Begriff der Referentialität, der womöglich Assoziationen zum Begriff der Intertextualität hervorruft. Innerhalb der Literaturwissenschaft ist Intertextualität als Konzept, das die Verwobenheit zwischen Texten als zentralen Aspekt hervorhebt und damit eine Aufwertung der Rezipient_in als dekodierendes Subjekt impliziert, seit einigen Jahrzehnten verbreitet. Es hat auch Eingang in die Cultural Studies gefunden, auf die ich mich im theoretischen Teil (Kapitel 2) beziehe. Manfred Pfister (1985: 36) begreift Referentialität dabei als ein Merkmal von Intertextualität. Die vielfältigen poststrukturalistischen, linguistischen und literaturwissenschaftlichen Implikationen wurden für meinen Ansatz allerdings nicht berücksichtigt. Auch scheinen mir die postmodernen Schlussfolgerungen mit wissenssoziologischen Zugängen nicht so recht vereinbar. 
Referentialität differenziert. ${ }^{15}$ Die eineindeutige und die uneindeutige Referenz liegen an den gegenüberliegenden Polen des Kontinuums, dazwischen befindet sich die eindeutige Referenz. Die ästhetische Konfiguration von Samples und ihr Einsatz im Sinne künstlerischer Originalität werden entsprechend als Kombination, Selektion oder Variation bewerkstelligt. Selbstverständlich finden sich in den Zwischenräumen zahlreiche Abstufungen und hybride Formen (siehe Kapitel 6.2.2.I). Ihre Bezeichnung wird hier mit dem Hinweis auf die "fifty shades of referentiality « selbst in eineindeutiger Weise gerechtfertigt. ${ }^{16}$

I5 Der Begriff der Eineindeutigkeit ist der Mathematik entlehnt. Vereinfacht gesprochen versteht man darunter, dass eine Symmetrie zwischen zwei Mengen herrscht: Die Punkte der jeweiligen Mengen werdem eineindeutig aufeinander zugeordnet, wenn jeder Punkt ausschließlich einen einzigen Gegenpunkt hat und andersherum. Aufgrund dieser Symmetrie wird Eineindeutigkeit auch als Bijektivität bezeichnet. In einer wesentlich breiteren kulturhistorischen Perspektive untersucht Thomas Bauer (20I8) das Prinzip der Eindeutigkeit für die Moderne. Unter dem Stichwort der »Vereindeutigung der Welt« postuliert Bauer für die Moderne eine Tendenz zur Vereindeutigung, die er in zahlreichen gesellschaftlichen Bereichen wie Kunst, Wirtschaft oder Religion ausmacht. Einen wichtigen Treiber für eine solche Vereindeutigung sieht er im Aufstieg des Markts als gesellschaftskoordinierender Instanz, da dort ökonomische Werte eindeutig und exakt für Güter bestimmt werden. Das Nachlassen von Ambiguitätstoleranz, also dem Vermögen, Uneindeutigkeit auszuhalten und verschiedene Wahrheiten oder Deutungen in Bezug auf eine Sache anzuerkennen, das Bauer daraus folgert, könnte ein Ansatzpunkt sein, um auch urheberrechtliche Fragen zu vertiefen. Denn in der Perspektive des Urheberrechts, in der Werke und Schöpfer_innen in eindeutiger und exakter Weise aufeinander zugeordnet werden, um die Kommodifzierung der daraus entstehenden Güter zu gewährleisten, ist die Tendenz zur Vereindeutigung meiner Meinung nach deutlich zu erkennen: Uneindeutige, auf diverse Akteure distribuierte Autorschaft ist urheberrechtlich in der Regel genauso problematisch wie künstlerische Inspiration oder Refentialität. Auch in der urheberrechtlichen Autonomieästhetik und der Fixierung auf ein Original kommt eine solche Tendenz zur Vereindeutigung sichtbar zum Ausdruck.

I6 Dieser Verweis bezieht sich auf den populären Erotikroman "Fifty Shades« von Erika Leonard, dessen drei Teile die Autorin $201 \mathrm{I}$ und 2012 unter Pseudonym veröffentlicht hat und der 2015 als "Fifty Shades of Grey« verfilmt wurde. Sowohl die Bücher als auch die Filme waren popkulturell einflussreich und kommerziell sehr erfolgreich, weswegen ich von der allgemeinen Bekanntheit (zumindest) der Titel ausgehe. "Fifty Shades of Grey« ist selbst doppeldeutig: Der Titel referenziert einerseits auf die vielen Grauschattierungen zwischen Schwarz und Weiß, 
(I) Die eineindeutige Referentialität steht dem Zitat am nächsten. Von ihr lässt sich sprechen, wenn vorausgesetzt werden kann, dass das Ziel der Referenz so weit bekannt ist, dass es auf Seiten der Rezipient_innen ohne Schwierigkeiten identifiziert werden kann. Die Bekanntheit des Materials lenkt den Blick vor allem auf die Kreativität der Kombination. Das Genre des Mashup (bisweilen auch "Bastard-Pop" oder "Bootleg Remix" genannt) bildet hier das Beispiel par excellence: Hier werden bekannte Hits aus der Popkultur so "zusammengeschmissen" (englisch to mash up), dass aus ihrer Vereinigung ein irritierender Effekt entsteht. In der Regel werden sehr gegensätzliche Musikstücke dafür benutzt: So besteht »A Stroke of Genius" des britischen Mashup-DJs Freelance Hellraiser aus dem langsamen Gesang von Christina Aguileras Liebeslied "Genie in a Bottle« und dem doppelt so schnellen Instrumental von »Hard to Explain« der Indierock-Band The Strokes. Beide Stücke waren zu ihrer Zeit Charthits und laufen auch heute noch auf Formatradios. Döhl (2016: 324) zufolge sind Mashup-Künstler_innen an der »bipolare[n] Anordnung " ihrer Materialien interessiert, um "maximale Transformation bei minimaler Manipulation« zu erreichen. Die Samples sind daher meist recht lang und wenig bearbeitet; teilweise werden auch komplette Songs ausgewählt. Als künstlerischer Ansatz steht die reflexive Befolgung selbst gesteckter Auswahl- und Kombinierregeln im Vordergrund, wie zwei weitere Beispiele demonstrieren sollen: Das "Grey Album« von DJ Dangermouse (2004) verbindet den Rap von Jay-Zs berühmtem »Black Album» mit geloopten Samples des noch berühmteren »White Album« der Beatles (Sinnreich 2010: I43). Und für »Intro-Inspection« kombinierte Osymyso IoI Intros von Popsongs

hebt also die metaphorischen Grautöne zwischen zwei Polen hervor, andererseits auf den Nachnamen des Protagonisten Christian Grey. Die Vermischung des populären Filmtitels mit einer akademischen Differenzierung hin zu den "fifty shades of referentiality « soll eine Brücke zwischen den Kanons popkulturellen und akademischen Wissens schlagen. Diese Brücke bildet in übertragener Hinsicht also auch meinen eigenen Medienkonsum ab. Auch der sampelnde Vorgang der Selektion, für den aus einem Pool von Medienmaterialien etwas herausgegriffen und mit neuer Bedeutung versehen wird, ist mit einer Anspielung bedacht. 
zu einem mehr als zwölf Minuten langen, collageähnlichen Mashup, das trotz komplexer Schichtungen und Montagen seine Einflüsse deutlich erkennbar lässt; beispielsweise wenn Whitney Houston, Isaac Hayes und das »Pink Panther Theme« von Henry Mancini zusammen ertönen.

(2) Während bei Mashups die Referenzen im Sinne eineindeutiger Zitate gehandhabt werden (oder durch Hinweise auf verwendete Stücke eineindeutig gemacht werden), wird im Bereich des klassischen Hip Hop bevorzugt mit eindeutiger Referentialität gearbeitet. Auf diese Weise werden die Selektionen, was als Sample benutzt und weiterverarbeitet werden kann, hervorgehoben. Mit dem Begriff der Selektion möchte ich zum Ausdruck bringen, dass die Methode des Samplings im Hip Hop ohne Zweifel zentral ist, die Quellen aber oftmals unter teils strengem Verschluss gehalten werden und daraus Ambiguität entsteht: Es ist zwar eindeutig erkennbar, dass es sich um ein Sample handelt - der ästhetische Reiz der Rezeption wird aber im rätselhaften Status des wie und woher gesehen. Die Praktiken der Selektion werden auf diese Weise ins Zentrum des Geschehens gerückt: Die Entdeckung unbekannter, obskurer, rarer oder anderweitig als originell empfundener Samples wird zu einer kreativen Praxis. Die Praktiken der Selektion wurden von Joseph Schloss ausführlich vor dem Hintergrund einer impliziten "Ethik des Samplings" ethnografisch beschrieben. Schloss betont, wie durch das Setzen von Regeln Kreativität forciert, Auswahlprozesse reflexiv gemacht und dadurch eine bestimmte Form von Neuheit erforderlich werden (Schloss 2004). Der hier idealtypisch skizzierte Neuheitsimperativ im Sinne eindeutiger Referentialität unterstreicht also den aneignenden Prozess des Hervorholens und Wiederbelebens alter, übersehener oder gänzlich vergessener Quellen als künstlerische Geste. Auf Seite der Rezeption führt eindeutige Referentialität zu einem besonders starken Spiel mit der In- und Exklusion von Publika, denn die Obskurität der Originalquellen teilt die Zuhörer_innenschaft in Wissende und Unwissende. Als Beispiel möchte ich den weltweit bekannten Hip Hop-Track 
"Shook Ones Pt. 2« von Mobb Deep (veröffentlicht 1995) anführen, dessen Hauptsample ("Jessica» von Herbie Hancock, I969) erst 20II auf Basis der weltumspannenden digitalen Vernetzung des Internets eindeutig identifiziert werden konnte, nachdem jahrelang Genre, Autor, Label, Jahrgang und andere Merkmale des Originals in Internetforen spekulativ eingekreist worden waren. Der Hip Hop-Journalist und Forscher Oliver Wang stellt die Suche nach dem Originalsample sogar in Reihe mit Philatelie (»It's like finding a Blue Mauritius«) und biblischen Vorbildern: "The longer 'Shook Ones Part II kept its secrets, the more it became a holy grail for sample seekers, complete with debated theories and false leads." (Wang 20II)

(3) Im dritten Idealtyp der Referentialität wird die Eindeutigkeit eines Samples noch stärker problematisiert. Während es in den beiden anderen Typen mindestens eindeutig ist, dass es sich um ein Sample aus einem anderen Stück (oder einer anderen Fremdquelle handelt) und dieser Umstand ästhetische Betonung erfährt, steht dies bei der uneindeutigen Referentialität zur Disposition. Ich behaupte, dass hier nicht die Referenz auf eine externe Quelle, sondern die sonische Qualität des Samples zentral ist. Die Uneindeutigkeit bezieht sich also auf das zeitliche musikalische Arrangement, innerhalb dessen das Sample eingesetzt wird. Allenfalls wird hier eine weit entfernte Anspielung auf das Originalsample zur Verfügung gestellt - wenn überhaupt. Uneindeutig ist ein solches Sample aber auch, weil es eine interne Referenz produziert: Durch geringfügige Variationspraktiken soll eine Aktualisierung eines musikalischen Moments hergestellt, also auf einen früheren internen Moment des gleichen Stücks referenziert werden. Beide Aspekte lassen sich auch in der Kürze des verwendeten Samples begründen: eineindeutige Referenzen sind verhältnismäßig lang und enthalten großflächige, leicht zu identifizierende Ausschnitte eines Stücks; eindeutige Referenzen sind in der Regel wenige Sekunden bis mehrere Takte lang, ihre Quellen aber nicht ohne Weiteres zu erkennen; uneindeutige Referenzen hingegen bewegen sich oft im Bereich von unter einer Sekunde, da sie aus einzelnen Schlägen, Sounds, Riffs 
oder anderen Klangfetzen bestehen. Uneindeutige Samples werden meist instrumentell, das heißt als sonische Bausteine, für die Produktion von Tracks aus den DJ-getriebenen Genres elektronischer Tanzmusik wie House, Techno, Dubstep oder Drum'n'Bass eingesetzt. Tracks dieser Genres zeichnen sich durch einen repetitiven Rhythmus und eine hohe strukturelle Ähnlichkeit aus. Dies erleichtert es den DJs, sie in zusammenhängende und unterbrechungsfreie DJ-Sets zu überführen, wobei der Hauptzweck in der Unterhaltung von sich auf Tanzflächen bewegenden Körpern liegt. Jan-Michael Kühns soziologischer Technoforschung zufolge ist die Entwicklung und Aufrechterhaltung von "Groove« dabei »ein zentrales ästhetisches Ziel (Kühn 2009: 63). Mit Hilfe des Samplings können beispielsweise einzelne Momente aus einem Gesang herausgegriffen, zerstückelt und innerhalb eines repetitiven Techno-Loops als kurze, markante Sounds wieder eingesetzt werden. Ein eigentlich melodischer Gesang wird beispielsweise durch »das Benutzen von unverständlichen Vocalstücken als groovige[m] Element" (Kühn 2009: 78) zu einem perkussiven Detail umgewidmet. Mit Blick auf das besonders rhythmusbetonte Genre Drum'n'Bass nennt Martin Pfleiderer noch weitere Gestaltungsmittel, die durch das Sampling kurzer und kürzester Elemente hervorgerufen werden:

»[...] Isolation einzelner Patternteile bzw. Drum-Impulse, die dann zu neuen Rhythmen zusammengeklebt werden; Schnitte auch innerhalb einzelner Klänge (z. B. Weglassen des Attacks); rückwärts abgespielte Klänge; sehr kurze, quasi stehende Loops (< 50 Millisekunden), wodurch auch bei perkussiven Klängen, z. B. Trommelschlägen, eine Tonhöhenwahrnehmung hervorgerufen wird.» (Pfleiderer 2006: 325)

Das hochgradig repetitive Arrangement der genannten Genres erwirkt eine Forderung nach Neuheit daher hauptsächlich in Form der Variation, nämlich durch Akzente, Verschiebungen und inkrementelle Veränderungen, die durch die Hinzu- oder Wegnahme von einzelnen Elementen realisiert werden. Der Loop bleibt gleich, denn er 
besteht aus der fortlaufenden Kopie eines Samples, und doch ändert er sich, auch wenn der Unterschied oftmals erst nach mehreren Takten deutlich wird. Die Monotonie sensibilisiert für marginale Veränderungen des klanglichen Geschehens. Der Einsatz von Samples im Sinne uneindeutiger Referenzialität ist daher vorwiegend im Bereich des Instrumentellen angesiedelt, indem weniger auf etwas Externes, sondern auf die Aktualisierung des Internen (des Loops, des Tracks oder auch des DJ-Sets) aufmerksam gemacht wird.

\subsection{Résumé und forschungsanleitende Fragen}

Ausgehend vom Streit um das Sample aus "Nur mir« diente dieses Kapitel dazu, einen Zugang zum Themenbereich Urheberrecht und Kreativität in der samplingbasierten Musikproduktion zu finden, der für die weitere Untersuchung eine Perspektive auf das Verhältnis von rechtlichen Restriktionen und technischer Reproduzierbarkeit eröffnet. Zur Freilegung der tieferliegenden gesellschaftlichen Konfliktlinie wurde gezeigt, dass mit der historischen Steigerung technischer Reproduzierbarkeit antagonistische Bewegungen der Suspension erkennbar werden, welche sowohl grammatisch in Regelsystemen festgehalten wie auch pragmatisch umkämpft sind. Um rechtliche Geltungsansprüche auf Eigentum zu behaupten, wird die Hoheit zur technischen Reproduzierbarkeit auch an bestimmte Technologien delegiert, die wiederum zu Reaktionen auf Seiten der Nutzer_innen führt. Die urheberrechtliche Konfiguration der künstlerischen Praxis Sampling wird in der Untersuchung als Fall verstanden, in der das Verhältnis von Schutz und Wiederbenutzung Geistigen Eigentums besonders verdichtet zum Vorschein kommt, da sich bereits um Samples im Mikrobereich jahrelange urheberrechtlichen Streitigkeiten entzündet haben. Zur näheren Spezifizierung des Problems konnte herausgearbeitet werden, dass das Urheberrecht einem bürgerlich-romantischen Werkverständnis mit Autonomieästhetik 
folgt und als Kontrollinstrument dabei eine Reihe von derivativen ästhetischen Praktiken ausschließt. Als Kontrollinstrument konfligiert das Urheberrecht insbesondere mit künstlerischen Praktiken, die die Autonomieästhetik anderer Werke übergehen und deren Geschlossenheit gezielt missachten. Die Praxis des Samplings ist dabei von lehrreichem Wert, denn mit ihr verknüpfen sich verschiedene, in Genres manifestierende Grade von Referentialität und Konzepte von Neuheit, die nicht deckungsgleich mit dem urheberrechtlichen Begriff der Neuheit sind. Parallel zur abstrakten urheberrechtlichen Konfiguration ergibt sich daher auch eine ästhetische Konfiguration technischer Reproduzierbarkeit.

Auf Grundlage der vorgestellten Typologie verschiedener Grade von Referentialität lässt sich schlussfolgern, dass Sampling im Sinne uneindeutiger Referentialität dem Neuheitsverständnis des Urheberrechts am nächsten steht. Denn das Urheberrecht bevorzugt Werke, die, wenn sie ein anderes Werk oder Teile daraus verwenden, diese externe Referentialität überwinden oder zumindest so gering wie möglich halten (vom Sonderfall der Parodie oder des Musikzitats einmal abgesehen, siehe Fußnote II). Allerdings zeigen die juristischen Auseinandersetzungen seit den I990er Jahren, dass auch kurze und kürzeste Samples zu langwierigen Schwierigkeiten führen können (siehe Kapitel 4).

Das Kraftwerk-Sample aus "Nur mir« verorte ich dabei zwischen dem eindeutigen und dem uneindeutigen Idealtyp der Referentialität: Es ist relativ kurz, hat rhythmisch-perkussiven Charakter, ist aber, wie viele andere Stücke von Kraftwerk, innerhalb der Samplingwelt schon einige Male gesampelt worden, weswegen man von einer relativen Bekanntheit in einer bestimmten adressierten Hörer_innenschaft ausgehen kann. Von Pelham ist es nur geringfügig in der Geschwindigkeit verändert worden. Trotz seiner prominenten Stelle in den ersten Takten von "Nur mir" spielt es im Gesamtverlauf des Lieds sicherlich nur eine untergeordnete Rolle. Nach seiner Funktion als Intro verliert es sich im weiteren Verlauf des Stücks unter dem dominanten Gesang Sabrina Setlurs, der schroffen Gitarre, die zusam- 
men mit dem Gesang die Hauptmelodie vorgibt, und den anderen Rhythmuselementen.

Die restriktive urheberrechtliche Regulierung von Kopierpraktiken im Bereich des Samplings, so wie sie in Deutschland bis 2016 vorherrschte, wirft einige Fragen auf, die die Untersuchung heuristisch anleiten und für entsprechende Aspekte sensibilisieren sollen:

- Was bedeuten die grammatisch festgeschriebenen urheberrechtlichen Konfigurationen technischer Reproduzierbarkeit für die Praxis des Samplings?

- Wie gehen Produzent_innen und Labelbetreiber_innen mit den Restriktionen um und welche strategischen Kooperationen mit Akteuren des Rechts gehen sie dafür ein?

- Mit welchen Methoden wird Geistiges Eigentum umzäunt und gegen unerwünschte Nachnutzungen abgesichert?

- Mit welchen Argumenten und innerhalb welcher Narrative werden künstlerische Aneignungsstrategien legitimiert?

- Und schließlich: Stellt das Urheberrecht mit seinen Neuheitsimperativen und Lizenzierungserfordernissen eher einen Anreiz oder ein Hemmnis für Kreativität dar?

Der angeführte Fragenkomplex wirkt an dieser Stelle noch etwas ungeordnet, daher werden die einzelnen Aspekte in Kapitel 5 hierarchisiert, um die eigentliche Forschungsfrage für die empirische Erhebung und Analyse zu respezifizieren. Zuvor werde ich jedoch in Kapitel 2 ein theoretisches Konzept für die weitere Untersuchung erarbeiten und in den Kapiteln 3 und 4 die Geschichte des Samplings aufrollen. 


\section{Neuheit und Kreativität in der Innovationsgesellschaft}

Die Gegenüberstellung der Neuheitsverständnisse aus Urheberrecht und Remixkultur hat gezeigt, dass mit je unterschiedlichen Auffassungen von Neuheit operiert wird. Daraus ergeben sich teils divergierende und gegeneinander arbeitende Neuheitsimperative: Während das Urheberrecht vor allem auf abgeschlossene und eigenständige Werke im Sinne einer Autonomieästhetik drängt, ist in den beschriebenen popmusikalischen Genres ein abgestufter Neuheitsimperativ zu beobachten, der verschiedene Grade von Referentialität zulässt und einfordert.

Das auf den folgenden Seiten entwickelte theoretische Konzept stellt nun die Frage, wie das Verhältnis von Neuheit, Kreativität und Innovation in der sozialwissenschaftlichen Forschung theoretisch gefasst werden kann, um den Blick für die empirische Datenerhebung zu schärfen und operationalisierbare Begriffe für die historische Entwicklung des Samplings und die Aufarbeitung des Forschungsstands $\mathrm{zu}$ erarbeiten. Die induktiven, also in der Empirie gewonnenen Erkenntnisse, dienen dann wiederum zur Weiterentwicklung und Verfeinerung des Theorievokabulars. Aus der bisher erfolgten Untersuchung lässt sich eine vorläufige Definition von Kreativität ableiten: Darunter verstehe ich heuristisch das Vermögen, Neuerungen zu produzieren, die im Sinne jeweils angelegter kultureller Maßstäbe als wertvoll validiert werden. Nun geht es darum, den Kreativitätsbegriff differenzierter zu fassen und ihn für kollektives Handeln zu spezifizieren.

Zur Umsetzung dieses Vorhabens sind drei Abschnitte ausgearbeitet. Zuerst werden grundlegende innovationssoziologische Be- 
grifflichkeiten geklärt und im Zusammenhang mit der Entwicklung der Kreativindustrien erläutert. Darauf aufbauend werden zentrale Ausgangspunkte aus der Perspektive der Kunstsoziologie erörtert. Schließlich werden vier verschiedene Modi der Neuheitsproduktion vorgestellt, die Kreativität als Praktiken der Kontribution, der Exploration und Rekonstruktion sowie der Symbolisation verstehen.

\subsection{Das Neue als Zentralkategorie der Innovationsgesellschaft: Innovationen als nachhaltige Neverungen}

Die gemeinsame geteilte Ausgangsposition des Graduiertenkollegs "Innovationsgesellschaft heute: Die reflexive Herstellung des Neuen" besteht in dem Verständnis von Neuheit als Zentralkategorie gegenwärtiger westlicher Gesellschaften. Damit werden Neuerungen sowie ihre reflexive Planung, Verbreitung und Verfestigung als Innovationen quer durch sämtliche gesellschaftlichen Teilbereiche "zur dominanten treibenden Kraft zukünftiger Gesellschaften" (Rammert et al. 20I6: 3). Die vorliegende Arbeit versteht sich als Fallstudie zu dieser These, indem sie sie auf das Beispiel des Samplings anwendet und damit im Schnittfeld der Bereiche Kunst, Recht und Wirtschaft empirisch untersucht. Die Orientierung am Neuen wird im Forschungsprogramm des Graduiertenkollegs in drei analytischen Ebenen schwerpunktmäßig beobachtet: Während sich auf der Ebene der Semantik das Auftreten von Neuem vorwiegend als diskursives Phänomen in sprachlichen und symbolischen Ausformungen zeigt, wird für die Ebene der Pragmatik explizit das auf Innovationen bezogene Handeln berücksichtigt, also die Frage, wie Neues in sozialen Praktiken kreiert, angeeignet und routinisiert wird. Schließlich wird auf der Ebene der Grammatik danach gefragt, nach welchen Regeln und in welchen institutionalisierten Ordnungen die Produktion des Neuen gesellschaftlich gefordert und gefördert wird (Hutter et al. 20I6: 
22-3). Alle drei analytischen Ebenen sind dabei nicht auf individuelle Akte, sondern auf kollektive, das heißt soziale Prozesse im Sinne Webers bezogen, also als "aufeinander gegenseitig eingestelltes und dadurch orientiertes Sichverhalten mehrerer" (Weber 2002 [I922]: 29, Hervorhebung weggelassen). Weniger bahnbrechende Erfindungen einzelner Genies, sondern eher das kollektive Zusammenspiel aus semantischer Bewertung, praktischer Routinisierung und grammatischer Verregelung sind damit die interessanten Phänomene einer derartig ausgerichteten soziologischen Innovationsforschung.

Mit dieser analytischen Schwerpunktsetzung verbunden ist die Überwindung eines enggeführten Innovationsbegriffs, der vorwiegend auf technische und wirtschaftliche Neuerungen und deren inhärenten Erfolgs- und Durchsetzungskriterien abstellt (Windeler et al. 2017: II). Die Perspektiverweiterung erlaubt es, Innovationen verschiedenster Couleur empirisch einzufangen, sie beispielsweise als kulturelle, soziale, künstlerische, rechtliche oder religiöse Strukturveränderungen genau zu beschreiben und zu theoretisieren. Entsprechend abstrahiert sich das Kriterium zur Identifizierung einer Innovation damit von vorwiegend technizistischen Attributen wie technischer Überlegenheit, betriebswirtschaftlich einwandfreier Planung oder kommerziellem Markterfolg hin zum Kriterium der nachhaltigen Veränderung einer Praktik, eines sozialen Felds oder gar eines gesellschaftlichen Funktionssystems (Rammert 20I0: 39). Mit der Betonung der Nachhaltigkeit sind Innovationen einerseits abgegrenzt von schnelllebigen und wenig signifikanten Neuheiten mit mikrotemporalen Aktualisierungs- und Versionszyklen, wie sie beispielsweise in der Distinktionsdynamik der Mode (Esposito 2004: 27), der auf Nachrichten (news) fokussierten Medienwelt (Buschow 20I8) oder bei inkrementellen technischen Verbesserungen wie Software-Updates (von Gehlen 2013: 55) auftreten. Diese Bereiche stehen beispielhaft für die Dominanz geringfügiger Neuerungen. Auf der anderen Seite lassen sich Innovationen gegenüber Revolutionen abgrenzen, die mit Hanna Arendt (1963: 33) dadurch charakterisiert sind, "dass sich innerhalb der weltlichen Geschichte etwas ganz und gar 
Neues ereignet, dass eine neue Geschichte anhebt«. Diese revolutionäre Art der nahezu alles umstürzenden Strukturveränderung beruht zwar oft auf Innovationen, ist aber auf der Makroebene gesamtgesellschaftlicher Ordnung und am oberen Ende zeitlicher Relationen angesiedelt. Der Neuerungsgrad der selten anzutreffenden Revolution betrifft daher besonders drastische Neuerungen, "die hundert oder mehrere hundert Jahre gewachsene Formen und tradierte Felder der Produktion, des Wirtschaftens, des Bauens oder der politischen Praxis radikal in zehn, zwanzig oder dreißig Jahren verändern und zu neuen gesellschaftlichen Institutionen und technischen Errungenschaften führen« (Rammert 20I0: 30 ).

Eine Innovation im nachhaltigkeitstheoretischen Sinne liegt vor, wenn eine Neuerung zeitliche Wiederholung, räumliche Ausbreitung und soziale Stabilität erlangt. Um verschiedene Grade der Innovativität zu unterscheiden, kann der Indikator für eine Innovation variabel gelegt werden. Die Flexibilität des Grundkonzepts erlaubt es, eine in einem sozialen Feld stabilisierte Neuerung als Innovation zu identifizieren, wie beispielsweise die Erfindung, Verankerung und Ausbreitung der Zentralperspektive in der Kunst ab dem I5. Jahrhundert (vgl. Hutter 2015b: 92). Gleichermaßen kann eine Innovation natürlich auch über Feldgrenzen hinweg bestehen oder zur Entstehung eines neuen Felds führen. In dieser Perspektive wird also nicht allein danach gesucht, was das Neue vom Alten sachlich unterscheidet oder in welchem zeitlichen Verhältnis es zu ihm steht, sondern mit welcher sozialen Wirkung sich eine Neuerung als Anderes wahrgenommen wird, im Bestehenden - semantisch, pragmatisch, grammatisch - niederschlägt, übersituativ verankert und bestehende Strukturen transformiert. Diese innovationssoziologische Perspektive mit evolutionstheoretischen Anleihen hat den grundlegenden Vorteil, die Spannung zwischen den einzelnen Ebenen einfangen, aufeinander beziehen und dadurch theoretisch nutzen zu können. So kann beispielsweise der Typ der Scheininnovation diagnostiziert werden, also einer semantisch intensiv und rhetorisch stark beworbenen, sich aber weder in Praktiken oder Grammatiken signifikant äußernden 
Veränderung wie eine weitere Klinge auf einem Rasiergerät oder die neue Scheinwerferform eines Automobils. Gleichermaßen lassen sich Innovationen nach dem Grad ihrer Reflexivität unterscheiden, das heißt, ob Neuerungen strategisch intendiert, machtvoll als solche definiert und entsprechend lanciert werden, oder ob es sich um unintendierte Strukturveränderungen handelt (Windeler et al. 20I7: 8). Schließlich, und dieser Typ ist hier von besonderem Interesse, lässt sich nach Schatteninnovationen fragen. Das sind Neuerungen »im Schatten der öffentlichen Aufmerksamkeit«, die »trotz hinderlicher Regelsysteme und ohne ausdrückliche Rede sich gleichsam still implizit in Praktiken und versteckt in materialen Produkten durchsetzen" (Hutter et al. 20I6: 23).

Aus der nachhaltigkeitstheoretischen Fassung des Innovationsbegriffs ergibt sich als Konsequenz eine vergleichsweise hohe Anforderung zur Erreichung eines Innovationsniveaus. Denn in der skizzierten Perspektive lassen sich klare Grenzen zwischen den oftmals synonym verwendeten Begriffen der Neuerung, Kreativität und Innovation schaffen. Prinzipiell gehe ich in Anlehnung evolutionstheoretischer Prinzipien davon aus, dass es sich hierbei um drei verschiedene Stufen der Neuheitsselektion handelt. Zwar entstehen fortlaufend Neuerungen, beispielsweise als unintendiertes Ergebnis von Serendipität, Zufällen oder Fehlern, oder auch als intendierte Variationen, Rekombinationen oder Bricolagen. Die meisten dieser Neuerungen werden als profan oder störend ignoriert. Manche werden aus dem unübersichtlichen Angebot der sozialen Welt jedoch herausgegriffen, weil sie als wertvoll, interessant, faszinierend, als kreativ betrachtet werden. Von diesen selegierten Neuerungen wiederum werden allerdings nur wenige als so wertvoll, nachahmenswert und notwendig wahrgenommen, dass sie tatsächlich über die Situation hinaus durch kollektive Selektion nachhaltige Veränderungen von Praktiken, Institutionen oder Feldern anstoßen und bewirken.

Es liegt nahe, dass die Entwicklung von Neuerungen, die sich dann als Innovationen verfestigen, besonders an den gesellschaftlichen Orten stattfindet, die Grenz- und Schnittbereiche etablierter 
Institutionen und gesellschaftlicher Funktionssysteme darstellen. Denn wenn das Neue im streng relativen Sinne als Variation oder Rekombination von etwas Bestehendem gedacht wird, werden Transfers, Hybride, Grenzobjekte, Übersetzungen, Rekontextualisierungen, Umgehungsstrategien, Im- und Exporte und andere Praktiken interessant, die bisher Unverbundenes miteinander verbinden und in Beziehung setzen können. Die Mesoebene der Innovationsfelder, in denen Akteure an den Schnittstellen etablierter gesellschaftlicher Bereiche wechselseitig aufeinander bezogen reflexive Innovationen entwickeln, avanciert damit zum "analytischen Schwerpunkt des Innovationsgeschehens" (Windeler et al. 20I7: I2). Die Reflexivität der Prozesse zur Hervorbringung von Neuerungen ist dabei bemerkenswert. Sie ist oftmals als Forderung in die dominierenden Grammatiken der Innovationsfelder eingeschrieben, wie am Beispiel des Neuheitsimperativs in Urheberrecht und Remixkultur bereits gezeigt wurde. In etwas größerem Maßstab lässt sich die systematisch-reflexive Produktion von Neuerungen in den Zweigen der Kreativindustrie gut untersuchen. Diese lassen sich als Innovationsfeld mit einer Verschränkung aus künstlerischen, wirtschaftlichen und rechtlichen Praktiken und einem daraus resultierenden Neuheitsimperativ verstehen, welche für die ästhetische Praxis Sampling als Produktionsumgebung fungieren. Zwar ist die Entwicklung der Kreativindustrien ein vielschichtiger historischer Prozess, der sich in all seiner Komplexität anhand des skizzierten Innovationsbegriffs nicht vollständig erklären lässt. Trotzdem ist es hilfreich, das institutionelle Gefüge der Kreativindustrien unter dem Innovationsaspekt zu erläutern, um eine historisierende Perspektive für die Analyse des Samplings als musikalischer Praxis sowie seiner urheberrechtlich-kreativen Verflechtungen zu erhalten. Dies möchte ich durch die Beschreibung zweier Innovationen leisten: einerseits die Etablierung des Idealtyps des Kreativsubjekts, andererseits die Installierung von Strukturen der Propertisierung. 


\subsection{Zwischen gewohnten Überraschungen und Propertisierung: Das Kreativsubjekt an der Schnittstelle von Kunst, Wirtschaft und Recht}

Wie sich anhand verschiedener Diskurse in den Bereichen des Managements, des Designs, der Werbung und der Mode nachzeichnen lässt, entsteht im 20. Jahrhundert mit den Kreativindustrien ein gesellschaftlicher Bereich, der eine "Strukturähnlichkeit von ökonomischen und künstlerischen Praktiken" (Reckwitz 20I2: I45) hervorbringt und damit die Grenzen der Funktionssysteme Kunst und Wirtschaft zumindest stellenweise überbrückt. Für die Entwicklung des Samplings ist es wichtig, zumindest einige zentrale Merkmale der Kreativindustrien zu kennen, weil ich davon ausgehe, dass die zeitgenössische Musikproduktion innerhalb einer musikindustriellen Umgebung stattfindet, die permanent nach Neuheit, Kreativität, Innovation verlangt - technologisch im Sinne von neuen Kanälen und Apparaten zur Rezeption und Vermarktung musikindustrieller Produkte, künstlerisch im Sinne von neuen Werken, die überraschende Aspekte und damit Abwechslung bei der ästhetischen Affizierung versprechen. Die Produktion dieser Güter ist gerahmt von staatlich vorgegebenen Gesetzen (wie dem Urheberrecht) und wird vorangetrieben von Akteuren des musikindustriellen Komplexes (wie Verwertungsgesellschaften oder Labels). Sie sind daran interessiert, die Nutzung und Verwertung ihres Geistigen Eigentums unter eigener Kontrolle zu behalten, also »die Fiktion ausschließbarer Nutzung von Medieninhalten aufrechtzuerhalten « (Hutter 2018: 20), gleichwohl ihre Produkte heutzutage größtenteils kopierbar und damit nie komplett kontrollierbar sind. Musikindustrielle Akteure arbeiten daher fortlaufend daran, ihre Reproduktionshoheit abzusichern und sich gleichzeitg neue Bereiche zu erschließen, die sich "propertisieren«, also in eigentumsförmige Einheiten und Beziehungen überführen und dadurch exakt verwalten lassen (vgl. Siegrist 2006). Wer auf Grundlage von Samples bereits existierender und urheberrechtlich 
geschützter Musik neue Musik produziert, tut dies also in einer industriell ausdifferenzierten und von diversen Strukturen durchzogenen Umgebung, die Anforderungen in rechtlicher, wirtschaftlicher und ästhetischer Hinsicht stellt.

Innerhalb der Kreativindustrien steht die Subjektfigur des bzw. der Kreativen im Vordergrund. Sie zeichnet sich dadurch aus, »dass [sie] auf zwei Klaviaturen zugleich spielt: der ästhetisch-expressiven der Kreation und der ökonomischen des Marktes" (Reckwitz 20IO: 254). Dabei zeigt sich in der von Richard Florida (2002) ${ }^{17}$ vorgelegten Milieuanalyse, die im internationalen Konkurrenzkampf der Metro-

I7 Der Einfluss von Floridas wirtschaftstheoretischer These zur kreativen Klasse ist sicherlich als bedeutend zu klassifizieren, nicht nur innerhalb der sozial- und raumwissenschaftlichen Kreativitätsforschung. Auch in dem von Florida analysiertem empirischen Feld selbst, also in Unternehmen, städtischen Behörden und politischen Institutionen der Raumplanung, hat der Diskurs um die kreative Klasse Veränderungen angestoßen, insofern dort nun vermehrt auf Kreativität als Treiber wirtschaftlicher und sozialräumlicher Innovation orientiert wird. Das Leitbild der kreativen Stadt ist besonders gut auf der semantischen Ebene zu beobachten, beispielsweise in der verstärkten Nachfrage und Behauptung von Kreativität - und einer kreativitätsstimulierenden Umgebung - in Stellenausschreibungen, öffentlichen Förderanträgen und Selbstbeschreibungen von Unternehmen. Diese oberflächlichen empirischen Beobachtungen dürfen aber nicht darüber hinwegtäuschen, dass Floridas Ansatz umfassender und teils profunder wissenschaftlicher Kritik unterzogen wurde. Beispielsweise ist statistisch äußerst fraglich, ob die Messung von Patentanmeldungen überhaupt als geeigneter Indikator für Innovativivät herhalten oder ob der sogenannte "Gay-Index " belastbar über die gleichgeschlechtliche Zusammensetzung von Haushalten erhoben werden kann - und falls ja, ob er dann auch aussagekräftig für Diversität, Offenheit oder Toleranz ist (Peck 2005). Auch die theoretische Konzeption von Floridas kreativer Klasse, ja sogar von Kreativität und damit die Unterscheidung zwischen kreativer und nicht-kreativer Arbeit wird in der akademischen Debatte teilweise als simplifzierend oder zumindest als schwer nachvollziehbar diskutiert (siehe beispielsweise Markusen 2006, Wilson/Keil 2008 oder Boschma/Fritsch 2009). Schließlich wird auch Floridas wissenschaftlicher Stil, der fehlende kritische Distanz zum eigenen empirischen Feld erkennen lässt, problematisiert. Daraus leitet sich schließlich die Kritik ab, dass Florida durch seine Medienpräsenz, seine Popularität als politischer Berater und seine extensive Vortragstätigkeit den eigenen Forschungsgegenstand zumindest teilweise in Richtung einer selbsterfüllenden Prophezeiung selbst beeinflusst und verzerrt hat, was die Stadtsoziologin Silke Steets (20II) als »Floridaisierung der Stadtpolitik» bezeichnet. 
polen auch zum Leitprogramm und zur Selbstbeschreibung der Städte avanciert (Merkel 2009), dass es sich bei der »kreativen Klasse« um sehr gut ausgebildete und nach Devianz strebende, aber in hochgradig flexibilisierten und oftmals prekären Arbeitsverhältnissen tätige Menschen handelt, deren Drang zu künstlerischer Freiheit und Selbstverwirklichung zu einem idealisierten »kreativem « Lebensstil führt. Das Angebot, das dieser Lebensstil schafft, und gleichzeitig die Herausforderung, die er mit sich bringt, besteht in der Versöhnung von selbstunternehmerischen, auf ständige Selbstoptimierung zielenden Praktiken des Wirtschaftens (Bröckling 2007: 66) mit ästhetischen, expressiven und experimentellen Arbeitsformen aus der Kunst (Boltanski/Chiapello 2006). Die gegenseitige Durchdringung von Kunst und Wirtschaft führt damit gewissermaßen zu einer Erweiterung des Schumpeter'schen Bilds vom Entrepreneur, der Erfindungen charismatisch, disruptiv und durchsetzungsstark gegen Widerstand als Innovationen etablieren kann (Schumpeter 1934: II8). Ich begreife dies als eine Erweiterung, weil in den Kreativindustrien nun auch ästhetische Rekombinationen marktreif und warenförmig gemacht werden, die noch bis zur Zeit der Aufklärung vor allem unter das Patronagesystem der Kirche oder der Fürst_innen fielen und erst nach und nach marktlichen Bedingungen ausgesetzt wurden (vgl. Zolberg 2015: 897).

Die Semantik der romantischen Genieästhetik wird im Zuge des Aufstiegs der Kreativindustrien somit nicht fallen gelassen, sondern an die Ressourcen des Kreativsubjekts gekoppelt, dessen wirtschaftliche und künstlerische Praktiken sich stark ineinander schieben. Kreative sind dabei stets mit einem grammatischen Imperativ nach Neuheit konfrontiert, der sich in den verschiedenen kreativindustriellen Zweigen wie Film, Musik, Design, bildenden und darstellenden Künsten, Software, Werbung, Computerspielen, Büchern, Zeitschriften, Kleidung und anderen symbolischen Gütern spezifisch ausbildet. Der Konsum dieser Produkte, realisiert durch Genuss, Benutzung und Aneignung, soll die Erfahrung von Neuheit bewirken - zumindest einer Neuheit geringer Dosis, die mit Michael Hutter als "gewohnte Überraschung« charakterisiert werden kann: 
"Surprises that are fit for commercial products are carefully calibrated in their deviation from user expectations. The user must not be bored by evident repetitions or shocked by danger and provocation. Familiar surprises, combining thrill with comfort, are the most frequent and successful commercial variety." (Hutter 20II: 204)

Entsprechend erfordern Güter der Kreativindustrien nicht nur Kreativität auf der Seite der Produktion im Sinne ästhetischer Arbeit, sondern auch auf der Seite der Rezeption. Das Publikum wird in den Kreativindustrien als ästhetisch eigensinnige Instanz mit »allgemeine[r] Überraschungserwartung" (Reckwitz 2012: 19I) adressiert und bei der Produktion der Güter als imaginierter Akteur miteinbezogen, wie zum Beispiel Antoine Hennion (1989) in einer Studioethnografie von einer Popsongproduktion zeigt.

Neben der Innovation des Kreativsubjekts als Idealtyp der Kreativindustrie ist ein umgreifender Prozess der De-Materialisierung und Digitalisierung zu beobachten, durch den sich die Art der Arbeit wie auch die »industrially reproducible copies" (Hutter 20I5a: 59) zu großen Anteilen entstofflichen. Diese Entwicklung sorgt dafür, dass Eigentumsbeziehungen rekonfiguriert und rejustiert werden, um die monetäre Verwertung kreativer Arbeit langfristig zu sichern. Die Überführung geistiger Produkte in eigentumsförmige und kommodifizierbare Werke ist dabei eine Entwicklung, die historische Vorläufer kennt und die der Historiker Hannes Siegrist als Propertisierung versteht: Wissen, Informationen und Kultur, die sich aus kollektiven Quellen speisen, werden als Eigentum behandelt, individualisiert und privatisiert. Siegrist beobachtet, dass diese Vorstellung im ausgehenden 19. Jahrhundert aufgrund erhöhter technischer Reproduzierbarkeit stark zunimmt und sich ausbreitet:

"Das ursprünglich enge Spektrum der geschützten Werke - gedruckte Text-, Bild- und Notenwerke - wurde seit dem späten I9. Jahrhundert ergänzt durch Fotografien, Geschmacksmuster, mechanisch reproduzierte Tonwerke (von der Schallplatte bis zur Compact Disc), 
Filme, Rundfunk- und Fernsehsendungen, künstlerische Leistungen von Sängern und Schauspielern sowie schließlich Computerprogramme und vieles andere mehr.« (Siegrist 2006: 77)

Die Vorgänge der Propertisierung lassen sich als Innovation verstehen, die in zahlreiche Regelsysteme eingelassen wird, semantische Vorstellungen in Bezug auf das Verhältnis von Autorschaft und Werkherrschaft prägt und dadurch künstlerische Praktiken verändert. Kreativindustrielle Kompetenz bedeutet damit nicht mehr nur Integration von künstlerischen und wirtschaftlichen, sondern zunehmend auch von rechtlichen Praktiken. Einhergehend gewinnt das rechtliche Konstrukt des Immaterialgüterrechts beziehungsweise des Geistigen Eigentums (intellectual property) deutlich an Bedeutung, denn es stellt die rechtliche Grundlage für die »commodification of culture» (Hesmondalgh 2013: 70), also die wirtschaftliche Lizenzierung, Kontrolle und Verwaltung immaterieller Arbeit und ihrer Autorschaft.

Ein geeignetes Beispiel für diese innovative Entwicklung ist die Erfindung von Verwertungsgesellschaften zur treuhändischen, kollektiven Rechtewahrnehmung. In Frankreich wurde bereits Mitte des 19. Jahrhunderts eine solche Organisation gegründet, deren Nachfolgerin SACEM die urheberrechtlich abgeleiteten Nutzungsrechte ihrer Mitglieder bis heute verwaltet. Der Gründung vorausgegangen war ein Streit zwischen dem Pariser Musiker Ernest Bourget und dem Betreiber eines Straßencafés. In dem Café wurde zur Unterhaltung der Gäste Livemusik aufgeführt, unter anderem auch ein von Bourget komponiertes Stück - für diese Aufführung wurde Bourget allerdings weder um Erlaubnis gebeten noch eine Lizenz mit ihm ausgehandelt. Als der Musiker das Stück in besagtem Café hörte und sich daraufhin weigerte, die Getränkerechnung zu bezahlen - mit der Begründung, auch für die Aufführung seines Werks nicht bezahlt worden zu sein entstand ein folgenreicher Streit. Es folgte ein Gerichtsprozess, der zu Bourgets Gunsten entschieden wurde: Öffentliche Musikaufführungen waren von da an nur noch mit Autorisierung der beteiligten Urheber_innen erlaubt; der Cafébetreiber musste nachträglich 
Lizenzgebühren erstatten und Bourget gründete daraufhin mit anderen Komponist_innen die erste Verwertungsgesellschaft (Seifert et al. 2008: 75I).

Anfang des 20. Jahrhunderts wurde mit der AFMA in Deutschland eine vergleichbare Organisation aufgebaut, die I9I5 in die GEMA überging, der heutigen "Gesellschaft für musikalische Aufführungsund mechanische Vervielfältigungsrechte«. Die GEMA bildet heute die mächtigste deutsche Verwertungsgesellschaft und vertritt vorwiegend Autor_innen, Komponist_innen und Textdichter_innen, die sich für die kollektive Rechtewahrnehmung ihrer Werke registriert haben, um deren Verwertungs- und Verwendungsweisen damit zumindest teilweise wieder kontrollierbar zu machen (Hutter 2006: 86). ${ }^{18}$ Dementsprechend nahe liegt die Diagnose der Musikindustrie als einer "copyright industry" (Wikström 20I0: 17), deren Unternehmen und Profite "are no longer organised around making things but depend on the creation of rights« (Frith 1988: 57).

I8 Interessant in diesem Zusammenhang sind die Ausdifferenzierungsprozesse der Verwertungsgesellschaften, die sich um die kollektive Wahrnehmung von Bild-, Film-, Sende-, Text-, Leistungschutz- und anderen Rechten kümmern. Neben der GEMA und der GVL ("Gesellschaft zur Verwertung von Leistungsschutzrechten«) im Musikbereich gibt es beispielsweise die VG Wort zur Verwertung von Textmedien oder die GÜFA für die von pornografischen Medien. 2014 wurde mit der $\mathrm{C}_{3} \mathrm{~S}$, der "Cultural Commons Collecting Society«, eine Verwertungsgesellschaft mit europäischem Anspruch und einem Schwerpunkt auf Creative Commons-lizenzierter Musik ins Leben gerufen. 1996 wurde außerdem als zentrale Anlaufstelle für Lizenzierungsfragen die CMMV, die „Clearingstelle Multimedia für Verwertungsgesellschaften von Urheber- und Leistungsschutzrechten«, gegründet. Um die Klärung fragmentierter Rechte zu beschleunigen, war die CMMV einige Jahre lang Ansprechpartnerin für Kreativschaffende, die fremde Werke oder Anteile daraus nutzen wollten - eigentlich eine ideale Anlaufstelle für die Lizenzierung von Samples. Die CMMV versprach, entsprechende Anfragen zur Identifizierung von Urheber_innen und Rechtesituation innerhalb von zwei Wochen zu beantworten und damit Kontaktanbahnungen zwischen Sampelnden und Gesampelten zu beschleunigen (für Funktion und Arbeitsweise der CMMV siehe Grünig 2008: 273-300). 2007 wurde die CMMV allerdings "mangels praktischer Nachfrage aufgelöst" (Himmelmann 2008: 859). 
Die grammatische Logik des Urheberrechts mit seiner kreativen, das heißt auf abgeschlossene Originale fixierten Autonomieästhetik, unterstützt und treibt diesen Prozess weiter voran. Dieser Befund wird auch von Monika Dommann (20I4: 2I) bestätigt, die an der Historie von Fotokopie und Musikaufnahme den interdependenten Innovationsprozess nachzeichnet, der sich von 1850 bis 1980 zwischen den technischen Kopiermöglichkeiten und ihren urheberrechtlichen Einschränkungen vollzog. Dommann macht historisch plausibel, dass sich - bewerkstelligt vor allem durch die Lobbyarbeit der entstehenden Kreativindustrien - diverse urheberrechtliche Konfigurationen technischer Reproduzierbarkeit wie die Einführung von Lizenzzwang, Privatkopie oder "Apparateabgabe» (Dommann 20I4: 23I) etablieren, die bis heute stabil sind. Die urheberrechtlichen Kategorien des originalen Werks und seiner kreativen Autor_in werden für die industriellen Gefüge durch semantische Vereinnahmung wie der Konstruktion individueller Autorschaft anschlussfähig gemacht und grammatisch eingepasst (vgl. Woodmansee 1984).

Kreativität, das zeigen die angeführten Studien, ist im Zusammenhang der Kreativindustrien ein Schlüsselbegriff im Feld, der so offen wirkt, dass er verschiedene schöpferische Prozesse fassen kann, gleichzeitig aber so geschlossen bleibt, dass diese Prozesse einigermaßen deutlich bezeichnet sind. In diesem Punkt schließe ich an Reckwitz an, der Kreativität konstruktivistisch, also als »hochspezifisches soziales, kulturelles und historisches Produkt « (Reckwitz 20I6: 250) begreift, das in seiner Ausformung als »Kreativitätsdispositiv« zwischen den Funktionssystemen wie Kunst, Wirtschaft und Recht liegt, aber auch in den Massenmedien, der psychologischen Beratung oder der Stadtplanung ein dominantes semantisches Muster darstellt. In dieser Perspektive rücken die sozialen Zuschreibungs- und Bewertungsprozesse von Kreativität in den Fokus, je nachdem ob sie beispielsweise innerhalb rechtlicher, ökonomischer oder künstlerischer Zusammenhänge artikuliert werden. Dementsprechend werde ich im weiteren Verlauf Kreativität als soziokulturelles Konstrukt verstehen, um die damit verbundenen Praktiken, semantischen Zuschreibungen 
und grammatischen Regelgebilde der Neuheitsproduktion präziser aufschlüsseln zu können. Für dieses Vorhaben nutze ich im nächsten Abschnitt verschiedene Konzepte aus der Kunstsoziologie, um eine eingebettete Perspektive auf Kunstproduktion zu erhalten.

\subsection{Kunstsoziologische Perspektiven auf Neuheit und Kreativität}

In seiner unvollendet gebliebenen soziologischen Mozart-Studie untersucht Norbert Elias die Bedingungen der gesellschaftlichen Konstruktion eines Genies. Elias verbindet dabei individuelle Ausprägungen Mozarts mit der langfristigen makrostrukturellen Emanzipierung der höfischen Kunst vom Patronagesystem hin zu einem freien und anonymen Kunstmarkt. Die Qualität der Neuheit, die Mozart in seiner Musik zum Ausdruck bringen konnte, wird hier zum Schlüsselpunkt:

"Dabei war das Entscheidende, dass sich [Mozarts] Phantasie in Gestaltkombinationen äußerte, die zwar im Rahmen des von ihm erlernten gesellschaftlichen Musikkanons blieben, aber innerhalb seiner weit über die zuvor bekannten Kombinationen und die Gefühlsmitteilungen, die sie enthielten, hinausgingen.« (Elias 1999: 79).

Zur Verdeutlichung dieses Arguments der bisher ungekannten, von Mozart eingebrachten musikalischen Neuheit stellt Elias Kunstschaffen und Träumen gegenüber: Traumphantasien haben die Eigenschaft, dass sie Zusammenhänge herstellen, die von den Träumenden bisher so noch nicht gesehen wurden - dementsprechend verworren und wenig nachvollziehbar sind sie meist, gerade für Außenstehende. Die Erschließung eines neuen Zusammenhangs, die Verbindung des bisher Unverbundenen, ist jedoch ein Gesichtspunkt, der auch für die soziologische Erforschung von Neuheit von Interesse ist. Wäh- 
rend Elias zufolge die Traumphantasie eine private Erfahrung darstellt, ist das "Eigentümliche an innovatorischen Phantasien in der Gestalt von Kunstwerken [...], dass es sich dabei um Phantasien handelt, die sich an einem für viele Menschen zugänglichen Material entzünden. Kurz gesagt: es handelt sich um entprivatisierte Phantasien." (Elias 1999: 80). ${ }^{19}$

Ich stelle Elias' Zitate den kunstsoziologischen Ausführungen voran, um die gesellschaftliche Verquickung von Neuheit und Ästhetik zu illustrieren und den Transformationsprozess zu veranschaulichen, den die Kunst zur Erlangung von Autonomie und bis hin zu ihrer Verflechtung mit wirtschaftlichen und rechtlichen Praktiken in der heutigen Kreativindustrie durchlaufen hat. Zudem sind durch den Aufstieg technischer Reproduzierbarkeit neue künstlerische Praktiken aufgetaucht, die den wirtschaftlichen Begriff des (Privat-)Eigentums herausfordern. Während für Elias nämlich entprivatisiertes, also allgemein zugängliches künstlerisches Material »Worte, Farben, Steine, Töne oder was auch immer« (Elias I999: 80) sind, wird diese Grenzziehung mit der Etablierung von DJing, Sampling und weiteren Techniken der Reproduzierbarkeit angreifbar und durchlässig. Denn heute kann nahezu auf den ganzen, physisch in Tonträger eingelassenen, popkulturellen Klangkatalog zugegriffen werden, der im offenen künstlerischen Prozess dadurch den allgemein zugänglichen Status freien Materials erhält. Diese künstlerische Entprivatisierung des Materials steht im Widerstreit zu dem im Sinne des Urheberrechts geschützten Geistigen Eigentum. Darüber hinaus streicht Elias an der Figur Mozarts die Entwicklung der Kunst hin zu einem autonomen gesellschaftlichen Bereich heraus, dessen Strukturen und Bewertungskriterien den musikalischen Produkten Mozarts als »cultural lag" (Ogburn 1923) zuerst hinterher hinken, da sie noch nicht von einem autonomen Kunstbereich ausgehen. Mozart ist seiner Zeit sprichwörtlich voraus und muss »Verkanntseinaushaltefähigkeit» ent-

I9 Elias verwendet »innovatorisch « in seiner Studie nicht im Sinne einer nachhaltig ausgebreiteten Neuerung, sondern bezeichnet damit individuelle Prozesse, die im weitesten Sinne kreativ, schöpferisch, phantasievoll sind. 
wickeln, wie Luhmann (I988: I6) diese Strategie der Resilienz später nennt.

Neben Elias bieten sich weitere Perspektiven aus der Spezialdisziplin der Kunstsoziologie an, um ein vertieftes Verständnis künstlerischer Prozesse, ihrer Kreativität und gesellschaftlichen Einbettung als Modus sichergestellter Neuheitsproduktion zu erhalten. ${ }^{20}$ Den Kunstsoziologinnen Dagmar Danko (2012: IO) sowie Nina Zahner und Uta Karstein (2014: 190) zufolge stellen die Distinktionstheorie und der Begriff des Kunstfelds von Pierre Bourdieu, die interaktionistisch inspirierte Theorie der Kunstwelt von Howard Becker und der systemtheoretische Kunstbegriff nach Niklas Luhmann die derzeit dominierenden Ansätze der Kunstsoziologie. Sie bieten auch für die vorliegende Arbeit zentrale kunstsoziologische Bezugspunkte, ${ }^{21}$ wenngleich in unterschiedlicher Hinsicht: Bourdieu und Luhmann sind vor allem aus makrotheoretischer Perspektive interessant, da mit ihnen die institutionellen Gefüge der Kunst als historisch gewachsene Strukturen wichtig werden und sich aus der Autonomie der Kunst Implikationen für das Selbstverständnis als Kreativsubjekt plausibel machen lassen. Um im Sinne einer kunstsoziologisch informierten Perspektive auf das aktuelle Verhältnis von Urheberrecht und Kreativität in der samplingbasierten Musikproduktion zu blicken und dieses empirisch als Lebenswelt erforschen zu können, benötige ich jedoch einen Ansatz, der mehr Offenheit und Operationalisierbarkeit

20 Teilweise wird die Soziologie der Kunst auch als pluralistische Variante gefasst. Als Soziologie der Künste steht sie für ein erweitertes Kunstverständnis und damit für künstlerische Spielarten wie Musik, Literatur, Theater, Film und weiteren jenseits der bildenden Kunst. Grundsätzlich ist mir die pluralistische Variante sympathisch, aus Ermangelung einer etablierten Systematik beziehe ich mich im Folgenden jedoch auf die klassische Formulierung als Kunstsoziologie.

2I Die hier erfolgte Darstellung kunstsoziologischer Arbeiten bleibt an dieser Stelle, ähnlich wie zum Innovationsbegriff, überblicksartig und damit notwendigerweise lückenhaft. Es liegen jedoch ausgezeichnete einführende und vertiefende Texte zu Geschichte und Fragestellungen der Kunstsoziologie vor. Die wichtigsten sind für mich Zolberg (1990, 2015), Zahner (2006), Danko (2012), Smudits et al. (2014) und Steuerwald (2017), im Bereich der Musik(soziologie) vor allem DeNora (2000), Hesmondhalgh (2013) und Martin (2006). 
für die Mikroebene verspricht. Einen solchen Ansatz bietet Beckers Konzept der Kunstwelten. Ich beginne daher makrotheoretisch mit Luhmann und Bourdieu und arbeite mich anschließend mit Becker in Richtung Mikroebene vor.

\subsubsection{Die Kunst als autonomes gesellschaftliches Funktionssystem}

Für Luhmann ist der Prozess der Autonomisierung der Kunst hin zu einem unabhängigen gesellschaftlichen Funktionssystem das zentrale Thema seiner Systemtheorie der Kunst. Den evolutionären Prozess der Systembildung samt Ausdifferenzierung und Ausbildung von Subsystemen zeichnet er ausführlich in "Die Kunst der Gesellschaft» (1997) historisch nach. Das Kunstsystem hat demnach seine eigenen Bewertungsinstanzen ausgebildet, die es ihm ermöglichen, die Grenze zwischen Kunst und Nicht-Kunst, zwischen System und Umwelt, unabhängig von anderen Funktionssystemen wie Politik, Wirtschaft oder Recht, Wissenschaft oder Religion zu ziehen. Die Systemgrenzen werden durch Selektion konstituiert, wobei in Luhmanns Theoriearchitektur nicht die menschlichen Akteure wie Künstler_innen oder Rezipient_innen, sondern die Kunstwerke selbst die zentralen Elemente sind, da über diese die Kommunikationsprozesse ablaufen. Um die Anschlussfähigkeit der Kommunikation sicher zu stellen, entsteht in der Kunst ein Code, also »eine laufend durchgehaltene binäre Orientierung nach `Passen` und `Nichtpassen` der zu wählenden Formen.« (Luhmann 1997: 190). Ähnlich wie die Binärcodes Recht/Unrecht im rechtlichen oder Geld/Nicht-Geld im wirtschaftlichen System bildet sich in der Kunst die Unterscheidung ästhetisch/ nicht-ästhetisch heraus, wobei sich diese Entwicklung über mehrere Jahrhunderte erstreckt.

Die komplexen und voraussetzungsreichen Ausführungen Luhmanns werden hier nur angedeutet, da ich nicht beabsichtige, für den weiteren Gang der Arbeit seine systemtheoretische Perspektive zu 
vertiefen und durchgehend mit seinem Theorievokabular zu arbeiten. Sie sind aber für eine Kontextualisierung der Genese und Autonomie des Kunstsystems und seinem Verhältnis zu anderen gesellschaftlichen Funktionssystemen von Gewinn: Die entpersonalisierte Theoriesprache zwingt dazu, die historische Kontingenz der Kunst und ihrer Erscheinungsformen, beispielsweise ihrer Autonomie oder des Geniekults, ernst zu nehmen. Das bringt die Implikation mit sich, dass sich zeitgenössische Künstler_innen und Musiker_innen an den jeweiligen sozialen Konventionen der Neuheitsproduktion orientieren müssen, seien diese nun semantisch formuliert in den Begriffen Kreativität, Originalität und Überraschung, oder Spontanität und Authentizität.

Luhmanns Soziologie der Kunst wird vor dem Hintergrund von Fragen zu Innovation und Kreativität, aber auch zu Kopien und technischer Reproduzierbarkeit besonders an der Stelle interessant, an der die Neuheit von Kunstwerken wie auch von Künstler_innen als entscheidendes semantisches Kriterium zur Bewertung ins Spiel kommt: "Neu heißt hier seit dem I7. Jahrhundert nicht mehr nur: ein weiteres Exemplar, sondern vielmehr etwas, was vom vorherigen abweicht und dadurch überrascht." (Luhmann 2008a: I48). Die Aufwertung des Neuen im Sinne einer sozialen Devianz vom Normalen sieht Luhmann in der Kunst schneller und radikaler durchgesetzt als in anderen Gesellschaftsbereichen, wobei er seine These an die Entwicklung eines dominierenden Originalitätspostulats und eines damit einhergehenden Narrativs künstlerischer Genialität im Sinne außergewöhnlicher Individualität knüpft. So setzt sich Luhmann zufolge die Vorstellung durch, dass die individuelle Besonderheit der Schöpfer_in die Produktion eines Kunstwerks entscheidend präge. Dies ebnet dem Geniegedanken der Romantik den Weg und führt gleichzeitig zu Nachahmungseffekten:

"Niemand kann wirklich leben, ohne zu kopieren. Wenn man glaubt, dass man originell ist, dann heißt das nur, dass man die Idee kopiert, originell zu sein; wenn man ein Genie sein will, dann heißt das nur, 
dass man die Idee des 19. Jahrhunderts von der Existenz des Genies kopiert.« (Luhmann 2008b: 62)

Daneben brauche es das Originalitätspostulat im Zuge der Loslösung der Kunst vom Patronagesystem hin zum Kunstmarkt, auf dem »das Desiderat der Originalität als Garantie für Knappheit [dient] « (Luhmann 1995: 70). Diese Innovation des Originalitätspostulats, das bis heute die Kunst, aber auch die Wissenschaft dominiert, beschleunigt und verstärkt sich Luhmann zufolge, nachdem sich die Kunst an Mode und Massenmedien Anleihen holt. Diese operieren als Steigerungsphänomene stark nach dem Code der Neuheit (Luhmann 2008a: 179). Das Merkmal der Mode besteht darin, kopierfähig zu sein - die Kunst hingegen setzt auf die Einmaligkeit des Kunstwerks: "Das Kunstwerk dagegen verachtet seine Kopien, und wenn es sich an der Reproduktion von Kunst beteiligt, dann in der Weise, dass es über Stil zu unterscheidbaren Kunstwerken anregt." (Luhmann 2008a: I83). Die bisher stärkste Form der künstlerischen Steigerungstendenz sieht Luhmann schließlich in den Provokationen und Irritationen der modernen Avantgarde, die die Grenzen der Kunst künstlerisch thematisiert, indem sie sich als ihre eigene Negation, als Nicht-Kunst ausgibt und beispielsweise mit nicht-künstlerischen Materialien und Methoden wie Lärm oder Zufällen arbeitet (vgl. Luhmann 1995: 97). Die Avantgarde - so bemerkt die Literatursoziologin Christine Magerski in Bezug auf Luhmann und unterstreicht damit dessen These von der Autonomie der Kunst - »hat die Kunst an ihre eigene Grenze geführt, indem sie die Erzeugung von Beliebigem und Zufälligem bis hin zu jenem Punkt betrieb, an dem das Unterscheidungsproblem von Kunst und Nicht-Kunst auftauchte" (Magerski 20II: IOO).

Der soziologisch gefärbte, wenn auch kursorisch bleibende Überblick über historische Zusammenhänge, der sich durch Luhmanns Arbeiten ergibt, ist dank seiner enormen Lesekapazität äußerst ertragreich. Da Luhmann für seine Ausführungen vorwiegend Literatur heranzieht, die oftmals schwer erreichbar ist, und sich auch sonst nur in Ausnahmefällen mit empirischen Nachweisen aufhält, bleiben seine 
komplexen Ausführungen bisweilen zwar schlüssig, aber schwer zu be- oder widerlegen. Für die vorliegende Arbeit dienen sie mir daher eher als Inspiration. Als Ausgangspunkte behalte ich vor allem die soziohistorische Kontingenz der Kunstautonomie, die Forderung nach Neuem sowie das daran geknüpfte, historisch gewachsene Subjektverständnis im Hinterkopf.

\subsubsection{Die Regeln (il)legitimer Kunst}

Einen Gegenentwurf zur systemtheoretischen Perspektive Luhmanns bietet Pierre Bourdieu, dessen Werk ähnlich einflussreich und umfangreich ist. Ich werde mich in diesem Abschnitt darauf beschränken, zentrale Begriffe aus der Kunstfeldtheorie Bourdieus zu erarbeiten. Dabei beziehe ich mich auf seine kunstsoziologisch vermutlich am stärksten ausgerichtete Studie zu den »Regeln der Kunst « (Bourdieu 200I), in der er entlang der Biographien des Malers Edouard Manet und vor allem des Schriftstellers Gustave Flaubert die Genese des Felds der Malerei beziehungsweise des literarischen Felds in Gänze erklärt. Bourdieus Ziel besteht in der historischen Rekonstruktion der Autonomisierung des Felds hin zu einer eigenständigen sozialen Struktur, die sich ihre eigenen Regeln zu geben und sich so selbst zu reproduzieren vermag. Die Maxime von der freien, »reinen« Kunst, die sich selber und keiner anderen gesellschaftlichen Instanz dienen muss, wird als Leitgedanke des Felds entwickelt und in ihm als eigene Logik etabliert:

"Die Maler bieten so, nach der Art einer rexemplarischen Prophetie im Sinne Max Webers, den Schriftstellern das Modell des reinen Künstlers, das sie im Übrigen erfinden und durchzusetzen trachten; und die reine Malerei, befreit von der Pflicht, einer Sache zu dienen oder schlicht etwas zu bedeuten, die sie der akademischen Tradition vorwerfen, trägt dazu bei, die Möglichkeiten einer sreinen` Kunst zu materialisieren.« (Bourdieu 200I: 220) 
Die bereits maßgeblich entwickelte Theorie des sozialen Felds (Bourdieu 1987) weist den Weg für Bourdieus anspruchsvolles Vorhaben. Als »Feld « versteht Bourdieu die "agonale» Struktur (Danko 20I2: 56), innerhalb derer die Akteure miteinander um Einfluss, Stellung und Macht ringen. In diesen sozialen Kämpfen wird das Verhältnis ihrer sozialen Positionen zueinander bestimmt. Ihre Strategien und Interessen, und damit auch ihre Handlungen, sind bestimmt vom inkorporierten Habitus und den verfügbaren Ressourcen, die als ökonomisches, soziales und kulturelles Kapital eingesetzt werden. Das Feld wird dabei dominiert von überindividuellen gesellschaftlichen Strukturen der Ungleichheit, die "von Willen und Bewusstsein der Akteure relativ unabhängig sind " (Zahner 2006: 6I). Sie zeigen sich aber im Habitus und bedingen die gesellschaftliche Konstruktion des künstlerischen Kreativsubjekts:

"Was man 'Kreation`, sschöpferisches Schaffen` nennt, das ist das Zusammentreffen zwischen einem sozial konstituierten Habitus und einer bestimmten bereits institutionalisierten oder möglichen Stellung innerhalb der arbeitsteilig organisierten kulturellen Produktion (und darüber hinaus, auf zweiter Ebene, der arbeitsteilig organisierten Herrschaft); die Arbeit, anhand deren der Künstler sein Werk und untrennbar damit sich selbst als Künstler schafft (und, falls das zu den Ansprüchen des Feldes gehört, zu einem originellen, einzigartigen Künstler), kann beschrieben werden als dialektische Beziehung zwischen seinem >Posten`, der häufig bereits vor ihm besteht und ihn überdauert (mitsamt Verpflichtungen, beispielsweise dem `Künstlerleben`, Attributen, Traditionen, Ausdrucksweisen usw.) und seinem Habitus, der ihn mehr oder weniger vollständig dazu prädestiniert, diesen Posten auszufüllen oder ihn [...] vollständig zu verändern.« (Bourdieu 20II: 158 )

Die agonale Feldstruktur determiniert im Sinne Bourdieus die Grammatik, nach der verfahren und beispielsweise Originalität bewertet wird. Daraus schlussfolgert Bourdieu, dass der Wert eines Kunstwerks 
nicht durch die Künstler_in selbst entsteht, sondern durch das sie umgebende "Produktionsfeld als Glaubensuniversum" (Bourdieu 200I: 362). Die Bewertungsmaßstäbe kommen im Kampf um die Definitionsmacht an die Oberfläche, also bei der Frage, welcher Akteur nach welchen Regeln und mit welcher Macht die Grenzen des Felds zieht und damit über das Innen und Außen entscheidet - und diese Entscheidungen durchsetzen kann. Dieses ungleichheitstheoretische Interesse, das bei Bourdieu anhand von Distinktionsphänomenen empirisch untersucht wird, findet sich beispielsweise in einem frühen Aufsatz über "Die gesellschaftliche Definition der Photographie» (1981 [1965]). Die Fotografie ist ähnlich wie das Sampling ein Mittel der technischen Reproduzierbarkeit, das singuläre Momente aus dem visuellen und zeitlichen Kontinuum herausgreifen und speichern kann:

"Als plötzlicher Schnitt in die sichtbare Welt ist die Photographie das Mittel, die solide und kompakte Wirklichkeit der alltäglichen Wahrnehmung in eine unendliche Vielfalt flüchtiger Ansichten aufzulösen, einmalige Konstellationen, Aspekte der wahrgenommenen Welt festzuschreiben, die - darauf hat Walter Benjamin hingewiesen - ihrer Flüchtigkeit wegen im Grunde gar nicht wahrgenommen werden können.« (Bourdieu I98I: 87)

Die Fotografie gilt in der damaligen Hierarchie der Künste allerdings als »illegitim«, denn sie ist ab den I96oer Jahren auch für amateurhafte Fotograf_innen mit geringen Kapitalien zugänglich. Diese bilden, entsprechend ihrer sozialen Position, eigene fotografische Praktiken aus: Beispielsweise variiert die Art und Weise, wie einzelne Gesellschaftsschichten den Fotoapparat einsetzen, um bestimmte Ausschnitte auszuwählen oder Motive zu inszenieren, je nach Schichtzugehörigkeit und Habitus eklatant. Die Praktiken des Fotografierens unterer Schichten werden von den oberen Schichten als künstlerisch belanglos delegitimiert, indem Motivauswahl, künstlerisches Wissen und gebildeter Geschmack als besondere Befähigung der Oberschicht 
unterstellt werden. Der »barbarische Geschmack« der unteren Schichten, der sich an den der oberen orientiert, wird auf diese Weise abgewertet, die feinen Unterschiede zwischen den Schichten reproduziert. Bourdieu (198I: I07) schließt den Aufsatz mit einer hierarchischen Aufstellung der Künste hinsichtlich ihrer jeweiligen gesellschaftlichen Legitimität. Während (klassische) Musik, bildende Künste, Literatur und Theater der "Sphäre der Legitimität mit universalem Anspruch" angehören und legitime Legitimierungsinstanzen wie Akademien oder Universitäten zur Verfügung haben, befinden sich Mode, Sportveranstaltungen und Inneneinrichtungspraktiken in der »Sphäre des Beliebigen«, die im Wesentlichen auf illegitime Legitimierungsinstanzen wie Werbung gründen. Dazwischen sind mit Film, Fotografie, Jazz und Chanson Anwärter_innen auf die legitime Sphäre zu finden, die konkurrierende Legitimierungsinstanzen wie Clubs oder Kritiken ausgebildet haben, sich aber zur Legitimation nach oben orientieren:

"Anders als eine legitime Praxis stellt eine Praxis, die dies erst noch werden will, ihre Anhänger vor die Frage nach ihrer Legitimität, ja sie nötigt sie ihnen geradezu auf. Es ist kein Zufall, wenn die passionierten Photographen jeweils die ästhetische Theorie zu ihrer Praxis entwickeln, also ihre Existenz als Photographen dadurch zu rechtfertigen versuchen, dass sie die Existenz der Photographie als wahre Kunst rechtfertigen.« (Bourdieu I98I: I09)

Wohlgemerkt ist diese Aufstellung im Frankreich der 1960er Jahre entstanden und für heutige Verhältnisse nicht mehr voll zutreffend. Bourdieus Perspektive ist aber für das Studium anderer, neu aufkommender Kunstpraktiken in der Gemengelage zwischen fine art und low art wie beispielsweise beim Comic (Becker 20IO), der Fanfiction (Reißmann et al. 20I7) oder natürlich dem Sampling (Williams 20IO) wertvoll. Wichtig für diese Arbeit bleibt daher vor allem Bourdieus genereller Gedanke einer sozialen Hierarchisierung der Künste, die in Konkurrenz zueinander stehen und mit unterschiedlichen Graden und Institutionen der Legitimität ausgestattet sind. Dieses agona- 
le Prinzip wirkt sich auch auf die sozialen Kämpfe innerhalb einer Kunstrichtung aus, insofern auch dort um Definitionsmacht, $\mathrm{Zu}$ gang zu Ressourcen und Positionen gerungen wird. Mit Bourdieu wird daher vor allem die Aneignung von Legitimationsinstanzen und -praktiken zur Verbesserung oder Konsolidierung der eigenen sozialen Position wichtig. Auch seine Hinweise auf die soziale Struktur künstlerischen Geschmacks und habitueller Praktiken sind äußerst wertvoll, um den Blick für die makrostrukturell gewachsenen sozialen Gebäude und deren oftmals unbemerkten, aber bis in die Mikroebene dringenden Kräfte zu öffnen. Mit dem Feldkonzept schärft Bourdieu ein, die mikrologischen Kämpfe um Distinktion, Definitionshoheit und der Etablierung von grammatischen Systemen ernst zu nehmen, denn sie weisen einerseits auf die darunter liegenden Machtkonstellationen und ihre gesellschaftliche Reproduktion, andererseits auf die soziale Konstruiertheit beispielsweise von Kreativsubjekten hin: „Der Kampf um Definitionsmacht ist [...] die Existenzgrundlage eines jeden Felds." (Zahner 2006: 62).

In Bourdieus Ansatz taucht das Neue innerhalb der agonalen Feldstruktur auf und wird dort in machtvollen Konstellationen verhandelt. Dieser Prozess der (De-)Legitimierung ist verbunden mit der Erteilung oder Absage einer Berechtigung. Es handelt sich damit also um eine Platzzuweisung innerhalb, außerhalb oder an den Grenzen des Felds, die im Zusammenhang der Konkurrenz von Hoch- und Popkultur besonders interessant wird. So demonstriert Sarah Thornton in ihrer Analyse zur Etablierung des Subfelds der Popkultur, das später zu einem eigenen Feld mit autonomer Struktur avanciert, dass die dortigen Distinktionskämpfe nun um die Erlangung von "subcultural capital« zentriert sind und zur Ausbildung einer entsprechenden Grammatik der Authentizität führen (Thornton 2003). Wichtig für die vorliegende Arbeit bleibt daher vor allem die ungleichheitstheoretische Perspektive Bourdieus hinsichtlich der Frage, mit welchen Mitteln und aus welcher Position heraus künstlerische Regeln als Originalitätsgrammatik und damit als Treiber der Neuheitsproduktion verankert werden. Ich werde diese Überlegung im Abschnitt 
zur kontributionalistischen Kreativität wieder aufnehmen (siehe Kapitel 2.4.I), nachdem ich die interaktionistische Perspektive Beckers erörtert habe.

\subsubsection{Kunst als kollektives Handeln}

Der US-amerikanische Soziologe Howard S. Becker hat mit "Art Worlds" (2008) [1982] einen kunstsoziologischen Ansatz erarbeitet, der sich als theoretisch-methodologisches Werkzeug für die empirische Forschung von zeitgenössischen künstlerischen Prozessen eignet. Beckers Perspektive ist dabei stark von seinen empirisch fundierten arbeits- und kriminalsoziologischen Vorarbeiten geprägt: Zwar gesteht auch er der Kunst zu, eine autonome Sphäre der Gesellschaft zu sein, jedoch legt er seinen Fokus auf die konkrete Erforschung der interaktiven Prozesse der Konvention und Kooperation, die Kunstwelten strukturieren.

Mit seinem Kunstweltkonzept wendet sich Becker in den I98oer Jahren gegen die damals dominanten kunstsoziologischen Ansätze, die vorwiegend philosophisch geprägt Werturteile über gute Kunst entwickeln, theoretisch arbeitend das allgemeine "Wechselverhältnis von Kunst und Gesellschaft« (Danko 20I5: 83) untersuchen oder im Sinne einer kunstgeschichtlich informierten Stoßrichtung Kunst als Abfolge bestimmter Stile analysieren. Kunstwelten sind für Becker hingegen dynamische kollektive Gefüge, die in allen denkbaren gesellschaftlichen Formen künstlerischen Ausdrucks vorkommen. Beckers Ansatz ist vergleichsweise bodenständig und nah an der praktischen Ebene der Kunstproduktion orientiert: Er differenziert nicht zwischen Hoch- und Populärkultur, bezieht das Publikum als relevante Komponente einer Kunstwelt mit ein, hält Kunstwerke weder für abgeschlossen noch statisch, befreit sich auch gänzlich davon, ästhetische Urteile abzugeben. Und er nimmt gehörigen Abstand von der Idee, wie Arthur Danto oder Theodor W. Adorno nur eine ästhetische Elite von Expert_innen zu adressieren. 
Als sozialwissenschaftlicher Begriff ist die "Welt« spätestens seit Anselm Strauss und seinem Aufsatz "A Social World Perspective" in Umlauf; von der Chicago School wurde er zwar früher eingesetzt, dabei aber eher sporadisch und deskriptiv, wie Strauss anmerkt (I978: II9). Explizit von einer "Kunstwelt" schreibt erstmals der Kunstphilosoph Arthur C. Danto (1964), der die Expert_innendiskurse der Definition, die um ein künstlerisches Objekt kreisen, als Kunsttheorien näher bestimmen will. Becker bezieht sich an einigen Stellen auf Danto, übernimmt den Begriff selbst aber eher in loser Anlehnung. Für Becker scheinen der philosophisch formulierte Hinweis und die Hinwendung zur Konstruktion von Kunsturteilen und ihrer Kontingenz zwar anschlussfähig, aber in der sozialwissenschaftlichen Weiterführung unterkomplex, da Danto nur die Expert_innen einer Kunstwelt fokussiert und Interaktionen unberücksichtigt lässt (vgl. Danko 20I5: 85). Dagegen fordert Becker für die sozialwissenschaftliche Analyse einer Kunstwelt ein differenziertes Verständnis der interaktiven und interpretierenden Prozesse ein, welche Produktion, Rezeption und Distribution eines Kunstwerks organisieren.

Diese Punkte lassen eine deutliche Nähe zu Ansätzen der britischen Cultural Studies erkennen, die sich zeitlich ähnlich ab Mitte der I97oer Jahre etablieren. Noch deutlicher lässt sich Beckers Forschung innerhalb der interpretativen Traditionslinie der Soziologie verorten. Für ihn spielen vor allem die Chicago School und der Symbolische Interaktionismus nach Herbert Blumer eine zentrale Rolle. ${ }^{22}$ Beide zeigen eine deutliche Sympathie für qualitativ-empirische Untersuchungen und induktive Herangehensweisen (Keller 20I2: 62). So werden mit der ethnografischen Erforschung der Großstadt und ihrer Milieus durch die Chicago School verschiedene Aspekte des menschlichen Zusammenlebens sichtbar, unter anderem Arbeitsteilung, Individualisierung, Devianz und die Diversität sozialräumlicher Welten (vgl. Park 1915).

22 Becker führt Blumers berühmte Aufsätze „Collective Behaviour« (I95I) und "Fashion: From Class Differentiation to Collective Selection« (I969) nicht explizit in "Art Worlds" als Quellen an, aber seine impliziten Bezüge zu Blumers Ansatz sind ersichtlich. 
Das theoretische Programm des Symbolischen Interaktionismus', der im Anschluss an die Chicago School von Herbert Blumer entwickelt wurde, führt diese Forschungsinteressen weiter. Es arbeitet dabei auf der Grundlage des konstruktivistischen Standpunkts, dass Wirklichkeit nicht qua Natur determiniert wird, sondern Menschen ihre Wirklichkeit stets aus dem gegenseitig aufeinander bezogenen, interpretierenden Handeln erschaffen. Art und Qualität der Interaktionen sind dabei davon abhängig, wie die jeweilige Situation von den Teilnehmer_innen gedeutet wird. Wirklichkeit, so die Folgerung, ist immer soziale Wirklichkeit und über diese Sozialität dynamisch und veränderbar. Oder anders formuliert: „Der symbolische Interaktionismus", schreibt die Kunstsoziologin Nina Zahner, "untersucht mithin die fortwährende Konstruktion symbolischer Welten durch ihre Teilnehmer und betont so die Veränderbarkeit und Beweglichkeit sozialer Prozesse« (Zahner 2006: 49). Soziale Wirklichkeit konstituiert sich vor diesem Hintergrund als individuelle, prozesshafte Sozialwelt. Daraus ergibt sich nicht die eine Welt, in der wir leben, sondern zahlreiche verschiedene, die neben- und nacheinander existieren. In Konsequenz werden für die empirisch arbeitende Sozialforscher_in dann die jeweilige Welt und die dafür strukturierenden Bedeutungen und Interaktionen als Untersuchungseinheit relevant, in Beckers Fall die Welt(en) der Kunst.

Auch wenn bei Kunstwerken in der Regel singuläre Autorschaften kommuniziert werden - das neue Theaterstück der berühmten Regisseurin, die überraschende Neuerscheinung jenes Erfolgsschriftstellers, das wegweisende erste Album einer Rockband usw. - ist für Becker die Kunst kein einsames Unterfangen. Die singuläre Autorschaft verdeckt seiner Meinung nach eher, welche sozialen Interaktionen notwendig sind, um ein bestimmtes künstlerisches Produkt zustande zu bringen. Becker (2008: I) interessiert sich daher für die »cooperative networks through which art happens«. Diese netzwerkartige Struktur, die durch die kooperativen Verbindungen entsteht, nennt Becker "Kunstwelt» (»art world»); er meint damit den Verbund aus all denjenigen Personen und Handlungen, die ihren - wie auch immer 
aussehenden - Beitrag zur Produktion, Distribution und Rezeption eines künstlerischen Werks leisten und daher arbeitsteilig miteinander kooperieren. Notwendigerweise produziert eine Kunstwelt dabei symmetrische wie asymmetrische Abhängigkeiten zwischen den Beteiligten:

"Whatever the artist, defined as the person who performs the core activity without which the work would not be art, does not do must be done by someone else. The artist thus works in the center of a network of cooperating people, all of whose work is essential to the final outcome. Wherever he depends on others, a cooperative link exists." (Becker 2008: 24-5).

Dabei ist klar, dass die jeweiligen Akteure unterschiedliche Aufgaben wahrnehmen: Becker unterscheidet zwischen dem künstlerischen und dem unterstützenden Personal (»support personnel«). Während das künstlerische Personal den Kernaktivitäten der jeweiligen Kunstproduktion nachgeht und in der Regel mit Autorschaft und Verantwortung ein Kunstwerk zeichnet, liefert das unterstützende Personal andere Arbeiten, ohne die die künstlerischen Kernaktivitäten allerdings umständlich oder problematisch, mitunter sogar unmöglich werden (Becker 2008: 16-7). ${ }^{23}$ Becker hält etwaige Restriktionen nicht für absolut, denn »[y]ou can always do things differently, if you are prepared to pay the price in increased effort or decreased circulation of your work. (Becker 2008: 33) Aber: "[J]ede Entscheidung für oder gegen den Einsatz von unterstützendem Personal ändert das Kunstwerk«, bemerkt Danko (2012: 65) im Gefolge Beckers. Die Ästhetik eines Kunstwerks wird so aus der praktischen Verfügbarkeit von

23 Im Bereich der Musik ließe sich hier beispielsweise an Agenturen, Labels oder Verlage, Distributoren, Betreuer_innen (Artists and Repertoire, meist als "A \& R « abgekürzt), Konzertveranstalter_innen, Verwertungsgesellschaften, Technologieentwickler, Sponsor_innen, usw. denken, die um die produzierende Arbeit der Musiker_innen herum angeordnet sind und bei der Vermarktung, Distribution und Rezeption mittun. 
künstlerischen Materialien und dem Zugang zu Produktionsnetzwerken erklärt und damit fernab von Aura, Expressivität oder göttlicher Inspiration geerdet. Ähnlich wie die Fabrikation naturwissenschaftlicher Erkenntnis im Labor teilweise von profan erscheinenden Mitteln abhängig ist (Knorr-Cetina 1999), beruht bei Becker die Kunstproduktion nicht nur auf freien ästhetischen Entscheidungen nach dem romantischen Ideal der künstlerischen Expressivität, sondern auf handfesten Aktivitäten, die soziologisch untersucht werden können.

Mit der hemdsärmeligen, vermeintlich naiven Herangehensweise verfolgt Becker das Projekt einer Entzauberung der Kunst: Einerseits wird der gesellschaftliche Bereich der Kunst zu einem soziologisch erforschbaren Gegenstand wie andere auch erklärt; andererseits lässt sich mit der Ausweitung der netzwerkartigen Schöpfungszone auch der "Kult des Individuellen" (Glauser 2013: 23) problematisieren und die damit verbundene singulär-geniale Kreativität des künstlerischen Subjekts dekonstruieren:

"Works of art, from this point of view, are not the products of individual makers, rartists who possess a rare and special gift. They are, rather, joint products of all the people who cooperate via an art world's characteristic conventions to bring works like that into existence." (Becker 2008: 35, Hervorhebung im Original)

Neben dem Augenmerk auf die kooperativen Verbindungen wird in diesem Zitat auch der Fokus auf die Konvention als zweites zentrales Moment künstlerischer Produktion deutlich. Damit sind all diejenigen Übereinkünfte gemeint, "die nicht jedes Mal von Neuem ausgehandelt werden müssen " (Danko 20I2: 66), aber die Produktion eines Kunstwerks im Sinne einer Kooperation bedingen und ermöglichen. Konventionen sind quasi sedimentierte, komprimierte Wissensbestände, die - einst sozial ausgehandelt und nun fixiert - den Produktionsprozess strukturieren, stabilisieren und effizient halten. Es handelt sich um lebendige, aber bewährte "Selbstverständlichkeiten, über die nicht zwangsläufig nachgedacht wird» (Danko 2015: 90), die 
aber von der Forscher_in wirkungsvoll kommunikativ aufgebrochen und erklärungsbedürftig gemacht werden können, wenn die impliziten Regeln, Normen, Standardverfahren, Kanons und Traditionen einer Kunstwelt erforscht werden sollen. ${ }^{24}$

Die statische Konnotation, die im Wort "Konvention" mitschwingt, sollte nicht über Gebühr bemüht werden; genauso wie die mögliche Folgerung, dass Kooperationen und Konventionen Ausdruck von konflikt- oder reibungsfreien Aushandlungsprozessen voller Harmonie sind. Konventionen sind freilich dynamisch gedacht, sie können sich ändern und auf veränderte Umstände reagieren (Becker 2008: 59), gleichzeitig ihre stabilisierende Funktion aber beibehalten. Oftmals sind Konventionen Ergebnis langwieriger sozialer Verhandlungen, die von mit mehr oder weniger Macht ausgestatteten Akteuren zu eigenen Gunsten beeinflusst und installiert werden. Die Funktionen, die von Konventionen bereitgestellt werden, changieren zwischen loser Orientierung und zwingender Beachtung. Daraus folgert Becker, dass die Nicht-Beachtung bestimmter Konventionen nicht unbedingt das Misslingen eines Kunstwerks nach sich zieht, aber seine Herstellung deutlich umständlicher werden lässt:

"Conventions make collective activity simpler and less costly in time, energy, and other resources; but they do not make unconventional work impossible, only more costly and difficult. Change can and does occur whenever someone devises a way to gather the greater resources required or reconceptualizes the work so it does not require what is not available.« (Becker 2008: 35)

24 Innerhalb der französischen Wirtschaftssoziologie hat sich seit den I98oer Jahren mit der "Economie des conventions" eine sozialwissenschaftliche Forschungsbewegung formiert, die den Begriff der Konvention ebenfalls als zentralen theoretischen Ausgangspunkt zur Analyse ökonomischer Institutionen behandelt. Ähnlich wie bei Becker werden Konventionen als kollektive interpretative Rahmen behandelt, die Koordinations- und Evaluationspraktiken ermöglichen. Für eine umfassende Einführung siehe Diaz-Bone (2015). 
Der Wandel, also Genese, Veränderung und Niedergang von Kunstwelten ist nach Becker ein konstantes Merkmal (2008: 350). Wandel wird dabei in Form eines Kontinuums zwischen »drift" und "revolution« beschrieben: Solange Veränderungen in einer Kunstwelt so kleinschrittig und graduell ablaufen, dass die eingespielten Konventionen und Kooperationsmuster nicht gestört werden, befindet sich die Kunstwelt in einem Drift. Es ergeben sich geringfügige Abweichungen, z. B. in Form kleinerer Experimente, die aber keine großen Folgen zeitigen. Die Kunstwelt bleibt stabil. Für Becker ist der Drift der Normalzustand, insofern die minimalen Verschiebungen von der Kunstwelt weder semantisch etikettiert werden noch sich merkliche praktische Probleme im Betriebsablauf ergeben:

"No one is inconvenienced because someone else insists on doing things differently. No support personnel have to produce a new kind of material or perform in a wholly new and uncomfortable way. No audience has to pay more, to stay longer, or to exert itself in an unaccustomated way to enjoy the work. No one loses rank in a system of esteem or power [...].«(Becker 2008: 304)

Auf der anderen Seite des Kontinuums stehen Veränderungen, die die Standardaktivitäten innerhalb einer Kunstwelt viel stärker und fundamentaler beeinflussen, so dass sich daraus Konsequenzen in der netzwerkartig verschalteten Kunstproduktion und in den Produkten selbst ergeben. Kunstwelten halten zwar eine ganze Menge an Veränderungen aus, die fortlaufend an sie herangetragen werden, aber für Becker scheint es eine Art Kipppunkt oder Momentum zu geben, an dem sich einflussreiche Akteure auf die Seite einer neuen Kunstwelt schlagen. Ähnlich wie beim Begriff des Paradigmenwechsels von Thomas Kuhn (2015 [1962]) oder der nachhaltigkeitstheoretischen Fassung des Innovationsbegriffs ist es für Becker entscheidend, den Prozess zu verstehen, "by which participants ignore, absorb, or fight change, for those responses define the seriousness and extent of the change, which make it a revolution or something less dramatic." (Be- 
cker 2008: 308). An dieser Stelle zeigt sich, wie zentral das Moment der Kooperation bei Becker ist, denn ohne Kooperationsaktivitäten würde eine Kunstwelt aufhören zu existieren. Somit ist die Genese einer Kunstwelt entscheidend davon abhängig, wie gut und schnell sich Kooperationsbeziehungen entwickeln und verstetigen.

In Verbindung mit der Frage, wie Neues in der Kunst auftritt und sich verstetigt, ermuntert das Konzept der Kunstwelten zu einer soziologischen Ausweitung der Suchzone: Nicht die einsame Produktion, sondern die begleitenden Strukturen, ihre Reichweite, Beachtung und Umgehung werden interessant. Das Neue - und damit auch künstlerische Kreativität im Sinne eines Vermögens zur Schaffung von Neuem - wird weniger oder nicht nur in der künstlerischen Expressivität in Werk und Künstler_in an sich gesucht, sondern mehr in dem die Kunstwelt strukturierenden Geflecht aus Kooperationen und Konventionen. In diesem Zusammenhang weist Oliver Berli darauf hin, dass die Reichweite einer Konvention nicht nur in grammatischen, sondern auch in materiellen Objekten berücksichtigt werden muss: "Insbesondere in Form von Artefakten objektivierte Konventionen lassen sich nur schwer umgehen."(Berli 2017: 670) Die Arten des Umgangs und der Umgehung von Konventionen werden also relevant und eröffnen Fragen: Welche Strategien verfolgen Künstler_innen für den gewünschten Erfolg, welche Konventionen beachten sie wie weit und welche Kooperationen gehen sie notwendigerweise ein? Oder noch spitzer: Wie stellen Künster_innen reflexiv sicher, genügend Ressourcen und Unterstützung zu finden, um eine etwaige neue Konvention und die damit verbundenen Vorteile zu etablieren? Becker (2008: 34) versteht daher "any [artistic] work as the product of a choice between conventional ease and success and unconventional trouble and lack of recognition."

Aus diesem Punkt ergibt sich ein theoretischer Raum, den Becker mit einer Typologie verschiedener Künstler_innen füllt. Er unterscheidet je nach Wissen, Orientierung und Integration zwischen den "integrated professionals«, "mavericks«, "naive artists" und »folk artists«. Interessant sind hier vor allem die ersten beiden dieser Ideal- 
typen: Integriert ist Becker zufolge eine Künstler_in, wenn sie die konventionellen Regeln zur Produktion komplett internalisiert anwendet und vollständigen Zugriff auf die nötigen Ressourcen hat; damit ist sie in der Lage, kanonische Kunstwerke entlang der Regeln zu produzieren: "He would cause no trouble for anyone who had to cooperate with him, and his work would find large and responsive audiences. [...] Because they know, understand, and habitually use the conventions on which their world runs." (Becker 2008: 229)

Im Sinne des Kuhn'schen Paradigmas ließe sich diese Form der Kunstproduktion auch als "normal" bezeichnen (vgl. Hieber 20I2: 274). Mit den Mavericks bezieht Becker stärker das Element künstlerischer Devianz mit ein, wobei er sich hier implizit auf seine Vorarbeiten aus der Devianz- und Kriminalsoziologie beruft (vor allem Becker 1963). Mavericks (von Danko als "Abtrünnige« oder "Alleingänger" übersetzt) haben wie die Integrierten auch die Konventionen internalisiert und durchdrungen, verhalten sich aber distanzierter dazu und befinden sich tendenziell auch am Rand der jeweiligen Kunstwelt. In der Regel stehen sie für eigenwillige, unkonventionelle Kunst, Techniken oder Materialien, die mit den zeitgenössischen Konventionen gar nicht oder nur schwerlich in Anschluss zu bringen sind. Die Konnotation der pionierhaften Künstler_in, die »ihrer Zeit voraus« ist, zeitlebens verkannt wird und erst ex post als innovativ deklariert wird, ist merklich zwischen den Zeilen zu greifen.

Sicherlich sind die historischen und makrostrukturell informierten Ansätze von Luhmann und Bourdieu sozialtheoretisch deutlich weiter entwickelt. Sie lenken daher den Blick auf andere, oftmals weniger profane Aspekte der Kunstproduktion. Beckers Verständnis von Kunst als kooperativ organisierten Arbeitswelten, die auf gemeinsam geteilten Konventionen beruhen, hingegen gesteht individuellen Entscheidungen und nicht sozial determinierten Praktiken deutlich mehr Freiraum zu als beispielsweise Bourdieus Feldtheorie. Becker ist daher näher am praktischen Geschehen und der Mikroebene des Kunstmachens orientiert, wenngleich er auch kollektive Mechanismen miteinbezieht und dadurch an verschiedenen Stellen Mikro-Ma- 
kro-Brücken schafft. Wenngleich sich Becker meines Wissens nicht explizit auf Vertreter_innen des Pragmatismus' bezieht, stellt er eine gewisse Nähe zu pragmatistisch informierten Theorien her, die ich zum Ausgangspunkt nehmen möchte, um mein Verständnis von Kreativität darzulegen.

\subsection{Kreativität als kollektives Handeln}

In Anschluss an Becker möchte ich in diesem Abschnitt dem Phänomen der Kreativität näher kommen. ${ }^{25}$ Grundlegend für das vorgestellte Verständnis von Kreativität ist die Denkfigur von der Verbindung des bisher Unverbundenen. Einerseits kommt damit die basale Einsicht zum Ausdruck, dass das Neue nicht ex nibilo kreiert, sondern stets aus dem Alten abgeleitet wird. Andererseits wird dadurch deutlich, dass das Neue je nach Perspektive und Akteur unterschiedlich aufgefasst werden kann. Um diesen Gedanken fortzuschreiben, unterscheide ich drei verschiedene Seiten der Kreativität, auf denen jeweils unterschiedliche Praktiken der Neuheitsproduktion beobachtet werden können:

\section{Kontribution}

2. Exploration und Rekonstruktion

3. Symbolisation

Erstens die Seite der Kontributionalität, die die Regeln meint, nach denen neue Verbindungen als kreativ validiert werden. Denn nicht alle neue Verbindungen werden von Akteuren, die mit Deutungsmacht ausgestattet sind, als kreativ eingestuft. Die sozial ausgehan-

25 Um einen systematischen Einstieg in die ansonsten nur schwer zu überblickende und interdisziplinäre Kreativitätsforschung vorzunehmen, habe ich mich an den Darstellungen von Carsten von Wissel (2012), Reijo Miettinen (2006) und Robert Sternberg (1999) orientiert. 
delten Konventionen künstlerischer Originalität werden damit als Neuheitsgrammatik sichtbar, nach denen Neuerungen als kreativ, überraschend oder abweichend validiert werden. Zweitens die Seite der Exploration und der Rekonstruktion, welche im gegenseitigen Wechsel das praktische und oftmals methodische Hervorbringen von Neuerungen ermöglichen, seien sie noch so geringfügig und unscheinbar. Und drittens die Seite der Symbolisation, die die Produktion neuer Bedeutungen, Semantiken und Codes als separate Untersuchungseinheit behandelt, auf der insbesonderse Eigentumsund Verfügungsbeziehungen verhandelt und symbolisch markiert werden.

Die Kategorien der Neuheitsproduktion sind als analytische Idealtypen von Praktiken zu verstehen, die in der Theorie sicherlich trennschärfer erscheinen, als sie in der Unübersichtlichkeit der Welt, ineinander verschränkt oder verhakt, auftauchen. Grundlegend ist dabei das Verständnis von Andreas Reckwitz (2012: 25), der Praktiken definiert "als sich wiederholende und intersubjektiv verstehbare, körperlich verankerte Verhaltensweisen - auch im Umgang mit Artefakten $-[\ldots]$ in denen ein implizites Wissen verarbeitet wird und die immer auch die Sinne auf eine bestimmte Weise organisieren«. Die analytische Auffächerung der Praktiken berücksichtigt zudem den Zweifel, komplexe Prozesse (wie den der Musikproduktion) auf eine einzelne Form von Kreativität zurückführen zu können. Vielmehr scheint es mir notwendig, verschiedene Formen, Gewichtungen und Überschneidungen unterscheiden zu können. Ein theoretisches Konzept, das diesen Zweifel ernst nimmt, sollte es für die empirische Untersuchung leisten können, die spezifischen Unterschiede zu erkennen, einzufangen und in ein Verhältnis miteinander zu stellen. Da mit dem Kreativitätsbegriff zahlreiche Botschaften, Metaphern, Assoziationen und auch Wünsche verbunden sind, ist es zudem sinnvoll, den Untersuchungsgegenstand jenseits seiner mystifizierenden Seiten betrachten und mit analytischer Distanz beschreiben zu können.

Das vorliegende Konzept leitet sich aus der theoretischen Auseinandersetzung mit dem Begriff der Kreativität ab, welche sich in der 
soziologischen und sozialwissenschaftlichen Literatur seit den I990er Jahren vollzieht. Ich werde mich an der Literatur orientieren und die Grundannahmen für den jeweiligen Kreativitätsbegriffs skizzieren, diesen aber nur solange folgen, wie es das Verständnis von Kunst als kollektivem Handeln ermöglicht und nahelegt.

\subsubsection{Kreativität als Kontribution}

Kreativität lässt sich zunächst verstehen als gelungene neue Kontribution. Damit meine ich die Aufnahme eines Produkts in eine existierende soziale Sammlung, die durch erfolgreich erfolgte Validierung eines mit entsprechender Autorität ausgestatteten Akteurs vollzogen wird. Diesen sozialen Prozess der Aufwertung beschreibt der Kunsttheoretiker Boris Groys am Beispiel des modernen, sich durch Sammlungen auszeichnenden Museums. Da die räumlichen und finanziellen Ressourcen des Museums in der Regel begrenzt sind, werden durch die interne »Logik der Sammlung« Selektionskriterien bereitgestellt, die die Auswahl beziehungsweise den Ausschluss von Kunstwerken strukturieren. Wiederholungen und Ähnlichkeiten werden tendenziell marginalisiert, da im Sinne einer kunsthistorisch informierten Abfolge von Stilen und Epochen die Differenzen zwischen den Kunstwerken herausgestellt werden sollen. Diesen Prozess der Musealisierung analysierend folgert Groys aus der Logik der Sammlung daher weniger eine künstlerische Freiheit, sondern

»einen Zwang, anders und neu zu sein, der von der Sammlung auferlegt wird. Der Künstler muss das Neue produzieren, um in die Sammlung aufgenommen zu werden. Dieser Zwang wird besonders in der Moderne oft durch die Rhetorik der künstlerischen Freiheit verdeckt. [...] Die wahre Freiheit des Künstlers bestünde eigentlich darin, sowohl das Alte wie auch das Neue produzieren zu dürfen. Solche Freiheit aber hat es in der Moderne nie gegeben. Die Wiederholung des Alten wurde vielmehr als Epigonentum, als Kitsch oder, 
wie man heute sagt, als Kaufhauskunst bezeichnet - und damit des Museums verwiesen."(Groys 1997: 30-I).

Das Museum ist dadurch als derjenige gesellschaftliche Ort bestimmt, der klassischerweise die soziale Differenz zwischen Kunst und NichtKunst konstituiert und, so ließe sich mit Bourdieu ergänzen, damit auch die Hierarchie der Legitimität verschiedener Künste beeinflusst. Groys lenkt den Blick dadurch auf die Kanonisierungsregeln, die Kontributionen im Sinne ästhetischer Neuheit validieren und regulieren. Das Verhältnis von Konvention und Devianz, innerhalb dessen sich ein Kunstwerk unter den prüfenden Augen der Kurator_innen bewähren muss, wird so zu einem Treiber ästhetischer Produktion. Die Logik der Museumssammlung stellt eine verfestigte Konvention im Sinne Beckers dar, die Validierung durch das Museumskuratorium bedingt eine entsprechende Kooperation. Künstlerische Kreativität, so lässt sich in diesem Sinne weiterführen, besteht also in einer gelungenen Kontribution: das Prinzip der Neuheit führt zur planvollen Begutachtung des state of the art und zur Identifizierung einer künstlerischen Leerstelle, die für sich reklamiert und ausgefüllt werden kann (vgl. Groys 1992: 82). Das Werk wird mit der Sammlung in Verbindung gesetzt.

Die Kreativität der Kontribution zielt nicht auf die radikale Ausreizung oder Überwindung der Sammlung (beispielsweise ein Musikgenre), sondern auf die produktive Ausfüllung und eigene Platzierung innerhalb derselben - auch dann, wenn die ästhetische Grammatik dazu auffordert, sich selbst zu problematisieren oder zu negieren, wie in der historischen Avantgarde (vgl. Hieber 20I2). Selbst die avantgardistischen Praktiken der radikalen Neuheitsproduktion lehren, innerhalb eines vorgegebenen Rahmens die richtigen ästhetischen Objekte zu finden und sie mit der passenden Dosis Neuheit zu verbinden. Kontributionalistische Praktiken erfordern daher eine gewisse konventionale Grundlage, innerhalb der sich Künstler_innen verorten und auf die sie Beiträge adressieren können. Dabei ist Groys' Museumsverständnis freilich stark an einem traditionellem und 
eher schematischem Kunstbegriff orientiert, der auf die Selektionsfunktion und die Machtposition der Kurator_innen als gatekeeper setzt. Die soziogrammatische Seite der Neuheitsvalidierung und die daraus resultierende Interaktion werden besonders betont, es ist allerdings zweifelhaft, inwieweit künstlerische Kreationen wie Musik, Filme oder Texte ausschließlich als zielgerichtete Bewerbungen auf eine etablierte Sammlung hin verstanden werden können. Als alleinige Orientierung der Neuheitsproduktion sind kontributionalistische Praktiken für die analytische und empirische Untersuchung meines Erachtens nicht ausreichend - die Triangulation mit anderen Seiten der Kreativität ist notwendig.

\subsubsection{Kreativität als Exploration und Rekonstruktion}

Die zweite Seite der Kreativität beinhaltet zwei ineinandergreifende Modi der Neuheitsproduktion: Exploration und Rekonstruktion. Zunächst zur Exploration, die ich in Anlehnung an Heinrich Popitz' anthropologisch gefärbtem Zugang näher ausführe. Popitz reiht sich dafür in die Tradition derer ein, die annehmen, dass Menschen inhärent mit Kreativität ausgestattet sind. Popitz bezeichnet dieses kreative Vermögen als Allozentrik:

»Es ist vor allem diese Begabung, die den Menschen über das Vorgefundene hinausträgt. Weil er fähig ist, das Anderssein, die Alterität, the otherness' des Außer-ihm-Seienden zu ergründen, weil er diese dezentrierende Wende vollziehen kann, ist er in der Lage, nicht im Gegebenen unterzugehen und die Welt im Licht des Anders-Möglichen zu sehen. Die Kategorie des Andersseins macht ihn kreativ.» (Popitz 2000: IOO)

Innerhalb des Bereichs der Phantasie sieht Popitz mit dem Suchen, Gestalten und Sinnstiften drei verschiedene Wege der Urheberschaft, die zwar unterschiedliche Formen annehmen, aber als Kräfte offen 
füreinander sind und auch synergetische Effekte haben können. Er arbeitet stark mit Metaphern und Assoziationen, was seinen Text grundsätzlich inspirierend, teilweise vielleicht etwas undifferenziert macht. Für die Phantasie wählt er als Metapher die »Vergegenwärtigung des Verborgenen" und das "Eindringen in Verborgenes" (2000: 92), verortet »den Weg ins Verborgene« sogar als "Grundmuster der Phantasie« (2000: 107).

Mich interessiert im Folgenden die grundlegende Figur, die Popitz als »Strategien des entdeckenden Erkundens« bezeichnet und die er insbesondere beim Handeln kleiner Kinder beobachtet. Prozesse des Suchens, Erforschens, Stöberns, Aufspürens, Ausprobierens, Auskundschaftens, Entdeckens und Fragens stehen hier im Mittelpunkt. Ich fasse diese unter dem Stichwort der Exploration zusammen, mit dem verdeutlicht werden soll, dass es sich hier um eine Praxis des Öffnens handelt, die dem Vorhandenen Neues abringt. Die Neuerung, die durch explorative Praktiken entsteht, ist oftmals, aber nicht nur, eine serendipity im Sinne Robert Mertons (Merton/Barber 2004), also die Entdeckung einer Sache, die eigentlich nicht gesucht beziehungsweise an einem unvermuteten Ort gefunden wurde. Was mit dem Neuen passiert, ist dagegen eine nachgeordnete Angelegenheit - mit dem Begriff der Exploration sind zunächst einmal nur die öffnenden Praktiken selbst akzentuiert, die das Knüpfen neuer Verbindungen vorbereiten.

Explorative Praktiken stehen denen der Rekonstruktion entgegen, die dementsprechend als Schließung zu verstehen sind. Exploration und Rekonstruktion begreife ich als Gegenstücke einer changierenden, hin- und herschwingenden Bewegung, die als Experiment gekennzeichnet werden kann. Von Hans Joas stammt dabei die einflussreiche Formulierung des Kreativitätsbegriffs auf Basis der Rekonstruktion. Auch er sieht Kreativität als immanente Dimension menschlichen Handelns, wenngleich er diese nicht anthropologisch, sondern handlungstheoretisch und in der Tradition des amerikanischen Pragmatismus' fundiert. Für Joas steht die Rekonstruktion eines unterbrochenen Handlungszusammenhangs als kreative Leis- 
tung im Vordergrund. Er beruft sich an zahlreichen Stellen auf John Dewey, der den Begriff der Erfahrung (experience) pragmatistisch reformuliert hatte. Die Unabgeschlossenheit einer Handlung, egal wie profan sie sein mag, ist hier Deweys Ausgangspunkt:

"Oftentimes [...] the experience had is inchoate. Things are experienced but not in such a way that they are composed into an experience. There is distraction and dispersion; what we observe and what we think, what we desire and what we get, are at odds with each other. We put our hands to the plow and turn back; we start and then we stop, not because the experience has reached the end for the sake of which it was initiated but because of extraneous interruptions or of inner lethargy.» (Dewey 1934: 35, Hervorhebungen im Original)

Abgeschlossene Handlungen hingegen bringen Dewey zufolge eine Erfahrung besonderer Qualität hervor, die Joas (1996: 205) als »Ganzheitlichkeit « versteht. Es geht also um eine perfekte, das heißt in diesem Sinne abgeschlossene, zu Ende gebrachte und daher erfüllende Erfahrung:

"In contrast with such experience, we have an experience when the material experienced runs its cours to fulfilment. Then and then only is it integrated within and demarcated in the general stream of experience from other experience. A piece of work is finished in a way that is satisfactory; a problem receives its solution; a game is played through; a situation, whether that of eating a meal, playing a game of chess, carrying on a conversation, writing a book, or taking part in a political campaign, is so rounded out that its close is a consummation and not a cessation. Such an experience is a whole and carries with its own individualizing quality and self-sufficiency. It is an experience." (Dewey 1934: 35, Hervorhebungen im Original)

Joas setzt an diesem Punkt an, indem er die Fähigkeit zur Überbrückung eines unterbrochenen Handlungszusammenhangs als Krea- 
tivität der Rekonstruktion begreift und zum zentralen Punkt seiner Handlungstheorie ausbaut. Die "Gewohnheitserschütterung", um eine treffende Formulierung von Heidi Salaverría (2007: 104) zu zitieren, wird bewältigt, indem die problematische Situation auf eine neue, bisher ungekannte und daher auch nicht routinierte Weise überbrückt wird:

"Gelingt es durch veränderte Wahrnehmung die Handlung umzuorientieren und damit wieder fortzufahren, dann ist etwas Neues in die Welt gekommen; eine neue Handlungsweise, die sich stabilisieren und selbst wieder zur unreflektierten Routine werden kann. Alles menschliche Handeln wird so im Blick der Pragmatisten in der Spannung zwischen unreflektierten Handlungsgewohnheiten und kreativen Leistungen gesehen. Das heißt zugleich aber auch, dass Kreativität hier als Leistung innerhalb von Situationen, die eine Lösung fordern, gesehen wird, und nicht als ungezwungene Hervorbringung von Neuem ohne konstitutiven Hintergrund in unreflektierten Gewohnheiten.« (Joas I996: 190)

Der pragmatistische Zugriff ist grundsätzlich sehr hilfreich, da er die mikrologische Ebene des Handelns erschließt und ähnlich wie Popitz auch kleine, profan erscheinende Handlungsweisen berücksichtigt. Bei Joas ist die Schwelle zur Kreativität bereits so niedrig gelegt, dass daraus sein Anspruch resultiert, "für alles menschliche Handeln eine kreative Dimension zu behaupten (Joas 1996: 15). Diese Stelle ist bei Joas missverständlich formuliert, denn es geht Joas in meiner Lesart nicht darum, für sämtliche Handlungen Kreativität zu behaupten, selbst wenn sie beispielsweise bereits in Routinen eingebettet sind und lediglich unreflektierter Wiederholung folgen - sondern darum, das menschliche Handeln an sich in einem pragmatistischen Sinne als kreativ zu verstehen, insofern es immer wieder an Probleme, Herausforderungen und unterbrochene Zusammenhänge stößt, denen 
es kreativ, mit neuen Lösungsansätzen begegnet. ${ }^{26}$ Vor allem folge ich dabei der pragmatistischen Hauptfigur von Joas und Dewey, die in der Rekonstruktion des unterbrochenen oder als unterbrochen wahrgenommenen Zusammenhangs besteht. Als Gegenstück zur Exploration bringen die Praktiken der Rekonstruktion wieder zusammen, überbrücken, schließen und stellen fertig, sie verbinden, was unverbunden erscheint.

\subsubsection{Kreativität als Symbolisation}

Schließlich möchte die dritte Seite der Kreativität skizzieren, deren Modus der Neuheitsproduktion sich an der »symbolic creativity « nach Paul Willis (1993, 20I4 [1978]) orientiert und im Bereich symbolischer Vorherrschaft operiert. Ähnlich wie die geschilderten Praktiken der Exploration und der Rekonstruktion richtet auch Willis sein Augenmerk auf profane Situationen des Alltags, die er ethnografisch im Medienumgang mit britischen Jugendlichen und jungen Erwachsenen aus der Arbeiter_innenschicht und in Subkulturen erforscht hat.

Willis gilt als wichtiger Vertreter der britischen Cultural Studies, die die Kulturindustriethese Horkheimers und Adornos empirisch zu entkräften und zu überwinden suchen, indem sie die vermeintliche Passivitität des Konsums und Dichotomien wie die zwischen fine arts und low culture angreifen. Adorno und Horkheimer zufolge führe kulturindustriell produzierte Massenware wie populäre Musik

26 Der weitreichende handlungs- und auch sozialtheoretische Anspruch des Pragmatismus' und insbesondere seiner Fortschreibung durch Joas wird bezüglich der avisierten Allgemeingültigkeit freilich stark kritisiert. Richard Münch beispielsweise bemängelt, dass der in den USA entstandene Pragmatismus seine eigene partikulare Kulturgebundenheit nicht genügend reflektiert und damit die Kontingenz menschlichen Handelns unterschätzt. Münch verordnet Bescheidenheit und kritisiert (2002: 34I), "dass uns der Pragmatismus kein allgemeingültiges Modell der Kreativität bietet, sondern allein ein Modell mit eingeschränkter Geltung, das nur im Rahmen eines allgemeineren Modells der Kreativität eine Rolle spielen kann." 
oder Jazz zu einer einheitlichen Kultur und einem Massengeschmack, der die ewige Wiederholung des Gleichen bedinge: „Ewig grinsen die gleichen Babys aus den Magazinen, ewig stampft die Jazzmaschine." (Horkheimer 1987: 175) Die von Adorno als »leichte Musik« abgetane Pop- und Schlagermusik lasse aufgrund der serialisierten Form und ihrer Allgegenwart sogar die Rezeptionsfähigkeit abstumpfen (Adorno 2003: 19). Um diese pessimistische Sicht zu überwinden, interessiert sich Willis für die Frage, wie in Gruppen neue Bedeutungen auftauchen, kollektiv ausgehandelt und damit kulturindustrielle Produkte auf symbolische Weise angeeignet werden. Diese Praktiken der Symbolisation, wie ich sie im Folgenden nenne, verweisen auf einen Modus der Neuheitsproduktion, der zwar profan erscheint. Jugendliche, so weist Willis in seiner Studie zu Rocker- und Hippiekulturen aber nach, konsumieren nicht einfach stumpf kulturindustrielle Produkte, sondern kleiden diese in diverse Rituale, zweckentfremden sie entgegen ihrer Bedienungsanleitungen oder drehen auf andere Weise die mitgelieferten Bedeutungen um. Dadurch verwandeln sie die eigentlich abgeschlossenen Massenprodukte zu einer aktiv schöpfbaren Ressource für symbolisch vermittelte Formen des Ausdrucks oder der Kritik, wie Willis am Beispiel des Kosmetik- und Drogeriesortiments zeigt:

»These cultures work through profane materials: simple functional commodities, drugs, chemicals and cultural commodities exploitatively produced by the new consciousness industry`. And yet from the rubbish available within a preconstituted market these groups do generate viable cultures, and through their work on received commodities and categories, actually formulate a living, lived out and concretized critique of the society which produces these distorted, insulting, often meaningless things." (Willis 20I4: 4-5, Hervorhebung im Original)

Komplementäre Praktiken des Medienkonsums seien hier als weiteres Beispiel angeführt: Die Rockergruppe bevorzugt Singles aus dem 
Rock'n'Roll der "goldenen" I95oer Jahre, die sie in Jukeboxen abspielen und dadurch in eine präferierte Reihenfolge bringen lassen. LP's hingegen sind bei ihnen verpönt, da man sich auf die vorgegebene Reihenfolge der Stücke einlassen muss und dies als Kontrollverlust erlebt. Neben typischen Praktiken wie das Fachsimpeln über Musikstücke oder das Choreografieren neuer Tanzelemente, stößt Willis auf ein beliebtes maskulines Spiel in der Gruppe, das darin besteht, eine Single in der Jukebox anzusteuern, sich schnell auf das Motorrad zu schwingen und eine Runde um den Block zu rasen, bevor die Platte ihr Ende erreicht (Willis 20I4: 50). Bei den Hippies hingegen interessiert man sich mehr für das bewusste, kontemplative Durchdringen einer LP, um deren Sinn, musikalische Aussage und roten Faden nachzuvollziehen. Es geht nicht um das impulsive und rasante Erleben von Musik wie in der Rockergruppe, das diese durch entsprechende Praktiken stimuliert und zelebriert - sondern um eine intensive Hörerfahrung und ein nuanciertes Musikverständnis, das in langwierigen Diskussionen kommunikativ ausgelotet wird und oftmals auf Drogen induzierten, synästhetischen Hörerfahrungen beruht. Das von der Hippieszene favorisierte Format ist dementsprechend das Konzeptalbum, das über mehrere Stücke hinweg der Ausformulierung einer musikalischen Idee oder eines thematischen Programms folgt. Singles erlebt man als kurz und limitiert (Willis 20I4: 206; vgl. Fischer 20I3: 26).

Die symbolische Kodifizierung komplementärer Praktiken, die hier in kollektiven Ritualen vollzogen wird, stellt nach Willis eine Ressource der Neuheitsproduktion dar, die für die vorliegende Untersuchung im Sinne von Praktiken der Symbolisation verfolgt werden soll. Aus dieser Blickrichtung erscheint die Profanität jener Praktiken nachrangig oder dass vergleichbare Gruppen ähnliche Praktiken entwickeln, denn der Status der Neuheit adressiert nicht eine gesamtgesellschaftliche Ebene, sondern die Prozessualität und das transformative Potential der Polysemie von bereits (kulturindustriell) vorgeprägten Produkten: 
This is the production of new (however small the shift) meanings intrinsically attached to feeling, to energy, to excitement and psychic movement. [...] Symbolic creativity can be seen as roughly equivalent to what an all-embracing and inclusive notion of the living arts might include (counterposed, of course, to the current exclusions of 'art'.) Symbolic creativity may be individual and/or collective. It transforms what is provided and helps to produce specific forms of human identity and capacity. Being human — human be-ing-ness means to be creative in the sense of remaking the world for ourselves as we make and find our own place and identity." (Willis I993: II, Hervorhebungen im Original)

Willis plädiert mit seiner symbolischen Kreativität dafür, die Interdependenz zwischen Akten des Konsumierens und Produzierens ernst zu nehmen, ohne die Relevanz kulturindustrieller Strukturen vollständig zu negieren. Symbolisierende Praktiken der Neuheitsproduktion betonen die verschiedenen Techniken und Rituale zur Freisetzung neuer Bedeutungen, die komplementär, überschreibend oder als Angriff auf hegemoniale Strukturen angelegt sind. Sie arbeiten also vorwiegend auf der Ebene symbolischer Vorherrschaft und dienen dazu, sich etwas Fremdes zu Eigen zu machen, es beispielsweise durch eine neue Anordnung oder neue Relationen zu transformieren und damit an seine eigene Identität zu binden. Dieser Modus der Neuheitsproduktion wird also dazu verwendet, über Fremdes - zumindest symbolisch - nach eigenen Vorstellungen zu verfügen und Kontrolle zu erhalten.

In einer kurzen Zusammenfassung möchte ich festhalten, dass ich Neuheit als zugeschriebene Eigenschaft von Objekten oder Handlungen verstehe. Kreativität hingegen verstehe ich als das soziale Vermögen, die Eigenschaft der Neuheit im Bestehenden zu sehen, zu forcieren und herauszuarbeiten. Kreativität steht damit als Sammelbegriff 
für die verschiedenen Praktiken der Neuheitsproduktion, die ich in meinem Verständnis hinsichtlich Kontributionalität, Experimentalität und Symbolizität differenziere: Während es bei kontributionaler Neuheit um ein Objekt geht, das in einer Sammlung platziert wird und damit eine neue Verbindung zwischen den Elementen entstehen lässt, rücken mit der experimentellen Neuheit die Praktiken der Exploration und Rekonstruktion in den Vordergrund, mit denen einem bestehenden Objekt eine neue Seite, ein neuer Aspekt abgerungen wird. Die neue Verbindung wird also auf Grundlage von Entdeckungs- und Überbrückungstechniken geknüpft. Der Begriff der symbolischen Neuheit hingegen betont, mit welchen symbolischen Kodes die neue (kontributionale oder experimentelle) Verbindung in neue Praktiken gekleidet, mit Bedeutung besetzt und dadurch angeeignet wird. Als Innovation schließlich verstehe ich das Phänomen, wie Neuheit sich gesellschaftlich niederschlägt, nachhaltig verfängt und ausbreitet sowie die bis dahin bestehenden Strukturen ergänzt, verdrängt oder auf andere Weise transformiert.

Nach dem Problemaufriss und der theoretischen Vertiefung aus den ersten beiden Kapiteln möchte ich nun im historischen Teil der Arbeit zeigen, wie sich das Sampling als Innovation im 20. Jahrhundert technisch entwickelt, soziostrukturell verbreitet und in neuen ästhetischen und rechtlichen Praktiken verankert hat. Dafür skizziere ich in Kapitel 3 entlang diverser Schübe gesteigerter technischer Reproduzierbarkeit zunächst die Geschichte des Samplings. Danach zeige ich in Kapitel 4, wie das juristische System mit Akten der urheberrechtlichen Propertisierung reagiert und wie sich daraus ein akademischer Diskurs einer stärker empirisch orientierten Urheberrechtsforschung ergibt. 
TEIL 2 - HISTORIE 



\section{Historische Entwicklung von Sampling im 20. Jahrhundert}

Die Entwicklung der musikalischen Praxis des Samplings lässt sich erzählen als eine Innovationsgeschichte des 20. Jahrhunderts, welche eng an die Möglichkeiten der technischen Reproduzierbarkeit von Tönen gebunden ist und über die Kunst hinaus deutliche Beziehungen zu Wirtschaft, Recht, Wissenschaft und Technologie aufweist. Bevor sich in den I980er Jahren das digitale Sampling innerhalb der Popmusik durchsetzen konnte und innovative Folgen in wirtschaftlichen, rechtlichen und künstlerischen Zusammenhängen sichtbar wurden, traten diverse analoge Vorläuferbewegungen auf. In diesen wurden in künstlerischen Experimenten ästhetische Praktiken, Konventionen und klangliche Welten schon erkundet und erprobt, welche dann in den I980er Jahren beim digitalen Sampling Anwendung fanden, sich verstärkten und ausdifferenzierten (vgl. Fischer 2013).

Um ein grundsätzliches, medien- und technikhistorisch informiertes Verständnis von der Steigerung technischer Reproduzierbarkeit und ihrer rechtlichen Einhegung zu erhalten, werden die Hintergründe des analogen Samplings in drei Kapitelabschnitten skizziert. Im ersten Abschnitt soll dargestellt werden, wie die Speicherung und Verfügbarmachung von klanglichen Informationen ab dem Ende des 19. und zu Beginn des 20. Jahrhunderts in Verbindung mit einigen künstlerischen, technischen, rechtlichen und wissenschaftlichen Entwicklungsschüben stand, die im Zusammenhang mit dem Sampling gesehen werden können, aber damals noch eher verstreut blieben. Nach dem Zweiten Weltkrieg, so der zweite Abschnitt, verdichteten sich die Anstrengungen und institutionalisierten sich in unterschiedlichen Kunstwelten, die sich an verschiedenen geografischen und 
gesellschaftlichen Orten ansiedelten. Technische Reproduzierbarkeit von Klang, so wird im dritten Abschnitt schließlich gezeigt, wurde nach und nach für immer mehr Bevölkerungsgruppen zugänglich und bildete die soziotechnische Umgebung, innerhalb derer sich die moderne Form des Samplings herausbildete: zuerst durch die Rekombination von Ausschnitten analoger Abspielmedien wie Schallplatten und Tonbändern, später durch die Übertragung dieser bereits konventionalisierten Praktiken auf digitale Sampler.

\subsection{Steigerung technischer Reproduzierbarkeit und vereinzelte künstlerische Experimente (1878-1945)}

Die Steigerung technischer Reproduzierbarkeit lässt sich anhand der zunehmenden Ausdifferenzierung von Verfahren zur Speicherung, Vervielfältigung und Verfügbarmachung von Klängen illustrieren, die im ausgehenden I9. Jahrhundert beginnt und damit vergleichbaren Verfahren für visuelle Medien wie Bild und Text deutlich hinterherhinkt (Schrage 2007: I4I). Mit der Patentierung des Phonographen durch Thomas Edison (1878) und der Weiterentwicklung zum Grammophon durch Emil Berliner (1887) ergaben sich bisher ungekannte Möglichkeiten zur Fixation, Repetition, Manipulation und auch Transportation der eigentlich flüchtigen auditiven Reize (Katz 2004). Anfangs wurde der Phonograph als talking machine, als Diktiergerät im Büroeinsatz eingesetzt, erst später zur Aufnahme von Musik verwendet. Die Klangqualität wurde kontinuierlich durch die Entwicklung neuer Aufzeichnungsmedien verbessert. Die physische Materialität der Kopiervorgänge war anfangs noch prägend: Erst arbeitete man mit Stanniolwalzen, dann mit tellerförmigen Blechplatten, die zuerst an der Oberfläche mit Wachs bestrichen, später dann mit Nickel überzogen wurden. Während es zunächst gelang, Sprache und andere Umweltklänge in ihrer klanglichen Originalität auf einem 
Medium reproduzieren zu können, wurden die Nickelplatten um I892 herum selbst als Aufnahmenegativ reproduzierbar. Damit gelang es, das Medium inklusive seiner eingeschriebenen Klanginformationen ohne weiteren Klangverlust seriell zu kopieren (Burow 200I): Nicht nur die Umwelt konnte nun also mimetisch kopiert werden, sondern auch der Tonträger selbst.

Die gesteigerte technische Reproduzierbarkeit wirkte sich innerhalb weniger Jahre auch auf die Produktion von Kunst und Musik aus. Mit dem Speichern ergaben sich auch Praktiken des Sammelns, Sortierens und Archivierens. ${ }^{27}$ Mehrere tausend phonographische Aufzeichnungen von Volksliedern beispielsweise wurden bereits bis zum ersten Weltkrieg vom ungarischen Komponisten Béla Bartók gesammelt. Diese frühen musikethnologischen Unternehmungen im osteuropäischen und arabischen Raum beeinflussten auch Bartóks kompositorische Arbeit. Mithilfe der Phonographie ließen sich laut Bartók die klanglich-materiellen Nuancen der Folklore besser dokumentieren als über den Umweg durch die Notation, weil ihre klangliche Originalität eingefangen und in der Wiederholung des Abspielens leichter verglichen werden konnte (Bartók I957 [1936]).

Ab Beginn des 20. Jahrhunderts konnten Schallwellen auch elektromagnetisch umgewandelt werden, was den Aufbau des Hörfunks befeuerte. Es entwickelte sich eine Bewegung privater Bastler_innen (Fickers 2006), die wellenreitend die Senderskala nach fremden Sendern absuchten und dabei auf "Fiepen und Rauschen, das zufällige Nebeneinander von Sprache, Musik und Geräusch auf dem Wellenband « (Föllmer 2003: 83) stießen. Auch bei der Künstlergruppe der

27 Die Praktiken des Sammelns, Sortierens und Archivierens von Zeitungsartikeln, die ausgeschnitten und nach bestimmten Ordnungsprinzipien aufgeklebt wurden, wurden Ende des I9. Jahrhunderts von Dienstleistern der Medienindustrie professionalisiert und industrialisiert. I879 wurde in Paris das erste Büro für Zeitungsausschnitte gegründet, das Informationen zu bestimmten Themen bündelte und dadurch (vergleichbar mit einem Pressespiegel) für eine interessierte Kundschaft aufbereitete. Auch internationale Zeitungen konnten in dem sich immer stärker ausdifferenzierenden Zeitungsmarkt berücksichtigt werden. Wenige später eröffnete in Berlin ein vergleichbares Ausschnittbüro (Heesen 2006). 
italienischen Futuristen war man von den fremden Klängen des Radios und der bebenden Großstädte fasziniert: Im Manifest »L'arte dei rumori« forderte der futuristische Künstler Luigi Russolo, die Geräusche von Zügen, Motoren, Maschinen und andere industriell-urbane Klänge zu speichern und zu einer Geräuschmusik zu kombinieren (Russolo I986 [19I3]). Ähnliche Forderungen brachten dann in der zweiten Hälfte der I930er Jahre die Komponisten Edgar Varèse und John Cage ein in den sich langsam bildenden ästhetischen Diskurs um die technologische Zukunft der Musik. Sie forderten, die klangliche Limitierung klassischer Musikinstrumente zu überwinden und verstanden Musik als Organisation von Klängen. Cage phantasierte sogar von einem Phonographenquartett, welches Regenprasseln, Lastwagenbrummen und den menschlichen Herzschlag miteinander kombinieren und die Geräusche wie auf Musikinstrumenten kontrollieren könnte (Cage 1987 [1937]).

In den I920er Jahren entwickelten sich weitere Aufzeichnungsmethoden und mit ihnen künstlerische Strategien der Klangbearbeitung. I923 schlug der ungarische Maler und Fotograf László Moholy-Nagy vor, "aus dem Grammophon als aus einem Reproduktionsinstrument ein produktives zu schaffen, so dass auf der Platte ohne vorherige akustische Existenzen durch Einkratzen der dazu notwendigen Ritzschriftreihen das akustische Phänomen selbst entsteht." (Moholy-Nagy 1989 [1923]: 53). Und der Schriftsteller Bertolt Brecht, seinerseits vor allem aus politischen Gründen interessiert an den technischen Möglichkeiten des Radios, bemängelte in seiner Radiotheorie die Asymmetrie zwischen Sender und Empfänger. Stattdessen wollte Brecht (1967 [1932]: 129) den Rundfunk umfunktionieren und forderte, ihn "aus einem Distributionsapparat in einen Kommunikationsapparat zu verwandeln. [...] also den Zuhörer nicht nur hören, sondern auch sprechen zu machen und ihn nicht zu isolieren, sondern ihn auch in Beziehung zu setzen."

Der Aufstieg des Radios etablierte Rundfunkanstalten als Akteure mit eigenen Interessen, die nicht mit denen von Autor_innen und Verleger_innen deckungsgleich oder ihnen sogar entgegengesetzt 
waren. 1922 beispielsweise war die British Broadcasting Company (BBC) in Großbritannien von britischen und US-amerikanischen Geräteherstellern gegründet worden, um den Verkauf von Radiogeräten voranzutreiben und dafür ein eigenes Radioprogramm anzubieten. Die Schallplatten, die in diesen Programmen ausgestrahlt wurden, senkten natürlich die Kosten: Statt eine Band oder eine andere Formation für Liveauftritte zu bezahlen, konnten die Radio-DJs und -moderator_innen die bereits auf Tonträgern fixierte Musik abspielen, zwischendurch eine Anekdote erzählen oder Werbung machen, was deutlich günstiger war als Live-Musiker_innen zu engagieren. Die Auszahlung von Tantiemen für diese öffentliche Schallplattendarbietung musste allerdings erst durch Vertragsverhandlungen und die Einbeziehung von Verwertungsgesellschaften konfiguriert werden - anfangs vertraten die Radiostationen nämlich die Ansicht, mit dem Kauf einer Schallplatte sei die öffentliche Nutzung via Radio bereits abgegolten (Becker 2008: I7I; Dommann 20I4: I87-I96).

Die Rundfunktechnik hatte von Beginn ihres Einsatzes nicht nur die ästhetische Funktion, Töne zu übertragen und damit ein Publikum zu unterhalten, sondern freilich auch raumüberwindende und geradezu grenzüberschreitende Implikationen. Während der Rundfunk in Europa strengen lizenzrechtlichen Bestimmungen unterlag und von öffentlich-rechtlichen Behörden territorial kontrolliert wurde, fehlte in den USA ein solches System nahezu vollständig. Dies hatte zur Folge, dass sich dort bereits in den I920er Jahren werbefinanzierte, kommerzielle Programme rasch ausbreiteten und flächendeckend etablierten. Werbeindustrie und Rundfunkstationen gingen dadurch eine produktive, wirtschaftlich äußerst rentable Konvergenz miteinander ein. In Europa hingegen war die Situation restriktiver: Hier war der Äther stärker kontrolliert und aufgrund der nationalstaatlichen Grenzen teilweise fragmentiert. Dies führte nach dem Zweiten Weltkrieg durch Ausnutzung rechtlicher Schlupflöcher zwangsläufig zu räumlichen Umgehungsstrategien, um den territorialen Kontrollen und Einflussbereichen der Behörden zu entgehen: Verschiedene Radiosender siedelten sich beispielsweise 
in Kleinstaaten wie Andorra oder Monte Carlo an, sendeten aber gezielt nach Frankreich. Dadurch konnten sie Steuern sparen und die Sendereglementierungen umgehen. Eine vergleichbare Strategie verfolgten die sogenannten "Piratensender", die vor der britischen Küste von Schiffen oder verlassenen Seefestungen aus sendeten - unter anderem um urheberrechtliche Tantiemen zu vermeiden (Mrozek 2019: 382-393).

Neben dem Rundfunk war es vor allem die Nähe zum Film und seiner Montagetechnik, die in den I920er Jahren zur Verwendung von vorgefundenen Klängen anregte. Der Berliner Filmregisseur Walter Ruttmann nutzte das damals gebräuchliche Lichttonverfahren, welches für den aufkommenden Tonfilm ausgeklügelt worden war, für seine Großstadthommage »Weekend «. Das 1930 erstmals im Hörfunk gesendete Stück lässt sich demgemäß auch charakterisieren als Montage von diversen vorgefundenen Großstadtgeräuschen wie Taubengurren, dem Stakkato der Schreibmaschinen oder dem Röhren der Straßenbahn. Ruttmann übertrug das Montageverfahren aus dem Film auf die auditive Ebene und schuf durch Ausschneiden und Aneinanderkleben von Bandstücken eine rund elf Minuten lange "photographische Hörkunst ", die ein Berliner Wochenende klanglich nacherzählt - und dabei mit zahlreichen Anspielungen gespickt ist: So inszeniert Ruttmann beispielsweise den "Ausklang" des Wochenendes, indem er das Gläserklirren beim Zuprosten, das Läuten von Tierglocken und eines Kirchturms direkt hintereinander schneidet, dicht gefolgt vom schrillen Klingeln des Weckers, der jäh den Arbeitsbeginn am nächsten Morgen einläutet (Ruttmann 1994 [1929]).

Das aus dem Film stammende Lichttonverfahren blieb ein Nischenmedium, das sich nicht nachhaltig in der Medienindustrie etablieren konnte und auch als Verfahren in der Avantgardekunst nicht weiter verfolgt wurde. Die ihm zu Grunde liegende fotoelektrische Speicherung von Informationen inspirierte trotzdem zur Entwicklung eines Instruments, das aufgezeichnete Klänge kontrolliert in neuem Arrangement wiedergeben konnte. Die von Edwin Welte entworfene »Lichtton-Orgel« beispielsweise war eine von mehreren elek- 
trischen Orgeln, die Anfang der I930er Jahre präparierte Töne über eine Klaviatur ansteuern konnte (Davies 1996: 7). Auch Ruttmans "Weekend « übte, obwohl es vermutlich die erste mit dem modernen Sampling vergleichbare Geräuschmontage darstellt und damals im Zusammenhang des avantgardistischen Films als ernstzunehmender deutscher Beitrag diskutiert wurde, wenig Einfluss auf die damalige Kunstwelt aus, da es nach seiner Radiopremiere bis in die späten I970er Jahre verschollen blieb.

Neben dem Lichttonverfahren konnte sich ab den I920er Jahren nach und nach die Schallplatte durchsetzen, auf der sich mit Hilfe eines elektroakustischen Verfahrens Tonsignale speichern ließen. Als Material wurde zunächst Schelllack, nach dem Zweiten Weltkrieg Vinyl verwendet, wodurch sich zusätzliche klangliche Verbesserungen einstellten, aber auch die Portabilität des Mediums gesteigert wurde (Bartmanski/Woodward 2015: 6). Die zunehmende Kommodifizierung der Schallplatte in der entstehenden Kreativbranche der tonträgerbasierten Musikindustrie wirkte fortan auf die Produktion und damit die Klangästhetik der Musik zurück, indem unter anderem Länge und Tonumfang der Stücke durch die industrielle Herstellung und die materiellen Eigenschaften der Tonträger determiniert wurden. Damit sich die Schallplatte als Massenmedium etablieren konnte, waren natürlich auch entsprechende Abspielgeräte notwendig, die innerhalb des musikindustriellen Komplexes oft von Majors selbst entwickelt und verkauft wurden. ${ }^{28}$

Die Musikindustrie beruht damit ihrerseits zu großem Anteil auf serieller technischer Reproduzierbarkeit. In Form des Musikverlagswesens wurden bereits ab etwa 1900 industriell gefertigte Noten-

28 Ein gutes Beispiel für diese strategische Kopplung aus Abspielgeräten, -medien und -inhalten ist Decca Records, die ab I9I4 zuerst tragbare Grammophone herstellten, ab etwa 1930 dank eines erworbenen Presswerks als Label agierten, Künstler_innen aufbauten und Schallplatten distribuierten, sowie später Rundfunk-, Fernseh- und ab 1939 sogar Radar- und Funkgeräte entwickelten. Nach dem Zweiten Weltkrieg wurde zusammen mit dem deutschen Elektronikkonzern Telefunken die TelDec Schallplatten GmbH gegründet. 
drucke angeboten; mit der Schallplatte und dem Hörfunk schließlich konnte Musik in klingender Form aufTonträger gebannt beziehungsweise über den Äther in die Welt geschickt werden. Dieser Übergang von einem eigentlich auf Schriftlichkeit ausgerichteten hin zu Klang reproduzierenden Medien ist dabei auch von urheberrechtlichen Konfigurationen gekennzeichnet, denn mit sinkenden technischen Barrieren kamen weitere amateurhafte Akteure ins Spiel, die ihrerseits Aufnahmen kopierten und speicherten, ohne um Erlaubnis zu bitten. Bereits Anfang des 20. Jahrhunderts reagierte die Musikindustrie auf diesen Kontrollverlust mit öffentlichen Kampagnen zur Stärkung der "Originalaufnahmen" und mit Warnungen vor "Nachahmungen" minderer Qualität, delegierte den Schutz ihres Geistigen Eigentums aber auch rasch an technische Mittel: An den Beginn der Aufnahme wurde der Firmenname eingesprochen, der - ähnlich einem auditiven Wasserzeichen - die Kopierenden davon abhalten sollte, das komplette Stück mitzuschneiden. Diese wiederum reagierten freilich mit Umgehungsstrategien und ließen den Anfang einfach weg, woraufhin "die Fabrikanten dazu übergingen, den Sänger bereits in die Ansage des Titels hineinsingen zu lassen oder eine rakustische Schutzmarker während der Aufnahme anzubringen (Dommann 20I4: 76-7, Hervorhebung im Original).

Während sich ab den I93oer Jahren mit Ruttmann, Russolo, Cage und weiteren ein theoretisch-künstlerischer Diskurs und erste praktische Versuche am konkreten Klangmaterial einstellten, wurden in der Wissenschaft hoch abstrakte Ansätze entwickelt, die die mathematisch-naturwissenschaftlichen Grundlagen digitaler Reproduzierbarkeit legten. 1933 publizierte der sowjetische Elektrotechniker Wladimir Kotelnikow erstmals eine mathematisch exakte Formulierung des Abtasttheorems zur Speicherung analoger Signale. Offenbar in Unkenntnis von Kotelnikows Formulierung legten der Mathematiker Claude Shannon und der Physiker Harry Nyquist 1949 ihre Version des gleichen Theorems vor, die vor allem im Globalen Westen als "Sampling-Theorem" bekannt wurde und bis in die 1980er Jahre dominierte. 
In diesem Theorem wird die notwendige Abtastrate definiert, die notwendig ist, um ein Eingangssignal ohne Klangverfälschung abbilden zu können (Ackermann I99I: 77). So muss eine analoge Schallwelle mit einer mindestens doppelt so hohen Frequenz wie das menschliche Gehör abgetastet werden, welches etwa bis $20 \mathrm{kHz}$ reicht. Die in den 1980ern eingeführte $\mathrm{CD}$ beispielsweise hat eine Abtastrate von 44,I kHz, um eine klangliche Bandbreite bis $22,5 \mathrm{kHz}$ zu gewährleisten. Pro Sekunde werden also 44IOo Abtastungen vorgenommen. Je höher die Abtastrate, desto detaillierter kann auch das Frequenzspektrum abgebildet werden. ${ }^{29}$ Das Abtasttheorem formulierte damit die nachrichtentheoretische Grundlage für die später aufkommenden Analog-Digital-Wandler, welche analoge Schallwellen in digitale Entsprechungen umwandeln und damit in digital kodierten Informationen abspeichern konnten.

\subsection{Ausbreitung und Institutionalisierung von Cut and Paste-Verfahren in verschiedenen Kunstwelten (1945-1970)}

Bis zum Zweiten Weltkrieg traten die Praktiken des Sammelns, Auswählens, Bearbeitens und Rekombinierens von konkretem Klangmaterial eher lose und verstreut auf. Vorwiegend waren sie in intellektuellen und künstlerischen Kreisen der Oberschicht zu finden, die dank der Akkumulation notwendiger Kapitalien auf entsprechende Ressourcen zugreifen konnten. Ab etwa der Mitte des 20. Jahrhunderts verdichtete und institutionalisierte sich an der Schnittstelle von Technologie, Wissenschaft und Kunst das Geschehen. Der Hörfunk spielte dabei eine zentrale Rolle: Durch die Kooperation heterogener Akteure wurden technologische, wissenschaftliche und künstlerische

29 Aktuell wird in der Studiotechnik mit Abtastraten von $196 \mathrm{kHz}$ oder sogar $384 \mathrm{kHz}$ gearbeitet. 
Zukunftsvisionen miteinander gebündelt, was unter anderem in der Gründung von experimentellen Klangstudios in Paris und Köln mündete. Dank sinkender Preise von Aufnahmetechnik etablierte sich auch in popmusikalischen Kontexten das Studio und mit ihm die Figur der Produzent_in, die durch die Praktiken des Kopierens und Mischens Klänge planvoll miteinander ins Verhältnis setzen konnte.

$\mathrm{Ab}$ den I950er Jahren wurden Tonbandgeräte auch für Privathaushalte zugänglich und erschwinglich. Das führte dazu, dass sich nicht nur die Praktiken der Manipulation, sondern auch die Art des benutzten musikalischen Materials selbst ausdifferenzierten: Nicht mehr nur profane Alltagsgeräusche, sondern auch Musik, also symbolisch bereits vor-ausgestattete Klänge, gelangten zunehmend in das Repertoire der Anwender_innen und veränderten damit die künstlerischen Konventionen. Teilweise mussten die Konventionen neu ausgehandelt, teilweise konnten sie auch aus bereits existierenden Kunstgattungen übertragen und angepasst werden. So wurden die Möglichkeiten der De- und Rekontextualisierung symbolisch vorgeprägten Materials (als Kopien oder physische Objekte) mit der Collage in der Malerei seit den I920er Jahren erprobt und vorbereitet (beispielsweise durch Hannah Höch oder Pablo Picasso). In der visuellen Kunst gab es vergleichbare Arbeiten bereits ab den I9ıor Jahren (beispielsweise durch Marcel Duchamp), in der Literatur folgte der Cut-Up in den 1950er Jahren (beispielsweise durch Brion Gysin oder William Borroughs); und natürlich die Montage im Film seit den I920ern, beispielsweise durch Sergei Eisenstein oder Béla Balázs, der dafür den paradox wirkenden Begriff der "dichtenden Schere» vorschlug (2004 [1930]: 280). Viele der in diesem Zusammenhang wichtigen Künstler_innen unterfütterten ihre Werke mit theoretischen Abhandlungen oder brachten sich politisch im öffentlichen Diskurs ein (Diederichsen 2006). Sicherlich erhöht dieser semantische Überschuss ihre damalige und auch retrospektive Sichtbarkeit. Bei den amateurhaften "Tonjägern" (Dommann 20I4: 222) lassen sich aber genauso auch Cut and Paste-Praktiken finden, die unterhalb 
der Sphäre der intellektuell aufgeladenen Neuheitsproduktion stattfanden und stabile Formen annahmen.

In Paris ist die Gründung des ersten experimentellen Studios maßgeblich mit dem Radioingenieur und Komponisten Pierre Schaeffer und seiner von ihm begründeten Avantgardebewegung der Musique concrète verbunden. Auch hier lässt sich ein Medienwandel von Schallplatten hin zu Tonbandgeräten beobachten: Während die ersten, noch recht rudimentären Klangstudien der Musique concrète mit Schallplatten realisiert wurden, ließen sich die verschiedenen Praktiken des Rearrangierens und Wiederholens von konkreten Klangausschnitten auf Tonbandgeräte übertragen und dadurch filigraner ausführen. Die künstlerische Motivation der Musique concrète lässt sich auf die Aufwertung des Geräuschs hin zu einem musikalischen Objekt zurückführen, um daraus nicht eine abstrakt notierte, sondern eine am konkreten Material selbst kreierte Kom-Position zu erschaffen.

1948 fing Schaeffer am Pariser Bahnhof diverse Lokomotivgeräusche ein, die er an Plattenspielern zur "Étude au chemin de fer" (»Eisenbahnstudie«, 1948) hintereinander montierte (Schaeffer 1998 [1952]: 39). Um dabei den klanglichen Qualitäten näher zu kommen, schloss er einzelne Rillen, so dass das Klangfragment darin gefangen war (sillon fermé) und durch repetitives Hören analysiert werden konnte. Die ersten Arbeiten hatten noch eher unvermittelte Schnitte und klangen grob, aber mit dem Umstieg auf die Cut and Paste-Methode am Tonband und durch die Zusammenarbeit mit dem Schlagzeuger Pierre Henry verfeinerten sich die Methoden. Nun wurden auch andere Töne wie profane Körpergeräusche oder Klänge von präparierten Instrumenten rekombiniert, wie beispielsweise in der "Symphonie pour un homme seul « ( Sinfonie für einen einzigen Menschen", 1950). Auch das Spektrum der Klangbearbeitungsmethoden erweiterte sich: Änderungen in der Abspielrichtung und der Geschwindigkeit, rhythmische Verschiebungen, Überlagerungen und Filtereffekte wurden eingeführt (Smith Brindle I975: IOO-2).

Noch weiter ging der Komponist Karlheinz Stockhausen, der als „Enfant terrible« der europäischen Avantgarde (Schwarz 1996: 28) be- 
rühmt-berüchtigt wurde und einen radikalen Neubeginn der Musik nach dem Zweiten Weltkrieg forderte. Die Grenzen dessen, was bisher als Musik galt, sollten Stockhausen zufolge angegriffen und verschoben werden. Das Projekt der Aufweichung und Destruktion paradigmatischer musikalischer Konventionen, das bereits in der Avantgarde der ersten Jahrhunderthälfte durch die ästhetische Legalisierung von Geräuschen und Lärm betrieben worden war, radikalisierte sich mit Stockhausen weiter. In strikter Abkehr zu klassischen Kompositionsmethoden, aber auch durch die Einbindung aleatorischer Methoden und die Überwindung des Gedankens der Collage produzierte Stockhausen viele seiner Stücke im Studio für Elektronische Musik in Köln. Dieses war 195I nach Pariser Vorbild vom WDR als experimentelles Tonstudio gegründet und mit entsprechend moderner Technik ausgestattet worden.

In »Studie I « und »Studie II» (1953 und 1954) arbeitete Stockhausen zunächst mit einem Sinuston, den er in mehreren Schichtungen und anderen Manipulationen auf Tonband verarbeitete. Später wandte er sich in der "Telemusik» (I966) der Kombination und synthetischen Verschmelzung von konkreten, oftmals tribalen Musikstücken zu, die er aus unterschiedlichen geografischen Räumen zusammengesammelt hatte. Die »Telemusik« umfasste das komplette Spektrum von eineindeutigen bis uneindeutigen Referenzen. Darin finden sich spanischer Flamenco genauso wie zeremonielle Musik von brasilianischen Stämmen oder buddhistischen Tempelritualen, die Stockhausen umständlich miteinander modulierte und so versuchte, eine übergeordnete ästhetische Ebene zu erreichen:

"Telemusik ist keine Collage mehr. Vielmehr wird - durch Intermodulationen zwischen alten, gefundenen Objekten und neuen, von mir mit modernen elektronischen Mitteln geschaffenen Klangereignissen - eine höhere Einheit erreicht: Eine Universalität von Vergangenheit, Gegenwart und Zukunft, von entfernten Ländern und Räumen: Tele-Musik." (Stockhausen zitiert nach Utz 2002: I45). 
In den »Hymnen« (1967) übertrug und erweiterte Stockhausen seine Methoden auf offizielle Nationalhymnen, deren eigentlich intendierte Erhabenheit und Nationalidentität er dadurch extrem verfremdete. Durch Auswahl und vor allem Manipulation versuchte Stockhausen also die vorgefassten Symboliken nationalstaatlicher Identitätskonstruktion zu überwinden und eine emergente, aber trotzdem kontrollierbare Ebene zu erreichen. Mit diesen und weiteren experimentellen Studien prägte Stockhausen das Genre "Elektronische Musik" entscheidend mit, dessen unerhörte Klänge und Methoden über verschiedene Wege auch in den Bereich der Popmusik eindringen. ${ }^{\circ}$ Trotz aller Radikalität und Überwindungsmotivation blieb man in der Musique concrète wie auch in der Elektronischen Musik der klassischen Konvention schriftlich fixierter Partituren treu. Gerade bei Stockhausen nahmen diese Partituren allerdings eine derart komplizierte und voraussetzungsvolle Gestalt an und glichen eher einer Bedienungsanleitung für technische Geräte, so dass sie selbst für musikalisch geschultes Personal vermutlich nicht dekodierbar waren.

Gegenüber den vielbeachteten ästhetischen Experimenten der musikalischen Avantgarde fanden sich auch Künstler_innen, die bei ihren Tonbandexperimenten weniger Scheu vor populärer Musik zeigten. Der Gitarrist Les Paul beispielsweise experimentierte bereits in der zweiten Hälfte der I940er Jahre mit mehrfach geschichteten Aufnahmen seines Gitarrenspiels; zuerst auf wachsbeschichteten Platten, später dann mit Tonbandgeräten. Durch diese Methode, die später unter dem Begriff Overdubbing firmierte, konnte Paul einzelne Melodieführungen seiner Gitarre aufeinanderlegen, um sie harmonisch oder rhythmisch miteinander zu kombinieren. Auch stellte er

30 Personell lässt sich dies beispielsweise an dem Bassisten Holger Czukay und dem Keyboarder Irmin Schmidt illustrieren, die in Köln bei Stockhausen studierten und 1968 die international erfolgreiche Band "Can« gründeten. Can steht für eine besonders experimentelle und mit elektronischen Mitteln angereicherte Kombination aus Free Jazz und Krautrock. Eine der ersten Platten von Can ist eine 1968 aufgenommene Jamsession, die 1984 als "Prehistoric Future» erschien und mit deutlich hörbaren Samples von Studierendenprotesten aus Paris arbeitet. 
Versuche mit dem zeitlichen Ablauf seiner Aufnahmen an, wie beispielsweise Manipulationen der Bandgeschwindigkeit, zeitversetzte Aufnahmen (tape delays) und Echoeffekte. In den I95oern entwickelte sich sogar eine Kooperation zwischen dem Gitarristen und dem Tonbandgerätehersteller Ampex, bei dem Les Paul eigene Ideen zur Umsetzung in Auftrag gab und bei der technischen Entwicklung von Mehrspurverfahren beteiligt war (Baumgärtel 20I6: I25). Ähnlich wie Schaeffers Studien sind auch Pauls Experimente durch den Fokus auf den musikalischen Parameter der Zeit und einen montageähnlichen Charakter gekennzeichnet.

In dieser Periode entstehen durch die Kombination von Aufnahmen, welche aus verschiedenen Quellen stammen, aber auch populärmusikalische Stücke, die sich noch stärker an dem kuratierenden Gedanken der Collage oder dem narrativen Muster von Hörspielen orientieren. Für »The Flying Saucer« beispielsweise schnitten die Radiomoderatoren Dickie Goodman und Bill Buchanan bereits 1956 zahlreiche Aufnahmen von Rock'n'Roll-Stücken zusammen, so dass daraus eine Art Hörspiel mit eineindeutigen Referenzen entstand, in dem eine Invasion von Aliens inszeniert wurde. Aufgrund des Charterfolgs von »The Flying Saucer« ließen Fortsetzungen, Antworten und Nachahmungen nicht lange auf sich warten, genauso wie eine Klage wegen mindestens i9 verschiedenen Copyright-Verletzungen. Diese wurde allerdings richterlich zurückgewiesen. Die Begründung: Goodman und Buchanan hatten trotz des großzügigen Einsatzes popkultureller Zitate ein neues Werk geschaffen und fremde Musik nicht einfach nur kopiert (Goodman 2000: 3I).

Während »The Flying Saucer ähnlich wie Ruttmanns »Weekend " eine hörspielartige, narrative Rekombination vorhandener Klänge darstellte, wurden ab den i96oer Jahren auch Tonbandexperimente beliebt, die sich wie ein moderner Remix an einem einzigen Stück abarbeiteten, seine Ausschnitte rearrangierten oder verfremdeten. So manipulierte der US-amerikanische Künstler John Riley, der im Genre der Minimal Music aktiv war, das kurz zuvor erschienene Stück "You're Nogood» der New Yorker Bluesband Harvey Averne Dozen. 
Mit Hilfe von Tonbändern, Synthesizer und Sinuswellengenerator sezierte Riley verschiedene Ausschnitte aus dem Lied heraus und setzte sie als Kopien - teilweise rhythmisch überlappend und verzögert, aber als durchgehender Loop erkennbar - zu einer knapp 20-minütigen, hypnotisierenden Komposition zusammen, die auch in Diskotheken gespielt wurde - »with entertaining results« (Potter 2002: 120).

Bereits ein paar Jahre vor Riley versuchte sich James Tenney an Elvis Presleys "Blue Suede Shoes« von 1956. Tenney nahm am Tonband diverse Ausschnitte aus dem Stück und kreierte daraus ein Stück namens "Collage \#I" (196I) - in Anlehnung an die in der bildenden Kunst bereits etablierte Vokabel und Verfahrensweise der "Collage«. Vermutlich griffen Yoko Ono und John Lennon diese Bezeichnung auf für ihre "Collage \#9" (1968), für die sie 20 Stücke aus dem Katalog ihrer Plattenfirma EMI auf Tonband und andere Sounds miteinander kombinierten. Für "Collage \#9" wurden weder Lizenzgebühren gezahlt noch eingefordert, vermutlich weil sich alles in house, also unter dem gemeinsamen Dach einer einzigen Plattenfirma, abspielte (McLeod/DiCola 20II: 39).

Es ist auffällig, dass das Verfahren des Samplings bis zu den späten I970er Jahren unter unterschiedlichen semantischen Bezeichnungen firmiert und je nach soziokulturellem Zusammenhang mit unterschiedlichen Ideen verknüpft ist. Die Begrifflichkeiten von schon etablierten künstlerischen Konventionen (wie der Collage oder der Montage) werden adaptiert oder problematisiert, was sich als Strategie zur Legitimation interpretieren lässt und die prinzipielle Offenheit für neue Verfahren dieser Phase veranschaulicht. Gerade in den I96oern scheint das Spiel mit Arrangement, Referentialität und Dekontextualisierung von profanen und popkulturellen Materialien in unterschiedlichen Kunstwelten als Thema geradezu in der Luft zu liegen (vgl. Crane 1989: 65, Jones 1995: I28; Reckwitz 20I2: II7). Zu dieser Zeit war in der avantgardistisch orientierten Kunstwelt der Neuen Musik die Kopierpraxis von konkreten Klängen, also das, was wir heute als "Sampling« bezeichnen, offenbar ein konventionales Mittel unter vielen. Es diente einem höheren Zweck: der Entgrenzung, Problematisie- 
rung oder sogar Negation des traditionellen Musikbegriffs mit seinen harmonischen, rhythmischen und melodischen Konventionen.

Aufgrund seiner Möglichkeit zur Speicherung von Klängen lud das Tonband auch dazu ein, die Entwicklung eines Musikinstruments mit präparierten Tönen weiterzuführen. Mit dem "Chamberlain" und dem "Mellotron« erschienen ab den I95oer Jahren elektromechanische Vorläufergeräte zu digitalen Samplern, die vor allem zur Vertonung von Filmen eingesetzt wurden. Wegen ihrer Störanfälligkeit, voraussetzungsreichen Bedienung und des hohen Preises wurden diese Geräte allerdings nur in sehr geringer Stückzahl produziert. Über eine Klaviatur konnten polyphone Loops und auch einzelne Instrumente abgespielt werden. Insgesamt waren bereits mehrere hundert Sounds abrufbar. In ihrer Kombination konnten so an diesen, dem Klavier noch recht ähnlichen Instrumenten, bereits komplexe Geräuschkulissen erzeugt werden (Holmes 20I2: 327).

In Folge der aufkommenden technischen Gerätschaften und damit induzierten Praktiken bildeten sich während der I96oer Jahre in Deutschland starke Mechanismen zur urheberrechtlichen Konfiguration technischer Reproduzierbarkeit heraus. Anhand des Tonbands wird der größere Zusammenhang zwischen der Steigerung technischer Reproduzierbarkeit und der Kontrolle Geistigen Eigentums auf der Ebene amateurhafter und hobbymäßiger Klangaufnahme und -bearbeitung gut sichtbar: Tonbänder waren in den I950er und I96oer Jahren in weiten Teilen Europas und der USA allgemein erschwinglich und die Praktiken des Cut and Paste damit für breite gesellschaftliche Schichten zugänglich geworden: Tonbandmaschinen ermöglichten es ihren Besitzer_innen, Aufnahmen auf Tonbändern zu löschen, zu kopieren und wieder zu beschreiben. In Deutschland führte dies zu einer Kultur der »Tonjäger «, die »nicht Tonträger kaufen, sondern selbst Töne jagen" wollten (Dommann 20I4: 233) und damit die "Wellenreiter" der I92oer Jahre beerbten. Mit der Technik zur Klangfixierung schälte sich aus der Rezeption so langsam eine Praxis heraus, die zunehmend produktive Anteile hatte. Dommann (20I4: 222) beschreibt das Hobby des Töne Jagens gar als »kreati- 
ves Handwerk: Durch Schneiden und Kleben konnte sich jeder aus Schallplattenaufnahmen, Radiosendungen und selbsteingefangenen Tönen seine eigene Musik zusammenbasteln.«

Gegenüber dieser Ermächtigung privater Akteure gab es freilich Widerwillen im musikindustriellen Komplex, insofern man dies als Angriff auf die eigene, urheberrechtlich gestützte Reproduktionshoheit wertete und monetäre Einbußen befürchtete. In jahrelanger Lobbyarbeit konnte in Westdeutschland die Allianz aus Rundfunkanstalten, Musiklabels und der Verwertungsgesellschaft GEMA mit der sogenannten "Apparateabgabe« dann eine urheberrechtliche Konfiguration technischer Reproduzierbarkeit durchsetzen, die 1966 in Kraft trat und bis heute stabil ist. Die Apparateabgabe ist eine pauschale Abgabe, die auf Leermedien erhoben wird, mit denen es technisch möglich ist, urheberrechtlich geschütztes Material ohne Erlaubnis der Urheber_innen zu kopieren. Die zeitgenössische »Tonbandfibel« warnte 1967 daher auch eindringlich: „Die Wahrscheinlichkeit, dass man beim Aufnehmen irgendeiner Rundfunksendung etwa keine urheberrechtlich geschützten Werke erwischt, ist ebenso groß, als wenn man mit der flachen Hand in eine Sahnetorte schlägt und erwartet, von keinem Spritzer getroffen zu werden.« (Menke I967: 73-4)

\subsection{Konsolidierung und Ausdifferenzierung analoger Remixkulturen (1969-1979)}

Während die bisherige Darstellung jener dem Sampling ähnlichen Methoden und Geräte besonders auf den westlichen Kulturraum Europa und USA beschränkt war, soll dieser Abschnitt stärker jene Produktionsweisen berücksichtigen, die sich vor allem in afroamerikanisch geprägten Kunstwelten etablierte. Die musikalische Kunstwelt des Dub, die sich ab Ende der I96oer Jahre aufgrund erschwinglicher Studiotechnik und eines dysfunktionalen urheberrechtlichen Systems in Jamaika aus dem Reggae heraus entwickelte, ist hierfür besonders 
relevant. Denn im Dub wurden erstmals verschiedene Techniken der Versionierung von phonographisch fixierten Aufnahmen als ästhetische Konventionen zentral gestellt. Noch vor Durchsetzung des digitalen Samplings bildete sich so eine samplingbasierte Kunstwelt heraus, die mit heutigen Remixkulturen vergleichbar ist und deren Praktiken in den I97oern vor allem in den USA und in Großbritannien einflussreich wurden.

Ungleichheitstheoretisch betrachtet könnte der Gegensatz zwischen der Neuen Musik und dem Dub nicht krasser sein: auf der einen Seite eine akademisch-ästhetische, international vernetzte weiße Elite, die intellektuell unterfüttert und kopflastig das Projekt betreibt, den klassischen Kunstbegriff herauszufordern - auf der anderen Seite eine wirtschaftlich und politisch eher instabile karibische Insel mit erst 1962 beendeter britischer Kolonialherrschaft und einer demografischen Struktur aus vorwiegend People of Color, deren Vorfahr_innen im 17. und I8. Jahrhundert als afrikanische Sklav_innen durch gewaltsame Migration nach Nord- und Südamerika gekommen waren. Im Sinne des »black atlantic» (Gilroy 1993) kann Jamaika damit als kulturelle Diaspora charakterisiert werden, in der typisch afrikanische Kulturformen (wie beispielsweise oral tradierte Musik oder kollektiv gedachte Autorschaft) neue, hybride Formen annahmen.

Larissa Mann (2012: 67-79) zufolge war das jamaikanische Copyright Law bis in die I980er Jahre hinein auf dem Stand des britischen Copyright Acts von I9II. Es bot damit keinerlei finanziellen Anreiz zur Produktion neuer Werke. Mit dem Begriff der "phonographic orality« umschreibt Larissa Mann die grundsätzliche Diskrepanz, dass das britische Copyright stark auf schriftlicher Fixation von Noten fußt, in Dub, Reggae und Ska hingegen musikalische Ideen erst im Studio oder bei einer Aufführung erstmals fixierte Gestalt erhalten. Entsprechend hielt das Recht nicht mit den technologischen Entwicklungen Schritt und wurde praktisch nicht als regulatives Instrument angewendet. Damit wurde die urheberrechtlich nahezu kaum konfigurierte Steigerung technischer Reproduzierbarkeit in Jamaika zentraler Ausgangspunkt für die Kunstwelt des Dub. 
Die Praxis des Kopierens stand auch Patin für Begrifflichkeiten: Das im Slang gebrauchte Wort dub leitet sich nämlich von to double $\mathrm{ab}$, bezieht sich ursprünglich also auf den außermusikalischen seriellen "Kopiervorgang von Tonträgern" (Burkhart/Pfleiderer 2017: 59). Versioning hingegen verweist auf innermusikalische, referentielle Kopiervorgänge, nämlich, dass ganz gezielt verschiedene Versionen eines Musikstücks produziert und in Umlauf gebracht wurden. In der Regel wurden dabei die Riddims ${ }^{31}$, also die Instrumentalspuren des Stücks neu besungen; genauso war es beliebt, mit Hilfe von Mehrspurmischpulten im Studio bestimmte Spuren oder Passagen eines Stücks zu isolieren oder zu verlängern, mit Effekten wie Reverb oder Echo zu belegen oder den Sound (insbesondere den Bass) kräftiger abzumischen (re-mix). Als versions zirkulierten viele dieser, meist auf Acetat gepressten Musikstücke in Kleinauflagen (dub plates) und wurden zum Ausgangsmaterial von Weiterbearbeitungen. Dabei entwickelte sich eine ästhetische Konfiguration technischer Reproduzierbarkeit: Auf der einen Seite bestand ein allgemeiner und geteilter "pool of riddims serving as a creative commons" (Manuel/Marshall 2006: 462), auf der anderen Seite herrschte auf Seite der Produzenten durchaus ein deutlicher Werkstolz, was sich daran zeigt, dass es als verpönt galt, die Riddims eines Konkurrenten als die eigenen auszugeben (Okpaluba 20I0: 380).

Wichtige Figuren dieser frühen Zeit des Dub waren beispielsweise King Tubby, Lee »Scratch» Perry oder Scientist ${ }^{32}$, die sich als

3I Das Wort Riddim leitet sich vom englischen rhythm ab.

32 Bemerkenswert ist, dass in der populären, studiozentrierten Musikproduktion viele Referenzen auf Naturwissenschaften und Labore kursieren, wie beispielsweise die Pseudonyme Scientist oder Mad Professor nahelegen. Auch wird auf das Studio gerne als "Labor" beziehungsweise als lab verwiesen, in dem nach neuen Klängen wie nach unbekannten chemischen Substanzen geforscht wird soziale Devianz explizit miteingeschlossen. Das Album »SiLLiUM» der deutschsprachigen Hip Hop-Gruppe 5 Sterne Deluxe (1998) beispielsweise ist mit einem Cover ausgestattet, das die Musiker in einem Chemielabor beim Hantieren mit bunten Flüssigkeiten zeigt. Die Texte und der eigensinnig geschriebene Titel "SiLLiUM", vermutlich ein Kofferwort aus »silly», "ill« und der Endung "-um» für ein fiktives chemisches Element, betonen als Referenzen sozial deviante Prak- 
Musikproduzenten Einfluss verschafften und damit zur allgemeinen Statusaufwertung der Produzent_innenfigur im Musikgeschäft beitrugen. Von zentraler Bedeutung war auch die jamaikanische Kultur der Soundsystems. Dabei handelte es sich um mobile Diskotheken mit Lautsprechersystemen, die ab den I950ern auf Tour waren und auf denen DJs zuerst US-amerikanische Soul und Rhythm and BluesSingles, später dann ihre eigenen Versionen auflegten. So war King Tubby's Soundsystem bekannt als »Tubby's Home Town Hi-Fi« und hatte den Ruf einer besonders lauten und kraftvollen Beschallungsanlage (Burgess 20I4: 93); zusätzlich sangen und intonierten MCs auf die Riddims, was über karibische Einwander_innen in die USA einen entscheidenden Einfluss auf die Entstehung von Hip Hop haben sollte (Gilroy 1993: 82; Sullivan 20I4: 97).

Insgesamt lassen sich am dub plate meiner Meinung nach fünf wichtige Konventionen im Sinne Beckers ablesen, die das Verhältnis von gestiegener technischer Reproduzierbarkeit und der Abgeschlossenheit von künstlerischen Werken betreffen. So schreibt Veal:

"The dub plate thus represented a conjunction of two creative practices: the multitrack recording machines through which musical performances could now be partially disassembled, and the interruptive logic of sound system deejays, who thought nothing of continuously interrupting songs with their improvised vocalizing." (Veal 2007: 55-6)

Mit Veal steht das dub plate also für die Verwendung von Studio- und Aufführungstechnik, die es erlaubt, (I) auf Tonträgern fixierte Musik zu zerlegen und neu zu organisieren sowie (2) eine einhergehende kulturelle Unbefangenheit, andere Musik als prinzipiell unabgeschlossen zu begreifen und Referentialität als stilistisches Merkmal zuzulassen.

(3) Darüber hinaus symbolisiert das dub plate auch die durch tech-

tiken wie Drogenkonsum, dadaistische Wortspielereien und einen künstlerischen Habitus. 
nische Reproduzierbarkeit erfolgte Ermächtigung, selbst Musik auf Tonträgern fixieren und distribuieren zu können. Im Dub werden die neuen Versionen bewusst wieder in den Kreislauf der Musikproduktion eingespeist, um als musikalisches Material der Bearbeitung anderer zur Verfügung zu stehen.

(4) Weil dub plates in der Regel nur in Kleinauflage verfügbar waren und sich auch schnell abnutzten, ${ }^{33}$ bildete sich zudem die Grundlage für eine ästhetische Konfiguration technischer Reproduzierbarkeit aus. Damit meine ich eine ästhetische Grammatik, die künstlerische Originalität stärker über mediale Knappheit reguliert und dabei die künstlerische Kompetenz des Kuratierens betont - also weniger die Autonomie und Expressivität eines Kunstwerks honoriert, sondern mehr das Wissen und den Zugriff auf seltene oder schwer zu beschaffene Werke.

(5) Die grundsätzliche Spannung zwischen technischer Reproduzierbarkeit und dem Schutz eigener kreativer Werke machte sich aber auch in der Kunstwelt des Dub bemerkbar. Um den fehlenden urheberrechtlichen Schutz auszugleichen und das entstandene Problem des Kontrollverlusts zu umgehen, behalfen sich viele Produzent_innen mit der Markierung ihrer Riddims durch Kontrollobjekte, indem sie also ein auditives Wasserzeichen, ein trade mark in ihre Stücke einbauten. Zwar konnte durch diesen unauffälligen Kopierschutz der Akt des Kopierens nicht unterbunden, aber zumindest sollte die eigene Autorschaft, die eher mit Studios und Produzent_innen verknüpft war, nachverfolgbar gemacht und pirates überführt werden: "[They] include[d] a snippet of the original vocal within the dub mix, in order to place an indelible identifying stamp on the music. (Veal 2007: 66)

Während sich der Dub auf Jamaika in den I97oer Jahren entwickelte, etablierte sich in den USA der Musik- und Tanzstil Disco. Ursprünglich aus Philly Soul, Funk, lateinamerikanischer Musik und

33 Paul Sullivan (20I4: 26) bemerkt, dass dub plates oftmals nur ein dutzend Abspielungen vertrugen. Um ihre Knappheit und Vergänglichkeit zu betonen (vermutlich aus Gründen des Marketings), wurden sie daher manchmal als »One Offs« betitelt. 
der subkulturellen Schwulen- und Lesbenströmung hervorgegangen, wurde Disco über typische musikindustrielle Kanäle wie Schallplatten und Radio, später auch Filme wie "Saturday Night Fever" (1977) kommerzialisiert und in den USA bekannt gemacht. Die Rolle von professionellen DJs in dieser "disc culture" (Thornton 2003) war dabei entscheidend, denn sie spielten die Musik nicht live wie eine Band, sondern mischten sie an Schallplattenspielern zusammen. ${ }^{34}$ Über technische Verbesserungen in der Studio- und Aufnahmetechnik wie Mehrspurmischpulte und Bandmaschinen konnte, ähnlich wie im Dub, Musik zerlegt und rearrangiert werden. Für die DJs wurden im Studio "extended versions" angefertigt, die oftmals auf Io Minuten oder länger gestreckte Radiosingles waren und entsprechend nicht auf eine 7"-Single passten. Die bis heute bei DJs beliebte I2"-Maxi mit einem Stück pro Seite und besserem Klang ist Ergebnis dieser Praktiken (Fikentscher 2000: 50).

Der gleichmäßig im 4/4-Takt pulsierende Discobeat mit seinem charakteristischen Bassdrum-Kick sorgte zusammen mit genereller Tiefenbetonung und hallfreier Produktion für einen speziell auf Diskotheken zugeschnittenen Schalldruck. Der Begriff des Remix' geht hierbei auf den Produzenten Tom Moulton zurück, dessen Abmischung, zuerst bekannt als »Tom Moulton Mix«, besonders druckvoll und kräftig klang. Zahlreiche Radiohits wurden von Moulton und anderen durch Neuabmischung und Rearrangement in den I970er Jahren für die Diskothek als DJ-Versionen aufbereitet (Straw 2002). Disco gilt als wichtige musikalische Grundlage für das ebenfalls DJ-getriebene Genre House, das sich etwas später vor allem in Chicago entwickelte und in den I980er Jahren in Europa Einfluss gewann (Rietveld 20II).

Platten ineinander zu mischen war im New York der I970er Jahre bereits eine bekannte, wenn auch vorwiegend in den Discoclubs Manhattans verbreitete Praxis, als etwa Mitte der I970er Jahre dort

34 Der Genrename Disco leitet sich ebenfalls von dieser Praxis ab, bezeichnet also den Musikstil, der in der discotheque gespielt wird, wo keine Konzerte, sondern Schallplatten aufgeführt werden. 
mit Hip Hop das vermutlich wichtigste und heute am stärksten ausdifferenzierte Genre samplingbasierter Popmusik entstand. New York war ab den I950er Jahren von einschneidenden stadtplanerischen Maßnahmen (zum Beispiel für den Bau von Autobahnen) und umfassender Grundstücksspekulation betroffen, die im Zusammenspiel mit der einsetzenden Deindustrialisierung besonders im Stadtteil der Bronx einen großflächigen »urban decay« (Ewoodzie 20I7: 20) nach sich zogen. Dort, am Rande der Stadt und gleichzeitig am Rande der Gesellschaft, waren weite Teile der Wohngebäude und der öffentlichen Infrastruktur marode, wegen Versicherungsbetrugs ausgebrannt oder sogar komplett zerstört. Aufgrund erschwinglicher Mieten und Kettenmigration ließen sich viele Familien mit afrodiasporischer oder lateinamerikanischer Herkunft in den betroffenen Stadtteilen nieder, wo sie bereits Verwandte und Bekannte hatten, und importierten auf diese Weise ihre kulturellen Gepflogenheiten (Chang 2007: 13).

I967 kam mit den jamaikanischen Einwander_innen auch Clive Campell in die südliche New Yorker Bronx, wo er bald unter dem Alias Kool DJ Herc mit eigenem Soundsystem auftrat. Hier war es in der Nachbarschaft bereits üblich, sich zu block parties an öffentlichen Plätzen im Freien wie Sportplätzen oder Hinterhöfen treffen, zu tanzen und Spaß zu haben. ${ }^{35}$ Zur Unterhaltung wurden Musikanlagen aufgestellt, die mit von zu Hause mitgebrachten Schallplatten bespielt wurden, was sich sehr gut mit der karibischen Kultur der Soundsysteme verband. Kool Herc gilt heute als einer der ersten, die an zwei Plattenspielern und einem dazwischen geschalteten Mischpult einzelne rhythmische Fragmente aus Schallplatten rekombinierten. Er mischte Stücke aus dem Reggae, Funk und Soul so kunstvoll mit- und ineinander, dass die Musik neue Gestalt annahm und dem

35 Die block parties entstanden teilweise als spontane nachbarschaftliche Zusammenkünfte, teilweise auch als gezielte Veranstaltungen, um Jugendliche mit Tanzen (break dancing) zu beschäftigen und sie so davor zu bewahren, in den Straßengangs kriminell zu werden. Gleichzeitig waren die block parties natürlich auch eine schichtspezifische Antwort auf die Diskos, zu denen Jugendliche aus der Bronx in der Regel keinen Zugang hatten. 
Publikum trotzdem bekannt vorkam (Ewoodzie 2017: 45). Auf seinem lauten Soundsystem klangen die breaks besonders gut und kraftvoll, also diejenigen Rhythmuspassagen, in denen für wenige Takte meist nur Schlagzeug, Basslauf und Rhythmuselemente als kurze Soli zu hören sind. Gerade die Breaks animierten das Publikum zum Tanzen und Jubeln, auch wenn sie - kaum angeklungen - schon wieder zu Ende waren. Mit zwei Exemplaren der gleichen Schallplatte gelang es Herc, dieses Problem zu lösen und den Tanzfluss des Publikums aufrecht zu erhalten. Er schaffte es, die Breaks künstlich zu verlängern und damit über den Umweg der Kopie den eigentlichen, dem Stück zu Grunde liegenden Groove der Schlagzeuger_in zu rekonstruieren: Während die eine Schallplatte das Fragment abspielte, wurde die andere gerade zurückgedreht; das dabei entstehende, charakteristische Geräusch wurde über die Schieberegler am Mischpult ausgeblendet. Wurde diese Methode des "Merry-Go-Round«, wie Herc sie nannte, sauber ausgeführt, konnte der Break im ständigen Wechsel quasi endlos und ohne hörbare Nahtstelle in die Länge gezogen werden (Poschardt 1997: 164-7).

Nicht nur die Verlängerung der Breaks ist eine »Bricolage« im Sinne Levi-Strauss' (1968), also eine eigensinnige Bastelei mit den gerade zur Verfügung stehenden Mitteln, die ursprünglich für andere Zwecke entworfen worden waren. Auch die Sound Systems selbst bestanden aus zweckentfremdeter und zusammen gestöpselter Unterhaltungstechnik, für die oftmals auch die öffentliche Stromversorgung illegal angezapft wurde. Durch kreative Aneignung und Modifizierung des Vorhandenen wurde es für diese musikalischen Amateur_innen möglich, ohne Noten lesen zu können oder ein klassisches $\mathrm{Mu}$ sikinstrument zu beherrschen, sich künstlerisch auszudrücken und eigene Autorschaft über die Aneinanderreihung der Schallplatten zu entwickeln. ${ }^{36}$

36 Neben den DJ-Praktiken gelten Graffitis, Breakdance und Rap als weitere zentrale Säulen der Hip Hop-Kultur, die sich in dieser Phase entwickelten. Das Wort »Hip Hop« bezeichnete ursprünglich hier einen Hüftsprung. 
In den folgenden Jahren wurden die Techniken der Schallplattenmanipulation (auch als turntableism bekannt) von anderen DJs wie Grandmaster Flash, Afrika Bambaataa, Grandmaster Flowers oder Grand Wizzard Theodore aufgegriffen, verbessert und mit weiteren wie Scratching, Cutting und Mixing ergänzt. Der ursprünglich als Elektriker ausgebildete Grandmaster Flash bastelte selbst an Mischpulten herum und integrierte eine von ihm benötigte Vorhörfunktion für den einen, gerade nicht auf laut gestellten Plattenspieler. Diese Privatisierung des Vorhörens brachte enorme Vorteile bei der Durchführung des DJ-Sets und verschaffte auch den Tanzenden einen kontinuierlicheren Musikfluss (McLeod/DiCola 20II: 55). War die Anzahl der DJ-Crews aus der Bronx anfangs noch recht übersichtlich und ihr Schaffen entsprechend nur innerhalb enger lokaler Grenzen bekannt, änderte sich dies mit einem 24 Stunden dauernden Stromausfall, der 1977 New York lahmlegte. Es kam zu zahlreichen Ladenplünderungen, in denen sich viele junge Menschen aus den armen Vierteln Schallplattenspieler, Mischpulte, Beschallungsanlagen und auch Platten besorgten, die für sie unerschwinglich waren. In Folge dieses illegalen Ermächtigungsakts von Produktionsmitteln schossen zahlreiche neue amateurhafte DJ-Crews und Soundsysteme wie Pilze aus dem Boden (Ewoodzie 2017: I28), was zeigt, dass der Wunsch zur ästhetisch-kreativen Betätigung mit Unterhaltungselektronik und Schallplatten kollektiv schon verbreitet war.

Die kurzerhand gestiegene Konkurrenz verstärkte die Dynamik zur ästhetischen Distinktion und Ausdifferenzierung innerhalb der New Yorker DJ-Welt: Neben der Leistungsfähigkeit der Soundsystems und den Abspieltechniken mussten die DJs nun ihr Können vor allem in der Auswahl der Schallplatten unter Beweis stellen. Die vorgegebene Einheit der Musik in Form abgeschlossener und musikindustriell distribuierter Stücke wurde angreifbar und durchlässig, so dass sich beispielsweise ein eigentlich uninteressantes Stück wegen einer kurzen Passage und geschickter Manipulation in ein interessantes verwandeln konnte. Kreativitätstheoretisch gesprochen wurde so das Verhältnis von Exploration und Rekonstruktion als urbarer 
Raum erschlossen. Es galt, buchstäblich neue Seiten auf den Schallplatten zu entdecken und diese nicht mehr als abgeschlossene ästhetische Einheiten, sondern als unfertige Probleme zu verstehen, die innerhalb eines DJ-Sets zu einer neuen Ganzheit mit eigener Qualität transformiert werden konnten. Bekannte Platten mussten auf neue, überraschende Weise aufgeführt, unbekannte Platten kontinuierlich gesucht und aufgestöbert werden, wie DJ Afrika Bambaataa in einem zeitgenössischen Interview beschreibt:

"I started playing all forms of music. Myself, I used to play the weirdest stuff at a party. [...] I would play >Honky Tonk Woman Rolling Stones and just keep that beat going. I'd play something from metal rock records like Grand Funk Railroad. 'Inside Looking Out is just the bass and drumming... [...] and everybody starts freaking out. I used to like to catch the people who'd say: `I don't like rock. I don't like Latin. I'd throw on Mick Jagger - you'd see the Blacks and the Spanish just throwing down, dancing crazy. I'd say, ,I thought you said you didn't like rock.` They'd say: ।Get out of here. I'd say: ,Well, you just danced to the Rolling Stones. । You're kidding! I'd throw on seargent Pepper's Lonely Hearts Club Band - just that drum part. One, two, three, BAM - and they'd be screaming and partying. I'd throw on The Monkees, `Mary Mary - just the beat part where they'd go 'Mary Mary, where are you going? - and they'd start going crazy. I'd say: 'You just danced to The Monkees. They'd say: 'You liar. I didn't dance to no Monkees؛. I'd like to catch up people who categorise records." (Afrika Bambaataa zitiert nach Toop I984: 65-6)

Die Interaktion mit dem Publikum wurde zu einem zentralen Element zur Auslotung des Neuen in der Kunstwelt des Hip Hop. Musikgenres wie Rock, Disco, Jazz und andere erweiterten das Repertoire der DJs. Die Logik des Seltenen und Obskuren, die Schloss (2004) für das digitale Sampling unter dem Stichwort crate digging diskutiert, fing an diesem historischen Punkt an, die explorativen Praktiken der DJs zu bestimmen. Ihre kreative Leistung sahen die DJs in 
der Suche und Auswahl der besten Musikstücke; um ihre Autorschaft und Quellen vor der Konkurrenz zu schützen, verdeckten viele bei Auftritten die Plattenlabels, wuschen sie in der Badewanne ab oder kratzten sie aus (Poschardt 1997: 159; Ewoodzie 2017: 128). Selbstverständlich gab es eine ganze Palette an allgemein bekannten Hits, die alle DJs kannten und für ihre Sets nutzten. Trotz dieser commons sahen sie sich dazu gezwungen, ihren eigenen Stil vor unerwünschter Nachahmung zu schützen und den Zugang zu entsprechenden Informationen zu privatisieren. Diese Form der Geheimhaltung wiederum macht deutlich, wie zentral verankert die Idee der Aneignung fremder Musik in der gerade erst entstehenden Kunstwelt des Hip Hop bereits war und steht damit in Tradition mit anderen Formen des Kopierschutzes.

1979 wurde der Song "Rapper's Delight« von der Band Sugar Hill Gang veröffentlicht, der auf das relativ wohlhabende New Yorker Quartier Sugar Hill im Norden Manhattans Bezug nimmt. Das gleichnamige Label war eigentlich auf Disco spezialisiert. Der Song gilt gemeinhin als erste kommerziell erfolgreiche Hip Hop-Veröffentlichung auf Schallplatte und löste einen regelrechten Boom aus, der bei der internationalen Etablierung und Sichtbarkeit von Hip Hop großen Anteil hatte. Für die DJs aus der Bronx hingegen war "Rapper's Delight" ein externer Schock, der ihre internen Konventionen erschütterte: Bis dahin war Hip Hop kein musikindustriell kommodifiziertes Musikgenre gewesen, das sich im Plattenladen in fixierter Form kaufen oder im Radio anhören ließ, sondern eine lokal begrenzte, DJ-getriebene Untergrundkultur, die als gemeinsam geteilte soziale Praxis an öffentlichen Orten und Clubs stattfand. Zwar zirkulierten schon Aufnahmen von Live-Auftritten auf Tape, die die Bekanntheit von Hip Hop in- und außerhalb der Bronx vorantrieben. Diese Tapes stellten aber die Kunstwelt-interne Reproduktionshoheit nicht in Frage, da sie von den Mitgliedern selbst in Umlauf gebracht wurden (Ewoodzie 20I7: I8I). Für eine professionelle Veröffentlichung auf einem musikindustriellen Label inklusive Distribution und radio airplay waren in der Bronx offenbar noch keine Ressourcen vorhanden. 
Das Interessante an "Rapper's Delight" ist daher der innere Widerspruch hinsichtlich der vermittelten Authentizität, der Hip Hop fortan als Metathema begleitete und der bis heute regelmäßig angesprochen wird: Mitnichten handelte es sich bei dem Basslauf nämlich um ein an Plattenspielern künstlich verlängertes Fragment, also um eine authentische Hip Hop-Praxis aus der Bronx, sondern um eine Interpolation ${ }^{37}$ des Basslaufs aus dem Discohit "Good Times" von Le Chic, also eine studiotechnische Nachahmungspraxis. Die originären Bassisten Nile Rodgers und Bernard Edwards von Le Chic wurden nicht um Erlaubnis gefragt, sondern erst nachträglich finanziell beteiligt (Okpaluba 20I4: 79). Auch als Rapper wurden Szeneoutsider engagiert, denn aus der Bronx ließ sich niemand finden (Chang 2007: I32). Grandmaster Flash und andere Pioniere veröffentlichten erst ab den I98oer Jahren ihre Musik auf Platte.

"Rapper’s Delight« war ein erster musikindustrieller Versuch, den Sound der Straße einzufangen und die Öffnung der Majors gegenüber dem neuen Genre Hip Hop zu voranzutreiben. Aus afrodiasporischen Genres wie Jazz, Rhythm'n'Blues, Funk oder Dub waren bereits Praktiken bekannt, die Musik nicht als abgeschlossene, originale und damit unantastbare Werke, sondern als Ausgangspunkt für Aneignung, Improvisation und Weiterentwicklung begriffen. Viele afroamerikanische Hip Hop-Künstler_innen der frühen Stunde waren aufgrund ihrer soziodemographischen Stellung musikalisch eigentlich unbefugt, konnten aber durch Praktiken der Bricolage und des unsachgemäßen Gebrauchs Unterhaltungstechnik entgegen ihrer Bedienungsanleitung bedienen und damit Limitationen überwinden. Diese reorganisierende Praxis zeigte sich auch bei der Videokassette (Hilderbrand 2009) und insbesondere der Musikkassette durch Kopieren, hintereinander Montieren und übereinander Schichten von Tönen: Über die Pause- und Spultasten konnten auf der Kassette eine

37 Mit Interpolation ist das Nachspielen von einzelnen musikalischen Fragmenten gemeint. Eine Coverversion hingegen bezieht sich auf die komplette Nachstellung eines Stücks hinsichtlich Melodie, Rhythmus, Arrangement und Text (Huck 20I4). 
zeitliche Stelle einigermaßen genau angesteuert, mit der Aufnahmetaste bei gleichzeitigem Abklemmen der Löschfunktion verschiedene Schichten übereinandergelegt werden, woraus die Praxis der pause tapes resultierte (McLeod/DiCola 20II: 53-4; Pelleter/Lepa 2007: 20I).

Die abermals gestiegene technische Reproduzierbarkeit in Form bespielbarer Kassetten auf Ebene der Konsumentinnen und Amateure veranlasste die Musikindustrie zu Experimenten mit Kopierschutztechnologien: Um die eigene Reproduktionshoheit zu verteidigen, bastelte man hier bereits ab den I960er Jahren an einem Störsignal von $20 \mathrm{kHz}$ (sogenanntes spoiler signal), das auf Vinyl-Langspielplatten eingelassen werden sollte und für das menschliche Gehör nicht wahrnehmbar ist. Der hohe Ton sollte unautorisierte Kopiervorgänge auf Musikkassetten verhindern, indem er die magnetische Aufnahme irritierte. Die Technologie setzte sich vorerst allerdings nicht durch. Eine vergleichbare Technik wurde dann auch auf die Musikkassetten selbst und ab 1983 auch auf VHS-Videokassetten übertragen (Heylin 1995).

\subsection{Von analogen Praktiken hin zu digitalem Sampling (ab 1979)}

Das Jahr 1979 markiert auch in technologischer Hinsicht einen entscheidenden Wendepunkt in der Geschichte des Samplings: Mit der beginnenden Verfügbarkeit digitaler Samplingtechnologien erhielt die musikalische Cut and Paste-Praxis im Laufe der I980er Jahre eine neue Semantik und ermöglichte eine deutlich verbesserte Manipulation von Klängen bis hinunter auf deren granulare Ebene. 1979 kam mit dem australischen Synthesizer Fairlight CMI das erste Musikinstrument mit digitaler Samplingfunktion auf den Markt. Mittels eines eingebauten Analog-Digital-Wandlers auf Grundlage des mathematischen Samplingtheorems erlaubte das Gerät, beispielsweise über das Mikrofon aufgenommene Töne wie die eigene Stimme oder an- 
dere Geräusche digital zu speichern und via Klaviatur in verschiedenen Tonhöhen oder übereinander lagernd wieder abzuspielen. Schon in der kleinen Ausführung kostete das Gerät mehrere zehntausend US-Dollar und war daher nur für etablierte Tonstudios und Musiker_innen erschwinglich. Auch war es umständlich zu bedienen und erforderte im Grunde eine klassische musikalische Ausbildung sowie profundes technisches Verständnis, denn der CMI musste über zwei Klaviaturen sowie einen angeschlossenen Computer mit Bildschirm und Tastatur betätigt werden. ${ }^{3}$ Auch die Klangqualität und Länge der Samples war zunächst sehr limitiert. Das liegt mit daran, dass der Fairlight CMI eigentlich als Synthesizer konzipiert worden war, der vorprogrammierte klassische Musikinstrumente wie Streicher oder Bläser als simulierte Klänge abrufbar machen sollte: Ziel war die möglichst realistische Imitation eines Orchesterklangs durch die Bedienung eines einzigen Geräts. Die Samplingfunktion war demnach zweitrangig - erst durch den Gebrauch und die Anwendung der Nutzer_innen wurden die Aufnahme und Manipulation fremder Klangquellen als Hauptmerkmal zukünftiger Sampler weiterentwickelt und angeboten (Harkins 20I6: 34; Großmann 2005: 32I).

Die technologisch-mathematische Semantik "Sampling» hielt fortan Einzug in die musikalische Welt. Ab den frühen I980er Jahren kamen vor allem in den USA, später dann auch in Europa Geräte in den Handel, die weniger die Simulation klassischer Instrumente, sondern mehr die Samplingfunktion in den Vordergrund stellten und gezielt als "Sampler" vermarktet wurden, wie der Emulator I (I98I) und der SPI200 (1985) von E-Mu Systems oder der MPC 6o (I988) der japanischen Firma AKAI. Zwar waren auch diese ersten Sampler in ihrer Klangqualität äußerst beschränkt und kosteten einige tausend Dollar (Schloss 2004: 3I), wegen ihrer einfacheren haptischen

38 In einer TV-Dokumentation aus den frühen I98oer Jahren sind die beiden Jazzmusiker Herbie Hancock und Quincy Jones bei der Arbeit mit dem Fairlight CMI zu sehen. Teilweise ist ein Techniker (engineer) zugegen, der parallel zum Spiel an der Klaviatur am Computer aufgenommene Samples präpariert: https:// www.youtube.com/watch?v=9SHh6zObiiQ (05.I0.2017) 
Zugänglichkeit über Pads statt Klaviaturen verfügten sie allerdings über geringere Einstiegshürden. Sie waren auf ein größeres, also auch amateurhaftes Publikum zugeschnitten, das nach dem kommerziellen Markterfolg von Hip Hop sich zuhause an einer Musik aus Musik versuchen wollte und dabei einen intuitiveren Zugang zur Technik benötigte. Die Samples wurden dafür in recht bescheidener Qualität extern auf Disketten gespeichert, welche aus der Computerindustrie als Speichermedien bekannt waren. Die Kapazität des internen Arbeitsspeichers der frühen Sampler war ebenfalls stark limitiert, so dass anfangs ein typisches Gerät wie der Emulator I maximal ein nur etwa zwei Sekunden langes Sample in dumpfer 8-Bit-Qualität speichern konnte.

Trotz - oder gerade wegen - dieser aus heutiger Sicht schwerlich vorstellbaren Unzulänglichkeiten regten die Sampler zu kreativem, unsachgemäßen Gebrauch an. Es ist ein wiederkehrendes Muster in der Geschichte des Samplings, dass technologische Unzulänglichkeiten und Limitationen kreative oder zumindest ästhetisierte Reaktionen nach sich ziehen. Die Kapazitätsgrenzen der frühen Sampler machten sich beispielsweise in der Klangästhetik der produzierten Stücke bemerkbar, weil Produzent_innen die gewünschten Samples auf höherer Geschwindigkeit einspielten. Aus der eigentlichen technischen Limitation wurde ein ästhetischer Anreiz, denn durch kreative Umgehung entstand ein charakteristischer "Chipmunks«-Effekt (Reynolds 1998: 136), der in vielen Vocalsamples im Techno der frühen I990er Jahre zu hören war. Ähnliches berichten McLeod und DiCola mit Verweis auf den Hip Hop-Produzenten RZA vom Wu-Tang Clan:

"Speaking to the limitations of the technology at the time, RZA explains that the machine could only store two seconds of sound. To bypass this, he would increase the turntable speed so he could import more musical information into those two seconds, and then slow the playback as much as possible. This degraded the quality of sampled recording but it gave RZA and other producers more time to play 
with - and it also created a certain >dirty digital sound that appealed to hip-hop fans and artists at the time, and continues to do so today." (McLeod/DiCola 20II: 6I)

In Anlehnung an die Praxis der DJs bezeichnet Poschardt (1997: 235) den Sampler als »digitale Plattenkiste«, in der Ausschnitte bereits präfabrizierter Musik aufgrund ihrer digitalen Reproduzierbarkeit, das heißt in Form von "Samples" deutlich präziser abrufbar wurden als auf den bekannten analogen Massenmedien Schallplatte, Tonband und Kassette. Tatsächlich waren es diverse DJ-Praktiken, die auf die Sampler als grundlegende Techniken übertragen und dadurch verfeinert, erweitert oder gesteigert wurden; zum Beispiel die Praxis des "third record «, die der Musikwissenschaftler Mark Butler für die Arbeit von House-, Techno- oder Drum'n'Bass-DJs beschreibt:

"The manipulation of textural layers is a central component of the art of DJing as well. The most obvious manifestation of this phenomenon is the practice of mixing two or more records together. To be a successful DJ, one must be able not only to match beats, but also to choose records that will work well when they played simultaneously. [...] If the records are mixing well, the audience will not be able to tell that the sounds are coming from different sources. Instead of hearing two different records, the will hear an integrated combination of sounds - a hybrid that is often called the third record.." (Butler 2006: 94)

Butler beschreibt die DJ-Technik der virtuellen "dritten" Platte, die aus der Vereinigung zweier anderer Platten emergiert, bewusst als handwerklich-ästhetische Kunstform, die Übung und Sinn für Timing erfordert. Denn die Verbindung unverbundener Töne aus präexistenten Musikstücken an Plattenspielern oder Tonbändern ist nicht trivial und in der Ausgestaltung medieninhärenten Grenzen unterworfen. So ist die Wiederholung einer kurzen, einmaligen Stelle auf der Platte nicht ohne weiteres möglich, sondern kann nur durch 
das Zurückdrehen der Platte oder die manuelle Versetzung der Nadel erzielt werden. Die bewusste Stelle bleibt ephemer und muss immer wieder auf's Neue durch das Zusammenbringen von Nadel und Rille angesteuert werden.

Dieses Problem der präzisen Ansteuer- und Wiederholbarkeit löste der Sampler im Sinne eines "akustischen Skalpell[s] « (Pelleter/ Lepa 2007: 202). Dadurch enstand eine Fülle an neuen Rekombinationsmöglichkeiten, die die technisch-künstlerische Grundlage für diverse samplebasierte Genres legte: Mithilfe der mit den Jahren verbesserten Samplingfunktionen ließen sich digitale Klänge beliebig oft ansteuern, ohne iterativen Klangverlust und ohne Mühe wiederholen, zeitlich ausdehnen und verkürzen, im Tempo beschleunigen und verlangsamen, in der Tonhöhe verändern sowie in diversen neuen, filigranen Formen reorganisieren (Schloss 2004: 39). So erklärt auch der deutsche Hip Hop-Musiker Sascha Klammt der Band Kinderzimmer Productions die vielfältigen neuen Möglichkeiten des Samplers als Grundlage zur Ausdifferenzierung der vom DJing bekannten DJ-Praktiken:

„Ein Sampler kann eine Vielzahl von Klängen verwalten, die auf Abruf sofort bereit stehen. Das entspricht der Möglichkeit, auf Knopfdruck eine große Anzahl von Plattenspielern zu starten und sie nach Ablauf einer musikalischen Sequenz direkt zu wiederholen. Darüber hinaus können die Klänge in Echtzeit in ihrer Geschwindigkeit weitaus stärker verändert werden als mit einem Plattenspieler. Samples können editiert, also genau beschnitten und dauerhaft gespeichert werden. Kurz gesagt: Jedes Sample entspricht einer optimierten Schallplatte, die keinen Plattenspieler benötigt und sofort zur Verfügung steht.« (Klammt 20IO: 3)

Die vielfältigen Möglichkeiten des digitalen Samplings erlaubten es, dekontextualisierte Klänge nicht mehr nur hintereinander in der Horizontalen zu montieren, sondern auch übereinander in der Vertikalen zu schichten. Die an den analogen Medien Tonband, Schallplatte 
und Kassette vorbereiteten ästhetischen Methoden fanden mit den Samplinggeräten ihre digitale Entsprechung und erlebten einen bemerkenswerten Entwicklungsschub, der in den I990er Jahren durch softwaregestützte Computersysteme abermals gesteigert wurde. Die Euphorie bezüglich gesteigerter technischer Reproduzierbarkeit fand in hochreferentiellen, besonders samplelastigen Alben, die mitunter mehrere hundert Samples nach ästhetischen Konfigurationen miteinander kombinierten, ihren Ausdruck. Meines Wissens war keiner der damals im Umlauf befindlichen Sampler mit einer urheberrechtlichen Konfiguration ausgestattet, so dass Klänge jeglicher Provenienz ohne Kopierschutz aus ihren ursprünglichen Zusammenhängen gelöst und als Kopien innerhalb neuer Zusammenhänge bearbeitet werden konnten. Ähnlich wie sich bei der Fotografie belichtete Elemente in einem visuellen Medium festhalten lassen, bot der Sampler die vielversprechende Möglichkeit, musikalische Momente zu fixieren und sich damit stichprobenartig an der bisherigen Musikgeschichte zu bedienen - um beispielsweise die eigene Zugehörigkeit zur afrodiasporischen Identität zu artikulieren (Gilroy 1993: 82; Rose 1994).

Diese Möglichkeit der kopiebasierten Bearbeitung transformierte retroaktiv den historischen Katalog der Popmusik. Die bisherige Musik erschien nun nahezu vollständig angreifbar und re-interpretierbar. Und es wurde möglich, sich selbst in den Kreislauf einzuschreiben. Damit stieg auch der Bedarf nach unverbrauchter, übersehener und vergessener Musik, nach beiläufigen musikalischen Momenten, die prominent aufgewertet und mit anderen rekombiniert werden konnten.

Trotz zunehmender Ausdifferenzierung und Verbreitung stand die Praxis des Samplings stets unter Legitimationsdruck (vgl. Reynolds 20II: 3I4). Es enthielt zwar bereits eine Nähe zu bekannten künstlerischen Verfahren wie der Collage oder der Montage, des cut up oder der appropriation art, wurde aber trotzdem aufgrund der digitalen Reproduzierbarkeit von Klängen als neue, den tradierten Formen des bildungsbürgerlichen Originalitätsbegriffs entgegenlaufende und damit dem Plagiat beziehungsweise der Piraterie nahestehende Herangehensweise aufgefasst (vgl. Diederichsen 2006). Bis zum 
Ende des Jahrtausends etablierte sich das digitale Sampling nicht nur als produktionstechnische Grundlage von Hip Hop, sondern wurde - durch seine Einbettung in softwarebasierte Digital Audio Workstations (DAW) - ab Anfang der I99oer Jahre auch zentral für andere klangbasierte und DJ-getriebene Genres wie House, Techno, Drum'n'Bass und weitere. Wie Simon Reynolds (1998) in seiner umfangreichen historischen Betrachtung nachweist, breitete sich das Verfahren des Samplings, zunächst vor allem mit dem Hip Hop aus den USA kommend, in Japan und über Großbritannien auch in Kontinentaleuropa aus, verband sich mit regionalen musikalischen Stilen und verankerte sich in den Praktiken der Turntablism-DJs und Musikproduzent_innen.

Die nachhaltige Stabilität der auf Sampling bezogenen Praktiken lässt sich bis heute empirisch nachvollziehen, weswegen ich einer Beschreibung an dieser Stelle nicht vorgreifen möchte (siehe Kapitel 6). Das digitale Sampling machte sich ab etwa Mitte der I980er Jahre auch in anderen gesellschaftlichen Funktionssystemen bemerkbar und beschäftigte fortan heterogene Akteure. Es wurde nicht nur als musikalische Praxis betrachtet, sondern strahlte auch in andere Bereiche aus und von dort wieder zurück. Die künstlerischen, akademischen und journalistischen Beschäftigungen mit dem Sampling als neue ästhetische Praxis flankierten den kommerziellen Aufstieg von Hip Hop und verstärkten sich wechselseitig. Innerhalb der Musikindustrie wurden Wege geebnet, wie sich Sampling als gewinnbringende Produktions- und Verwertungspraxis integrieren lassen konnte, was wiederum rechtliche Diskussionen nach sich zog. In Fortführung der historischen Perspektive werde ich nun in Kapitel 4 die Reaktionen des Rechtssystems auf die technisch-künstlerische Innovation des Samplings aufarbeiten und anschließend in der Betrachtung des Forschungsstands zum Thema Sampling die Defizite der empirisch orientierten Urheberrechtsforschung herausstellen. 



\section{Sampling zwischen Kreativität und Kriminalität}

Im vorangegangenen Kapitel wurde die historische Entwicklung des Samplings hin zu einer digitalen Praxis aufgearbeitet und im Sinne einer sich nachhaltig stabilisierenden Innovation gezeigt, dass sich die ästhetischen Praktiken bis Mitte der I980er noch relativ unbeeindruckt von der urheberrechtlichen Sphäre verfestigen konnten. Um die heutigen Narrative um Sampling besser zu verstehen, steht in diesem Kapitel nun die Frage im Vordergrund, wie die technisch-ästhetischen Entwicklungen des digitalen Samplings ab den I980er Jahren das Rechtssystem systematisch irritieren und es darauf reagiert, indem es versucht, die ästhetischen Konfigurationen technischer Reproduzierbarkeit als urheberrechtliches Problem zu deuten und dadurch unter Kontrolle zu bringen. Der Schwerpunkt dieses Kapitels liegt daher auf einer sozialwissenschaftlich informierten Nachzeichnung und Analyse des Diskurses um den Themenkomplex Sampling, Kreativität und Urheberrecht beziehungsweise Copyright Law, der sich ab Mitte der 1980er Jahre in juristischen Debatten formiert und über die Grenzen des Rechts dominant wird.

Während die Entwicklung der Praxis Sampling bis hierhin vor allem unter dem Blickwinkel gesteigerter technischer Reproduzierbarkeit untersucht und gelegentliche Suspensionen derselben eingeflochten wurden, drehe ich diese Perspektive nun in gewisser Weise um. Ich wende mich dazu der semantischen Aushandlung von urheberrechtlichen Grammatiken und Neuheitsimperativen zu, die für Suspension und Einhegung technischer Reproduzierbarkeit sorgen sollen, und ergänze stellenweise die künstlerischen Reaktionen. Für dieses Vorhaben berücksichtige ich wesentlich zwei Schwerpunkte: 
die Behandlung des Samplings unter Rückgriff auf einer an physischem Eigentum orientierten Diebstahlsrhetorik und die Ausbildung von sample clearing als innovative Vermittlungspraxis zwischen Wirtschaft, Recht und Kunst. Daran anknüpfend erarbeite ich im zweiten Teil des Kapitels den derzeitigen Stand der interdisziplinären, stärker empirisch arbeitenden Urheberrechtsforschung mit Fokus auf das Sampling, welche auch nicht intendierte Effekte des Rechts einzufangen weiß. Zu Beginn des Kapitels ist die Darstellung noch etwas kleinteilig; mit zunehmender Wiederholung der Argumente und der Stabilisierung von Narrativen kann dann geraffter dargestellt werden.

\subsection{Urheberrechtliche Konfigurationen technischer Reproduzierbarkeit. Sampling als illegale Kunst}

\subsubsection{Neve Technik, neve Fragen: "Digital sampling: Is it theft?"}

Die frühen Publikationen der I980er Jahre stehen deutlich unter dem Eindruck der Neuheit der digitalen Samplingtechnologie, den zu erwartenden Chancen und Risiken für die Musikindustrie. Als grundsätzlicher Tenor überwiegt in der fachjuristischen wie in der medialen Debatte deutlich die Sorge um den Kontrollverlust durch unerlaubte Kopien gegenüber den schöpferischen Möglichkeiten der Rekombination, die durch das Sampling entstehen. Die semantischen Vorstöße sind daher vor allem delegitimierender Natur. Zwar hatten sich Mitte der I980er Jahre bereits eine Vielzahl an Produktionspraktiken im Zusammenhang mit dem Sampling ausgebildet, unklar blieb allerdings, ob, wie und für welche Interessen die juristische Grammatik auf das Sampling angewendet werden könnte. Dementsprechend grundsätzlich wird im August 1986 im Branchenblatt Billboard gefragt: „Digital sampling: Is it theft?» (Dupler 1986a). Eine 
Woche später ist man sich schon recht sicher: Elf Anwälte hatten eine Einschätzung abgegeben. Neun von ihnen bestätigen, dass Sampling gegen das US-Copyright Law verstoße; nur zwei antworten zögerlich und ausweichend (Dupler 1986b).

In rechtswissenschaftlichen Fachzeitschriften diskutiert man zur Bewertung des Samplings mögliche neue Potentiale und die Bedrohung gewohnter Kontrolle in der Musikindustrie: "[T]he balance is a struggle between the right of artists to control their own work and that of unencumbering the creative opportunities inherent in a new technology." (McGraw 1989: I52) Sampling, so wird an anderer Stelle festgestellt, sei sogar eine neue Form der Piraterie: "Piracy is no longer limited to simple copying of an entire song. The crucial distinction is that digital sampling pirates today utilize only parts of a song." (Thom I988: 310) Oder es wird auf die Zweischneidigkeit technischer Reproduzierbarkeit abgehoben, da wegen ungezügelter und unkontrollierbarer Kopien der Anreiz für Kreativität unterminiert würde:

"On the one hand, digital technology may greatly enrich the creative process by generating countless new, transformative works. On the other hand, if the original works can be freely manipulated, the technology may actually diminish the production of new works by undermining creative incentives." (Szymanski 1996: 330)

Vor diesem Hintergrund interessieren in den frühen Publikationen vor allem Fragen, ob und wie einzelne Sounds überhaupt unter dem US-amerikanischen Copyright Law Act von 1976 geschützt seien, wie sich die rechtlichen Mittel zur Kontrolle und Regulation anwenden lassen oder welche rechtlichen Unterschiede zwischen den nationalen Rechtssystemen beim Sampling zu beachten seien (Albright 1988, Arn 1989, Bently 1989, Marcus 1991, Baroni 1993, Litman 1988). Charakteristisch für diese Phase ist auch die Diskussion verschiedener rechtlicher Wege zur Prüfung der Legalität eines Samples (McGiverin 1987; Houle 199I; Kravis 1993). 
Ronald Wells (1989) beispielsweise lässt grundsätzliche Sympathie für die expressiven Möglichkeiten des Samplings erkennen, indem er seinen Aufsatz in Referenz an den berühmten Song der Rolling Stones mit "You Can't Always Get What You Want But Digital Sampling Can Get What You Need!" betitelt - und sich beeilt, in einer Fußnote brav hinzuzufügen, dass das Copyright an Text und Musik dieses Stücks bei Mick Jagger und Keith Richards liege. Auch bringt er das Verhältnis von Kreativität und Copyright ins Spiel, als er das Dilemma zwischen technischen Möglichkeiten und rechtlicher Grenzziehung formuliert: "Depending on your outlook, copyright law can be seen as either helping or hindering these musicians. (Wells I989: 69I) Das Problem erscheint ihm dabei eher akademischer Natur, denn er verfolgt es in dem Aufsatz nicht weiter. Hauptanliegen bleibt die rechtliche Einordnung des Samplings und seine zukünftige Rolle in der von Urheberrechten getriebenen Musikindustrie:

"Nevertheless, digital sampling will undoubtably make its way to the forefront of the copyright infringement arena. Although digital sampling is a potential Pandora's Box to the music industry, present copyright law appears broad enough to address any problems that digital sampling may cause." (Wells I989: 705)

Andere hegen im Zusammenhang mit dem Sampling Zweifel an dem Zweck des Copyright Law, Wissenschaft und Künste zu fördern. Jeffrey Houle legt dabei allerdings ein besonders romantisches Kreativitätsverständnis an den Tag, wenn er pathetisch bilanziert: »Those [...] violate the copyright protections of a fellow artist should not be allowed to profit from their actions. Only in this way will true creativity be spawned and true genius discovered." (Houle I99I: 902)

An anderer Stelle wird Sampling als Problem identifiziert, das auch die Gewerkschaften beschäftigen sollte:

"There is a growing black market of sampled musicians and of recording engineers who keep libraries of samples to use in lieu of flesh 
and blood performers. [...] Hit hardest thus far, however, are percussionists, bassists, and brass and string players, whose sounds have been the most successfully copied and who have, in effect, lost their jobs to a computer. Unlike most other victims of technological advance, however, these musicians find themselves jobless because their own original efforts are being appropriated and used in competition against them." (McGiverin 1987: 1723)

Ein weiteres typisches und wiederkehrendes Motiv zeigt die Sorge an, dass Sampling in die falschen Hände geraten könnte - nämlich in die der Unbefugten und Amateure. Der hart erarbeitete Ruf einer Musiker_in, und damit letztlich auch ihre Kreativität, ließe sich durch unautorisiertes Sampling leicht beschädigen: „Unfortunately, digital sampling places that sound at the fingertips of even the most inexperienced musician."(Arn 1989: 69).

In Abgrenzung zu diesem Kulturpessimismus entwickelt der $\mathrm{Mu}-$ siksoziologe Simon Frith eine kritischere Position. Er betont stärker die Kultur der Referentialität, die aus dem Sampling hervorgeht, samt ihrer postmodernen Züge: "All sounds could be grist to this mill, whether politicians' speeches, police sirens, bugged conversations, or the accidental effects of electronic distortion itself." (Frith 1986: 276) Allerdings seien viele Hip Hop-Songs nicht legal erhältlich, da die Benutzung von vorgefundenem Klangmaterial (»found sound «) in den Augen der Musikindustrie zu Piraterie und der Verletzung von Eigentumsansprüchen führt. Der Kampf der Industrie, so Frith, würde dabei ironischerweise »in the language of individual creativity" geführt:

"What is happening now is that technology is disrupting the implicit equation of artists' 'ownership of their creative work and companies' ownership of the resulting commodities - the latter is being defended by reference to the former. Copyright has become both the legal, ideological weapon with which to attack the 'pirates and, increasingly, the source of multi-national leisure corporations' income, as they 
exploit the rights in their productions by licensing them for use by smaller companies and other media." (Frith 1986: 276)

Den identifizierten Antagonismus von Kreativität und Piraterie, den Frith als argumentativen Vorstoß der Musikindustrie zu enttarnen versucht, spitzt er in einem wenig später erscheinenden Artikel noch zu:

"For the music industry the age of manufacture is now over. Companies (and company profits) are no longer organised around making things but depend on the creation of rights. [...] Musical rights (copyrights, performing rights) are the basic pop commodity and to understand the music business in the 1980s we have to understand how these rights work.« (Frith 1988: 57)

In Bezug auf das Sampling sieht Frith daher ein gravierendes verwertungsrechtliches Problem, das Sampling in die Illegalität treibe, insofern das US Copyright Law nicht mit dem Kopieren und Re-Arrangieren von Samples als künstlerische Eigenleistung umzugehen wisse. Als Beispiel nennt er einen sogenannten "Megamix « aus verschiedenen Beatles-Songs, die Medley-artig auf einen Discobeat montiert wurden, der nicht lizenziert und entsprechend verwertet werden konnte. Als Cover hingegen konnte das Medley später durchaus unter einem anderen Produzenten und von angeheuerten Studiomusikern für die bekannte Reihe "Stars on 45" neu eingespielt und dadurch einwandfrei kommodifiziert werden. Der Sound der Beatles wurde hierbei bewusst imitiert: »The latter duly got their mechanical royalties as composers; the $\mathrm{dj}$ whose idea/beat/sequence was exactly copied was entitled to nothing at all." (Frith 1988: 66). Ohne es als solche zu bezeichnen, weist Frith hier auf eine kreative Umgehungsstrategie hin, mit der die paradoxe rechtliche Situation zu Ungunsten des erfindenden DJs gelöst wurde. Frith macht damit auf die verwertungsrechtliche Ungleichbehandlung verschiedener Reproduktionstechniken aufmerksam und kritisiert die Bevorzugung des Coverings gegenüber dem Sampling. 
Von einem anderen rechtlichen Schlupfloch profitierten die DJs Double Dee und Steinski bereits in der ersten Hälfte der I980er Jahre: Für ihren Megamix »Lesson I", besser bekannt als »The Payoff Mix", mischten sie zahlreiche Songs, aber auch Ausschnitte aus Fernsehsendungen und Filmen in- und übereinander. Das Label veröffentlichte das Stück wegen der zahlreichen Samples nicht auf Schallplatte dank einer Lizenzvereinbarung, die es Radio-DJs erlaubte, auch Medleys und kurze Ausschnitte aus Stücken im Radio zu spielen, wurde "Lesson I « trotzdem »one of the first sillegal« hits« (McLeod 2015: 607, Hervorhebung im Original).

Auch in der intellektuellen künstlerischen Szene reagierte man auf die Möglichkeiten und Risiken des digitalen Samplings. Der kanadische Komponist John Oswald prägte den Begriff plunderphonics für die neue, auf existierenden Sounds aufbauende Kunstform. 1985 bereits stellte er in dem Essay »Plunderphonics, or Audio Piracy as a Compositional Prerogative« die Frage, in welchem Ausmaß sich man legal bei den Klängen Dritter bedienen darf, und problematisierte das Verhältnis von eindeutiger Autorschaft und der komplexen rechtlichen Herstellungskette kommodifizierter Popmusik. Er stellt dabei die aktive Zuhörer_in sowie die Erkennbarkeit der Referenzen als entscheidende Faktoren in den Vordergrund: "A plunderphone is a recognizable sonic quote, using the actual sound of something familiar which has already been recorded [...] Taking Madonna singing 'Like a Virgin` and rerecording it backwards or slower is plunderphonics, as long as you can reasonably recognize the source." (Oswald 1985)

\subsubsection{Neue, kriminelle Kunst: "Thievery in the form of sampling"}

Im Laufe der I980er Jahre setzt sich unter Musikproduzent_innen und Labelbetreiber_innen die Erkenntnis durch, dass das unautorisierte Kopieren von Ausschnitten fremder Musik zu empfindlichen 
rechtlichen, monetären und künstlerischen Verwicklungen führen kann (Okpaluba 20I4). Mediale Berichte über Klagen und Gerichtsverhandlungen befeuern die Debatte und prägen den Diskurs über Sampling entscheidend mit. ${ }^{39}$ Besonders medienwirksam ist dabei die Klage der Band The Turtles gegen die Hip Hop-Gruppe De La Soul auf I,7 Millionen Dollar wegen eines zwölf Sekunden langes Samples aus dem Lied "You showed me" (1969). De La Soul benutzten das Sample für das kurze Stück »Transmitting Live From Mars« in Form eines verlangsamten Loops und kombinierten es mit Samples aus einer Französisch-Lernkassette. De La Soul hatten ihrem Label zwar eine Liste der Samples für das Album ausgehändigt, für das TurtlesSample wurde aber - versehentlich oder intentional - keine Genehmigung angefragt.

Das Album wurde ein enormer kommerzieller Erfolg für De La Soul, was für sie jedoch gleichermaßen das Risiko erhöhte, verklagt zu werden. Die Parteien einigten sich auf einen Vergleich von 50000 Dollar. Eine gerichtliche Entscheidung blieb folglich aus, so dass die Chance verpasst wurde, faire Regeln und Summen für Fälle dieser Art auszuhandeln und die Rechtslage genauer zu bestimmen (Simon 2005). Wie so oft in diesen Fällen, wurde auch hier Sampling mit Diebstahl gleichgesetzt und mit dem Fehlen jeglicher Kreativität in Verbindung gebracht: »Sampling is just a longer term for theft [...] Anybody who can honestly say sampling is some sort of creativity has

391987 veröffentlichte die britische Elektronikformation The JAMs, später besser bekannt als KLF, ein Album mit zahlreichen unautorisierten Samples aus bekannten Popsongs, woraufhin das Label von ABBA eine Klage einreichte und die britische Verwertungsgesellschaft PRS forderte, die unverkauften Kopien des Albums einzustampfen. Wenig später veröffentlichten The JAMs als Protest gegen das als Zensur empfundene Vorgehen eine Version des Albums, in der alle Fremdsamples entfernt waren, so dass zahlreiche stille Passagen in den Stücken zu hören waren. Im gleichen Jahr waren die Produzenten M/A/R/R/S mit einer Klage wegen eines Samples konfrontiert, das sie für ihren Charthit »Pump up the Volume " verwendet hatten und das sie nach einer außergerichtlichen Einigung dann entfernten. Das Stück selbst baute auf einer Vielzahl anderer, rechtlich aber offenbar unproblematischer Samples auf. 
never done anything creative«, so das Statement eines der TurtlesMitglieder (Volman zitiert nach McLeod/DiCola 20II: 63).

An anderer Stelle wird zur Vermeidung solcherlei Komplikationen ein System umfassenden Sample Clearings vorgeschlagen, basierend auf "good faith and fair dealing" (Marcus I991: 790). Daneben sieht Jason Marcus die Zukunft des Sample Clearings nicht als Zwangslizenz, sondern macht den versöhnlichen Vorschlag für »a voluntary scheme, which, if effective over an extended period of time, could then be reported to Congress and the Copyright Office with the goal of possibly amending the Copyright Act to apply to digital sampling." (Marcus 1991: 787) Als Informant wird der Anwalt Ken Anderson herangezogen, der für das Album "Paul's Boutique« der Beastie Boys um die 400 Samples klärte; nach eigener Angabe "for little or no cost« (Marcus I99I: 768). ${ }^{40}$ Auf Grund dieser Erfahrung sei Anderson überzeugt, dass gesampelte Künstler_innen vor Veröffentlichung um Erlaubnis gefragt werden wollten, denn es ginge ihnen um »respect and recognition most of all«.

Marcus nennt weitere Beispiele für gelungene Lizenzierungen: Für nur 3000 Dollar beispielsweise kauften Stetsasonic für »Talking all that jazz« dem Musiker Lonnie Listen Smith das komplette Copyright an dessen Song "Expansions" ab; und De La Soul beteiligten den Funkmusiker George Clinton zu einem bestimmten Prozentsatz an ihren Albumerlösen (Marcus 1991: 786). Demgegenüber bestehe allerdings weiterhin das Problem, mit einer Anfrage abgewiesen zu werden und damit dem gesampelten Label einen Informationsvorsprung zu gewähren, wie ein weiterer mit Sample Clearing befasster Anwalt erklärt:

40 Diese Aussage ist bis heute strittig: So bezieht sich Johnson Okpaluba auf den damaligen Studiotechniker der Beastie Boys, der behauptet, das Album habe etwa 250000 Dollar Lizenzgebühren gekostet (Okpaluba 20I4: 87). Dieser Betrag klingt schon realistischer, wenn man in Betracht zieht, dass die Beastie Boys mit den Verkäufen ihres Debütalbums »Licensed to Ill« (1986), dessen Titel auch schon auf den Prozess des Sample Clearings anspielt, bereits Platinstatus erreicht hatten und einen erfolgreichen Ruf in der Musikindustrie genossen. 
"Working out a legal defense for clients concerned about crossing the line of copyright is tricky business. [...] Most lawyers will tell their clients not to ask for legal permission because if they get turned down and sued then it is intentional infringement." (Weiner zitiert nach Marcus 1991: 787; vgl. Sewell 20I4: 298)

Dass die Praxis des Samplings in den USA juristisch bekämpft und musikwirtschaftlich unter Kontrolle zu bringen versucht wird, nimmt man in der Hip Hop-Welt anfangs mit Argwohn und Unverständnis zur Kenntnis. Zur Verteidigung und Begründung ihrer illegitimen - und teils bereits als illegal eingeschätzten - Kunst melden sich Rapper_innen in journalistischen Interviews und vor allem in ihren Songtexten zu Wort. In "Talkin’ all that Jazz« (1988) beispielsweise rechtfertigt die New Yorker Rapgruppe Stetsasonic ihre Praxis, indem sie sie als neue Form des Jazz präsentiert und damit in den Kontext einer etablierten, afroamerikanischen Kunstgattung stellt. Zu Beginn des Musikvideos ${ }^{41}$ ist ein Anwalt zu sehen, der selbstbewusst einer Reihe von Journalist_innen ein Interview gibt:

"Of course we expect to win. Any self-respecting intelligent person knows that this so-called band Stetsasonic and the rest of this Hip Hop music is a fad which one, is not creative, two, inspires violence, and three, encourages thievery in the form of sampling."

In diesem Moment treten Stetsasonic auf die Journalist_innen zu, schnappen sich in einem Akt medialer Selbstermächtigung das Mikrofon und verschaffen sich Gehör für ihre Sache:

"Well here's how it started, heard you on the radio / Talking 'bout rap, saying all that crap / About how we sample, giving examples / Think we'll let you get away with that? / You criticize our method of how we make records / You said it wasn't art, so now we're gonna rip you apart /

4I Abrufbar unter https://www.youtube.com/watch?v=2kdQ4soLcac (24.08.20I8). 
Stop, check it out my man / This is the music of a hip-hop band / Jazz, well you can call it that / But this jazz retains a new format / Point, where you misjudged us / Speculated, created a fuss / You've made the same mistake politicians have / Talkin' all that jazz [...]

You see, you misunderstood, a sample's just a tactic / A portion of my method, a tool, in fact it's / Only of importance when I make it a priority / And what we sample's loved by the majority / But you a minority in terms of thought / Narrow minded and poorly taught / About hip-hop, playing all the silly games / To erase my music so no one can use it $[\ldots]$

Think rap is a fad? You must be mad / Cause we're so bad we get respect you never had / Tell the truth, James Brown was old / 'Til Eric and Ra came out with \I Got Souk / Rap brings back old R\&B / And if we would not, people could've forgot [...]

Stetsasonic, the hip-hop band / And like Sly and the Family Stone, we will stand / Up for the music we live and play / And for the song we sing today / For now, let us set the record straight / And later on we'll have a forum and a formal debate [...] Talkin' all that jazz' " (Stetsasonic 1988)

Indem Stetsasonic die Polysemie des Wortes »Jazz« hervorheben - einerseits als abwertendes, im Slang gebrauchtes Wort für Schwachsinn oder Schmarrn, andererseits als afroamerikanisches Musikgenre bringen sie die Spannung zwischen den konfligierenden Perspektiven zum Ausdruck. Den extern herangetragenen Abwertungen von Sampling als bloßer Mode, Diebstahl und Teil einer gewalttätig-kriminellen Bewegung stellen sie ihre interne Sicht entgegen, die Sampling als Erweiterung der afroamerikanischen Kunstform Jazz durch die Wiederbelebung und Weiterentwicklung vergessener $\mathrm{Mu}$ siken begreift (Shustermann 1992: 220).

Zwei Punkte sind hier wichtig, denn sie tauchen in der Diskussion um das Sampling immer wieder auf und bilden Eckpunkte eines 
Narrativs zur Legitimierung: Erstens die argumentative Figur des valorisierenden Vergleichs, der eine Referenz herstellt zwischen Altem und Neuem, genauer gesagt zwischen etwas, das weithin bereits als etabliert und legitim gilt, und dem, das noch um gesellschaftliche Anerkennung ringt und seine ästhetische Illegitimität abschütteln will. So ziehen DJs beispielsweise die Pop Art Andy Warhols (Wilder 2005: 89) oder die Kunstform der Collage (Sinnreich 2010: 99) zum Vergleich heran, um einen für sie günstigen Maßstab zur ästhetischen Bewertung des Samplings zu schaffen. Zweitens das vorgebrachte Argument, Sampling verstärke die Nachfrage nach den gesampelten Originalen, das ich hier als Reoriginalisierung bezeichne (vgl. Fischer 20I6). In einer australischen TV-Dokumentation über Sampling von I988 berichtet die von Coldcut gesampelte Sängerin Ofra Haza über das gestiegene Interesse an dem Original ihrer Stimme und der Hip Hopper Fresh Prince erklärt: "Let's take James Brown for instance. James Brown was finished. James Brown was old. Rap and sampling made James Brown new again. ${ }^{42}$ Auch in späteren Abhandlungen wird das Argument der Reoriginalisierung durch Sampling eingebracht (vgl. Schuster 20I5; Chang 2007; von Gehlen 20I0: 75).

\subsubsection{Neve Probleme: "All Samples Cleared?"}

Hatte sich das US Copyright Law bis Anfang der I99oer Jahre im amerikanischen Hip Hop eher als diffuse und noch in Aushandlung befindliche Dimension erwiesen, endete diese Situation der Unklarheit mit dem Rechtsstreit zwischen Gilbert O'Sullivan und Biz Markie. Zwar gab es bis dahin schon eine Handvoll ähnlicher Streitigkeiten, so dass sich viele Hip Hop-Produzent_innen bereits mit dem Vorwurf der Illegalität konfrontiert sahen. Doch wurden bisher alle Auseinandersetzungen außergerichtlich in Vergleichen abgewickelt, so dass keine Rechtssicherheit für die Verwendung von Samples, sondern ten-

42 Abrufbar unter https://www.youtube.com/watch?v=cu38AL4 $\mathrm{E}_{7} \mathrm{I}_{4}$ (24.IO.20I7). 
denziell eine Grauzone vorherrschte (Sewell 20I4: 295). Das Urteil ist daher vermutlich die erste in der Rechtsprechung formulierte urheberrechtliche Konfiguration technischer Reproduzierbarkeit für Sampling und stellt klar: Ohne Erlaubnis der gesampelten Rechteinhaber_innen ist Sampling nach US-amerikanischem Copyright Law illegal.

Der Streit spielte sich folgendermaßen ab: Für sein Stück »Alone Again « hatte der Rapper Biz Markie ein circa 20-sekündiges Sample des Singer-Songwriters Gilbert O'Sullivan (1972) benutzt und sich von der generellen Stimmung des melancholischen Stücks inspirieren lassen. Auch der Songtitel war der gleiche. Biz Markie fragte eine Lizenz bei O'Sullivan an; dieser verweigerte, vermutlich weil er die Version von Biz Markie mit seinen ironischen Zwischentönen und dem parodieähnlichen Charakter nicht mochte. Biz Markie veröffentlichte trotzdem - ohne jegliche Genehmigung - und wurde daraufhin verklagt. Den nachfolgenden Gerichtsprozess Grand Upright Music v. Warner Bros. Records Inc. verlor er. Richter Kevin Duffy erkannte Diebstahl Geistigen Eigentums und ließ das vorgebrachte Argument, dass Sampling im Hip Hop bereits gewohnheitsmäßig stattfände, nicht gelten. Die Eröffnung des Urteils mit dem Verweis auf das siebte biblische Gebot ist heute legendär:

"'Thou shalt not steal has been an admonition followed since the dawn of civilization. Unfortunately, in the modern world of business this admonition is not always followed. Indeed, the defendants in this action for copyright infringement would have this court believe that stealing is rampant in the music business and, for that reason, their conduct here should be excused. The conduct of the defendants herein, however, violates not only the Seventh Commandment, but also the copyright laws of this country." (Duffy zitiert nach Sewell 20I4: 296)

Eine nachträgliche finanzielle Beteiligung schloss O'Sullivan aus, da es ihm vorrangig um die ästhetische Kontrolle seiner Stücke ging. Biz Markies Label musste das bereits gepresste und im Handel erhältliche 
Album »I need a Haircut« vernichten. 1993 veröffentlicht der Rapper dann einen nur mäßig erfolgreichen Nachfolger unter dem bezeichnenden Titel »All Samples Cleared«. In der übrigen Samplingwelt zog man nach diesem ersten Urteil zwei grundsätzliche Lehren: Die Veröffentlichung einer kopierten Passage in Form eines rekontextualisierten und wiedererkennbaren Samples bedarf stets der Zustimmung der gesampelten Originalurheber_innen. Falls die Lizenzierung misslingt, handelt es sich bei einer etwaigen Veröffentlichung um eine intentionale Verletzung des Copyrights der Originalurheber_innen, die - dank der erfolgten Lizenzierungsanfrage - bereits informiert sind und sich dementsprechend in einer guten Verhandlungsposition wiederfinden (Szymanski 1996: 29I). Die Benutzung von Samples findet, so legt es die Konsequenz aus diesen zwei Lehren nahe, also unter großer rechtlicher Unsicherheit statt.

Andere Streitigkeiten zeigen, dass die Regeln des US-Copyright Law durchaus unterschiedliche Interpretationen von urheberrechtlichen Konfigurationen technischer Reproduzierbarkeit zulassen. So gesteht die Fair Use-Doktrin der Verwendung von fremden Werkausschnitten größeren Spielraum zu, insofern daraus transformative Werke entstehen, beispielsweise Parodien, die sich antithematisch mit einem Werk auseinandersetzen, oder wissenschaftliche oder journalistische Publikationen, die andere Werke als Beleg oder zur Illustration heranziehen (Samuelson 20I6). Insofern die entnommenen Teile in einem angemessenen Verhältnis zum transformativen Werk stehen und das Originalwerk dadurch keine Konkurrenz erfährt, dürfen zum Zwecke der Kritik, Redefreiheit, öffentlichen Bildung und ähnlichem im Rahmen der Fair Use-Regelung ohne Autorisierung urheberrechtlich geschützte Werke teilweise übernommen werden (Aufderheide/Jaszi 20II: 24). Soweit ich es überblicke, wurde Fair Use in den USA bisher allerdings nur bei wenigen Sampling-Urteilen als valide Begründung berücksichtigt. ${ }^{43} \mathrm{Im}$ Fall Campbell v. Acuff-Rose

43 I99I wurde die kalifornische Rockband Negativland von U2 verklagt, da diese eine Platte mit dem Titel » $\mathrm{U}_{2}$ « herausgebracht und dort die gleichnamige Band ausgiebig gesampelt hatten. Negativland beriefen sich auf Fair Use, mussten aber 
Music beispielsweise wurde der 2 Live Crew in einer Copyright-Klage vorgeworfen, sich für ihre Version von "Pretty Woman« unautorisiert bei dem Original von Roy Orbison (1964) bedient zu haben. 2 Live Crew bestritten nicht, Gitarre, Bass und Schlagzeug sowie Teile der Gesangsmelodie und des Textes übernommen zu haben, beriefen sich aber auf Fair Use, da sie eine Parodie angefertigt hatten, in der sie von »Hairy Woman« und ähnlich mysogynen Anspielungen rappten und daher eine unterschiedliche Zielgruppe ansprachen (Schur 2015: 86) ${ }^{44}$

Anfang der 1990er Jahre gibt es auch in Europa erste Gerichtsentscheidungen zum Sampling. In dem britischen Fall $B B C v$. Precord geht es um Ausschnitte aus einem Interview, das ein BBC-Reporter mit einem Labour-Politiker Neil Kinnock geführt hatte. Offenbar kam es in dem Interview zu Beschimpfungen zwischen den Parteien, die aber in der offiziell von der BBC veröffentlichten Version herausgeschnitten waren. Eine Rap-Gruppe namens Verbal Vandalism gelangte an das vollständige Interview, sampelte 63 Worte daraus und veröffentlichte diese, unterlegt mit eigener Musik und Text, als eigenes, parodistisches Stück mit dem Titel »Rhondda Rhant Rhap«. Es kam zur Klage seitens der BBC, die vor Gericht eine einstweilige Verfügung gegen den Song erwirkte; das Gericht sah die Vorwürfe

trotzdem ihr Album vernichten. Den langwierigen Rechtsstreit samt anwaltlicher Konversation und Pressespiegel haben Negativland in einem eigenen Buch (Negativland 1995) umfassend dokumentiert.

44 Für Bourdieu markiert das Auftauchen von Parodien innerhalb des agonalen Felds der einzelnen Kunstgenres einen Moment der Emanzipation seitens aufstrebender Kunstformen. Bourdieu bezeichnet die Parodie daher auch als »häretischen Bruch«. Indem durch eine Parodie ein klassisches, kanonisches oder zumindest bekanntes Werk aufgenommen und dadurch referenziert, aber auch gleichzeitig ästhetisch angeeignet und konventional gebrochen wird, kann sie innerhalb des Kunstfelds einen neuen Pol, eine neue Perspektive aufzeigen und die Beziehungen der Akteure im Feld verändern. Durch die Parodie attackiere oder überwinde man, so Bourdieu, "the dominant mode of thought and expression not by explicitly denouncing it but by repeating and reproducing it in a sociologically non-congruent context, which has the effect of rendering it incongruous or even absurd, simply by making it perceptible as the arbitrary convention which it is.« (Bourdieu: 1983: 313) 
bestätigt, dass die Eigentumsrechte der BBC an der Originalaufnahme verletzt wurden (Bently/Sherman I992: I58). So wenig über diesen Fall heute zu finden ist, er zeigt in dem Verhältnis von Geistigem Eigentum und Kopiertechnologien die informationelle Dimension technischer Reproduzierbarkeit auf, die stärker um die nicht autorisierte Verwendung und Veröffentlichung von Informationen im Sinne eines leaks zentriert ist. Vermutlich nicht aus ökonomischen oder ästhetischen Interessen, sondern um politischen Schaden abzuwenden, hatte die $\mathrm{BBC}$ ihre urheberrechtliche Reproduktionshoheit behauptet.

Diese beiden Sampling-Entscheidungen aufgreifend, fordern die Juristen Lionel Bently und Brad Sherman 1992 eine differenziertere wissenschaftliche und juristische Betrachtung der "cultures of copying". So bezweifeln sie beispielsweise die Annahme, die originalen und gesampelten Stücke verhielten sich immer in Konkurrenz zueinander. Auch hegen sie Zweifel an der den sampelnden Musikern gerne unterstellten Intention, durch Sampling einfach nur Ressourcen zu sparen. Je nach künstlerischer Verortung sei die Suche und Auswahl von Samples sogar aufwändiger als die Interpolation:

"Indeed, it is arguable that in certain situations, sampling involves more time and effort than the independent production of the sample by a sound-alike. [...] A sample may operate, for example, as a reference, an allusion, as a quotation, a parody or, in turn, may function to historicise the work within a musical genre." (Bently/ Sherman 1992: 159)

Die Autoren schieben augenzwinkernd hinterher: "In the same way that Judge Duffy quotes from the Bible in Grand Upright, musicians increasingly quote from earlier works as a part of their common vocabulary." (Bently/Sherman 1992: 159) Zudem beklagen sie die hohen Transaktionskosten und die rechtliche Unsicherheit, die das Sample Clearing mit sich bringt. Das Fehlen eines funktionalen Lizenzierungssystems führen sie auf Marktversagen zurück. Gleichsam 
sehen sie die juristischen Tendenzen, mit urheberrechtlichen Mitteln Sampling-Kreativität zu unterdrücken, sehr kritisch. Vielmehr habe das Copyright Law die Aufgabe, die Regulation von Kopien, aber auch die Förderung von Kreativität zu gewährleisten. Diese Doppelaufgabe konnte bis zum Aufkommen erschwinglicher Kopiertechnologien wie dem Sampler und den damit verbundenen künstlerischen Folgen einigermaßen in Balance gehalten werden. Die Streitereien lassen aber erkennen, dass die Balance in einen Widerspruch zu kippen droht, wenn sich kein praktikables Lizenzierungssystem etablieren kann:

"Ultimately, the extent to which copyright law restricts or promotes copying depends on the availability of effective licensing schemes. This leads on to the final point which is that while the issue of the legality of sampling is important, far more important is the effectiveness of licensing schemes in facilitating copying and, in turn, whether the redistribution of wealth and culture that the copyright system promotes is equitable.«(Bently/Sherman 1992: I63)

Auch im deutschen Sprachraum erscheinen Ende der 1980er Jahre die ersten Texte zum Phänomen des Samplings in Publikumszeitschriften. Auch hier bilden eigentumsrechtliche Bezüge den Ausgangspunkt, zum Beispiel James Browns Klagen gegen zahlreiche Produzent_innen, die seine berühmten Ausrufe wie »Hit me« oder »Take me to bridge" ungefragt gesampelt hatten. Diederich Diederichsen sieht darin die Kopierbarkeit des eigentlich Unkopierbaren: „Der vermeintlich unverwechselbare Ausdruck hat eine neue Stufe der Reproduzierbarkeit erreicht." (Diederichsen 1987: 53, Hervorhebung im Original).

In der fachjuristischen deutschsprachigen Debatte ist Sampling seit den I980er Jahren ein Randthema, das in wenigen Zeitschriftenbeiträgen (Tenschert 1987, Hoeren 1989, Hertin 1989, Schorn 1989, Spieß 199I) und später auch Dissertationen (Schramm 1992, Münker 1995, Häuser 2002, Salagean 2008) behandelt wird. Die Probleme 
und Fragen ähneln größtenteils der anglo-amerikanischen Debatte. Sie sind nahezu ausschließlich aus der Perspektive der gesampelten Rechteinhaber_innen formuliert und kreisen größtenteils um den Schutz von Sound als genereller musikalischer Komponente, um Länge und Schöpfungshöhe von melodischen und rhythmischen Elementen sowie um das Verhältnis von urheber- und leistungsschutzrechtlichen Zustimmungspflichten. Kreativität spielt eine nachrangige Rolle, in der Regel lediglich angeführt als zu schützendes Gut der gesampelten Musiker_innen.

Bemerkenswert in diesem Zusammenhang erscheint mir vor allem das Plädoyer von Reiner Münker für eine spezifische Bewertungspraxis von Popmusik, die sich von den Parametern der Ernsten Musik (E-Musik) differenziert, da im Pop die Arbeit mit konkretem Klang viel stärker im Zentrum steht. Zwar bestätigt auch Münker die Zustimmungspflicht gesampelter Originalurheber_innen, spricht sich aber gegen eine zu strenge Regelung hinsichtlich der Leistungsschutzrechte aus, da durch das Kopieren eines kurzen Samples noch nicht von einer Konkurrenzbeziehung der Tonträgerhersteller ausgegangen werden könne: „Nur wenn diese konkrete wirtschaftliche Position des Herstellers durch die erneute körperliche Festlegung seiner Herstellerleistung in messbarer Weise beeinträchtigt wird, kann das Vervielfältigungsrecht des Tonträgerherstellers betroffen sein« (Münker 1995: 262).

\subsubsection{Neve Normalität: "Get a License or do not sample!»}

In der ersten Hälfte der 200oer Jahre wird die juristische Debatte um die urheberrechtliche Konfiguration technischer Reproduzierbarkeit in den USA weiter befeuert. Zwei Gerichtsentscheidungen sind hierbei zentral: 2003 wurden die Beastie Boys von dem Jazz-Flötisten James Newton wegen eines etwa sechs Sekunden langen Samples verklagt (Newton vs Diamond). Zwar hatte sich das Label der Rapper bereits 1992 die Genehmigung an der Aufnahme des Stücks gesichert, 
nicht aber das Recht an der Komposition, das bei dem Künstler selbst lag. Trotz der vergleichsweise einfachen Tonfolge war Newton der Ansicht, dass sein Urheberrecht verletzt worden war. Er begründete dies mit einer besonderen Spieltechnik (multiphonics), bei der durch gleichzeitiges Blasen und Singen ein charakteristischer Klang entsteht. Die Gerichte folgten Newtons Meinung allerdings nicht; die Klage wurde mit Begründung auf die nicht erreichte Schöpfungshöhe des betreffenden Ausschnitts abgelehnt. (Reilly 2008: 368)

Diese im US-amerikanischen Copyright Law de minimis genannte untere Grenze schöpferischen Handelns wurde im zweiten wichtigen Fall 2005 Bridgeport v. Dimension Films allerdings missachtet. Dies führte zu einem vollkommen unterschiedlichen rechtlichen Resultat. In dem betreffenden Streit wurde ein etwa zwei Sekunden langes Sample verhandelt, das die Rapgruppe N.W.A. für "Ioo Miles and Runnin'" (1990) ohne Lizenzvereinbarung aus dem Gitarrenriff von Funkadelic kopiert hatten. Das Gitarrenriff selbst wurde von einem Studiomusiker für 50 Dollar Gage eingespielt, womit er das Copyright an der Komposition abtrat. Angestrengt hatte die Klage Bandleader George Clinton zusammen mit dem Label Bridgeport Music. ${ }^{45}$ Im Original befindet sich das betreffende Sample am Anfang des Stücks "Get Off Your Ass and Jam" (I975). Es fungiert hier sozusagen als Eröffnungsriff. In dem Stück von N.W.A., das aufgrund seiner vielen Spuren einen charakteristischen, besonders dichten Sound hat, ist das Sample aber nur eines unter vielen. Auch wird es sehr sparsam als kaum wahrnehmbares rhythmisches Element eingesetzt. Trotz der Kürze und des transformativen Einsatzes urteilte der Richter zu Gunsten Clintons: Die de minimis-Ausnahme wurde zurückgewie-

45 Williams (2015: 212) bemerkt, dass Bridgeport Music nicht als Label im klassischen Sinne, das Künstler_innen betreut und aufbaut, agierte, sondern ein Unternehmen, das systematisch Copyrights von verschiedenen Musikkatalogen aufkaufte und anschließend nach ungeklärten Samples dieses Katalogs suchte. 200I strengte Bridgeport etwa 500 Klagen an. Auch George Clinton galt aufgrund seiner eigenen Sample-Compilations als bereits recht versiert im Lizenzierungsgeschäft (siehe Abschnitt 4.2.2.I) 
sen, da der Richter der Auffassung war, Klangkopien müssten unabhängig von Länge und Originalitätsgrad immer lizenziert werden (Sinnreich 20I0: 137). Paradoxerweise wird im Urteil jedoch betont, dass die durch Sample Clearing anfallenden Kosten und Mühen keinen Einfluss auf den kreativen Prozess der Musikproduktion haben würden:

"Get a license or do not sample. We do not see this as stifling creativity in any significant way. It must be remembered that if an artist wants to incorporate a >riff" from another work in his or her recording, he is free to duplicate the sound of that riffı in the studio." (Bridgeport v. Dimension Films zitiert nach McLeod/DiCola 20II: 220)

Als Reaktion auf dieses Gerichtsurteil initiierte die Plattform downhillbattle.org unter dem Titel "3 Notes and Runnin" einen Remixwettbewerb und rief dazu auf, kreative Versionen des betreffenden Samples einzureichen. Damit wollte die gemeinnützige Organisation auf die Bandbreite der Sample-Bearbeitungen aufmerksam machen und gleichzeitig für eine liberalere urheberrechtliche Ausrichtung und fairere Lizenzierungspraktiken in der Musikindustrie werben. ${ }^{46}$ Die Aktivist_innen von downhillbattle.org waren auch im Fall um das »Grey Album« maßgeblich beteiligt, wegen dem im gleichen Jahr die bereits intensiv geführte Debatte einen weiteren Höhepunkt erreichte. Produziert wurde das "Grey Album« von DJ Dangermouse, der dafür die Acapellaspuren von Jay-Zs »Black Album» (2003) mit

46 Der Aufruf auf downhillbattle.org war wie folgt formuliert: "To protest this decision, we are creating a forum for sample-based musicians and artists to share their own 30 second songs which have been created using only the sample in question. By doing so, we hope to showcase the potential and diversity of sample based music and sound art, and to call into question the relationship between a sample and its use. [...] Your song must use only the designated two seconds of the intro to Funkadelic's "Get off Your Ass and Jam" as source material. You can slice it, layer it, loop it, stretch it, filter it, smack it up, flip it, and rub it down, but you can't bring any other sounds into the mix.« http://www.downhillbattle. org/3notes/ (25.10.2017). 
geloopten Samples aus dem »White Album« der Beatles (1969) kreuzte. Als Mashup-Album konzipiert wollte Dangermouse den eigenartigen musikalischen Kontrast ausloten, der durch die Vereinigung der Stücke entsteht, wenn also Jay- $Z$ über, mit und auf den Beatles rappt. Ursprünglich schickte Dangermouse das Album in der geringen Auflage von 3000 selbstgebrannten CDs und Schallplatten an einige Plattenläden und stellte es auf seiner eigenen Website als $\mathrm{MP}_{3}$ zum kostenlosen Download bereit. Schnell tauchte es in illegalen Tauschbörsen auf, woraufhin die Plattenfirma EMI, die die Rechte an den Aufnahmen der Beatles hält, Dangermouse zur Unterlassung aufforderte. Der DJ kam dieser Forderung nach. Doch nach Presseberichten und lobenden Rezensionen erhielt das illegale Album eine enorme öffentliche Aufmerksamkeit, bis sich im Internet großfächiger Protest formierte - vermutlich auch, weil sich das "Grey Album« als Metapher für rechtliche Grauzonen hervorragend eignet. In einem Akt digitalen Ungehorsams stellten nach dem Aufruf von downhillbattle.org knapp I70 Websites am 24. Februar 2004 das Album online. Alleine an diesem "Grey Tuesday« wurde es hundertausendfach heruntergeladen (Rimmer 2005; Sinnreich 20IO: I2I; Sterne 2012: 225).

Der Kampf um die Reproduktionshoheit, der sich im digitalen Protest und den urheberrechtlichen Klagen der Musikindustrie offenbart, veranschaulicht, wie verhärtet Anfang des neuen Jahrtausends die Fronten zwischen neuen, unbefangenen Praktiken des Sampelns und alten Strukturen der Kontrolle sind. Diese Konfliktlinie, die mit dem »Grey Album» besonders deutlich zu Tage tritt und der eine bisher ungekannte öffentliche Aufmerksamkeit zuteil wurde, hatte sich nicht über Nacht entwickelt, sondern über das 20 . Jahrhundert hinweg in zahlreichen juristischen Auseinandersetzungen aufgebaut und sich dann am »Grey Tuesday« blitzartig entladen. Die Gesamtheit der kreativwirtschaftlichen und zivilgesellschaftlichen Bemühungen um die Vorherrschaft der Kopierregeln demonstriert aber auch die Stabilität und soziale Akzeptanz des Samplings in Kunst, Wirtschaft und Recht zu Beginn des 2I. Jahrtausends. Das unterstreicht den Innova- 
tionscharakter des Samplings als etwas Neuem, das seine Eigenschaft als gesellschaftlich Anormales zunehmend verliert und "von immer mehr sozialen Akteuren oder einer relevanten sozialen Gruppe als neue Normalität mit anderen Regeln angeboten, bekämpft oder anerkannt wird“ (Rammert 20IO: 34).

Auch lässt sich am »Grey Album« und seiner ungehorsamen Musikdistribution über Filesharing-Netzwerke ein gesellschaftlicher Umschlagspunkt ablesen, an dem zwei digitale Formen technischer Reproduzierbarkeit aufeinandertreffen: einerseits in Form des Samplings, also im Sinne einer referentiellen Kopie, andererseits in Form digital bewerkstelligter Musikdistribution, mittels derer sich in $\mathrm{MP}_{3}$-Dateien umgewandelte Musikstücke über das Internet als Kopien versenden lassen - und damit wiederum als Ausgangsmaterial für neue samplingbasierte Musik werden können. Mit den jamaikanischen dub plates oder den Hip Hop-Mixtapes hatten sich autonome Strukturen der Musikdistribution historisch bereits angekündigt. Auch die auf der Hobbyebene entstandenen Praktiken des Töne Jagens, Radio Tapings und CD Brennens können in diesem Zusammenhang als Vorbereitung gesehen werden, wenn auch innerhalb relativ enger sozialer Grenzen (siehe Kapitel 3.2 und 3.3). Die Verflüssigung von Musikstücken in digitale $\mathrm{MP}_{3}$-Dateien und ihre weltumspannende Distribution über Kanäle des Internets verschafften der technischen Reproduzierbarkeit damit einen qualitativ neuen Schub. 


\subsection{Urheberrecht als Anreiz und Hemmnis für Kreativität}

\subsubsection{Dominante Perspektiven: Stimulations- vs. Marginalisierungsthese}

Vor dem Hintergrund abermals gestiegener technischer Reproduzierbarkeit und einer zunehmend restriktiver werdenden Rechtslage in den USA verfestigt sich ab circa 2000 ein akademischer, teils auch öffentlich geführter Diskurs, der das Verhältnis von Kreativität und Geistigem Eigentum stärker ins Zentrum stellt. Insbesondere die Frage, ob das Copyright seiner Stimulationsfunktion von Kreativität weiterhin nachkommt, steht hier zur Diskussion. Denn das US-amerikanische Copyright Law ist der Förderung von Wissen und Kultur verpflichtet und damit integraler Bestandteil für Prozesse von Kreativität und Innovation (Sprigman 2017; Cohen 2007: II92; Woodmansee 2006). Im deutschen Urheberrecht wird der Beziehung zwischen Urheber_in und Werk größere Bedeutung zugestanden, wodurch sich der Kreativitätsanreiz indirekt über die Kontroll- und Verwertungsfunktion des eigenes Werks ergibt (Dreier/Nolte 2006: 48; Peifer 2008). Beides möchte ich als urheberrechtliche Stimulation von Kreativität - oder kürzer: als Stimulationsthese - zusammenfassen.

Während die Diebstahls- und Eigentumsrhetorik in der juristischen Debatte der I990er Jahre vor allem auf eine Marginalisierung technischer Kopiermöglichkeiten abstellte und die Grenzen der Reproduktionshoheit eng zog, bildet sich etwa zur Jahrtausendwende eine neue akademische These, die der Stimulationsthese entgegensteht. Vertreter_innen dieser Marginalisierungsthese sehen die Sampling-Kreativität von zu restriktiven urheberrechtlichen Mechanismen bedroht, da der rechtliche Schutz neue schöpferische Praktiken und den Umgang mit geschütztem Medienmaterial verunmöglicht. Der urheberrechtliche Schutz, so die Vertreter_innen dieser These, habe sich in den vergangenen Jahrzehnten enorm verhärtet, verfeinert und sich auf ursprünglich nicht oder nur geringfügig davon 
abgedeckte Bereiche ausgeweitet, so dass er nun so wirkmächtig sei, dass die kreative Auseinandersetzung mit urheberrechtlich geschütztem Material verkümmere. Kreativität werde zu Gunsten eines industriellen Wettbewerbsschutzes unterdrückt, von einem System, das eigentlich als Anreiz für Kreativität fungieren sollte. Das dominante Argument hierbei ist, dass urheberrechtliche Praktiken wie Abmahnungen, Lizenzierungen und Klagen sich zunehmend ausbreiten und dadurch ein für Kreativität feindliches Klima schaffen, in dem künstlerisches Schaffen marginalisiert, also deformiert, erschwert oder sogar vollständig verhindert wird (McKenna 2000; Litman 200I; Vaidhyanathan 2003; Lessig 2004; Demers 2006; Tushnet 2007; Aufderheide/Jaszi 20II; McLeod/DiCola 20II; Sayers 20I4).

Prominent unterstützt wird diese Marginalisierungsthese von dem Rechtswissenschaftler Lawrence Lessig. Mit Blick auf einen filmaffinen Anwalt, der Retrospektiven auf einflussreiche Schauspieler_innen anfertigen wollte und dafür überaus komplizierte und langwierige Rechteklärungen anstrengen musste, fragt Lessig (2004: I04) pointiert: "[...] how much creativity is never made just because the costs of clearing the rights are so high? « Auch in der kulturhistorischen Perspektive, die Siva Vaidhyanathan für die Analyse des US-amerikanischen Copyright Laws im 20. Jahrhundert einnimmt, wirkt die Ausweitung und Verschärfung des Eigentumsgedankens hinderlich bis unterdrückend auf Kreativität. Er zieht zahlreiche Beispiele zur Untermauerung dieser These heran. Im Kapitel zur Musik beschreibt Vaidhyanathan den sich im 20. Jahrhundert verschärfenden urheberrechtlichen Schutz existierender musikalischer Werke als Hemmschuh für anschließende kreative Künstler_innen: "These shifts have handcuffed newer artists who want to participate in the chain of creativity." (Vaidhyanathan 200I: I26) Die Praxis des Samplings wird in diesem Zusammenhang gerne als Extrembeispiel herangezogen, das stellvertretend für andere künstlerische Praktiken die rechtliche Regulation oder Bedrohung sichtbar machen soll (wie beispielsweise für Comics oder Dokumentarfilme). Teilweise geht die Kritik sogar noch weiter, wenn traditionell-westliche Autorschafts- 
verständnisse als unterkomplex oder veraltet abgelehnt und musikindustrielle Verwertungsstrukturen als Mittel sozialer Ungleichheitsreproduktion beklagt werden (Schumacher 1995; Negus/Pickering 2004; Hesmondalgh 2006; McLeod 2005; Boyle 2008; Collins 2008; Sinnreich 20I0).

Es ist auffällig, dass der Diskurs zum Verhältnis von Kreativität und Geistigem Eigentum beim Sampling relativ umfangreich ist, die Studien mit empirischer Evidenz jedoch in einem äußerst übersichtlichen Rahmen bleiben und eher von zusammengetragenen Anekdoten und persönlichen Erfahrungen aus dem anwaltlichen Umfeld geprägt sind. Grundsätzlich überwiegen in der Literatur zwar auf den ersten Blick schlüssige, aber empirisch nicht oder nur unzureichend bestätigte Vermutungen. Nach dem Urteil Bridgeport vs. Dimension Films von 2005 beispielsweise prognostizierte ein juristischer Kommentator einen sportlichen Anreiz für kreative Umgehungsstrategien, der sich aufgrund der abermals verschärften Regeln für sampelnde Musiker_innen ergäbe: "To avoid identification, artists will have to think of more creative ways to finagle a sound recording sample to forgo detection by those holding its copyright." (Shultz 2005: 335) Ein anderer Jurist sieht, wohlgemerkt in der Retrospektive knapp zehn Jahre nach besagtem Urteil, drei Entwicklungswege für das Sampling: "pay for and clear every single sample used on an upcoming recording, completely give up on the art of sampling due to a lack of funds necessary for sample clearance, or figure out a creative way to get around litigation while continuing to sample on the cheap." (Cox 20I4: 22)

Doch wie sieht die tatsächliche Praxis aus? Lassen sich die drei genannten Alternativen - umfassendes Sample-Clearing, Komplettaufgabe des Samplings oder kreative Umgehungsstrategien - empirisch behaupten, insbesondere für den deutschen Rechtsraum? Um diese Aspekte zu vertiefen, wende ich mich im folgenden Abschnitt Studien zu, die in Abgrenzung zu den juristischen Abhandlungen und Einordnungen die urheberrechtliche Dimension künstlerischen Schaffens explizit empirisch untersuchen. Wo es notwendig erscheint, 
werde ich auch theoretische Beiträge einflechten und damit den breiteren sozialwissenschaftlichen Diskurs um das Sampling abbilden. Wie schon bei der historisch rekonstruierten fachjuristischen Debatte um das Sampling stammt der Großteil der empirischen Studien aus dem angloamerikanischen Raum und lässt die deutschsprachige Diskussion darauf folgen.

Der im folgenden Abschnitt aufgearbeitete Forschungsstand adressiert eine dreifache Forschungslücke: Erstens wird gezeigt, dass die bisherige auf Sampling bezogene empirische Forschungstradition stark US-amerikanisch dominiert und im deutschsprachigen Raum mit Fokus auf das Urheberrecht im Grunde genommen nahezu non-existent ist. Zweitens wird in Abgrenzung zu den zahlreichen rechtswissenschaftlichen Studien an eine sozialwissenschaftlich orientierte Forschungstradition mit empirischer Datengewinnung angeschlossen, die Licht auf die tatsächlichen Kooperationen und ihre Konsequenzen in der Samplingwelt werfen kann. Und drittens legt die bisherige, besonders interviewlastige Forschung nahe, im Forschungsdesign entsprechend zu reagieren und den Aspekt kreativer Umgehungsstrategien systematisch zu berücksichtigen. Das bedeutet in der Konsequenz die Gewinnung weiterer Datentypen (wie Beobachtungsdaten) und eine entsprechende Triangulation (siehe Kapitel 5).

\subsubsection{Ansätze einer empirisch orientierten Urheberrechtsforschung}

\subsubsection{Umgehungsstrategien als afrodiasporische Praktiken des Widerstands}

Im Rahmen ihrer ethnografischen Studie mit jungen Menschen aus der Arbeiterschicht Birminghams weisen Simon Jones und Paul Willis aus der Perspektive der Cultural Studies bereits 1990 die Verbreitung des Samplings als jugendkulturelle Praxis nach (vgl. Kapitel 2.4.3). Sie 
verorten das Sampling dabei als Ausdruck einer gemeinsamen Kultur, die weitere referentielle Praktiken wie home taping, DJing oder Platten Sammeln, genauso aber auch Mode, Tanz und andere jugendkulturelle Formen beinhaltet. Konsumpraktiken müssten daher auch als aktive Ressource von Kreativität begriffen werden:

"[...] most pop musicians begin as fans and create by copying sounds from records and cassettes: they become producers as consumers. Most musical activity, then, begins as and from consumption, from the process of listening to music. But consumption itself is creative." (Jones in Willis I990: 60)

Gerade für Kinder von jamaikanischen oder afrikanischen Einwander_innen, die sich ab den I95oer Jahren auch in Großbritannien niedergelassen hatten, bietet das Abspielen und Aufführen von Musik auf selbst gebastelten Soundsystemen die Möglichkeit, sozialer Exklusion und Marginalisierung, wenn nicht strukturell, so doch mindestens symbolisch entgegenzuwirken. Aus dem vermeintlich passiven Konsum wird durch das Mischen von Schallplatten, die Bearbeitung von Samples und die Veröffentlichung eigener Stücke in subkulturellen Netzwerken ein aktiver Umgang mit präfabrizierten Symbolen und industriell vorgefertigten Bedeutungen:

"With two turntables, a cassette recorder and skilful use of pause buttons, switches and faders, it is possible to mix tapes and create cutups for circulation amongst friends. In this process the hardware and software of consumption have become the instruments and the raw materials of a kind of cultural production." (Jones in Willis 1990: 77)

Zentral ist dabei also der Versuch, durch die teilnehmende Beobachtung eine symbolische Form von Kreativität herauszuarbeiten, die durch den bewussten Umgang mit vorgegebenen Bedeutungen die eigene Identität stärkt. Einem ähnlichen Ansatz folgt auch Tricia Rose im Rahmen ihrer postkolonialen Einordnung von Hip Hop in 
größere soziohistorische, ökonomische und technologische Zusammenhänge. Anhand von Interviews mit US-amerikanischen Produzent_innen, Songtexten und Musikvideos analysiert sie die sozialen Umstände der Diaspora, in denen Hip Hop entstanden ist. Rose bezieht explizit die gesellschaftlichen Machtgefüge mit ein, hier ausgedrückt als Kampf einer illegitimen afroamerikanischen Kunstform (»black sonic forces») gegen die dominante weiße Kultur:

"Rap's black sonic forces are very much an outgrowth of black cultural traditions, the postindustrial transformation of urban life, and the contemporary technological terrain. Many of its musical practitioners were trained to repair and maintain new technologies for the privileged but have instead used these technologies as primary tools for alternative cultural expression.« (Rose 1994: 63)

Ausgehend von dieser Denkfigur der Zweckentfremdung und symbolischen Rückgewinnung von Macht gegenüber der vorwiegend weißen Musikindustrie legt Rose dar, wie Hip Hop-Produzent_innen sich gegen traditionelle westliche, weiße Konventionen der Autorschaft, des Eigentums, musikalischen Arrangements oder der schriftlichen Fixierung von Musik wenden. Sie knüpft dabei an das diasporische Narrativ von Sampling als Form der Selbstermächtigung an (Gilroy 1993) und erweitert es in Richtung symbolischer Kreativität:

"In fact, prior to rap, the most desirable use of a sample was to mask the sample and its origin; to bury its identity. Rap producers have inverted this logic, using samples as a point of reference, as a means by which the process of repetition and recontextualization can be highlighted and privileged.« (Rose 1994: 73)

Die von Rose befragten Produzent_innen betrachten Sampling nicht als Diebstahl, sondern als referentielle Kunstform oder als musikalische Archäologie, da für die Suche nach dem richtigen Sample zeitraubende Anstrengungen erforderlich werden. Die Vermeidung einer 
Interpolation, gleichwohl günstiger und unkomplizierter zu klären, wird zu einer künstlerischen Konvention des widerständigen, geradezu unökonomischen Beharrens auf originales Klangmaterial und erhält dadurch Züge einer symbolischen Strategie des Widerstands. In der Bevorzugung des Samples anstelle der Interpolation wird auch hier eine Fixierung auf Originalität erkennbar - wenngleich ironischerweise als Kopie:

"Sampling, as it is used by many of hip hop's premiere producers, is not merely a shortcut used to 'copy` musical passages. If this were so, then producers would spare the legal costs of clearing usage of other artists' recorded material by programming or replaying very similar musical sequences.« (Rose 1994: 79, Hervorhebung im Original).

In loser Folge weist Rose auf Umgehungsstrategien im Hip Hop hin, die sie afrodiasporisch mit der kolonialen Ausbeutungshistorie von People of Color durch Weiße begründet. Das Verweigern und Unterlaufen des kleinteiligen und komplizierten Sample Clearings wird zu einem rebellischen, ideologisch gefärbtem Akt gegenüber der weiß dominierten Unterhaltungsindustrie. Gleichzeitig beobachtet sie ein steigendes Interesse an den Originalstücken: Einerseits werden die gesampelten Originale aus den I960er und I970er Jahren stärker nachgefragt und daher oft neu aufgelegt; andererseits entdecken die gesampelten Funk-Künstler Sampling als eigene Einnahmequelle der Funkmusiker George Clinton sogar vorbei an den Verlagen, die im US-amerikanischen Copyright Law die Rechte an den Aufnahmen halten und bei einem etwaigen Sample Clearing berücksichtigt werden müssten:

"Clinton has recently released the first of a six-volume collection of sounds and previously unreleased out takes and songs entitled Sample Some of Disc, Sample Some of DAT. As reported in the Village Voice's Rockbeat column, while the original hits are still the property of the labels on which they were recorded, jam sessions and live re- 
cordings (even of classic tracks) owned by Clinton can be at your fingertips. Sample Some of Disc is designed to attract young artists and producers; it features a how-to-get sample clearance guide with a collaborative-minded fee system: No upfront fee is charged, producers or musicians are sharged only per record sold, so if your single flops, you won't be in the red.« (Rose 1994: 92, Hervorhebung im Original)

In dieser Strategie, die Verlage bei der Lizenzierung zu umgehen, erkennt Rose mehr als nur die ökonomische Dimension. Sie sieht darin eine symbolische Rückgewinnung derjenigen kreativen Arbeit, die schwarze Studiomusiker_innen bei Songaufnahmen geleistet haben, für die sie aber in der Regel nicht vertraglich beteiligt, sondern pauschal per buy out abgespeist wurden (vgl. Kartha 1997). ${ }^{47}$ Durch das Sampling im Hip Hop und seinem starken Fokus auf Rhythmen, Breakbeats und andere Sounds eröffne sich auf diese Weise eine Art der »Heimzahlung" ("payback»): Das Sampling von Schlagzeugelementen wie einzelnen Schlägen oder anderen kurzen Rhythmuspassagen sei Rose zufolge bis dato relativ unbedenklich, da es zu sehr schwierig sei, die Urheberschaft an den kurzen Elementen zu identifizieren und entsprechende Klagen anzustrengen oder Lizenzen ein-

47 Traurige Berühmtheit erlangten in diesem Zusammenhang vor allem die Schlagzeuger Clyde Stubblefield und Gregory Coleman, die die berühmten Breakbeats in "The Funky Drummer" (1970) beziehungsweise "Amen, Brother" (1969) eingespielt hatten. Beide Breaks wurden tausendfach gesampelt, ohne dass die Schlagzeuger dafür je Tantiemen kassieren konnten, da sie die Rechte abgetreten hatten. Ähnlich verhielt es sich mit der Studioband The Funk Brothers des berühmten US-Labels "Motown", die in wechselnder Besetzung während der I96oer und I970er Jahren an der Komposition und Aufnahme nahezu aller Motown-Hits beteiligt waren, aber ebenfalls nur per buy out beteiligt wurden. Der Bassist Jamie Jamersson, "as a permanent member of the Funk Brothers, cowrote more number-one hit songs than the Beatles, the Rolling Stones, the Beach Boys, and Elvis combined" (Uzzi/Spiro 2005: 448). Der Dokumentarfilm »Standing on the Shadows of Motown« (2002), basierend auf dem Buch von Alan Slutsky (1996 unter dem Pseudonym Dr Licks erschienen), bietet einen guten Einblick in die Geschichte der Funk Brothers: https:/www.imdb.com/title/tto3I4725/ (22.03.2018). 
zufordern. Folglich klärten Hip Hop-Produzenten nur in absoluter Ausnahme Drum-Samples und blieben ansonsten widerständig und unter dem Radar der Musikindustrie. Das rechtliche Schlupfloch werde damit in die andere Richtung ausgenutzt, so Rose:

»By defining music in such a way as to obscure black contributions and achievements, the music industry and the legal system have rendered current measurement of black rhythm, intonation, and timbre-for their profit-virtually inaccessible. The very laws that justified and aided in the theft from and denigration of an older generation of black artists have created a profitable, legal loophole and a relatively free-play zone for today's black artists.« (Rose I994: 93)

Die von Rose befragten Hip Hop-Produzent_innen sehen ihre Musik durch aggressive Klagen gefährdet, insbesondere wenn sie mit eineindeutigen, langen Samples operieren: "making bold sample uses, especially samples from the more powerful publishers and artists less likely.» (Rose 1994: 93). Das musikindustrielle Feld mit seinen Machtstrukturen wird auf diese Weise ein Ort, an dem Produzent_innen ihre soziale Position mit Umgehungskreativität behaupten müssen. Die Steigerung der technischen Reproduzierbarkeit geht auch auf Seiten der Musikindustrie und ihren Anwält_innen mit einer Steigerung der Detektabilität von Samples einher, wodurch auf Seiten der Produzent_innen ausgefeiltere Tarn- und Ausweichstrategien notwendig werden: "[...] it encourages more sophisticated cloaking devices-ways to use interesting material without detection." (Rose 1994: 93) Es ist bemerkenswert, dass Roses recht einflussreiche Studie bis heute Renommee genießt, die von ihr angedeuteten Umgehungsstrategien aber in späteren Studien nicht systematisch als explizites Untersuchungsobjekt berücksichtigt wurden. 


\subsubsection{Sampling im Spannungsfeld von Postmoderne und Urheberrecht}

In anderen akademischen Studien zeigt sich eine deutliche Verbindung von Sampling und postmoderner Theorie. Thomas Schumacher beispielsweise versteht Sampling als postmoderne Dekonstruktionsund Verweistechnik, die eine doppelte Kritik leiste: einerseits an der Idee einer singulären Autor_in, an deren einzig im Text verkörperte Stimme und an der daran geknüpften Abgeschlossenheit ihres Werks (vgl. Barthes 2000 [1968]; Foucault 2000 [1969]); andererseits an der Idee des Geistigen Eigentums an einem Klang, die sich letztlich aus den Implikationen materiellen Eigentums heraus speise:

"Sampling is a way of appropriating this property, of subverting the proprietary status of sound and allows for a new kind of poaching on the aural commons. [...] By selecting recorded sounds and reusing them in new recordings, rap music offers its critique of the ownership of sound." (Schumacher 1995: 265).

Andreas Rauscher spezifiziert diesen Gedanken durch seine Bemerkung, dass die Aneignung von Klängen durch Sampling nicht nur als verbeugende Referenz, sondern auch als »Attacke« innerhalb der Hip Hop-Kultur selbst verstanden werden kann. Vielmehr "sprengt [Sampling] den klassischen Zitatbegriff, nach dem das Aufgreifen eines Samples im besten Falle eine Anspielung/Hommage oder im schlechtesten das Plagiat eines anderen Songs wäre." (Rauscher 1997: 89) Die Einteilung des US-amerikanischen Hip Hop der I99oer Jahre in East Coast und West Coast lasse sich, so Rauscher weiter, auch auf musikalischer Ebene der Samples identifizieren. Die Aneignung von als feindlich wahrgenommenen Samples und Klängen werde als Angriff auf die Hoheit eines quasi territorial gesicherten Sample-Fundus' verstanden, was einem informellen Urheberrecht auf gefundene Samples gleichkommt: 
»Eines der konstanten Kriterien ist, ausgefallene Samples und somit auch Styles zu finden, die als Markenzeichen für die eigene Crew dienen oder den jeweiligen Background entsprechend repräsentieren können. [...] Das Samplen eines mit einer bestimmten Gruppe assoziierten Riffs kann dabei als Grundlage für eine Attacke gegen diese verwendet werden.« (Rauscher 1997: 89)

Die ethnografisch und qualitativ orientierte Sampling-Forschung, die urheberrechtliche Aspekte erfassen will, greift diesen Aspekt informellen Urheberrechts auf. Damit bezeichne ich einen intellektuellen Ansatz, der nicht nur auf die formellen urheberrechtlichen Regeln und ihre Wirkung beispielsweise in Kunstwelten abstellt, sondern nach den internen grammatischen Systemen fragt, die im Sinne einer Ethik mit ungeschriebenen Gesetzen die künstlerische Produktion reglementieren und dabei Eigentumsverhältnisse zentral stellen (vgl. Andean 20I4; Iljadica 20I6; Katzenbach et al. 20I6; Darling/ Perzanowski 20I7; Reißmann et al. 20I7; Hofmann et al. 2012). Die Regeln lassen sich als informell verstehen, da sie nicht wie formelles Recht die umfangreichen Prozesse gesellschaftlicher Legitimation durchlaufen und schriftlich kodifiziert sind. So wird beispielsweise in einer empirischen Studie von 1988 gezeigt, dass sampelnde $\mathrm{Mu}$ sikproduzent_innen im Profibereich sich zwar lose an den postmodernen Ideen einer Kreativität des "Plünderns« und einer "politics of stealing " orientieren. Sie bleiben ansonsten aber einem kontributionalistischen Schöpfungsverständnis verhaftet, wollen also vor allem einem kulturellen Kanon etwas Wertvolles, bisher noch nicht Existentes hinzufügen und dadurch ihre Position im künstlerischen Feld absichern (Goodwin I988: 47).

Während Andrew Goodwins Datenmaterial mit nur zwei Interviewausschnitten aus journalistischen Zeitschriften sehr dünn ist, geht der Medienanthropologe Thomas Porcello einen Schritt weiter: Auch er stellt die Frage, wie sich Geistiges Eigentum an spezifischen Klängen im Zeitalter ihrer technischen Reproduzierbarkeit verändert. Auch erkennt er die Relevanz formaler Copyright-Regeln für das 
Sampling an. Allerdings rekonstruiert er aus Zeitschriften und qualitativen Interviews mit vier US-amerikanischen Studiotechnikern eine informelle Sampling-Ethik, die gewisse Berührungspunkte mit dem Copyright aufweist, aber nicht deckungsgleich ist: Sampling müsse beispielsweise von den Studiotechnikern bewusst eingesetzt werden und dürfe kein »technological free-for-all« sein. Auch klassifizierten die Studiotechniker die Benutzung von Samples hinsichtlich ihrer ethischen Vertretbarkeit gegenüber den gesampelten Künstler_innen. Die Grenzen der informellen Ethik sollten ihrer Meinung nach grundsätzlich in der Praxis gezogen werden und nicht nur gesetzlich vorgegeben sein. Sampling müsse allerdings auch die formalen Rechte der gesampelten Musiker beachten, wobei die Studiotechniker hier durchaus ein pragmatisches Verständnis zur Vermeidung rechtlicher Schwierigkeiten an den Tag legten und sich dafür fortlaufend über aktuelle Gerichtsurteile informierten. Schließlich seien die Grenzen der Ethik prinzipiell flexibel und verschiebbar, wenn es ein Auftrag erfordere (Porcello I99I).

Die von Porcello entwickelten Merkmale interessieren im weiteren Verlauf nicht allzu sehr im Detail; entscheidend ist die sozial verhandelte Balance zwischen formal-legalen und informell-legitimen Sampling-Praktiken und ihre Einbettung in die Kultur der Studiotechniker (Porcello I99I: 78). Klar ist, dass die Techniker das Hoheitsgebiet ihrer in der Musikindustrie angesiedelten Profession argumentativ verteidigen und entsprechend bestimmte Gruppen von der Reproduktionshoheit ausschließen. Diese Distinktion in der Kompetenz zeigt sich auch in ihrem zur Schau gestellten Wissen über aktuelle Sampling-Gerichtsverfahren. Problematisch an Porcellos Untersuchungsdesign ist, dass er die Identität der Informanten vollständig offenlegt. Hier zeigt sich deutlich das Problem der sozialen Erwünschtheit, da die Studiotechniker damit rechnen, dass ihre Antworten extern von Kund_innen und anderen Akteuren aus der Musikindustrie wahrgenommen werden, was potentielle Verzerrungen in ihrem Antwortverhalten impliziert. 


\subsubsection{Ethik und Ästhetik samplebasierter Musikproduktion}

Mehr als zehn Jahre später wird Porcellos Idee einer informellen, die Produktion und Kreativität der beteiligten Künstler_innen regulierenden Sampling-Ethik von dem Musikethnologen Joseph Schloss aufgegriffen und spezifiziert. Für seine umfassende ethnografische Studie begleitete Schloss über Jahre hinweg eine Vielzahl von US-amerikanischen Hip Hop-Produzent_innen. Er bilanziert, dass "the aesthetics of composition are determined by a complex set of ethical concerns and practical choices that can only be studied from within the community of hip-hop producers." (Schloss 2004: 20) Zwar berücksichtigt Schloss die größeren sozialen Umstände, unter denen Hip Hop entstehen und sich verfestigen konnte - mit dem starken wissenssoziologischen Fokus auf die Erforschung der Mikroebene geraten diese für ihn allerdings bewusst in die Peripherie. Damit integriert Schloss die Idee der Aneignung, die seiner Meinung nach den harten paradigmatischen Kern der Hip Hop-Kultur darstellt, mit seiner eigenen Methodologie:

»[...] I have tried to problematize the relationship between general societal factors-culture, politics, and especially economics-and hip-hop music, arguing that individual artists often have more control over the way these issues affect their work than they are given credit for. In other words, I am not so much interested in the conditions themselves as I am interested in the way hip-hoppers, given those conditions, were able to create an activity that was socially, economically, and artistically rewarding." (Schloss 2004: 2I)

Die Aneignung fremder Sounds durch Sampling wird in der von Schloss untersuchten Kunstwelt mit einer implizit geteilten, also konventionalen Ethik reguliert, deren Artikulation Schloss innerhalb seines ethnografischen Ansatzes leistet. Jene Ethik hat den vergleichsweise konservativen Anspruch, eine künstliche Erschwerung des Samplings zu organisieren. Auf diese Weise wird eine ästhetische 
Konfiguration technischer Reproduzierbarkeit erreicht, die eine besonders puristische Hip Hop-Ästhetik aufrechterhält (Schloss 2004: I04). Weitere Regelungen dienen der Qualitätskontrolle, offenbaren aber auch Züge eines Kopierschutzes: So darf ein bereits von einem anderen Produzenten verwendetes Sample nicht oder nur in einer anderen kreativen Variante verwendet werden (»no biting «). Es darf nur von Vinyl gesampelt werden und die Platte muss sich in der eigenen Sammlung befinden, das heißt zuvor selbst "ausgegraben" worden sein (»crate digging «). Originalauflagen sind zu bevorzugen, Wiederauflagen gelten als verpönt. Es darf nur unter bestimmten Voraussetzungen von anderen Hip Hop-Veröffentlichungen gesampelt werden, beispielsweise wenn es sich um ein Zitat eines Rap Vocals handelt. Ganz besonders verehrte Stücke werden nicht gesampelt, außer, der transformative Track würde das Sample noch veredeln. Und: Von einem Stück - manchmal noch rigider: von einem ganzen Album darf nur ein einziges Samples verwendet werden (Schloss 2004: I0533). Die Erneuerung des Genres durch Rückgriff auf alte, unbekannte Samples steht dabei im Vordergrund - Hits, also bereits bewährte Musik, untransformativ zu sampeln ist verpönt: "[...] a producer that too often samples songs that a broad audience would know is considered to be pandering (or worse, to not have rare records in his crates)." (Schloss 2004: 146-7)

Die künstlichen Barrieren zur Selektion der passenden Samples spiegeln sich auch im diggin' in the crates, also dem Graben und Suchen in den Plattenkisten nach "unerhörten ", ästhetisch interessanten, aber noch unverbrauchten Samples. Schloss beschreibt das Diggin' als Pendelbewegung zwischen Serendipität und Systematik, was beinhaltet, von den üblichen Routinen und Suchorten abzuweichen - und teils unter Zuhilfenahme von Tricks und Überredungskünsten - Zugang zu besonders attraktiven crates und raren Platten zu erhalten. Diggin' setzt außerdem ein breites, fast schon enzyklopädisches Wissen darüber voraus, welche Samples bereits verwendet wurden. Damit verbunden ist der edukative Anspruch, neue Stücke und Musiker_innen kennenzulernen - im Original wie in zweiter Ebene als Sample. 
Durch Diggin' sollen kreative Prozesse angestoßen werden, die sich in Form von Inspiration, im Finden neuen Materials, neuer Referenzen und Rekombinationen äußert (Schloss 2004: 92). Wie andere Sammelleidenschaften, ist auch das Diggin' eine besonders konsumtive Praxis - Zeit, Geld und Nerven gleichermaßen verbrauchend.

Auch wenn diese Konventionen nicht immer vollständig beachtet werden und sie spezifische, teils weit dehnbare Einschränkungen enthalten, dienen sie trotzdem als symbolisches Raster, um das Handwerk einer Produzent_in als authentisch und qualifiziert auszuweisen: Wer es schafft, innerhalb des engen Regelsystems einen ästhetisch überzeugenden Track zu produzieren, gilt als kreativ und professionell im Feld. Die selbst auferlegten Beschränkungen fungieren damit als Innovationsgrammatik, da sie regelhaft Devianz, Originalität und Kreativität fordern; ein Aspekt, den Jennifer Lena (2004: 307) treffend als »symbolische Distinktion« bezeichnet. Aus der Regelaufstellung lässt sich eine Art informeller Urheberrechtsschutz auf bereits benutzte Samples herauslesen. Das heißt in Konsequenz, dass die Kopierkultur des samplingbasierten Hip Hop durchaus das Problem des Plagiats kennt, es aber spezifisch konfiguriert: Urheberschaft wird weniger über die Kreation eines Werks definiert, sondern vielmehr über die Entdeckung und Aneignung des Samples. Dass gesampelt wird, ist für alle Beteiligte dieser Kunstwelt ja unangezweifelte Grundlage es geht eher um das Was und das Wie. Man könnte auch sagen: Autorschaft zeigt sich weniger beziehungsweise nicht ausschließlich als Werkstolz, sondern mehr als Entdeckungsstolz (vgl. Schur 20I5: 86). Auch zeigt Schloss überzeugend die Ambiguität zwischen offenem, kanonischen Sample-Wissen und geheim gehaltenen Sample-Quellen. Denn es ist erklärter Wettbewerb zwischen den Produzent_innen, eigene Samples geheim zu halten und die der anderen Feldmitglieder zu dechiffrieren, gleichwohl es die Ethik verbietet, Samples zu "snitchen", also öffentlich zu machen (Schloss 2004: I2I).

Die Geheimniskrämerei hat ihre Wurzeln in der DJ-Kultur und im Crate-Diggin'-Ethos, wird aber durch die urheberrechtliche Situation noch verstärkt. Schloss deutet die rechtlichen Implikationen 
über das Buch hinweg nur an einigen Stellen an. Gegen Ende erklärt er, dass das Thema Sample Clearing "a difficult methodological issue for the researcher" sei, er die Zögerlichkeit der Produzent_innen, diesbezügliche Informationen preiszugeben, verstehe und er sich daher dazu entschieden habe "not to even inquire about this issue in interviews" (Schloss 2004: 175). Trotz der Umgehung des heiklen Themas extrahiert Schloss aus dem generellen Tenor und den absichtlich nicht aufgezeichneten Gesprächen einige Aspekte: Sample Clearing sei alles in allem zu teuer, zu unwägbar und kompliziert, als dass jedes Sample lizenziert werden könne; das Copyright Law werde in der Samplingwelt mehr als Macht- und Geldmechanismus wahrgenommen denn als Kreativitätsanreiz oder Künstler_innenrecht; die Übertragung der Eigentumsidee auf einen Klang, eine Melodie oder einen Rhythmus werde genauso abgelehnt wie die Übertragbarkeit von Copyrights. Den Einfluss von Copyrights und Sample Clearing auf die Produktion schätzt er recht gering ein; für die Veröffentlichung der Stücke seien sie jedoch entscheidend:

"Nevertheless, sample clearance-in principle-has little effect on how people produce records. Many producers, for example, make beats that they know in advance will be impossible to clear. [...] While such songs are not released, they are valued precisely as an indicator that a producer's work is unfettered by legal or monetary restrictions. The fact that producers make music that they know they cannot sell shows their lack of concern for the marketplace." (Schloss 2004: 180)

Damit zeigt Schloss erneut, auf welche Weise Makrostrukturen, wie in diesem Fall das Copyright Law, in die Kultur hineingeholt und symbolisch rekodiert, also für eigene Zwecke respezifiziert werden. Allerdings stimme ich mit Schloss an dieser Stelle nicht überein: Gerade die - fast trotzig - zur Schau gestellte Robustheit gegenüber den Copyright-Implikationen verteidigt das hehre, puristische Ideal einer authentischen, unbeeinflussbaren Künstlerpersönlichkeit. Über das 
bewusste Ignorieren gelangt das Copyright auf indirekte Weise, sozusagen "durch die Hintertür«, wieder in die Produktion mit hinein, so dass die Auseinandersetzung mit den Mechanismen Geistigen Eigentums eben doch eine Rolle spielen. Dass Hip Hop deutliche Züge eines informellen Copyrights aufweist, die teilweise sogar restriktiver sind als die formellen Copyright-Regeln, lässt sich mit Schloss erst in der systematischen Zusammenschau der Konventionen erkennen. Das Copyright ist hier also ein semantisches Vehikel, ein rhetorisch ausgestellter Schauplatz, an dem die Distinktion zwischen authentischer Subkultur und profitorientierter Industrie demonstriert und reproduziert wird.

Es ist zudem auffällig, dass Schloss die urheberrechtliche Ebene des Samplings nur unsystematisch und damit vereinzelt behandelt, jede seiner Nennungen aber im Zusammenhang mit Umgehungsphänomenen steht. So nennt er den generellen Rückgang in der Benutzung von Samples in den letzten Jahren aufgrund von Copyright-Schwierigkeiten (Schloss 2004: 6); die Interpolation eines Samples aus finanziellen Gründen (Schloss 2004: 73); die Angst vor der Detektion der benutzten Samples, vor allem bei längeren Breaks (Schloss 2004: 98); das Ressentiment gegenüber Breakbeat-Compilations (Schloss 2004: I26); sowie die Entstehung von spezialisierten Sample Clearing-Agenturen (Schloss 2004: 207, Fn. 3).

Schloss liefert somit einige Hinweise auf die Relevanz von Umgehungsstrategien für die Produktion samplingbasierter Popmusik, systematisiert und verdichtet diese Beobachtungen allerdings nicht. Auch ist unklar, inwieweit seine Ergebnisse auf andere Kunstwelten übertragbar sind. Meine Vermutung ist, dass der puristische, nahezu elitäre Ethos der von Schloss beschriebenen Samplingkultur zwar in anderen DJ-getriebenen Genres weiterbesteht und reproduziert wird, aber in abgeschwächter oder modifizierter, gewissermaßen entkoppelter Form. Mit der Formulierung der Binnenperspektive konzentriert sich Schloss auf den inneren Kreis der Produzent_innen und klammert bewusst weitere Akteure dieser Kunstwelt, wie beispielsweise Anwält_innen, aus. Viele Aspekte des beschriebenen subkulturellen 
Ethos tragen Züge einer ästhetischen Elite, deren Konventionen in die Musikindustrie und nach und nach in Amateurkulturen diffundieren, dort adaptiert, das heißt befolgt, gebrochen und remixt werden.

Dieses Thema nimmt Aram Sinnreich (2010) für seine Studie "Mashed Up« auf. Darin veranschaulicht der Kommunikationswissenschaftler, wie tradierte Ordnungen durch die Steigerung technischer Reproduzierbarkeit ins Wanken geraten können. Klassische Dichotomien wie beispielsweise zwischen Kunst und Handwerk, Künstler_in und Publikum oder Original und Kopie stünden durch die Veränderungen der »konfigurablen Kultur« wie DJing, Mashups, Remix oder Sampling, aber auch Filesharing-Plattformen zur Disposition und würden zunehmend verwischt. Im Gegensatz zu Schloss, der auch Beobachtungsdaten erhob, stützt sich Sinnreich nur auf Interviews. Er ist dadurch auf die Informationen angewiesen, die ihm von Mashup-Musiker_innen und Anwält_innen verraten werden, und kann seine Daten nicht triangulieren. In der von Sinnreich skizzierten Mashup-Welt spielen Copyrights vor allem seit dem "Grey Album « und dem Bridgeport-Fall eine gewichtige Rolle, insbesondere weil die Produzent_innen Klagen und Abmahnungen befürchten.

Im Gegensatz zu der von Schloss beschriebenen Hip Hop-Welt, die auf uneindeutigen bis eindeutigen Referenzen, einer Sakralisierung von Sample-Quellen und einem daraus abgeleiteten Entdeckerstolz aufbaut, konzipiert Sinnreich die Kunst des Mashups über die überraschende Rekombination eineindeutiger, popkulturell bekannter Quellen, die oftmals über illegale Tauschbörsen zirkulieren (Sinnreich 20I0: 130). Durch den zweifelhaften urheberrechtlichen Status von Mashups, so bemerkt Sinnreich, entsteht eine Verschiebung in der Konstruktion von Originalität. Der Hauch des Halbseidenen umgibt die tendenziell illegalen Mashups und trägt zu ihrer Einzigartigkeit bei, da diese schnell wieder aus den Tauschbörsen verschwinden können. Diese illegale Aura wird oft auch für Marketingzwecke genutzt. Während Schloss künstlerische Originalität vor allem über die Seltenheit der Quellen begründet, wird für Mashups 
ein anderer Weg zur Konstruktion von Originalität gefunden. Weil diese mit leicht zugänglichem und bestbekanntem popkulturellen Material spielen, entsteht die ästhetische Anziehungskraft aus der Rekombination der Quellen und der daraus resultierenden, urheberrechtlich induzierten Verfügbarkeit des Produkts (Sinnreich 20IO: 144).

\subsubsection{Die Kosten der Lizenzierung}

Ab etwa 2004 erscheinen einige Studien, die das Sample Clearing als Lizenzierungspraxis im US-amerikanischen und britischen Rechtsraum thematisieren und dafür einen empirischen Zugang wählen. So interviewte der Musikwissenschaftler Mark Katz den DJ und Produzenten Fatboy Slim alias Norman Cook zu seinem Welthit "Praise you " (1998), den Cook entscheidend auf einem Sample aus Camille Yarbroughs "Take Yo' Praise« (1975) aufbaute. In Analyse und Interview spielen die "legal issues of sampling « dabei eine untergeordnete Rolle. Der kommerziell bereits sehr erfolgreiche Fatboy Slim sicherte der unbekannten Camille Yarbrough die Ko-Autorenschaft für den Song und eine Beteiligung von $60 \%$ der Einnahmen vertraglich zu. Katz vermutet, dass dies aus der Befürchtung heraus geschah, sonst wegen ungeklärter Samples wieder in einen teuren Rechtsstreit verwickelt zu werden und am Ende Ioo\% der Einnahmen an die Gesampelten abtreten zu müssen, wie an die Rockband The Who bei einem Stück auf Fatboy Slims Vorgängeralbum »Better Living Without Chemistry« (Katz 2004: 150).

So glimpflich es hier ausging, so absurd können die Sample Clearing-Kosten in anderen Fällen werden, wie Johanna Demers (2006: 90), Kembrew McLeod (2005: 88) und auch Richard Schur (2015) mit einer Handvoll Beispielen zeigen. So zahlte Puff Daddy beispielsweise offenbar mehr als I Million Dollar, um Stücke von Led Zeppelin und The Police zu sampeln. Diese Extremform, für den Kunstbetrieb von Wolfgang Ullrich (2016) treffend als »Siegerkunst» 
beschrieben, ${ }^{48}$ firmiert in der Literatur zum Sampling bisweilen als "luxury rap" (Okpaluba 20I4: 95) oder als "hip hop mogul paradigm«. Dem Mogul gehört sprichwörtlich die Welt und er leistet sich teure Samples wie Statussymbole: "[...] these songs also clearly display the artist's ability to employ samples not available to less successful artists" (Schur 20I5: 90). Der medial zur Schau gestellte Stolz über die extrem teure, aber erfolgreich geglückte Lizenzierung markiert das obere Ende für Lizenzkosten von Samples. Das damit verbundene Kreativsubjekt repräsentiert sich hinsichtlich der eigenen Ressourcen dadurch in dreifacher Weise: erstens als ästhetisch originell, indem es im Gegensatz zur Logik des crate diggin' kein seltenes, sondern ein popkulturell ikonisches und weltbekanntes Riff als Sample aneignet; zweitens als wirtschaftlich erfolgreich und begütert, weil ihm die beträchtlichen monetären Ressourcen für den Erwerb der Lizenz zur Verfügung stehen; und drittens als rechtlich versiert, weil es vermutlich bemerkenswerter Anstrengungen bedurfte, um den Vertrag zwischen den Parteien und den vertretenden Plattenfirmen auszuhandeln.

Gegenüber diesen Extremformen weist Justin Morey in seiner empirischen Studie, die auf Interviewdaten mit DJs und Produzent_innen beruht, nach, dass diese ein sehr strapaziöses und oftmals

48 Puff Daddys Gebrauch enorm kostspieliger Samples und seine mediale Darstellung in Musikvideos lässt sich im Sinne des Kunsthistorikers Wolfgang Ullrich als Geste der "Siegerkunst« verstehen. Damit bezeichnet Ullrich den derzeit auf dem Kunstmarkt beobachtbaren Trend, dass eine globale Elite von Superreichen unvorstellbare, ja geradezu absurd hohe und irritierende Summen für den Erwerb bestimmter Kunstwerke ausgibt. Ullrich zufolge werden durch den Besitz dieser nur als Unikate erhältlichen Kunstobjekte und ihrer Verknüpfung mit einer außergewöhnlichen Kaufsumme Formen von Distinktionsgewinn und Statusrepräsentation erreicht, die sich durch reguläre Konsumstile gar nicht realisieren ließen: "Im Kauf von Siegerkunst kann der Superreiche also die Folgen seines kapitalistischen Agierens genießen und zugleich seine Unabhängigkeit von diesem beweisen, ja sich gar zum Kritiker von Profitstreben und Effizienzdenken stilisieren. Er überhöht sich als doppelt mächtig und damit als letztlich absolut souverän: erfolgreicher als andere im Geldverdienen, mutiger als andere im Geldausgeben.« (Ullrich 2016: 33). 
auch zum Scheitern verurteiltes "Copyright Management" auf sich nehmen, um ihre Samples zu klären. Wie dieses im Detail aussieht und vor allem, welche Folgen es für die Musikproduktion hat, bleibt in seiner Studie aber offen (Morey 2013). Differenzierter ist die systematisch angelegte und umfassende empirische Untersuchung von Kembrew McLeod, die er zusammen mit dem Juristen Peter DiCola durchführte. In ihrem Buch "Creative License« zeigen die beiden Autoren die Anstrengungen auf, die sampelnde Künstler_innen aufgrund des ineffizienten Lizenzierungssystems auf sich nehmen müssen, sowie die Auswirkungen auf Produktion, Verwertung und Distribution samplingbasierter Musik. Anhand qualitativer Interviews mit Musiker_innen und Anwält_innen sowie einer quantitativ orientierten, hypothetischen Analyse heutiger Lizenzierungskosten für berühmte Hip Hop-Alben kommen die Autoren zu dem Schluss, dass Aufwand und Ergebnis in einem deutlichen Missverhältnis zueinander stehen. Wegweisende, samplelastige Alben wie beispielsweise "Fear of a Black Planet" von Public Enemy (I990) oder "Pauls Boutique« von den Beastie Boys (1989), die sowohl hinsichtlich ihrer Kritiken wie auch ihres kommerziellen Erfolgs besonders einflussreich waren und den Weg Hip Hops von einem Untergrundgenre in die Musikindustrie ebneten, wären heute nicht mehr finanzierbar: Die Lizenzierungskosten wären so hoch, dass das Label mit jedem verkauften Tonträger Verlust machen würde (McLeod/DiCola 2OII: 2OIO).

Zur Begründung ihrer These führen die Autoren folgende Aspekte an: Oftmals könnten die Originalurheber_innen beziehungsweise die richtigen Ansprechpartner_innen nicht ohne weiteres identifiziert werden, zum Beispiel weil Rechte nur fragmentiert vorlägen und daher aufwändige, teils ergebnislose Recherchen notwendig würden. Oftmals scheitere allein die einfache Kontaktaufnahme, weil Anfragen in den Abteilungen großer Majors versickerten oder aus strategischen oder ökonomischen Gründen nicht beantwortet würden. Durch die rechtliche Situation und die kooperativen Produktionsgefüge in der Musikindustrie müssten in der Regel mehrere, bisweilen auch unter- 
einander zerstrittene Parteien der Genehmigung zustimmen, was zu Verzögerungen und weiteren koordinativen Problemen führe; denn stimmen nicht alle involvierten Rechteinhaber_innen zu, scheitere die korrekte Lizenzierung. Diese Umstände führen, so McLeod und DiCola, zu einer generell schlechten Verhandlungsposition auf Seiten der Sampelnden, die bittstellend auftreten müssten. Alles in allem sprechen die hohen Transaktionskosten gegen eine ökonomisch verhältnismäßige Lizenzierung besonders von samplelastiger Musik, die nicht nur auf einem Sample aufbaut, sondern zahlreiche rekombiniert (McLeod/DiCola 20II: I50).

Diese problematische rechtliche Situation macht auch die US-amerikanische Musikwissenschaftlerin Amanda Sewell (20I4) zum Ausgangspunkt ihrer Studie. Allerdings bemängelt sie die Polarität der akademischen Debatte. Sie erkennt die verhärteten Fronten an, identifiziert aber auch eine dominante "good-versus-evil rhetoric in which the producers of sample-based hip hop are David to the Goliaths of major record labels, disingenuous copyright holders, and sample troll companies such as Bridgeport." (Sewell 20I4: 313). Insbesondere kritisiert sie McLeod und DiCola für die nostalgische Verklärung eines "Golden Age of Sampling « bis etwa 1991, in dem "many hip-hop artists [had] the opportunity to make music exactly as they imagined it, without restrictions" (McLeod/DiCola 20II: 20), das die Autoren aus den Interviews und vorliegenden Studien herleiten. Hier werden Hip Hop-Künstler_innen beispielsweise semantisch als deviante "copyright outlaws" (Schur 2015) markiert, was gut zum allgemeinen Hip Hop-Narrativ passt, welches soziale Marginalisierung als zentralen Punkt miteinbezieht, aber auch die faktische Entwicklung von Praktiken verdeckt oder verzerrt. Vor diesem Hintergrund entwickelt Sewell die Forderung, die Debatte differenzierter und mit mehr empirischem Gehalt zu führen.

Sowohl Sewell (2014: 298-300) als auch McLeod und DiCola (20II: I87-20I) identifizieren verschiedene veränderte Formen des Umgangs auf Seite der Produzent_innen. Folgende Umgehungsstrategien kommen nach dem ersten Sampling-Urteil aufgrund erhöhter 
rechtlicher Beobachtung und verfeinerter Detektionsmechanismen als »cloaking devices" (Rose 1994: 93) zum Einsatz:

- vermehrter Einsatz von Interpolationen, also selbst eingespielten Samples, um weniger Rechte klären zu müssen, sowie anderweitig nachgestellte Samples (»mimicking the sound of sampling", McLeod/DiCola 20II: 192)

- stärkere Transformation von Samples in Richtung uneindeutiger Referenz, beispielsweise durch rearrangierende Praktiken wie "Chopping« oder »Flipping« (Sewell 20I4: 298) oder anderen Formen der Tarnung und Maskierung (McLeod/DiCola 20II: 194)

- die Vermeidung von Samples von Musiker_innen, von denen bekannt ist, dass sie beim Sample Clearing Probleme bereiten;

- das Abstand Nehmen von Samples mit gescheiterter Lizenzierung, wodurch für das problematische Sample entweder Ersatz gefunden oder es einfach aus dem Stück herausgenommen werden muss;

- sowie eine generelle Strategie, die McLeod/DiCola (20II: 196) als "flying below the radar" bezeichnen und die an Guerillataktiken und andere Kriegsrhetorik erinnert; hierbei ist vor allem die Veröffentlichung heikler samplingbasierter Musik gemeint, die musikindustrielle Kontrollmechanismen unterläuft, wie zum Beispiel die Veröffentlichung nur in bestimmten Netzwerken, in Kleinauflagen oder auf wenig populären Tonträgern (wie beispielsweise Kassette).

Neben diesem qualitativen Zugang entwickelt Sewell auch eine musikwissenschaftliche Typologie, die in der Lage ist, verschiedener Sample-Einsatzmöglichkeiten zu differenzieren. Sewell interessiert der tatsächliche Einsatz von Samples im US-amerikanischen Hip Hop während dieser Phase des Übergangs, als das Eindringen verwertungsrechtlicher Logiken in die Samplingwelt einen externen Schock auslöste - anschließend aber neue kooperative Konstellationen zwischen Produzent_innen, Labels, Anwält_innen und gesampelten 
Künstler_innen entstanden, die das in den I980er Jahren gewachsene Gefüge samplingbasierter Musikproduktion veränderten. Sie tut das mit dem Ziel »to open a discussion about how musicians were able to maintain a sense of their earlier musical styles even when their primary creative tools - that is, samples — were severely restricted (Sewell 20I4: 296; für eine ähnlich pragmatistisch angehauchte Kritik siehe auch Okpaluba 2014).

Sewell (2014: 304) unterscheidet drei Typen von Samples, die unterschiedliche musikalische Funktionen haben: (I) strukturelle Samples, die die Charakteristik des neuen Stücks maßgeblich bestimmen, indem sie als gelooptes Hauptsample in fortlaufender Wiederholung durch das komplette Stück gehen. Sewell differenziert hier zwischen intakten strukturellen Samples aus einer einzigen Quelle und aggregierten strukturellen Samples, die zwar nach einer Einheit klingen, aber bei denen die einzelnen Instrumente aus verschiedenen Quellen stammen; (2) "surface samples«, also oberflächlich und eher zur Dekoration eingesetzte, vereinzelt auftauchende und tendenziell kürzere Samples, die den strukturellen Samples untergeordnet sind und ihnen zuarbeiten (hier von mir als "dekorative Samples« bezeichnet); (3) lyrische Samples, also gesampelter Gesang oder Rap, ähnlich wie dekorative Samples eher spärlich oder unauffällig eingesetzt. Ich gehe davon aus, dass die Referentialität in dieser Typologie bei strukturellen Samples am höchsten ist, wenngleich dieser Faktor je nach Bekanntheit der gesampelten Quelle variieren kann.

Auf Basis dieser Typologie analysiert Sewell jeweils vier Albumveröffentlichungen von fünf erfolgreichen Rapgruppen zwischen I986 und 1996. In ihrer Untersuchung von insgesamt 328 Samples kommt sie zu detaillierten Ergebnissen, von denen ich die wichtigsten herausgreife. Wenig überraschend fällt die Gesamtzahl der pro Stück benutzten Samples ab etwa 1990 ab, um Lizenzierungen gering zu zu halten - von durchschnittlich 4 Samples gegen 1990 hin zu durchschnittlich weniger als 2 Samples zwischen 1994 und 1997 (Sewell 2014: 300-303). Anhand der drei Sample-Typen und ihrer Subtypen kann Sewell diesen Trend jedoch pro Album spezifizieren 
und Änderungen in der Verwendungsweise aufzeigen: Sie weist nach, dass der Einsatz von strukturellen Samples pro Album im Verhältnis zu dekorativen und lyrischen Samples eher gering abfällt: War dieser Wert bei den jeweils ersten Alben bei knapp 40\%, erreicht er bei den zweiten Alben knapp 60\% und sinkt dann für die dritten und vierten Alben auf etwa 50\% ab. Wurden dekorative und lyrische Samples bei den Ende der 1980er Jahre erschienenen Alben noch jeweils etwa zu etwa $30 \%$ verwendet, geht die verhältnismäßige Nutzung dann jedoch signifikant auseinander: Lyrische Samples werden bei den vierten Alben zu etwa $47 \%$ eingesetzt, dekorative fallen auf einen Wert unter Io \% (Sewell 20I4: 305). Auch wenn hier rechnerische Ungenauigkeiten zu verzeichnen sind, ist der signifikante Trend, nach I99I dekorative Samples zu vermeiden und lyrische zu bevorzugen, deutlich zu erkennen. Für strukturelle Samples zeigt Sewell außerdem, dass die Vielfalt der Samplequellen nachlässt: Waren vor I99I aggregierte strukturelle Samples aus unterschiedlichen Quellen sehr beliebt, da ihre Rekombination entscheidend zu einem originalen Klangbild beitrug, werden strukturelle Samples von da an vor allem von einer einzigen Quelle gesampelt und intakt behandelt - um nur noch ein Sample klären zu müssen. Eine andere Strategie ist, strukturelle Samples aus lizenzpflichtigen und lizenzfreien Samples zusammenzusetzen, zum Beispiel aus einem Basslauf von einem Tonträger und Schlagzeugsounds von Drum Machines oder selbst eingespielt. Alle genannten Ansätze dienen dazu, die Anzahl der insgesamt zu klärenden Samples niedrig zu halten und damit Kooperationsbeziehungen im Sinne Beckers zu vermeiden, gleichzeitig aber die bereits entwickelten Praktiken rekombinativer Klangproduktion zu stabilisieren (Sewell 2014: 306).

Indem sie indirekt dazu auffordert, nicht nur die Aussagen der Interviewpartner als semantische Daten zu analysieren und damit bewährte Narrative aus dem Untersuchungsfeld zu reproduzieren, sondern unabhängig davon die Entwicklung der Praktiken empirisch zu untersuchen, leistet Sewell einen wichtigen Beitrag zu der Debatte, in der die grammatischen Regeln des Copyrights und die der Kreativität 
gerne gegeneinander ausgespielt und damit als normatives Argument für eine Marginalisierung von Kreativität genutzt werden.

Weitere Arbeiten zeigen, dass Lizenzierungsanstrengungen über das Sample Clearing im Musikbereich hinaus verbreitet sind und zu vergleichbaren Umgehungsstrategien (workarounds) führen, mit denen sich die generelle Praxis notbehelfsmäßig aufrechterhalten lässt. Workarounds können dafür mit Gabriele Schabacher (20I7) als Verfahren zur Problembearbeitung beschrieben werden, mit denen das eigentliche Problem nicht aufgelöst, sondern nur verschoben wird. Akteure arbeiten situativ um ein Problem herum, vertagen es aber dadurch lediglich und tragen auf diese Weise dazu bei, es am Leben zu erhalten. Drei empirische Studien sind in diesem Zusammenhang aufschlussreich:

Als zentralen Aufhänger ihrer Arbeit wählen Patricia Aufderheide und Peter Jaszi (20II) die oftmals den Kreativschaffenden unbekannten Potentiale der US-amerikanischen Fair Use-Regelung, die sich für Lizenzierungspraktiken - in ihrem Fall von Dokumentarfilmer_innen - in Stellung bringen ließen. Denn auch Dokumentarfilmer_innen kopieren Ausschnitte aus den Werken Dritter mit komplizierten Rechteketten (beispielsweise Fernsehsendungen oder Imagevideos von Firmen), was insbesondere bei Majors zu Lizenzierungsschwierigkeiten führt:

"Filmmakers also told us their frustrations with copyright, which were legion. Even when documentary filmmakers wanted to license copyrighted material, they often couldn't find anyone to pay. Large copyright holders such as Disney or Viacom either didn't answer an e-mail (probably because the transaction costs would be too high for such a small licensing fee), or set a grossly inappropriate licensing fee, or weren't certain who owned the copyright. Every time they licensed a piece of film or a snatch of music or an image, that single piece of film might include a host of rights to be cleared - and one hour of film could involve dozens of such licenses." (Aufderheide/ Jaszi 20II: 95) 
Diese Interviewstudie aufgreifend und weiterführend untersuchen Kylie Papparlado et al. (20I7), wie sich die Arbeit australischer Kreativschaffender in Bezug auf urheberrechtliche Verwicklungen aktuell darstellt. Die Zeit, Geld und Nerven kostenden Lizenzierungserfordernisse zur rechtssicheren Verwendung von Ausschnitten existierender Werke zeigen sich nicht nur in der Musik, sondern auch im Film, der Spielebranche, text- und bildbasierten Künsten und weiteren Branchen der Kreativindustrie. Die in der Studie aufgezeigten Probleme decken sich im Wesentlichen mit den bereits für das Sampling beschriebenen: Unsicherheiten, Ängste und das Gefühl, vom Copyright Law eher im kreativen Prozess behindert als unterstützt zu werden. Als Antwort auf die restriktiven urheberrechtlichen Mechanismen sind die für die Studie anonymisierten Kreativschaffenden unter anderem darauf angewiesen, Verweispraktiken auf andere Werke fallen zu lassen, in ein anderes Land mit laxeren urheberrechtlichen Bedingungen auszuweichen oder mit anderen workarounds ihre Arbeit aufrechtzuerhalten, wenngleich diese eher als praktische Notbehelfe für einen umfassenderen Problemkomplex gesehen werden (Pappalardo et al. 2017: 27). Diesen Befund erhält auch Claudy Op Den Kamp für die Nutzung von Werken aus Filmarchiven. Unter dem Stichwort "aesthetics of access" erörtert die Filmwissenschaftlerin verschiedene Strategien des "circumventing both archives and rights owners" $(\mathrm{Op}$ Den Kamp 20I7: 9I) wie beispielsweise das erneute Abfilmen von Filmen oder das Ausweichen auf verwaiste Werke.

\subsubsection{Sampling und empirische Urheberrechtsforschung im deutschsprachigen Raum}

Mit zunehmendem kommerziellem Erfolg von samplingbasierten Genres wie Hip Hop, House, Techno oder Drum'n'Bass werden seit etwa Mitte der I990er Jahre die Themen Sampling, Remix oder Mashups auch in deutschsprachigen, vor allem kultur- und populärmusikwissenschaftlichen Publikationen berücksichtigt. Neben 
rechtswissenschaftlichen Abhandlungen dominieren damit ebenfalls hauptsächlich theoretische Zugriffe. Exemplarisch hierfür sind diverse Sammelbände (beispielsweise Reck/Fuchs 1995, Fehrmann et al. 2004, Bidner/Feuerstein 2004). Trotz der rechtlich restriktiven Situation ist die empirische Forschung zum Verhältnis von Sampling und deutschem Urheberrecht bisher nahezu ausgeblieben. Im Grunde sind mir nur drei Arbeiten bekannt. Der Musikwissenschaftler Helmut Rösing, der auch als Gutachter für rechtliche Streitigkeiten gefragt ist, skizziert eine "forensische Popmusikanalyse", die in der Lage ist, die Spuren des Samplings in Stücken musikwissenschaftlich aufbereiten und detailliert untersuchen zu können (Rösing 20I2). Gegenüber einer solchen ex post-Analyse betont Oliver Kautny (20IO) stärker die Erforschung der tatsächlichen Praktiken in situ. Er plädiert für eine "analytische Grundlagenforschung im Bereich des Samplings", äußert im gleichen Aufsatz aber wegen rechtlicher Verwicklungen die "Befürchtung, Wissenschaftler könnten durch ihre Analysen die Hip Hop-Produzenten und ihre möglicherweise illegal genutzten Quellen gegenüber den Copyright-Anwälten der Majorkonzerne 'verraten « (Kautny 20I0: 7, Hervorhebung im Original). In der Folge werden in dem Schwerpunktband zum Thema Sampling ${ }^{49}$ zwar einige Produktionsstudien selbst vorgelegt, das Thema Urheberrecht wird aber bewusst voll ausgeblendet. Leonhard Dobusch (20I4) schließlich

49 Der Schwerpunktband zum Thema Sampling (Kautny/Krims 20Io) geht auf eine Tagung im Jahr 2009 zurück, an der einige Hip Hop-Produzent_innen teilnahmen. Darunter auch Sascha Klammt von der deutschen Band Kinderzimmer Productions, deren erstes Album 1994 wegen unlizenzierter Samples wieder vom Markt genommen wurde und erst 1998 regulär erschien. In der ursprünglichen Version enthielt das problematische Stück »Back" mindestens vier Fremdsamples; die mit ihrem Stück »Golden Brown" gesampelte Rockband The Stranglers war zwar einverstanden, nicht aber ihre Plattenfirma, die wegen der Verletzung der Leistungsschutzrechte das Verbot des Tonträgers anstrengte. In einer aktualisierten Version von "Back« (1998) wird das betreffende Sample nicht mehr als Klangkopie verwendet, sondern in abgewandelter, am Klavier eingespielter Form, die auffällig disharmonisch klingt. Ich vermute, dass dieser Fall die erste oder zumindest eine der ersten deutschen Samplestreitigkeiten darstellt und das rechtliche Bewusstsein in der jungen deutschen Hip Hop-Szene schärfte. 
machte in Interviews mit professionellen Musikproduzent_innen eine ähnliche Erfahrung: Oft wird die tatsächliche Produktionspraxis und das damit verbundene Wissen im Kontext mit Urheberrechten nur oberflächlich angedeutet, mit Allgemeinplätzen umschrieben oder gänzlich verborgen. Aufgrund zahlreicher Interview-Ablehnungen vergleicht Dobusch diese Informationskluft daher mit einer tabuisierenden "Don't ask, don't tell«-Logik.

Auf Grundlage der bisherigen theoretischen und historischen Kapitel der Arbeit lässt sich bilanzieren, dass die Kunstwelt des Samplings auf einer vielfältigen und umkämpften Geschichte aufbaut, die die Praktiken, Diskurse und Regelungsformen des Samplings und seines urheberrechtlichen Status' bis heute beeinflusst - auch im deutschen Rechtsraum. Die Breite und Tiefe dieser Geschichte zeigt sich besonders deutlich in der gesellschaftlichen Debatte um das Sampling als rechtlich-wirtschaftlich propertisiertes Gut auf der einen und als ästhetisch-technisch kulturalisierte Ausdrucksform auf der anderen Seite. Nach Darstellung insbesondere der empirischen Forschungsdesiderate zum Themenbereich Urheberrecht und Kreativität beim Sampling kann ich das bisher noch sehr breit gefasste Forschungsinteresse im empirischen Teil dieser Arbeit nun enger führen und zuspitzen: In Kapitel 5 formuliere ich die finale Forschungsfrage für die eigene Erhebung und übersetze sie in ein Untersuchungsdesign, sodass ich in Kapitel 6 meine eigenen empirischen Daten in verdichteter Form darstellen kann. 

TEIL 3 - EMPIRIE 



\section{Methodik}

\subsection{Forschungslücke und Formulierung der Forschungsfrage}

Die beiden vorangegangenen Kapitel haben die rechtlichen, wirtschaftlichen, ästhetischen und technischen Bezüge des Kampfs um die Reproduktionshoheit beim Sampling im 20. Jahrhundert historisch klargemacht. Die Aufarbeitung der Historie und des Forschungsstands zum Themenbereich Geistiges Eigentum, Kreativität und Sampling stellte dabei eine dreifache Forschungslücke heraus: (I) eine fehlende empirische Studie zum Sampling im deutschen Rechtsraum, die dafür (2) eine dezidiert sozialwissenschaftliche beziehungsweise kunstsoziologische Perspektive auf die notwendigen Kooperationsgefüge einnimmt und (3) in Ergänzung zu den bisherigen interviewlastigen Studien Aussagen und beobachtete Praktiken miteinander trianguliert, um nicht-thematisierte Umgehungsstrategien zu berücksichtigen.

Zur Bearbeitung dieser dreifachen Forschungslücke wird der folgende Fragenkomplex angewendet, der die bereits in Kapitel I aufgeworfenen forschungsanleitenden Fragen nun auf Basis des Forschungsstands hierarchisieren und enger fassen kann. Wie in Abschnitt 4.2 herausgearbeitet, werden über die Opposition zwischen Stimulations- und Marginalisierungsthese die urheberrechtlichen Anforderungen und damit verknüpften Praktiken entweder als Anreiz oder als Hemmnis von Kreativität verantwortlich gemacht. 
Um diese Opposition aufzubrechen, lautet die übergeordnete Fragestellung:

In welcher Weise fungiert das Urheberrecht als Anreiz, aber auch als Hemmnis für die kreative Produktion neuer samplingbasierter Stücke?

Um diese Hauptfrage für die empirische Untersuchung aufzubrechen und beantwortbar zu machen, bieten sich folgende Unterfragen an:

- Wie wird die musikalische Praxis des Samplings innerhalb des widrigen rechtlichen Systems aufrechterhalten?

- Welche Rolle spielen dabei die sich historisch andeutenden, kreativen Umgehungsstrategien bei aktuellen Produktionsprozessen?

- An welchen Orten und in welchen Situationen werden urheberrechtliche Konfigurationen technischer Reproduzierbarkeit relevant und der Kampf um die Reproduktionshoheit ausgetragen?

- Wie wirkt sich die urheberrechtliche Geschlossenheit von Werken auf die Samplingstrategien aus, die ja entscheidend auf der Öffnung von Werken basieren?

- In welchen Kooperationen und mit welchen Mitteln wird um die Hoheit zur technischen Reproduzierbarkeit gekämpft?

- Durch welche Konfigurationen wird die technische Reproduzierbarkeit von samplingbasierter Popmusik in diesen Kooperationen eingeschränkt und verhindert, aber auch zugelassen und organisiert?

Die Beantwortung dieser Fragen macht einen qualitativ-ethnografischen Ansatz erforderlich, der teilnehmende Beobachtung und narrative Interviews verbindet. Die Verzahnung der empirischen und theoretischen Erkenntnisse erfolgt in Kapitel 7. 


\subsection{Methodische Ausgangspunkte}

\subsubsection{Sensible soziale Bereiche im Lichte des Interpretativen Paradigmas}

Das methodische Vorgehen trägt dem Umstand Rechnung, dass der Umgang mit urheberrechtlichen Komplikationen in der Samplingwelt ein sensibler und daher aller Vermutung nach ein von den Akteuren selbst geschützter Bereich ist, insofern hier oftmals in einer rechtlichen Grauzone oder sogar außerhalb der Legalität operiert wird. Verschiedene sozialwissenschaftliche Studien weisen auf die besonderen Aspekte einer solchen Situation hin, in der formale Regeln und diesen widerlaufende, informelle Praktiken bestehen.

So erarbeitete Erving Goffman einen ethnomethodologischen Ansatz, der vorwiegend auf der Basis von ethnografischen Studien das auf den ersten Blick Unsichtbare von Interaktionsordnungen hervorhebt und damit die Kluft zwischen dem Gesagten und dem Getanen markiert. Indem Goffman die Metapher des Theaters benutzt, wird das Versteckte präziser beschreibbar. So differenziert er die "front stage" von der - für das Publikum unsichtbaren - "back stage«, auf der die »dirty work" stattfindet. Damit bezeichnet Goffman die im Endprodukt unsichtbaren Mühen und Fehler, oftmals "physically unclean, semi-illegal, cruel, and degrading in other ways" (Goffman 1956: 28), die für die Herstellung zwar oft notwendig, aber aus diversen Gründen nicht ersichtlich sind. Am Beispiel eines zur Reparatur gegebenen Fernsehers beschreibt Goffman diesen Endzustand als einen, der "incidentally conceals the amount and kind of work that had to be done, the number of mistakes that were first made before getting it fixed, and other details the client would have to know before being able to judge the reasonableness of the fee that is asked of him» (Goffman 1956: 7I).

Auch Robert Merton wies mit seiner grundlegenden Denkfigur der Ziel-Mittel-Diskrepanz auf diverse Anpassungsleistungen hin, die Individuen oder Gruppen entwickeln, wenn sie angestrebte gesell- 
schaftliche Ziele (wie beispielsweise ökonomischen Wohlstand) aus sozialstrukturellen Gründen (wie schichtspezifischen Zugangsbarrieren zu Ressourcen) nicht mit den zur Verfügung stehenden Mitteln erreichen können. In dieser funktionalistischen Perspektive verschieben sich durch die Nicht-Zugänglichkeit institutionell erlaubter Mittel bei gleichzeitigem sozialem Druck zur Zielerreichung die Praktiken in illegitime oder sogar illegale Bereiche, die in der Regel durch latente, also gar nicht oder nur wenig sichtbare Strukturen gekennzeichnet sind, wie unternehmerische Tricks zu Steuerverschiebung oder Mafiasyndikate (Merton 1957). Mit dem Begriff der »brauchbaren Illegalität" findet sich bei Niklas Luhmann eine ähnliche, ebenfalls paradox wirkende Denkfigur, mit der er fokussiert auf die stabilisierenden, aber selten offen zur Schau gestellten »adaptiven Strategien jeder Art, mit denen sich ein Organisationsmitglied helfen kann, wenn es Strecken problematischer Legalität durchwandern muss" (Luhmann I999: 304; vgl. Kühl 2007). Die Aufdeckung von Praktiken des Einhaltens und Unterlaufens, Erfindens oder Zweckentfremdens von Regeln in versteckter oder geschützter Form ist dementsprechend zentrales Thema in Studien mit Fokus auf Umgebungen mit bürokratischen Kontrollstrukturen, beispielsweise bei der illegalen Verwendung bestimmter Werkzeuge beim Flugzeugbau (Bensman/Gerver 1963), der erleichternden Wirkung »inoffizieller Regeln« bei der Briefzustellung (Harper/Emmert 1963) oder den diversen Tricks der Kunstfälschung (Fine 1983; Grafton 1990).

In diesem Zwielicht stand mindestens bis zum Urteils des Bundesverfassungsgerichts (2016) auch die Praxis des Samplings, bei der sich urheberrechtliche Grammatik und kunstwelteigene ästhetische Regeln nur in unzureichendem Maße miteinander vereinbaren lassen. Diese prinzipielle, formal-urheberrechtliche Illegalität und die daraus folgenden Kontrollstrukturen liegen mit der tatsächlichen Praxis also in beträchtlicher Spannung. Die Aufarbeitung der Verwicklungen von Sampling und US-amerikanischem Copyright hat zudem gezeigt, dass die Konstruktion von Kreativität eine umkämpfte soziale Tatsache darstellt, die im Recht und in der Kunst unter- 
schiedlich konfiguriert und legitimiert wird. Zur Beantwortung der aufgeworfenen Forschungsfragen ist genaueres und empirisch abgesichertes Wissen über das Verhältnis von deutschem Urheberrecht und Kreativität in der Samplingwelt erforderlich. Um dieses zu generieren, wird ein methodischer Zugriff benötigt, mit dem sich aus der Binnenperspektive der samplingbasierten Musikproduktion die jeweiligen Rechtfertigungsstrategien und insbesondere die tatsächlichen adaptiven Praktiken in Bezug auf urheberrechtliche Restriktionen erfassen lassen.

Vor diesem Hintergrund verorte ich meine Arbeit im Interpretativen Paradigma des methodologischen Spektrums der empirischen Sozialforschung und wende mich in Konsequenz den qualitativen Forschungsmethoden zu. Nach Reiner Keller artikuliert sich im Interpretativen Paradigma die "Betonung des aktiven und kreativen menschlichen Zeichen- und Symbolgebrauchs, des permanenten Zusammenspiels von Deuten und Handeln in konkreten Situationen sowie der interaktiven Herstellung sozialer Ordnungen " (Keller 20I2: 17, Hervorhebung weggelassen). Innerhalb des Interpretativen Paradigmas wird außerdem die explorative Seite des Erkenntnisgewinns besonders herausgestrichen, durch die sich also bestimmte Bereiche des Lebens erkundend erforschen und die vorgefundenen Strukturen aufbrechen lassen - insbesondere, wenn von diesen Bereichen angenommen wird, dass das dort verhandelte Wissen nicht ohne Weiteres allgemein zugänglich ist.

\subsubsection{Fokussierte Ethnografie}

Um der urheberrechtlichen Sensibilität samplingbasierter Popmusik gerecht zu werden, wähle ich für die Erhebung und Analyse von empirischen Daten einen ethnografischen Zugriff, der die Strukturen eines sozialen Zusammenhangs mit Hilfe eines reflektierten Blicks von Innen heraus leisten kann. Grundlegend beziehe ich mich auf die von Hubert Knoblauch entwickelte fokussierte Ethnografie (Knoblauch 
200I, 2002), wobei ich den Fokus auf die Konfigurationen technischer Reproduzierbarkeit beim Sampling richte.

Ursprünglich in den I920er Jahren als methodisches Instrument der Ethnologie und Anthropologie zur oftmals kolonialen Erforschung fremder Völker und Stämme von Bronislav Malinowski (I994 [1923]) formuliert, erfährt die Ethnografie seit einigen Jahrzehnten zunehmende Beachtung in den qualitativ orientierten Sozialwissenschaften und weit darüber hinaus. Als Methode zeichnet sich die Ethnografie insbesondere durch die systematische, präzise und detaillierte Beschreibung einer bestimmten Kultur und ihrer sozialen Strukturen aus der ihr eigenen Perspektive aus. Nach Clifford Geertz (1987: 9) besteht das Ziel der Ethnografie darin, durch die Einnahme der nativen Perspektive und der Benutzung endonymer Begriffe das "selbstgesponnene Bedeutungsgewebe« der beforschten Kultur rekonstruktiv zu erfassen.

Mit der zunehmenden gesellschaftlichen Ausdifferenzierung des Globalen Nordens und damit einhergehenden Entwicklungen wie Urbanisierung, Rationalisierung und Modernisierung haben sich auch in westlichen Gesellschaften Teilbereiche entwickelt, deren innere Dynamiken und Strukturen Außenstehenden unbekannt und fremd erscheinen. Die Soziologie reagierte auf diese Entwicklungen, indem sie das Fremde im Eigenen zu untersuchen begann. Exemplarisch stehen hierfür die Arbeiten der Chicago School, in denen das "nosing around" an den Straßenecken der zahlreichen migrantisch geprägten Viertel mit ihren besonderen Sozialfiguren und arbeitsteilig spezialisierten Orten Chicagos wie Krankenhäusern, Hotels oder Fabriken zu einer Methode des Erkenntnisgewinns mit journalistischen und soziologischen Anteilen ausgebaut wurde (vgl. Anderson 1923; Park 1928; Hayner 1936; Whyte 1993 [1943]).

In gewisser Weise erfüllt sich durch die in der Ethnografie zentral gestellte Forderung körperlicher Präsenz der Forscher_in beim praktischen Vollzug eines sozialen Vorgangs die ursprüngliche Bedeutung des Begriffes "Interesse", das vom lateinischen Kompositum inter esse (dabei sein, teilnehmen, beiwohnen) herrührt. Entsprechend er- 
schöpft sich das Interesse der ethnografischen Forscher_in nicht nur in Interviews, Befragungen und Analysen gesammelter, also bereits fixierter Daten, sondern manifestiert sich in Form teilnehmender Beobachtung an noch flüssigen, sich im Vollzug befindlichen Praktiken (Goffman 1989). Diese besonders involvierte Form des Erkenntnisgewinns durch körperlich-praktische Teilnahme trifft auch auf die fokussierte Ethnografie nach Knoblauch zu, mit der sich ein spezifischer Ausschnitt einer Gesellschaft unter Berücksichtigung eines eng gefassten Forschungsinteresses untersuchen lässt.

Knoblauch (200I: 127) konzipiert die fokussierte Ethnografie dabei nicht als Konkurrenzmethode zu bisherigen Ethnografien. Vielmehr streicht er die fokussierenden Elemente des ethnografischen Arbeitens heraus, die er mehr oder weniger versteckt in der soziologischen Tradition der Laborstudien, Szeneforschung und Milieubeschreibungen erkennt. Es geht also nicht wie in der Ethnologie um die möglichst komplette Erfassung des typischen Wissenskorpus' einer fremden Kultur, sondern um die reflektierte, ausschnittsweise Erfassung eines Gesellschaftsbereichs, dessen Strukturen bereits durch seine Angehörige selbst Interpretationen zugesprochen bekommen haben und entsprechend vorgedeutet sind. Insofern handelt es sich bei der soziologischen Ethnografie um eine Methode "gesellschaftliche[r] Selbst-Beobachtung “ (Knoblauch 200I: 134, Hervorhebung weggelassen).

Während die »ethnologische Ethnografie», wie sie Knoblauch (200I: 124) zur Abgrenzung bezeichnet, das Hineinwachsen ins fremde Feld über relativ lange Zeit und die dabei langfristig gewonnenen Erfahrungsdaten als relevante Komponente betont, stehen bei der soziologischen Variante der fokussierten Ethnografie eher kurze, aber dafür besonders datenintensive Feldaufenthalte auf dem Programm. Die Gewinnung detaillierter und umfangreicher Daten, die auch verschiedene Typen wie videografische Daten (Tuma 2016) oder andere Protokollformate berücksichtigen kann, führt in der Konsequenz zu einer Analysesituation, die die Genese intersubjektiv plausibilisierbarer Interpretationen durch den systematischen Einbezug von Dritten 
(wie beispielsweise Forschungskolleg_innen) sicherstellt (Knoblauch 200I: I3I).

Daneben wird durch weitere Techniken der analytischen Distanzierung und Sensibilisierung schon während der Erhebung gewährleistet, dass blinde Flecken, mitgebrachte Vorurteile oder Alltäglich- und Selbstverständlichkeiten auf ein Minimum reduziert werden. Hierbei sind etwa Explikation des eigenen Vorwissens und der eigenen Erwartungen vor Beginn der Datenerhebung sowie eine kontinuierliche Selbstdokumentation und Protokollierung zu nennen (Kühn 20I6: 285; siehe Anhang AI). Knoblauch betont zudem den generell konstruktivistischen Charakter der ethnografischen Feldforschung, sowohl bei der konventionellen, insbesondere aber bei der fokussierten Ethnografie. So werden sowohl für die Wahl des Ausschnitts bereits eine gewisse Kenntnis des Felds wie auch für den $\mathrm{Zu}$ gang zu diesem bereits Feldkontakte vorausgesetzt (Knoblauch 2002: I33). Die Selektion der Ethnografierten und Deutung der Forschungsergebnisse beruht auf spezifischen Interessen, die sozialstrukturell abhängig sind. Das bedeutet, dass der Forscher_in bestimmte Felder oder Subfelder zugänglich sind, andere aber nicht, was methodisch reflektiert werden muss. Als systematische soziologische Forschungsmethode reagiert die fokussierte Ethnografie damit auf den Umstand gemeinsamen kulturellen Wissens, dass also die Angehörigen eines bestimmten gesellschaftlichen Bereichs zwar spezifisches Wissen ausgebildet haben, das nicht allen zugänglich ist, aber trotzdem noch eine Schnittmenge mit dem Wissen der Ethnograf_in aufweisen und dadurch nicht komplett unabhängig erscheinen:

"Das Modell des von der Außenwelt abgeschnittenen, von der Zivilisation weit entlegenen $>$ Dorfes als paradigmatischem Forschungsort, gilt in modernen Gesellschaften sicher als kaum mehr angemessen. Insbesondere dann nicht, wenn Kommunikation und Kooperation über weltweite Netze realisiert werden, wenn globale Forschungsprojekte oder wenn zeitliche begrenzte Ereignisse in den Interessenfokus der Forschenden rücken.« (Tuma 20I6: 8I, Hervorhebung im Original) 
Die soziologische Ethnografie begegnet der Subjektivität der Forscher_in damit nicht, indem sie diese aus dem Forschungsprozess heraus zu drängen sucht, sondern indem sie sie systematisch problematisiert, das heißt dokumentiert, kontrolliert und dadurch nutzbar macht. Auffälligkeiten, Widersprüche, Probleme und Routinen, das Betonte und das Übergangene, aber auch das Alltägliche und vermeintlich Irrelevante werden sorgfältig dokumentiert und festgehalten, um es der Analyse zuzuführen.

\subsubsection{Schauplätze}

In Erweiterung der grundlegenden methodischen Ausgangspunkte, die die fokussierte Ethnografie nahelegt, und für die Umsetzung des Forschungsvorhabens in ein ethnografisches Forschungsdesign mit entsprechenden Untersuchungseinheiten folge ich in meiner Studie dem zentralen Gedanken einer "multi-sited ethnography» von George Marcus (1995). In der Tradition der Cultural Studies stehend schlägt Marcus vor, die verschiedenen Schauplätze (»sites«) des beforschten Gegenstands und dadurch die mit ihm verbundenen, über die einzelnen lokalen Situationen hinaus wirkenden Prozesse zu berücksichtigen. Dadurch wird es möglich, dem Gegenstand beim Wandern durch verschiedene soziale Zusammenhänge zu folgen und die hierbei entstehenden Spuren einzufangen, die beispielsweise aufgrund makrostruktureller Grammatiken in die Objekte eingeschrieben werden. Eine solche ethnografische Methode, die über verschiedene Schauplätze hinweg erhebt, bietet den analytischen Vorzug, etwaige Dichotomien wie beispielsweise global/lokal, eigen/fremd oder Konsum/Produktion wirkungsvoll aufzubrechen und die sich im Objekt manifestierende Transformation hinsichtlich seines Status' zu erkennen. Die multi-sited ethnography legt damit ihren Schwerpunkt auf das "tracing the shifting status of things as commodities, gifts, and resources in their circulations through different contexts" (Marcus 1995: I07; vgl. Grünewald-Schukalla 2018: 44). 
Diese »verfolgende Betrachtung" eröffnet gegenüber der lokal situierten konventionellen Ethnografie damit »eine integrierende Perspektive, welche es auch erlaubt, bislang nicht beachtete Phänomene an den Schnittstellen und in den Zwischenräumen wahrzunehmen und zu thematisieren " (Tuma 20I6: 93). Im Fall der vorliegenden Untersuchung sind es genau jene Prozesse und Praktiken, die in den Zonen zwischen den großen Funktionssystemen wie Wirtschaft, Recht und Kunst stattfinden und verhandelt werden, die mich als Ethnografen interessieren. Ausgehend von Beckers Konzept der Kunstwelten, das die bereichsübergreifenden Netzwerke der Produktion von Kunst adressiert, sind es die Schauplätze, an denen samplingbasierte Popmusik hergestellt, lizenziert, veröffentlicht und verwertet wird. Ich lege also den Fokus auf das Wandern von Samples, also ausschnittsweisen Kopien bereits existenter Musikstücke, um damit die "complex paths of circulation - of objects, money, ideas, and people - that were either previously not seen, ignored, or devalued by the art world « (Marcus/ Myers 1995: 34), nachzuvollziehen.

\subsection{Methodisches Vorgehen}

\subsubsection{Feldzugang und theoretisches Sampling}

Ich begreife das Forschungsprojekt als Möglichkeit, mein bisheriges Wissen über und meine Kontakte in die Kunstwelt der samplingbasierten und DJ-getriebenen Popmusik strategisch zu nutzen, um Musikproduzent_innen zu begleiten und an den verschiedenen Schauplätzen ihrer Arbeit ethnografisch zu erforschen. ${ }^{50}$ Seit Jahren beschäftige ich mich in vielfältiger Weise mit den verschiedenen Aspekten samplingbasierter Musik. Als DJ lernte ich die Techniken des

50 Eine ausführliche Reflektion meiner Rolle, meiner Aktivitäten und meines Forschungsinteresses findet sich im Anhang dieser Arbeit. An dieser Stelle erfolgt daher lediglich eine kurze Skizze dieser Positionsbestimmung. 
Auflegens und Selektierens von Musik ab etwa 2004 kennen und war bis 2016 regelmäßig in zahlreichen Clubs aktiv. Als Journalist interessiere ich mich seit etwa 20 Io für das Schreiben und Sprechen über Musik; seit etwa 2014 verfolge ich auch ein journalistisches Interesse für urheberrechtliche Verwicklungen in anderen Bereiche wie Verwertungsgesellschaften, Softwareschutz oder Plagiaten. ${ }^{\text {.1 }}$ Mit der Abgabe meiner Diplomarbeit (2013) über die Innovationsgeschichte des Samplings im 20. Jahrhundert schließlich begann auch meine wissenschaftliche Rolle bei der Erforschung von Sampling, Kreativität und Popmusik. Die drei Tätigkeiten sind dadurch gekennzeichnet, dass sie alle in gewisser Form auf einer Metaebene relativ zur Musikproduktion stattfinden. Zwar war ich schon vor Beginn der ethnografischen Forschung an Orten, an denen auf Basis alter Samples neue Musik produziert wird, jedoch bin ich bis heute ein Laie bei der tatsächlichen Herstellung von Stücken im Studio geblieben. Bisher zog ich es vor, bereits existierende Musik auszuwählen, sie aneinander zu reihen und mit einander zu mischen, über sie zu sprechen und die sozialen Bedingungen ihrer Existenz und Ästhetik zu theoretisieren.

Ausgehend von meiner Position im Feld und auf Basis der iterativen Einkreisung meines Forschungsinteresses erhob ich zwischen Sommer 2014 und Winter 2017 meine Daten in fokussierten Ethnografien und leitfadenbasierten Interviews mit Expert_innen, für die ich insbesondere juristisch definierte Termini wie Schöpfungshöhe, Bearbeitung und ähnliche zu Fragen oder verbalen Gesprächsanstößen operationalisierte. Meine bisherigen Verbindungen zu Vertreter_innen der samplingbasierten Kunstwelt waren dabei deutlich von Vorteil. Insbesondere die journalistischen Rezensionen, Interviews und anderen Formen der Berichterstattung in Radio und Internet bescheinigten mir gegenüber den Beforschten ein legitimes (Forschungs-)Interesse. Mein Hintergrund als DJ und als Betreiber des Blogs "Jäger und Sampler« wies mich zudem als Teil des Felds aus

5I Siehe dazu beispielsweise die bei iRights.info veröffentlichten Artikel: https:// irights.info/author/georg-fischer (28.II.20I7). 
und verschaffte mir den notwendigen "Stallgeruch«, um Zutritt zu Studios erhalten. ${ }^{52}$

In das Zentrum meines Interesses stellte ich das Verhältnis von Urheberrecht und Kreativität, das ich am Fall samplingbasierter $\mathrm{Mu}-$ sikproduktion für den deutschen Rechtsraum untersuchen möchte. Als Untersuchungseinheit für die Erhebung und Analyse legte ich die Praktiken fest, die von den verschiedenen Akteuren zur Produktion, Distribution und Verwertung samplingbasierter Popmusik angewendet und von ihnen selbst als solche beschrieben werden. In den Anbahnungen der Interviews explizierte ich meist per Telefon oder Email mein Interesse mit der allgemeinen Frage, »... wie man eigentlich eine Platte macht? «. Mein Interesse für urheberrechtliche Probleme umschrieb ich mit vagen Formulierungen, wenngleich ich es nicht komplett unerwähnt ließ. Meist erkundigte ich mich nach dem Verfahren des Samplings, seinen technischen Grundlagen und rechtlichen Besonderheiten, so dass der urheberrechtliche Fokus als einer von mehreren erschien. Die Gesamtheit des Prozesses der Musikproduktion, beginnend beim Finden der passenden Samples über ihre Rekombination hin zur Veröffentlichung in neuen Stücken, sollte gegenüber den Produzent_innen in den Vordergrund gerückt werden. Gegenüber den Anwält_innen konnte ich mein Interesse für Sampling und Urheberrecht mit Verweis auf die aktuelle Rechtsprechung, die im Fall Pelham vs. Kraftwerk mit dem Urteil des Bundesverfassungsgerichts im Juni 2016 ihren vorläufigen Höhepunkt erreichte, ausreichend belegen.

52 Beispielsweise hatte ich 2013 eine Rezension von einem Album verfasst und dafür die Presseabteilung des Labels kontaktiert. Einige Monate später rief ich die Presseagentin dieses Labels, deren Telefonnummer ich der Signatur ihrer Email entnehmen konnte, wieder an und erzählte ihr von meinem besonderen Interesse für das Sampling. Ich erkundigte mich bei ihr nach neuen samplingbasierten Veröffentlichungen des Labels und nach passenden Kandidat_innen, denen es recht wäre, wenn ich sie einmal im Studio besuchen würde. Die Agentin notierte sich mein Anliegen und versprach, mich wieder zurückzurufen. Zwar musste ich selbst nochmals nachfassen, aber über die bewusste Agentin kam tatsächlich der Kontakt zu einer Musikproduzentin zustande, die ich 2014 dann im Studio traf. 
Trotzdem scheiterten auch einige Anbahnungen. In diesen Fällen wurden meine Anfragen per Mail und Telefon, auch nach mehrmaligen Versuchen und über bekannte Dritte, nicht beantwortet. Auch zwei bereits vereinbarte Termine, zu denen ich in die entsprechenden Städte angereist war, wurden von Seiten der Musikproduzent_innen kurzfristig abgesagt. Ihren Beteuerungen, man werde einen neuen Termin finden, folgten allerdings keine Antworten mehr auf meine neuerlichen Anfragen. Insofern kann ich die ausschlaggebenden Gründe für das verloren gegangene Interesse nicht zweifelsfrei einschätzen. Allerdings vermute ich, dass es für manche Musikproduzent_innen nicht hilfreich erscheint, mir mehrere Stunden ihrer Zeit zur Verfügung zu stellen, wenn sich dies für sie nicht in einem geeigneten Gegenwert wie medialer Berichterstattung oder einem Honorar auszahlt.

In räumlich-kreativwirtschaftlicher Hinsicht war die Konstellation in Berlin insbesondere für die Anfangsphase meiner Forschungsbemühungen ideal. Aufgrund seiner besonderen historischen Entwicklung zieht die Stadt seit Jahren aufstrebende wie etablierte Kreative aus unterschiedlichen Bereichen an. Nach dem Fall der Mauer entwickelte sich auf etlichen Brachflächen, in verlassenen Gebäuden und anderen zwischengenutzten Räumen eine lebendige Clubszene, deren Ruf heute international bekannt ist. Vergleichsweise niedrige Mietpreise und große Freiheiten trugen ihren Teil dazu bei, dass sich in Berlin neben den Clubs auch zahlreiche (Nischen-)Plattenläden, Studios, Agenturen, Unternehmen im Musiksoftwarebereich (wie Ableton oder Native Instruments) sowie mehrere hundert Indielabels niedergelassen haben. Auch andere musikwirtschaftliche Akteure, die in Berlin angesiedelt sind oder zumindest Vertretungen haben, waren wichtige Anlaufstellen, wie beispielsweise der Verband unabhängiger Tonträgerunternehmen (VUT), die Berlin Music Commission (BMC), das Majorlabel Universal, der Bundesverband Musikindustrie (BVMI), Verwertungsgesellschaften wie die GEMA oder die Gesellschaft zur Verwertung von Leistungsschutzrechten (GVL).

Der Zuschnitt meines Forschungsprojekts erforderte es, in Berlin und anderen deutschen Städten auf musikwirtschaftliche und rechts- 
wissenschaftliche Veranstaltungen wie beispielsweise "Most Wanted Music« der BMC, dem »Reeperbahnfestival« in Hamburg oder dem "Kongress Urheberrechtspolitik« zu gehen, um ein Gespür für die jeweiligen Perspektiven zu bekommen, Kontakte zu knüpfen und Interviews vor allem mit den Jurist_innen anzubahnen. Insgesamt erforderte es hohen persönlichen Einsatz, im Sinne des ethnografischen Forschungsdesigns die Kunstwelt der samplingbasierten Popmusik in ihren netzwerkartigen Kooperationsbeziehungen heuristisch zu kartieren und dabei relevante Akteure zu erfassen. Neben meiner Anwesenheit auf dutzenden Diskussionsveranstaltungen, Konferenzen und Partys streifte ich in meiner Freizeit oft durch Plattenläden und auf Flohmärkten herum, stöberte online auf Plattformen und verlor mich in Fachforen wie whosampled.com oder discogs.com, konsumierte stundenlang Videos, Reportagen, Interviews und etliche Artikel, Urteilsbegründungen und andere Texte aus dem Feld wie Blogeinträge oder Copyright-Credits, um iterativ ethnografische Schauplätze und implizites Wissen zu identifizieren.

\subsubsection{Datenerhebung und -analyse}

Die Methode der fokussierten Ethnografie erfordert ein bestimmtes Maß an Vorwissen der Forscher_in, um den zu erforschenden Feldausschnitt festlegen zu können und dadurch eine "Konzentration auf bestimmte Aspekte von Feldern" (Knoblauch 200I: I26) zu erhalten. Um mir meiner impliziten Vorannahmen gewahr zu werden und sie mir selbst gegenüber öffentlich zu machen, verfasste ich vor Beginn der Erhebungsphase im Sommer 2014 eine umfassende Selbstreflexion meines Wissens als Feldakteur. Zu diesem Zweck schrieb ich eine Skizze meines persönlichen Werdegangs und meiner derzeitigen Feldposition als DJ, beobachtender Journalist und analysierender Soziologe. Diese Skizze ergänzte ich während der weiteren Forschungsarbeit um wenige Aspekte. Die ausgearbeitete Selbstreflexion ist der Arbeit angehängt. 
Im Sinne der Grounded Theory, an deren Grundprinzipien Offenheit, Iterativität und induktiver Kategorienbildung aus dem Material ich mich orientiere (Corbin/Strauss 1990; Strübing 2002; Rosenthal 20I4), greifen Datenerhebung, Entwicklung der Forschungsfrage und Analyse ineinander. Die Verzahnung macht es möglich, das Forschungsinteresse während des Forschungsprozesses kontinuierlich zuzuspitzen und feiner zu justieren, was sich auch in der vorliegenden Arbeit an der Entwicklung der Forschungsfrage in Kapitel I und 4 zeigt.

Für das theoretische Sampling der zu ethnografierenden Musikproduzent_innen stellte ich weniger die Kontraste, sondern die Typik in den Vordergrund. Als idealtypisch identifizierte ich erfahrene und erwerbsorientierte Musikproduzent_innen, »integrated professionals" im Sinne Beckers (2008: 229), die in der Vergangenheit bereits eine Reihe eigener Stücke veröffentlicht, dabei die genrehaften Konventionen internalisiert und aller Vermutung nach auch mit Labels und Anwält_innen zur Lizenzierung zusammengearbeitet hatten. Wichtig dabei ist vor allem der deutsche Rechtsraum, in dem das deutsche Urheberrecht greift, wenngleich in dem globalisierten Musikgeschäft auch internationale Copyrights und andere Rechte betroffen waren. Auch fokussierte ich solche Produzent_innen, die neben der $\mathrm{Mu}$ sikproduktion als DJs und/oder Manager ihres eigenen Labels aktiv sind. Als typische samplingbasierte und mit verschiedenen Graden von Referentialität operierende Genres der Popmusik identifizierte ich Hip Hop, House, Techno, Drum'n'Bass und Dubstep, wobei ich weitere Genres nicht kategorisch ausschloss.

Als Schauplätze schienen mir alle diejenigen Orte interessant, an denen samplingbasierte Musik produziert, verwertet und veröffentlicht wird und an denen ich den typischen Vollzug der Praxis teilnehmend beobachten konnte. Hauptsächlicher Schauplatz war das Studio, aber auch Flohmärkte, Plattenläden, Clubs, Hinterzimmer und im weiteren Forschungsprozess auch Anwaltskanzleien kamen in Frage, um die typischen Netzwerke der Kooperation zu erheben. Daneben waren es auch digitale Orte im Internet, wo entsprechendes 
Wissen ausgetauscht und gebündelt oder Musik öffentlich zur Verfügung gestellt wird.

Grundsätzlich betrachte ich jegliche Form von Daten als relevant, um Informationen zu erhalten. Insbesondere folge ich dem Rat Beckers (2008: I62), Problemen, Störungen, widersprüchlichen Definitionen und Ungereimtheiten nachzugehen, wenn sie sich im Rahmen der Datenerhebung zeigen. Dahinter steht der Gedanke, die unter den Unregelmäßigkeiten liegenden Konventionen aufzubrechen und dadurch erklärungsbedürftig und abrufbar zu machen. $\mathrm{Zu}$ den Produktionssessions, an denen ich teilnahm, brachte ich beispielsweise selbst Stücke mit und erfragte die Kriterien, nach welchen sie als Samples taugen könnten oder nicht. Auch recherchierte ich vorab die Sample-Credits der Veröffentlichungen oder die bei der Online-Repertoiresuche der GEMA einsehbaren Informationen zu Komposition, Text und Verlag. Auch erkundigte ich mich nach den Schritten, die notwendig waren, um das jeweilige Stück bis zur Veröffentlichung zu bringen. Oftmals waren es gerade Unregelmäßigkeiten in den Credits, die mich skeptisch machten und mit denen ich die Beforschten konfrontierte. ${ }^{33}$ Mit diesen und ähnlichen methodischen Kniffen strategischer Naivität gelangte ich zunehmend und iterativ zu Insiderwissen, auf welche Weisen Samples ausgewählt, bearbeitet und lizenziert werden.

53 Bei manchen Veröffentlichungen wunderte ich mich bei der Vorbereitung beispielsweise darüber, dass die Originalurheber_innen des gesampelten Stücks in den GEMA-Credits des sampelnden Stücks auftauchten. Daraus schloss ich, dass ein unsachgemäßer Weg der Lizenzierung gewählt wurde, um die Leistungsschutzrechteklärung des betreffenden Samples zu umgehen, gleichzeitig aber die originalen Urheber_innen an der Rechtewahrnehmung durch Verwertungsgesellschaften zu beteiligen. Eine andere Unregelmäßigkeit bemerkte ich in der Weise, wie die Nennung von lizenzierten Fremdsamples auf dem Tonträger oder dessen Cover erfolgte: in einigen Fällen waren für die bekannteren Stücke des Albums lizenzierte Samples angegeben (»contains a sample of«), für die unbekannteren hingegen nicht - auch wenn es offensichtlich war, dass auch in diesen fremde, genehmigungsplichtige Samples in referentieller Weise verwendet wurden. Dies legte für mich nahe, dass unterschiedliche Umgangsweisen für unterschiedlich bekannte Samples gefunden wurden. 
Während und direkt nach den teilnehmenden Beobachtungen verfasste ich extensive handschriftliche Feldnotizen, in denen ich eingeprägte Umgebungen und Eindrücke, Stimmung und Informationen jeglicher Art in tagebuchähnlicher Form festhielt. Im Zentrum dieser Feldnotizen standen dabei die Praktiken und Aussagen der Beforschten, aber auch meine eigenen Lernfortschritte, die ich im Zuge der Musikproduktion machte. Solange sich die erlebte Situation noch frisch in meinem Bewusstsein hielt, berücksichtigte ich auch Kleinigkeiten, Unauffälliges und banale Dinge, beispielsweise wie reibungslos der Kontakt ablief, mit welchen sonstigen Gegenständen das Studio ausgestattet war oder wie sich die Situation für mich anfühlte. Oft machte ich auch Skizzen von den Schauplätzen, in mehreren Fällen auch Fotos. Die handschriftlichen Notizen verdichtete ich am Computer in Memos, anonymisierte und analysierte sie mit verschiedenen Kodiertechniken.

Die Erhebung meiner Daten beschränkte sich nicht auf Berlin, sondern führte mich während zwei Erhebungsphasen in verschiedene deutsche Großstädte. In der ersten Erhebungsphase zwischen Sommer 2014 und Frühjahr 20I5 führte ich fokussierte Ethnografien mit vier verschiedenen Musikproduzent_innen durch. Ich begleitete diese jeweils zwischen zwei und sechs Mal zu verschiedenen Schauplätzen und Stadien des Produktionsprozesses. Die in dieser Phase gewonnenen Daten wurden zu Memos verschiedenen Umfangs verdichtet, die meine Beobachtungen und erste theoretische Schlussfolgerungen enthielten. Die induktiv daraus generierten Kodes wurden zur Grundlage für die zweite Erhebungsphase zwischen Sommer 2015 und Winter 2017. Hier führte ich die ethnografische Forschung mit weiteren vier Musikproduzent_innen fort und ließ in den Produktionssessions nun auch ein Aufnahmegerät laufen. Parallel dazu erhob ich in leitfadenbasierten Expert_inneninterviews weitere Daten, die zur Vertiefung und Triangulation der bisherigen Erkenntnisse dienten. Das theoretische Sampling der Expert_innen gründete ich auf kontrastiven Merkmalen, um die Bandbreite der Praktiken erfassen zu können. Fünf Rechtsanwält_innen und drei hauptberuflich als 
Labelbetreiber_innen Tätige standen mir in dieser Phase Rede und Antwort auf meine jetzt schon spezifischeren und fokussierten Fragen. Die Aufnahmen wurden transkribiert, kodiert und analysiert. Den Wechsel zwischen Forschungsfeld und Schreibtischarbeit nutzte ich methodisch, um Abstand zum Erlebten zu bekommen, mich auf Basis soziologischer Theorie zu informieren und auch die Veränderungen in der Rechtslage im Auge zu behalten.

Während der zweiten Erhebungsphase hob das Bundesverfassungsgericht Ende Mai 2016 das Urteil des Bundesgerichtshofs (20I2) auf, was für mich nach der zunehmend restriktiv werdenden Rechtsprechung seit den I990er Jahren unerwartet kam. Da der Bundesgerichtshof 2017 zur Harmonisierung des EU-Rechts an den Europäischen Gerichtshof weiterverwies und kein eigenes weiteres Urteil fällte, herrschte ab diesem Zeitpunkt eine unklare Rechtslage. Einerseits hatte das Bundesverfassungsgericht einige Vorschläge gemacht, wie Sampling urheberrechtlich zu beurteilen sei, andererseits wurden diese bis dato nicht in der Rechtsprechung spezifiziert. Dies brachte mich in die Situation, die persönlichen Interpretationen der Anwält_innen und möglichen Szenarien in die eine oder andere Richtung detailliert abfragen zu können.

Für die Kodierung des erhobenen Datenmaterials orientierte ich mich an den Grundprinzipien der Grounded Theory, die Offenheit, Iterativität und induktive Kategorienbildung vorsieht. Nach der ersten Erhebungsphase mit fokussierten Ethnografien führte ich eine Reihe von Expert_inneninterviews durch, die vollständig transkribiert wurden. Um das Material aufzubrechen, kodierte ich die Daten zunächst offen. Das heißt vor allem, dass endonyme Begriffe aus dem Feld als Ethnosemantik kodiert wurden (auch als in vivo-Kodieren bekannt): Je nach Gesprächspartner_in und Interviewzuschnitt waren das eher musikalische Begriffe (wie beispielsweise "choppen", "Soundalike", "diggen" sowie metaphorische Klangbeschreibungen wie "macht auf" oder "groovt«) oder eher juristische Fachtermini (»Schöpfungshöhe«, »Rechte Dritter«, »Lizenzgeber«, »Originalveröffentlichung«, "Schutzfrist« etc.). Viele, wenn auch nicht alle dieser 
Begriffe waren mir aus den fokussierten Ethnografien bereits bekannt. Daneben umfasste das offene Kodieren jene besonders kleinteiligen Kodierungen, in denen ich einzelne Prozesse in Sinneinheiten zergliederte und in ihrer Abfolge zu erfassen suchte. Hierbei versuchte ich neben den endonymen Begriffen eigene ad hoc-Begriffe zu finden und sie als Kodes festzuhalten. Ein gutes Beispiel dafür sind die unzähligen und oft verborgenen Kopierprozesse, die in Aussagen und beschriebenen Praktiken zum Ausdruck kommen (»herunterladen«, "loopen", "Demoversion", etc.) sowie die damit verbundene ästhetische Vorliebe für klangliche Originalität der Sampelnden. Mithilfe offener Kodiertechniken gelangte ich nach und nach von einem recht konkreten, noch nah an der Sache und den Aussagen der Akteure orientierten Verständnis zu einem abstrakteren Verständnis und einem sensiblen Blick für unerwähnte Zusammenhänge oder besonders betonte Aspekte.

Aus der Phase des offenen Kodierens entstanden mehr als 2300 Kodes, die ich auf etwa 2000 Kodes bereinigte und zusammenfasste. Nach dem Ende der Erhebung begann ich die offen kodierten Interviews mit der Technik des selektiven Kodierens stärker systematisch zu bearbeiten und bereits entstandene Zusammenhänge, Ideen und Argumente zu verdichten. Hierbei bezog ich die aufgearbeitete Literatur und die erarbeiteten theoretischen Konzepte (unter anderem zu kreativer Kontribution, Exploration/Rekonstruktion und Symbolisation) mit ein, mit dem Ziel, die vorhandenen Kodes zu verfeinern, sie besser in Beziehung zueinander zu setzen und ein abstrahiertes Verständnis von samplingbasierter Musikproduktion unter den Bedingungen des Urheberrechts zu erlangen. Besonders wertvoll waren in dieser Phase meine Feldnotizen und die aus dem körperlichen Mitvollzug der Praktiken entstanden Beschreibungen, mit denen ich die Aussagen der interviewten Akteure triangulierte und durch axiales Kodieren in Beziehung setzte. Erst durch den Miteinbezug dieser verschriftlichten teilnehmenden Beobachtungen gelang es mir, einen qualitativen Schritt über die endonymen Feldbeschreibungen hinaus zu erreichen und ein analytisches Verständnis von der Kunstwelt zu 
erlangen. Aus dieser Phase heraus entstanden eigene theoretische Begriffe wie Reoriginalisierung, Detektabilität oder die Idealtypik der "50 shades of referentiality«. Die These der Umgehungskreativität als Schatteninnovation arbeitete ich vor allem aus der historischen Betrachtung der Literatur heraus, so dass ich unter dem Kode der „Umgehung " nun bestimmte Phänomene aus meiner eigens erhobenenen Empirie besser sehen und schließlich in Typen respezifieren konnte.

\subsubsection{Strategische Sensibilisierung für Eigen und Fremd}

Das in den Interviews und teilnehmenden Beobachtungen immer wieder thematisierte Verhältnis zwischen Eigen und Fremd (in Bezug auf verwendetes musikalisches Material) spielt auch in meinem Forschungsdesign eine Rolle (in Bezug auf methodische Reflexivität). Um die relativ große Menge an Daten zugänglich zu machen und zu durchdringen, unterschied ich systematisch zwischen den endonymen Begriffen des Felds (Ethnosemantik) und meinen exonymen, analytischen Begriffen. Zwar betont Knoblauch in Abgrenzung zu Hirschauer und Amann (1997; Hirschauer/Breidenstein 2002) besonders die Qualität des feldinternen Wissens, das sich die Ethnograf_in reflektiert aneignet und davon ausgehend analytische Begriffe generiert. In meinem persönlichen Fall jedoch fand ich die strategische Sensibilisierung, das sich selber "fremd machen « für die Profanität des Alltags besonders hilfreich (vgl. Strübing 2008: 29, mit Verweis auf Herbert Blumer), um die Übergänge zwischen Abtauchen in die beforschte Lebenswelt und Auftauchen in meiner eigenen Lebenswelt zu gestalten.

Ausgangspunkt einer zentralen Strategie zur methodischen Sensibilisierung war ein Zufall im Juni 2015, den ich mir autoethnografisch zunutze machte. Aufgrund einer Unachtsamkeit ging mein Smartphone kaputt. Nach dem Ausfall des Geräts holte ich mir - wie ich zuerst dachte - ein provisorisches, für den Übergang gedachtes Handy. Das war allerdings nicht smart, sondern - um in der Metapher 


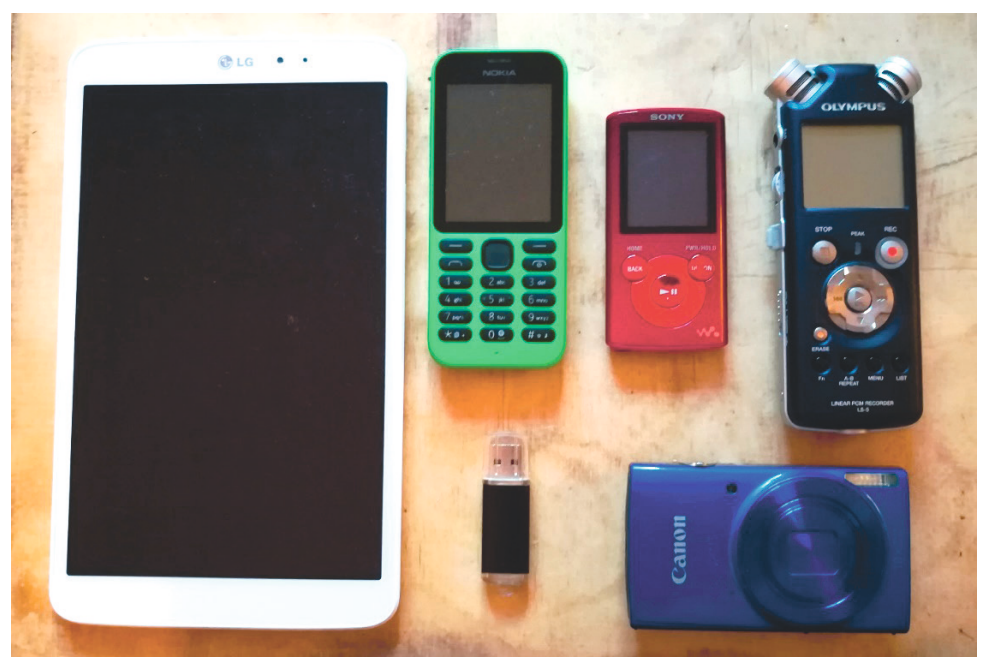

Abbildung 1: Untereinander nicht vernetzte Kopiertechniken; im Uhrzeigersinn links beginnend: Tablet, Handy, MP3-Player, Audiorekorder, Digitalkamera, USB-Stick

zu bleiben - dumb: ein simples Billigtelefon, mit dem es nicht mehr möglich war, Fotos aufzunehmen, Musik abzuspielen oder Whats$A p p$-Nachrichten zu schreiben. Lediglich Funktionen wie SMS und Anrufe waren technisch durchführbar, wenn auch in rudimentärer Form (beispielsweise konnte ich nicht mehr als zehn SMS speichern). Nach einer Umgewöhnungsphase von wenigen Wochen gefiel mir der digital detox, wie es ein Freund bezeichnete, da ich nicht mehr mobil ins Internet gehen und andere Aktivitäten an meinem Telefon machen konnte, die mich, wie ich nun erkannte, eigentlich mehr gestresst als mir genützt hatten. Ich beschloss, mir kein neues Smartphone zu kaufen, sondern das einfache Handy zu behalten.

Durch dieses technische downgrade waren meine bisher so selbstverständlichen, unsichtbaren Kopiervorgänge allerdings unterbrochen. Das Smartphone war dazu designt, Emails empfangen und schreiben, Musik streamen, Daten transportieren oder selbstgemach- 
te Fotos verschicken zu können. Mein neues Telefon konnte nichts davon, so dass ich komplementäre Geräte hinzuziehen musste: USBStick, Digitalkamera, $\mathrm{MP}_{3}$-Player, Tablet und Audiorekorder (siehe Abbildung I) halfen mir nun dabei, meine verloren gegangene Reproduktionshoheit mehr oder weniger zurückzugewinnen. So souverän und einfach, wie das vernetzte Kopieren mit dem Smartphone erschien, so umständlich wurde es nun mit der veränderten technischen Umgebung, da ich nun meist über den Computer zusätzliche Kopiervorgänge miteinbeziehen musste, um beispielsweise ein Foto in sozialen Netzwerken zu veröffentlichen. Die neue, selbstgewählte Umständlichkeit schärfte jedoch meinen Blick für stille, versteckte oder übersehene Kopiervorgänge, für die "underlying work practices« (Suchman 1995: 56), die mir nun wie blinde Flecken erschienen. Gleichzeitig entwickelte ich größere analytische Distanz für diverse Praktiken zur Rückgewinnung der Reproduktionshoheit, mit der ich den bereits erhobenen und noch zu erhebenden Daten begegnen konnte. Diese Gründe waren dafür ausschlaggebend, das durch einen Zufall begonnene Experiment eines Lebens ohne Smartphone für die Anfertigung der Dissertation und darüber hinaus aufrechtzuerhalten. 


\section{Kopieren, Komponieren, Koordinieren - Die Kunstwelt samplingbasierter Popmusik und ihre urheberrechtlichen Verwicklungen}

In diesem Kapitel werde ich anhand von verdichteten ethnografischen Memos und transkribierten Interviewausschnitten mit Musikproduzent_innen, Labelbetreiber_innen und Jurist_innen die Kunstwelt der samplingbasierten Popmusik in ihren Umrissen beschreiben und mit besonderer Berücksichtigung auf urheberrechtliche Verwicklungen untersuchen. Dabei orientiere ich mich an den Kategorien, die sich in der Analyse des Materials als am fruchtbarsten erwiesen haben. Die drei Praktiken Kopieren, Komponieren und Koordinieren identifizierte ich in der Materialanalyse als wesentliche und die verschiedenen musikindustriellen Bereiche übergreifende Tätigkeiten, mit denen sich die Strukturen der beschriebenen Lebenswelt mit Gewinn aufschlüsseln lassen. Entsprechend gliedert sich das Kapitel in drei Unterkapitel, die mit den drei Kernpraktiken Kopieren, Komponieren und Koordinieren überschrieben sind. Trotz des daraus resultierenden, vergleichsweise großen Umfangs habe ich mich dazu entschieden, diese drei unter dem thematischen Dach eines gemeinsamen Kapitels zu behandeln. Freilich wären auch andere Wege der Darstellung möglich gewesen - mit dem Fokus auf die drei genannten Kernpraktiken ist es aber möglich, die übliche Linearität in der Darstellung musikindustrieller Prozesse (Produktion, Distribution und Rezeption) stückweise aufzubrechen und die Querbeziehungen, das typische Hin und Her, für das Sampling als charakteristisches Merkmal herauszuarbeiten. 
Die dichten Beschreibungen, die in vergleichbaren ethnografischen Studien auch als "Vignetten« bezeichnet werden, sind kursiv gesetzt und eingerückt. Zitate aus dem Untersuchungsfeld werden mit "Anführungszeichen" markiert und sind ebenfalls eingerückt. Teilweise sind auch kurze, in Anführungszeichen gesetzte Phrasen oder endonyme Begriffe zu lesen, die ich ohne Zuordnung der Autorschaft angegeben habe, weil sie als Feldbegriffe immer wieder auftauchten und ich nicht nur von einer individuellen, sondern einer kollektiven Verwendung ausgehe. Um die zugesicherte Anonymität zu wahren, wurden ihre Aussagen von mir pseudonymisiert und, wo es nötig erschien, teilweise mit dem Kürzel $=^{*}=$ zensiert. Meine eigenen verbalen Äußerungen sind mit den Initialen GF markiert. Weitere Kürzel wurden verwendet: P steht für Produzent_in, L für Labelbetreiber_in und J für Jurist_in, wie der folgende Überblick meiner Interviewpartner_innen zeigt:

\begin{tabular}{|c|c|}
\hline Kürzel & Tätigkeiten/Organisation \\
\hline P-I_I4 & Produktion, v. a. Hip Hop \\
\hline PL-2_I4 & $\begin{array}{l}\text { Produktion, Labelbetrieb, v. a. House und Techno; DJ } \\
\text { international }\end{array}$ \\
\hline P-3_I4 & Produktion, v. a. Hip Hop; Mastering \\
\hline PL-4_I5 & $\begin{array}{l}\text { Produktion, Labelbetrieb, v. a. Hip Hop, Breakbeats, } \\
\text { Drum'n’Bass }\end{array}$ \\
\hline PL-5_I5 & $\begin{array}{l}\text { Produktion, Labelbetrieb, v. a. Hip Hop und House; DJ } \\
\text { international }\end{array}$ \\
\hline PL-6_I5 & $\begin{array}{l}\text { Produktion, Labelbetrieb, v. a. Hip Hop und House; DJ } \\
\text { international }\end{array}$ \\
\hline PL-7_I5 & $\begin{array}{l}\text { Produktion, Labelbetrieb, v. a. Hip Hop und House; DJ } \\
\text { international }\end{array}$ \\
\hline PL-8_16 & Produktion, Labelbetrieb, Mastering, v. a. House, Funk, Jazz \\
\hline PL-9_I6 & $\begin{array}{l}\text { Produktion, Labelbetrieb, v. a. Hip Hop und Breakbeat; DJ } \\
\text { national }\end{array}$ \\
\hline
\end{tabular}




\begin{tabular}{|c|c|}
\hline PL-IO_I7 & $\begin{array}{l}\text { Produktion, Labelbetrieb, v. a. Drum'n'Bass, Dubstep; DJ } \\
\text { international }\end{array}$ \\
\hline L-I_IS & Labelbetrieb, Marketing, v. a. Hip Hop \\
\hline L-2_I6 & Labelbetrieb, DJ international, v. a. House und Techno \\
\hline L-3_16 & $\begin{array}{l}\text { Labelbetrieb, Journalismus, PR, Marketing, DJ national, } \\
\text { v. a. Hip Hop }\end{array}$ \\
\hline J-I_IS & Verwertungsgesellschaft \\
\hline $\mathrm{J}-2 \_15$ & Anwaltskanzlei spezialisiert u. a. auf Urheberrecht \\
\hline $\mathrm{J}-3+\mathrm{I} 6$ & Anwaltskanzlei spezialisiert u. a. auf Urheber- und Filmrecht \\
\hline $\mathrm{J}-4 \_17$ & $\begin{array}{l}\text { Anwaltskanzlei spezialisiert u. a. auf Urheber- und Marken- } \\
\text { recht }\end{array}$ \\
\hline $\mathrm{J}-5 \_\mathrm{I} 7$ & $\begin{array}{l}\text { Anwaltskanzlei spezialisiert u. a. auf Urheber- und Medien- } \\
\text { recht }\end{array}$ \\
\hline
\end{tabular}

Tabelle 1: Interviewpartner_innen, gegliedert nach ihren jeweligen Tätigkeiten beziehungsweise Organisationen

\subsection{Kopieren}

Samplingbasierte Popmusik beruht ihrem Wesen nach auf der Verwendung von Kopien. Es würde allerdings zu kurz greifen, nur den Kompositionsprozess ins Auge zu fassen, wenn man eine Aussage über das Verhältnis von urheberrechtlichen Restriktionen und Kreativität beim Kopieren treffen möchte. Das Kopieren von Samples ist vielmehr eingebettet in eine Reihe weiterer Kopiervorgänge, die die Produktion samplingbasierter Popmusik in ihren verschiedenen Stationen ermöglichen und stabilisieren. Viele davon sind so profan, dass sie in den Gesprächen nicht besonders hervorgehoben werden oder gänzlich unerwähnt bleiben, weshalb ich sie auf der Grundlage meiner teilnehmenden Beobachtungen und einigen, daraus entwickelten 
dichten Beschreibungen beleuchten werde. Die Unterscheidung zwischen Kopien als technisch exakten, digitalen Reproduktionen bestehender Objekte und ihrem referentiellen Einsatz im Sinne von Zitaten, Verweisen und Anspielungen bildet dabei einen Ausgangspunkt, wird aber von den Akteuren selbst nicht immer aufrechterhalten.

\subsubsection{Konsum und Beschaffung: Wie Serendipität gemanagt wird}

\subsubsection{Die Ausstellung des eigenen Konsums}

Musikproduzent_innen besorgen sich auf verschiedenen Wegen neues Material für ihre Musik. Die Beschaffung neuer Samples ist ein Geschäft, das von Zufall, Intuition und der Befolgung bestimmter Konventionen geleitet wird. Für die Exploration neuer Samples schaffen sich Produzent_innen selbst Umstände, die die Entdeckung eines glücklichen Funds zwar nicht erzwingen, so doch zumindest begünstigen können. Ein solches Management der Serendipität ist innerhalb der Kunstwelt an verschiedenen Phasen und Orten anzutreffen, beispielsweise bei der Miteinbeziehung von Fehlern oder der überraschend gelungenen Kombination zweier Stücke beim DJing. Besonders deutlich tritt es jedoch bei der Suche und Selektion der passenden Samples hervor. Oftmals haben Produzent_innen einen Hintergrund als DJs und/oder Plattensammler_innen, wodurch sie sich profundes Wissen über musikhistorische Zusammenhänge, die Biografien von Musiker_innen, Verlagsstrukturen und Veröffentlichungspraktiken angeeignet haben.

Viele besitzen Plattensammlungen mit hunderten oder tausenden Exemplaren (copies), die sie nach Merkmalen wie Kaufdatum, Label, Format, Farbe oder Nutzungsweise als DJ kategorisieren und sortieren. Diese Vorgänge schaffen die notwendige Ordnung, um den materiellen Zugriff auf gewünschte Platten und Samples zu erleichtern. Indem die Produzent_innen nach eigenen Kriterien sortieren, verfesti- 


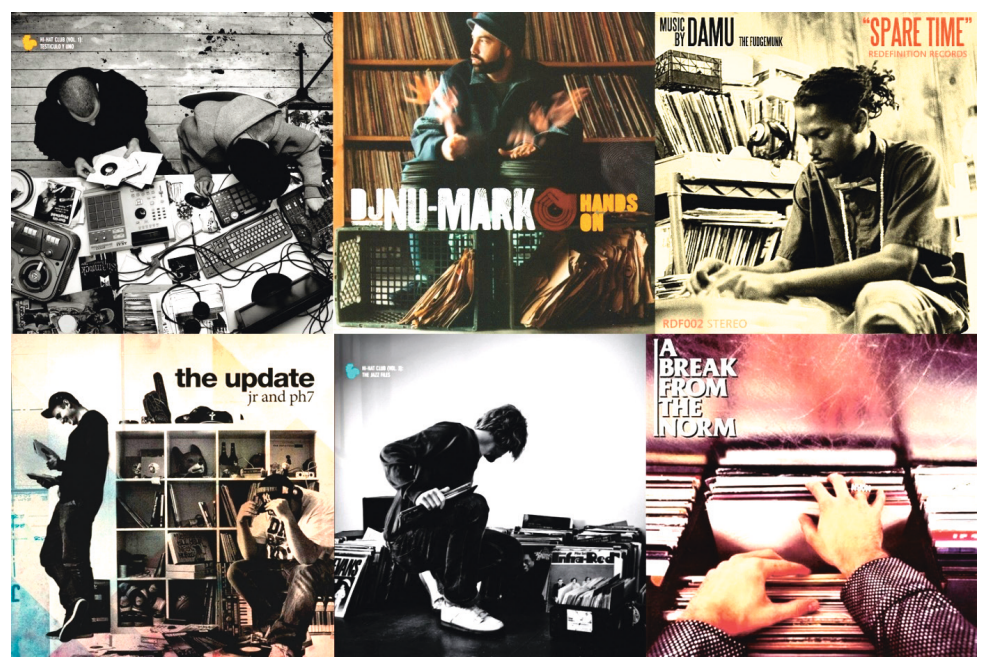

Abbildung 2: Typische Plattencover samplebasierter Popmusik

gen sie aber auch die symbolische Ordnung über die klanglich fixierte Musik von anderen Musiker_innen, die sie kontrollieren und über die sie verfügen. Sie bringen die Musik in eine gewünschte Reihenfolge und stellen ihre eigene individuelle oder kulturelle Identität damit an den Anfang. Typisch ist das Regal »Expedit« von IKEA, das sich aufgrund seiner Abmessungen hervorragend zur Aufbewahrung von I2" großen Schallplatten eignet und daher auch auf Plattencovern zu finden ist (siehe Abbildung 2). Besonders wertvolle oder begehrte Platten werden im Regal mit dem Cover hin zum Raum präsentiert und dadurch wie Jagdtrophäen hervorgehoben. Der eigene Konsum und der damit verbundene Geschmack werden auf diese Weise betont und ausgestellt. Das Sammeln ist dennoch keine Tätigkeit, die sich nur auf Tonträger wie Schallplatten, CDs oder MP3s beschränkt. Bei den von mir besuchten Produzent_innen konnte ich oft umfangreiche Sammlungen anderer Konsumgüter begutachten. Viele sammeln VHS-Kassetten und DVDs, Bücher, Comics und Zeitschriften, aber auch Partyflyer, Plakate mit dem eigenen Pseudonym und Backstagepässe. 
Angesprochen auf seine Sammlung von mehr als 80 Paar Turnschuhen, davon etwa 50 in Weißtönen, entgegnete mir PL-4_I5: "Es geht eben nicht nur um Schallplatten. Ü̈ber dem Schuhregal war zudem eine lange Leiste angebracht, an der rund 40 Baseballcaps hingen.

Um neue, ästhetisch anschlussfähige Samples zu finden, eignen sich Produzent_innen diverse Praktiken der Exploration an, die ihren Medienkonsum im Wechselspiel aus Serendipität und Systematik strukturieren. Der Vorgang lässt sich beschreiben als mehrfach gestufter Prozess der Selektion, mit dem sich Produzent_innen ihren Weg durch die riesige Menge an verfügbarer Musik und potentieller Referenzen bahnen, auf die sie in Plattenläden, zu Hause oder im Internet zugreifen. Mit diesem, der Abduktion ähnlichen Verfahren hangeln sie sich entlang an dem, was ihnen bereits bekannt ist und oft - wenn auch nicht immer - ihren ästhetischen Präferenzen entspricht, hinein in die Zone des Unbekannten. Dieser Prozess ist einerseits sehr offen und schafft Raum für freies Assoziieren, er ist andererseits deutlich von der Absicht zur Rekonstruktion gekennzeichnet, von dem inneren Imaginieren eines Samples auf einen potentiellen neuen musikalischen Zusammenhang zu schließen. Manche Produzent_innen suchen gezielt nach einzelnen Instrumenten oder musikalischen Ären. Sie suchen nach dem rohen Material, das sie im Studio nach ihrem Geschmack verändern, verbessern oder veredeln. Während des Musikkonsums erhoffen, erwarten, ja verlangen sie den Kairos, eine Überraschung, einen unerhörten musikalischen Moment, der sie aufhorchen, inspirieren oder irritieren lässt. Freilich ist der Beschaffungsprozess nicht nur darauf ausgerichtet, Samples ad hoc in neue eigene Stücke zu übersetzen. Oft werden Samples auch auf Vorrat gesammelt und archiviert, wo sie als Kopien abgelegt, vergessen und wiedergefunden werden können. Auch diese Praxis der Sampleakkumulation soll im Kompositionsprozess den glücklichen Zufall und die serendipische Entdeckung befördern.

Als Sample kommt prinzipiell Schall jeglicher Quelle in Frage, insofern er sich aufnehmen, als digitale Kopie speichern und damit für die Bearbeitung zugänglich machen lässt, wie präfabrizierte $\mathrm{Mu}$ - 
sik, Gespräche, Natur- und Alltagsgeräusche und weiteres. Gemäß meines Forschungsinteresses konzentriere ich mich in der weiteren Analyse vorwiegend auf präfabrizierte Klangmedien, die in der Regel urheberrechtlich geschützt und auf Tonträgern erschienen sind. Auf meine Frage, welche Rolle das Sammeln von Platten beim Sampling spiele, wird mir erklärt:

"[...] ich ähm gehe auf Flohmärkte, Platten kaufen, bin ich in 'ner anderen Stadt geh' ich nich' erst ins Museum, sondern in andere Plattenläden. Ich hör' super viel Musik, ich geh' auf super viele Konzerte, veranstalte auch hin und wieder auch mal 'n Konzert [...]. Ich bin einfach Musikliebhaber und äh deswegen, ich hab' größten Respekt vor der Musik und deswegen find' ich's eigentlich schlimm, dass man als Musiker, der Sa- Samples benutzt, halt so auf der Hut sein muss, aber Leute, die eigentlich so ganz offensichtlich die Musik ähm einfach nur so benutzen um Erfolg zu haben und richtig Scheißmusik machen und ganz offensichtliche einfach irgendwelche Melodien klauen, weißte, von- von Tracks so, die noch dafür abgefeiert werden, aber eigentlich dann schon doch eher so ver- verachtend so oder verächtlich so über- über Typen wie mich denken. Das is' nich' so ganz ähm- ich weiß nich' Mann, da wird mit zweierlei Maß gemessen, so." (PL-7_I5)

"Klar, ich meine, das ist schon auch die Kultur, die da so ein bisschen mitspielt. Also, da geht man natürlich dann auch in einen Second Hand-Laden und guckt, was gibt es Neues? Dann gibt es ja auch Kriterien, welche Platten man rauszieht und überhaupt dann auch anhört. Ja, also das ist dann auch ein bisschen die Erfahrung. Das Label, oder wenn der und der Musiker mitspielt, oder so eine Instrumentierung ist spannend. So das sind dann so die ersten Indikatoren, dass da was drauf sein könnte. Und dann hört man halt durch. Und dann findet man was. Dann nimmt man es mit nach Hause. Und dann fängt man das an zu loopen. So, das ist ganz klar Teil der Kultur." (PL-IO_I7) 
Die Suche nach Samples erfordert intensive wie extensive Formen des Hörens, die es den Produzent_innen erlauben, umfangreiche Mengen an Musik zu sichten und zu "scannen ", ${ }^{54}$ gleichzeitig diese aber auch selektiv und tiefgehend zu hören. Um aus dem riesigen Angebot an Musik die passenden Samples zu »diggen «, treffen Produzent_innen auf der Basis von Stichproben (samples) und den daraus gezogenen Schlussfolgerungen ästhetische Selektionsentscheidungen, die wie Filter den Produktionsprozess bedingen. Dafür besuchen sie, manchmal ausgerüstet mit mobilen Plattenspielern, Flohmärkte oder Plattenläden, wo sie durch die Plattenkisten »flippen«, unzählige Cover sichten und die Credits studieren. Manchmal läuft dieser Prozess offen, nebenbei und eher unstrukturiert $a b$, manchmal aber auch sehr zielorientiert und auf eine bestimmte Sorte Samples fokussiert. Eine bestimmte Schlagzeuger_in, ein favorisiertes Studio, in dem die Aufnahme gemacht wurde, oder ein bisher unbekanntes Label kann Aufmerksamkeit erregen und dazu einladen, die Schallplatte genauer zu begutachten:

"Ja gut, auf der einen Seite ist es schon sehr wohl dieses technische Verständnis. Dass ich weiß, damit kann ich gut arbeiten. Was weiß ich, der Beat ist jetzt kein 3/4-Beat und es ist nicht stark geshuffelt, da ist genug Platz, um selber noch Instrumente hinzuzufügen. Das sind dann eher so technische Überlegungen, aber dann natürlich ganz klar: fühl ich dabei was? Und das ist natürlich auch schwer zu entschlüsseln. Ich weiß, es gibt bestimmte Harmonien, auf die ich anspreche oder bestimmte Instrumente und vor allen Dingen halt auch eine bestimmte Ära in der Musikgeschichte, die mich halt an-

54 Aufgrund der Schwierigkeit, Klänge intersubjektiv zu beschreiben und insbesondere für Externe geeignet zu verbalisieren, ist die Sprache der Interviewpartner_innen oft an visuellen Metaphern orientiert, teilweise auch an technischen Begriffen, die von Software oder Gerätschaften stammen. Um akustische Phänomene zu übersetzen, wurden innerhalb des Produktionsprozesses gerne Adjektive wie "fett" oder "deep" verwendet. Auch bildliche Übertragungen wie "Track macht auf«, "das Sample trägt« oder »der Sound schiebt« waren gängig. 
spricht. [GF: Also jetzt was zum Beispiel?] Speziell die späten $70 e r$. Also das ist halt das, sag ich mal, wo ich auch eigentlich fast alle meine Samples herhole aus diesem, alles was sich aus dieser Jazzdiaspora sich in dieser Zeit entwickelt hat. Eigentlich kann man so wirklich sagen Ende 6oer bis Ende 7oer, das ist so das, wo die meisten Samples herkommen.«(PL-IO_I7)

Viele Produzent_innen geben einem Stück in systematischer Absicht drei Chancen, indem sie für wenige Sekunden die Nadel jeweils an den Anfang, in die Mitte und an das Ende des Stücks legen, um sich auf Basis dieser Informationslage einen ersten Höreindruck zu verschaffen. Anhand dieser Stichproben entscheiden sie, ob sich das weitere Durchhören der Platte und auch der Kauf lohnen könnten. Neben diesem akustischen Verfahren lesen Produzent_innen Vinyl auch visuell. Sie prüfen den Zustand der oft gebrauchten Platten, suchen sie nach Kratzern und Staubnestern ab, die ihnen bei der Preisverhandlung einen argumentativen Vorteil verschaffen könnten. Manche von ihnen sind auch in der Lage, allein von der visuellen Beschaffenheit der Rillen auf das musikalische Arrangement zu schließen. Anhand der Rillenbreite und -tiefe erkennen sie beispielsweise, wo die begehrten Breakbeats anfangen oder eine besonders dichte, das heißt mit vielen Instrumentenspuren ausgestattete Passage zu finden ist, die anschlussfähige Samples beinhalten könnte.

Ein potentielles Sample entspricht in der Regel internalisierten ästhetischen Kriterien wie Groove, Melodik oder Rhythmik und repräsentiert damit den Geschmack der Produzent_in." Das Sample

55 Auch der gegenteilige Fall ist möglich, beispielsweise wenn Produzent_innen sich von einem Stück oder einem Klang so sehr gestört fühlen, dass sie ihn "umdrehen « möchten. In der Szenelogik der am Underground orientierten DJs und Produzent_innen kommt es manchmal vor, dass ein aktueller Song aus den Charts wegen seines Aufbaus, seiner Aussage oder seiner musikindustriellen Formelhaftigkeit - bildlich gesprochen - "geschlachtet" wird. Die Dekonstruktion kann ein absichtliches Zerschneiden und Zerteilen ("chopping") sein oder über andere Effekte (zum Beispiel "glitches«) entstehen, so dass klar wird, dass durch den Remix eine Distanz zum Original hergestellt wird. 
kann im neuen Stück analog zu seiner ursprünglichen Funktion weitergenutzt werden, beispielsweise als Bass- und Schlagzeuglauf, muss es aber nicht. Das Sample kann auch einen höheren Grad der Modifikation erfahren, wenn es seiner ursprünglichen Funktion enthoben und ihm eine neue zugeschrieben wird. So kann ein einmaliger kurzer ekstatischer Ausruf, wie er im Funk der I970er Jahre zu finden ist, zu einem fortlaufenden, dem neuen Stück als Rhythmus dienender "Lick" eingesetzt werden. Ein Choruselement kann zu einem Intro umgedeutet werden, profane Momente werden zu prominenten geadelt und vice versa.

Das "Loopen«, das in dem oben genannten Zitat genannt wird, enthält dabei schon einen doppelten Kopiervorgang: Erstens von der Schallplatte in den Sampler beziehungsweise auf die Festplatte des Computers, zweitens durch die Wiederholung des Samples als fortlaufende Schleife. Durch den Loop können Produzent_innen zudem eine bestimmte klangliche Eigenschaft eines Ausschnitts genauer abhören, was sie in die Lage versetzt, dem Vorhandenen explorativ neue Seiten abzutrotzen und tiefer in die Klangstrukturen einzudringen. Beispielsweise können sie das Mischungsverhältnis zwischen den einzelnen Instrumentalspuren genauer bestimmen oder einen schwer hörbaren Moment durch die ständige Wiederholung aus dem Sample herausholen, der ihnen beim einmaligen, oberflächlichen Hören verborgen bleiben würde. Damit symbolisiert der Loop auch den Übergang von einem eher technischen hin zu einem eher referentiellen Einsatz der Kopie.

Die ästhetische Affizierung durch die Qualität musikalischer Neuheit bildet für viele die Grundlage und den Antrieb für ihre Musiksammlung, aus der sie Samples kopieren und auf diese Weise Musik schöpfen, die neu eingespeist werden kann in den Kreislauf der Musikproduktion. Platten haben damit eine Doppelfunktion: Die Präsentation der Plattensammlung weist die Produzent_in einerseits als erfahren und bewandert hinsichtlich des eigenen musikalischen Wissens aus, so wie Belesenheit durch Bücherregale repräsentiert wird (siehe Abbildung 2). Andererseits werden Platten als Trägermedium 
gesehen, das das rohe Klangmaterial für neue Musikkompositionen bereitstellt. In diesen Kreislauf kann sich die Produzent_in durch eigene Kontributionen selbst einschreiben:

»[...] ich möchte das einfach auch physikalisch haben so, sonst würd' ich das ja auch einfach alles als Download anbieten so, aber da ich halt Platten- Vinyl-Liebhaber bin, weißte, das- ich seh' das ja auch so: Die- die- mit den Zutaten so produzier' ich ja neue Platten so, ich halt' das Medium am Leben und ne, dadurch holen sich ja dann auch vielleicht so Sechzehnjährige mal wieder 'ne Platte so, die sich aber auf der anderen Seite vielleicht keine ähm- keine Wes Montgomery-Platte kaufen würden, so. Aber vielleicht peilen die irgendwann, wie ich damals so, weißte: `Oh shit mann, der Typ hat ja- das is' ja 'n Sample von Donny Hathaway, uh, was hat Donny Hathaway noch gemacht, woa, der hat noch auf der Donny Hathaway-Platte Gitarre gespielt, ah, der hat auch so 'ne Sachen gemacht, boah, die hol ich mir, oh, was ist das für 'n Label, was kam denn noch auf dem Label raus`, so- so entwickelt sich ja auch so ein Geschmack und 'ne Plattensammlung so, weil man so, praktisch auf so 'ner Vorschuss-Basis. Man hört das ja- weißte, man nimmt das ja nicht einfach nur so hin."(PL-7_I5)

Das Diggin' in the Crates und Plattensammeln wird von den Produzent_innen als wichtige Beschaffungstechnik neuer Samples angeführt, wobei es nur eine - wenngleich materiell und kulturell sehr sichtbare - Möglichkeit von mehreren darstellt. Auch Quellen im Internet werden befragt. Plattformen wie Youtube, Spotify, Discogs und Soundcloud sind beliebte Hilfen und oft frequentierte Datenbanken. Ihre algorithmisch generierten Vorschläge für ähnliche $\mathrm{Mu}-$ sik werden aber als eher restriktiv betrachtet, weil sie den eigenen Geschmack reproduzieren. Tools wie forgotify.com oder spezielle Seiten, die per Zufallsgenerator nach bestimmten Begriffen suchen und damit obskure Musik auf Youtube vorschlagen, werden ergänzend ein- 
gesetzt. ${ }^{56} \mathrm{Um}$ die Selektionsprozesse zu unterstützen, bedienen sich die Produzent_innen auch Sampledatenbanken wie dontsample.me oder whosampled.com. P-I_I4 zeigt mir ein Buch, das in den späten 2oooer Jahren in der US-amerikanischen Hip Hop-Szene kursierte und einen Vorläufer von whosampled.com darstellt. Er leiht es mir für ein paar Tage aus. Das im Eigenverlag herausgegebene Buch »The Sampling Dictionary", das auch in der eigentümlichen Schreibweise mit (umgedrehten) Ziffern betitelt ist, enthält eine Liste der bisher verwendeten Samples (siehe Abbildung 3) mit dem stillen Aufruf zur Abweichung vom bereits Benutzten, was sowohl musikalische Quellen meint als auch die Orte, an denen gesucht wird. Die auf der Rückseite des Buches (siehe Abbildung 4) formulierten Regeln bringen die kompetitive Diggin'-Ethik und damit verbundene Findigkeit, neue Wege zu gehen, deutlich zum Ausdruck.

\subsubsection{Legalität und Legitimität der Beschaffung}

Die Konventionen der Kunstwelt samplingbasierter Popmusik, die in dem Buch zum Ausdruck kommen, legen nahe, dass Originalität mehrfach erstrebt wird. Im Sinne der rigiden Hip Hop-Ethik ist es regelrecht verpönt, bereits benutzte Samples erneut zu verwenden, wenn dabei kein qualitativ neues Ergebnis erzielt wird. Eine solche, untransformative Sampleverwendung würde informell als Plagiat gewertet werden, da sie die bereits erbrachte Leistung der Entdeckung nur noch einmal nachahmt und die bereits bewährte Rekombination kopiert. Den Produzent_innen ist es wichtig, eine gelungene Kontribution in ihrer Kunstwelt zu leisten. Gleichzeitig wird der Akzent stärker auf die Originalität, auf die im Konsumprodukt fixierte

56 forgotify.com schlägt Stücke aus Spotify vor, die noch kein einziges Mal angeklickt wurden: http://forgotify.com/ (20.0I.20I8). "Sample Search« ist eine Suchmaske, die zufällige Begriffe und Jahreszahlen bei Youtube sucht, so dass seltsam-obkurse Musikstücke als Ergebnis angezeigt werden: http://sampled. pro/ (I2.IO.2018). 


\section{THE54MRL1NGDICTIONARY2008}

\begin{tabular}{|c|c|c|c|}
\hline HOUSE OF PAIN & ALL MY LOVE & DENINIS COFFEY & SCORPIO \\
\hline HOUSE OF PAIN & ALL THAT & CANNONBALL. ADDERLEY & SNAKIN THE GRASS \\
\hline HOUSE OF PAIN & APHRODITE & CHASE & OPEN UP WIDE \\
\hline HOUSE OF PAIN & BOOM SHALCCK & JOHN LEE HOOKER & I COME TO YOU BABY \\
\hline HOUSE OF PAIN & COME \& GET SOME OF THIS & GROOTNA & IM FUNKY \\
\hline HOUSE OF PAIN & FED UP (REMX) & JEAN JACQUES PERREY & E.V.A. \\
\hline HOUSE OF PAIN & GUESS WHO'S BACK & ALBERT KING & COLD FEET \\
\hline HOUSE OF PAIN & HOUSE OF PAIN ANTHEM & CHASE & OPEN UP WIDE \\
\hline HOUSE OF PAIN & JUMP AROUND & BOB \& EARL. & HARLEM SHUFFLE \\
\hline HOUSE OF PAIN & JUMP AROUND & JEANNE \& THE DARLINGS & SOUL GIRL \\
\hline HOUSE OF PAIN & JUMP AROUND & PRINCE & GETT OFF \\
\hline HOUSE OF PAIN & JUMP AROUND & SOUND EFFECTS & 144 GENUINE SOUND EFFECTS \\
\hline HOUSE OF PAIN & JUMP AROUND (PETE ROCK REMIX) & LOU DONALDSON & POT BELLYY \\
\hline HOUSE OF PAIN & JUMP AROUND (PETE ROCK REMIX) & LOWELL FULSOM & TRAMP \\
\hline HOUSE OF PAIN & LEGEND & JOHN BARRY & ON HER MAJESTY (MAIN THEME) \\
\hline HOUSE OF PAIN & ONPOINT & CANNONBALL ADDERLEY & INSIDE STRAIGHT \\
\hline
\end{tabular}

Abbildung 3: Auszug aus "The Sampling Dictionary"

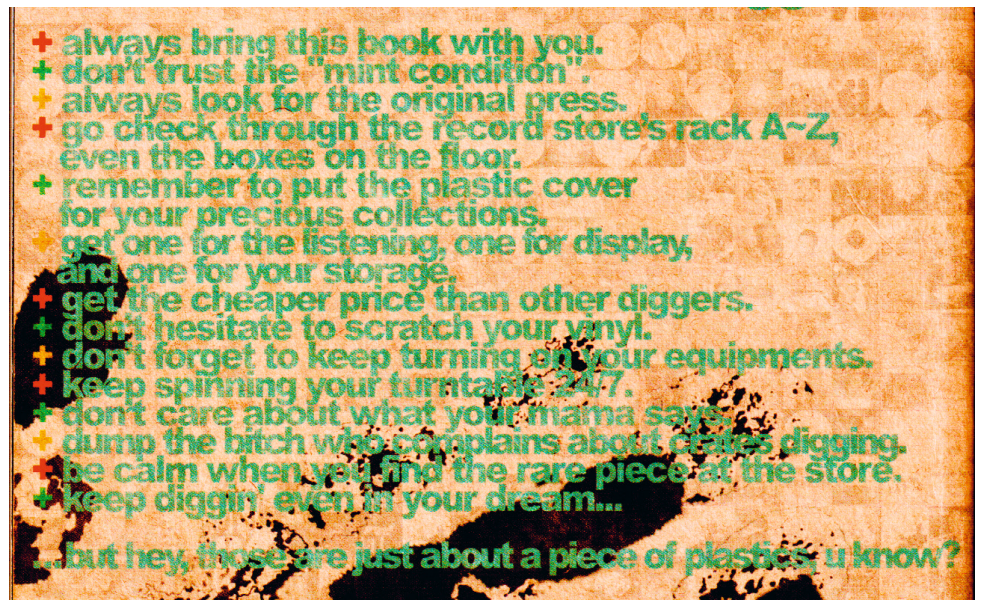

Abbildung 4: Rückseite von "The Sampling Dictionary"

Ursprünglichkeit des Samples gelegt: "Always look for the original press." Meiner Wahrnehmung nach wird dieses Szeneethos oftmals kommunikativ als Narrativ reproduziert und mit Bezug auf die »Kultur" von Hip Hop und Crate Diggin' legitimiert. Ich konnte aber auch beobachten, wie diese Regeln in der Praxis ohne besondere kommunikative Markierung umgangen werden, weil sie als unnötige Restriktion empfunden werden. In der Aussage von PL-IO_I7 wird 
das "Diggin' in the Crates" als einer von mehreren möglichen Wegen beschrieben, der sich seiner Wahrnehmung nach durch digitales Diggin' aber erweitert:

"Aber in letzter Zeit ist halt auch mehr und mehr das ganze online Digging so ein Thema geworden. Dass halt wirklich auch ganz viel rares Material mittlerweile auf Spotify auftaucht. Also viele Platten, die unheimlich teuer sind, kann man da halt mittlerweile als digital remastered dann hören. Das sind halt auch so unter Umständen, sage ich mal, ja, ist halt auch eine Frage des Ethos'. Ich habe früher auch gesagt: wenn ich etwas sample, dann eigentlich immer von der Originalplatte. Aber mittlerweile gab es ja auch schon genug Gelegenheiten, wo ich einfach auch gemerkt habe: Ok, ich will das jetzt einfach hier einbauen und ich habe jetzt irgendwie nicht 200 Dollar zur Verfügung, um dann halt die von einem Sammler aus New York mir dann schicken zu lassen. Und dann nimmt man halt das digitale Sample. Die ganzen jungen Produzenten, die sampeln gar nicht mehr von Vinyl. Diese ganze SP-404-Szene, die sind alle - nicht alle, aber die meisten, die ich kenne - die machen halt wirklich viel Youtube, Youtube-Sampling. (PL-IO_I7)

Auch andere Medien kommen in Frage und bringen spezifische $\mathrm{Zu}$ gangsschwierigkeiten mit sich, wie in diesem Fall VHS-Kassetten:

"Auf jeden Fall ist da ein Sample, den ich immer überkrass fand, übergeil. Und ich wusste nich', was das ist. Und dann hab ich irgendwann nachts Fernsehen geguckt und dann lief irgendwie auf RTL [...] nee auf ARD, genau am Samstag, Samstagnacht. `Die Entführung der U-Bahn I23‘. Und da hab ich dieses Sample gehört und ich so , Woah krass und dann bin ich losgegangen und wollte den Soundtrack dieses Films kaufen. Gab's nich'. Egal wo ich nachgefragt habe, alles was ich durchgeguckt habe, das muss so '94 oder so gewesen sein. Nichts! Und dann hab ich zufällig, da hab ich ja angefangen journalistisch zu arbeiten und dann durft ich 'n Interview mit ' $m={ }^{*}=$ machen und ich 
hatte dann $=^{*}=$ da sitzen und meinte so: `Digger ... Ähm ich weiß, dass das 'Taking of Pelham I23 'is', so, den Soundtrack, den gibt's nich'. Wo hast du des Sample her? Und er so: गJa, ich hab auch alles abgesucht, aber des gibts halt nich', des is nie veröffentlich worden und ich hab des von 'ner VHS gesampletı. Ich so: ,Wie, du kannst doch nicht von 'ner VHS samplen? Weil für uns war immer nur von Schallplatte. ‘Du kannst doch nicht von VHS samplen. > Doch! Ich so: ,Woah krass. Woow.` Des war für mich so 'ne völlig- mein Gehirn wurde gesprengt, weil ok krass, der hat so geilen Beat gebaut und das von 'ner VHS gesamplet." (L-3_I6)

Produzent_innen investieren große Anteile ihrer Ressourcen für das Finden neuer Samples; sie verbrauchen Geld, Zeit, Raum und Nerven für die Exploration und Aufbewahrung ihrer Schätze. Trotz Bemühungen sind aber auch nicht alle Schallplatten erreichbar, beispielsweise weil weltweit nur wenige Kopien davon existieren oder aufgrund anderer Umstände gerade hoch gehandelt werden. ${ }^{57}$ Das Durchforsten von Internetforen und digitalen Plattformen wie Discogs, Ebay, Soundcloud, Mixcloud wie auch illegalen FilesharingNetzwerken ergänzt die klassischen explorativen Praktiken, die sich auf Vinyl fokussieren. Das Finden neuer Wege zur Beschaffung ersehnter Musik kann damit auch in urheberrechtliche Grauzonen führen.

Im Studio, das sich P-3_I4 in einem Zimmer seiner Privatwohnung eingerichtet hat, stehen die üblichen Geräte herum, auf die ich immer wieder treffe: Ein Plattenspieler, von dem der Produzent die analogen Samples digital auf die Festplatte des Computers kopiert ("rüberzieht"), ein Mischpult, ein Keyboard, auf dem die Samples in unterschiedlicher Tonhöhe und Reihenfolge abgespielt werden, ein Mikrofon, teure Stu-

57 Es ist gang und gäbe, dass DJs die Nachfrage nach bestimmten alten oder raren Platten auf Plattenbörsen neu befeuern und sie dadurch verteuern, beispielsweise wenn sie ihre DJ-Sets in renommierten oder populären Formaten wie dem Essential Mix auf BBC Radio I oder dem Boiler Room präsentieren. 
diolautsprecher. Er selbst bezeichnet sich als professionellen Musikproduzenten. Da er jedoch mit dem Verkauf seiner Musikstücke über Labels und deren Vertrieb an Streamingservices nur noch wenig Geld verdient, finanziert er die Musikproduktion über Masteringaufträge quer. Nach eigener Angabe kennt er sich sehr gut mit Computern und Software aus, mehrmals fält das Stichwort "hacken". Dafür habe er sich sogar etwas Russisch beigebracht, denn in den illegalen russischen Foren gäbe es seiner Meinung nach das beste Angebot für gecrackte Software. Auch Musik und Filme bekomme er meistens über russische Internetseiten. Er zeigt mir eine seiner favorisierten Websites: sehr viele auch nur wenig bekannte Künstler_innen und Labels haben dort eigene Threads, die immer mit den neuesten Veröffentlichungen bestückt werden. Es sind viele deutsche Musiker_innen dabei und das Forum ist erstaunlich aktuell. Ich bin verblüft. Auch viele "Leaks", also unautorisierte Veröffentlichungen, zum Beispiel von "promotional copies" für Radiostationen oder Kritiker_innen sind darunter, teilweise Wochen vor dem offiziellen Erscheinungstermin, wie ich später nachrecherchiere. In diesem Forum frequentiert P-3_I4 bestimmte Uploader_innen nach deren neuesten Bereitstellungen. Manche von ihnen haben offenbar einen ähnlichen Musikgeschmack wie er, vor allem Soul und Funk aus den späten I96oer und I97oer Jahren. Manche müssen Schallplattensammler_innen sein, vermutet P-3_I4, denn "sonst kämen die nicht an den heißen Scheißu. Er meint damit vor allem alte 7"-Platten, die bei Discogs oder Ebay hohe Preise erzielen, weil sie so rar und begehrt sind, und hier in bester Qualität in den audiophilen Formaten WAVE oder FLAC angeboten werden.

Für die Beschaffung neuer Dateien von den russischen Filehostern benutzt P-3_I4 verschiedene Tricks, die er sich durch seine Computerkenntnisse beigebracht hat. Bei bestimmten Hostern kann er die Wartezeit oder andere Limitierungen (wie Paralleldownloads) umgehen, indem er im Quelltext der Website nach dem »deep link« der Datei sucht. Manchmal sei dieser einfach zu finden, manchmal aber auch verschlïsselt. Auf diese Weise kann er Filme von Streaming-Hostern schnell und einfach von den Servern kopieren. Er erläutert mir, dass die benutzten Server oftmals nur langsame Downloadraten zur Verfügung stellen. Das Musikalbum, das 
er gerade herunterlade, sei etwa $250 M B$ groß, trotzdem würde es noch 3 Stunden dauern, bis der Download fertig sei. Da er so schnell wie möglich mit dem Sample arbeiten möchte, umgeht er die Wartezeit, indem er die temporäre Downloaddatei auf seine Festplatte kopiert und bereits entpackt. Dadurch stehen die ersten zwei der insgesamt I4 Stücke des Albums bereits zur Verfügung, während die restlichen noch heruntergeladen werden. Die Arbeit kann beginnen.

Ich bin sichtlich beeindruckt, was P-3_I4 offenbar gefällt. Er fühlt sich angespornt und deutet an, dass er auch manchmal ein Programm benutzt, das die IP seines Computeranschlusses automatisch wechselt, so dass die gegenüberliegende Seite denkt, er sei ein anderer Nutzer. Auch Plattformen wie Soundcloud und Youtube werden von ihm genutzt. Da es dort in der Regel nicht vorgesehen ist, die Musik herunterzuladen, kopiert er den Link und fügt ihn auf der Website anything2mp3.com ein. Wenige Sekunden später kann er das Lied herunterladen. "Das funktioniert aber nur bei Liedern, die in Deutschland verfügbar sind, "schiebt er hinterher. Mit etwas Geduld funktioniere es aber sogar bei territorial gesperrten Videos. Er ruft Youtube auf und sucht einen Song, der aufgrund der damaligen urheberrechtlichen Verhandlungen zwischen GEMA und Google nicht in Deutschland freigegeben ist. ${ }^{58}$ Über ein kleines Addon im Browser wird nun automatisch vorgegankelt, dass sein Computer aus einem Land zugreift, in dem das Lied nicht gesperrt ist. Auf dem Bildschirm steht: "Das Video wird nun entsperrt... "Wenige Augenblicke später erscheint das eigentlich in Deutschland gesperrte Musikvideo. P-3_I4 kann das Video nun ansehen und anhören, herunterladen geht aber nicht. Dazu müsse er über einen VPN-Proxy zugreifen, was aufwendiger und langsamer sei, in der Regel aber funktioniere.

582017 schloss die deutsche Verwertungsgsellschaft GEMA nach jahrelangen Verhandlungen einen Lizenzvertrag mit der US-amerikanischen Videoplattform Youtube, um die Verwertung der dort hochgeladenen Musik wahrnehmen zu können. Bis zu diesem Zeitpunkt waren etliche Videos auf Youtube nicht zugänglich. Über die Details des Vertrags gelangten keine Details an die Öffentlichkeit. Es ist lediglich bekannt, dass er rückwirkend bis ins Jahr 2009 gilt. 
Der Zugang zu raren und teuren Erstpressungen auf Vinyl wird nicht nur durch monetäre Ressourcen begrenzt. Der Wettbewerb der Suche nach der gewünschten Musik und unbekannten Samples ist mitunter auch ein Problem mangelnder Information, wie mir die Produzentin PL-2_I4 erklärt. Sie erzählt mir von ihrer Methode, mit der sie an die Titelinformationen herankommt, wenn diese von den DJs bewusst nicht öffentlich gemacht, sondern unter privatem Verschluss gehalten werden: Um die eigene Feldposition zu behaupten, geben DJs oft keine Tracklists zu ihren DJ-Sets oder ignorieren entsprechende Anfragen. Wenn PL-2_I4 einen Track aus einen DJMix wissen möchte, nutzt sie daher, wie viele andere DJs und Fans auch, die bekannte Identifizierungsapp "Shazam «s9. Wenn der Katalog von Shazam jedoch House- und Technotracks nicht erkennt, besorgt sie sich die jeweiligen $\mathrm{DJ}$-Sets als $\mathrm{MP}_{3}$ und lädt diese unter einem von ihr extra für diesen Zweck eingerichteten Account bei mixcloud.com hoch. Die britische Plattform Mixcloud ist auf Radiosendungen, DJ-Sets, Hörspiele und ähnliche Formate spezialisiert und hat ein Abkommen mit der britischen Verwertungsgesellschaft, gleichzeitig greift sie auf andere Datenbanken zu. Die bei Mixcloud hochgeladene Musik wird automatisch innerhalb einiger Minuten identifiziert und die Titelinformationen werden zugänglich, wovon auch PL-2_I4 profitiert. Sobald sie die gewünschten Stücke identifiziert hat, löscht die Produzentin die hochgeladenen $\mathrm{MP}_{3}$ s wieder bei Mixcloud - "zur Sicherheit, damit niemand denkt, das ist mein Set", betont sie. PL-2_I4 umgeht damit das Problem künstlich knapper Informationen, das DJs als informellen Kopierschutz einsetzen (siehe Kapitel 4.2.2.2), indem sie sich die technische Reproduzierbarkeit digitaler Dateien durch missbräuchliches Hochladen bei Identifi-

59 Die Musikerkennungssoftware Shazam identifiziert auf der Grundlage von sogenannten akustischen Fingerabdrücken gerade abgespielte Musik. Dazu wird mit Hilfe des Mikrofons eines Smartphones eine kurze Probe des Musikstücks aufgenommen und online mit der in Datenbanken gespeicherten Musik abgeglichen. Im Dezember 2017 wurde Shazam von Apple für 400 Millionen US-Dollar aufgekauft (Briegleb 2017). 
zierungsplattformen zu Nutze macht und die Quellen des DJ-Sets detektieren lässt.

Im Gegensatz zu den privatisierten Informationen bei manchen DJ-Sets tauschen Produzent_innen auch untereinander Musik und Samples. Sie kopieren MP3s auf USB-Sticks und geben diese an befreundete Produzent_innen weiter, um ihren Musikgeschmack zu zeigen und ihre Sammlung zu teilen. Sie versenden Youtube-Links, um auf bestimmte Musikstücke aufmerksam zu machen oder sich nach den gesampelten Quellen zu erkundigen. Oft handelt es sich um eine Art Ratespiel, bei dem es darum geht, das eigene Wissen zu präsentieren oder andere Produzent_innen mit bisher nicht öffentlich gelisteten Samples zu konfrontieren. Nachdem ich mit P-I_I4 mehrere "Sessions « verbracht und wir in seinem Studio zusammen bereits einige "Beats gebaut« hatten, brachte ich ihm einen USB-Stick mit ein paar meiner DJ-Sets und auch persönlichen Lieblingsalben mit, um sie ihm vorzuspielen. Ohne dass ich ihn dazu gebeten hatte, kopierte er einige Musikordner von seiner Festplatte auf meinen Stick und forderte mich dazu auf, mich bis zum nächsten Treffen mit der Musik vertraut zu machen: "Hör Dir das mal an, dieses Album hat mich sehr beeinflusst." (P-I_I4) Ohne mein Wissen kopierte er mir auch die digitalisierte 25-teilige Compilationreihe »Ultimate Breaks and Beats", die in den I980er Jahren von einem DJ und Sammler zusammengestellt wurde und zahlreiche Breaks zum Sampling und Auflegen enthält. ${ }^{60}$ Insgesamt umfasst die Reihe mehr als I50 Stücke, aus denen zehntausende Hip Hop-, House- und Drum'n'Bass-Tracks abgeleitet wurden. Diese Originale fungieren damit quasi wie commons, also ähnlich wie ein gemeinsam geteilter, wenn auch vermutlich illegal zirkulierender musikalischer Schatz, auf den Produzent_innen immer wieder zurückgreifen.

60 Eine komplette Auflistung dieses re-issue release findet sich unter https://en.wiki pedia.org/wiki/ Ultimate_Breaks_and_Beats (I5.I2.20I7). 


\subsubsection{Distribution und Publikation: Wie Zugang ermöglicht und Aufmerksamkeit geschaffen werden}

\subsubsection{1 Öffentliche, teilöffentliche und private Musik}

Um ihre Musik distribuieren, bewerben, publizieren und aufführen zu können, sind Musikproduzent_innen und Labelbetreiber_innen in vielfältiger Weise auf das Kopieren ihrer Stücke angewiesen. Verschiedene Aspekte lassen sich hier anführen:

Das reproduzierende Herstellungsverfahren von Schallplatten als serielle Kopien ist technischer Natur. So werden die Auflagen von Vinylveröffentlichungen anhand der Anzahl der Kopien bestimmt, die Presswerke herstellen, beispielsweise 500 Singles. Damit die Presswerke diese produzieren können, benötigen sie die Musik in Form digitaler Dateien. Viele Presswerke bieten den Upload über eigene Server an. Auch die GEMA bietet seit 2016 zur Wahrnehmung der Urheberrechte ihrer Mitglieder an, dass diese ihre Musik direkt als $\mathrm{MP}_{3}$ hochladen. Auf Basis der digital zum Abgleich verwendbaren Dateien kann für das Diskothekenmonitoring eine höhere Identifizierungsquote erreicht werden. Auch Masteringaufträge werden über den Austausch von Kopien realisiert.

In öffentlich aufgeführten DJ-Sets werden die gespielten Stücke als Schallplatten oder digitale Dateien so instrumentell eingesetzt und derart miteinander gemischt, dass für das Publikum eine zusammenhängende Narration und damit emergente Bedeutungen entstehen. Da die Stücke nicht als eigenständige Werke, sondern stets im Zusammenhang mit anderen aufgeführt werden, wird ihnen als technisch reproduzierten Kopien zu neuen referentiellen Formen des Ausdrucks verholfen. Daneben kopieren Musiker_innen und Labels ihre Musik zur Eigenpromotion und für Verdienste aus dem Streaminggeschäft auf digitale Plattformen wie Youtube, Soundcloud, Bandcamp und weiteren. Dort werden die digitalen Dateien als Streams und Down- 
loads für Konsument_innen zugänglich, oftmals auch passwortgeschützt und daher nur teilöffentlich.

Um ihre Musik zu bewerben und aus der Menge an verfügbaren Videos auf Youtube herausstechen zu lassen, erstellen viele Produzent_innen und Labels Musikvideos. Manchmal werden dafür alte Kinofilme, Zeichentrickserien oder Dokumentationen in einer Weise zusammengeschnitten, die die visuelle Narration auf den musikalischen Takt abstimmt und eine kontrastive Atmosphäre oder einen Retroeffekt entstehen lässt. Beispiele sind »Eis am Stiel« (1978), Disneys "Winnie the Pooh" (1966) oder Natur- und Gesellschaftsreportagen wie "Koyaanisqatsi“ (1982) oder Baraka (1992), wobei die Copyrights an den jeweiligen Filmen nach wie vor existieren und teilweise bei großen Medienunternehmen liegen. Das führt dazu, dass die $\mathrm{Mu}-$ sikvideos bei entsprechenden »Notice and Take down«-Beschwerden automatisch gesperrt werden - auch dann, wenn die Uploader_innen gut gemeinte, aber freilich wirkungslose Hinweise wie »No copyright (infringement) intended " oder "Only for promotional use» anbringen. ${ }^{61}$

Bis zur Einigung zwischen der deutschen Verwertungsgesellschaft GEMA und dem US-amerikanischen Konzern Google im November 2016 zeigte sich zusätzlich das Problem, dass die hochgeladene eigene Musik auch ohne Bildmaterial Dritter oftmals hinter einer Sperrtafel verschwand, von niemand angehört und dadurch auch nicht über Werbemaßnahmen monetarisiert werden konnte. Nahezu alle

6I Auch bei der Covergestaltung kann es natürlich zu urheberrechtlichen Problemen kommen, wenn urheberrechtlich geschützte Medienmaterialien collagiert oder montiert werden. Ein oft angeführtes Beispiel ist das Cover von »As Heard on Radio Soulwax Pt. 2« des DJ-Duos 2ManyDJs. Die Lizenzverhandlungen für etwa 60 Samples scheiterten für das Album, etwas mehr als IIo gelangen. Die Nutzungsbedingungen für das Cover, ursprünglich ein bearbeitetes SchwarzWeiß-Foto mit Elton John in London, dem eine Papiertüte über den Kopf montiert wurde, konnten ebenfalls nicht erfolgreich ausgehandelt werden. In Folge dessen wurde fast das komplette Foto vermutlich mit Tipp-Ex übermalt, so dass nur noch die braune Papiertüte zu sehen war. Siehe http://www.2manybootlegs. com/bootleg-albums/as-heard-on-radio-soulwax/part-2/ (20.01.20I8). 
Produzent_innen berichteten mir in meiner Erhebung von diesem Problem, insofern sie selbst zu diesem Zeitpunkt GEMA-Mitglieder waren. Daneben sind es nicht lizenzierte Samples oder Stücke in DJSets, die zur automatischen Sperrung von Uploads führen. DJs und Produzent_innen, aber auch Fans behelfen sich damit, indem sie die Musik modifizieren, kurze Pausen einbauen oder die Geschwindigkeit so verändern, dass die algorithmische Detektion versagt, wie bei diesem Youtube-Video:

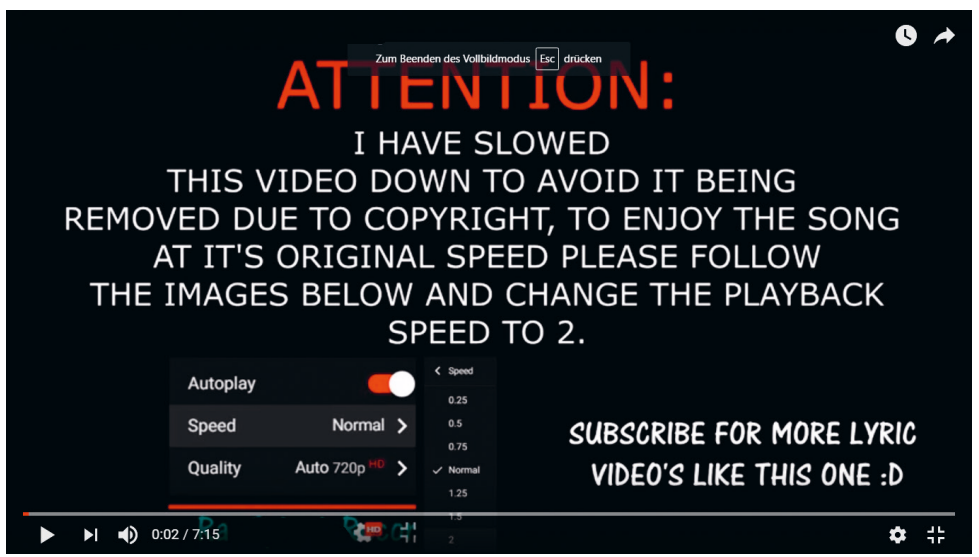

Abbildung 5: Youtube-Video mit urheberrechtlicher Umgehungsstrategie (Screenshot)

Die Anleitung im obigen Youtube-Video steht beispielhaft für verschiedene Strategien der Tarnung, Verwirrung und Verschleierung innerhalb digitaler Kontrollumgebungen, die in der Samplingwelt weit verbreitet sind. Der Produzent PL-7_Is umgeht ein vergleichbares Problem, indem er die algorithmische Detektion mittels Störgeräuschen - in diesem Fall Vogelzwitschern - unterläuft:

"Ja, hat' ich ja auch mal was, da hab ich 'n Beat hochgeladen so, und dann- bei Soundcloud und dann so hat das nicht geklappt, ich so: 'Häh? Und dann irgendwie gesehen: Ah, Mail bekommen von 
Soundcloud und dann so: Ja, Sie ham hier- ähm es liegt 'ne Copyright-Verletzung vor, das ist der Track von $=^{*}=$ und DJ äh, was weiß ich, ne, und dann so: Der Summertime-Remix von irgend so 'ner voll läpp'schen House-Nummer und ich hatte so'n- so $78 \mathrm{bpm}$ Boombap-Beat hochgeladen und ich dachte: ,Was? Wie kommt ihr da drauf so? Es hat andere Harmonie, hat andere- 'n anderes Tempo so, da hat auf jeden Fall der Soundcloud-Roboter versagt."

GF: „Und was is’ dann passiert?»

»Äh ne, konnt ich nich' hoch- obwohl doch, ich hab dann- ich hab dann irgendwie so ähm ähm 'ne halbe Minute Vogelgezwitscher vorher aufgenommen äh davor gepackt und dann hat der das nicht mehr erkannt. Ja."

GF: „Also vor den Track hast du’s dann...?»

„Vor den Track ja, hab ich dann einfach- weißte, weiß der scannt praktisch immer nur die ersten dreißig Sekunden so."

GF: »Und der Anfang war dann- also der Rest vom Lied ist dann gleich geblieben?»

"Ja ja, äh ich hab das Lied gelassen, ich hab nur noch 30 Sekunden Vogelgezwitscher davorgepackt. [GF: Das' natürlich witzig.] Ja, so kann man Soundcloud austricksen.« (PL-7_I5)

Tarnungs- und Verschleierungsstrategien lassen sich auch in anderen Medien bei der Veröffentlichung beobachten. Da samplingbasierte Popmusik in verschiedene Tonträger eingelassen ist und entsprechend in unterschiedlichen Netzwerken zirkuliert, ergeben sich medienspezifische Ausprägungen. Innerhalb der auf Vinyl fixierten DJ- und Sammelkultur haben sich besonders bemerkenswerte Praktiken ausgebildet. So finden sich in Plattenläden, die sich auf elektronische Tanzmusik konzentrieren, viele Schallplatten unklaren Ursprungs, die, wenn überhaupt, nur über die Katalognummer oder eine vom Vertrieb mitgeteilte Nummer identifizierbar sind. Diese sogenann- 
ten white labels enthalten keine, nur spärliche oder sogar irreführende Informationen zu den Künstler_innen, Titeln oder Labels. Die Platten werden auch als promos (kurz für promotional copies) oder als test pressings bezeichnet, da sie früher für Radiosender und DJs verteilt wurden, um ein Stück probehalber auf seine Wirkung zu testen.

Viele White Labels (siehe Abbildung 6) kommen in einem schlichten, generischen Cover und sind bloß gestempelt, was die Do it yourself-Herangehensweise der Indielabels unterstreicht. Die Stempel bilden beispielsweise Figuren aus der Popkultur ab, wie Mickey Mouse oder Darth Vader, assoziieren mit bestimmten Sozialfiguren wie Pirat_innen oder Indianer_innen oder klären über die Exemplarnummer der Pressung auf (zum Beispiel "48/300«). Pseudonyme, Aliases, Abkürzungen und generische Titel mit fortlaufender Nummerierung sind beliebt. Die prinzipielle Knappheit von wenigen hundert Exemplaren wird dabei als Marketingstrategie genutzt, wenn solche White Labels als "Limited Vinyl Only Release« beworben werden, die nur für wenige DJs der Stadt oder kurze Zeit verfügbar sind. ${ }^{62}$

Es liegt nahe, White Labels für nicht autorisierte Remixes oder unlizenzierte Samples einzusetzen, die nur einer bestimmten Menge an Akteuren zugänglich sein soll. Um der Identifizierung zu entgehen, werden von etablierten Labels auch kleinere Sublabels gegründet, die gar nicht oder zumindest nicht auf den ersten Blick mit den Mutterlabels in Verbindung gebracht werden können. Um trotzdem für die Konsument_innen die Verbindung sichtbar zu halten, werden beispielsweise Anagramme gebildet: So wird aus dem britischen Label "Futureboogie« für bestimmte Releases »Boogiefuturo « ${ }^{63}$; Stücke, die

62 Es ist auffällig, dass die meisten DJs versuchen, ihre Karrieren über eigene Musikproduktionen anzukurbeln. In der Regel sind nicht die Verkaufszahlen und die damit verbundenen Einnahmen das Ziel, sondern die zusätzliche Sichtbarkeit über die Einbindung in Distributionskanäle: DJs werden eher gebucht, wenn sie eigene Tracks veröffentlicht und damit Erfolge erzielt haben. Umgekehrt tendieren auch zunehmend Musikproduzent_innen dazu, sich ein zweites Standbein über eine DJ-Tätigkeit aufzubauen.

63 Siehe https://www.discogs.com/de/label/327035-Boogiefuturo (20.12.2017). 


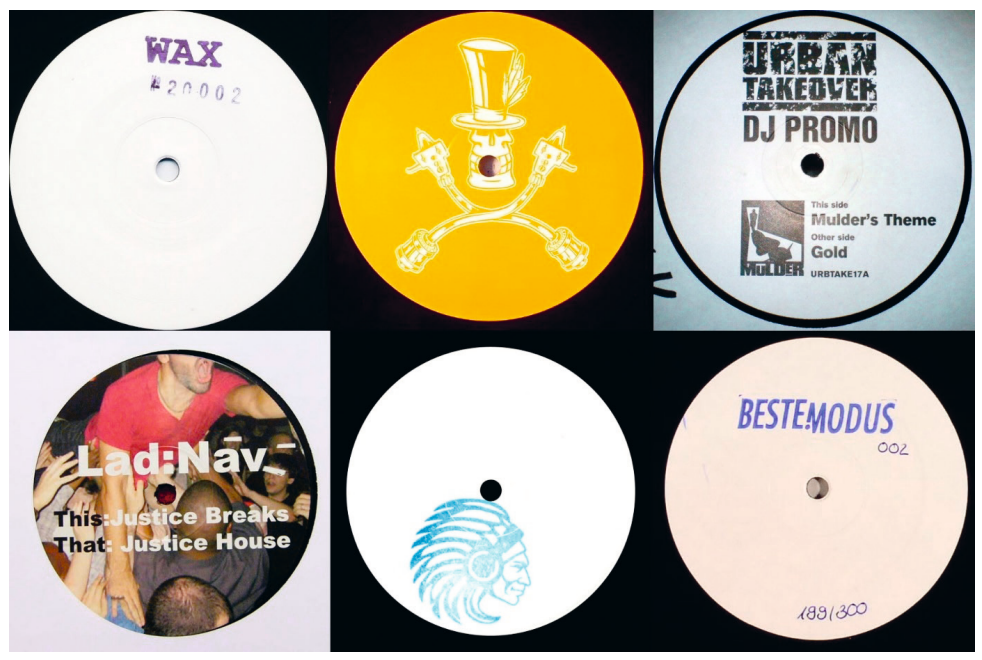

Abbildung 6: White Label-Releases

Samples enthalten, referenzieren dies ein- bis uneindeutig im Titel ${ }^{64}$ (beispielsweise »Rinsing Quince«, das ein Stück von Quincy Jones sampelt); und DJ Vandal veröffentlichte einen Remix unter seinem Alias Lad:Nav (siehe Abbildung 6).

\subsubsection{Steigerung der Detektabilität}

Die verschiedenen Strategien der Verschleierung und Tarnung ermöglichen den Musikproduzent_innen und Labelbetreiber_innen halb offen, halb verborgen agierend, neue stilistische Varianten aus-

64 Nicht nur die Titel der gesampelten Stücke werden referenziert, sondern auch die Situationen der Produktion oder mögliche Funktionen. Manche beispielsweise erinnern in ihrem Titel an Reisen zu bestimmten Orten oder Aufenthalte in einem Club ("Brooklyn by Night«, "Berghain«); anderen heißen "3 A. M." oder "Peak Time Mix«, was darauf hinweist, zu welchem Zeitpunkt eines DJSets das Stück eingesetzt werden soll. 
zuprobieren und nach einem etwaigen Erfolg der Veröffentlichung abschätzen zu können, ob sich die Anstrengungen für Sample Clearing lohnen oder man »unter dem Radar« bleibt:

"Oder bleib' einfach unter'm Radar, was ich hoffe. Dann ham wir hier zum Beispiel das Album $=^{*}=$, was ich gemacht hab', das wurde vom Label ganz bewusst nicht digital gemacht, weil da halt so ein paar Sachen dabei waren, da hat der Labelchef auch gecheckt mit so, wie heißt das, Shazam, ob irgendwas davon erkennt und da der Track $=^{*}=$, hier, relativ offensichtliche Sample hat, [GF: Ist das das $=^{*}=$ oder so was?] Ne, das 'ne brasilianische Band. Also ist nicht zu bekannt, aber ist halt einfach zu erkennen so, weißt du, wenn man's kennt. Im Gegensatz zum Beispiel zu 'nem Track, den hier, wo ich so ein paar kranke Horns einfach gelayert hab'."(PL-7_I5)

Es ist nicht nur die algorithmische Detektion, die zur automatisierten Identifizierung benutzter Quellen führt. In manchen Fällen sind es auch jüngere Angehörige der Gesampelten oder sogar eigens spezialisierte Agenturen (sample trolls):

"Hab ich auch schon alles gehört, dass die Kinder von Leuten, die Mucke machen, die Samples ihrer Eltern erkennen, das den Eltern sagen und dann geht's halt los. Ja, das muss man tatsächlich mit einrechnen, dass wenn man heute Beats veröffentlicht, «(L-3_I6)

"Da spielen- [...] das können Rechtsanwalte einsetzen, es gibt sogar Agenturen, die das gemacht haben in den Anfangszeiten, Anfang der Nullerjahre, da gab's richtige so- ich find das ein bisschen heikel, wenn sich quasi der Urheber als auch das Label selber des gar nich' mitkriegt oder auch gar kein Interesse daran haben und dann Dritte, wie Rechtsanwaltskanzleien, die das als Geschäftsmodell entwickeln, äh zu sagen: 'Hier wir haben da was entdeckt, können wir- äh gibst du uns die Rechte, dass wir die da verklagen können? Das find' ich schlimm, weil das kommt dann in 'ne Ecke, dass einfach Leute damit 
Geld verdienen, weil das gab's durchaus viel und das gibt's auch wahrscheinlich immer noch, dass sich Kanzleien mit sowas beschäftigen und Shazam und sowas nutzen um rauszufinden ähm, ob sie- die müssen sich dann vom Klienten, also [...] vom Sample-Urheber natürlich das Mandat verschaffen, also sie dürfen das natürlich nicht so- einfach so machen, aber wenn sie dem sozusagen 'n Flo ins Ohr setzten: >Hier kannst du viel Geld verdienen`, dann wird er vielleicht zustimmen und dann wird er vielleicht zum ersten Mal auch überhaupt darauf aufmerksam gemacht, dass- dass sein Werk genutzt wurde.« (L-2_I6)

Die panoptische Situation der ständig drohenden Beobachtung bei gleichzeitiger Unklarheit, von wem beobachtet wird, empfinden viele Produzent_innen als belastend. Das bringt sie dazu, eher im Untergrund zu agieren und ihre Musik zu verstecken, insofern sie ungeklärte Samples enthält. Allerdings stößt diese Haltung, die eigene Reichweite künstlich zu beschneiden, mitunter an Grenzen oder widerspricht dem eigenen künstlerischen Ehrgeiz:

"Oder im PC typisch halt anders arrangiert, anders einspielt. Dass man die Snare, die Kick rausschneidet, ein paar Hi-Hats und ein paar Akkorde oder sonst was und die dann anders einspielt, in 'nem anderen Rhythmus. [Ja.] Man weiß, wo's herkommt, aber es ist trotzdem 'ne eigene Interpretation. Bis zu 'nem gewissen Grad kann man's ja machen, aber weiß ich nich', ob man da immer Bock drauf hat. Dann äh versuchen- zu versuchen unter'm Radar zu bleiben- eigentlich will ich ja, dass die Musik gehört wird und dass ich möglichst äh über'm Radar bin ((lacht)). [Klar. Ja, verstehe.] Des is' halt 'n starker Einschnitt irgendwo. Aber natürlich hilft des auch einem schneller bekannt zu werden, wenn man entsprechend bekannte Samples auch benutzt.«(PL-8_I6)

Diese Aussage von PL-8_i6 führt gut vor Augen, wie die Steigerung technischer Reproduzierbarkeit auch mit einer Steigerung der De- 
tektabilität verbunden ist. Neben der algorithmisch-automatischen Identifikation von Musik durch den digitalen Abgleich mit Datenbanken bei GEMA und Shazam, wird die Originalität von Samples auch manuell von Menschen dechiffriert und in sozialen Situationen diskutiert. Denn mit dem kommerziellen Erfolg eines samplingbasierten Tracks erhöht sich auch das Interesse der Fans und der Konkurrenz, die Originale zu enttarnen. Es ist nicht unüblich, dass innerhalb weniger Tage nach der Veröffentlichung einer bekannten Hip Hop-Produzent_in bereits alle Samples decouvriert sind. Im Falle von Jay-Zs Album "4:44" dauerte es sogar nur wenige Stunden, bis in einer kollaborativen Aktion mehr als 20 Originalquellen dekonstruiert und bei whosampled.com öffentlich gelistet waren. Auch bei gefilmten DJ-Sets wie Boiler Room werden in den Youtube-Kommentaren innerhalb kurzer Zeit die gespielten Stücke kollaborativ identifiziert. ${ }^{65}$

Da es über Datenbanken wie whosampled.com mit user-generated content auch zu urheberrechtlichen Verwicklungen von unlizenzierten Samples kommen kann, versuchen manche Labels und Produzent_innen Einfluss auf die dort gelisteten Inhalte zu nehmen. Der US-amerikanische Hip Hop-Produzent RJD2 beispielsweise ist bekannt für seinen extensiven Gebrauch von Samples. Er wurde auch von meinen Interviewees mehrfach und unabhängig voneinander als Inspiration und Vorbild genannt. Bei whosampled.com sind allerdings nur I5 von ihm benutzte Samples aufgeführt - wenngleich sicherlich mehr als zehn Mal so viele aus seinen Produktionen bekannt sind. Im Rahmen eines Interviews mit RJD2 wies WhoSampled darauf hin, dass von Nutzer_innen eingeschickte Datenbankeinträge in Absprache mit RJD2 moderiert werden: "WhoSampled manages RJD2's page on the site in cooperation with the artist. ${ }^{66}$ Mit hoher Wahrscheinlich-

65 Siehe https://twitter.com/whosampled/status/880868797204373504 (30.06.2017). Eine vergleichbare kollaborative Dekonstruktion der Quellen ist seit einigen Jahren auch im wissenschaftlichen Bereich bekannt (vor allem im Zusammenhang mit der Plattform vroniplag).

66 Siehe http://www.whosampled.com/news/2009/II/o5/rjd2-the-whosampled-in terview/ (I3.04.2017). 
keit finden sich für RJD2 bei whosampled.com also nur Samples, die einwandfrei vertraglich lizenziert werden konnten und damit keine rechtlichen Probleme mehr verursachen können. Die technische Reproduzierbarkeit des Quellenwissens wird an dieser zentralen Stelle im Internet damit künstlich knapp und privat gehalten. Allerdings zirkuliert in illegalen Tauschbörsen eine inoffizielle, vermutlich von Fans herausgegebene Compilation mit zahlreichen Originalsongs ${ }^{67}$

Strukturell gesehen führt das besonders wachsame Hören, das von den Produzent_innen als Explorationstechnik angewandt wird, in Kombination mit der öffentlichen Zugänglichkeit und Überprüfbarkeit von Sampledatenbanken zu Problemen auf Seite der Produzent_innen. So wie sie präfabrizierte Musik prinzipiell als unabgeschlossen betrachten und mit Hilfe von Samplern und Software ästhetische Kontrolle darüber erhalten, so schnell kann ihnen die Kontrolle über die Informationshoheit ihrer Quellen entgleiten. Ein ähnlich ambivalentes Verhältnis entsteht durch die Kopierbarkeit von $\mathrm{MP}_{3}$ s, die einen zentralen Stellenwert in der digitalen Musikdistribution einnehmen. Snippets, also kurze Ausschnitte oder Medleys von Alben oder EPs, werden bei digitalen Plattformen als Kostproben für Konsument_innen bereitgestellt. Meist sind diese Snippets maximal ein bis zwei Minuten lang. Über PR-Agenturen werden allerdings auch Vollversionen (Promos) für Journalist_innen und DJs verteilt.

Auf diese Praxis angesprochen, erklärt mir PL-2_I4, dass die verfügbaren $\mathrm{MP}_{3}$ s bei den Agenturen oft auch geleakt werden, also ohne Autorisierung in Tauschbörsen oder auf Youtube gelangen; teilweise Wochen vor dem eigentlichen Releasetermin. Für eine lange Zeit, so schildert mir die Musikerin, war für das Label unklar, durch wen die Musik geleakt wurde, da die digitalen Kopien natürlich vollkommen identisch und damit ununterscheidbar sind. Man behalf sich probeweise mit einer Finte: Für eine Veröffentlichung wurden die Promos nicht komplett identisch ausgeliefert, sondern mit unauffäl-

67 Diese Doppel-LP »R.J's Originals« stellt ein bootleg, also eine inoffizielle Veröffentlichung da: (I3.04.2017). 
ligen Hi-Hat-Variationen individualisiert. Ohne Kenntnis davon zu haben, erhielt jede Empfänger_in sozusagen ein Unikat, das für sie als solches aber nicht erkennbar war. Auf diese Weise konnte später "die undichte Stelle«, über die die unautorisierten Kopien verfügbar gemacht wurden, identifiziert werden. Andere Agenturen versehen ihre Promos explizit mit dem Hinweis auf digitale Wasserzeichen, die in die Stücke eingebaut, aber unhörbar sind, und mit denen sich die digitale Mobilität einer Datei nachverfolgen lässt. ${ }^{68}$

\subsection{Komponieren}

Im Verständnis des deutschen Urheberrechts ist die Kreation eines neuen Werks der entscheidende Moment, in dem der Künstler_in das Urheberrecht am entstandenen Werk zufällt. Das bedeutet, dass das Urheberrecht am geschaffenen Werk nicht beantragt oder von einem weiteren Akteur genehmigt werden muss - es entsteht im Moment der Kreation und ist ohne weiteres Zutun gültig. Aus diesem Grund räume ich dem Prozess der Komposition von neuen Werken in dieser Darstellung einen besonderen Punkt ein. Ich vertrete dabei ein breites Verständnis des Kompositionsprozesses, das die relevanten Aspekte klangbasierter Musikproduktion einzufangen weiß und nicht auf die abstrakte Fixierung musikalischer Ideen in ein schriftliches Notationssystem festgelegt ist. Auf diese Weise wird der traditionelle

68 Ein Unternehmen, das diese Technik anbietet, wirbt mit der besonderen Robustheit seines Produkts. Dies ist vermutlich ein Indiz dafür, dass das unhörbare Wasserzeichen nicht (ohne Weiteres) aus der Datei entfernt werden kann: "Our watermarking service ensures your promo material is protected from the moment it leaves the studio. Our watermarks are highly robust and virtually indestructible ensuring your pre-releases sent to tastemakers, press and influencers are secure. Watermarking is the best deterrent to dissuade industry from leaking. It also makes all recipients of your material Ioo \% accountable. If they leak your release you'll soon know about it with our automated notifications." Siehe http:/www.audiolock.net/watermarked-promo-delivery (4.I.20I8). 
Kompositionsbegriff, wie er vor allem aus der klassischen Musik, aber auch aus dem Jazz oder dem Mainstream Pop bekannt ist, erweitert: Komponieren beinhaltet nun auch das Kom-Ponieren, also das $\mathrm{Zu}$ sammenstellen von konkreten Klängen in Digital Audio Workstations (DAW).

\subsection{1 Ästhetische Reparaturen und klangliche Originalität}

\subsubsection{Klänge und Limitationen}

Genau wie die explorativen Suchvorgänge von neuen Samples und die Publikations- und Distributionsvorgänge neuer Stücke beruht auch die Komposition im Wesentlichen auf der technischen und referentiellen Verwendung von Kopien. Für diese Tätigkeit wählen Produzent_innen selbst oft technisch-handwerkliche Metaphern wie "Tracks basteln« oder "Beats bauen«, bezeichnen sich selbst auch als "Klötzchenschieber«, "Frickler«, "Schrauber« oder "Sampleschubse«. Sie verweisen damit indirekt und ironisch auf die am Bildschirm als Blöcke visualisierten Samples, mit denen sie hantieren. Ich möchte mit dem analytischen Begriff der ästhetischen Reparatur daran anschließen, da er die verschiedenen Übersetzungsleistungen der Produzent_innen metaphorisch passend beschreibt. Damit wird die Motivation zur Rekontextualisierung und die Perspektive der Unabgeschlossenheit betont, mit der Musik als unfertig betrachtet wird und die dazu auffordert, ein Sample zu extrahieren, ein Stück zu remixen, ein DJ-Set zusammen zu stellen - kurz: bestehende Musik in einer neuen Version oder übersetzt in ein neues Genre verfügbar zu machen. Der Begriff der Reparatur bietet zudem die Möglichkeit, das handwerkliche und technische Können der Komposition angemessen zu charakterisieren.

Nachdem die passende Schallplatte, CD oder ein anderer Tonträger mit attraktiven potentiellen Samples ins Studio geschafft wurde, 
werden die entsprechenden Passagen vom Abspielgerät in den Sampler oder auf die Festplatte des Computers kopiert. Um Samples nach eigenen Wünschen zu rekonstruieren, sind in der Regel Reparaturarbeiten notwendig. Diese betreffen oft originale Aufnahmespezifika wie beispielsweise die asymmetrische Verteilung von Instrumentengruppen im Stereosignal: Befindet sich das gewünschte Instrument nur auf der linken Spur des Stereosignals, kann dieses durch den - per Kopiervorgang realisierten - Austausch mit dem rechten Signal ohne größere Problem freigelegt werden, wie mir P-I_I4 anhand einer Klavierspur vorführt. Dieses Verfahren ist auch üblich bei Gesangsamples.

Etwas schwieriger ist es, wenn der komplette Gesang aus einem Stück extrahiert werden soll, wie mir PL-4_Is erklärt. Viele Musikstücke erscheinen im Rahmen einer Singleauskopplung als Vollversion sowie in einer rein instrumentalen Version. In der Regel sind diese beiden Versionen hinsichtlich des Arrangements identisch, von der Gesangsspur abgesehen. Indem Instrumental- und Vollversion "übereinandergelegt«, also Kopien davon im Sequencer mit dem gleichen zeitlichen Startpunkt platziert werden, kann das Acapella aus der Subtraktion der beiden Spuren generiert werden. Aufgrund des dadurch entstandenen sogenannten Artefakts, einem unerwünschten klanglichen Überbleibsel, hört sich das Acapella nach dieser Bearbeitung zwar manchmal etwas »röhrend" oder »blechern« an, aber dies lässt sich durch geschickte Frequenzfilterung kaschieren.

Die Arbeit mit Samples ist stark an der Qualität konkreter Klänge orientiert. So wie viele DJs es als zentrale Erfahrung ihrer Tätigkeit beschreiben, den auf einer Schallplatte fixierten Klang "anfassen« zu können, ihn in rhythmischen Scratchbewegungen hin- und herzuwiegen, Schallplatten ineinander zu mischen und auf diese Weise neue, oftmals überraschende Sounds zu erzeugen, so ist die variierende und rekombinierende Arbeit mit digitalen Samples ebenfalls am konkreten Klang ausgerichtet. Anhand eines paraphrasierten Gesprächs, das L-3_I6 im Interview mir gegenüber wiedergibt, wird der besondere Klangfokus des Samplings und die Distinktion zu anderen musikalischen Traditionen deutlich: 
"Also konkret hatt' ich das zum Beispiel mit Bob James, der nun auch mit zu den Leuten gehört, die extrem viel gesampelt wurden, und der is' halt einfach ein ganz krasser Vollblutmusiker alter Schule. [...] Er ist halt Musiker und für ihn is' es viel krasser, dass jemand eben, der kein Instrument lernt, Musik mit der Musik anderer Leute macht. Das versteht der nich'. Und dann hab ich versucht ihm zu erklären, weil er hat mir folgende Frage gestellt: ,Wieso geben mir diese Kids Geld dafür, dass sie den Drumbreak benutzen, wo bei mir einer 'ne Cowbell schlägt, die können sich doch selber, also die zahlen mir da halt keine Ahnung mehrere Tausend Dollar für, die können doch sich einfach für fünf Dollar selber 'ne Cowbell kaufen und das selber einspielen. . Und da hab' ich ihm gesagt: `Genau das ist der Knackpunkt. Das wollen die nich'. Die Cowbell, die die sich kaufen und einspielen ist nich' so geil wie die, die ihr bei Rudy Van Gelder im Studio eingespielt habt.< Und genau diese Sound-Frage, es geht um Sound, das ist das, was die geil finden und mit dem die arbeiten möchten. [...] Und das ist eben 'ne Klang-Frage, und die ist dir egal, denn dir geht es nur um die Notenabfolgen, die du spielst, und ob du das auf 'm Klavier, auf 'nem E-Piano oder 'nem Synthesizer spielst ist für dich unerheblich. Und des war der Moment, wo's glaub ich bei Bob James Klick gemacht hat."(L-3_I6)

Die hier von L-3_I6 angesprochene "Klang-Frage», die sich in der künstlerischen Entscheidung für ein oder gegen ein Sample zeigt, steht im Zusammenhang mit der Schaffung von künstlichen Barrieren und Restriktionen. Um sich auf ihre Klangarbeit angemessen einlassen und konzentrieren zu können, treffen manche Produzent_innen mit sich selbst Vereinbarungen. So geben sie sich beispielsweise ein zeitliches Fenster vor, innerhalb dessen sie nur einen bestimmten Arbeitsschritt ausführen. Ist diese Zeit abgelaufen, gehen sie zum nächsten Arbeitsschritt über. Dadurch sind sie gezwungen, die Kontingenz der verfügbaren klanglichen Möglichkeiten einzuschränken und mit dem Ziel eines produktiven Ergebnisses Entscheidungen zu treffen. Andere schotten sich vom Internet ab, während sie kompo- 
nieren, beispielsweise indem sie ihr Smartphone auf Flugzeugmodus schalten oder sich von einem Computerprogramm den Zugang zum Internet für eine gewisse Zeitspanne blockieren lassen. Andere haben einen, meist älteren Rechner, der gar nicht erst ans Netz angeschlossen und nur für die Musikproduktion vorgesehen ist. Diese selbst eingeführte, restringierende technische Grenze hat gleichermaßen den Vorteil, so wird mir öfters erklärt, weniger anfällig für Computerviren und ständige automatische Softwareupdates zu sein, die als gefährlich beziehungsweise störend für die Routine empfunden werden.

Der besondere Fokus auf die Klanglichkeit musikalischer Kopien und die selbst eingezogenen Barrieren spornen Musikproduzent_innen an und fordern sie heraus, indem sie den Bereich des kompositorisch Möglichen auf ein erträgliches, sogar produktives Maß limitieren, ohne den Anspruch auf kontributionale Neuheit aufzugeben. Auf diese Weise tragen die Konventionen funktional dazu bei, den Arbeitsfluss im Kompositionsprozess zu kanalisieren und die situative Affizierung für ästhetische Neuheit und Überraschungsmomente in die gewünschten Bahnen zu lenken. Grundlegend dabei sind für viele Produzent_innen die ästhetischen Konventionen des Hip Hop, auch bei der Produktion von House und Techno. Teilweise werden sie paradigmatisch und als unhinterfragte Handlungsgrundlage fortgeschrieben, teilweise bewusst interpretiert, in Frage gestellt oder übertreten, also elastisch behandelt und weiterentwickelt:

"Früher war ich so echt sehr strikt, dass ich nur von Platten gesampelt habe und auch also nur Platten und auch nicht über 1985 oder so. Ich weiß nicht wieso, aber das war halt irgendwie so ein bisschen diese Hip Hop-Doktrin wahrscheinlich so. Ich weiß nicht, nichts Aktuelles sampeln, es sei denn es sind irgendwelche Cuts aus Acapellas, aber so das Grundsample auf keinen Fall irgendetwas neues, sondern es musste eine alte Jazz- oder Soulplatte sein. Wo ich dann aber irgendwann aber dachte: `Okay, das macht keinen Sinn. Ich finde kein griffiges Argument irgendwie, warum ich das beibehalten sollte, so. 
Das macht kein Sinn. Das Sample wird nicht besser dadurch, weil es von Platte kommt. Dann habe ich halt auch von CDs gesampelt, oder MP3s oder Youtube. Ist mir dann wurscht! [GF: Hmhm.] Wobei man dann immer noch so gewisse Regeln und so gewisse Grenzen sich da immer noch setzt. Also ich sampel nicht alles. Ich habe da immer noch so gewisse Blockaden glaube ich."

GF: »Was sampelst du nicht?»

"Naja, ich sample zum Beispiel jetzt nichts von Youtube, was ich auch so kriegen könnte, wo ich auch einfach so rankommen könnte auf einer Platte oder auf irgendwie. Das versuche ich dann schon zu vermeiden. Oder auch nicht zu offensichtlich und nicht auch wenn ich weiß: Okay, der und der hat es schon benutzt. Dann sample ich es halt auch nicht. Meistens. Es sei denn jemand anders hat es benutzt, aber ich finde es scheiße, wie er es benutzt hat [lacht], dann mache ich es schon. Aber so ein bisschen so seltsame Regeln setze ich mir schon. Ich weiß nicht wieso. Aber halt so bisschen Limitieren ist halt immer ganz gut glaube ich [GF: Hmhm.] für den kreativen Prozess«. (PL-5_I5)

Das Ethos des Crate Diggin's scheint in diesem Fall so mächtig zu sein, dass die Entscheidung, nicht von Vinyl zu sampeln, begründungslastig wird. Gleichzeitig wird im zweiten Teil des Zitats herausgestellt, dass ein bereits benutztes Sample tabu ist - außer, die eigene Interpretation würde eine ästhetisch wertvolle neue Kontribution leisten und das Sample dadurch in seiner bereits interpretierten Form reparieren, das heißt in einer neuen Version einpassen. Im Umkehrschluss besteht natürlich immer auch die Gefahr, dass ein besonders attraktives Sample bereits verbraucht wurde, bevor man selbst die Möglichkeit hat, sich damit zu beschäftigen:

"Da zum Beispiel, weißte, leg’ die Platte auf, hör’ so, denk so: `Oh, das find' ich schon nicht schlecht.، Ein anderer Typ hätte wahrscheinlich damit 'n Lied gemacht, ne.«(PL-7_I5) 


\subsubsection{2 Ästhetisierung von Kopiervorgängen}

Bei vielen Produzent_innen beginnt die Kompositionsarbeit dort, wo der Konsum an Grenzen stößt. Sie wollen eine Passage, die sie interessant, spannend oder irritierend finden, mehrmals und fortlaufend hintereinander hören. Dies funktioniert an Platten- und CD-Spielern nur begrenzt, auch im herkömmlichen Audioplayer am Computer ist es umständlich. Um den bereits imaginierten klanglichen Kreis zu schließen und die entsprechende Passage in der gewünschten Wiederholung tatsächlich zu rekonstruieren, »laden«, das heißt kopieren Produzent_innen das Sample in ihre DAW. Dort werden die analogen Schallwellen visuell an einem Bildschirm reproduziert und für eine weitere, genauere Bearbeitung vorbereitet. Um die richtige Nahtstelle zu finden, an der das Sample von vorne beginnen soll, muss der diffizile Vorgang des "Schneidens" so lange wiederholt und angepasst werden, »bis das Sample nicht mehr hängt« oder "rund läuft«.

Auch in dieser Phase des Prozesses befinden sich Produzent_innen in einer Lauerstellung gegenüber minimalen akustischen und musikalischen Überraschungen, beispielsweise gegenüber eigenartigen Effekten, die durch das Loopen entstehen. Durch die Wiederholung eines Fragments kann sich aber auch herausstellen, dass die Band nicht ganz sauber eingespielt hat oder durch den Abspielprozess am Plattenspieler Gleichlaufschwankungen oder melodische Verzerrungen entstehen. P-3_I4 beispielsweise hatte während meiner teilnehmenden Beobachtungen mit einem leicht defekten Plattenspieler zu kämpfen. Er musste, so erklärt er mir, den Antriebsriemen austauschen. Allerdings habe der neue Riemen nicht die exakt benötigte Länge, was sich zwar nur geringfügig auf die Abspielgeschwindigkeit auswirke, allerdings die Tonalität des Samples vermiese. Wegen der minimalen Verschiebung habe er nun das Problem, dass das Sample leicht dissonant klinge und er es nicht mit anderen harmonischen Samples kombinieren könne. Er überlege noch, wie er mit dem Problem umgehe. Einerseits könne er das Sample möglicherweise "von Youtube ziehen", andererseits habe es auch seinen 


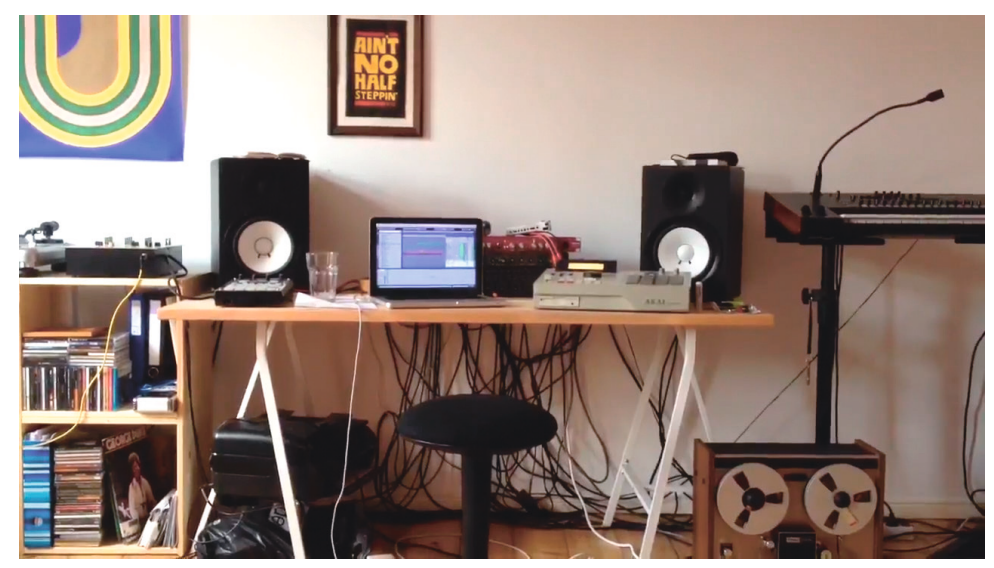

Abbildung 7: Homestudio von PL-5_15 mit Plattenspieler, Mixer, Boxen, Computer, AKAl Sampler, Tonband und Keyboard (von links nach rechts)

Reiz, es einfach in dieser unperfekten, aber charakteristischen Form $\mathrm{zu}$ belassen.

Auch bei den beiden Produzenten PL-5_I5 und PL-6_I6, die ich in ihrem Studio (Abbildung 7) besucht habe, werden während der Suche nach den passenden Klängen Unwuchten und Verzerrungen billigend in Kauf genommen, ja sogar als ästhetisches Stilelement für die Komposition gesucht und erzwungen:

Die Stimmung zwischen PL-S_IS und PL-6_IS schwankt zwischen angespannt und blöden Witzen. Sie frotzeln fortlaufend und treiben sich gegenseitig an. Bis jetzt war die Session von Zeitdruck geprägt, da sie später noch einen Termin mit dem Labelpartner haben und vorher den Track fertig bekommen wollen. Die Hektik macht es für mich teilweise sehr schwierig, genau nachzuvollziehen, was die beiden eigentlich am Computer machen. Ich will auch nicht in ihren eingespielten kommunikativen Austausch eingreifen. Sie reden viel und kennen sich gut. Gerade hat PL-6_IS am Keyboard improvisiert und PL-S_Is hat sich eine Stelle aus der Aufnahme ausgesucht und diese zurechtgeschnitten. Nun knien 
beide auf dem Boden vor dem alten Magnettonbandgerät. Mit einem lauten Klickgeräusch setzen sich die Spulen in Bewegung und das rote Licht zeigt an, dass die Aufnahme gerade begonnen hat. Die beiden Produzenten lassen den etwa eine Minute langen Breakdown laufen und tippen währenddessen immer wieder einmal, in für mich nicht nachvollziehbaren, a-rhythmisch und zufällig wirkenden Intervallen auf die Bandteller, auf denen das Tonband aufgerollt ist. Dadurch gewinnen sie in der Aufnahme kaum hörbare Mikropausen und-verzögerungen. Nach diesem irgendwie rituell wirkenden Prozess, bei dem die beiden das erste Mal an diesem Nachmittag gleichzeitig ruhig waren und eine nahezu heilige Stimmung herrschte, erklären sie mir feierlich, dass die minimalen Temposchwankungen einen gewissen Groove in die Aufnahme bringen sollen und die Klangästhetik dadurch aufgelockert wird: "Klingt einfach authentischer", wird mir erklärt. Gemeint ist die Humanisierungsfunktion der DAW, die einen ähnlichen Effekt digital produziert.

Indem Produzent_innen die klangliche Materialität und Technizität der Kopierprozesse als ästhetisches Merkmal ihrer Stücke nicht zu verschleiern versuchen, sondern - ganz im Gegenteil - diese teilweise gezielt herbeiführen und herausstellen, referenzieren sie auf die technisch-materielle Originalität der benutzten Produktionsmittel. Sie gehen mit dem Knistern der Schallplatten, dem Frequenzrauschen der Geräte oder den klanglich-harmonischen Verschiebungen, die durch Kopierprozesse entstehen, wie mit anderen ästhetischen Ressourcen um und beziehen sie in ihre kompositorischen Entscheidungsprozesse mit ein. Dies geht so weit, dass diese eigentlich klanglichen Unzulänglichkeiten eigene stilistische Charakteristika begründen können, um damit die Arbeitsweise als authentisch zu deklarieren und die enge Beziehung zu den Gerätschaften und Materialien symbolisch zu betonen:

»Wir mussten ja früher auch immer den Leuten im Studio erklären, wenn wir irgendwo hingegangen sind und was abmischen lassen haben, also das waren dann damals meistens Rocker. Und die haben im- 
mer gesagt: Moment mal, wir können das nicht benutzen.` 'Warum?

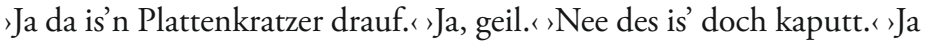
ne, wir finden das geil, dass das kaputt ist. Und das ist genau dieser Aspekt, dass man das was andere ästhetisch hässlich finden, selbst eben ästhetisch schön findet, und ähm zum Markenzeichen seinerseiner Kunst erklärt.«(L-3_I6)

»Für mich persönlich jetzt kein klinisch sauberen Sound. Also schon Leben, also ich mag es, wenn ich so in dem Sound an sich noch so Leben raushören kann irgendwie, also nicht so etwas klinisch Sauberes. Was mir dann bei anderen Leuten teilweise ziemlich gut gefällt, wenn sie so ein' klinisch sauberen Sound haben. Für mich aber, wenn ich produziere, habe ich halt immer gemerkt, dass ich da ja dann irgendwie schon immer bei lande. Ich weiß nicht warum. Wahrscheinlich auch wegen so einer Sache, die irgendwie geprägt hat. Andererseits auch: ich benutze ziemlich billiges Equipment glaube ich [beide lachen] und da lässt sich es also bei vielen Sachen, die ich gerne sauberer haben würde, die kommen dann einfach auch nicht sauberer an, weil es ist einfach so: ein Grundrauschen der billigen Mixer und billiger Synthie geht durch eine billige Soundkarte, da haste halt so ein Grundlevel also so am Rauschen hast du halt immer da. Das ist so, das mixt sich wahrscheinlich einfach."(PL-5_I5)

„Das ist meine Soundkarte, die so knistert.« (PL-7_I5)

Die in die technischen Geräte eingeschriebenen klanglichen Charakteristika werden auf diese Weise genauso originalisiert wie die Verwendung von Samples im Allgemeinen. Auch für PL-4_I5 ist die Schlampigkeit mancher Musikaufnahmen, die er sampelt, eine gleichwertige ästhetische Ressource, die er abwägen und einsetzen kann. Einerseits korrigiere und repariere er die Samples, wenn es für den weiteren Prozess notwendig erscheine. Dies sei beispielsweise der Fall, wenn es sich um einen kleinen spielerischen Fehler handle, den er durch das "Reinkopieren" eines gleichwertigen Elements ausgleichen könne. Manchmal sei eine Stelle vom Arrangement her »eigentlich ideal", 
nur ein kurzer Moment müsse eben durch einen besser gelungenen ersetzt werden. Andererseits sehe er manchmal auch Sinn darin, ein Sample in seiner Unvollkommenheit zu belassen, gerade weil es etwas "weird" und »irgendwie anders" klinge. Manche Samples würde er bewusst nicht mit der Quantisierungsfunktion der DAW, die eigentlich Ungenauigkeiten verbessern solle, bearbeiten, um den »Originalsound" des Samples zu bewahren, weil er so »unique» sei.

\subsubsection{Lost in the Loop}

\subsubsection{Praktiken der Versionierung}

Die Entscheidungen für oder gegen die ästhetische Reparatur eines Samples sind im Zusammenhang mit Fragen des Arrangements zu sehen. Hierbei sind diverse Praktiken der Versionierung beobachtbar, mit denen Samples mit methodischer Absicht in unterschiedlichen Graden der Neuheit und der Referentialität transformiert werden. In Anschluss an die drei analytischen Idealtypen eineindeutiger, eindeutiger und uneindeutiger Referentialität (siehe Kapitel I.2.2) ordne ich an dieser Stelle die Versionierungspraktiken beim Sampling unter den Gesichtspunkten von Kombination, Selektion und Variation. Diese Unterscheidung erweist sich als sinnvoll, da mit ihr spezifische Aspekte von Neuheit als Referentialität hervorgehoben werden können. Allerdings möchte ich nochmals auf den analytischen Charakter einer solchen Idealtypik hinweisen: Aufgrund der historischen Entwicklung von samplingbasierten Musikgenres und der prinzipiellen ästhetischen Offenheit treten die Praktiken der Kombination, Selektion und Variation von Samples heute nicht so rein und analytisch distinkt auf, wie es der theoretische Zugriff nahelegt. Meine Beobachtung ist dagegen, dass mit den verschiedenen shades of referentiality bewusst gespielt und hybride Formen, Verflechtungen und Vermischungen in Kauf genommen werden oder diese sogar als Quelle situativer Neuheit forciert werden. So kann sich beispielsweise der referentielle Cha- 
rakter eines Samples im Kompositionsprozess stark verändern oder im gleichen Stück in mehrfacher Weise - zum Beispiel als kombinatives Element und als Geste der Selektion gleichermaßen - eingesetzt werden. Insofern gilt auch hier, dass ästhetische Genrekonventionen die Komposition anleiten und eingrenzen, aber im breiten Spektrum von paradigmatisch-unhinterfragt bis elastisch-problematisierend angewendet werden. Konventionen sind damit selbst Gegenstand von Remixpraktiken, da sie fortlaufend interpretiert, adaptiert oder problematisiert werden.

(I) Selektion: Eine Versionierungspraxis der Produzent_innen sehe ich darin, ein charakteristisches, besonders markantes Sample als Ausgangpunkt zu benutzen, es als dominantes Hauptthema zu verwenden und ihm nach und nach dekorative, zuarbeitende Samples beziehungsweise Spuren hinzufügen. Diese Verwendung »struktureller« Samples im Sinne Armanda Sewells (2014: 304) ist typisch für Ausschnitte, welche aufgrund ihrer künstlerischen Originalität bereits sehr eigenständig sind, im Sinne des Urheberrechts also eigene Schöpfungshöhe für sich beanspruchen können und mehrere, entsprechend abgemischte Spuren enthalten. Produzent_innen beschreiben den Typ struktureller Samples oft als "catchy«, als kurzen, aber auffälligen und einprägsamen Moment eines Stücks, den sie unbedingt aus dem originalen Zusammenhang herauslösen und in Wiederholung bringen möchten. Sie werden in spontanen Akten der Inspiration vom originalen Tonträger kopiert und sofort zum Einsatz gebracht, genauso aber auch auf Vorrat gesammelt und archiviert, um sie bei Bedarf abzurufen:

"Ja, es fängt schon häufig auch mit einem Sample an muss ich sagen. Also ich habe halt so einen Arbeitsablauf, wo ich mir das auch immer in verschiedene Schritte unterteile und zum Beispiel gibt es eben einen Arbeitsschritt, wo ich mich dann nur hinsetze mit Platten und die dann durchhöre und dann Elemente aufnehme, die mir gefallen und die katalogisiere ich dann eben hinterher nach Instrumenten 
und zum Teil dann auch schon nach Tonarten oder Geschwindigkeiten. Dass ich im Prinzip immer so ein Stash habe, auf den ich dann zurückgreifen kann und wenn ich dann eben inspiriert bin oder sage ১Okay, jetzt produziere ich etwas Neues!, dann gucke ich da durch und dann finde ich irgendetwas, dann loope ich das, dann kommt ein Beat dazu, dann kommt eben auch so Interpolation, dass ich dann selber ein Element aus dem Sample nachspiele oder addiere und manchmal fliegt das Sample dann am Ende auch ganz raus und nur die Elemente, die ich dann selber eingespielt habe, bleiben übrig. Das ist dann immer unterschiedlich. Aber es ist schon, Sample ist immer sehr wichtig für mich.«(PL-IO_I7)

(2) Variation: Um ein Sample stärker zu variieren, es gegebenenfalls innerhalb eines Stücks auch zu aktualisieren, stehen verschiedene Methoden der Verfremdung zur Verfügung, die auf strukturelle wie freilich auch auf dekorative und lyrische Samples angewendet werden können:

GF: »Was sagt der Typ da eigentlich?»

"Es ist nämlich eine Frau [lacht]. Es ist ein $=^{*}=-$ Sample [...] Ja, ich habe es einfach so runtergepitcht, damit es halt vom Tempo her reinpasst. Ist eigentlich eine Frau. Aber das hat sich dann irgendwie auch geil angehört, weil es ganz seltsam, also die Stimme kriegt so einen komischen Klang." (PL-5_I5)

"Ein paar [Samples] sind total offensichtlich, klar. Manchmal werden die aber auch so gefiltert oder gedreht und so dann- gedreht und gepitcht, was man da halt alles machen kann an Verfremdung." (PL7_I5)

"Ich meine, ist ja auch der Trick so, dass man ja auch immer zumindest so Sachen, die ich aus Produktionssicht nice find, ist ja auch immer das so: hey, scheiße, finde erstmal raus, was es für ein Sample war! Das ist ja schon auch so eine Challenge, so ein Sample zu neh- 
men und das so unkenntlich zu machen wie möglich, so dass halt auch der Urheber oder der das damals geschrieben oder produziert hat gar nicht merkt ich habe etwas von ihm. Das ist ja schon auch gerade durch die Bearbeitung, dass du schneidest und Effekte verwendest, irgendwie ein Sample umdrehst, ja im Endeffekt ist das ja nur ein neues Instrument. Du machst ja etwas Eigenes!« (PL-9_I6)

Die hier angesprochenen Verfremdungsmethoden sind Abschwächung oder Verstärkung bestimmter Frequenzanteile (»Filtern«), die Änderung der Abspielrichtung (»Drehen«) und die Veränderung der Geschwindigkeit (»Pitchen" beziehungsweise "Stretchen", mit und ohne Tonhöhenveränderung). Innerhalb kurzer Zeit können durch die Variation diverse Versionen eines Samples erarbeitet werden, die auch in eine vollkommen neue, absolut eigenständige klangliche Qualität kippen können. Etwas anders funktioniert das »Chopping «, das vor allem dann zum Einsatz kommt, wenn die originale Klangcharakteristik als Referenz behalten und gleichermaßen »dem Sample eine eigene Handschrift" (P-I_I4) gegeben soll. Beim Chopping wird ein Sample in kleinere Elemente zerlegt und diese werden in neuer zeitlicher Abfolge arrangiert, beispielsweise über das Einspielen auf den Drucktasten auf Samplern. Dadurch kann dem Sample eine neue rhythmische und melodische Form gegeben werden, ohne die referentiellen Verbindungen komplett zu kappen und ohne sie zu offensichtlich zu halten.

Während ich noch damit beschäftigt bin, die gesampelte Schallplatte wieder in ihr Sleeve zurückzufummeln, hat PL-4_Is bereits den ausgesuchten Schlagzeugbreak als visualisierte Schallwelle auf seinem Bildschirm vor sich. Er wechselt in die Ansicht des Sequencerprogramms und koppelt den Rechner via USB an sein kleines, mit 24 Tasten ausgestattetes Keyboard. Routiniert schneidet er die einzelnen Instrumente des Schlagzeugbreaks (Bassdrum, Snare, Open Hihat, Closed Hihat) zurecht und sucht sich eine bereits vorinstallierte Clap aus der Sample Library. Um diese Einzelteile zu einem neuen Rhythmus zusammenzufügen, benutzt 
er nur fünf Tasten der Klaviatur. Jede Taste spielt ein Instrument: Wenn er auf dem Keyboard eine Taste anschlägt, wird der darauf programmierte Sound im Sequencer abgespielt; ist zudem die Aufnahmefunktion aktiviert, erscheint das abgespielte Sample als kleiner farbiger Strich im Sequencer. Jeder Sound hat seine eigene Farbe und seine eigene Spur.

Das Original hat eine Geschwindigkeit von etwa Ioo BPM; da PL4_IS jedoch einen Beat mit mindestens I25 BPM bauen will, legt er sich nur die einzelnen Sounds auf das Keyboard und spielt sie, akustisch geleitet von einem digitalen Metronom, neu ein. Er braucht ein paar Versuche und probiert verschiedene Varianten des Rhythmus' durch. Dabei lässt er die Aufnahmefunktion des Programms laufen und entscheidet sich hinterher für den besten Take. Die Tonhöhe bleibt gleich, die einzelnen Schläge klingen ebenfalls noch wie das Original, sogar das kurze Knacken, das auf der Snare liegt und von der staubigen Schallplatte stammt, ist noch ganz fein hörbar. Und doch ist ein neuer Rhythmus entstanden, der viel wilder und schneller ist.

PL-4_IS zoomt im Sequencer die einzelnen, bunten Striche heran und verschiebt sie minimal. Anhand des grafischen Rasters, das den Takt in I/I6-Segmente unterteilt, fällt mir auf, dass die Clap eine leichte rhythmische Verschiebung hat und dezent hinterherhinkt. Nicht viel, aber genug, um meine rhythmische Erwartung für den Bruchteil einer Sekunde ins Leere laufen zu lassen. PL-4_IS kann auch die Länge der einzelnen Striche verändern, da diese dadurch bestimmt ist, wie lange die jeweilige Taste gedrückt wurde. Er hat große Kontrolle über das selbst eingespielte Schlagzeug. Insgesamt sind es zwei Takte, die weiter im Sequencer verbleiben. Der Rest "fliegt raus". Es ist das Grundgerüst, auf dem er nun alle weiteren Spuren aufbaut und an denen er sich im weiteren Prozess orientiert.

Mit dem Chopping-Verfahren werden die einzelnen Schläge des hier beschriebenen Breaks so rearrangiert, dass ein neuer, schnellerer und härterer Rhythmus daraus entsteht, der anschließend nach und nach mit weiteren Spuren wie Bass, Synthesizer etc. aufgefüllt wird. Der entstandene Schlagzeug-Loop bildet damit die Grundlage für ein 
neues Stück und fungiert ähnlich wie ein strukturelles Sample. Die Neuheit des entstehenden Stücks verhält sich damit relativ zu dem dafür gesampelten Break, aber auch zu den kanonisierten Stücken des gleichen Genres. Die Arbeit mit Samples ist insofern ein andauerndes Austarieren der richtigen Dosis an Neuheit, die einerseits schon erfrischend und nach Abwechslung zum Bekannten klingt, andererseits aber noch anschlussfähig sein soll.

(3) Kombination: Die dritte wichtige Versionierungspraxis sehe ich in der Kombination von Samples. Die Vereinigung mehrerer Samples zu einer neuen, ästhetisch sinnvoll erlebten Einheit wird in den Aussagen der Produzent_innen oftmals als besonderer Moment gerahmt. So findet es PL-2_I4, die auch als DJ aktiv ist, "magisch", wenn sie an den Plattenspielern zwei Tracks so ineinandermischt, dass diese überraschend für "wenige Takte total gut zusammen passen", dass es "einfach BÄM macht« (PL-2_I4). Sie meint damit beispielsweise denjenigen Augenblick, in dem die Bassspur des einen Tracks schlagartig die Melodie des anderen unterlegt, dadurch die Führung übernimmt und unerwartet einen neuen Zusammenhang, eine virtuelle dritte Platte (Butler 2006: 94), emergieren lässt. Auch in Bezug auf die Komposition werden solche Momente der Emergenz beschrieben:

»[...] weil einfach auch die Art und Weise, wie ich das mache, ist ja für mich auch eine eigene Kunstform. Ich nehme mir jetzt nicht Michael Jackson und dann Prince und lass die beiden Dinger zusammen laufen, sondern dann hast du eine Platte, die irgendwie in Brasilien erschienen ist 1972 und das andere Ding ist dann irgendwie eine New Orleans-Funkplatte und die muss man dann halt so kunstvoll kombinieren, am Ende ist das ja auch im Prinzip eine eigene Disziplin.» (PL-IO_I7)

Während PL-IO_I7 sich hier von Kombinationen distinguiert, die er wegen der Bekanntheit der Quellen als profan erlebt, hebt er die Verbindung von weniger nahe beieinander liegenden Quellen als »ei- 
gene Kunstform« hervor. Auf diese Weise reproduziert er den Entdeckungsstolz und das Ethos des Crate Diggin's und untermauert den Anspruch von samplingbasierter Musik auf »eine eigene Disziplin«. Die Herstellung von originellen Kontributionen wird damit mit der gelungenen Rekombination verschiedener Elemente, die sorgfältig ausgesucht und eingepasst wurden, gerechtfertigt. Damit scheinen sich die zwei Bedeutungsfacetten von Originalität - Ursprünglichkeit und gelungene individuelle Kontribution - ineinander zu verschränken:

"Aber mein Weg war von Anfang an, ich nehme die Instrumente, die sie früher genommen haben, ich nehme die Drums und so weiter authentisch von früher, und tue so, als wäre ich diese Band, die heute noch leben würde, und mache die Musik, wie sie sie damals gemacht hätten vielleicht, nur mit meiner eigenen Art und Weise, mit meinem eigenen Groove, den ich eben durch die ganzen Jahre mir eingebläut hab. Also ich schaffe praktisch Originale, wie wenn sie aus den 7oern kommen würden, oder 8oern. Also das ist so meine Art und Weise, wie ich den Erhalt der ursprünglichen Musik, da wo alles herkommt, immer ein Stück mitzunehmen, damit dieses Original, diese Wurzel niemals stirbt.« (PL-8_I6)

"Ja [...] zum Beispiel hab' ich gedacht bei dem Lied möcht' ich so 'ne- möcht' ich so 'ne Soul-Mann-Stimme, so bisschen Johnnie-Taylor-mäßig, vielleicht ein bisschen Otis Redding, irgendwie so eine und dann hab' ich die Joe Tex als erstes gesehen und hab' gedacht: 'Ey, passt! [...] Weil das ist halt das Geile, was auch so Spaß macht, weißte, ich würde fast behaupten man hat so'n- also ich weiß, ein paar Kombinationen hat noch keiner gemacht, weißte, wenn du irgendwie so, sagen wir, zum Beispiel 'ne Gitarre von Kenny Burrell nimmst und dann 'n Piano von Oscar Peterson plus ein paar Drums von Pretty Purdie- vielleicht gab's die Kombination schon mal, aber dann nimmst du noch ein Vocal von- von George [unverständlich] oder irgend 'nen brasilianischen Shit oder so was. Das Gefühl, der 
erste zu sein, der die Kombination gemacht hat, so ... is' immer wieder ein- immer wieder ein Flash.»(PL-7_I5)

Die Emergenz neuer Kombinationen wird nicht nur vor dem Hintergrund der eigenen, ästhetischen Affizierung durch die erlebte musikalische Neuheit wahrgenommen (»immer wieder ein Flash«), sondern genauso mit dem Vorrat bereits verbrauchter Rekombinationen abgeglichen (»vielleicht gab's die Kombination schon mal«) und damit hinsichtlich der Chancen der eigenen Kontribution evaluiert (»der erste zu sein, der die Kombination gemacht hat«). Das Neue wird hier als zufällige Überraschung erlebt, wenngleich es auch als Resultat eines funktionierenden Serendipitätsmanagements gesehen werden kann. Denn es baut auf den bisher getanen Mühen der Exploration auf, in denen in unzähligen Situationen dem Vorhandenen neue Qualitäten abgetrotzt und in rekonstruktiver Intention neue Versionen ausprobiert wurden.

»Das hat vor allen Dingen aber auch natürlich mit dem Anspruch des jeweiligen Künstlers an seine Kunst zu tun. Wenn du jetzt ein Stück produzierst, wo du einfach nur jetzt sage ich mal drei Loops, die zufällig zueinander passen, unverändert kombinierst, ist ja auch dein Part, dein künstlerischer Part ja auch nicht so riesengroß. Und wenn du dann noch irgendwelche Stücke nimmst, die jeder eh schon kennt, dann wird das keiner gut finden. Von wegen: Öh, das haben wir schon mal gehört, diese Bassline!^ Es sind die meisten Künstler eher von ihrem kreativem Anspruch getrieben, da eben möglichst etwas Obskures zu finden, und es vielleicht auch so zu schneiden und $\mathrm{zu}$ arrangieren, dass man eben nicht mehr wirklich zurückverfolgen kann, wo es herkommt.« (L-I_I5) 


\subsubsection{2 "Wo dieses Nachdenken einfach aufhört»}

Der beschriebene wechselseitige Vorgang aus Exploration und Rekonstruktion des Neuen findet während des Kompositionsprozesses oftmals bei laufendem Loop statt. Der Loop bildet den Ausgangspunkt für neue Stücke. Die ständige Wiederholung einer musikalischen Phrase kann einen Sog erzeugen und zu einem situativen Flow-Erleben führen, welches mir Produzent_innen immer wieder geschildert haben und das ich auch selber während der Sessions machen konnte. Dieses besonders intensive und in die akustischen Qualitäten eines Samples eintauchende Hören wird angestoßen von einer ästhetischen Affizierung und weiter angetrieben von dem Versuch, den bereits affizierenden Klang noch besser und toller zu machen.

"Also am kreativsten fühle ich mich, also am befreitesten, wenn ich einfach draus los produziere. Und irgendwie gibt es halt immer so ein' Moment, wo es dann einfach so klickt. Weil man von diesem Rumdümpeln dann so eine Stelle hat: Okay, jetzt macht es Sinn, so. Und ab da läuft es alles, ohne dass man es merkt. Und dann kommt irgendwann wieder der Punkt, wo man es auch alles wieder mischen muss. Also wo es dann in den Mix Down geht und wo das Arrangement irgendwie kommt. Also es ist bei mir zumindest sehr häufig so, dass sehr viele Sachen einfach durch Fehler, die ich mache, entstehen. Also durch so wenn ich aus Versehen die Nadel irgendwo hinfallen lasse, wo ich es eigentlich wollte und so, aber dann - und das zufällig vielleicht auch noch aufgenommen wurde und ich dann: 'Ah, ok cool! Und dann lief aber gerade noch die MPC dabei und dann war dann irgendwie so ein kurzer Moment, wo ich: 'na ok, das passt! « Und dann halt solche Sachen, oder ja, man findet irgendwie auf einmal einen Akkord, der dann so schön zu dem Drumloop passt, der gerade drunter läuft. Solche Sachen. Ich glaube so Hip Hopper würden jetzt sagen: ^in the zoner. Da bist du halt irgendwie dann, auf einmal bist du drin und dann merkst du es halt auch nicht mehr, auch dann blendest du halt alles aus. Und dann läuft 
halt alles ohne dass du nachdenkst. Wo dieses Nachdenken einfach aufhört.«(PL-5_I5)

Der Loop läuft nebenbei und fungiert in gewisser Weise als musikalischer Teppich, auf dem neue Variationen und Kombinationen getestet und bei Bewährung für den weiteren Prozess verwendet werden. Sollte ein neues Sample nicht passen, wird es herausgenommen und der Loop läuft einfach weiter. Bei manchen Produzent_innen ist dieser Prozess ein Kommen und Gehen neuer Samples, beispielsweise wenn aus hunderten Clap-Sounds einer vorinstallierten Library der passende herausgesucht werden muss. Wenn ein Loop gefällt, wenn er "groovt", "schiebt" oder "rockt«, kann sich das auch in rhythmisch koordinierten körperlichen Bewegungen ausdrücken, beispielsweise im Wippen eines Fußes oder im Kopfnicken. Die ästhetische Affizierung des Geistes, wo ja die Musik gehört wird, ist im Studio manchmal so stark, dass diesem Gefühl der Intuition, des vollständigen InEinklang-Seins mit Technik und Musik, körperlich (und nicht verbal) zum Ausdruck verholfen wird. Gleichzeitig trägt dieses Gefühl wieder weiter, wenn es in einer Situation mal nicht so recht klappt:

"Es ist schon wirklich mehr als Eintauchen, man verschwindet wirklich in einer ganz abstrusen Welt. Über die ganzen Jahre hinweg- Was wichtig ist, ist dass man seine Programme und alles kennt, in- und auswendig, alles, was du bedienst, wird- irgendwann passiert es automatisch. Irgendwann hörst du im Geist schon, bevor du irgendwas tust, wie es klingen wird. [...] Was passiert, wenn ich einen Autofilter auf ein Klavier lege, dann ein LFO in einer Geschwindigkeit, in einer bestimmten einstelle, dann weiß ich, wie das klingen wird, das muss ich nicht erst ausprobieren. Und somit- Dadurch, dass man sein Programm in und auswendig kennt, muss man nicht mehr drüber nachdenken, was man tut, und kann absolut am Song kreativ arbeiten. Und das ist dann der Moment, wo man dann geistig komplett eine barrierefreie Arbeitsweise hat. Der Computer hält einen nicht mehr auf, die Computer sind inzwischen weit- die sind ausgereift ohne 
Ende, dass sie eigentlich alles umsetzen können, was sich der Mensch vorstellt. Und- also dadurch, dass ich diese- sbarrierefreie Arbeiten nenne ich das, dass ich nicht mehr drüber nachdenke, was ich tue, das lässt einen eben komplett verschwinden, und es ist oft so, man sitzt 6, 7 Stunden lang da ohne Unterbrechung, und das einzige, was einen dann aufweckt, ist entweder der Hunger, oder man muss aufs Klo. Aber ansonsten ist man eigentlich tatsächlich komplett- ja man ist die ganze Zeit in so einer Märchenwelt, es ist schwer, zu beschreiben." (PL-8_I6)

Innerhalb von loopbasierten und DJ-getriebenen Genres wie Techno, House oder Drum'n'Bass findet ein Stück oft seinen Höhepunkt in einem besonderen Arrangement der Steigerung, das auf der wiederholten Halbierung des Loops basiert. Vermutlich hat dieses Steigerungsarrangement seine Wurzel in den frühen DJ-Sets im Hip Hop (siehe Kapitel 3.3), bei denen der Loop noch über die künstliche Aneinanderreihung von zwei Kopien der gleichen Schallplatte erreicht wurde. Verkürzt man die geloopte Passage um jeweils die Hälfte, ergibt sich daraus eine Steigerung: von 2 Takten auf I, von I auf $1 / 2$, dann auf $1 / 4$ Takt und so weiter. Die technische und handwerkliche Umständlichkeit begrenzt dieses Verfahren am Plattenspieler schon nach wenigen Verkürzungen, so wie sich auch ein Blatt Papier nur einige Male falten lässt. Innerhalb der digitalen Musikproduktion lässt es sich aber so lange weiter führen, bis am Ende nur noch ein einziger, oszillierender Ton, ein stehender Loop (Pfleiderer 2006: 325), übrig bleibt.

\subsection{Koordinieren}

Die Tätigkeit des Komponierens wird von allen befragten Musikproduzent_innen als erfüllender, beflügelnder und teils auch therapeutischer Teil ihres Lebens beschrieben, der einen hohen Stellenwert in ihrem persönlichen Alltag einnimmt und sich in ihrem Lebens- 
stil bemerkbar macht. Gegenüber dem intuitiv, offen und fließend erlebten Kompositionsprozess im Studio erscheinen die nachgelagerten Prozesse der Lizenzierung und Rechteklärung dagegen als kleinteilig, langwierig und unwägbar, insofern koordinative Verfahren wie Abstimmungen und Verhandlungen mit weiteren Akteuren wie Labelbetreiber_innen, Anwält_innen und Rechteinhaber_innen notwendig werden. Die "unmöglichen Kooperationen", wie ich sie nennen möchte, sind als innermusikalische Kombinationen in der DAW unproblematisch, führen beim Schritt ins Außermusikalische aber regelmäßig zu Problemen, wenn gesampelte Urheber_innen eigentumsrechtliche und monetäre Ansprüche geltend machen. Dieses Problem, so möchte ich zeigen, verschleppt sich bis zur Verwertung.

\subsubsection{Unmögliche Kooperationen}

\subsubsection{1 "Wenn man Glück hat"}

Wie dargestellt, besteht das Musizieren mit Samples aus einer Aneinanderreihung von künstlerischen Entscheidungen, die sich in Selektionsvorgängen, der Produktion von Versionalität existierender Musik und dem bewussten Umgang mit Referentialität genauso niederschlagen wie im gewollten Einbezug von Barrieren zur eigenen Fokussierung und Limitierung. Demgemäß ist samplingbasierte Popmusik durch den besonderen Umstand gekennzeichnet, dass sie auf Musik fußt, die selbst das Ergebnis einer Reihe bereits getroffener künstlerischer Entscheidungen ist und entsprechende Stadien der Auswahl, technischen Aufnahme und Publikation durchlaufen hat. Die koordinative Arbeit, beispielsweise die Häufigkeit, wie oft eine gesampelte Musiker_in ein bestimmtes Riff einstudieren oder ein Solo im Studio einspielen musste, um für die Veröffentlichung berücksichtigt zu werden, ist dieser Musik aber in der Regel nicht anzuhören. Sie enthält nur eine Version und gibt keinen Aufschluss über die dafür notwendigen Takes. In ihrer Fixierung auf dem Tonträger erscheint 
sie als abgeschlossenes Werk und invisibilisiert die notwendigen Entscheidungen, Mühen und Kooperationen, die für die Produktion des Werks hinsichtlich Autorschaft zwischen den beteiligten Musiker_innen, Labels und Verlagen ausgehandelt wurden.

Durch Sampling wird diese Geschlossenheit der Musik wieder aufgebrochen und zumindest in Teilen neu zur Verhandlung gestellt, spätestens wenn es zu Fragen der Lizenzierung kommt. Denn die Komposition von Samples, die aus unterschiedlichen und weit auseinander liegenden Quellen zusammenkopiert wurden, führt zu einer Musik mit eigentlich unmöglichen, aber erzwungenen Kooperationen im Innermusikalischen, die in der Realität aufgrund von räumlichen, zeitlichen, technischen oder sozialstrukturellen Unterschieden sich nicht manifestieren konnte oder sich auch niemals hätte manifestieren können. Eine andere Seite des Unmöglichen betrifft die urheberrechtliche Situation und damit die Notwendigkeit zur außermusikalischen Kooperation: Denn die Verwendung und Veröffentlichung eines einzigen unautorisierten Samples, so einfach und praktikabel es im Studio im Kompositionsprozess auch erschien, kann die Veröffentlichung eines ganzen Albums verunmöglichen, wie mir ein Vertreter einer Verwertungsgesellschaft erklärt:

"Und das Problem ist ja nur, da wird einer eigentlich in die Pflicht genommen, ohne gefragt zu werden. Und das ist eben auch dieser künstlerpersönlichkeitsrechtliche Aspekt, der das so ein bisschen schwierig macht. [...] wenn jemand das gut findet, dann ist das häufig auch so, der sagt: Ja klar, kannst du super machen. Und ich meine letztlich minimiert ja da jetzt auch das Internet die Hürden, mit denen zu kommunizieren. [GF: Ja.] Also man kann so etwas ja auch super rüberschieben zu jemandem und sagen: [GF: Und wenn sie nicht mehr leben oder so?]. Ja, gut aber da muss man sagen, ist eben die Situation bei den ausübenden Künstlern doch eine entspanntere, denn das Leistungsschutzrecht ist ja deutlich kürzer. Also ich kann diesen Leuten nur empfehlen: nehmt Aufnahmen, die bis einschließlich 1962 sind und ihr habt keine Probleme, braucht ihr eigentlich 
keinen mehr zu fragen. Und da ist ja auch super interessante Musik dabei. Und danach dann wird es - also ist ja nicht so, dass das da nicht auch kreative Spielräume gäbe.» (J-I_I5)

Zwar verringern sich durch die weltumspannende Vernetzung via Internet gewiss die Barrieren der Kommunikation und entsprechende Recherchen und Lizenzanfragen lassen sich prinzipiell beschleunigen. Allerdings ersetzt dies natürlich noch nicht die notwendige ausnahmslose Autorisierung aller gesampelten Rechteinhaber_innen, bevor ein samplingbasiertes Werk veröffentlicht und der Verwertung zugeführt werden kann. Insofern stehen der prinzipiellen Offenheit und Intuitivität, mit der sich im Studio Aufnahmen von Musiker_innen aneignen, rekombinieren und zu neuen Stücken verschalten lassen, Geschlossenheit, Komplexität und Unwägbarkeit in Lizenzierungsfragen entgegen:

"Aber es ist ähnlich eigentlich wie bei einer Filmproduktion. Wenn du so viele Kreativschaffende hast, die in einem Werk zusammenkommen - so sehe ich ein Hip Hop-Album mit 200 [Samples, GF] ja. Weil bei einer Filmproduktion, ich mache ja auch viel Filmrecht, da holst du ja auch alle Rechte ein, von Kostüm bis Kamera, Regie, Schauspieler, Tontechniker. Also du hast hunderte von Verträgen, die dann abgeschlossen werden und die fließen dann in ein Gesamtwerk. Bei Hip Hop-Produktionen oder bei sampleintensiven Produktionen ist es auch so." (J-3_I6)

Die Einholung einer Zustimmung zur Veröffentlichung eines benutzten Samples ist nicht nur eine monetäre, sondern auch eine geschmacklich-ästhetische Frage. Gefällt das neue Stück der gesampelten Künstler_in nicht, kann sie die Autorisierung verbieten. Die Höhe der Auflage spielt für die prinzipiellen rechtlichen Bedingungen keine Rolle. Was zählt, ist der Vorgang der Veröffentlichung, in diesem Sinne der öffentlichen Zugänglichmachung eines Stücks. Dies kann auch ein Upload bei Online-Plattformen wie Soundcloud oder 
Youtube sein. Diese Praxis der free downloads wird von Produzent_innen meist zur besseren Sichtbarkeit ihrer Arbeit genutzt und ist nicht zwingend mit direktem kommerziellen Interesse durch den Verkauf des Stücks verbunden.

"Ja, das Ding ist ja so, also sie müssen ja, jeder angefragte potentielle Lizenzgeber kann ja auch einfach nein sagen. [...] die Entscheidung vom Bundesverfassungsgericht stellt das jetzt so ein bisschen in Frage, aber grundsätzlich ist es bisher so als Regel, der Lizenzgeber, der Rechteinhaber muss gefragt haben und wenn er keine Lust hat, dann kann er auch einfach nein sagen und er muss auch gar nicht antworten, wenn er keine Lust hat. Und damit ist das Projekt dann geplatzt, was das konkrete Sample anbelangt, weil es dann eigentlich nicht rechtlich, also weil es nicht legal benutzt werden darf in dem Moment, ne? Insofern habe ich gesagt 'wenn man Glück hat', weil also das ist oft auch so, wenn sie anfangen Samples zu klären oder versuchen, Samples zu klären, dann je nachdem, wer der Rechteinhaber ist, kann das eben auch sein, dass das die gar nicht juckt und dass die sich damit gar nicht beschäftigen, weil die sagen, der administrative Aufwand für uns, da jetzt irgendein' Vertrag zu stricken, der ist so hoch, das rechtfertigt irgendwie das Projekt, welches anfragt, quasi den Administrationsaufwand schon gar nicht, weil wenn dann nachher 2000 Platten verkauft werden, spielt das für uns keine Rolle, ne? Also jetzt mal so als Beispiel.« (J-5_I7)

"Also Angst habe ich auch keine, um ehrlich zu sein. Weil einfach auch die Art und Weise wie ich das mache, ist ja für mich auch eine eigene Kunstform. [...] Also ich habe auch Freunde, die wurden dann halt auch schon dann kontaktiert von Rechteinhabern und mussten dann zum Teil halt ihre Sachen einstampfen oder dann sich da irgendwie einigen. Aber bei den Stückzahlen? Also was kann man so jemand anbieten? Klar. Das ist ja dann auch immer, muss ja immer realistisch für den Schaden, im Verhältnis zu dem Schaden stehen, der entstanden ist. Und wenn ich davon halt irgendwie s ooo free 
downloads auf Soundcloud habe, was kann ich demjenigen dann anbieten?« (PL-IO_I7)

"Und das- manche scheißen drauf, manche nicht, und der Großteil der Beats, die veröffentlicht werden, sind halt eh for free, da macht das dann eh nichts, aber jedes Label muss sich jedes Mal wieder die Frage stellen: 'Mach' ich das jetz' oder mach' ich das nich'? Und äh, die Labels, die's machen, die ich kenne, sind wie gesagt immer wieder mit der Problematik konfrontiert, regelmäßig. Und die ziehen's trotzdem durch, die meisten, sie erzählen's auch nich' laut, aber sie sind damit regelmäßig konfrontiert und es ist ein immer mitschwingendes Risiko, was so'n Label auch spä- also irgendwann potenziell das Genick brechen kann, nicht muss, aber kann." (L-2_I6)

"Wenn du's einfach nur auf YouTube stellst oder auf Bandcamp, for free, wird dir das weggelöscht, oder auf Soundcloud und das wars. Dein Account wird dir vielleicht geschlossen, aber du kriegst nich' sofort 'ne Klage an den Hals. Da sie's aber gewerblich veröffentlich haben und damit halt Geld verdient haben, is' es halt umso risikoreicher und das is' halt die Ebene, die- in der immer diese Gedankengänge stattfinden, das heißt, ich mach 'nen kleinen Release, ok, das ist eh nich' so auffällig, aber dann hab ich halt Beatles gesampelt und keine Ahnung, Stella McCartneys Kind, das I6 is', hört das Ding und findet's geil, geht zu seiner Mutter und Mutter erkennt, des is' aber vom Großvater, also von ihrem Vater und schwupp hast du ein Problem.«(L-3_I6)

\subsubsection{Lizenzierungsstrategien unter Risiko}

In vielen Fällen kooperieren Labels und Produzent_innen zur Lizenzierung mit Anwält_innen, um Autorisierungsanfragen zu koordinieren und zu klären, ob überhaupt eine urheberrechtliche Schöpfungshöhe oder eine Verletzung von Rechten vorliegt. Aufgrund des klangorientierten Ansatzes samplingbasierter Musik kann das Verglei- 
chen der jeweiligen Stücke mitunter problematisch sein, so dass je nach Verständnis Expertisen eingeholt werden - oder auch nicht:

"Mit Laptop und Software habe ich im Prinzip die gleichen Tools zur Verfügung, vielleicht sogar noch besser, noch schneller, noch einfacher. Und insofern gibt es fast kein Soundgefüge, kein Klang, den ich nicht nachspielen, nachproduzieren kann im Tonstudio heute. Es ist sogar möglich mit relativ geringem Aufwand Dinge wirklich so eins zu eins nachzubasteln, nachzubauen, dass man in einem a/b-Vergleich mit dem menschlichen Ohr den Unterschied kaum noch wahrnimmt.« (J-4_I7)

"Also was ich mache ist, ich hole mir ein musikwissenschaftliches Gutachten und lass genau prüfen, ob die Noten, also ich lasse es notieren und zwar das Original, also das verletzte Werk, mit dem neuen Werk und lass mir gegenüberstellen, ob die Notierung übereinstimmt. Ich kann das nämlich vom Hören manchmal gar nicht so beurteilen und genau, deswegen arbeite ich mit Musikwissenschaftlern zusammen, die das können, die da drauf geschult sind und das machen.«(J-3_I6)

Manche Veröffentlichungen enthalten auch Hinweise auf die zwar versuchte, aber gescheiterte Kontaktaufnahme mit den gesampelten Künstler_innen und die an sie gerichtete Bitte, sich für die Rechteklärung beim Label zu melden. Gerade bei fragmentierten Copyrights im angloamerikanischen Raum, wo Immaterialgüterrechte ja veräußert werden können, wird so über den umgekehrten Weg versucht, die Rechteinhaber_innen ausfindig zu machen. Allerdings birgt diese Methode das spezielle Risiko, mit einer möglicherweise vollkommen unbeteiligten Person eine Kooperation einzugehen, also "SampleTrolls« zu beteiligen, die sich fremde Autorschaft anmaßen:

"Also man könnte jetzt ein Disclaimer auf das Album schreiben und sagen, man hat das und das verwendet und wenn man denjenigen 
kennt, dann möge der sich bitte an das Tonträgerlabel wenden führt allerdings dann zu Trittbrettfahrern. Also das würde ich nicht empfehlen, so etwas zu machen.«(J-3_I6)

Auch zwischen Produzent_innen und Labels, die samplingbasierte Musik als Geschäft herausbringen, vertreiben und bewerben, wird dem Risiko einer Klage durch etwaige ungeklärte Samples vertraglich begegnet. In den Verträgen wird mit der Produzent_in vereinbart, dass diese alle erkennbaren Samples auflister und an das Label übermittelt. Im Gegenzug begleiten oder übernehmen dann Labels die Kontaktaufnahme und die Lizenzverhandlungen:

»Das Label hat gesagt: JJa, ihr hättet vorher irgendwie mal ein $\mathrm{OK}$ einholen müssen`, oder so ne, was aber bei der Platte unmöglich war, weil ich da so viele Samples verbraten hab und auch nich' großartig v- ich dachte wir machen da vielleicht 300, 500 Stück von. Was soll ich dann irgendwie an die Verwertungsgesellschaft von- oder die äh irgendwie die Rechteinhaber von $=^{*}=$ Kohle zahlen, wenn wir- wenn ich da vielleicht ein paar hundert Euro selber nur mit mache, so ne. Und dann ham die halt gesagt: Ja ihr hättet irgendwie euch mal anan uns wenden müssen, so, und wie machen wir das jetzt? Und dann hat der Typ vom Label das so mit denen gedealt, dass der gesagt hat: ,OK, wir zahlen euch für die verkauften Exemplare 'n paar hundert Dollar und für die zukünftigen digi- Digital Sales irgendwie kriegt ihr 50 Prozent von den Leuten, die sich das Intro runterladen. Wird also auch nicht die Welt gewesen sein.«(PL-7_I5)

"[...] sondern sie sind gezwungen, weil wenn sie mit Labels zusammen arbeiten und 'nen Vertrag vorgelegt bekommen, steht da halt, dass sie garantieren müssen, dass sie keine Rechte Dritter verletzen, plus es sind ja auch immer Klauseln dabei, die ihnen sämtliche Kosten aufbürden, wenn denn die dritte verletzte Partei kommt und was einklagt.«(L-3_I6) 
"[...] und es kommt jemand, der sagt: 'Ja, das hat meine Oma geschrieben, das weiß ich ganz genau. Ich hab hier noch eine Kassette, wo sie das gesungen hat. Wie bei Fanta 4 [Die Fantastischen Vier, GF] und da gab es doch dieses indische Sample. Kannst du dich erinnern? »Die da" war ein Sample, ja. Und die Tochter dieser Sängerin, die eben in Indien gelebt hat, die Tochter oder die Enkelin war in Deutschland und hat hier studiert und hat es gehört und hat gesagt: ,Das ist ja meine Mama, meine Oma, oder meine Mutter! Die war Sängerin und ... oder hat diese Musik geschrieben, genau. (J-3_I6)

Je nach genereller Labelstrategie, dem Umfang und der Länge des Samples sowie seines Einsatzes im neuen Stück erfolgen Lizenzierungsanfragen proaktiv im Vorhinein oder, in der Hoffnung unbemerkt zu bleiben, im Nachhinein:

"Das ist immer so Verhandlungssache. Äh wenn- also wenn's ein klares Sample, ein melodisches Sample ist, das den Song bestimmt, [...] dann sollte man's klären, äh wenn- wenn's ein Teil ist, oder nur ein Riff oder so, dann ist die Beteiligung relativ gering und prozentual auch vielleicht zwischen zehn und 30 Prozent. Und des natürlich immer auf beiden Seiten, nämlich auf der Verlagsseite und auf der Masterseite."(L-2_I6)

„Meistens äh waren dann die Forderungen zu hoch. [Ah ja.] Also wenn die gleich anfangen mit pauschal mal 7000 , 15000 Euro Vorschuss ohne, dass du's rausgebracht hast, sondern du fragst ja im Vorfeld, dann rechnet sich das einfach nicht, dann lassen wir's, dann sagen wir dem Künstler: 'Tut mir leid, das geht jetzt nichtı, und wenn wir angefragt haben, dann dürfen wir's auch auf keinen Fall rausbringen, weil da begibst du dich auf absolutes Glatteis [...] Wobei letztendlich der Künstler ja dafür in letzter Instanz haftet, das Label ist immer in- immer in der Klagekette vorne, ist ganz klar, weil das Label das rausbringt, also die Gefahr für's Label ist natürlich wesentlich größer, weil das Label das auch absolut bis zum Zahl- oder bis zum 
Ende des Gerichtstreits oder bis zur Zahlung durchziehen muss und kann sich theoretisch dann aufgrund seiner Verträge, die es mit dem Künstler hat, vom Künstler wiederholen, aber wenn der Künstler arm ist, dann sag' ich mal: es ist echt schwierig, 'nem nackten Mann in die Tasche zu greifen, äh kriegt er- hat er halt 'ne hohe Negativverechnung in seinem Tantiemenstatement, ähm ja." (L-2_I6)

"Wenn du zum Beispiel auf dieser Aufnahme jemand Gitarre spielen lässt, dann hast du vorher dich mit dem Gitarristen darauf geeinigt, dass er hundert Euro bekommen hat von dir oder aber ihr habt dann das zusammen komponiert und er ist Mitcomposer oder wenn du jetzt eben ein Sample benutzt hast, dann hast du vorher mit dem Inhaber des Samples geklärt, dass du das nutzen darfst. [GF: Hmhm.] Das unterschreibst du uns. Und wenn es dann irgendein Problem gibt, weil das Sample nicht geklärt ist, dann hast du komplett alleine das Problem. [GF: Ja.] [...] Deshalb haben wir in der Regel, das sind aber jetzt wirklich Interna, ja es ist so eine Art Gentlemen's Agreement zwischen Label und Künstler. Das heißt, wir gehen da zusammen rein und wenn es ein Problem gibt, dann lösen wir das zusammen. Das heißt in dem Fall, erster Teil der Lösung ist natürlich erstmal dann, wenn der Rechteinhaber sich meldet, mit dem zu verhandeln, gucken, dass man da irgendwie eine Einigung findet, mit der man leben kann, obwohl du natürlich, wenn du der Entdeckte bist, immer natürlich in der schwächeren Position bist - ist klar. Und wenn dann halt Kosten dadurch entstehen, [...] dass Künstler und Label sich das dann zusammen teilt.«(L-I_I5)

Natürlich sind sich sampelnde Musikproduzent_innen der Situation bewusst, dass ihre Musik selbst jederzeit gesampelt, remixt, gemasht, in DJ-Sets aufgelegt oder in anderer Weise zu neuen unmöglichen Kooperationen weiterverarbeitet werden kann. Bei einer Produktionssession, bei der P-I_I4 aus Schlagzeug-Samples unterschiedlicher Quellen einen neuen Breakbeat komponiert hatte und wir beide besonders von dieser neuen Passage ästhetisch affiziert waren, sagte er zu 
mir, dass dies genau die Stelle sein würde, die andere Produzent_innen wiederum sampeln werden. Ihn würde dies stolz machen, wenn eine andere Person in seiner Musik etwas bemerkte, dass sie dazu bringen würde, damit zu arbeiten. Er führte diesen Gedanken nicht weiter aus, aber ich nahm ihn zum Anlass, um andere Interviewees mit dieser Frage zu konfrontieren:

"[...] würd' ich mich irgendwie mal in einer geremixten Form irgendwo hören, würd's mich stören? Is' die Frage: wer remixt einen und wie hört sich der Track an und da ist dann wieder die Frage des Geschmacks, wenn irgendeiner irgend 'nen Track raushaut, der total- nach meiner Meinung nach totaler Mist ist und total schlecht klingt und es wären meine Samples drin, wär ich wahrscheinlich eher angepisst, als wenn jemand äh aus- aus meinem Track irgendwie was Saugeiles gemacht hätte und vielleicht auch ein Künstler der einen gewissen- gewissen Namen hat. Aber man kann sich's nich' aussuchen und so können sich's auch die Künstler von früher nich' aussuchen. Wenn sie dann irgendwo ihren Track verarbeitet hören in irgendwas, was sie selber gar nicht verstehen, dann natürlich ist das scheiße ((lacht)) und ärgert denjenigen auch. Und sobald man in ein Wespennest sticht kann's halt gefährlich werden.«(PL-8_I6)

"Wenn jetzt zum Beispiel ein Typ bist, der so echt nie ein Schimpfwort in seinen Texten hatte und echt immer großtmöglichen Respekt so Menschen gegenüber gebracht hat in seiner Musik, wie, was weiß ich, Curtis Mayfield oder so, dann nimmt sich-schnappt sich einer'n Part davon und rappt da über Goldketten und Schlampen ähm, das kann ich zum Beispiel verstehen, weißte, [...] Oder würd' so [...] jemand so'n Autotune-Technotrack draus machen, wär ich auch nich' so'n Freund von. Einfach aus dem Grund ne, weil ich die Musik dann vielleicht scheiße finde. Aber ey, man kann sich nicht immer das OK einholen, weißte, würd' ich, bevor ich irgendwas sample, irgendwie versuchen, irgendwie- oder ne, bevor ich irgendwas rausbringe, alles zu klären und so, dass auch jeder glücklich ist, ich bin schon froh, 
wenn ich mich dran erinnere, wer alles mitgewirkt hat auf der Platte und so, wer das Coverfoto geschossen hat, das gehört natürlich auch alles dazu, ne, aber so- sonst würd' das einfach Jahre dauern. Jahre dauern und viel Kohle und dann würd' das einfach nich' rauskommen.«(PL-7_I5)

\subsubsection{Scheiternde Lizenzierungen}

\subsubsection{Künstlerische Reaktionen}

Aufgrund der kleinteiligen Situation gibt es keinerlei Garantie dafür, dass Lizenzierungen gelingen. Grundsätzlich gilt: Je mehr Samples verwendet werden, desto mehr Aufwand wird notwendig für eine korrekte Lizenzierung, weil für jedes Sample in der Regel die Rechte an der Komposition sowie die Leistungsschutzrechte an der Aufnahme eingeholt werden müssen. Verweigert eine Rechteinhaber_in, gilt es, eine Lösung für das Problem zu finden. Je nach Ressourcenlage und ästhetischen Präferenzen kann das betreffende Sample versteckt, verkürzt und dadurch unkenntlich gemacht, komplett entfernt oder mit einem anderen Sample beziehungsweise einer Interpolation, also einer selbst eingespielten oder anderweitig hergestellten Version des Samples, ausgetauscht werden.

Vor einigen Jahren hatte PL-2_I4 mit einem von ihr produzierten Track einen kleinen "Underground Hit", wie sie selbst sagt. Zu ihrer Überraschung wurde der Track, der in der ursprünglichen Version zwei fremde Samples enthielt, zu einem wichtigen Treiber in der frühen Phase ihrer DJ-Karriere, da sie nach der Erstveröffentlichung (3ooer-Auflage "vinyl only") überregional bekannt und gebucht wurde. Sie spielt mir das Stück vor, nachdem ich sie auf das offensichtliche Trompetensample angesprochen hatte. Ich bin nicht der erste, der danach fragt, auch in Blogeinträgen und Interviews gibt es bereits Aussagen von ihr zu diesem Fall. Eigentlich wurde der Track von einem zweiten melodiösen Sample, 
einer kurzen Klarinettenfigur, maßgeblich getragen. Die Trompete und die Klarinette ergänzten sich hervorragend, erklärt sie, aber als sie wegen des Erfolgs die Platte nachpressen wollte, suchte sie den Kontakt zu den Rechteinhabern und wurde mit Beteiligungsforderungen konfrontiert. Für die erste, sehr kleine Auflage handelte sie nachträglich eine pauschale Beteiligung aus ("buy out"), für alle zukünftigen Veröffentlichungen und die digitale Distribution verlangte der eine Rechteinhaber 50\%, der andere $60 \%$ der Einnahmen. Beide waren offensichtlich der Meinung, ihr Ausschnitt bestimme maßgeblich das Stück. Das hätte zu der abstrusen Situation geführt, dass mit jeder verkauften Platte ein Minus entstanden wäre, das ihr Label hätte ausgleichen müssen. PL-2_I4 entschied sich dafür, nur ein Sample zu benutzen. Sie nahm das Sample mit 50\%iger Fremdbeteiligung und tauschte das andere gegen ein in der Library vorinstalliertes, im Vergleich zum ursprünglichen Sample ähnlich klingendes, aber eher generisch wirkendes Saxofon. Die Originalveröffentlichung ist aufgrund der Knappheit der Erstpressung bei Discogs eine sehr gefragte und teure Platte, wenngleich PL-2_I4 natürlich nichts von den dort gehandelten Summen abbekommt.

Bei seinem Sampling-Urteil legte der Bundesgerichthof (20I2) einen Schwerpunkt auf die Herstellung von Interpolationen und legte fest, dass Samples nur dann genehmigungsfrei wären, wenn sie nicht von einer durchschnittlichen Musikproduzent_in nachgespielt werden könnten. Damit stärkte es die prinzipiell im Urheberrecht verankerte kontributionalistische Interpretation von Kreativität, die stark auf die Ursprünglichkeit und Individualität von Kreationen abstellt. In den Aussagen damit befasster Jurist_innen wurde diese Sichtweise sehr deutlich:

"Also bisher ist jedenfalls ein großer Teil der Meinung dahingehend gegangen, dass [...] es sich auf urheberrechtliche Werke, also Melodien, Texte und so weiter beziehen, und nicht auf Tonaufnahmen. Jetzt hat das Bundesverfassungsgericht das aber anders gesehen, aber auch der BGH davor schon und hat das damit begründet, dass er 
gesagt hat: wenn sogar - und das ist natürlich eine Argumentation, die nicht ganz von der Hand zu weisen ist - wenn sogar das Urheberrecht über eine freie Benutzung eine Beschränkung erfahren darf, dann muss das doch auch erst Recht für das Tonträgerherstellerrecht gelten. Denn das Tonträgerherstellerrecht ist ja ein weniger im Vergleich zum Urheberrecht. Dieser Rückschluss ist meines Erachtens falsch. Deswegen halte ich auch das Urteil für falsch. Da bin ich jetzt wahrscheinlich einer der wenigen, der das so sieht. Aber dieser `ErstRecht-Schluss ist falsch, weil es gibt keine Abstufung, die sagt: 'Das Urheberrecht ist mehr wert und das Tonträgerherstellerrecht ist weniger wert und deswegen muss das, was für das Urheberrecht gilt, erst recht auch für das Tonträgerherstellerrecht gelten.« (J-4_I7)

»Hier ist es ja wirklich ein kreativer Akt, den sie selber machen können, ohne in die Rechte der Künstler einzugreifen zu müssen. Wenn sie eben den Klang selber auch erzeugen. Das kann natürlich dann kompliziert werden. Und das hat ja der BGH dann auch gesagt: wenn der Klang so nicht mehr herstellbar ist, dann wird man das im Interesse der Freiheit dann auch zulassen. Aber prinzipiell finde ich eigentlich den Ansatz richtig. Also warum gegen den Willen, also warum soll ich einfach nur hier mich bedienen bei einer künstlerisch aufwändig erzeugten Produktion, die jemand anderes gemacht hat, obwohl ich es selber könnte? [GF: Hmhm.] Ja, beziehungsweise warum soll ich das auch noch letztlich umsonst machen? Klar, man kann den fragen. Und der kann auch sagen: ich will das. Oder: ich will das nicht. Ich finde es eigentlich den kreativeren Akt, wenn man wirklich sagt: die Klangerzeugung selber, also dieser Klang steht so, wie er in dem Sample erhalten ist, das mache ich einfach eben genauso. Das stößt natürlich musikalisch zum Teil an Grenzen. Und ist zum Teil auch, gerade wenn es irgendwie zum Teil Live-Mitschnitte sind, das ist auch eine Akustik, die sie zum Teil nicht mehr so herstellen können.«(J-I_I5) 
Obwohl die prinzipielle Nachspielbarkeit jeglichen Klangs bezweifelt wird, erfährt die originäre Herstellung eines Klangs oder einer Melodie in den Aussagen der hier zitierten Jurist_innen eine Privilegierung gegenüber der Kopie. Diese vom Bundesgerichtshof vertretene Auffassung wurde vom Bundesverfassungsgericht (2016) widerrufen. Das Bundesverfassungsgericht berief sich dabei unter anderem auf die besondere Stellung des Klangs beim Sampling und die diesbezügliche Ausdehnung leistungsschutzrechtlicher Prinzipien auf jegliche, sogar bis ins Granulare reichende Tonfetzen (siehe auch Kapitel I):

"Ja also das Problem war natürlich ganz klar die Rigorosität dieses Tonträgerherstellerrechts, nich', also während man eben beim Urheberrecht ja so etwas wie eine Untergrenze hat, nämlich eben in Gestalt der Schöpfungshöhe, ähm und diese Untergrenze führt dann dazu, dass wenn ich nur den einzelnen Ton sample, dass ich dann jedenfalls urheberrechtlich da nichts gegen einzuwenden ist, anders beim Tonträgerherstellerrecht, was eine solche Untergrenze nich' kennt und selbst wenn ich also ein- ein atomisch- einen atomar-kleinen Schnipsel aus einer Aufnahme rausnehme, also selbst wenn's nur 'ne Millisekunde ist oder so, dass es eigentlich gar nicht mehr hörbar ist vielleicht, selbst dann hätt' ich ja nach der alten Rechtsprechung eigentlich grundsätzlich gegen dieses Tonträgerherstellerrecht verstoßen."(J-2_I6)

\subsubsection{Umgehungsstrategien ("Wenn die Klänge nicht frei sind, dann wird's kompliziert»)}

Vor dem Hintergrund dieser besonders restriktiven Situation haben sich in der Praxis entsprechende Strategien zur Bearbeitung des Problems ausgebildet, die die eigentlichen juristischen Schwierigkeiten zwar nicht aufösen, sondern lediglich umgehen. Interpolationen beispielsweise versprechen durch die Vermeidung zusätzlicher, aufgrund des Leistungsschutzrechts notwendiger Kooperationspartner_innen 
eine Abkürzung des Lizenzierungsverfahrens, da so nur die Kompositionsrechte, nicht aber die Leistungsschutzrechte geklärt werden müssen. Die Kapazitäten dafür sind aber nicht bei allen Musikproduzent_innen ausreichend. Oder sie präferieren die Nutzung von Samples aufgrund ästhetischer und klanglich-materieller Spezifika, die sich in genrehaften Konventionen ausdrücken:

"[...] der Flavour, weißte man, wie das mit irgendwelchen Bändchen-Mikrofonen vielleicht die Snare oder was weiß ich abgenommen haben, das kriegst du so nich'- so nich' hin.«(PL-7_I5)

"Also, das ist für mich auch immer so ein Argument, was ein Sample eben transportiert. Das ist ja auch eine Aufnahme von einer gewissen Stimmung und das kann man jetzt versuchen so nachzustellen. Aber allein die Intention beim Spielen, wenn man die nicht so hat, dann fehlt da auch etwas.«(PL-IO_I7)

»Ich meine, ich hab ganz wenig nur benutzt. Aber eben diese Chords. Und die versuchen wir jetzt nachzubauen mit anderen Chords sozusagen. [GF: Ja, ok.] Und da haben wir jetzt - man kann sie auch einspielen, aber mit einem Sample klingt, hat man halt immer irgendwie so eine Frequenz, die sonst fehlt.« (PL-6_I5)

"[...] was ich an Nachspielen immer so hässlich finde, is' genau wiederum der Grund, warum man sampelt. Nämlich, dass man ja den geilen Klang haben will. Und wenn man's nachspielt, klingt's halt nachgespielt schlecht, meist. Und inzwischen gibt's halt die Möglichkeiten, und das wird ja auch genutzt, dass halt solche Leute wie Deton Records und Gabriel Roth, die halt in der Lage sind, Sachen heute aufzunehmen, die so klingen, als wären sie in den 6oern und $70 e r n$ eingespielt, tatsächlich angegangen werden mit der Bitte, Sachen einzuspielen, die man dann samplen kann. Oder eben Andrew Young, der jetzt mit Premo [DJ Premier, GF] dann auch ein Album gemacht hat. Das is' halt dieselbe Grundlage, dass man, es geht halt am Ende immer um diesen Sound. Das is' der entscheidende Faktor. 
Um Klänge halt, und wenn die Klänge nicht frei sind, dann wird's kompliziert."(L-3_I6)

"[...] weil das natürlich immer so der worst case ist, versuchen wir eigentlich seit ungefähr zwei Jahren bei den Produktionen, wo wir davon ausgehen, dass die größer werden könnten, möglichst auf Samples zu verzichten oder wirklich nur ganz oder das nur so benutzen, dass es quasi nicht zurückverfolgbar ist, weil es so obskure Stücke sind, weil die so nochmal verändert wurden. Das ist natürlich grundsätzlich trotzdem super schwer abzuschätzen. Aktuell arbeite ich gerade an einer Veröffentlichung, das ist eine neue Künstlerin hier aus $=^{*}=$, arbeiten an der ersten Single und das Demo, ist jetzt quasi noch Demoversion, da gibt es eine Bassline von einem $=^{*}=$ Stück. Das ist aber eigentlich ein Künstler aus den 9oern. Und da habe ich jetzt gerade ein neues Producerteam drangesetzt, mit dem Auftrag: 'Hey, wir können diese Bassline, diese Bassmelodie nicht benutzen. Guckt doch mal, ob ihr irgendwie etwas hingekriegt, was ungefähr ähnlich ist, aber eben nicht das ist!« (L-I_I5)

Bestimmte Tonstudios haben die hier angesprochene Marktnische für klanglich äquivalente Interpolationen erkannt und sich bereits auf die Produktion von »sample replays« spezialisiert, für die sie von Musikproduzent_innen eigens beauftragt werden. So wirbt ein spanisches Studio mit besonders hoher Klangtreue interpolierter Samples selbst bei mehreren Instrumenten oder komplexen musikalischen Strukturen:

"The service we provide enables producers and media co's to completely circumvent the problem of mechanical copyright clearance. As a SCORCCiO client, you will be the Master Recording owner; no matter if the replayed sample is 5 seconds or 15 minutes long. We recreate samples and replay music like nobody else can. That's why we are the Music Industry's NUMBER I choice! [...] The best producers to remake beats, music, instruments and vocals. Closely matched to 
sound just like the original versions. We create authentic sounding productions to help you avoid expensive, slow and sometimes impossible to get sample clearance. ${ }^{69} 7^{70}$

Einen eher am reverse engineering orientierten Weg zur Umgehung der Unwägbarkeiten des Sample-Clearings entwickelte das kanadische Startup Legitmix, das zwischen 2012 und 2016 eine technikbasierte Möglichkeit zum Verkauf von Remixes und Mashups anbot. Auf legitmix.com wurde eine Applikation bereitgestellt, bei der geringfügig bearbeitete Musik wie Mashups unter Nennung der Quellen hochgeladen und verkauft werden konnten. Statt des Endprodukts verkaufte Legitmix aber nur die Bauanleitung. Wurden beispielsweise zwei Stücke miteinander gekreuzt, rechnete die Software aus, in welcher Weise und zu welchen Anteilen die beiden Stücke vermengt wurden. Aus diesen Informationen wurde ein abstrakter Bauplan errechnet, der von Konsument_innen gekauft und heruntergeladen werden konnte. Über die Applikation wurde dieser Bauplan auf der Festplatte der Konsument_in wieder in ein konkretes Musikstück zurück übersetzt. Die Konsument_in musste dafür die Bauteile, also die verwendeten Songs entweder neu als $\mathrm{MP}_{3}$ kaufen oder schon auf der Festplatte gespeichert haben. Auf diese Weise konnten eine künstlich errechnete Kopie des Mashups hergestellt und damit sowohl die originalen Rechteinhaber_innen wie auch die Remixer_innen beteiligt werden. Der Clou von Legitmix, die rechtlich-bürokratischen Hürden der Li-

69 Siehe http://www.scorccio.com/scorccio.html (25.0I.20I8).

70 Ein anderes Tonstudio, das sich ebenfalls auf "Recreating Samples« spezialisiert hat, wirbt mit den folgenden, sehr nachdrücklichen Worten: »The original publisher will get its earning automatically from the publishing rights generated from the new exploitation of your production containing a portion of their composition. On the contrary if you want to use the original sample without to use our Recreating Samples service you will have to pay more and more money to get the original audio master authorization contacting the label company which usually owns the property, IF YOU LET US RECREATE A SAMPLE, YOU WILL SAVE MONEY FOR SURE, IT’S GUARANTEED !“ (sic) Siehe http:// www.recreatingsamples.com/recreating-sample/recreating-samples-faq.html (3I.OI.20I8). 
zenzierung über den Zukauf der verwendeten Stücke zu umgehen und damit die Kosten auf die Konsument_innen abzuwälzen, war aber vermutlich auch sein Problem. Denn ein ganzes Mashup-Album mit all seinen Quellen kostete beispielsweise 58 US-Dollar. ${ }^{71}$ Die Website wurde 2016 eingestellt. ${ }^{72}$

Entscheiden sich Produzent_innen oder Labels gegen eine Interpolation, beispielsweise weil sie die klangliche Originalität der gesampelten Quellen als eigenes ästhetisches Merkmal aufrechterhalten wollen, werden die Leistungsschutzberechtigen zustimmungspflichtig. Im Zuge meiner Recherchen und Beobachtungen begegneten mir aber auch andere Wege, um derartige Probleme zu umgehen oder die Lizenzierungsvorgänge zu vereinfachen. Denn im Gegensatz zu Samples können Coverversionen, also neu eingespielte Versionen bestehender Stücke, die rhythmisch, harmonisch und textlich identisch arrangiert sind, bei der GEMA ohne größere Umstände als Aufführungen registriert und dadurch lizenziert werden. Die Lizenzierung solcher unwesentlichen Bearbeitungen funktioniert, wenn beide Parteien Mitglied bei der Verwertungsgesellschaft sind. Die Verfügbarkeit dieser Lizenzierungsform machte sich das Label von P-I_I4 zu Nutze: Es registrierte mehrere samplebasierte Stücke als Coverversionen, wodurch über Umweg den Originalurheber_innen entsprechende Tantiemen zugeordnet werden konnten, ohne die eigentlich notwendigen Genehmigungen für Bearbeitungen einzuholen. ${ }^{73}$ Das Label ging diesen Weg aber nur, weil die Stücke jeweils zentral

7I Siehe von Gehlen (2017).

72 Siehe http://legitmix.com/ (I7.05.20I7).

73 Die einfache Lizenzierbarkeit von Coverversionen wird auch in die andere Richtung angewendet. Beispielsweise finden sich auf zahlreichen, vor allem in den I990er Jahren von Majors veröffentlichen Compilations nachgespielte Versionen von Hits, um die Klärung von Leistungsschutzrechten beziehungsweise master rights zu vermeiden. Für die Konsument_innen ist auf den ersten Blick in der Regel nicht zu erkennen, ob es sich um die originale oder eine nachgespielte Aufnahme handelt. Mit dem Siegeszug digitaler Distribution von MP3s ergab sich zudem eine Nachfrage für bestimmte Künstler_innen auf den neuen Plattformen. Für die Beatles ist beispielsweise bekannt, dass sie wegen des fragmentierten Katalogs nicht auf iTunes zu finden waren. Dies führte zur Produktion 
auf einem einzelnen Sample basierten; wären mehrere Samples und dadurch mehrere Berechtigte beteiligt gewesen, hätte dies wieder Autorisierungen vorausgesetzt.

Ein ähnliches Vorgehen bemerkte ich bei einer Compilation, die PL-4_I5 als DJ vor einigen Jahren zusammengestellt hatte, bei der ich in der Tracklist einige Auffälligkeiten feststellte: Der Mix hatte eine große Anzahl an fremden Stücken, wobei zwischen diesen immer wieder "Bonus Beats" als Stücke genannt wurden. Tatsächlich handelte es sich hierbei um Remixes, die PL-4_Is selbst produziert hatte, um sie bei seinen Auftritten als DJ zu spielen, und die er nun auf der Compilation unterbringen wollte. Um die Rechteklärung für die Compilation einfacher zu gestalten, lizenzierte das Label die benützten fremden Stücke komplett als Originale für die Zweitveröffentlichung auf Compilations und nicht als Bearbeitungen, die ein komplizierteres Zustimmungsverfahren vorausgesetzt hätten. Entgegen der Lesart, die die Tracklist suggeriert, wurden bei den betreffenden Stücken also nicht nur "Bonus Beats« hinzugefügt, sondern die Stücke wurden rearrangiert und mit neuen Spuren wie kräftigerem Bass oder ähnlichem unterlegt. Für die bürokratischen Modalitäten der Lizenzierung und Abrechnung wurden die eigentlich bereits vereinigten Spuren also wieder auseinandergenommen, um sie als separate künstlerische Leistungen abzurechnen.

Werden mehrere Samples verwendet und treten diese im neuen Stück nicht gleichzeitig, sondern zeitlich mit Abstand zueinander versetzt auf, können die verwendeten Samples auch unabhängig voneinander in separaten Stücken lizenziert werden. Dieser spezielle Fall wurde mir von PL-2_I4 geschildert, die ein Stück mit zwei Samples lizenzieren wollte: ein Sprachsample nur in der ersten Hälfte, ein Keyboard-Sample nur in der zweiten Hälfte des Stücks. Um zu vermeiden, dass sich die Forderungen der Rechteinhaber_innen addieren und es dadurch zu einem Minusgeschäft kommt, spaltete sie ihr

von entsprechenden Coverversionen, die dann statt der Originalaufnahmen bei einer Suchanfrage nach den Beatles auftauchten. Vgl. dazu Setaro (2015). 
Stück in »Part I « und »Part II « auf und klärte die Samples unabhängig voneinander. Sowohl auf der CD wie auch auf der Schallplatte läuft das Stück ohne Unterbrechung durch, so dass es als Einheit rezipiert und von DJs aufgelegt werden kann. Um den Anforderungen für die Abrechnung nachzukommen, sind die einzelnen Parts einzeln ansteuerbar: auf CD mit eigener Tracknummer, auf Platte durch eine rein visuelle Markierung in den Rillen. Auch die Angaben (»contains a samples of «) sind entsprechend separiert.

Im Studio komponieren Produzent_innen prinzipiell jegliche $\mathrm{Mu}-$ sik, die sie interessiert, affiziert und bewegt - auch wenn so unmögliche Kooperationen entstehen und die Gefahr besteht, Rechte Dritter zu tangieren. Es ist schwerlich abzuschätzen, wieviel und welche Musik wegen urheberrechtlicher Verwicklungen nicht veröffentlicht wird, da zu dieser Frage keine systematisch quantifizierten Informationen vorliegen. Für Produzent_innen treten die urheberrechtlichen Anforderungen als unwägbare, abstrakte und oft undurchschaubare Regelsysteme auf, die meist in Form konkreter Probleme wie Lizenzierungs- und Veröffentlichungsschwierigkeiten sichtbar werden oder sich im diffusen, von Gerüchten und Hören-Sagen verursachtem Gefühl, etwas Verbotenes zu tun, äußern.

"Und diese ganzen urbanen Legenden, die sich heute noch durchtragen, das is genau dasselbe. Also diese Nummer mit $>$ Du darfst 6 Sekunden sampeln gehört. [...] Und es hält sich trotzdem noch in den Köpfen dieser Producer weil ich treffe ständig auf Leute, die mir diese Frage stellen, und ich sag immer Nein, Bullshit, nichts mit 6 Sekunden, nicht ein Takt, ist Dir nicht erlaubt«.»(L-3_r6)

Wenn Lizenzierungen misslingen oder der Gesamtprozess zermürbt, weil Anfragen negativ ausfallen oder Antworten auf sie gänzlich ausbleiben, überdenken Produzent_innen in der Regel ihren Ansatz, mehrere Samples pro Stück zu verwenden. Multireferentielle Kompositionen und die Auseinandersetzung mit prominenten, popkulturell 
bekannten Samples werden entsprechend heruntergefahren oder nur noch für Live-Auftritte verwendet; Samples werden kürzer, stärker verfremdet oder an unauffälligen Stellen eingesetzt, Veröffentlichungen werden sorgsamer überdacht, zurückgehalten oder in ihrer Sichtbarkeit beschnitten, beispielsweise durch Verschleierung der eigenen Autorschaft mittels anonymer oder pseudonymer Publikation.

"Aber mittlerweile bin ich da auch auf jeden Fall ein bisschen sensibler für geworden, würd' ich sagen. [GF: Wie äußert sich das?] Zum Beispiel hier so, meine letzte Platte, die $=^{*}=$. Das hier zum Beispiel. OK, das ist doch 'n Sample. Erst rückwärts. Wer den Pianisten kennt, kennt- und grade auch seine Werke aus der Zeit, kennt das schon. Hier das Sample [...] Das hier ist schwer zu erkennen, das ist auch wirklich so zusammengechopped aus so sechs Teilen von so 'nem- von 'nem Track. $=^{*}=$, den kennt man, klar. Des andere gefilterte, schwierig, auch 'n unbekannter Track. Dann kommt da noch 'n Vocal-Sample rein, aber das is' so- pass auf, versuch mal zu erkennen, was der da singt, weißte. Ich hab's selber nicht gepeilt. [PL-7_Is singt Text nach, GF]. Und dann ist das halt von so 'nem Part, wo der ähm singt, dass er sich so klein gefühlt hat, dass er das Gefühl hatte, dass er sich auf 'n Dime setzen kann ähm und seine Beine schaukeln lassen könnte, weißte, $[\ldots]$ is' auch noch irgendwie so ein bisschen zusammengeschnitten, weißte, auf jeden Fall [...]. Den kennt kein Schwein, da mach' ich mir keine Sorgen.« (PL-7_I5)

"Und ähm wir haben, was das betrifft, wahnsinnig viele Samples, wahnsinnig viele ungeklärte Samples, wir ham aber auch geklärte Samples und genau nach der Richtlinie: Sobald es zu auffällig ist, sobald es- also 'ne Melodie ist ganz klar, die eins zu eins ähm melodisch, harmonisch geklaut ist, also übernommen ist, versuchen wir das zu samplen äh- zu klären und ähm haben das auch, wir haben bestimmt IO, I5 verschiedene Sample Cli- Clients irgendwie, wir ham bestimmt auch schon 30 rausgeschickt und is ham nicht geklappt, dann ham wir sie entweder verworfen oder verändert:« (L-2_16) 
"[...] es kostet dich ganz, ganz, ganz, ganz viel Zeit und es kostet dich oft ganz, ganz viel Geld und es kann halt dazu führen, dass du das Stück gar nicht rausbringen kannst, weil du dich eben nicht einigst. [...] Ich weiß es gibt auch viele Labels, die grundsätzlich überhaupt gar keine Musik mehr veröffentlichen, die irgendwie irgendwelche Samples hat." (L-I_I5)

"Also ich sage mal so, zum einen sampel ich eigentlich keine Pop-Musik, sondern das sind ganz obskure Platten in 99 Prozent aller Fälle. Dann ist halt auch die Frage, wenn man das einfach als straighten Loop verwendet, klar dann kann man es wiedererkennen, aber wenn man wirklich sich nur in Elementen dann halt bedient oder halt das verfremdet, rearrangiert, die Tonhöhe verändert, dann ist es schon wesentlich schwieriger auch rauszufinden, dass es sich tatsächlich um das Original handelt.« (PL-IO_I7)

Es sind aber nicht nur urheberrechtliche Verwicklungen, sondern auch andere vertragliche Kooperation der Kunstwelt, die den $\mathrm{Mu}-$ siker_innen Regeln auflegen - und die in bestimmten Situationen umgangen werden:

Am Abend auf einer Party treffe ich PL-2_I4 hinter den Plattentellern. Sie hatte mich bei unserem Treffen im Studio persönlich eingeladen. Ich selbst hatte von der Party nichts gelesen, als ich mich über aktuelle Auftritte von ihr informiert hatte. Über dem Eingang des Clubs kündigen große Lettern ihr DJ-Pseudonym an, das aus zwei Wörtern besteht. Allerdings sind die jeweils ersten Buchstaben der Wörter vertauscht. Es ist trotzdem lesbar, verwirrt mich aber im ersten Moment. Als ich sie zu einem anderen Zeitpunkt darauf anspreche, erklärt sie mir, dass sie wegen eines Exklusivvertrags mit einem anderen ortsansässigen Club nicht unter ihrem eigentlichen, bekannteren Pseudonym auftreten kann. Durch den Buchstabendreher umgehe sie das Problem: auf diese Weise entstehe ein Pseudonym von einem Pseudonym. 
Durch die Fokussierung auf die drei Kernpraktiken Kopieren, Komponieren und Koordinieren war es mir möglich, die gegenwärtige Kunstwelt des Samplings für den deutschen Rechtsraum gleichermaßen verdichtet wie detailliert darzustellen. Die changierende Bewegung während des Erhebungsprozesses zwischen Nähe und Distanz implizierte zudem eine systematische Selbst- und Fremdbeobachtung - mit dem Resultat, die Sampling-Welt und ihren Umgang mit dem Urheberrecht von innen heraus verstehen und gleichermaßen von außen durchdringen zu können. Ich betrachte dies als Errungenschaft, weil ich so in der Lage bin, eine ausgewogene, theoretisch geleitete sowie historisch und empirisch informierte Analyse des Verhältnisses von Urheberrecht und Kreativität in der samplingbasierten Musikproduktion zu liefern, die die überbetonten und invisibilisierten Aspekte miteinander trianguliert. Im folgenden Diskussionsteil führe ich daher die theoretischen, historischen und empirischen Stränge dieser Arbeit zusammen, um die These von der Umgehungskreativität als Innovation im Schatten des Samplings zu fundieren und zu erläutern. 

TEIL 4 - DISKUSSION 



\section{Von der Umgehung der Kreativität zur Kreativität der Umgehung}

In diesem abschließenden Kapitel diskutiere ich auf Grundlage der theoretischen, historischen und empirischen Teile dieser Arbeit die Schlüsse, mit denen ich empirisch informiert und gleichermaßen abstrahiert die Forschungsfrage beantworte. Erst erörtere ich im Rückgriff auf das entwickelte theoretische Konzept die kreativen Prozesse beim Sampling und bette sie in die genrehaften Strukturen der Kunstwelt ein. Anschließend beantworte ich die Frage, in welcher Weise das Urheberrecht als Hemmnis und/oder als Anreiz für die Kreativität samplingbasierter Musikproduktion fungiert und damit die Produktion neuer Werke marginalisiert beziehungsweise stimuliert. Abgeschlossen wird das Kapitel mit drei Hinweisen auf mögliche weitere Anwendungsfelder und zukünftige Forschungsthemen, die sich an die vorliegende Arbeit anschließen lassen.

Zur Beantwortung der Forschungsfrage vertrete ich in der Diskussion die These, dass sich in der untersuchten Kunstwelt kreative Umgehungsstrategien in gravierender Form ausgebildet und als Schatteninnovation stabilisiert haben, mit denen die Akteure die Probleme der besonders restriktiven urheberrechtlichen Grammatik bewältigen beziehungsweise zu bewältigen versuchen: Ohne sich signifikant aneinander zu orientieren und ihre Umgehungsstrategien als kreativ zu thematisieren, ringen sie mit ihrer Umgehungskreativität um die Hoheit zur technischen Reproduzierbarkeit fremder Samples. Sie tun dies zu großen Teilen im Verborgenen oder im Stillen, in Umgehung und Unterlaufung der hierfür dysfunktionalen musikindustriellen Lizenzierungsstrukturen, was sie auf lange Sicht benachteiligt: Die Akteure sehen sich dazu gezwungen, ihre eigene Sichtbarkeit in 
den Schatten öffentlicher Auffindbarkeit zu stellen, die Verwertbarkeit ihrer eigenen Werke zu beschneiden oder die ästhetische Komplexität von unmöglichen Kooperationen einzuschränken.

Die Verlagerung der Prozesse ins Verborgene bedeutet, dass urheberrechtlich belastete Musik nicht vollständig öffentlich erscheinen und nicht ohne Einbußen kommodifiziert werden kann. Die auf dem Urheberrecht basierenden musikindustriellen Lizenzierungsstrukturen induzieren, das heißt erzwingen und ermöglichen gleichermaßen Umgehungskreativität als spezifische Kreativitätsform. Diese wird zur Überwindung der Hemmnisse notwendig und somit indirekt durch das Urheberrecht angereizt. Die widrige rechtliche Situation führt damit nicht zu einem Verlust von samplingbasierter Kreativität, sondern zwingt Kreativität in enge lizenztechnische, der Verwertung zuführbare und technisch wie ästhetisch unterkomplexe Ausdrucksformen, deren öffentliche Sichtbarkeit, gesellschaftliche Legitimität und Kombinationsvielfalt erheblich kupiert ${ }^{74}$ wird. Über den langen historischen Zeitraum dieser Untersuchung hinweg betrachtet, kanalisieren die urheberrechtlichen Konfigurationen technischer Reproduzierbarkeit also die Kreativität samplingbasierter Praktiken in Umgehungsstrategien, deren Stabilität und Ausformung eine analytische Klassifikation als Innovation im Schatten rechtfertigt. Es handelt sich um eine vertrackte Situation, die von den Akteuren zähneknirschend in Kauf genommen, aber zur kurzfristigen Erfüllung ihrer Ziele von ihnen selbst auch reproduziert wird.

74 Unter dem Begriff "Kupieren" versteht man im Allgemeinen das Abnehmen oder Kürzen von Teilen eines Lebewesens oder Objekts zum Zwecke der Zurichtung. Bei Hunden ist das Kupieren des Schwanzes bekannt, das vornehmlich aus ästhetischen Gründen erfolgt. Kühe werden oft an ihren Hörnern kupiert, um sich nicht gegenseitig zu verletzen (zum Beispiel im Stall). Man spricht aber auch bei Pflanzen wie Sträuchern oder Bäumen von Kupieren, wenn sie durch Beschnitt in ihrem Aussehen verändert und dadurch in der Form ihres natürlichen Wachstums modifiziert werden. Ich beziehe mich im Folgenden auf den Begriff des Kupierens, wenn ich zum Ausdruck bringen will, dass ein Vorgang oder ein Objekt durch bewusste Wegnahme oder Beschnitt seiner eigentlichen Elemente passend gemacht wird, um externen Kriterien zu genügen. 


\subsection{Sampling als kreatives kollektives Handeln}

Mit Hilfe des dreiseitigen Kreativitätskonzepts, das ich im theoretischen Teil dieser Arbeit in Anschluss an Beckers Verständnis von Kunst als kollektivem Handeln erarbeitet habe und hier kurz rekapituliere, ist es möglich, eine fundierte Aussage über die kreativen Prozesse in der beforschten Kunstwelt zu treffen. Wie in Kapitel 2 bereits dargestellt, gilt es, vier verschiedene Praktiken der Neuheitsproduktion zu unterscheiden: Um künstlerische Originalität und kollektive Validierungsprozesse individueller Kreativität zu erfassen, lässt sich kreatives Handeln erstens als gelungene Kontribution zu einer sozialen Sammlung verstehen. Diese kontributionalistische Seite der Kreativität betont das Zusammenpassen von genrehaften Konventionen mit darauf abzielenden Beiträgen. Zweitens sind es die experimentellen Praktiken der Neuheitsproduktion, mit denen dem Existierenden in entdeckerischer Absicht neue Seiten abgerungen und unterbrochene Handlungsabläufe wieder vervollständigt werden. Die Praktiken der Exploration und der Rekonstruktion stehen einander gegenüber, denn sie markieren zwei Pole einer experimentellen Situation: die Eröffnung neuer Möglichkeiten und die Schließung von handlungsunterbrechenden Problemen. Schließlich sind es drittens die symbolisierenden Praktiken der Neuheitsproduktion, mit denen mittels eigens generierter Bedeutungen Objekte, die als fremd begriffen werden, symbolisch rekodiert und dadurch angeeignet werden. Diese dritte Seite der Kreativität zielt auf die symbolische Vorherrschaft, mit der über Fremdes Kontrolle und Verfügung erreicht wird, indem dieses in eine neue symbolische Ordnung gestellt wird.

Das Datenmaterial, das in den historischen und empirischen Teilen dieser Arbeit bereitgestellt wird, deutet die Komplexität und Verschränktheit der verschiedenen kreativen Prozesse des Samplings bereits an. Mithilfe des entwickelten theoretischen Vokabulars möchte ich nun klären, wie sich Sampling auf Basis des Datenmaterials als kreatives kollektives Handeln verstehen lässt. Ich beginne dieses Projekt mit der Analyse der kollektiven Anteile und arbeite mich da- 
von ausgehend zur individuellen Ebene vor. Die kollektiven Anteile äußern sich vor allem in den genrehaften Konventionen, die ich als spezifische grammatische Neuheitsimperative interpretiere. Diese Neuheitsimperative bedingen und rahmen, so der weitere Gang der Argumentation, die individuellen künstlerischen Entscheidungen. Sie validieren, was als gelungene, kreative Kontribution gelten darf, definieren, welche Grade von Neuheit und Referentialität dafür notwendig werden, und fordern dazu auf, explorative, rekonstruktive und symbolisierende Praktiken der Neuheitsproduktion anzuwenden.

Samplinggetriebene Genres wie Hip Hop, House, Techno, Drum'n'Bass und weitere bewerten nach bestimmten Kriterien neue Stücke. Diese Kriterien sind als Neuheitsgrammatik mit kontributionalistischer Produktionslogik im Wissen der Akteure gebündelt und werden fortlaufend von diesen interpretiert, verhandelt und gebrochen. Manche Regeln sind lose und flexibel, manche rigide und verbindlich, aber in ihrer Gesamtheit fungieren sie als konventionales Regulierungsinstrument, das sowohl die Stabilität wie auch die Dynamik eines Genres sicherstellt. Die Regeln beinhalten einen Imperativ nach ästhetischen Überraschungen, fordern von einem Stück also die richtige Dosis Neuheit: Einerseits legen die genrehaften Konventionen die technischen Rahmenbedingungen fest, nach denen ein Stück typischerweise komponiert wird. Es hat bestimmte strukturelle Merkmale zu erfüllen, beispielsweise in Bezug auf Länge, Aufbau, Arrangement, Geschwindigkeit, etc. Diese Rahmenbedingungen sind tendenziell paradigmatisch unhinterfragt und bilden den harten Kern eines Genres, denn sie sorgen für die strukturelle Anschlussfähigkeit von Kontributionen; sie gewährleisten damit, dass die Stücke prinzipiell im Radio, in DJ-Sets oder der heimischen Stereoanlage spielbar werden und als typische Ausfertigung für ein bestimmtes Genre wahrgenommen werden.

Andererseits ist samplingbasierte Musik mit der Forderung nach ästhetisch Neuem konfrontiert, wobei die Art des Verhältnisses von Alt und Neu in diesem Fall näherer Erklärung bedarf. Samplingbasierte Stücke werden, so die Erkenntnis der Kapitel I und 6, dahinge- 
hend bewertet, wie sie mit Referentialität umgehen und wie sie durch verschiedene Versionierungspraktiken ästhetische Neuheit erzeugen: Nicht die autononome, spurlose Schöpfung mit absoluter Neuheit ist gefragt, sondern ein Kunstwerk, das aus (ausschnittsweisen) Kopien anderer Stücke besteht, sich innerhalb dieses Netzwerks von ästhetischen Bezügen positioniert und dadurch die kuratorische Kreativität der Produzent_in ausweist. Es zählen gelungene, überraschende Rekombinationen popkulturell bekannter Stücke, die dabei eineindeutig erkennbar sein sollen, wie im Mashup-Genre. Im Hip Hop dagegen dominiert vor allem die Selektion unbekannter, obskurer oder übersehener Samples aus alten Stücken, die als eindeutige Referenzen dekodiert werden können. Und in Genres der elektronischen Tanzmusik wie House, Techno oder Drum'n'Bass bestimmt vor allem die sonische Qualität eines Samples und die Art, wie es in einem typischem Stück beziehungsweise in einem DJ-Set zusammen mit anderen Stücken das interne zeitliche Arrangement ästhetisch aktualisiert; diese dritte Art der Referentialität habe ich als uneindeutig charakterisiert. Auch mediale, materielle und auf Kopiervorgänge bezogene Referentialität kann je nach (Sub)Genre erwünscht sein, da es die Authentizität der Produktion unterstreicht und die Gemachtheit der Stücke als klangliche Spuren ästhetisch miteinbezieht (zum Beispiel Schallplattenknistern).

Musikproduzent_innen, die sich den genannten Genres zuordnen, verfolgen in aller Regel das Ziel, Stücke veröffentlichen, die als außergewöhnliche, verblüffende oder originelle Kontributionen zu eben diesen Genres wahrgenommen und als kreativ validiert werden. Die Instanzen der Validierung sind unterschiedlich, aber grundsätzlich orientiert man sich an den Hierarchien existierender sozialer Sammlungen; beispielsweise daran, ob DJs - idealerweise mit gutem Ruf und internationalem Renommee - die Stücke in ihren Sets spielen, Radiosender sie in ihre Playlists aufnehmen oder Journalist_innen Rezensionen schreiben und Interviews veröffentlichen. Auch die ästhetische Affizierung des Publikums auf der Tanzfläche, das Wachsen der Anhängerschaft in sozialen Netzwerken und Vertragsabschlüsse mit einflussreichen Labels sind in diesem Zusammenhang 
als Faktoren für validierte Kontributionen zu sehen. An diesem Punkt wird die Feldhaftigkeit samplingbasierter Popmusik ersichtlich, da in ihr eine soziale Hierarchie vorherrscht, die sich an gesellschaftlich bewährten Validierungskriterien orientiert, wie Renommee, Reichweite oder Einfluss auf andere Künstler_innen.

Aufgrund der genannten kontributionalistischen Aspekte bedeutet die Benutzung von Samples also nicht, einen künstlerischen Anspruch auf Originalität, auf einen eigenen Stil oder auf ästhetische Alleinstellungsmerkmale aufzugeben, also das Bestehende einfach zu kopieren und dadurch Ressourcen einzusparen - die genrehaften Kriterien sind komplexer, als es der bürgerliche Kunstbegriff nahelegt, der Original und Kopie diametral zueinander denkt. In den Anfangsstadien überwiegt bei vielen Produzent_innen natürlich oft der Wunsch, einen bestimmten Sound nachzuahmen und durch die Imitation spielerisch Praktiken einzustudieren, um sich mit den Grundregeln des Genres vertraut zu machen. Mit zunehmender Professionalität und dem Hineinwachsen in das agonale Feld der Musikwirtschaft sind die meisten Produzent_innen aber nach einiger Zeit in der Lage, Vergleiche über Stücke anzustellen und sich differenzierte ästhetische Urteile über Arrangement, Abmischung oder Stil zu erlauben. Dies indiziert die Internalisierung eines genrehaften Geschmacks, durch den auch der Drang zum Ausdruck kommt, Stücke mit dezidiert eigener Handschrift zu komponieren und sich dafür vermehrt in die Zone des Unbekannten zu wagen.

Gerade die empirische Untersuchung der alltagsweltlichen Dimension von Musikschaffenden zeigt, dass Geschmacksurteile im gesamten Produktionsprozess gefällt, revidiert und aktualisiert werden. Vor allem strukturieren Geschmacksurteile die Situation der Exploration und Rekonstruktion von Samples, insofern in diesen fortlaufend fremde Musik nach interessanten Stellen abgehört und diese anschließend durch Aktualisierungs-, Rekombinations- und Variationsverfahren bearbeitet werden. Nach der Publikation ist die so entstandene Musik wiederum externen Geschmacksurteilen ausgesetzt, die nach ähnlichem Muster die Güte der Musik validieren und 
für eigene DJ-Sets, Remixes oder andere referentielle Verfahren der Klangbearbeitung prüfen. Auf diese Weise schließt sich der Kreis der geschmacklichen Begutachtung. So wie samplingbasierte Popmusik auf dem Prinzip der ästhetischen Offenheit von Stücken basiert, so ist auch die geschmackliche Beurteilung nie endgültig abgeschlossen, da bereits benutzte Samples von anderen Produzent_innen jederzeit in einer neuen, möglicherweise erfrischenden oder ungewohnten Art verwendet werden können, also einen neuen Aspekt des Samples explorativ hervorholen und es dadurch retroaktiv verändern.

Dieser Punkt der permanenten Möglichkeit zur ästhetischen Aktualisierung zeigt bereits an, dass explorative und rekonstruktive Praktiken als zentrale Methoden in der kontributionalistischen Produktionslogik samplingbasierter Popmusik eingeflochten sind und entsprechend gefordert werden. Die Suche nach Neuem, das heißt nach einer bisher unbekannten, vielleicht schon wieder vergessenen Referenz im kulturellen Gedächtnis des Genres, wird so zu einem zentralen Treiber der Musikproduktion. Sie kleidet sich gleichermaßen in explorative und rekonstruktive Praktiken, bei der auch minimale Neuheiten, Abweichungen, Fehler, Anomalien und serendipische Veränderungen Berücksichtigung finden, insofern sie den verinnerlichten ästhetischen Genrekonventionen Rechnung tragen. Exploriert werden alte, noch nicht verwendete Samples genauso wie neue Seiten an bereits verbrauchten Samples und Stücken, die in ihrer Gesamtheit das musikalische kulturelle Gedächtnis eines Genres bilden, aus dem Samples als Stichproben und referentielle Kopien entnommen werden. In Situationen der Exploration werden Schallplattenkisten durchforstet, extensiv Musik gehört und Klänge in ihre Bestandteile zerlegt, um ihnen neue Bedeutungen, Referenzen, Anschlussmöglichkeiten und sonische Qualitäten abzutrotzen, die - idealerweise - keine Konkurrent_in vorher bemerkt hat. Datenbankgestützte Systeme stellen zusätzliche kulturelle Vorkehrungen bereit, die den Kanon des bereits Verbrauchten kollektiv zusammentragen, dokumentieren und sortieren - und etwaige Wiederholungen vermeiden helfen und den kulturellen Imperativ zur Neuheit reproduzieren. 
Durch Rekombination und Variation wird dem Existierenden so eine neue Qualität abgerungen, die im besten Falle so bedeutungsvoll erscheint, dass sie Eingang findet in die Re-Konstruktion eines Samples in Form einer Skizze, Version oder eines neuen Stücks. Klänge, egal ob zufällige Umweltgeräusche oder in bereits organisierter Form als Musik, werden hierfür als unabgeschlossene, unfertige Ressourcen begriffen, die sich wie Instrumente spielen und wie Material formen lassen. In pragmatistischer Perspektive erscheint ein solcher musikalischer Moment, der als potentielles Sample wahrgenommen wird, wie eine Begegnung mit einem Problem. Mit dem Begriff des Problems ist hierbei eine Herausforderung oder Aufgabe bezeichnet, die innehalten lässt und damit den Anstoß gibt zur Re-Imagination des Samples innerhalb eines neuen Zusammenhangs. Durch die Rekonstruktion, das heißt die Wiedereinbindung des problematischen Samples in einen neuen musikalischen Zusammenhang nach den internalisierten Kriterien einer gelungenen Kontribution, erledigt sich die Aufgabe und es ist etwas in die Welt geraten, das in dieser Form vorher noch nicht existierte. Das Sample, zuerst als unperfekt und unfertig begriffen, hat nun eine Form angenommen, die als sinnvolle neue Einheit wahrgenommen wird.

Für dieses Ziel, ästhetisch anschlussfähige Stücke mit eigener, möglichst unverwechselbarer Autorschaft herzustellen und zu veröffentlichen, verfeinern und verzahnen Produzent_innen die im gegenseitigen Wechsel zueinander stehenden Verfahren der Exploration und Rekonstruktion fortlaufend. Oft taucht eine neue Bedeutung plötzlich und überraschend auf, beispielsweise wenn ein ursprünglich lineares Sample innerhalb eines Loops zu funktionieren scheint oder bisher unverbundene Samples miteinander harmonieren. Um das serendipisch auftretende Neue zu managen, führen Produzent_innen solche Situationen absichtsvoll herbei oder schaffen Bedingungen, unter denen die Entdeckung wahrscheinlich oder zwingend wird. Aus der Fülle an Möglichkeiten, die die Gerätschaften bieten und die die Geschichte der per Ton aufgezeichneten Musik bereitstellt, wird sorgfältig gefiltert und selektiert, verarbeitet und zusammengestellt. 
Am Ende des Kompositionsprozesses steht das fertige Produkt, das die verinnerlichten genrehaften Kriterien mit der richtigen Kalibrierung von Neu und Alt abbildet und dadurch den Imperativ nach Neuheit innerhalb der Kunstwelt reproduziert.

Auf Seite der Symbolisation wird die Zugehörigkeit des Neuen im Sinne eines angeeigneten Objekts betont. Generell lässt sich die Arbeit mit Samples als Verwaltung von Referenzen, Bedeutungen und symbolisch vorgeprägten kulturellen Produkten verstehen, die durch verschiedene Aneignungspraktiken hervorgebracht werden und daher nicht unbedingt im Sinne der originalen Rechteinhaber_in sein müssen. Als theoretischer Zugriff maßgeblich entwickelt in den Cultural Studies (Willis 1993, Willis 20I4), diente die Perspektive der symbolischen Kreativität dazu, auch die Hervorbringung minimaler Neuerungen in der Samplingpraxis zu erfassen und ernst zu nehmen, obwohl oder gerade weil die Akteure die urheberrechtlichen Bedingungen nicht strukturell verändern, sondern lediglich symbolisch neu besetzen können. Sampling ist ein hervorragendes Fallbeispiel, um Aneignungspraktiken zu studieren, mit denen sich Akteure kopierte oder materielle Objekte zu eigen machen, die sie als fremdes oder sogar feindliches Eigentum begreifen und über die sie - zumindest symbolisch - mit größtmöglicher Kontrolle verfügen, sie möglicherweise auch gegen die originalen Rechteinhaber_innen einsetzen möchten. Denn Sampling bedeutet das explorative und rekonstruktive Spiel mit Ausschnitten bereits veröffentlichter Musik und den darin eingearbeiteten Bedeutungen, Gefühlen und ästhetischen, wirtschaftlichen oder rechtlichen Entscheidungen - Musik, deren Form als geschlossene Einheit wahrgenommen, nicht aber wieder aufgebrochen werden soll.

Schon vergleichsweise einfache und auch unter Amateur_innen verbreitete Praktiken wie das Suchen, Sammeln und Sortieren von Tonträgern lassen sich in diesem Zugriff als Maßnahme begreifen, eine neue, eigene symbolische Ordnung zwischen den Objekten zu kreieren. Die neue Reihenfolge erlaubt es, sich selbst an die erste Stelle zu setzen und dadurch symbolische Vorherrschaft auch über 
kulturindustrielle Produkte zu erreichen. Dass in samplingbasierten Genres nicht nur ein Werkstolz über eigene Kontributionen herrscht, sondern auch ein Stolz über das Entdecken vergessener oder obskurer Samples, und ein kultureller Wettbewerb um das Wissen und die Identifikation von Samples anderer Produzent_innen entsteht, betrachte ich als kollektive Ausformung dieser symbolischen Kreativität. Denn der strategische Einsatz von eineindeutigen, eindeutigen oder uneindeutigen Referenzen impliziert zugleich die In- und Exklusion bestimmter Publika, die die originalen Quellen als Zitate zu lesen und zuzuordnen vermögen - oder eben nicht.

Die Kreativität der Symbolisation ist dadurch genauso an die genrehaften Kriterien gelungener Kontributionen gekoppelt wie an die Praktiken zur Exploration und Rekonstruktion neuer Samples. Das Suchen, Sammeln und Sortieren, aber auch das Ausstellen und Repräsentieren von Tonträgern (beispielsweise im IKEA-Regal) ist damit eine Vorstufe zum eigentlichen, auf Kopien fußenden Kompositionsprozess, bei dem die Kontrolle und Verfügung über fremde Musik unter Beibehaltung der gewünschten Referentialität umgesetzt wird. Auch das Loopen stellt eine Möglichkeit dar, um einem eigentlich linearen Sample eine uneigentliche, neue Bedeutung zu entlocken, die von der originalen Urheber_in nicht intendiert war. Noch deutlicher wird die Seite der symbolischen Kreativität bei unmöglichen Kooperationen, in denen eigentlich unverbundene Musiker_innen in neuer Weise verbunden werden, indem man mit ihren dekontextualisierten Samples - im doppelten Sinne - spielt und dadurch symbolische Kontrolle über ihre Werke erzwingt.

Aus der Analyse lässt sich ein wichtiger Punkt schlussfolgern, der das Verhältnis von Urheberrecht und Sampling betrifft: Die Position, dass samplingbasierte Popmusik erkennbare Anteile anderer, bereits publizierter Musik vorwiegend deshalb verwendet, um ohne große Mühen die Früchte fremder Arbeit zu ernten und entstandene Werke als eigene auszugeben, kann widerlegt werden. Mit anderen Worten: Ein Verständnis von Sampling im Sinne einer bloßen Umgehung von Kreativität ist empirisch nicht haltbar und missachtet die Aus- 
formung spezifischer Bewertungskriterien, nach denen die Originalität samplingbasierter Popmusik kulturell verhandelt wird und die mit dem dargestellten theoretischen Zugriff analytisch scharf gestellt werden können. Das soll nicht heißen, dass keine Plagiate vorkommen, für die sich sampelnde Musikproduzent_innen fremde Autorschaft anmaßen. Selbstverständlich treten auch in samplinggetriebenen Genres entsprechende Fälle auf, wie gerade der ethnografische Zugriff und die lebensweltliche Perspektive deutlich gemacht haben. Allerdings ist der Umkehrschluss, nämlich aufgrund der Dominanz von Kopierpraktiken das Vorhandensein von Originalität und Kreativität beim Sampling zu negieren, nicht zutreffend, da die Bewertungskriterien genrespezifisch ausgebildet sind. Auch überschneiden sich die hochkulturellen, am romantischen Schöpfungsideal orientierten Vorstellungen spurloser Kreativität, die Jahrzehnte lang die Rechtsprechung prägten, zwar teilweise mit den erwünschten Graden der Referentialität aus der Samplingwelt, sind mit ihr aber nicht deckungsgleich.

\subsection{Kreative Umgehungsstrategien}

In diesem Abschnitt möchte ich die Wege diskutieren, die die Akteure der Kunstwelt gefunden haben, um unter den widrigen rechtlichen Voraussetzungen die von ihnen bevorzugte Art samplingbasierter Musikproduktion aufrechtzuerhalten. Daran anschließend möchte ich in Kapitel 7.3 herausarbeiten, was ihnen auf diesen Wegen abhandenkommt: Indem ich aufzeige, welche Einbußen die Akteure im Hinblick auf Sichtbarkeit, Verwertbarkeit und Komplexität in Kauf nehmen, möchte ich die schattierenden Effekte urheberrechtlicher Marginalisierung für die Kunstwelt samplingbasierter Popmusik herausarbeiten. Dieser Schritt dient auch dazu, die These von der Umgehungskreativität als Innovation im Schatten näher zu charakterisieren. 
Jenseits der dichotomen Logik von Marginalisierung und Stimulierung von Kreativität durch urheberrechtliche Konfigurationen offenbaren die Ergebnisse meiner Untersuchung einen Weg zur Bearbeitung urheberrechtlicher Verwicklungen, den ich unter dem Stichwort einer "Kreativität der Umgehung« - oder kurz: »Umgehungskreativität« - zusammenfasse. Die These von der Umgehungskreativität entspricht weder der einen, noch der anderen Perspektive vollumfänglich. Sie zu vertreten bedeutet, das Urheberrecht weder als ein reines Hemmnis noch als reinen Anreiz für Kreativität zu sehen, sondern je nach Situation entsprechende Gewichtungen zu berücksichtigen. Dadurch lässt sich auch für eine differenzierte Auseinandersetzung mit den urheberrechtlichen Konfigurationen technischer Reproduzierbarkeit eintreten. Denn die Behauptung einer Umgehungskreativität weist nicht zurück, dass urheberrechtliche Barrieren marginalisierende oder stimulierende Effekte für die Produktion neuer Werke haben können, versucht aber, das Verhältnis genauer zu klären und simplifizierende Determinismen zu vermeiden.

Mithilfe des breiten kreativitätstheoretischen Zugriffs konnte ich die mannigfaltigen Gründe aufzeigen, die Menschen dazu motiviert, mit Samples zu arbeiten: Beispielsweise die Auseinandersetzung mit bereits existenter Musik und die Einschreibung in deren historischen Kreislauf, die Schaffung ästhetisch-emotionaler Expression und einer eigenen künstlerischen Sprache, die Suche nach Anerkennung und Reputation, die Erarbeitung von Kritik oder einer spezifischen Perspektive, das explorativ-rekonstruktive Spiel mit Referenzen und Bedeutungen sowie die Erzeugung körperlich-sinnlicher Affizierung und ästhetischer Flow-Erlebnisse alleine und mit anderen Menschen. All diese Erfahrungen sind auch Jugendlichen und Amateur_innen zugänglich, die einen aneignenden Zugang zur Musik an Samplern und Plattenspielern suchen, und ihre Musik mit anderen teilen wollen, ohne bereits an die monetäre Verwertung ihrer Produkte zu denken.

Auch belegen sowohl die historische Aufarbeitung (siehe Kapitel 4) wie auch die empirische Erhebung (siehe Kapitel 6), dass urhe- 
berrechtliche Restriktionen und in Verbindung stehende Praktiken (wie beispielsweise Rechtsprechung, Abmahnungen oder Lizenzierungsvorgänge) nicht gleichzusetzen sind mit der externen Bedrohung der Kunst durch das Recht, durch den sprichwörtlichen »langen Arm des Gesetzes", dem Akteure hilflos ausgeliefert sind. Die Urteile des Bundesverfassungsgerichts (2016) und des Europäischen Gerichtshofs (2019) haben zur Stärkung der musikalischen Praxis des Samplings beigetragen. Doch auch in den Jahren 2014 bis 20I7, in denen die empirischen Daten für diese Untersuchung erhoben wurden und die Forschungsliteratur aufgearbeitet wurde, existierte samplingbasierte Popmusik in bemerkenswert ausdifferenzierter und stabiler Form - allen Befürchtungen und urheberrechtlichen Restriktionen zum Trotz. Allein diese Feststellung spricht dafür, dass die betreffenden Akteure Wege gefunden haben, ihre kreativen ästhetischen Strategien an widrige rechtliche Bedingungen anzupassen und auf Dauer zu stellen - wenngleich das für sie stets merkliche Abstriche hinsichtlich Sichtbarkeit, Verwertbarkeit und Komplexität bedeutet (siehe Kapitel 7.3).

Die These von der Umgehungskreativität schließt an die Beobachtung solcher Anpassungsleistungen an. Sie gesteht den Akteuren zu, passende situative Strategien zur Überwindung von Barrieren und praktikable Auswege aus urheberrechtlichen Verwicklungen zu rekonstruieren, gerade weil diese in der Samplingwelt besonders vielfältig, präsent und drückend sind. In der untersuchten Kunstwelt ist Sampling derart verbreitet und paradigmatisch ausgeformt, dass es nicht als produktionstechnische und ästhetische Grundlage der Musikherstellung angezweifelt wird. Genauso sind auch Konflikte wegen Samples alltäglich. Es ist normal, dass Gerichtsprozesse stattfinden, sich Jurist_innen um die Auslegung von Schöpfungshöhe streiten, Stücke wegen fehlender Lizenzen vom Markt genommen werden und sich Labels davor scheuen, Musikstücke mit (vielen) Samples zu veröffentlichen - „normal« in dem Sinne, dass alle Akteure die urheberrechtliche Restriktivität als soziale Normalität akzeptieren, sich diskursives Wissen über entsprechende Fälle aneignen 
und samplingbasierte Musik stets in dem Bewusstein produzieren, die rechtlich-wirtschaftlich-ästhetische Konstellation der benutzten Samples für die Verwertung im Auge behalten zu müssen. Oder anders ausgedrückt: Das Recht ist nichts Externes mehr in der aktuellen samplinggetriebenen Musikproduktion, das unerwartet auf die Akteure hereinbricht, sondern es gibt internalisierte Annahmen, bewährte Verfahren und kreative Wege zur Bearbeitung urheberrechtlicher Verwicklungen innerhalb der Kunstwelt, die sich in neuen Kooperationen und Konventionen zwischen den Akteuren zeigen.

Dass Akteure Regulationsmechanismen umgehen - insbesondere, wenn diese widrige, restriktiv verregelte Situationen mit hoher Unsicherheit und ausgefeilten Kontrollmaßnahmen zur Folge haben ist gang und gäbe: So ist von James Brown beispielsweise bekannt, dass er zum Zwecke der Steuerhinterziehung zwei seiner Töchter als Mit-Urheberinnen zahlreicher Stücke angab, obwohl diese damals nur drei und sechs Jahre alt waren (McBride 20I6: 70); Unternehmen der deutschen Autoindustrie haben nachweislich Abschaltvorrichtungen (defeat devices) in die Abgasanlagen ihrer Fahrzeuge eingebaut, um damit jahrelang die Kontrollen der US-amerikanischen Umweltbehörde erfolgreich zu unterlaufen. Und während des Regimes des Nationalsozialismus' waren verbotene politische Organisationen wie die KPD oder die SPD auf sogenannte "Tarnschriften« angewiesen, mit denen sie die Bevölkerung mit illegalen programmatischen Texten versorgten. Getarnt wurden diese Schriften mit harmlos aussehenden Umschlägen von Kochrezepten, Gebrauchsanweisungen oder Ratgebern, die dadurch die Zensur umgingen (Scheibe 20I5). Den genannten Beispielen ${ }^{75}$ ist gemeinsam, dass sie allesamt workarounds darstel-

75 Es gibt freilich zahlreiche andere Beispiele, an denen sich signifikant ausgebreitete Umgehungsstrategien von Regelwerken und Kontrollstrukturen studieren lassen: Auf drei Beispiele weise ich hin: Die virtuelle Verknappung von Gütern durch Goldman Sachs, Ubers greyball-Software und die Tarn- und Schmuggelaktivitäten während der Zeit der Alkoholprohibition. (I) Der Soziologin Saskia Sassen zufolge arbeitete die Investmentbank Goldman Sachs mit einer Reihe von bemerkenswerten Praktiken, um die Preise für bestimmte Güter zu beeinflussen. Beispielsweise wurde eine vermeintliche Knappheit von Aluminium fingiert, 
len, also Verfahren zur Problembearbeitung, mit der das eigentliche Problem nicht aufgelöst, sondern um es herumgearbeitet, dadurch verschoben und am Leben gehalten wird (vgl. Schabacher 20I7).

indem Lastwagenfahrer_innen große Mengen des Leichtmetalls zwischen einzelnen Lagerstätten quasi im Kreis hin- und hertransportierten. Auf diese Weise kamen die Lieferungen nicht real bei den Lagerungsstätten an, geschweige denn bei den weiterverarbeitenden Unternehmen; die virtuelle Verfügbarkeit des Guts wurde durch Umgehung der Detektionsmechanismen der Lagerstätten also geschickt verknappt, um den Preis in die Höhe zu treiben (Sassen 20I7). (2) Die US-amerikanische Firma Uber, die mithilfe einer App kostenpflichtige Fahrten in Autos, Chauffeurdienste und ähnliches vermittelt und damit ähnlich wie ein Taxiunternehmen agiert, operierte nachweislich mit einer Software, die die Kontrollen von Polizist_innen und Behörden im städtischen Raum aushebeln sollte. Uber-Fahrzeuge sind in der Regel nicht von gewöhnlichen Autos zu unterscheiden, ihre Bewegungen im Raum werden in der Uber-App aber live und sekundengenau angezeigt. Das sogenannte greyball-Programm jedoch sammelte systematisch Metadaten von behördlichen Smartphones, so dass deren Standorte automatisch detektiert werden konnten. Auf diesen Geräten wurden dann die tatsächlichen Standorte von Uber-Fahrzeugen ausgeblendet. Dagegen wurden phantom cars angezeigt, also Uber-Fahrzeuge, die nur auf dem Display existierten, nicht aber real unterwegs waren. Mithilfe dieser Tricks unterlief Uber systematisch die behördlichen Kontrollen (Calo/Rosenblat 20I7: I629). (3) Während der Zeit der Alkoholprohibition in den USA zwischen 1920 und 1933 ließ sich die Manifestierung und Ausdifferenzierung von Umgehungsphänomenen sogar innerhalb eines ganzen Lands beobachten. Nachdem der kulturell verankerte Genuss von Alkohol gewissermaßen über Nacht verboten und dadurch bis dato legale Praktiken nahezu vollständig illegalisiert worden waren, trat der gewünschte Effekt allerdings nicht ein: die US-amerikanische Bevölkerung wurde nicht $d r y$. Im Gegenteil: Die rigoros veränderte Rechtslage führte vielmehr zu einer innovativen Verlagerung von Produktion, Distribution und Konsum alkoholischer Getränke in den Untergrund, das heißt in nicht sichtbare, geheime und versteckte Bereiche. Zur Produktion beliebter Alkoholika experimentierte man mit neuen Methoden: Die Zutatenvielfalt für Whiskey beispielsweise wurde vielerorts reduziert, um das etwaige Risiko einer Verfolgung zu minimieren; Brauereien entwickelten alkoholfreie Sirupe, mit denen sich durch die Hinzugabe einer weiteren Substanz zuhause selbst Bier herstellen ließ. Weiter entstanden sogenannte »Flüsterkneipen« (speakeasys) mit Alkoholausschank, eine Reihe von kreativen und ausgeklügelten Schmuggel- und Tarnpraktiken genauso wie weitverzweigte Infrastrukturen zum unbemerkten Transport und Verteilung großer Mengen Alkohol, die von verbrecherischen Organisationen aufgebaut und betrieben wurden (vgl. Welskopp 20IO, Funderburg 20I4). 
Vergleichbare Konzeptionen von Umgehungskreativität lassen sich an anderer Stelle finden: So schlägt der französische Historiker und Kulturphilosoph Michel DeCerteau in seinem Buch »Die Kunst des Handelns" in einem machttheoretischen Zugang eine Unterscheidung von Strategie und Taktik vor. Unter einer "Strategie" versteht er die

"Berechnung [...] von Kräfteverhältnissen, die in dem Moment möglich wird, wenn ein mit Willen und Macht versehenes Subjekt (ein Unternehmen, eine Armee, eine Stadt oder eine wissenschaftliche Institution) ausmachbar ist. [...] Wie beim Management ist jede strategischer Rationalisierung vor allem darauf gerichtet, das ‘Umfeld ‘ von dem reigenen Bereich`, das heißt vom Ort der eigenen Macht und des eigenen Willens abzugrenzen.« (DeCerteau I988: 87)

Strategien bauen also eigene Umgebungen auf, die sie zeitlich wie örtlich kontrollieren und zur Ressourcengewinnung nutzen können; die machtvoll ausgestatteten Akteure delegieren ihre Absichten damit in Strukturen, die von anderen vorgefunden werden und mit denen jene umgehen müssen. Das konzeptionelle Gegenstück zu den Strategien sind die "Taktiken" (in meiner Konzeption: Umgehungsstrategien), die DeCerteau zufolge nicht auf etwas Eigenes zurückgreifen können, sondern sich in den vorgefundenen Strukturen zurecht finden müssen. Taktiken sind flüchtig, leben von "günstigen Gelegenheiten«, vom »Umfunktionieren« des Gegebenen und sind entsprechend abhängig von der aufgezwungenen Umgebung:

"Die Taktik hat nur den Ort des Anderen. Sie dringt teilweise in ihn ein, ohne in vollständig erfassen zu können und ohne ihn auf Distanz halten zu können. Sie verfügt über keine Basis, wo sie ihre Gewinne kapitalisieren, ihre Expansionen vorbereiten und sich Unabhängigkeit gegenüber den Umständen bewahren kann.» (DeCerteau 1988: 23) 
Die Taktik stellt also eine situative Anpassungsleistung dar und muss immer wieder neu erarbeitet werden, spätestens dann, wenn sich die Umgebung ändert. Die Taktik ist mit einer List oder Finte zu vergleichen, die sich in der aufgezwungenenen Umgebung temporär ausbreitet, aber nicht oder nur unter großen Anstrengungen dauerhaft verankern kann. DeCerteau schreibt an einigen Stellen sogar von einer "Umgangsweise mit aufgezwungenen Systemem» (DeCerteau 1988: 59) und rückt die Praxis des Umgehens von Hidnernissen - er hat hier insbesondere Spaziergänger_innen vor Augen - in die Nähe von Kreativität.

Sowohl DeCerteaus wie auch Schabachers Vorschläge sind erhellend, um das Phänomen kreativer Umgehungsstrategien in Bezug auf Sampling und Urheberrecht differenzierter zu besprechen. Ich schließe daher einerseits an Schabachers Gedankenfigur des Workarounds an und beziehe mich andererseits auf DeCerteaus Begriffspaar von Strategie und Taktik - wenngleich ich eigene Bezeichnungen wähle: Was DeCerteau mit "Strategie« bezeichnet, nenne ich selbst "Struktur" und meine damit die Delegation eigener Ziele in stabile Umgebungen, in denen sich Dritte zurecht finden müssen; und für die "Taktik» behalte ich meine eigene Bezeichnung der "Umgehungskreativität" beziehungsweise der "kreativen Umgehungsstrategien" bei, die genau wie bei DeCerteau und Schabacher eine situativ-rekonstruktive Anpassungsleistung an vorgegebene, nicht veränderbare Strukturen meint, mit der kurzfristig um ein Problem herumgearbeitet, es aber nicht langfristig behoben wird.

Der Begriff der Umgehungskreativität hat neben der konsistenten Formulierung über die gesamte Arbeit hinweg den Vorteil, das semantische Feld, das das Wort "Umgehung" bietet, ausnutzen zu können. Dadurch lassen sich vier idealtypische Formen der Umgehungskreativität ableiten, die ich innerhalb meiner historischen und empirischen Untersuchung als dominante Wege zur Bearbeitung urheberrechtliche Probleme identifiziere: 
I. Das Schaffen von Distanz

2. Das Unterlaufen von Regeln

3. Das Herstellen von Zugang

4. Das Verfolgen von Kopien

(I) Die erste idealtypisch umrissene Umgehungsstrategie besteht im Schaffen von Distanz. Damit meine ich die Abkehr von samplingbasierter Musikproduktion, wenn Produzent_innen und Labels generell oder strategisch Abstand nehmen von der Idee, urheberrechtlich geschützte Samples zu benutzen. Sie wollen auf diese Weise Urheberrechtsstreitigkeiten aus dem Weg gehen und sind dazu gezwungen, gar keine oder einen signifikant geringeren Anteil erkennbarer Samples in ihren Stücken zu veröffentlichen, auf andere Arten des Materials auszuweichen oder sich auf das Musizieren mit anderen Instrumenten einzustellen. Indem etwaige problematische Stücke vorsätzlich oder nachträglich von Tonträgern entfernt werden, macht man einen Bogen um die strapaziösen Lizenzierungsstrukuren und versucht, auf legalem Terrain zu bleiben. Zu den Vermeidungsstrategien gehört auch, dass Musikproduzent_innen nur noch mit gemeinfreier, Creative Commons-lizenzierter oder anderweitig vor-lizenzierter Musik arbeiten, wobei die Möglichkeiten der Kombination, Variation und Aktualisierung dadurch natürlich stark kupiert werden. Ein weiterer Weg ist die Zuwendung hin zu konventionellen Musikinstrumenten und Gesang, was in vielen Fällen erst erlernt werden muss und hohe praktische Hürden bedeutet, mitunter aber auch neue schöpferische Potentiale freisetzen und einen neuen musikalischen Ansatz bedeuten kann. Auch ist es eine verbreitete Praxis im Studio, ein Sample lediglich als musikalisches Stützgerüst zu verwenden und es mit selbst eingespielten Spuren $\mathrm{zu}$ kombinieren, es nach dieser Inspirationsphase wieder zu entfernen und das Stück gänzlich ohne Sample zu veröffentlichen. In jedem Fall geht es darum, drohende urheberrechtliche Probleme, auch wenn diese letztendlich nicht aufösbar sind, weitmöglich zu umschiffen, um damit keine Angriffsfläche für Klagen, Abmahnungen und teure Lizenzabgaben aufgrund urheberrechtlich belasteter Samples zu bieten. 
(2) Das Unterlaufen urheberrechtlicher Regeln und Kontrollmechanismen bildet die zweite idealtypische Umgehungsstrategie. Sie wird dann verfolgt, wenn Produzent_innen und Labels sich nicht von der Idee verabschieden wollen, urheberrechtlich geschützte und erkennbare Samples einzusetzen, sich aber genauso wenig in der Lage sehen, alle betreffenden Samples ordnungsgemäß zu lizenzieren. Während die erste Umgehungsstrategie vor den restringierenden Mechanismen einer urheberrechtlichen "permission culture" (Lessig 2004: 192) kapituliert hat und sich durch Vermeidungsverhalten der urheberrechtlichen Forderung nach tendenziell spurloser Kreativität annähert, stellt das Unterlaufen ein Zugeständnis in eine andere Richtung dar - nämlich gegenüber der eigenen Sichtbarkeit als Künstler_in und der Produktion von ästhetisch gewollter Referentialität. Die militärische Metapher des "flying below the radar" (McLeod/DiCola 20II: 196), das als Manöver eingesetzt wird, um die feindliche Kontrolle zu unterlaufen, deutet den Kampf um die Hoheit zur technischen Reproduzierbarkeit bereits an. Die Grenzen des Kontrollgebiets sind dabei nicht statisch, sondern ebenfalls umkämpft und werden aufgrund des Anstiegs der Detektabilität durch digitale Abgleichinstrumente dynamisch verschoben.

Typisch für Strategien des Unterlaufens ist der symbolische oder praktische Rückgewinn von Kontrolle durch das teilweise Eindringen in die aufgezwungenen Lizenzierungsstrukturen und das Ausnutzen etwaiger Schlupflöcher. Dies bedeutet, eine Musik aus Musik, selbst wenn sie illegal ist, öffentlich oder eingeschränkt öffentlich zur Verfügung zu stellen. Dies kann durch die gezielte Direktbeteiligung von Urheber_innen mittels bewusster Missachtung lizenz- und verwertungsrechtlicher Regeln realisiert werden, beispielsweise wenn ein Sample als Coverversion bei der GEMA angemeldet und dadurch die Urheber_innen auf anderem Wege beteiligt werden. Auch die Substitution von Samples durch Interpolationen oder äquivalenten Samples, um damit weniger Rechteinhaber_innen zu beteiligen, ist in diesem Zusammenhang zu sehen. Dies führt sogar zu organisationalen Akteuren wie Studios, die sich auf perfekte Replays von Samples spezialisiert haben und damit die Umgehung urheberrecht- 
licher Schwierigkeiten als Geschäftsmodell zu nutzen wissen. Ebenso auf organisationaler Ebene lässt sich das Unterlaufen bei der Lizenzierung über Umwege durch spezialisierte Plattformen wie Legitmix oder Tracklib beobachten. Schließlich sind zur Praxis des Unterlaufens Tarn- und Verschleierungsmanöver zu rechnen: Das Verstecken, Tarnen, Rearrangieren und Unkenntlichmachen von Samples und samplingbasierten Stücken; die nicht-öffentliche Veröffentlichung samplingbasierter Musik, beispielsweise nur in geringer Auflage, in untergründigen Distributionskanälen oder auf bestimmten medialen Tonträgern (wie Vinyl oder Kassette); damit einhergehend anonyme oder pseudonyme Veröffentlichung, teilweise auf eigens dafür gegründeten und die Spuren verwischenden Sublabels.

(3) Der dritte Idealtyp kreativer Umgehungsstrategien lässt sich in Anlehnung an die "aesthetics of access" (Op den Kamp 20I7) als Herstellung von Zugang bezeichnen. Darunter klassifiziere ich all jene Praktiken, mit denen ein Zugang zu urheberrechtlich geschützten und mit kopierschutztechnischen Barrieren ausgestatteten Werken (wieder)hergestellt wird. Der Hintergrund dabei ist, dass urheberrechtliche Konfigurationen technischer Reproduzierbarkeit nicht nur in abstrakte Regelsysteme eingelagert, sondern auch an Technologien und automatisierte Kontrollsysteme delegiert sind. Insofern verschiebt und erweitert sich der Wettstreit um die Hoheit technischer Reproduzierbarkeit, wenn nicht mehr nur direkt mit Urheber_innen, Anwält_innen oder lizenzierenden Organisationen verhandelt und gerungen werden muss, sondern auch mit digitalen Dateien und materiellen Tonträgern selbst. Ein Zugang in diesem Sinne wird also eröffnet in Situationen, in denen DRM-geschützte Dateien in geschickter Weise digital geöffnet und aufgebrochen werden, was je nach DRM-Variante unterschiedlich schwierig und umfangreich ausfallen kann; weiter durch das Abfangen von digitalen Streams auf Plattformen wie Youtube, Soundcloud, Netflix oder den Mediatheken des öffentlich-rechtlichen Rundfunks, auf denen das Herunterladen von Dateien eigentlich gar nicht beziehungsweise nur unter bestimmten Umständen vorgesehen ist. 
In anderen Situationen soll dagegen weniger der formale urheberrechtliche Schutz eines Werkes umgangen werden, sondern der informelle Schutz, mit dem Akteure die verwendeten Quellen geheim halten, weil sie entweder urheberrechtliche Verwicklungen oder Konkurrenz befürchten. Insofern lassen sich unter dem Begriff des Zugangs auch alle diejenigen Praktiken einschließen, mit denen über Umwege Informationen über verwendete Samples oder Stücke aus DJ-Sets beschafft werden, wie beispielsweise durch das Hochladen fremder Musik bei Plattformen, die mit algorithmischer Identifizierungstechnologie operieren, oder das kollektive Zusammentragen von Sampleinformationen in Internetforen und -datenbanken wie whosampled.com. Schließlich sind damit jene, meist illegalen Praktiken verknüpft, die das Ziel allgemeiner Zugänglichkeit von Musik verfolgen. Dazu zählt beispielsweise der "Grey Tuesday“ des "Grey Album» aus dem Jahr 2004. Aber auch Wiederauflagen (»Re-Issues») obskurer oder vergessener Musik sowie (von Fans) zusammengestellte Kompilationen, die neue, unverbrauchte Samples präsentieren oder die originalen Quellen berühmter Samples öffentlich enttarnen.

(4) Das Verfolgen bildet die vierte Umgehungsstrategie und arbeitet gewissermaßen in die entgegengesetzte Richtung von Unterlaufen und Zugänglichmachen. Das Verfolgen steht auch der Schaffung von Distanz gegenüber, denn es stellt eine Maßnahme dar, der Verwendung von als Eigentum begriffenen Werken nachzugehen und damit die eigene Reproduktionshoheit abzusichern. In Anlehnung an DeCerteaus Gedankenfigur handelt es sich also um eine Umgehungsstrategie, die durch einen Akt der Unikatifizierung ${ }^{76}$ eine Grenze um ihr Eigentum zieht, sich dadurch gewissermaßen zu einer aufzwin-

76 Gegenüber dem traditionellen soziologischen Fachbegriff der Individualisierung, der sich bekanntlich auf Lebensstile und soziales Verhalten bezieht, spreche ich von »Unikatifizierung». Mit dem Bezug auf den technisch-handwerklichen Begriff des Unikats wird angezeigt, dass es sich hier um materialisierte Objekte handelt und nicht um soziale Verhaltensweisen. Daraus lässt sich das Verb »unikatifizieren« bilden, das den Herstellungsvorgang eines Unikats meint. 
genden Struktur wandelt und trotzdem weiterhin als Finte agiert. Das Kernprinzip des Verfolgens sehe ich darin, durch ein Verfahren der Unikatifizierung möglichst unbemerkt die Ununterscheidbarkeit von Kopien aufzuheben und dadurch die Schwierigkeiten einer etwaigen Beweislast zu umgehen. Denn tatsächlich erscheinen auch für sampelnde Musikproduzent_innen und Labels die formalen, aus der Grammatik des Urheberrechts abgeleiteten Regeln bisweilen nutzlos und Verfahren des Kopierschutzes erweisen sich als unzureichend, um die Verbreitung der eigenen Werke zu steuern oder zumindest einigermaßen unter Kontrolle zu halten (beispielsweise bei Vorab-Versionen für Journalist_innen). Bei Verlagen, die Karten herstellen, sind sogenannte »trap streets", die auch als "copyright traps" oder "copyright easter eggs« bekannt sind, seit Jahrzehnten eine Standardpraxis, auch wenn selten offen darüber gesprochen wird. Es handelt sich um fingierte Straßen (oder andere erfundene Einträge wie Plätze oder sogar ganze Orte), mit denen Plagiate konkurrierender Unternehmen identifiziert und verfolgt werden können, um die eigene Autorschaft zu behaupten und vor Gericht nachzuweisen (vgl. Monmonier I99I: 5I). Eine vergleichbare Technik wird auch bei der Produktion von Lexika durch fingierte Einträge (sogenannte »U-Boote») oder in der Unterhaltungsindustrie durch digitale, in Film- oder Musikdateien eingelassene Wasserzeichen realisiert, die bei nicht autorisierten Kopien unweigerlich und unwissentlich mitkopiert werden. Noch präziser ist die musikalische Unikatifizierung durch die Einarbeitung unterscheidbarer Samples, die als Kontrollelemente fungieren und anhand derer sich die Mobilität eines Stücks verfolgen lässt. 


\subsection{Umgehungskreativität als Schatteninnovation}

Die Umgehungskreativität hat konstituierende Kraft in Bezug auf den Produktionsprozess samplingbasierter Musik; das generelle Prinzip - die Anpassung an widrige Regeln und Umstände zur Aufrechterhaltung der Praxis - ist in der Lebenswelt der Akteure bereits angelegt, um beispielsweise mit technischen Barrieren oder vertragsrechtlichen Hürden umzugehen beziehungsweise diese zu umgehen. Aufgrund des urheberrechtlich-wirtschaftlichen Drucks, der sich mit den unmöglichen Kooperationen und deren Konsequenzen ergibt, prägt sich die Umgehungskreativität bei samplingbasierter Popmusik allerdings besonders stark aus: Die restriktive urheberrechtliche Neuheitsgrammatik lässt die Kreativität beim Sampling demnach nicht verschwinden, sie gibt aber auch nicht uneingeschränkt Anlass, sich dem Neuheitsregime der Spurlosigkeit und uneindeutiger Referentialität vollständig zu unterwerfen. Umgehungsstrategien sind damit praktische Rekonstruktionen unterbrochener Handlungsabläufe, die sich auf symbolischer Ebene als widerständige Techniken im Kampf um die Reproduktionshoheit deuten lassen.

Dabei ist offensichtlich, dass Umgehung nicht nur Abkürzung, sondern auch Verlängerung bedeutet. Je nach Kontext kann eine Umgehungsstrategie Verfahren beschleunigen oder verlangsamen, Ressourcen einsparen oder aufbrauchen. Nachdem die (Rück-)Ermächtigung der Akteure durch kreative Umgehungsstrategien erörtert wurde, interessiert mich im Folgenden, welche marginalisierenden Effekte sich in Bezug auf Umgehungsphänomene feststellen lassen. Dabei verstehe ich das empirisch nachweisbare Muster der Umgehungskreativität als deutliches Anzeichen dafür, dass die Praktiken des Samplings in den Schatten der Akteure und der öffentlichen Wahrnehmung wandern müssen, um weiterhin bestehen zu können. Dies möchte ich unter dem Stichwort einer Schatteninnovation diskutieren und so die Verluste spezifizieren, die durch die kupierenden Praktiken der Akteure entstehen. 
Die Ausbildung und Verankerung von Umgehungsstrategien interpretiere ich als Indikator für einen sozialen Bereich, in dem die Praktiken der Akteure und die herrschenden Grammatiken nicht aufeinander abgestimmt und ineinander verzahnt sind, sondern gegeneinander arbeiten und dadurch Friktion erzeugen. Umgehungsstrategien stehen damit für den symbolischen oder praktischen Rückgewinn von Kontrolle in einem stark verregelten Bereich, dessen Regeln die Akteure nicht kontrollieren oder zu ihren Gunsten ändern können. Ganz im Gegenteil: Die vielfältigen und weitreichenden urheberrechtlich-technischen Konfigurationen technischer Reproduzierbarkeit erzeugen eine hochgradig regulierte und vermeintlich kreativitätsfeindliche Umgebung für referentielle Samplingpraktiken. Workarounds sind dabei nur Behelfsmittel, mit denen sich kurzfristig und unter Einkauf von merklichen Einbußen der eigenen Ressourcen symbolisch oder praktisch Kontrolle zurückerlangen lässt: Oder anders gesprochen: Man erzwingt sich durch geschickte Durchdringung der herrschenden Grammatik und mühevolle Ausnutzung ihrer Schwachstellen ein wenig Handlungsspielraum, bringt infolgedessen an anderer Stelle aber wiederum merkliche Opfer.

Insofern lassen sich die vier umrissenen Strategien der Umgehung als reflexive Anpassungsleistungen auf drängende urheberrechtliche Schwierigkeiten interpretieren und als künstlerische Kompromisse verstehen, die die Akteure einzugehen bereit sein müssen, um weiterhin samplingbasierte Musik als bevorzugtes ästhetisches Mittel ihres Ausdrucks kontribuieren zu können. Konkret sehe ich urheberrechtlich induzierte Einbußen bei der eigenen Sichtbarkeit als Künstler_in, bei der Verwertbarkeit der eigenen Werke und bei der ästhetischen Komplexität der Kompositionen. Mindestens eine dieser drei Ressourcen muss komplett oder maßgeblich aufgegeben werden:

(I) Ihre eigene Sichtbarkeit kupieren Produzent_innen und Labelbetreiber_innen willentlich, wenn auch nicht zwanglos, wenn sie pseudonym, anonym, auf obskuren Sublabels und in untergründigen Netzwerken samplingbasierte Popmusik veröffentlichen. Sie verber- 
gen auf diese Weise teilweise oder vollständig ihre eigene Autorschaft und stellen die potentielle Reichweite ihrer Produktionen absichtlich in den Schatten des Urheberrechts. Sie kupieren die öffentliche Auffindbarkeit ihrer Arbeit, weil sie damit rechnen müssen, dass die rechtliche Unmöglichkeit ihrer Werke bei etwaigem Erfolg zu einem Bumerang wird. Das Ethos des Untergründigen, teils auch Widerständigen und latent Heroischen wird auf diese Weise reproduziert und verbindet sich mit der Kritik an der Dysfunktionalität des Urheberrechts. Die künstliche Verknappung durch geringe Auflagen und die oft nur kurzfristige Verfügbarkeit samplingbasierter Stücke wegen urheberrechtlicher Verwicklungen verstärken und erhärten dieses Ethos, wenn sie popkulturell als Verkaufsanreiz und zum Marketing gewendet werden.

(2) Ähnlich verhält es sich mit der Verwertbarkeit: Weniger Sichtbarkeit bedeutet möglicherweise kurzfristigen Erfolg und monetären Gewinn im Untergrund, langfristig geht die restriktive urheberrechtliche Lage aber auf Kosten der Verwertung von samplingbasierten Stücken. Denn diese lassen sich vergleichsweise schlecht veröffentlichen, lizenzieren und bewerben. Das zeigt sich zum Beispiel daran, dass sich die jeweiligen Stücke oftmals nicht und nur unzureichend bei Verwertungsgesellschaften anmelden, für Majorlabels kommodifizieren, auf etablierten Radio- und Fernsehsendern spielen und dadurch formal korrekt abrechnen und verwerten lassen. Eine Konsequenz dieser Problematik ist, dass samplingbasierte und urheberrechtlich belastete Stücke wiederum selbst nicht als einwandfreies Ausgangsmaterial für darauf aufsattelnde samplingbasierte Stücke herhalten können, was ich als Verschleppung und damit als Verschärfung des Problems interpretiere.

(3) Schließlich induzieren die engen Lizenzgefüge ästhetische Restriktionen in Bezug auf die Sampleauswahl, da sich insbesondere multireferentielle, extensive und prominente Quellen im Grunde verbieten, insofern man Sichtbarkeit und Verwertbarkeit einigermaßen 
aufrechterhalten will. Mashup-Produktionen und Medley-artige Stücke mit zahlreichen Samples eineindeutiger Referentialität beispielsweise sind technisch realisierbar und ästhetisch reizvoll, rechtlich und wirtschaftlich aber in der Regel nicht zu empfehlen. In der Folge kupieren Produzent_innen und Labelbetreiber_innen die ästhetische Vielfalt ihrer Kompositionen oder konzentrieren sich auf einzelne, leichter zu lizenzierbare Samples. Auch Remixes, die sich als kritische Kommentare verstehen und das Ausgangsmaterial ganz gezielt nicht im Sinne einer Hommage verwenden, sind im Regime urheberrechtlicher Autonomieästhetik entsprechend problematisch.

Ich verstehe die in Kauf genommenen Einbußen als Indiz für das wiederkehrende, über individuelle Fälle hinausgehende und empirisch dominante Muster, tendenziell unlösbare Probleme durch vorläufige Lösungsansätze zu bearbeiten. Das Muster der Umgehungskreativität klassifiziere ich als Schatteninnovation, das ich an verschiedenen Untersuchungsorten vorfinden konnte, seien es die Komposition, Lizenzierung und Verwertung, oder in Form individueller Kniffe und organisational ausgeformter Geschäftsmodelle. Auch ist die Idee der Umgehung innerhalb des internationalen Immaterialgüterrechts nicht unbekannt. Die sogenannten Anti-circumvention-Regeln, die bereits $1996 \mathrm{im}$ Rahmen der WIPO Copyright Treaties (WTC) als Bündel verschiedener Gesetze verankert wurden, verbieten die Umgehung technischer Barrieren von urheberrechtlich geschützten Gütern und erhöhen damit die Kontrolle der Rechteinhaber_innen. Die These von der Umgehungskreativität beim Sampling ist damit in gewisser Weise in der juristischen Grammatik bereits vorausgeahnt worden.

Die systematische Berücksichtigung umgehungskreativer Strategien beim Sampling wurde in den letzten 30 Jahren Forschung zu weiten Teilen überschattet zu Gunsten einer intellektuellen Auseinandersetzung mit den genrehaften Bewertungskriterien und ästhetischen Implikationen. Doch die empirische Feststellung der Umgehungskreativität erweitert den Forschungsdiskurs zum Verhältnis von Urheberrecht und Kreativität sicherlich um wertvolle Aspekte. 
Bisher dominierte der Fokus theoretischer und empirischer Studien auf den dichotomen Perspektiven von Marginalisierung und Stimulierung. Damit verbunden war die akademische Legitimierung und wissenschaftliche Herausarbeitung der künstlerischen Kreativität, die Produzent_innen beim Sampling implizit anwenden und deren endonyme Rechtfertigungsstrategien von den Forscher_innen nach außen verdichtet wurden. Nicht im Zentrum stand dagegen die systematische Untersuchung der notwendigen »dirty work« (Goffman 1956: 74), also Arbeit, die eher versteckt auf der Hinterbühne stattfindet und tendenziell nur unter vorgehaltener Hand verbalisiert wird. Die nun vorliegenden empirischen Ergebnisse bestätigen, dass neben der Herstellung von kreativen Kontributionen eine weitere stabile, in den Praktiken der Akteure verankerte und in der urheberrechtlichen Grammatik vorgedachte Form der Kreativität vorliegt, die bislang von der Forschung nur fragmentiert und unzusammenhängend, aber nicht unter Einnahme einer integrierten Perspektive systematisch untersucht wurde. Insofern trägt die vorliegende Studie dazu bei, die bisherige Forschung in dieser Hinsicht zu problematisieren und gleichzeitig eine Forschungslücke zu schließen.

Mit Gewinn lässt sich die These der Umgehungskreativität auch im Diskurs der Innovationsforschung diskutieren. Es liegt nahe, die Praxis des Samplings als Innovation zu beschreiben, die individuelle neue Kontributionen auf Basis einer neuen ästhetischen Grammatik ermöglicht und Innovationen in Rechtsprechung, Lizenzierungsmodalitäten oder im Verständnis künstlerischer Autorschaft nach sich zieht. Als wiederkehrendes Muster der Problembearbeitung sind umgehungskreative Praktiken beim Sampling aber in bemerkenswerter Spannbreite präsent, stabil und derart übersituativ verankert, dass die Umgehungskreativität an sich als Innovation behandelt werden kann. Für einen solchen Zugriff eignet sich besonders der im theoretischen Kapitel besprochene Typ der "Schatteninnovation«. Diese ist analytisch dadurch gekennzeichnet, dass sie als Neuerung »im Schatten der öffentlichen Aufmerksamkeit" und "trotz hinderlicher Regelsysteme und ohne ausdrückliche Rede sich gleichsam still implizit in Prakti- 
ken und versteckt in materialen Produkten durchsetz $[\mathrm{t}]$ « (Hutter et al. 20I6: 23).

Gerade beim Sampling, jener künstlerischen Praxis, die bis vor einigen Jahren in Deutschland nahezu illegal und mit allenfalls geringer gesellschaftlicher Legitimität ausgestattet war, dominierten im Diskurs Rechtfertigungsstrategien und Beteuerungen ästhetischer Qualität. Sampling sollte als Kunstform mit Traditionslinien zu Collage und Montage, zu Cut-up und Ready-made wahrgenommen werden, als Jazz, der ein neues Format verlangt, wie Stetsasonic 1988 rappten (Shusterman 1992: 232), nicht aber als schnöder Diebstahl, als amateurhafte Bastelei ohne jegliche Eigenständigkeit und künstlerische Originalität. Diese Situation, in der Produzent_innen und Labels mit dem Rücken zur Wand standen, festigte ihr öffentliches und eigenes Bild als »outlaws" (Schur 2015) und marginalisierte große Teile samplingbasierter Musikproduktion in Richtung Untergrund.

Vor diesem Hintergrund ist es nicht verwunderlich, dass die meisten Akteure ihre Umgehungsstrategien beim Sampling semantisch zur Ruhe bringen, also aus strategischen Gründen nicht thematisieren, verschweigen und invisibilisieren: Einerseits, weil sie ihnen als (meist) illegale Manöver zur Sicherung und Wiedergewinnung ihrer Reproduktionshoheit dienen und eine offene, gar offensive Thematisierung bisher vermutlich nur geschadet hätte. Die Akteure haben selbst kein besonderes Interesse daran, ihre dirty work, ihre eigens verschleierten Kniffe genau auszuleuchten und damit zu riskieren, dass sich ihre Geheimtricks herumsprechen und bekannt werden. Andererseits, weil sie sich der Bandbreite und Nachhaltigkeit ihrer Umgehungsstrategien größtenteils selbst gar nicht bewusst sind, da sie sich nicht gegenseitig daran orientieren und wegen deren Invisibilisierung keinen Gesamtüberblick gewinnen können. Vorwiegend wird in der Umgehungskreativität einfach der situative Zweck aufgeschobener, gewissermaßen gebastelter und vorläufiger individueller Lösungen gesehen.

Es herrscht zwar common sense in der aktuellen Generation der Produzent_innen, dass das Urheberrecht und daran geknüpfte Prakti- 
ken eine Menge Schwierigkeiten bereiten können. Wie ausgeführt, ist dies eine in der Kunstwelt internalisierte Gegebenheit, die akzeptiert wird wie andere nicht auflösbare Probleme auch. Selbstverständlich werden unter den Produzent_innen Tipps und Tricks im Umgang mit dem Urheberrecht ausgetauscht. Auch herrschen gefährliches Halbwissen und Gerüchte über urheberrechtliche Verwicklungen. Doch abgesehen von gemeinsam geteilten Erfahrungen beim Sample Clearing existiert meiner Einschätzung nach kein gemeinsam vertretenes Narrativ oder zumindest eine Position, in der die "dreckige» Arbeit als Narrativ gebündelt werden könnte. Dagegen dominieren die medial und akademisch vermittelten Narrative, wie beispielsweise das Narrativ von den Anfängen des Hip Hop in der Bronx als widerständig-kulturelle Praxis oder das Narrativ der Entstehung von Drum'n'Bass in Großbritannien als Fortführung afrodiasporischer Geschichte. Die Legitimationsrhetorik und die rituell reproduzierten kulturellen Narrative bestimmen also das Geschehen und überschatten die alltäglichen Praktiken der Umgehung, welche aufgrund ihrer rechtlich sensiblen Lage sowieso schon einer strukturellen Invisibilisierung ausgesetzt sind.

In der Gesamtheit erfüllt die Umgehungskreativität also die Kriterien einer Innovation im Hinblick auf die soziale Stabilität einer ausgebreiteten und übersituativ verankerten Neuerung, die einen Bereich prägt und bestimmt. Insbesondere auf den Ebenen von Pragmatik und Grammatik ist sie identifizierbar; gerade die ethnografische Untersuchung dieser Arbeit jedoch zeigt, dass Umgehungskreativität auf der semantischen Ebene invisibilisiert, zur Ruhe gebracht und in den Schatten wirkmächtigerer Narrative gestellt wird. Umgehungsstrategien sind entscheidende Faktoren im Umgang mit den verschiedenen Konfigurationen technischer Reproduzierbarkeit und haben maßgeblichen Anteil daran, die Kernpraktiken in der Kunstwelt samplingbasierter Popmusik unter dem dafür widrigen, dysfunktionalen Regelsystem des Urheberrechts zu stabilisieren.

Mit den verschiedenen Praktiken der Umgehung erhalten die Akteure die Kunstwelt samplingbasierter Popmusik aufrecht, ohne 
je in die Lage zu kommen, die eigentlichen, formalen urheberrechtlichen Probleme auflösen zu können. Den Befund einer solchen Umgehungskreativität, die als Innovation im Schatten der Akteure stabil verankert ist, interpretiere ich als Indikator für einen besonders von Friktionen durchdrungenen gesellschaftlichen Bereich, in dem die dominierenden Grammatiken nicht auf die dominierenden Praktiken passen. Gleichzeitig wirft der Befund einer Umgehungskreativität neues Licht auf die vermeintliche Dichotomie von Anreiz und Hemmnis grammatischer Restriktionen, denn er zeigt, dass die Überwindung von Hemmnissen selbst als Anreiz für Kreativität verstanden werden kann. Dies ermöglicht und erfordert ein nuanciertes, differenziertes Verständnis von Kreativität, das Neuheitsproduktion nicht nur als ästhetische Expression oder originelle Kontribution, sondern gerade im pragmatistischen Sinne als Problembewältigung konzipiert.

\subsection{Ausblick}

Zum Abschluss bietet es sich an, einige Aspekte herauszugreifen, die im Anschluss an die vorliegende Studie und für zukünftige Forschung relevant sein können. Ich beschränke mich auf drei Punkte, die ich entlang der bekannten Aufteilung in Pragmatik, Semantik und Grammatik skizziere.

Erstens stellt sich auf Ebene der Pragmatik die Frage nach der Ausformung von Umgehungsstrategien außerhalb des von mir untersuchten Bereichs, wo ebenfalls Restriktivität, Verregelung und Kontrollmechanismen herrschen: Mechanismen zur Steuerhinterziehung, jene Abschalteinrichtungen der deutschen Autoindustrie zur Umgehung von Kontrolltests sowie politische Tarnmanöver zum Unterlaufen der Zensur innerhalb der Schreckensherrschaft des Nationalsozialismus' wurden neben anderen (siehe Fußnote 75) bereits genannt. Dass nicht das Urheberrecht im Sinne eines abstrakt for- 
malisierten Gesetzes auf das Sampling Einfluss nimmt, sondern die verknüpften Praktiken und daraus erwachsenen urheberrechtlichen Konfigurationen technischer Reproduzierbarkeit, ist eine Lehre, die auf andere gesellschaftliche Bereiche unter der Perspektive einer sozialwissenschaftlichen empirischen Urheberrechtsforschung angewendet werden kann. Auch in anderen Bereichen ist man auf die Verwendung von (digitalen) Kopien angewiesen, beispielsweise innerhalb des wissenschaftlichen Publizierens und Verlagswesens. Da der unkomplizierte Zugang zu Fachliteratur für Wissenschaftler_innen entscheidend ist, dieser von einigen Großverlagen aber mit sehr teuren Abonnements knapp gehalten wird, wurde von einer Vertreterin der wissenschaftlichen Gemeinschaft mit Sci-Hub eine Website zur effektiven Umgehung der Restriktionen entwickelt. Sci-Hub fungiert als akademische Schattenbibliothek und arbeitet wie ein Workaround auf institutioneller Ebene: Automatisch sucht die Website via Proxy einen passenden Zugang über eine Universitätsbibliothek heraus und kann damit nahezu jeglichen wissenschaftlichen Aufsatz binnen Sekunden bequem zur Verfügung stellen (Lawson 2017). Auch im schulischen Bereich ist es für viele Lehrer_innen notwendig, aufgrund der großen Rechtsunsicherheit und der urheberrechtlichen Restriktionen für Lernmaterialien, Umgehungsstrategien zu entwickeln oder auf Open Educational Resources (OER) umzusatteln (Heimstädt/ Dobusch 20I7).

Zweitens wäre auf der Ebene der Semantik eine rechtssoziologische Untersuchung der juristischen Praxis selbst und ihrer rhetorischen Muster reizvoll. So könnte gefragt werden, ob und in welchem Maße Umgehungskreativität bei der Rechtsprechung zum Einsatz kommt? Denn abstrahiert man das Recht als eine formalisierte Ansammlung von unterschiedlichen Regeln, Regelsystemen und Anwendungsregeln, liegt der Gedanke nahe, dass um manche Regeln herumgearbeitet werden muss, um erfolgreich zu sein. Denkbar wäre dies zum Beispiel bei der Interpretation von Paragraphen, der Auswahl von Fällen oder dem strategischen Einsatz von rhetorischen Figuren. Ganz konkret würde dafür auch die Entscheidung des Bundesgerichtshofs 
(2012) zum Thema Sampling in Frage kommen, in der ja geschickt das Leistungsschutzrecht von Kraftwerk über die urheberrechtlichen Maßgaben hinaus ausgedehnt wurde, um der eigentlich schutzunwürdigen Passage aus "Metall auf Metall« über einen Umweg doch zu Schutz verhelfen und dadurch dessen geringe Schöpfungshöhe zu umgehen.

Daneben ist im Hinblick auf semantische Aspekte eine genauere kunstsoziologische Untersuchung der Legitimierungs- und Delegitimierungsstrategien innerhalb und außerhalb des Kunstfelds Sampling wünschenswert, die in dieser Arbeit zwar teilweise angestrebt, zu Gunsten des Fokus' auf die Praxisebene aber nicht vollumfänglich durchgeführt wurde. So hat das Urteil des Bundesverfassungsgerichts (2016) die besonders restriktive Rechtsprechung des Bundesgerichtshofs gerügt und dadurch die Kunstfreiheit des Samplings prinzipiell bestätigt. Auch ist auffällig, dass sich samplingbasierte Genres immer stärker den Institutionen der Hochkultur annähern. Hip Hop und Techno werden heute in Museen ausgestellt und in klassischen Konzerthäusern mit Orchester aufgeführt. Akteure definieren sich als professionelle Musiker_innen und distinguieren sich bewusst von Amateur_innen, denen sie die Befähigung zur Kunst mitunter absprechen. Besonders Aufsehen erregend war zudem die Aktion der Rapformation Wu-Tang Clan, die 2015 ein Album als Unikat veröffentlichte, das für 2 Millionen Dollar versteigert wurde. Die Pointe dieser Aktion besteht in der rivalen Materialität des Tonträgers, die sonst nur bei hochpreisigen klassischen Kunstobjekten inszeniert wird, in Verbindung mit den kopierten Samples, die die Musik auf dem Tonträger enthält.

Auch in den r980er und r990er Jahren, als sich Sampling mehr und mehr ausdifferenzierte und Grundlage für eine reichhaltige musikalische Popkultur wurde, finden sich rhetorische Muster, mittels derer sich Akteure ihren Platz innerhalb des Kunstfelds sichern wollen oder erstreiten müssen. Konkret werden gerne Vergleiche mit etablierten Kunstgenres wie Malerei, klassischer Musik, Jazz, Poesie, der filmischen Montage oder der Collage bemüht. Auch zu anderen 
Bereichen, die als gesellschaftlich relevant wahrgenommen werden wie beispielsweise Bergbau, Goldgräberei oder Archäologie, Handwerk, Kochkunst oder Naturwissenschaft werden Parallelitäten herausgestellt. Die genannten rhetorischen Muster leben zum Teil bis heute in den Aussagen der Akteure fort und werden entsprechend reproduziert, um die besondere Qualität des Samplings nach außen zu verteidigen und dadurch Legitimität zu erwerben.

Man könnte auch sagen, dass sich Akteure illegitimer Künste etablierte und in der gesellschaftlichen Hierarchie höher stehende, legitime Künste oder Bereiche zum Vergleich suchen, um Schnittpunkte zu deren Praktiken zu finden, ihre Legitimität auf die eigene Praxis zu übertragen und sich dadurch an ihnen nach oben zu hangeln. Eine andere Auffälligkeit in diesem Zusammenhang sind die rigiden Regelsysteme, wie sie beispielsweise Schloss (2004) für Hip Hop oder Döhl (20I6) für Mashup beschrieben haben. Diese auffällig strengen Regelsetzungen lassen sich einerseits interpretieren als internen Ansporn, um die bereits vorliegenden, kanonisierten Stücke nicht zu wiederholen. Andererseits könnte dies auch als eine Art Legitimationsüberschuss betrachtet werden, um Sampling als komplexe Hochkunst auszuweisen, die sich vom beliebigen Kopieren und Abkupfern distanziert.

Drittens hat die Untersuchung der rechtlichen und ästhetischen Grammatiken der Kunstwelt des Samplings vor Augen geführt, wie relevant urheberrechtliche Mechanismen für die zeitgenössische kreative Kulturproduktion sind - und wie widersprüchlich der Neuheitsimperativ des Urheberrechts teilweise scheint: Einerseits soll er kreative Kunstproduktion anregen, andererseits zieht er eine scharfe Grenze um das absolute Neue und privilegiert autonomieästhetische Kunstformen gegenüber anderen (beispielsweise durch das Melodienprivileg, siehe Kapitel I). Das Fallbeispiel der Kunstwelt samplingbasierter Popmusik mit den vielfältigen Genres, internen Regelsetzungen, Neuheitsforderungen und inneren Widersprüchlichkeiten erwies sich dabei als kultureller Mikrokosmos, in dem Verständnisse von Autorschaft und Originalität besonders verdichtet zu Tage treten, gerade 
weil sie hochgradig problematisiert sind und unter dem Legitimierungsdruck eines bürgerlichen Kunstbegriffs stehen. Sampling führte das Problem der Neuheit an die Grenze der Entscheidbarkeit, denn aufgrund seiner starken Referentialität provoziert diese Praxis Fragen, wie Rezipient_innen Musik auf welche Weise, mit welchem sozialstrukturellen Hintergrund und mit welchen genrehaften Erwartungen hören. Dadurch wurde die Frage nach der Neuheit hinunter bis auf die granulare Ebene des Klangs und kleinster Tonfetzen getragen.

Dass das Bundesverfassungsgericht 2016 auf die jahrzehntelange Verschärfung der urheberrechtlichen Grammatik bezüglich Sampling und anderer referentieller Verfahren reagierte und dabei die internen genrehaften Anforderungen für die Neuheitsproduktion als Kriterium zur Berücksichtigung einforderte, kann als Ausdruck für eine Irritation des Rechtssystems durch das Kunstsystem gedeutet werden. Um diesen Aspekt auch in der Zukunft über das Urteil des Bundesverfassungsgerichts hinaus weiter zu verfolgen, wären weitere Untersuchungen angebracht. So könnte aus dezidiert systemtheoretischer Perspektive nach dem aktuellen Verhältnis von Kunst und Recht gefragt werden. Die ästhetische Irritation des Rechts, die in den kommenden Jahrzehnten aufgrund steigender technischer Reproduzierbarkeit weiterhin relevant sein wird, könnte dabei als eigener Aspekt vertieft werden.

Schließlich hat die Arbeit am Beispiel des Samplings die Verflechtungen des musikindustriellen Komplexes angedeutet. Dieser besteht aus interdependent verwobenenen Organisationen wie Verlagen, Labels, Tonträgerherstellern, Verbänden, Distributoren, Agenturen, Streamingplattformen, Verwertungsgesellschaften und weiteren Organisationen unterschiedlicher Größe, in denen die Verwertung und Lizenzierung von werkbezogenen Rechten einen zentralen gemeinsamen Punkt bedeutet. Im Rahmen dieser Studie ließ sich erkennen, welchen Einfluss sich insbesondere Verwertungsgesellschaften in der Historie der Musikindustrie sichern konnten, insofern diese werkgenaue Abrechnungen bereitstellen und dadurch auch definitorische 
Deutungsmacht beispielsweise über Werke, Kreativität oder Autorschaft ausüben.

Verwertungsgesellschaften wie GEMA oder GVL bieten also einen vielversprechenden Ansatzpunkt, um die grammatischen, ja geradezu infrastrukturellen Verwertungsgefüge der Musik- oder Unterhaltungsindustrie genauer empirisch zu erforschen. Von den Sozialwissenschaften wurden Verwertungsgesellschaften als empirisches Phänomen jedoch nahezu komplett ignoriert; bis dato sind sie vor allem rechtswissenschaftlich oder unter ökonomischen Motiven untersucht worden. Aus soziologischer Perspektive erscheinen die organisatorische Geschlossenheit und die teilweise intrasnparenten Praktiken hinsichtlich Verrechnungsschlüsseln oder Abrechnungsmodalitäten besonders bemerkenswert. Eine empirisch orientierte Urheberrechtsforschung, die Verwertungsgesellschaften beispielsweise unter dem Gesichtspunkt von Offenheit und Geschlossenheit untersucht, könnte hier einen relevanten Diskussionsbeitrag leisten und ein neues akademisches Feld erschließen, das weit über den Bereich der Musik hinausreicht. 

ANHANG 



\section{A Methodischer Anhang}

\section{A.1 Reflexion der eigenen Feldposition}

Zur Reflexion meiner eigenen Rolle als Soziologe im Forschungsprozess und der damit verbundenen Subjektivität folge ich dem Beispiel Kühns fokussierter Ethnografie zu Musikproduzent_innen im Bereich elektronischer Tanzmusik (Kühn 20I6). Bevor ich im Sommer 2014 mit den ersten Kontaktanbahnungen zur Durchführung der fokussierten Ethnografien begann, verfasste ich eine erste Version dieser Reflexion, um mir selbst gegenüber meine auf das Urheberrecht bezogenen Vorannahmen und stillen Hypothesen sowie mein bereits vorhandenes Wissen als weißer, männlicher Feldakteur mit bildungsbürgerlichem Hintergrund klar zu machen und in der Analyse zu reflektieren. Dafür erschien es mir notwendig, meinen persönlichen Werdegang und meine Position im Feld zu verschriftlichen.

\section{A.1.1 Ästhetische Affizierung}

Zwischen 1999 und 2005 kam ich als Jugendlicher in meinem Heimatort das erste Mal in Kontakt mit Hip Hop, als ich mit Schulkameraden CDs tauschte. Durch diese Tauschgeschäfte auf dem Schulhof entdeckte ich zahlreiche weitere neue musikalische Stücke und Stile, die mir, weil ich vor allem Formatradio und die klassische Musik meiner Eltern gewohnt war, eine neue musikalische Welt aufschlossen. Oftmals waren es die Eltern oder die älteren Geschwister meiner Schulkamerad_innen, die im Besitz von interessanten, vom 
bekannten Radioprogramm abweichenden CDs waren und deren Sammlungen ich bei Besuchen durchstöbern durfte. In dieser Altersperiode von etwa 13 bis 18 Jahren lernte ich neben Hip Hop auch andere samplingbasierte Stile wie House oder Drum'n'Bass kennen, konsumierte aber auch viel Rock, Punk, Grunge sowie die Popmusik auf Musikfernsehsendern wie MTV oder VIVA. Das Hören, Tauschen, Besitzen, Kaufen und Diskutieren von Musik war zu dieser Zeit eine wichtige soziale Tätigkeit, wenn auch eine von mehreren, die ich neben anderen Hobbies wie Fußball oder Skateboarding zum Zeitvertreib betrieb. Durch den Konsum bestimmter Stile ließen sich zudem Zugehörigkeiten zu bestimmten Szenen, Freundeskreisen und peer groups zeigen, die sich in meinem Falle innerhalb weniger Jahre abwechselten.

Auch das Zusammenstellen von Mixtapes für Freund_innen war zu dieser Zeit eine beliebte Praxis, die sich mit dem Aufkommen erster CD-Brenner und dem Anschluss an das Internet digitalisierte und dadurch entscheidend erweiterte. Da ich mir von meinem eigenen Geld nicht so viele CDs leisten konnte, wie ich wollte, und das Kaufen von Musik gewissermaßen ein Glücksspiel war, wandte ich mich stärker Internet-Tauschbörsen und gebrannten CDs zu. Trotz - oder wegen - der Illegalität dieser Praktiken war ich von der Auswahl und den Möglichkeiten fasziniert, die sich in mehreren Hinsichten für mich durch das vernetzte Kopieren von $\mathrm{MP}_{3}$ s erschlossen. In musikalischer Hinsicht als Konsument und Kunde wurde der Kauf eines Albums oder einer Compilation auf CD schnell uninteressant für mich, da ich in der Situation im Laden nie genau einschätzen konnte, ob ich wirklich die Mehrzahl der Lieder auf der CD mochte und sich die Investition lohnte. Bei den Tauschbörsen hingegen war der Konsum komfortabel: Ich lud ganze Alben herunter und wenn mir Lieder nicht gefielen, löschte ich sie einfach wieder.

Gleichzeitig entstand durch die P2P-Vernetzung in den Tauschbörsen für mich das Gefühl, eine Welt kennen zu lernen, die weit über die Grenzen meiner Heimstadt reichte und die mir anderweitig verborgen bleiben würde. Aufgrund der Zeitverschiebung zwischen Europa 
und Amerika fand ich es reizvoll, mich ab dem Nachmittag bis spät in die Nacht in Tauschbörsen wie Soulseek herumzutreiben. Soulseek bot damals die Möglichkeit, die freigegebenen Ordner der anderen Nutzer_innen gezielt zu durchsuchen und serendipisch zu durchstreifen. Manche Nutzer_innen sortierten ihre, oftmals illegal erworbene Musiksammlung, nach Genres, Gehört/Nicht-Gehört oder anderen Kriterien, manche boten sogar Ordner mit ihren eigenen Empfehlungen an. Auch gab es durch eine Chatfunktion die Möglichkeit, mit den Leuten ins Gespräch zu kommen. Trotz gewisser Sprachbarrieren lernte ich durch diese Empfehlungskanäle immer mehr Musik kennen und baute fortlaufend Wissen in diesem Bereich auf. Auch Remixes spielten hierbei eine Rolle, da ich im Schneeballverfahren dutzende geremixte und remixende Künstler_innen entdeckte, die Originale mit den Versionen verglich und so herausfand, wie unterschiedlich sich musikalische Materialien interpretieren lassen.

Nach und nach internalisierte ich die Regeln des musikalischen Felds der Popmusik, wodurch sich mein Musikgeschmack formte und ich mehr und mehr in die Lage kam, in Gesprächen differenzierte Urteile über Musikstücke abzugeben. Jahre bevor Youtube oder Spotify die Musikindustrie durch algorithmische Empfehlungssysteme umkrempelten, hatte ich innerhalb der illegalen Sphäre des $\mathrm{MP}_{3}$-Tauschens mehrere tausend Musikstücke gehört, gesammelt und sortiert, unzählige CDs gebrannt und diese in meinem Freundeskreis verteilt. Es brachte mir Freude und Bestätigung, eigens zusammengestellte Mix-CDs an Freunde und insbesondere Freundinnen zu verteilen, da ich versuchte, sie zu auf diese Weise mit meinem Geschmack und meinem Wissen über Popmusik zu beeindrucken. Lob und die Bestellung neuer CDs bedeuteten mir sehr viel, schon leise Kritik oder Desinteresse traf mich hart. Ich identifizierte mich zunehmend mit der Musik, die ich hörte und über die ich verfügen konnte; andere Hobbies traten in den Hintergrund oder ich gab sie vollständig auf.

Zusammen mit einem Freund veranstaltete ich mit 17 Jahren das erste Mal eine eigene Party im örtlichen Jugendzentrum. Als DJs selektierten und mischten wir die Musik für das Publikum, das im 
Grunde nur aus den fünf oder sechs treuen Freund_innen bestand, die auf unsere Party kamen. Ein wirklicher, großer Erfolg war die erste Party also nicht, aber eine örtliche Kneipe stellte uns wenig später als Resident $D J s$ an, sobald wir volljährig geworden waren. Für etwa zwei Jahre bespielten wir nahezu wöchentlich diese Lokalität, erhielten geringe Gagen und kauften uns davon CD-Player und einen Mixer, die für DJs konzipiert waren. Mit diesen technischen Mitteln ausgestattet konnten wir unsere Mixes verfeinern, indem wir die Geschwindigkeiten der einzelnen Stücke manipulierten und aneinander anglichen. Von nun galt es, nicht mehr nur die richtigen Stücke in der richtigen Folge aneinanderzureihen, sondern auch die Übergänge zwischen den Stücken richtig, das heißt möglichst sauber und kunstvoll zu gestalten, dass daraus ein kontinuierlicher musikalischer Fluss entstand. Von dieser Tätigkeit des Zusammenmischens von eigentlich Unverbundenem und den dadurch entstehenden unerwarteten, aber ästhetisch reizvollen Effekten war ich teilweise stundenlang gefesselt und übte zuhause - oftmals zum Leidwesen meiner Eltern, die mich lieber bei der Vorbereitung auf mein Abitur gesehen hätten.

Nach dem Abitur nahm ich ein Magisterstudium der Soziologie, Philosophie und Politikwissenschaft an der Universität Augsburg auf, für das ich mich aufgrund des Ethikunterrichts in der Schule entschieden hatte. Im Ethikunterricht wurden grundlegende Themen wie Sozialstruktur oder das Demokratische System der BRD vermittelt, aber auch psychologische, politische und rechtliche Probleme, die ich zu diesem Zeitpunkt spannend und anregend fand. Nach dem Umzug in das studentische Milieu in Augsburg suchte ich Anschluss an die dortige Musikszene, was sich aber als recht schwierig herausstellte, da die jeweiligen Clubs ihre eigenen DJs hatten, die ihre Abende nicht abgeben oder teilen wollten.

Gleichzeitig organisierte ich zusammen mit Freund_innen weitere eigene Partys in einer clubähnlichen Lokalität in meinem Heimatort, für die auch eigene Flyer und damit Konzepte für den Ablauf des Abends erstellt wurden. Teilweise waren diese Partys mit etwa 250 Gästen sehr gut besucht und brachten uns einen bemerkenswerten 
Gewinn ein, teilweise waren sie auch ein Minusgeschäft. Als DJs verstanden wir uns zu dieser Zeit zugehörig zum lokalen Showgeschäft, die ein gutes Set auf die Bühne bringen und die Gäste auf der Tanzfläche unterhalten sollten. Auch der Zugang zu der metaphorischen Hinterbühne der Kneipen und Clubs, zu Hinterzimmer und Küche, wo die »Deals« ausgehandelt und die Gagen ausbezahlt wurden, faszinierte und distinguierte uns von anderen, plötzlich als eher bürgerlich wahrgenommenen Freund_innen, die das Nachtleben nur von der Tanzfläche aus kannten. Plätze auf Gästelisten und der Zugang hinter das DJ-Pult wurden zu Währungen, die meine soziale Stellung innerhalb meines Freundeskreises beeinflussten. Das Ausgehen wurde für mich zu einem wichtigen Teil meines Lebensstils und mit diesem verbunden war der regelmäßige Besuch von Clubs, Partys und Konzerten mit lauter Musik auf vollen Tanzflächen.

Die CD-Player tauschten mein Freund und ich gegen Plattenspieler ein, da sich damit die Stücke präziser ineinander mischen ließen. Zudem versprachen die Plattenspieler einen Zugewinn an kulturellem Kapital, da wir bemerkt hatten, dass »richtige« DJs mit Vinyl auflegten und dies als Alleinstellungsmerkmal pflegten. Verbunden mit diesem technischen Umstieg war auch eine Veränderung in musikalischer Hinsicht: War es zu Beginn des Auflegens noch eine bunte Mischung an verschiedenen musikalischen Stilen wie Hip Hop, House, Rock oder Funk, musste ich nun abwägen, wie ich mein ökonomisches Kapital für den Ankauf der relativ teuren Schallplatten ausgab. Alle Stile zu bedienen war finanziell nicht möglich.

Während der kommenden Jahre interessierte ich mich vor allem für das britische Genre der NuSkool Breaks sowie wie für House. Einerseits ließen sich die Stücke dieses Genres aufgrund ihrer strukturellen Gleichförmigkeit relativ gut ineinander mischen, andererseits war vor allem die Breaks-Szene zu dieser Zeit zwischen 2005 und 2007 in München und Augsburg aktiv. Zuhause an den Plattenspielern nahm ich eine Reihe von DJ-Sets auf, stellte sie ins Internet oder verteilte sie auf Partys auf selbstgebrannten CDs. In dem Internetforum themixingbowl.org, in dem Aufnahmen von Radiosendun- 
gen, Mitschnitten von Konzerten und zahlreiche DJ-Sets kursierten, wurde einer meiner Mixe mit einem Preis ausgezeichnet, was mir zusätzlichen Auftrieb verschaffte. Durch Auswahl und Arrangement der Stücke hatte ich eine Möglichkeit gefunden, mich künstlerisch ausdrücken zu können, und wenn diese Form des Ausdrucks auch das Publikum auf der Tanzfläche affizierte und sich damit kollektiv steigerte, empfand ich ein großartiges Gefühl der Anerkennung und Bestätigung. Dieses rauschhafte Gefühl beim Auflegen, die Tanzfläche ästhetisch zu affizieren und dadurch zeitgleich eine ganz konkrete, positive Rückmeldung für meinen eigenen Musikgeschmack zu erhalten, war für viele Jahre lang ein wichtiger Antrieb für mich.

Neben dem Auflegen versuchte ich mich sporadisch auch in der Produktion eigener Stücke, wobei mir allerdings meine eigene Ungeduld im Weg stand. Über wenige Mashups und hörspielartige Zusammenstellungen, die ich an illegal besorgter Software zusammenbastelte, gelangte ich im Bereich der Musikproduktion als selbstständiger Künstler bis heute nicht hinaus. Die Zutaten - Instrumental- und Gesangsspuren bekannter Popsongs - lud ich mir gleichfalls in Tauschbörsen herunter, teilweise in von anderen Nutzer_innen eigens dafür geschnürten Paketen.

Trotz meines mangelnden Talents in der Musikproduktion fand ich die Effekte faszinierend, die sich durch das Sampling eines Stückes ergaben: In der einen Richtung konnte durch das Herauslösen einer bestimmten Passage eine musikalische Momentaufnahme gewonnen werden, die durch weitere Manipulation neue klangliche und ästhetische Facetten freigab. In der anderen Richtung rief es enorme Aufmerksamkeit in mir hervor, wenn ich das Originalsample eines bestimmten Stücks erkannte und damit seinen ursprünglichen musikalischen Kontext enthüllte. Beides, das Nach-vorne- wie auch das $\mathrm{Zu}$ rück-Entdecken, wurde zu einer beliebten Beschäftigung von mir, der ich über den extensiven Konsum von DJ-Sets, Mashups und anderer samplingbasierter Musik nachging. Damit einhergehend frequentierte ich zunehmend Blogs, Foren und später auch Datenbanken wie who sampled.com, zu denen ich manchmal auch eigene Beiträge leistete. 


\section{A.1.2 Musik und Wissenschaft}

In den ersten Jahren nach meinem Umzug nach Berlin 2007 war ich regelrecht überwältigt vom Nachtleben und dem damit verbundenen musikalischen Angebot. In Bayern waren es vor allem Hip Hop-, House- und Breakbeat-Partys gewesen, auf die ich gehen konnte - in Berlin gab es für nahezu jeden Stil eine eigene oder sogar mehrere Party-Reihen, die regelmäßig am Wochenende und unter der Woche in den zahllosen Lokalitäten angeboten wurden: Drum'n'Bass, Deep House, Tech House, Techno, Dubstep, Garage, 2step, Bassmusic, Goa, Trance, Funk, Soul, Jazz und nahezu jede erdenkliche Mischform dieser Musikgenres, die ich bisher vorwiegend von meinen $\mathrm{MP}_{3}$ kannte, standen nun zur Entdeckung bereit, wenngleich ich wegen der viel härteren Einlasspolitik nicht in alle Clubs Eintritt fand und dies - als großer Musikfan, für den ich mich hielt - freilich sehr ungerecht fand. Zusammen mit Freund_innen, die ich im Studium kennenlernte, organisierten wir ab etwa 2009 kleinere wie größere Partys, zu denen wir DJs einluden und von diesen bald auch auf deren Partys gebucht wurden.

Neben der Partyszene war Berlin aber auch in akademischer und journalistischer Hinsicht für mich erfrischend. Mein Soziologiestudium an der TU Berlin mit der Vertiefung auf wissenschaftlich-technische Aspekte ließ mir die Freiheit, einige Kurse in »Popular Music Studies" an der HU Berlin zu besuchen und dort mein Wissen über Popmusik theoretisch und historisch zu vertiefen. Um 2010 begann ich mein Blog "Jäger und Sampler" und fing an, regelmäßig musikjournalistisch für verschiedene Radio- und Textmedien zu arbeiten. Hauptsächlich produzierte ich Interviews, Rezensionen für aktuelle Musik- und Bucherscheinungen und eigene Beiträge innerhalb meiner eigenen Radioshow, für die ich auch andere DJs und Produzent_innen einlud. Meine Rezensionen schickte ich bisweilen an die Musiker_innen selbst. Viele Male erhielt ich Antworten mit Dank und der Bemerkung zurück, dass ich das Musikalische sehr gut in Worte gekleidet hatte. Mit der Attestierung dieser Fähigkeit 
kamen oft auch Anfragen, Promotexte für weitere Releases zu verfassen, denen ich in manchen Fällen nachkam, insofern mich die Musik affizierte.

Über die verschiedenen Aktivitäten gewöhnte ich mir einerseits den spezifischen Szenesprech und Habitus an, andererseits lernte ich weitere Feldakteure kennen, die mich mit Promoversionen ihrer Musik, Gästelistenplätzen und Bitten um Ankündigungstexte für ihre eigenen Partys bedachten. Durch dieses Spiel gegenseitiger Gefälligkeiten konnte ich über ein paar Jahre hinweg mein Netzwerk kontinuierlich ausbauen, Kontakte sammeln und mein subkulturelles Kapital erhöhen. Alles in allem würde ich meine Involvierung in das Feld trotzdem eher als peripher denn als zentral und etabliert bezeichnen, da ich den Sprung in die Erwerbsorientierung nicht vollzog. Als DJ, Journalist und Partyveranstalter hatte ich innerhalb der heftig umkämpften Berliner Szene eine Außenseiterposition mit zwar regelmäßigen, aber finanziell wenig einträglichen Jobs. Die Auftragslage war ordentlich, die Bezahlung war es hingegen nicht. Es reichte nicht für meinen Lebensunterhalt und ich war nicht bereit, die notwendigen Positionskämpfe in der von wirtschaftlichen Strukturen durchdrungenen und durch soziale Geschlossenheit charakterisierten Szene auf mich zu nehmen. Da ich die Aktivitäten mehr als ernsthaftes Hobby sowie als Zusammenarbeit mit Freund_innen verstand, waren die erfahrene Anerkennung und situative Freude bei meinen DJ-Sets für viele Jahre als Antrieb ausreichend und die Überführung in ökonomisches Kapital nicht vordergründig. Ich denke, dass die Internalisierung und Performanz dieses Ethos' genauso Ausdruck meiner Szenezugehörigkeit sind wie die ästhetischen Urteile, die ich beim Zusammenstellen meiner DJ-Sets und Radiosendungen zu fällen lernte.

2008 nahm ich neben dem Studium eine Hilfskraftstelle am Max-Planck-Institut für Wissenschaftsgeschichte an, ab 2012 war ich dann am Graduiertenkolleg "Innovationsgesellschaft heute» der TU Berlin beschäftigt. Die an diesen Orten behandelten Texte und Fragestellungen inspirierten mich dazu, mein Wissen über Musik 
mit sozialwissenschaftlichen Theorien zu Kreativität, Innovation und Neuheit zu verbinden. Auf diese Weise ließen sich für mich der analytische Blick aus der Soziologie, das auf Referenzen basierende journalistische und akademische Schreiben sowie das internalisierte Wissen aus der Musikwelt zusammen bringen. Auch reizte es mich, das im Medium der Musik Transportierte sprachlich zum Ausdruck bringen und dadurch mit weiterer Bedeutung versehen zu können. Im Gegensatz zu der von mir als sehr intuitiv erlebten Tätigkeit des Auflegens war der Schreibprozess an sich meist schwierig und langwierig. Das Ergebnis erfüllte mich oft genug aber mit Zufriedenheit und versöhnte mich, was bei der Musikproduktion am Computer so nicht der Fall war. Es freute mich, dass der Schreibprozess über Musik informiert war durch das Machen von Musik als DJ und damit in gewisser Weise selbst ein künstlerischer Vorgang der Selektion und Aneinanderreihung der richtigen Inhalte war. Daneben brachte mich die soziologische Theorielektüre aber auch auf Distanz zu meinem Hobby, da ich die immanenten Logiken der Szene, die ich selbst teils ablehnte und doch reproduzierte, deutlicher erkannte als durch das bloße interne Wissen, das ich mir als Feldakteur angeeignet hatte.

Meine Sympathie für das Sampling fand ihre akademische Entsprechung schließlich in der 2013 abgegebenen Diplomarbeit, die gleichzeitig das Ende meines Studiums markierte. Am Ende dieser Arbeit, die die Geschichte des Samplings aus einer soziologischen Perspektive heraus untersuchte, erkannte ich das zunehmende Eindringen urheberrechtlicher Praktiken in die Musikwelt ab den I990er Jahren. Dieser Aspekt forderte mich heraus und regte mich zum kritischen Denken an, da ich es spannend fand, die Welt des Samplings aus einer externen, fremden und gewissermaßen bürokratisch-rechtlichen Perspektive zu sehen, die mit der von mir erfahrenden Lebendigkeit und Kreativität der ästhetischen Praktiken irgendwie in Widerspruch stand. Dieses "Irgendwie« war anfangs sehr diffus für mich und blieb es auch nach einiger Literaturrecherche noch, so dass ich beschloss, diesen Aspekt in der Diplomarbeit lediglich zu streifen, da ich keine gefestigte Position dazu entwickeln konnte. Ich nahm mir vor, das 
Themenfeld Urheberrecht und Kreativität in der Musikproduktion später in einer Dissertation mit empirischem Fokus zu bearbeiten.

$\mathrm{Ab} 2 \mathrm{OI} 3$ war ich nach der Anfrage von Leonhard Dobusch zudem stärker in die Arbeit der Initiative "Recht auf Remix" des Digitale Gesellschaft e. V. eingebunden, die sich nach dem hoch restriktiven Samplingurteil des Bundesgerichtshofs 2012 formiert hatte und das politische Ziel verfolgte, die Kulturpraxis des Remixings "als zentrale Ausdrucksform einer digitalen Gesellschaft «77 aus der urheberrechtlichen Illegalität zu hieven. Um den aufgestellten Forderungen Gewicht zu verleihen, sollten die ästhetischen Errungenschaften des Remixings und Samplings kulturhistorisch in einem Online-Museum präsentiert werden. Demgegenüber wurden die urheberrechtlichen Entwicklungen der vergangenen Jahre kritisch und distanziert erläutert, beispielsweise in Anlehnung an Lawrence Lessig und in der Sichtbarmachung der Vorteile der US-amerikanischen urheberrechtlichen Konfiguration Fair Use. Ich trug zur Initiative vor allem durch das Verfassen von Texten, das Einholen von Interviews mit Musiker_innen und meine Beteiligung in der Öffentlichkeitsarbeit bei. Im Rahmen dieser Tätigkeiten besprach ich mit Leonhard Dobusch, der zu dieser Zeit als Professor für Organisationstheorie an der FU Berlin arbeitete, kontinuierlich auch mein akademisches Forschungsinteresse und erarbeitete ein Exposé, das ich 2014 erfolglos bei einigen Stiftungen und wissenschaftlichen Institutionen einreichte. Anfang 20I5 wurde ich schließlich im Graduiertenkolleg »Innovationsgesellschaft heute " an der TU Berlin als Stipendiat angenommen, dem ich während der Erarbeitung der Dissertation bis 2018 angehörte.

Zur Festlegung des Forschungsgegenstands, der Methode und der grundlegenden theoretischen Perspektive benötigte ich etwa ein Jahr, wobei ich dabei kein lineares, sondern ein iteratives Vorgehen mit rekursiven Schleifen des Erkenntnisgewinns verfolgte. Diese grundlegende Iterativität zeigte sich auch in der Entwicklung der Forschungsfrage, insofern sie stets von der Pendelbewegung aus theo-

77 Siehe https://rechtaufremix.org/\#OI-manifest (2I.II.2OI7). 
retischen wie empirischen Erkenntnissen sowie den Diskussionen im Graduiertenkolleg, mit meinem Betreuer Michael Hutter und auf wissenschaftlichen Konferenzen geleitet wurde. Zwischen 2014 und 2018 besuchte ich zahlreiche Konferenzen, Workshops und Tagungen mit sozialwissenschaftlichen, juristischen und musikwissenschaftlichen Bezügen, auf denen ich mein Forschungsdesign, vorläufige Ergebnisse und theoretische Ansatzpunkte zur Diskussion stellte. Daneben fuhr ich meine musikjournalistischen Engagements zurück und wandte mich mehr dem Schreiben von journalistischen Texte für iRights.info, Informationsplattform und Online-Magazin für »Urheberrecht und kreatives Schaffen in der digitalen Welt « ${ }^{78}$, zu.

Aus der Gesamtheit dieser Aktivitäten entwickelte sich ein akademisches Netzwerk, dessen Institutionalisierung ich mit der Gründung des interdisziplinären Fachausschusses »Urheberrecht« in der Gesellschaft für Musikwirtschafts- und Musikkulturforschung (GMM) 2015 mit vorantrieb. Die regelmäßigen, vier Mal pro Jahr stattfindenden Treffen des Ausschusses gaben mir seitdem die Möglichkeit, den Fortschritt meiner Arbeit mit Fachkolleg_innen zu besprechen und mein Forschungsinteresse in quasi spiralförmigem Zugriff immer näher einzukreisen. Gleichzeitig zwangen mich diese Gespräche wie auch die Diskussionen im Graduiertenkolleg dazu, meine eigene Rolle im Forschungsprozess immer wieder auf's Neue zu hinterfragen und die Relevanz meiner Erkenntnisse zu überprüfen, da ich auf differente Lesarten und blinde Flecken aufmerksam wurde. Das Hineinwachsen in das akademische Feld der empirischen Urheberrechtsforschung mit interdisziplinären Bezügen brachte es mit sich, endonyme Begriffe und subjektive Annahmen empirisch zu belegen und in argumentative Züge und Beobachtungsbegriffe einzugliedern, deren Konsistenz in meiner eigenen Wahrnehmung in der Regel zuerst problemfrei erschien - nicht zwingend aber in der Wahrnehmung anderer.

78 Siehe https://irights.info/ (22.II.2017). 


\section{A.1.3 Verschiebungen}

In den Feldnotizen, die ich zur emotionalen und intellektuellen Selbstbeobachtung zwischen 2014 und 2017 anfertigte, zeichneten sich weitere Verschiebungen und auch Probleme ab. In der wissenschaftlichen Erkenntnisproduktion stellten sich beispielsweise Situationen der Klemme oder Überforderung ein. Diese erwiesen sich in der Reflexion oftmals als sehr fruchtbar, da ich meine eigenen Erwartungen durch gestörte Abläufe besser einfangen und die dahinter liegende Subjektivität deutlich besser einordnen konnte, als wenn alles glatt gelaufen wäre. Bisweilen war es zudem für mich schwierig, zwischen den jeweiligen Feldern meine eigene Position genau zu bestimmen, da ich mich zu einigen Zeitpunkten hin- und hergerissen fühlte. Dieses "Sitzen zwischen den Stühlen« erkannte ich auf mehreren Ebenen: Die eklektische und postmodern anmutende anything goes-Mentalität aus der Samplingwelt ließ sich nicht ohne Weiteres auf wissenschaftliche Erkenntnisproduktion übertragen, da ich den Verlust der Bezüge zwar als ästhetisch unproblematisch oder sogar gewünscht, in der Academia aber als tendenziell verpönt erlebte. In den rechtswissenschaftlichen Abhandlungen, die ich konsultierte, empfand ich die Darstellung von Samplingpraktiken oft unterkomplex und empirisch schlecht informiert; in den sozialwissenschaftlich orientierten Untersuchungen hingegen wirkte das Rechtliche hingegen oftmals einseitig und unausgewogen, wenngleich das methodische und theoretische Werkzeug eigentlich vorhanden war. Im ethnografischen Erhebungsprozess erkannte ich zudem, dass dem geordneten und methodisch geleiteten Vorgehen aus der Wissenschaft die von mir als eher chaotisch empfundene Lebenswelt der Musiker_innen entgegenstand, die sich nicht so zuverlässig, pünktlich und berechenbar verhielten, wie ich das am Schreibtisch vermutet hatte.

Mein früheres Partypensum mit seinen hedonistischen Elementen und den langen Erholungsphasen konnte ich nicht auf Dauer mit ernsthafter akademischer Erwerbsarbeit vereinbaren. Auch langweilten mich mit zunehmender Intellektualisierung die Partygespräche 
und strengten mich in den lauten Clubs an. Zwar genoss ich nach wie vor das egalitäre Erlebnis auf abgedunkelten Tanzflächen, auf denen es nicht so wichtig war, wer man »draußen« war, welche Kleidung man trug und was man in der bürgerlichen Welt verkörperte, sondern wie sich der Moment gestaltete und wie ich mich durch das Tanzen in Bezug zur Musik selbst ausdrücken konnte. Doch während mich für viele Jahre die ästhetischen Erlebnisse auf der Tanzfläche mit ihren gewohnt-überraschenden Neuheiten gelockt hatten, erweiterte sich mein ästhetisches Interesse an Neuheit schleichend in andere Bereiche wie Architektur, Stadtplanung, Jazz, Fotografie, Literatur oder Sport. Das Besondere, das ich in den Clubs gesucht hatte, fand ich interessanterweise auch im zuvor als profan Abgetanen, wenngleich nicht mit der gleichen durchschlagenden Qualität und Intensität. Auch bemerkte ich, dass meine Zugehörigkeit zur Szene nicht organisch als freiwilliges Hobby per se existierte, sondern ich mir die Aufrechterhaltung dieses Status' erarbeiten musste. "Gesichtsmassage", das "sich Blicken lassen" auf anderen Partys und in Plattenläden war auf meiner Ebene in der erbarmungslosen DJ-Hierarchie der Berliner Szene notwendig, nach einigen Jahren verbanden sich solche Besuche aber mehr mit einem Gefühl der Verpflichtung oder notwendigen Gefälligkeit, das ich als Widerspruch zur Freiwilligkeit und Hobbyhaftigkeit meines Tun interpretierte.

Als DJ und Partybesucher zog ich mich mit den Jahren aus der Berliner Clubkultur zurück. Während ich sukzessive das Interesse an der performativen Seite samplingbasierter Musik verlor, fokussierte und schärfte sich mein Blick für die Hinterbühne, auf der sie produziert und verwertet wurde. Bevor ich mit der Durchführung der fokussierten Ethnografien begann, verfasste ich eine erste Version dieser Reflexion, um meine auf das Urheberrecht bezogenen Vorannahmen und stillen Hypothesen sowie mein bereits vorhandenes Wissen als Feldakteur mir selbst gegenüber öffentlich zu machen. Auf diese Weise kamen die feldspezifischen, gewissermaßen kulturpessimistischen Vorannahmen und meine Skepsis gegenüber den urheberrechtlichen Restriktionen zum Vorschein. Erstens vertrat ich das Ar- 
gument von der ästhetischen Deformation, die das Urheberrecht an samplingbasierter Musik anrichte. Zweitens sah ich daran geknüpft das Urheberrecht vorwiegend als Bedrohung von Kreativität und als Verhinderungsfaktor von samplingbasierter Musik durch Lizenznotwendigkeiten. Dieser Blick wurde maßgeblich durch meinen Konsum von Interviews, Dokumentation und der kritischen Forschungsliteratur sowie natürlich durch die politische Arbeit mit "Recht auf Remix « bestimmt, in der ich das Echo dieses Narrativs vernahm. Daher notierte ich während der etwa 50 über "Recht auf Remix« veröffentlichten Interviews mit Kulturproduzent_innen den Verdacht, dass die sich wiederholenden Aussagen der Interviewees nicht einfach als detaillierte Beschreibungen ihres Alltags, sondern zusätzlich als strategische Diskurspositionen gefasst werden müssen. Die Eigendynamik der Interviewsituation mit standardisierten Fragen und die öffentlich einsehbaren Antworten bisheriger Interviews nährten drittens meine Skepsis hinsichtlich sozialer Erwünschtheit und führten zusammen mit der ethnografischen Forschungsliteratur zu der wissenschaftlichen Einsicht, die gegebenen Statements in Zusammenhang mit dem Alltag und den darin ablaufenden Praktiken der samplingbasierten Musikproduktion triangulativ erfassen zu müssen.

Um diese Kluft zwischen Pragmatik und Semantik zu nutzen, schrieb ich extensive Feldnotizen und verdichtete sie zu analytischen Memos. Das Schreiben dieser Texte empfand ich dabei anfangs als mühsam und manchmal sinnlos. Nach ein paar Monaten allerdings, in denen das Schreiben mehr zur Routine geworden war, lockerte es sich zu einer zwar Kraft raubenden, aber auch klärenden Tätigkeit mit therapeutischen Zügen. Ich begann, meine eigene Subjektivität nicht als zu exkludierenden, weil störenden Faktor zu sehen, sondern als wertvolle Ressource, an der entlang ich Überlegungen zum Zustand des beschriebenen Feldausschnitts entwickeln konnte. Das Schreiben führte mir abermals vor, dass ich mein selbst Erlebtes möglichst präzise beschreiben und "treffen« musste, damit es sich im intersubjektiven Prozess gegenüber den Leser_innen bewährte. Auf der anderen Seite klärten sich durch das Schreiben der Feldnotizen 
und durch das Verdichten hin zu analytischen Memos mit eigenen Begrifflichkeiten auch einige Punkte, da ich mir bisher unbemerkter Zusammenhänge und Widersprüche, verschiedener semantischer Bedeutungen eines Wortes, verschleiernder Metaphern und sich wiederholender Formulierungen besser bewusst wurde.

Meine empirisch fundierten Thesen entwickelte ich nicht alleine in der stillen Kammer, sondern bewusst in diskursiver Auseinandersetzung mit Kolleg_innen, vorliegenden Theorien und Studien sowie im komparativen Zugriff auf Parallelphänomene technischer Reproduzierbarkeit und andere Rechtsräume. Durch meinen Auslandsaufenthalt an der Queensland University of Technology in Brisbane konnte ich meine Beobachtungen mit den Kolleg_innen vom Intellectual Property Law and Innovation Center, die einen ähnlich empirischen Ansatz bei ihrer Forschung zu "Creators and Copyrights" verfolgten, intensiv besprechen, durchdenken und mich austauschen. Gleiches gilt für die Arbeit der Siegener Kolleg_innen, die sich empirisch mit den urheberrechtlichen Bedingungen bei der fan fiction auseinandersetzen. Dass sich urheberrechtliche Verwicklungen auch bei anderen Formen technischer Reproduzierbarkeit einstellen, wurde mir zudem durch die Beschäftigung mit Internet-Memes (Fischer/ Grünewald-Schukalla 20I8) vor Augen geführt. Indem ich kontinuierlich die Spezifika bereichsfremder Zitier- und Rekontextualisierungspraktiken aus der Wissenschaft, dem Journalismus und anderen Künsten untersuchte, fokussierte und präzisierte sich mein Blick für das Spezifische am Sampling - nämlich dem in seinen Referentialität besonders schattierten und hochreflexiven Umgang mit Klangkopien. 



\section{B Quellenverzeichnis}

\section{B.1 Literaturverzeichnis}

Ackermann, Philipp. 1991. Computer und Musik: eine Einführung in die digitale Klang- und Musikverarbeitung. Wien: Springer.

Adorno, Theodor Wiesengrund. 2003. Philosophie der neuen Musik. Frankfurt am Main: Suhrkamp.

Albright, Gregory. 1988. Digital Sound Sampling and the Copyright Act of 1976: Are Isolated Sounds Protected. In Copyright Law Symposion, 47-93.

Andean, James. 2014. Towards an Ethics of Creative Sound. Organised Sound I9(2):I73-I8I.

Anderson, Nels. 1923. The Hobo. The Sociology of the Homeless Man. Oxford: University of Chicago Press.

Antal, Ariane Berthoin, Michael Hutter, und David Stark (Hrsg.). 20I5. Moments of Valuation: Exploring Sites of Dissonance. New York: Oxford University Press.

Arendt, Hannah. 1963. Über die Revolution. München: Piper.

Arn, Thomas D. 1989. Digital Sampling and Signature Sound: Protection Under Copyright and Non-Copyright Law. University of Miami Entertainment \& Sports Law Review 6:6I-86.

Aufderheide, Patricia. 2013. Creativity, Copyright, and Authorship. In Media Authorship, Hrsg. Cynthia Chris, und David A. Gerstner, 2I-36. New York: Routledge.

Aufderheide, Patricia, und Peter Jaszi. 20Ir. Reclaiming Fair Use: How to Put Balance Back in Copyright. Chicago; London: University of Chicago Press.

Balázs, Béla (1930/2004): Montage, In Geschichte der Filmtheorie. Kunsttheoretische Texte von Méliès bis Arnheim, Hrsg. Helmut Diederichs, Frankfurt/Main: Suhrkamp, S. 279-287. 
Baldwin, Peter. 20I4. The Copyright Wars. Three Centuries of Trans-Atlantic Battle. Princeton/NJ: Princeton University Press.

Baroni, Michael L. 1993. A Pirate's Palette: The Dilemmas of Digital Sound Sampling and a Proposed Compulsory License Solution. University of Miami Entertainment \& Sports Law Review II(I):65-I04.

Barthes, Roland. 200o. Der Tod des Autors. In Texte zur Theorie der Autorschaft, Hrsg. Fotis Jannidis, 185-197. Leipzig: Reclam.

Bartmanski, Dominik, und Ian Woodward. 20I5. The Vinyl: The Analogue Medium in the Age of Digital Reproduction. Journal of Consumer Culture I5(I):3-27. DOI: https://doi.org/IO.II77/I469540513488403.

Bartók, Béla. 1957. Warum und wie sollten wir Volksmusik sammeln? [1936]. In Béla Bartók. Weg und Werk. Schriften und Briefe, Hrsg. Bence Szabolsci, I7I-I93. Budapest: Corvina.

Baudrillard, Jean. 1994. Simulacra and Simulation. Ann Arbor/MI: University of Michigan Press.

Bauer, Thomas. 2018. Die Vereindeutigung der Welt: Über den Verlust an Mehrdeutigkeit und Vielfalt. Ditzingen: Reclam.

Baumgärtel, Tilman. 2016. Schleifen: zur Geschichte und Ästhetik des Loops. Berlin: Kadmos.

Becker, Howard S. 1963. Outsiders. Studies in the Sociology of Deviance. London: Free Press of Glencoe.

Becker, Howard S. 2008. Art Worlds. 25th Anniversary Edition. Updated and Expanded. Berkeley; Los Angeles; London: University of California Press.

Becker, Thomas. 20I0. Sozioanalyse der Lust an einem hybriden Medium. In Struktur und Geschichte der Comics. Beiträge zur Comicforschung, Hrsg. Dietrich Grünewald, 309-326. Bochum; Essen: Ch. A. Bachmann.

Benjamin, Walter. 2012. Das Kunstwerk im Zeitalter seiner technischen Reproduzierbarkeit: drei Studien zur Kunstsoziologie [I935]. Frankfurt am Main: Suhrkamp.

Bennett, Joe. 20I4. Did Robin Thicke steal ‘Blurred Lines from Marvin Gaye? Joe Bennett. abrufbar unter: https://joebennett.net/20I4/o2/oI/ did-robin-thicke-steal-a-song-from-marvin-gaye, zugegriffen: 16.03.2018.

Bensman, Joseph, und Israel Gerver. 1963. Crime and Punishment in the Factory: The Function of Deviancy in Maintaining the Social System. American Sociological Review 28(4):588-598. DOI: https://doi.org/IO. 2307/2090074. 
Bently, Lionel. 1989. Sampling and Copyright: Is the Law on the Right Track? Journal of Business Law 2(405):II3-I25.

Bently, Lionel, und Brad Sherman. 1992. Cultures of Copying: Digital Sampling and Copyright Law. Entertainment Law Review 3(5):158-163.

Berli, Oliver. 2017. Howard S. Becker ( ${ }^{*}$ 1928). In Klassiker der Soziologie der Künste, Hrsg. Christian Steuerwald, 653-677. Wiesbaden: Springer.

Bigelow, Steve. 20I5. Automakers to Gearheads: Stop Repairing Cars. Autoblog. abrufbar unter: https://www.autoblog.com/2015/04/20/automa kers-gearheads-car-repairs, zugegriffen: 12.03.2018.

Bisges, Marcel. 20I4. Die Kleine Münze im Urheberrecht. Baden-Baden: Nomos.

Bloom, Harold. 1997. The Anxiety of Influence: A Theory of Poetry. New York: Oxford University Press.

Blumer, Herbert. 195I. Collective Behavior. In Principles of Sociology, Hrsg. Alfred McClung Lee, 67-I2I. New York: Barnes \& Nobles.

Blumer, Herbert. 1969. Fashion. From Class Differentiation to Collective Selection. Sociological Quarterly Io(3):275-291.

Boltanski, Luc, und Ève Chiapello. 2006. Der neue Geist des Kapitalismus. Konstanz: UVK.

Boon, Marcus. 20Io. In Praise of Copying. Cambridge/MA: Harvard University Press.

Borschke, Margie. 2017. This is Not a Remix: Piracy, Authenticity and Popular Music. New York: Bloomsbury Academic.

Boschma, Ron A., und Michael Fritsch. 2009. Creative Class and Regional Growth: Empirical Evidence from Seven European Countries. Economic Geography 85(4):39I-423.

Bourdieu, Pierre. 1981. Die gesellschaftliche Definition der Photographie. In Eine illegitime Kunst. Die sozialen Gebrauchsweisen der Photographie, 85-IIO. Frankfurt am Main: Europäische Verlagsanstalt.

Bourdieu, Pierre. 1983. The Field of Cultural Production, or: The Economic World Reversed. Poetics I2(4-5):311-356.

Bourdieu, Pierre. 1987. Die feinen Unterschiede: Kritik der gesellschaftlichen Urteilskraft. Frankfurt am Main: Suhrkamp.

Bourdieu, Pierre. 200I. Die Regeln der Kunst. Frankfurt am Main: Suhrkamp.

Bourdieu, Pierre. 20II. Aber wer hat denn die "Schöpfer" geschaffen? In Kunst und Kultur. Kunst und künstlerisches Feld. Schriften zur Kultursoziologie 4, Hrsg. Franz Schultheis, und Stephan Egger, I55-170. Konstanz: UVK. 
Boyle, James. 2008. The Public Domain: Enclosing the Commons of the Mind. New Haven/CT: Yale University Press.

Brecht, Bertolt. 1967. Der Rundfunk als Kommunikationsapparat [1932]. In Gesammelte Werke. Band I8. Schriften zur Literatur und Kunst, Band I, I27-I34. Frankfurt am Main: Suhrkamp.

Briegleb, Volker. 2017. Apple übernimmt Shazam. heise online. abrufbar unter: https://www.heise.de/newsticker/meldung/Apple-uebernimmt-Sha zam-3915615.html, zugegriffen: 15.12.2017.

Bröckling, Ulrich. 2007. Das unternehmerische Selbst: Soziologie einer Subjektivierungsform. Frankfurt am Main: Suhrkamp.

Burgess, Richard James. 20I4. The History of Music Production. New York: Oxford University Press.

Burkhart, Benjamin, und Martin Pfleiderer. 20I7. Reggae. In Handbuch Popkultur, Hrsg. Thomas Hecken, und Marcus S. Kleiner, 57-62. Stuttgart: J. B. Metzler.

Burow, Heinz. 200I. Mediengeschichte der Musik. In Handbuch der Mediengeschichte, Hrsg. Helmut Schanze, 347-372. Stuttgart: Kröner.

Buschow, Christopher. 2018. Die Neuordnung des Journalismus: eine Studie zur Gründung neuer Medienorganisationen. Wiesbaden: Springer.

Butler, Mark Jonathan. 2006. Unlocking the groove: Rhythm, meter, and musical design in electronic dance music. Indiana University Press.

Cage, John. 1987. Silence: Lectures and Writings [1937]. Middletown/CT: Wesleyan Univ. Press.

Calo, Ryan, und Alex Rosenblat. 20I7. The Taking Economy: Uber, Information, and Power. Columbia Law Review II7(6):1623-1690.

Carruthers, Bruce G., und Laura Ariovich. 2004. The Sociology of Property Rights. Annual Review of Sociology 30(I):23-46. DOI: https://doi.org/IO. II46/annurev.soc.30.0I2703.IIO538.

Celia, Lury. 1993. Cultural Rights: Technology, Legality and Personality. London: Routledge.

Chang, Jeff. 2007. Can't Stop Won't Stop: A History of the Hip-Hop Generation. New York: St. Martin's Press.

Cohen, Julie E. 2007. Creativity and Culture in Copyright Theory. UC Davis Law Review 40:II5I-I205.

Collins, Steve. 2008. Waveform pirates: Sampling, Piracy and Musical Creativity. Journal on the Art of Record Production 3:I-II. 
Corbin, Juliet, und Anselm Strauss. 1990. Grounded Theory Research: Procedures, Canons and Evaluative Criteria. Zeitschrift für Soziologie I9 (6):418-427.

Cox, Wayne M. 20I4. Rhymin' and Stealin: The History of Sampling in the Hip-Hop and Dance Music World and How US Copyright Law \& Judicial Precedent Serves to Shackle Art. Virginia Sports and Entertainment Law Journal I4(2):219-249.

Crane, Diana. 1989. The Transformation of the Avant-garde: the New York Art World, 1940-1985. Chicago; London: The University of Chicago Press.

Csíkszentmihályi, Mihály. 1999. Implications of a Systems Perspective for the Study of Creativity. In Handbook of Creativity, Hrsg. Robert J. Sternberg, 313-335. Cambridge/MA: Cambridge University Press.

Danko, Dagmar. 20I2. Kunstsoziologie. Bielefeld: Transcript.

Danko, Dagmar. 20I5. Zur Aktualität von Howard S. Becker: Einleitung in sein Werk. Wiesbaden: Springer.

Danto, Arthur. 1964. The Artworld. The Journal of Philosophy 6I(19):57I-584.

Darling, Kate, und Aaron Perzanowski (Hrsg.). 2017. Creativity Without Law: Challenging the Assumptions of Intellectual Property. New York: New York University Press.

Davies, Hugh. 1996. A History of Sampling. Organised Sound I(I):3-II.

DeCerteau, Michel. 1988. Kunst des Handelns. Berlin: Merve.

Demers, Joanna. 2006. Steal this Music. How Intellectual Property Law Affects Musical Creativity. Athens/GA: University of Georgia Press.

DeNora, Tia. 2000. Music's Social Powers: Soundtrack, Self and Embodiment in Everyday Life. Cambridge: Cambridge University Press.

Dewey, John. 1934. Art as Experience. New York: Capricorn.

Diaz-Bone, Rainer. 2015. Die "Economie des conventions«: Grundlagen und Entwicklungen der neuen französischen Wirtschaftssoziologie. Wiesbaden: Springer.

Diederichsen, Diedrich. 1987. Copyright. Diedrich Diederichsen über das Recycling von Tönen und die Eigentumsfrage in der Popmusik. konkret I2:52-53.

Diederichsen, Diedrich. 2006. Sampling und Montage: Modelle anderer Autorschaften in der Kulturindustrie und ihre notwendige Nähe zum Diebstahl. In Fälschungen. Zu Autorschaft und Beweis in Wissenschaften und Künsten, Hrsg. Anne-Kathrin Reulecke, 390-405. Frankfurt am Main: Suhrkamp. 
Djordjevic, Valie, und Leonhard Dobusch (Hrsg.). 20I4. Generation Remix: Zwischen Popkultur und Kunst. Berlin: iRights Media.

Dobusch, Leonhard. 20I4. Generation Remix. Popkultur und Kunst im rechtsfreien Raum? In Generation Remix. Zwischen Popkultur und Kunst, Hrsg. Valie Djordjevic, und Leonhard Dobusch, 9-I4. Berlin: iRights Media.

Döhl, Frédéric. 20I6. Mashup in der Musik. Fremdreferenzielles Komponieren, Sound Sampling und Urheberrecht. Bielefeld: Transcript.

Dolata, Ulrich. 2008. Das Internet und die Transformation der Musikindustrie. Berliner Journal für Soziologie I8(3):344-369.

Dommann, Monika. 20I4. Autoren und Apparate. Die Geschichte des Copyrights im Medienwandel. Frankfurt am Main: Fischer.

Dreier, Thomas, und Georg Nolte. 2006. Einführung in das Urheberrecht. In Wissen und Eigentum: Geschichte, Rechte und Ökonomie stoffloser Güter, Hrsg. Jeanette Hofmann, 4I-63. Bonn: Bundeszentrale für politische Bildung.

Dreyer, Gunda, Jost Kotthoff, und Astrid Meckel. 2009. Urheberrecht: Urheberrechtsgesetz, Urheberrechtswahrnehmungsgesetz, Kunsturhebergesetz. Heidelberg: Müller.

Dupler, Steven. 1986a. Digital Sampling: Is it Theft? Technology raises Copyright Questions. Billboard 98(3I):I-2.

Dupler, Steven. 1986b. Digital Technology May Violate Copyright Law. Experts doubt Legality of Sampling. Billboard 98(32):4.

Edelman, Lauren B. 1992. Legal Ambiguity and Symbolic Structures: Organizational Mediation of Civil Rights Law. American Journal of Sociology 97(6):I53I-1576.

Elias, Norbert. 1991. Mozart. Zur Soziologie eines Genies. Hrsg. Michael Schröter. Frankfurt am Main: Suhrkamp.

Esposito, Elena. 2004. Die Verbindlichkeit des Vorübergehenden: Paradoxien der Mode. Frankfurt am Main: Suhrkamp.

Ewoodzie, Joseph C. 2017. Break Beats in the Bronx: Rediscovering Hip-Hop's Early Years. Chapel Hill/NC: University of North Carolina Press.

Fehrmann, Gisela, Erika Linz, Eckhard Schumacher, und Brigitte Weingart. 2004a. Originalkopie. Praktiken des Sekundären. Köln: DuMont.

Fehrmann, Gisela, Erika Linz, Eckhard Schumacher, und Brigitte Weingart. 2004b. Originalkopie. Praktiken des Sekundären. Eine Einleitung. In 
Originalkopie. Praktiken des Sekundären, Hrsg. Gisela Fehrmann, Erika Linz, Eckhard Schumacher, und Brigitte Weingart, 7-17. Köln: DuMont. Feuerstein, Thomas, und Stefan Bidner. 2004. Sample Minds. Materials on Sampling Culture. Köln: Walther König.

Fickers, Andreas. 2006. Sichtbar hörbar! Rundfunkapparat und Stadt - Knoten im vernetzten Kommunikationsraum. In Die Stadt als Kommunikationsraum. Medialität und Raumgefüge der Großstädte im 20. Jahrhundert, Hrsg. Clemens Zimmermann, 83-IO3. Stuttgart: Steiner.

Fikentscher, Kai. 200o. „You Better Work!«: Underground Dance Music in New York. New Haven/CT: Wesleyan University Press.

Fine, Gary Alan. 1983. Cheating History: The Rhetorics of Art Forgery. Empirical Studies of the Arts $\mathrm{I}(\mathrm{I}): 75-93$.

Fischer, Georg. 20I3. Jäger und Sampler. Kreativität und Innovation am Beispiel des Samplings. Diplomarbeit. TU Berlin.

Fischer, Georg. 2016. Daft Punk und die Remixkultur: Ohne Kopien kein Original. iRights - Kreativität und Urheberrecht in der digitalen Welt. abrufbar unter: https://irights.info/artikel/daft-punk-und-die-remixkulturohne-kopien-kein-original/28052, zugegriffen: 8.4.2017.

Fischer, Georg. 20I7. Mixed Feelings: Britischem DJ droht Haftstrafe in Tunesien wegen Gebetsruf-Sample. Jäger und Sampler. abrufbar unter: https://jaegerundsampler.wordpress.com/2017/04/Io/mixed-feelingsbritischem-dj-droht-haftstrafe-in-tunesien-wegen-gebetsruf-sample, zugegriffen: 16.03.2018.

Fischer, Georg, und Lorenz Grünewald-Schukalla (Hrsg.). 2oI8. Originalität und Viralität von (Internet-)Memes. kommunikation@gesellschaft 19.

Fischer, Georg, und Erik Meyer. 20I7. Sampling: Ästhetik der Zitate oder Piraterie? In Global Pop, Hrsg. Claus Leggewie, und Erik Meyer, 76-8I. Stuttgart: J. B. Metzler.

Florida, Richard L. 2002. The Rise of the Creative Class: And how It's Transforming Work, Leisure, Community and Everyday Life. New York: Basic Books.

Föllmer, Golo. 2003. Audio Art. In Medien Kunst Netz. Medienkunst im Überblick, Hrsg. Rudolf Frieling, und Dieter Daniels, 80-II7. Wien; New York: Springer.

Foucault, Michel. 2000. Was ist ein Autor? In Texte zur Theorie der Autorschaft, Hrsg. Fotis Jannidis, 198-232. Leipzig: Reclam.

Frank, Arno. 20I7. Techno-Urväter Kraftwerk: PERFEKTION MEKANIK AERO DYNAMIK. Spiegel Online. abrufbar unter: http://www.spiegel. 
de/kultur/musik/kraftwerk-3-d-der-katalog-perfektion-mekanik-aerodynamik-a-II49567.html, zugegriffen: 7.3.IOI8

Frith, Simon. 1986. Art versus Technology: The Strange Case of Popular Music. Media, Culture \& Society 8(3):263-279.

Frith, Simon. 1988. Copyright and the Music Business. Popular Music 7(I):57-75. DOI: https://doi.org/I0.2307/853076.

Funderburg, J. Anne. 20I4. Bootleggers and Beer Barons of the Prohibition Era. Jefferson/NC: McFarland.

Geertz, Clifford. 1987. Dichte Beschreibung: Beiträge zum Verstehen kultureller Systeme. Frankfurt am Main: Suhrkamp.

Gilroy, Paul. 1993. The Black Atlantic: Modernity and Double Consciousness. Cambridge/MA: Harvard University Press.

Glauser, Andrea. 20I3. Soziologie der Kunst: Soziologische Revue Besprechungen neuer Literatur. Soziologische Revue(36):2I-3I.

Goffman, Erving. 1956. The presentation of self in everyday life. University of Edinburgh.

Goffman, Erving. 1989. On Fieldwork. Journal of contemporary ethnography I8(2):I23-I32.

Goodman, Jon. 2000. The King of Novelty: Dickie Goodman. o. A.: Xlibris.

Goodwin, Andrew. 1988. Sample and hold: pop music in the digital age of reproduction. Critical Quarterly 30(3):34-49. DOI: https://doi.org/IO. IIII/j.I467-8705.1988.tboo315.x.

Grafton, Anthony. 1990. Forgers and Critics: Creativity and Duplicity in Western scholarship. Princeton/NJ: Princeton University Press.

Grassmuck, Volker. 2006. Wissenskontrolle durch DRM: von Überfluss zu Mangel. In Wissen und Eigentum. Geschichte, Recht und Ökonomie stoffloser Güter, Hrsg. Jeanette Hofmann, I64-188. Bonn: Bundeszentrale für politische Bildung.

Großmann, Rolf. 2005. Collage, Montage, Sampling. Ein Streifzug durch (medien-)materialbezogene ästhetische Strategien. In Sound. Zur Technologie des Akustischen in den Medien, Hrsg. Harro Segeberg, und Frank Schätzlein, 308-331. Marburg: Schüren.

Großmann, Rolf. 2008. Die Geburt des Pop aus dem Geist der phonographischen Reproduktion. In PopMusicology. Perspektiven der Popmusikwissenschaft, Hrsg. Christian Bielefeldt, Udo Dahmen, und Rolf Großmann, II9-I34. Bieleld: Transcript. 
Groys, Boris. 1992. Über das Neue: Versuch einer Kulturökonomie. München: Hanser.

Groys, Boris. 1997. Logik der Sammlung: am Ende des musealen Zeitalters. München: Hanser.

Grünewald-Schukalla, Lorenz. 20I8. Eine Methodologie für kulturelle Musikwirtschaftsforschung. In Musikwirtschaftsforschung, Hrsg. Peter Tschmuck, Beate Flath, und Martin Lücke, 27-55. Wiesbaden: Springer.

Grünig, Karla-Maria. 2008. Die Urheberrechtliche Einordnung von Websites unter Berücksichtigung der französischen Diskussion von Multimediawerken. Göttingen: Cuvillier.

Guadamuz, Andrés. 2016. The Monkey Selfie: Copyright Lessons for Originality in Photographs and Internet Jurisdiction. Internet Policy Review 5(I).

Harkins, Paul Michael. 20I6. Following the Instruments and Users: The Mutual Shaping of Digital Sampling Technologies. Dissertation. University of Edinburgh.

Harper, Dean, und Frederick Emmert. 1963. Work Behavior in a Service Industry. Social Forces 42(2):216-225.

Häuser, Markus. 2002. Sound and sampling. Der Schutz der Urheber, ausübender Künstler und Tonträgerhersteller gegen digitales Soundsampling nach deutschem und US-amerikanischem Recht. München: Beck.

Hayner, Norman Sylvester. 1936. Hotel Life. Chapel Hill/NC: University of North Carolina Press.

Heesen, Anke te. 2006. Der Zeitungsausschnitt. Ein Papierobjekt der Moderne. Frankfurt am Main: Fischer.

Heimstädt, Maximilian, und Leonhard Dobusch. 20I7. Perspektiven von Open Educational Resources (OER) für die (sozio-)ökonomische Bildung an Schulen in NRW und in Deutschland. FGW Studie. Forschungsinstitut für gesellschaftliche Weiterentwicklung 6.

Hennion, Antoine. 1989. An Intermediary Between Production and Consumption: The Producer of Popular Music. Science, Technology, \& Human Values I4(4):400-424. DOI: https://doi.org/IO.II77/or622439890I400405.

Hertin, Paul. 1989. Sounds von der Datenbank. Eine Erwiderung auf Hoeren. Gewerblicher Rechtsschutz und Urheberrecht (GRUR) 8:578-579.

Hesmondhalgh, David. 2006. Digital Sampling and Cultural Inequality. Social \& Legal Studies I5(I):53-75.

Hesmondhalgh, David. 20I3. The Cultural Industries. Los Angeles: SAGE. 
Hesmondhalgh, David, und Sarah Baker. 20II. Creative Labour: Media Work in Three Cultural Industries. London: Routledge.

Heylin, Clinton. 1995. Bootleg! The Rise And Fall Of The Secret Recording Industry. New York: St. Martin's Press.

Hieber, Lutz. 20I2. Künstlerische und naturwissenschaftliche Kreativität. In Kreativität und Improvisation: Soziologische Positionen, Hrsg. Udo Göttlich, und Ronald Kurt, 263-293. Wiesbaden: Springer.

Hilderbrand, Lucas. 2009. Inherent vice: Bootleg Histories of Videotape and Copyright. Durham/NC; London: Duke University Press.

Himmelmann, Ulrich. 2008. Die Aufsicht über die GEMA. In Recht und Praxis der GEMA. Handbuch und Kommentar. 2., neu bearbeitete Auflage, Hrsg. Kreile, Reinhold, Jürgen Becker, und Karl Riesenhuber, 820-906. Berlin: DeGruyter.

Hirschauer, Stefan, und Klaus Amann (Hrsg.). 1997. Die Befremdung der eigenen Kultur. Frankfurt am Main: Suhrkamp.

Hirschauer, Stefan, und Georg Breidenstein. 2002. Endlich fokussiert? Weder 'Ethno noch , Graphier. Anmerkungen zu Hubert Knoblauchs Beitrag "Fokussierte Ethnographie«. Sozialer Sinn: Zeitschrift für hermeneutische Sozialforschung 3(I):I25-I28.

Hoeren, Thomas. 1989. Sounds von der Datenbank. Zur urheber-und wettbewerbsrechtlichen Beurteilung des Samplings in der Popmusik. Gewerblicher Rechtsschutz und Urheberrecht(I):II-I6.

Hofmann, Jeanette, Christian Katzenbach, und Merlin Münch. 20I2. Kulturgütermärkte im Schatten des Urheberrechts. Zur Pluralität praktizierter Regelungsformen. Aus Politik und Zeitgeschichte 62(41/42):39-45.

Holmes, Thom. 20I2. Electronic and Experimental Music: Technology, Music, and Culture. London: Routledge.

Horkheimer, Max. 1987. Kulturindustrie. Aufklärung als Massenbetrug. In Gesammelte Schriften. Band 5. "Dialektik der Aufklärung" und Schriften 1940-1950, 144-196. Frankfurt am Main: Fischer.

Houle, Jeffrey R. 1991. Digital Audio Sampling, Copyright Law and the American Music Industry: Piracy or just a Bad Rap? Loyola Law Review 37(4):879-902.

Huck, Christian. 20I4. Coverversionen. Zum populären Kern der Popmusik. POP. Kultur \& Kritik(4):154-173.

Hutter, Michael. 2006. Neue Medienökonomik. München: UTB. 
Hutter, Michael. 20II. Infinite Surprises: On the Stabilization of Value in the Creative Industries. In The worth of goods. Valuation and pricing in the economy, Hrsg. Jens Beckert, und Patrik Aspers, 20I-220. Oxford: Oxford University Press.

Hutter, Michael. 20I5a. Dissonant Translations. Artistic Sources of Innovation in Creative Industries. In Moments of Valuation. Exploring Sites of Dissonance, Hrsg. Ariane Berthoin Antal, Michael Hutter, und David Stark, 57-88. New York: Oxford University Press.

Hutter, Michael. 2015b. Ernste Spiele. Geschichten vom Aufstieg des ästhetischen Kapitalismus. Paderborn: Fink.

Hutter, Michael. 2018. Wertung in Medienwirtschaft und Medienökonomien. Zeitschrift für Medienwissenschaften IO(I):I8-27.

Hutter, Michael, Hubert Knoblauch, Werner Rammert, und Arnold Windeler. 20I6. Innovationsgesellschaft heute. Die reflexive Herstellung des Neuen. In Innovationsgesellschaft heute: Perspektiven, Felder und Fälle, Hrsg. Werner Rammert, Arnold Windeler, Hubert Knoblauch, und Michael Hutter, $15-35$. Wiesbaden: Springer.

IBM. 20I6. Copyright Infringement Prevention, abrufbar unter: https://pa tents.google.com/patent/US9928or5B2/en, zugegriffen: 7.5.2018.

Iljadica, Marta. 2016. Copyright Beyond Law: Regulating Creativity in the Graffiti Subculture. London: Bloomsbury.

Ismaiel-Wendt, Johannes. 20I6. Anmerkungen zum aktuellen Rechtsstreit über Musik-Sampling - "Kraftwerk (Ralf Hütter) v. Moses Pelham" und zur Frage nach rassismuskritischer, semiotischer Demokratie. In post_PRESETS. Kultur, Wissen und populäre MusikmachDinge, I7I-I84. Hildesheim: Universitätsverlag Hildesheim.

Jani, Ole. 2008. Urheberrecht. In Medienrecht: Praxishandbuch, Hrsg. ArturAxel Wandtke, 265-368. Berlin: DeGruyter.

Joas, Hans. 1996. Die Kreativität des Handelns. Frankfurt am Main: Suhrkamp.

Jones, Simon. 1995. Rocking the House: Sound System Cultures and the Politics of Space. Journal of Popular Music Studies 7(I):I-24.

Jütte, Bernd Justin, und Henrike Maier. 20I7. A Human Right to SampleWill the CJEU Dance to the BGH-Beat? Journal of Intellectual Property Law \& Practice I2(9):784-796.

Karstein, Uta, und Nina Tessa Zahner. 20I4. Autonomie und Ökonomisierung der Kunst. Vergleichende Betrachtungen von System- und Feld- 
theorie. In Hrsg. Martina Franzen, Arlena Jung, David Kaldewey, und Jasper Korte, 188-210. Weinheim: Beltz Juventa.

Kartha, Neela. 1997. Digital Sampling and Copyright Law in a Social Context: No More Colorblindness. University of Miami Entertainment \& Sports Law Review I4(2):218-242.

Katz, Mark. 2004. Capturing Sound: How Technology has changed Music. Berkeley; Los Angeles: University of California Press.

Katzenbach, Christian, Sarah Herweg, und Lies Van Roessel. 2016. Copies, Clones, and Genre Building: Discourses on Imitation and Innovation in Digital Games. International Journal of Communication I0:22.

Kautny, Oliver. 20Io. Talkin' all that Jazz. Ein Plädoyer für die Analyse des Sampling im HipHop. Samples. Online-Publikationen der Gesellschaft für Popularmusikforschung 9.

Kautny, Oliver, und Adam Krims (Hrsg.). 20Io. Sampling im HipHop, Samples. Online-Publikationen der Gesellschaft für Popularmusikforschung 9.

Keller, Reiner. 20I2. Das Interpretative Paradigma: Eine Einführung. Wiesbaden: Springer.

Klammt, Sascha. 20Io. Das Sample. Eine einzigartige Momentaufnahme als Basis für eine neue Komposition. Samples. Online-Publikationen der Gesellschaft für Popularmusikforschung 9.

Knoblauch, Hubert. 200r. Fokussierte Ethnographie. Soziologie, Ethnologie und die neue Welle der Ethnographie. Sozialer Sinn 2(I):I23-I4I.

Knoblauch, Hubert. 2002. Fokussierte Ethnographie als Teil einer soziologischen Ethnographie. Sozialer Sinn 3(I):I29-I36.

Knorr-Cetina, Karin. 1999. Epistemic Cultures: How the Sciences Make Knowledge. Cambridge/Massachusetts: Harvard University Press.

Kocatepe, Sibel. 2017. Fair Dealing im Zeitalter postmoderner Kreativität: Ein Privileg mit Hindernissen. In Immaterialgüter und Digitalisierung. Junge Wissenschaft zum Gewerblichen Rechtsschutz, Urheber- und Medienrecht, Hrsg. Moritz Hennemann, und Andreas Sattlers, 257-275. BadenBaden: Nomos.

Köhne, Daniel. 20IO. Fairplay im digitalen Zeitalter. Anspruch und Wirklichkeit des Digital Rights Managements. In Kulturen des Kopierschutzes II (=Navigationen Io(2)), 63-83. Siegen: Universitätsverlag.

Kotelnikov, Vladimir Aleksandrovich. 1933. On the Transmission Capacity of the sEther and of Cables in Electrical Communications. In Proceedings of the first All-Union Conference on the technological reconstruction of 
the communications sector and the development of low-current engineering. Moscow, Citeseer.

Kravis, Randy S. 1993. Does a Song by Any Other Name Still Sound as Sweet: Digital Sampling and Its Copyright Implications. American University Law Review 43(4):23I-276.

Kühl, Stefan. 2007. Person, Beratung, Organisation. Zur Funktion von Coaching in Organisationen. In Coaching im 2I. Jahrhundert. Kritische Bilanz und zukünftige Herausforderungen in Wissenschaft und Praxis, Hrsg. Frank Strikker, 40-56. Augsburg: ZIEL.

Kühn, Jan-Michael. 2009. Wie entsteht Neues bei der Produktion elektronischer Tanzmusik?: eine explorativ-ethnografische Erhebung. Diplomarbeit. TU Berlin.

Kühn, Jan-Michael. 20I6. Die Wirtschaft der Techno-Szene. Arbeiten in einer subkulturellen Ökonomie. Wiesbaden: Springer.

Kuhn, Thomas S. 20I5. The Structure of Scientific Revolutions. Chicago/IL: The University of Chicago Press.

Latour, Bruno. 1990. Technology is Society Made Durable. The Sociological Review 38(I_suppl):I03-I3I.

Lawson, Stuart. 2017. Access, Ethics and Piracy. Insights 30(I):25-30.

Lena, Jennifer C. 2004. Meaning and Membership: Samples in Rap Music, 1979-1995. Poetics 32(3-4):297-310.

Lessig, Lawrence. 2004. Free Culture. The Nature and Future of Creativitiy. New York: Penguin.

Lessig, Lawrence. 2008. Remix: Making Art and Commerce Thrive in the Hybrid Economy. London: Bloomsbury.

Lévi-Strauss, Claude. 1968. Das wilde Denken. Frankfurt am Main: Suhrkamp.

Litman, Jessica. 200I. Digital Copyright. Amherst/MA: Prometheus.

Litman, Jessica D. 1988. Performer's Rights and Digital Sampling under US and Japanese Law. Law Quad. Notes 32(2):37-43.

Luhmann, Niklas. 1988. Über Kreativität. In Kreativität - Ein verbrauchter Begriff?, Hrsg. Hans-Ulrich Gumbrecht, I3-20. München: Fink.

Luhmann, Niklas. 1995. Die Behandlung von Irritationen. Abweichung oder Neuheit? In Gesellschaftsstruktur und Semantik. Studien zur Wissenssoziologie der modernen Gesellschaft, Hrsg. Niklas Luhmann, 55-IOO. Frankfurt am Main: Suhrkamp.

Luhmann, Niklas. 1997. Die Kunst der Gesellschaft. Frankfurt am Main: Suhrkamp. 
Luhmann, Niklas. 1999. Funktionen und Folgen formaler Organisation. Berlin: Duncker \& Humblot.

Luhmann, Niklas. 2008a. Schriften zu Kunst und Literatur. Frankfurt am Main: Suhrkamp.

Luhmann, Niklas. 2008b. Darum Liebe, In Archimedes und wir: Interviews, Hrsg. Baecker, Dirk, Georg Stanitzek, und Niklas Luhmann, Berlin: Merve.

Maeße, Jens. 20I7. Deutungshoheit. In Macht in Wissenschaft und Gesellschaft, 29I-3I8. Wiesbaden: Springer.

Magerski, Christine. 20II. Theorien der Avantgarde. Wiesbaden: Springer.

Malinowski, Bronislaw. 1994. The Problem of Meaning in Primitive Languages [1923]. In Language and literacy in social practice: A reader, Hrsg. Janet Maybin, I-Io. Clevedon: Multilingual Matters.

Mann, Larissa. 20I2. Decolonizing Copyright: Learning from the Jamaican Street Dance. Dissertation. University of California, Berkeley.

Manuel, Peter, und Wayne Marshall. 2006. The Riddim Method: Aesthetics, Practice, and Ownership in Jamaican dancehall. Popular Music 25(3):447-470.

Marcus, George E. 1995. Ethnography in/of the World System: The Emergence of Multi-Sited Ethnography. Annual review of anthropology 24(I):95-II7.

Marcus, George E., und Fred R. Myers. 1995. The Traffic in Culture: Refiguring Art and Anthropology. Berkeley/CA: University of California Press.

Marcus, Jason H. 1991. Don't Stop that Funky Beat: the Essentiality of Digital Sampling to Rap Music. Hastings Communications and Entertainment Law Journal I3(4):767-790.

Mark, Monmonier. 1991. How to Lie with Maps. Chicago/IL: University of Chicago Press.

Markusen, Ann. 2006. Urban Development and the Politics of a Creative Class: Evidence from a Study of Artists. Environment and Planning A: Economy and Space 38(10):1921-1940.

Martin, Peter J. 2006. Music and the Sociological Gaze: Art Worlds and Cultural Production. Manchester: Manchester University Press.

Martin, Peter J. o.J. Musicians' Worlds: Music-Making as a Collaborative Activity. Symbolic Interaction 29(I):95-107.

McBride, James. 2016. Kill'Em and Leave: Searching for James Brown and the American Soul. New York: Spiegel \& Grau. 
McGiverin, Bruce J. 1987. Digital Sound Sampling, Copyright and Publicity: Protecting Against the Electronic Appropriation of Sounds. Columbia Law Review 87(8):I723-1746.

McGraw, Molly. 1989. Sound Sampling Protection and Infringement in Today's Music Industry. High Technology Law Journal 4(I):I47-I69.

McKenna, T. 2000. Where Digital Music Technology and Law Collide-Contemporary Issues of Digital Sampling, Appropriation and Copyright Law', Student Prize, 2000 (I). The Journal of Information, Law and Technology (JILT).

McLeod, Kembrew. 2005. Freedom of expression: Overzealous copyright bozos and other enemies of creativity. New York: Doubleday.

McLeod, Kembrew. 2015. Authorship, Ownership and Musical Appropriation. In The SAGE Handbook of Popular Music, Hrsg. Andy Bennett, und Steve Waksman, 598-6I2. New York: Sage.

McLeod, Kembrew, und Peter DiCola. 20Ir. Creative License. The Law and Culture of Digital Sampling. Durham/NC; London: Duke University Press.

Mejia, Sebastian. 2013. Fair Play: Copyright Issues and Fair Use in YouTube "Let's Plays" and Videogame Livestreams, SSRN Scholarly Paper. Rochester, NY: Social Science Research Network abrufbar unter:

Menke, Curt. 1967. Tonbandfibel: Der praktische Ratgeber für Tonbandamateure. München: Südwest.

Merkel, Janet. 2009. Kreativquartiere: Urbane Milieus zwischen Inspiration und Prekarität. Berlin: edition sigma.

Merton, Robert K. 1957. Social Theory and Social Structure. New York: Free Press.

Merton, Robert K, und Elinor Barber. 20II. The Travels and Adventures of Serendipity A Study in Sociological Semantics and the Sociology of Science. Princeton/NJ: Princeton University Press.

Metelmann, Jörg. 2016. Pop und die Ökonomie des Massenoriginals. Zur symbolischen Form der Globalisierung. POP. Kultur \& Kritik(8):I35-I49.

Miettinen, Reijo. 2006. The Sources of Novelty: A Cultural and Systemic View of Distributed Creativity. Creativity and Innovation Management I5(2):I73-I8I.

Moholy-Nagy, László. 1989. Neue Gestaltung in der Musik. Möglichkeiten des Grammophons (1923). In Broken Music. Artists' Recordworks, Hrsg. Ursula Block, und Michael Glasmeier, 53-54. Berlin: Daadgalerie. 
Morey, Justin. 2013. Copyright Management and its Effect on the Sampling Practice of UK Dance Music Producers. IASPM@Journal 3(I):48-62.

Mrozek, Bodo. 2019. Jugend-Pop-Kultur: Eine transnationale Geschichte. Suhrkamp Verlag.

Münch, Richard. 2002. Die Kreativität des Handelns. Hans Joas. In Soziologische Theorie. Band 2. Handlungstheorie, 329-346. Frankfurt am Main: Campus.

Münker, Reiner. 1995. Urheberrechtliche Zustimmungserfordernisse beim Digital Sampling. Frankfurt am Main; Berlin: Lang.

Navas, Eduardo, Owen Gallagher, und xtine burrough (Hrsg.). 2015. The Routledge Companion to Remix Studies. London: Routledge.

Negativland. 1995. Fair Use: The Story of the Letter $U$ and the Numeral 2. Concord/CA: Seeland.

Negus, Keith, und Michael J. Pickering. 2004. Creativity, Communication and Cultural Value. Los Angeles: Sage.

Ogburn, William Fielding. 1923. Social Change. With Respect to Culture and Original Nature. Journal of Philosophy 20(19):526-529.

Okpaluba, Johnson. 2010. 'Free-riding on the riddim? Open source, copyright law and reggae music in Jamaica. In Copyright and piracy. An interdisciplinary critique, Hrsg. Lionel Bently, Jennifer Davis, und Jane Ginsburg, 374-386. New York: Cambridge University Press.

Okpaluba, Johnson. 20I4. Digital sampling and music industry practices, re-spun. In Law and Creativity in the Age of the Entertainment Franchise, Hrsg. Kathy Bowrey, und Michael Handler, 75-IO2. Cambridge: Cambridge University Press.

Op den Kamp, Claudia. 2017. Circumvention and the Film Archive: Found Footage, Legal Provenance and the Aesthetics of Access, Hrsg. Holger Brohm, Sebastian Gießmann, Gabriele Schabacher, und Sandra Schramke. Workarounds (=ilinx. Berliner Beiträge zur Kulturwissenschaft 4):8294 .

Ortland, Eberhard. 2016. Blurred Lines: A Case Study on the Ethics and Aesthetics of Copying. In The Aesthetics and Ethics of Copying, Hrsg. Darren Hudson Hick, und Reinhold Schmücker, 225-250. London: Bloomsbury.

Oswald, John. 1985. Plunderphonics, or Audio Piracy as a Compositional Prerogative. In Wired Society Electro-Acoustic Conference, 5-8. Toronto. 
Pappalardo, Kylie, Patricia Aufderheide, Jessica Stevens, und Nicolas Suzor. 2017. Imagination foregone: A qualitative study of the reuse practices of Australian creators, Report. Brisbane: Queensland University of Technology.

Park, Robert E. 19I5. The City: Suggestions for the Investigation of Human Behavior in the City Environment. American Journal of Sociology 20(5):577-6r2.

Park, Robert E. 1928. Human Migration and the Marginal Man. American Journal of Sociology 33(6):88I-893.

Passoth, Jan-Hendrik, und Werner Rammert. 20I6. Fragmentale Differenzierung und die Praxis der Innovation: Wie immer mehr Innovationsfelder entstehen. In Innovationsgesellschaft heute: Perspektiven, Felder und Fälle, Hrsg. Werner Rammert, Arnold Windeler, Hubert Knoblauch, und Michael Hutter, 39-67. Wiesbaden: Springer.

Peck, Jamie. 2005. Struggling with the Creative Class. International Journal of Urban and Regional Research 29(4):740-770.

Peifer, Karl-Nikolaus. 2008. Der Schutz des kreativen Menschen im Recht. Zwischen Vermögens- und Entfaltungsschutz. In Innovation - Kunst Technik. Der Mensch - ein kreatives Wesen?, Hrsg. Heinrich Schmidinger, und Clemens Sedmak, 87-I00. Darmstadt: Wissenschaftliche Buchgesellschaft.

Pelleter, Malte, und Steffen Lepa. 2007. Sampling als kulturelle Praxis des HipHop. In HipHop meets Academia. Globale Spuren eines lokalen Kulturphänomens, Hrsg. Karin Bock, Stefan Meier, und Gunter Süss, 199-213. Bielefeld: Transcript.

Pfister, Manfred. 1985. Konzepte der Intertextualität. In Intertextualität. Formen, Funktionen, anglistische Fallstudien, Hrsg. Ulrich Broch, und Manfred Pfister, I-30. Berlin: DeGruyter.

Pfleiderer, Martin. 2006. Rhythmus. Psychologische, theoretische und stilanalytische Aspekte populärer Musik. Bielefeld: Transcript.

Popitz, Heinrich. 2000. Wege der Kreativität. Tübingen: Mohr Siebeck.

Porcello, Thomas. 1991. The Ethics of Digital Audio-Sampling: Engineers' Discourse. Popular Music Io(I):69-84.

Poschardt, Ulf. 1997. DJ Culture. Diskjockeys und Popkultur. Reinbek bei Hamburg: Rowohlt.

Potter, Keith. 2002. Four musical minimalists: La Monte Young, Terry Riley, Steve Reich, Philip Glass. Cambridge/MA: Cambridge University Press. 
Rammert, Werner. 20I0. Die Innovationen der Gesellschaft. In Soziale Innovationen. Auf dem Weg zu einem post-industriellen Innovationsparadigma, Hrsg. Jürgen Howaldt, und Heike Jakobsen, 2I-5I. Wiesbaden: Springer.

Rammert, Werner, Arnold Windeler, Hubert Knoblauch, und Michael Hutter (Hrsg.). 2016. Innovationsgesellschaft heute: Perspektiven, Felder und Fälle. Wiesbaden: Springer.

Rauscher, Andreas. 1997. Dropping da Bomp. Die Rolle des Sampling im Hip Hop. In Testcard\#4. Retrophänomene in den goern, Hrsg. Roger Behrens, 88-93. Mainz: Ventil.

Reck, Hans Ulrich, und Mathias Fuchs (Hrsg.). 1995. Sampling: ein Symposium der Lehrkanzel für Kommunikationstheorie an der Hochschule für angewandte Kunst in Wien, [20.-22.10.1994]. Wien: Hochschule für angewandte Kunst.

Reckwitz, Andreas. 20Io. Der Kreative. In Diven, Hacker, Spekulanten. Sozialfiguren der Gegenwart, Hrsg. Stephan Moebius, und Markus Schroer, 248-260. Berlin: Suhrkamp.

Reckwitz, Andreas. 20I2. Die Erfindung der Kreativität: zum Prozess gesellschaftlicher Ästhetisierung. Berlin: Suhrkamp.

Reckwitz, Andreas. 2016. Kreativität und soziale Praxis: Studien zur Sozialund Gesellschaftstheorie. Bielefeld: Transcript.

Reilly, Tracy L. 2008. Debunking the Top Three Myths of Digital Sampling: An Endorsement of the Bridgeport Music Court's Attempt to Afford Sound Copyright Protection to Sound Recordings. Columbia Journal of Law \& the Arts 31:355-408.

Reißmann, Wolfgang, Nadine Klass, und Dagmar Hoffmann. 20I7. Fan fiction, Urheberrecht und empirical legal studies. POP. Kultur \& Kritik (Io):I56-I72.

Reynolds, Simon. 1998. Generation ecstasy: Into the world of techno and rave culture. New York: Routlegde.

Reynolds, Simon. 20Ir. Retromania. Pop Culture's Addiction to Its Own Past. New York: Faber and Faber.

Rietveld, Hillegonda C. 20II. Disco's revenge: house music's nomadic memory. Dancecult: Journal of Electronic Dance Music Culture 2(I):4-23.

Rimmer, Matthew. 2005. The Grey Album: Copyright Law and Digital Sampling. Media International Australia Incorporating Culture and Policy II $4(\mathrm{I}): 40-53$.

Rose, Tricia. 1994. Black Noise: Rap Music and Black Culture in Contemporary America. New Haven/NC: Wesleyan University Press. 
Rosenthal, Gabriele. 20I4. Interpretative Sozialforschung. Eine Einführung. Weinheim; Basel: Beltz Juventa.

Rösing, Helmut. 20I2. Forensische Popmusik-Analyse. In Black Box Pop, Hrsg. Dietrich Helms, und Thomas Phleps, 257-277. Bielefeld: Transcript.

Russolo, Luigi. 1986. The Art of Noises. Translated from the Italian [I9I3]. New York: Pendragon.

Ruttmann, Walter. 1994. Neue Gestaltung von Tonfilm und Funk. Programm einer photographischen Hörkunst [1929]. In Walter Ruttmanns Tonmontagen als Ars Acustica, Hrsg. Jeanpaul Goergen, 25-26. Siegen: Universität Gesamthochschule Siegen.

Said, Amir. 20I5. The Art of Sampling. The Sampling Tradition of Hip Hop/Rap Music and Copyright Law. New York: Superchamp.

Salagean, Emil. 2008. Sampling im deutschen, schweizerischen und US-amerikanischen Urheberrecht. Baden-Baden: Nomos.

Salaverría, Heidi. 2007. Spielräume des Selbst: Pragmatismus und kreatives Handeln. Berlin: Akademie Verlag.

Samuelson, Pamela. 2016. Freedom to Tinker. Theoretical Inquiries in Law $17(2): 563-600$.

Sassen, Saskia. 20I7. Wenn bewundernswerte sozio-technische Fähigkeiten handfeste Brutalitäten hervorbringen. In Reclaim Autonomy. Selbstermächtigung in der digitalen Weltordnung. Übersetzt von Nikolaus Gramm, Hrsg. Jacob Augstein, 39-52. Berlin: Suhrkamp.

Sayers, Jeffrey John. 20I4. The Wrong Mix: Electronic Dance Music and its Copyright Problem. Seton Hall University Law School Papers 566:I-29.

Schabacher, Gabriele. 20I7. Im Zwischenraum der Lösungen. Reparaturarbeit und Workarounds, Hrsg. Holger Brohm, Sebastian Gießmann, Gabriele Schabacher, und Sandra Schramke. Workarounds (=ilinx. Berliner Beiträge zur Kulturwissenschaft 4): xiv-xxviii.

Schaeffer, Pierre. 1998. À la recherche d'une musique concrète [1952]. Paris: Éditions du Seuil.

Scheibe, Michaela. 20I5. Excentric Shampoo - Das Beste für die Haarpflege. Tarnschriften gegen die NS-Diktatur in der Staatsbibliothek zu Berlin. Bibliotheksmagazin. Mitteilungen aus den Staatsbibliotheken in Berlin und München IO(I):50-54.

Schloss, Joseph G. 2004. Making beats. The Art of Sample-Based Hip-Hop. Middletown/CT: Wesleyan University Press. 
Schorn, Franz. 1989. Sounds von der Datenbank. Eine notwendige Ergänzung zum Beitrag von Thomas Hoeren in GRUR I989, II ff. Gewerblicher Rechtsschutz und Urheberrecht (GRUR) 8:579-580.

Schrage, Dominik. 2007. Der Sound und sein soziotechnischer Resonanzraum. Zur Archäologie massenkulturellen Hörens. In Technische Reproduzierbarkeit: Zur Kultursoziologie massenmedialer Vervielfältigung, Hrsg. Lutz Hieber, und Dominik Schrage, I35-I62. Bielefeld: Transcript.

Schramm, Balthasar. 1992. Sample-Computer und das Recht der Musik. Hamburg; Münster: Lit.

Schröter, Jens. 2009. Das holographische Wissen und die Nicht-Reproduzierbarkeit. In Das holographische Wissen, Hrsg. Rieger, Stefan, und Schröter, Jens, 77-86. Zürich: Diaphanes.

Schröter, Jens. 20IO. Das Zeitalter der technischen Nicht-Reproduzierbarkeit. In Kulturen des Kopierschutzes I (=Navigationen Io(I)), 9-36. Siegen: Universitätsverlag.

Schröter, Jens. 2013. Von der Farbe zur Nicht-Reproduzierbarkeit. In AkteurMedien-Theorie, Hrsg. Tristan Thielmann, und Erhard Schüttpelz, 235264. Bielefeld: Transcript.

Schumacher, Thomas G. 1995. This is a Sampling Sport. Digital Sampling, Rap Music and the Law in Cultural Production. Media, Culture \& Society I7(2):253-273.

Schumpeter, Joseph. 1934. Theorie der wirtschaftlichen Entwicklung. Eine Untersuchung über Unternehmergewinn. Berlin: Duncker \& Humblodt.

Schur, Richard. 2015. Copyright Outlaws and Hip Hop Moguls. Intellectual Property Law and the Development of Hip Hop Music. In The Organic Globalizer: Hip Hop, Political Development, and Movement Culture, Hrsg. Christopher Malone, und Jr. Martinez George, 79-98. London: Bloomsbury.

Schuster, W. Michael. 20I5. Fair Use, Girl Talk, and Digital Sampling: An Empirical Study of Music Sampling's Effect on the Market for Copyrighted Works. Oklahoma Law Review 97(3):443-518.

Schwarz, Hillel. 1996. The Culture of the Copy. New York: Zone Books.

Schwarz, Robert K. 1996. Minimalists. London: Phaidon.

Seifert, Fedor. 20I4. Kleine Geschichte(n) des Urheberrechts. Entstehung und Grundgedanken des geistigen Eigentums. München: Mur.

Seifert, Fedor, Urban Pappi, Reinhard Nicklas, Alexander Wolf, et al. 2008. Die Lizenzierung. In Recht und Praxis der GEMA. Handbuch und Kom- 
mentar. 2., neu bearb, Aufl., Hrsg. Reinhold Kreile, Jürgen Becker, und Karl Riesenhuber, 75I-782. Berlin: DeGruyter.

Setaro, Shawn. 20I5. Soundalike Songs Are a Two-Faced Business. Digital music platforms are filled with copycat recordings—duplicitous remakes motivated not by artistry, but by money. Cuepoint. abrufbar unter: https://medium.com/cuepoint/soundalike-songs-are-a-two-faced-busi ness-f 44 ca9678bef, zugegriffen: I2.IO.20I8.

Sewell, Amanda. 20I4. How Copyright Affected the Musical Style and Critical Reception of Sample-Based Hip-Hop. Journal of Popular Music Studies 26(2-3):295-320.

Shannon, C. E. 1949. Communication in the Presence of Noise. Proceedings of the IRE 37(I):IO-2I.

Shultz, Brooke. 2005. Sound Recordings: Get a License or Do Not Sample. Tulane Journal of Technology and Intellectual Property 7:327-336.

Shusterman, Richard. 1992. Pragmatist Aesthetics: Living Beauty, Rethinking Art. Oxford; Cambridge/MA: Blackwell.

Siegrist, Hannes. 2006. Geschichte des geistigen Eigentums und der Urheberrechte. Kulturelle Handlungsrechte in der Moderne. In Wissen und Eigentum. Geschichte, Recht und Ökonomie stoffloser Güter, Hrsg. Jeanette Hofmann, 64-80. Bonn: Bundeszentrale für politische Bildung.

Simon, Jan. 2005. HipHop Urheberrecht. Die Rechtssprechung beeinflusst die Kunst. HipHop würde anders aussehen, wenn Sampling frei wäre. Vier Fälle. De:Bug 90:56-57.

Sinnreich, Aram. 2010. Mashed up: Music, Technology, and the Rise of Configurable Culture. Amherst/MA: University of Massachusetts Press.

Sinnreich, Aram. 2016. Sharing in spirit: Kopimism and the digital Eucharist. Information, Communication \& Society 19(4):504-517.

Slutksy, Alan. 1996. Standing in the Shadows of Motown: The Life and Music of Legendary Bassist James Jamerson. Wynnewood/PA: Hal Leonard.

Smith Brindle, Reginald. 1975. The new music: The Avant-garde since 1945. London: Oxford University Press.

Smudits, Alfred, Michael Parzer, Rainer Prokop, und Rosa Reitsamer. 2014. Kunstsoziologie. München: Oldenbourg Verlag.

Spieß, Andreas. 1991. Urheber- und wettbewerbsrechtliche Probleme des Sampling in der Popmusik. Zeitschrift für Urheber- und Medienrecht $35(\mathrm{II}): 524-535$. 
Sprigman, Christopher Jon. 2017. Copyright and Creative Incentives: What We Know (and Don't). Houston Law Review 55(2):45I-478.

Stalder, Felix. 20I6. Kultur der Digitalität. Berlin: Suhrkamp.

Steets, Silke. 20II. Die Stadt als Wohnzimmer und die Floridarisierung der Stadtpolitik. In Die Besonderheit des Städtischen: Entwicklungslinien der Stadt(soziologie), Hrsg. Heike Herrmann, Carsten Keller, Rainer Neef, und Renate Ruhne, 87-103. Wiesbaden: Springer.

Sternberg, Robert J. (Hrsg.). 1999. Handbook of Creativity. Cambridge: Cambridge University Press.

Sterne, Jonathan. 20I2. MP3: The Meaning of a Format. Durham/NC; London: Duke University Press.

Steuerwald, Christian. 2017. Klassiker der Soziologie der Künste. Wiesbaden: Springer.

Strauss, A. L. 1978. A Social Worlds Perspective. Studies in Symbolic Interaction I:II9-I28.

Straw, Will. 2002. Value and Velocity: The I2-Inch Single as Medium and Artifact. In Popular Music Studies, Hrsg. David Hesmondhalgh, und Keith Negus, I64-177. London: Arnold.

Strübing, Jörg. 2002. Just do it? Zum Konzept der Herstellung und Sicherung von Qualität in grounded theory-basierten Forschungsarbeiten. Kölner Zeitschrift für Soziologie und Sozialpsychologie 54(2):318-342.

Strübing, Jörg. 2008. Grounded theory. Wiesbaden: Springer.

Suchman, Lucy. 1995. Making Work Visible. Communications of the ACM 38(9):56-64.

Sullivan, Paul. 20I4. Remixology: Tracing the Dub Diaspora. London: Reaktion Books.

Szymanski, Robert M. 1996. Audio Pastiche: Digital Sampling, Intermediate Copying, Fair Use. UCLA Entertainment Law Review 3(2):273-33I.

Tenschert, Holger. 1987. Ist der Sound urheberrechtlich schützbar? Zeitschrift für Urheber- und Medienrecht 31:612-622.

Thom, Juan Carlos. 1988. Digital Sampling: Old-Fashioned Piracy Dressed Up in Sleek New Technology. Loyola Entertainment Law Journal 8(2):297-336.

Thornton, Sarah. 2003. Club Cultures. Music, Media and Subcultural Capital. Cambridge: Polity.

Toop, David. 1984. The Rap Attack: American Jive to New York Hip Hop. London: Pluto. 
Tuma, René. 20I6. Videoprofis im Alltag: die kommunikative Vielfalt der Videoanalyse. Wiesbaden: Springer.

Tushnet, Rebecca. 2007. Payment in Credit: Copyright Law and Subcultural Creativity. Law and contemporary problems 70(2):135-174.

Ullrich, Wolfgang. 2009. Raffinierte Kunst: Übung vor Reproduktionen. Berlin: Wagenbach.

Ullrich, Wolfgang. 2016. Siegerkunst: neuer Adel, teure Lust. Berlin: Wagenbach.

Utz, Christian. 2002. Neue Musik und Interkulturalität: von John Cage bis Tan Dun. Stuttgart: Steiner.

Uzzi, Brian, und Jarrett Spiro. 2005. Collaboration and Creativity: The Small World Problem. American Journal of Sociology III(2):447-504.

Vaidhyanathan, Siva. 2003. Copyrights and Copywrongs: The Rise of Intellectual Property and how it Threatens Creativity. New York: New York University Press.

Veal, Michael. 2007. Dub: Soundscapes and Shattered Songs in Jamaican Reggae. Middletown/CT: Wesleyan University Press.

Von Gehlen, Dirk. 20Iо. Mashup: Lob der Kopie. Berlin: Suhrkamp.

Von Gehlen, Dirk. 2013. Eine neue Version ist verfügbar - Update: wie die Digitalisierung Kunst und Kultur verändert. Berlin: Metrolit.

Von Gehlen, Dirk. 20I4. Teurer Spaß. Nie mehr Probleme mit Sample-Rechten bei Mashup-Alben? Die Website Legitmix schlägt eine originelle Lösung vor - die aber ihren Preis hat. sueddeutsche.de. abrufbar unter: https://www.sueddeutsche.de/kultur/mash-ups-und-urheberrecht-teu rer-spass-I.1917239, zugegriffen: I2.10.2018.

Wagner, Kristina. 20I6. Sampling als Kunstform und die Interessen der Tonträgerhersteller. Auswirkungen der BVerfG-Rechtsprechung auf die Kunstfreiheit. MultiMedia und Recht 19 (8):513-518.

Wang, Oliver. 20II. Mystery solved: "Bronco« settles Mobb Deep sampling question that's remained hidden since '95. LA Times Blogs - Pop \& Hiss. abrufbar unter: http://latimesblogs.latimes.com/music_blog/20II/o4/ mystery-solved-bronco-solves-mobb-deep-sampling-mystery-thats-re mained-hidden-since-95.html, zugegriffen: I2.IO.2018.

Weber, Max. 2002. Wirtschaft und Gesellschaft: Grundriss der verstehenden Soziologie 5., rev. Aufl. Tübingen: Mohr Siebeck.

Wells, Ronald Mark. 1989. You Can't Always Get What You Want but Digital Sampling Can Get What You Need. Akron Law Review 22(4):69I-706. 
Welskopp, Thomas. 20I0. Amerikas große Ernüchterung: Eine Kulturgeschichte der Prohibition. Paderborn: Schöningh.

Whyte, William Foote. 1993. Street Corner Society. The Social Structure of an Italian slum [1943]. Chicago, IL: University of Chicago Press.

Wikstrom, Patrik. 20Io. The Music Industry, Music in the Cloud. Cambridge; Malden/MA: Polity Press.

Wilder, Eliot. 2005. DJ Shadow's Endtroducing. New York: Bloomsbury.

Williams, Justin. 20I5. Intertextuality, Sampling, and Copyright. In The Cambridge Companion to Hip-Hop, Hrsg. Justin Williams, 206-220. Cambridge: Cambridge University Press.

Williams, Justin. 20Io. The Construction of Jazz Rap as High Art in HipHop Music. The Journal of Musicology 27(4):435-459.

Willis, Paul. 1993. Common Culture: Symbolic Work at Play in the Everyday Cultures of the Young. Milton Keynes: Open University Press.

Willis, Paul E. 20I4. Profane culture [1978]. Princeton/NJ: Princeton University Press.

Wilson, David, und Roger Keil. 2008. The Real Creative Class. Social \& Cultural Geography 9(8):84I-847.

Windeler, Arnold, Hubert Knoblauch, Martina Löw, und Uli Meyer. 2017. Innovationsgesellschaft und Innovationsfelder: Profil und Forschungsansatz des Graduiertenkollegs »Innovationsgesellschaft heute: die reflexive Herstellung des Neuen«. TUTS-Working Paper 2-2017.

Wissel, Carsten von. 2012. Wissenschaftliche Kreativität. Düsseldorf: Arbeitspapier, Bildung und Qualifizierung.

Woodmansee, Martha. 1984. The Genius and the Copyright: Economic and Legal Conditions of the Emergence of the "Author «. Eighteenth-Century Studies $17(4): 425-448$.

Woodmansee, Martha. 2006. Das Urheberrecht als Anreiz/Hemmnis für die schöpferische Produktion. In Fälschungen. Zu Autorschaft und Beweis in Wissenschaften und Künsten, Hrsg. Anne-Kathrin Reulecke, 29I-306. Frankfurt am Main: Suhrkamp.

Zahner, Nina Tessa. 2006. Die neuen Regeln der Kunst: Andy Warhol und der Umbau des Kunstbetriebs im 20. Jahrhundert. Frankfurt am Main: Campus.

Zolberg, Vera L. 1990. Constructing a Sociology of the Arts. Cambridge/MA: Cambridge University Press.

Zolberg, Vera L. 20I5. A Cultural Sociology of the Arts. Current Sociology $63(6): 896-915$. 


\section{B.2 Zitierte Internetseiten}

2manybootleg, »As Heard On Radio Soulwax pt. 2 (Official)«: http://www. 2manybootlegs.com/bootleg-albums/as-heard-on-radio-soulwax/part-2/ (20.0I.20I8)

Audiolock, "Watermarked Promo Delivery«: http://www.audiolock.net/wa termarked-promo-delivery (04.0I.2018)

Discogs, „Various - R.J’s Originals«: https://www.discogs.com/Various-RJsOriginals/release/1988322 (I3.04.2017)

Discogs, "Boogiefuturo«: https://www.discogs.com/de/label/327035-Boogie futuro (20.12.2017)

Downhillbattle, "3 Notes«: http://www.downhillbattle.org/3notes/ (25.10.2017)

Forgotify, http://forgotify.com/ (20.0I.20I8)

IMDB, "Standing in the Shadows of Motown (2002)«: https://www.imdb. $\mathrm{com} /$ title/tto3I4725/ (22.03.2018)

iRights.info, "Urheberrecht und kreatives Schaffen in der digitalen Welt«: https://irights.info/ (22.II.20I7)

iRights.info, „Georg Fischer«: https://irights.info/author/georg-fischer (28.II. 20I7)

Legitmix, "Legitmix is a revolutionary new way to monetize works made using copyrighted musicu: http://legitmix.com/ (17.05.2017)

Recht auf Remix, "Manifest«: https://rechtaufremix.org/\#OI-manifest (2I.II. 20I7)

Recreating Samples, »FAQ«: http://www.recreatingsamples.com/recreatingsample/recreating-samples-faq.html (31.0I.20I8)

Sample Search, http://sampled.pro/ (I2.IO.2018)

Scorcchio, "About us«: http://www.scorccio.com/scorccio.html (25.0I.20I8)

Tagesschau, "Bundesverfassungsgericht verhandelt über umstrittenes 'Sampling، (25.II.20I5)《 http://www.tagesschau.de/multimedia/video/videoI35863.html (20.12.20I5)

Tracklib, »The record store for sampling«: https://www.tracklib.com/ (26.oI. 20I8)

Tumblr, "... im Zeitalter technischer Reproduzierbarkeit«: http://reprodu zierbarkeit.tumblr.com (25.06.2016)

Twitter, "Whosampled: JAY-Z dropped his latest album 4 4:44 produced entirely by No I. D. and it's sample-HEAVY«: https://twitter.com/who sampled/status/880868797204373504 (30.06.2017) 
Wikipedia, „Ultimate Breaks and Beats«: https://en.wikipedia.org/wiki/Ulti mate_Breaks_and_Beats (I5.I2.2017)

Wiktionary, "mumpsimus«: https://en.wiktionary.org/wiki/mumpsimus (I0.03.2018)

Youtube, „Early Documentary about Sampling (1988)«: https://www.you tube.com/watch?v=cu38 $8 \mathrm{AL}_{4} \mathrm{E}_{7} \mathrm{I}_{4}$ (24.IO.2OI7)

Youtube, "Herbie Hancock - Fairlight CMI - Rockit«: https://www.you tube.com/watch?v=9SHh6zObriQ (05.10.2017)

Youtube, "Stetsasonic - Talkin’ All That Jazz (Official Music Video)«: https:// www.youtube.com/watch? $v=2 k d Q_{4}$ soLcac (24.08.2018)

Whosampled, "4:44 (2017). Album by Jay-Z«: https://www.whosampled. com/album/Jay-Z/4:44/ (30.06.2017)

Whosampled, „RJD2: The WhoSampled Interview«: http://www.who sampled.com/news/2009/II/05/rjd2-the-whosampled-interview/ (I3.04.2017)

\section{B.3 Abbildungs- und Tabellenverzeichnis}

Abbildung I (S. 22I): Eigene Aufnahme.

Abbildung 2 (S. 227): Diverse Plattencover, eigene Aufnahme.

Abbildung 3 (S. 235): The Sampling Dictionary, Beispielseite.

Abbildung 4 (S. 235): The Sampling Dictionary, Rückseite.

Abbildung 5 (S. 244): Youtube-Video (eigener Screenshot).

Abbildung 6 (S. 247): Diverse Plattencover, eigene Aufnahme.

Abbildung 7 (S. 259): Homestudio, eigene Aufnahme.

Tabelle I (S. 224f.): Eigene Darstellung 


\section{B.4 Weitere Ressourcen}

\section{B.4.1 Zitierte Gesetze}

Gesetz über Urheberrecht und verwandte Schutzrechte (Urheberrechtsgesetz, UrhG)

Urheberrechtsgesetz, $\$ 2$ Geschützte Werke (UrhG $₫$ 2)

Urheberrechtsgesetz, $\$$ I5 Allgemeines (UrhG $\$$ I5)

Urheberrechtsgesetz, $\$ 23$ Bearbeitungen und Umgestaltungen (UrhG $\$ 23$ )

Urheberrechtsgesetz, $\$ 24$ Freie Benutzung (UrhG $\$ 23$ )

Urheberrechtsgesetz, $\$ 28$ Vererbung des Urheberrechts (UrhG $₫ 28$ )

Urheberrechtsgesetz, $\$ 45$ Rechtspflege und öffentliche Sicherheit (UrhG $\$ 45$ )

Urheberrechtsgesetz, $\$$ 5I Zitate (UrhG $\$$ 5I)

Urheberrechtsgesetz, $₫ 59$ Werke an öffentlichen Plätzen (UrhG $\$ 59$ )

Urheberrechtsgesetz, $₫ 85$ Verwertungsrechte (UrhG $₫ 85$ )

\section{B.4.2 Verfahrensgang "Metall auf Metall»}

LG Hamburg, 08.10.2004 - 308 O 90/99

OLG Hamburg, 07.06.2006 - 5 U 48/05

BGH, 20.II.2008 - I ZR II2/06

OLG Hamburg, I7.08.20II - 5 U 48/05

BGH, I3.12.20I2 - I ZR I82/II

BVerfG, 31.05.2016 - I BvR I585/13

BVerfG, 09.0I.20I7 - I BvR I585/13

BGH, oI.06.2017 - I ZR II5/16

$\mathrm{EuGH}, 29.07 .2019-\mathrm{C}-476 / 17$ 


\section{B.4.3 Zitierte Gerichtsurteile und -verfahren}

Deutschland:

Bundesgerichtshof (20I2): BGH, Urteil vom I3.I2.2OI2 - I ZR I82/II, Metall auf Metall II - Zur Anwendbarkeit von $\$ 24$ Abs. I UrhG bei der Benutzung fremder Tonaufnahmen im Rahmen des Sound-Sampling.

Bundesgerichtshof (2017): Kraftwerk ./. Pelham \& Co. - Vorlage an den Europäischen Gerichtshof zur Zulässigkeit des Tonträger-Samplings.

Bundesverfassungsgericht (2016): Eingriff in Urheber- und Leistungsschutzrechte durch Sampling kann im Rahmen der künstlerischen Betätigungsfreiheit gerechtfertigt sein. BVerfG, Urteil vom 31.05.20I6 - I BvR I585/I3; Verfahren: BGH, Urteil vom I3.I2.20I2 - I ZR I82/II, MIR 2OI3, Dok. 025 .

Europäischer Gerichtshof (2019): Urteil des Gerichtshofs (Große Kammer), 29. Juli 2019 - in der Rechtssache C-476/17, Pelham GmbH, Moses Pelham und Martin Haas / Ralf Hütter und Florian Schneider-Esleben.

USA:

Grand Upright Music v. Warner Bros. Records, Inc., 780 F. Supp. I82 (S.D. N.Y. 199I).

Campbell v. Acuff-Rose Music, Inc., 510 U. S. 569 (1994).

Newton v. Diamond, 349 F.3d 59I (9th Cir. 2003).

Bridgeport Music, Inc. v. Dimension Films, 4IO F.3d 792 (6th Cir. 2005).

\section{Großbritannien:}

BBC vs Precord Ltd., SRIS C/89/9I Harman J in November 199I Chancery Division. 
B.4.4 Allgemeine juristische und musikindustrielle Ressourcen

Gesetzessammlungen:

De Jure, Urheberrechtsgesetz: https://dejure.org/gesetze/UrhG

Gesetze im Internet, Urheberrechtsgesetz: https://www.gesetze-im-internet. de/urhg/

Online verfügbare Kataloge von Verwertungsgesellschaften:

ASCAP: https://www.ascap.com/repertory

BUMA/STEMRA: http://www.bumastemra.nl/en/about-buma-stemra/titlecatalogue/

GEMA: https://online.gema.de/werke/search.faces

GVL: https://www.artsys.gvl.de/ (Login erforderlich)

Allgemeine Datenbanken für Musik- und Samplingfragen:

Allmusic: https://www.allmusic.com/

Discogs: https://www.discogs.com/

Whosampled: https://www.whosampled.com/

Streaming-Plattformen:

Mixcloud: https://www.mixcloud.com/

Soundcloud: https://soundcloud.com/

Spotify: https://www.spotify.com/

Youtube: https://www.youtube.com/ 


\section{B.4.5 Discografie}

Aphrodite (1998) Listen To The Rhythm (Remix) / Rinsing Quince, Eigenverlag.

Beastie Boys (1986): Licensed to Ill, Def Jam.

Beastie Boys (1989): Paul's Boutique, Capitol Records.

Beastie Boys (1992): Pass the Mic, Capitol Records.

Biz Markie (199I): Alone again, I need a Haircut, Cold Chillin'.

Buchanan \& Goodman (1956): The Flying Saucer, Radio Active Records.

Camille Yarbrough (1975): Take Yo Praise, The Iron Pot Cooker, Vanguard.

Can (1984): Prehistoric Future, Tago Mago.

Dangermouse (2004): The Grey Album, Eigenverlag.

De La Soul (1989): Transmitting live from Mars, 3 Feet High and Rising, Tommy Boy.

Double Dee \& Steinski (1985): Lessons I-3, Tommy Boy.

Elvis Presley (1956): Blue Sued Shoes, Radio Corporation of America.

Faith Evans / Julio Bashmore (200I): Love Like This / Father Father (B\&S Edits), Boogiefuturo.

Fatboy Slim (1998): Praise You, Skint Recordings.

Freelance Hellraiser (200I): A stroke of Genius, Eigenverlag.

Fünf Sterne Deluxe (1998): Sillium, Yo Mama Recordings.

Funkadelic (1975): Get off your Ass and Jam, Let's Take it to the Stage, Westbound.

Gilbert O'Sullivan (1972): Alone Again (Naturally), MAM.

Herbie Hancock (1969): Jessica, Fat Albert Rotunda, Warner Bros.

James Brown (1970): The Funky Drummer, Polydor.

James Newton (1982): Choir, AXUM, ECM Records.

James Tenney (196I): Collage \#I (Blue Suede), Eigenverlag.

Jay Z (2003): The Black Album, Roc-A-Fella Records.

Karlheinz Stockhausen (1953): Studie I, Deutsche Grammophon.

Karlheinz Stockhausen (1953): Studie II, Deutsche Grammophon.

Karlheinz Stockhausen (1966): Telemusik, Deutsche Grammophon.

Karlheinz Stockhausen (1967): Hymnen, Deutsche Grammophon.

Kinderzimmer Productions Back 1994 und 1998

Kraftwerk (1977): Metall auf Metall, Trans Europa Express, Kling Klang. 
Kraftwerk (198I): Computer Love / The Model, EMI.

Lad:Nav (2007): Justice Breaks / Justice House, White Label.

Led Zeppelin (1975): Kashmir, Physical Graffiti, Swan Song Records.

Les Paul (1947): Lover (When You're Near Me), Capitol Records.

M/A/R/R/S (1987): Pump up the volume, 4AD.

Mobb Deep (1995): Shook Ones Part II, Loud Records.

N.W.A. (1990): Ioo Miles and Running, Ruthless Records.

Negativland (199I): U2, SST Records.

Osymyso (2002): Intro-Inspection, Radar.

Pierre Schaeffer \& Pierre Henry (1950): Symphonie Pour Un Homme Seul, ORTF.

Public Enemy (1990): Fear of a Black Planet, Def Jam.

Puff Daddy feat. Jimmy Page (1998): Come With Me, Epic.

Quincy Jones (1973): Summer In The City, A\&M Records.

Roy Orbison (1964): Pretty Woman, London Records.

Sabrina Setlur (1997): Nur mir, Pelham Power Productions.

Schaeffer (1948): Études aux chemins de fer, ORTF.

Stars on 45 (198I): Beatles Medley (I2«-Mix), Long Play Album, Radio Records.

Stetsasonic (1988): Talkin' all that Jazz, Tommy Boy.

Sugar Hill Gang (1979): Rapper's Delight, Sugar Hill Records.

Terry Riley (1968): You're no good, Eigenverlag.

The 2 Live Crew (1989): Hairy Woman, Eigenverlag.

The Beatles (1968): The White Album, Apple Records.

The Harvey Averne Dozen (1968): You're no good, Viva Soul, Atlantic.

The JAMs (1987): 1987 (What the Fuck Is Going On?), The Sound of Mu(sic).

The Stranglers (1980): Golden Brown, EMI.

The Turtles (1969) You showed me, White Whale Records.

The Winstons (1969): Color Him Father / Amen, Brother, Pye International.

Verbal Vandalism (199I): Rhondda Rhant Rhap, Alphabet.

Walter Ruttmann (1929: Weekend, Reichsrundfunk Gesellschaft

Yoko Ono \& John Lennon (1968): Collage \#9, The White Album, Apple Records. 


\section{B.4.6 Zitierte Filme}

Baraka (1992), Magidson Films.

Blade Runner (1982), Warner Bros.

Eis am Stiel (1978), Golan-Globus.

Inception (2010), Warner Bros.

Jurassic Park (1993), Universal Pictures.

Koyaanisqatsi (1982), IRE.

Saturday Night Fever (1977), RSO.

Standing in the Shadows of Motown (2002), Artisan Entertainment.

The Matrix (1999), Warner Bros.

Winnie the Pooh and the Honey Tree (1966), Walt Disney. 


\section{Danksagung}

Dass Kunst schön ist - aber auch viel Arbeit macht - stellte bereits Karl Valentin fest, wobei der Münchner Komiker mit "Arbeit« vermutlich nicht gerade Lizenzierungsanstrengungen im Sinn hatte. Auch die Anfertigung dieser Studie brachte eine Menge Arbeit mit sich und zog sich über einen Zeitraum von etwa vier Jahren hinweg. Dass mir diese lange Zeit nicht wie pure Maloche vorkam, wie es im Berliner Volksmund heißt, sondern viele schöne Stunden bescherte, habe ich einer Vielzahl von Menschen zu verdanken.

Zunächst bin ich meinen beiden Betreuern Michael Hutter und Leonhard Dobusch zu großem Dank verpflichtet, die mir beide seit Beginn der Dissertation stets mit Rat und Tat zur Seite standen und die Fertigstellung in den letzten Monaten durch Lektüre und wertvolle Kommentare intensiv begleiteten. Sie bestärkten mich maßgeblich darin, meinem eigenen Denken zu vertrauen und gleichzeitig seine Grenzen zu überprüfen. Stefan Kirchner möchte ich ganz herzlich für seine Hilfsbereitschaft und die Übernahme des Gutachtens danken.

Dass meine Studie im Rahmen des Graduiertenkollegs »Innovationsgesellschaft heute« am Institut für Soziologie der TU Berlin entstehen konnte, war für mich ein besonderes Glück. Die Arbeitsbedingungen waren hervorragend und die kontinuierlichen Diskussionen für die Entwicklung und Schärfung einer eigenen innovationssoziologischen These überaus hilfreich. Ich möchte mich dafür besonders bei Miira Hill, Eric Lettkemann, Felix Maas, Arne Maibaum, Clelia Minnetian, Annelie Pentenrieder, Ingo Schulz-Schaeffer, Ariane Sept, Rene Tuma und Arnold Windeler bedanken. Phillip Graf, Isabel Kenngott, Hannah Kropla, Anika Redmann, Max Rütsche und Josef 
Steilen beschafften mir die abstrusesten Literaturwünsche und unterstützten tatkräftig bei der Veranstaltung von Workshops. Susann Schmeißer und Dominika Hadrysiewicz nahmen sich souverän und hilfsbereit aller organisatorischen Probleme an, die im universitären Alltag auftauchten. All das war ungemein hilfreich.

Die meisten Kaffeepausen zwischen Stabi Ost und Stabi West, zwischen Mensa Nord und Mensa Süd habe ich mit Lorenz Grünewald-Schukalla, Philipp Golka und Max Heimstädt verbracht. Über mehrere Jahre hinweg bekamen sie meine am wenigsten ausgereiften Gedanken zu hören. Sie halfen mir dabei, tragfähige Konzepte daraus $\mathrm{zu}$ machen und neue Ideen zu entwickeln; sicherlich keine leichte Aufgabe, aber ein umso größerer Freundschaftsdienst.

Den Mitgliedern des Fachausschusses "Urheberrecht" der Gesellschaft für Musikwirtschafts- und Musikkulturforschung (GMM) möchte ich für die vertrauensvolle Diskussionsatmosphäre danken, in der ich meinen eigenen Horizont in Bezug auf das Urheberrecht maßgeblich erweiterte. Dank Frédéric Döhl, Konstantin Hondros, Sibel Kocatepe, Sarah Mai-Dang, Rike Maier, Holger Schwetter, Michael Servatius und Sigrid Quack weiß ich, wie bereichernd und angenehm interdisziplinäre (Urheberrechts-)Forschung sein kann. Das Gleiche gilt für Patricia Aufderheide, Kylie Papparlardo, Nic Suzor und Patrik Wikstrom, mit denen ich während meines Aufenthalts an der QUT in Brisbane im Frühjahr 2017 die internationale Dimension von Geistigem Eigentum und empirischer Urheberrechtsforschung auslotete, und die mich besonders herzlich aufnahmen. Auch den Mitgliedern der DFG-Forschungsgruppe zur »Ethik des Kopierens« - namentlich Eberhard Ortland, Amrei Bahr und Reinold Schmücker - die ich für zwei Konferenzen und eine Summer School besuchen durfte, möchte ich für den wunderbaren Austausch danken.

Meiner Familie danke ich für das Vertrauen und das Verständnis, das sie mir über all die lange Zeit vermittelte. Meiner Mutter danke ich für die Liebe zur Kunst, meinem Vater für die Liebe zur Wissenschaft. Auch Florian und Margit Fischer sei für ihre Unterstützung gedankt. Hanna schob mich an, wann immer ich drohte festzuste- 
cken, und bremste mich, bevor ich mich verrennen konnte. Ohne sie hätte ich niemals die Dissertation begonnen - und ohne sie wäre ich auch niemals damit fertig geworden. Eine bessere Partnerin für dieses Projekt (und für alles andere) kann ich nicht bekommen.

Daniela Walter und Brigitte Fischer danke ich für die redaktionelle Betreuung des Manuskripts, Mareike Gill und dem BüchnerVerlag für die angenehme Zusammenarbeit bei der Publikation. Dass diese Studie nicht nur als physisches Buch erwerbbar, sondern unter einer Creative Commons-Lizenz im Internet offen zugänglich ist, habe ich der Unterstützung von Dagmar Schobert und Elena DiRosa von der Universitätsbibliothek der TU Berlin zu verdanken, die die Finanzierung durch den Open Access-Publikationsfonds der TU Berlin ermöglichten.

Dass ich durch das Interesse am Sampling eine enorme Menge alter, vergessener Musik vor allem von schwarzen Musiker_innen entdecken durfte, ist schön und in gewisser Weise komfortabel. Dass viel $\mathrm{zu}$ viele von ihnen ausgebeutet und diskriminiert wurden, weil sie dazu gezwungen waren, Copyrights und finanzielle Beteiligung an ihren Werken abzutreten, ist hingegen ein besonders trauriges Kapitel der Musikgeschichte des 20. Jahrhunderts. Ohne je dafür angemessen honoriert zu werden, gaben unzählige Musiker_innen in Studiosessions ihre Leidenschaft, ihre Ideen und ihr Können - ihre Musik lebt bis heute, ihre Namen hingegen tauchen fast nirgends auf. All jenen namenlosen und vergessenen Studiomusiker_innen im Schatten der Musikindustrie ist diese Arbeit gewidmet.

Berlin, im November 2019

Georg Fischer 